\title{
ESSAYS ON THE EFFECTS OF GROWTH, PUBLIC EXPENDITURES AND INFRASTRUCTURE INVESTMENTS IN DEVELOPING COUNTRIES
}

\author{
Dissertation \\ to obtain the Ph. D. degree \\ in the International Ph. D. Program for Agricultural Sciences in Göttingen (IPAG) \\ at the Faculty of Agricultural Sciences, \\ Georg-August-University Göttingen \\ Germany
}

presented by

Miguel Almanzar

born in

Santo Domingo, Dominican Republic 
D7

Name of co-supervisor

Name of co-supervisor

Member of Examination Committee

Date of dissertation
Prof. Dr. Matin Qaim

Maximo Torero, PhD

Prof. Dr. Bernhard Brümmer

12 July 2017 


\section{EXECUTIVE SUMMARY}

The general objective of this dissertation is to understand the relationship between economic growth, government expenditure in public services and infrastructure on different sectors of the population. Through three essays this dissertation pursues the objective by explicitly highlighting the importance of data, theory and methodology. This approach interprets findings in a literature that has few existing examples that demonstrate similar rigorous evidence on the effects of growth and infrastructure. This dissertation attempts to contribute to the literature by providing a sound framework to analyze the distributional effect of growth and government expenditures.

The first essay tackles the questions of how growth and government expenditures affect different socioeconomic groups in Rwanda and Tanzania. This essay provides a distributional framework through which we can better understand the effects of government expenditure and group by explicitly modeling the household sector and the government sector. This approach makes it possible to derive restrictions that allow us to estimate the elasticities of different types of expenditures (for example, social and non-social) across each quintile of the expenditure distribution in Rwanda and Tanzania. We find that, overall, mean expenditure growth benefits the top expenditure groups. The welfare spillovers are mostly present for the top $20 \%$ of the expenditure distribution, with the middle of the distribution in Tanzania responding slightly to these spillovers. Public/social expenditures do not appear to affect inequality considerably, but do tend to work toward decreasing inequality. However, mean expenditure growth is related to increases in inequality because the richest sectors of the population benefit the most from growth. The growth elasticity of expenditure is only above one for the top quintile in both countries. In Tanzania, a 1\% increase in average household expenditure is related to a $1.96 \%$ expenditure growth in the top quintile and $0.43 \%$ in the third quintile. In Rwanda, a $1 \%$ increase in average household expenditure is related to a $1.93 \%$ increase in household expenditure in the top $20 \%$ of the distribution.

The second essay assess the effects of improvement in rural road quality. Using the rehabilitation of the Northern Transnational Highway (NTH) we asses, whether the improvement in this rural road achieved its goal of "connecting northern El Salvador with the rest of the country, helping to create opportunities for the region's residents through increased access to markets." The essay identifies which bottle necks might have hindered achieving the goal and what aspects might have aided in achieving it. We evaluate the main impacts of the improvement of the NTH using two parallel approaches that use a panel household survey to exploit variation in the improvement of the road across time. This is achieved through a novel reduced form based on difference-in-difference and pipeline design and a continuous treatment structural design that exploits the variation induce in market access by the timing of the improvements of the road and the spatial distribution of households in the Northern Zone of El Salvador.

We find that the improvement of the NTH in El Salvador had modest impacts in the short run. We find clear evidence of improvement in market access through shorter times and costs of moving products to existing markets. Across the population in the Northern Zone, the traveling time to the nearest market decreased 
between 16 and 18 minutes on average. The evidence suggests modest effects, if any, on agricultural productivity and no effects in the value of land. We find limited effects on the probability of having a title for an agricultural plot in some areas along the NTH; an increase between 18 and 32 percentage points on the households in the west side of the road.

Some of the more salient effects of the road improvements is an in the probability of commercialization in agriculture. Households are 10 percentage points more likely to sell after the road improvement. We find some indication of an increase in stored grains; the value of agriculture production designated for autoconsumption, increased between 40 to 53 USD Because of the road improvement. These effects varied depending on the methodology used. Interestingly, we find negative impact on household income of 140 USD per year or $5 \%$ of annual income. This effect can be traced to dependent labor in the agriculture sector income and to independent/business income in the non-agriculture sector. We posit that these short-run effects might be due to a reallocation of dependent labor supply across sectors and an increase in business competition from areas that become newly accessible with ease following the road improvement.

The third essay quantifies the benefits of water, sanitation and hygiene interventions of the agreement. These interventions followed a community demand driven model that allowed us to design a rigorous impact evaluation that provides reliable estimates that are not plagued by placement bias and omitted variable bias that characterizes much of the evidence in the literature. We propose a rigorous quasi-experimental design that incorporates matching on pre-baseline census data, panel data and difference-in-difference estimation.

We find that the water, sanitation and hygiene interventions resulted in significant improvements in access to safe water and improved sanitation. We find robust and significant benefits across the measures of access to water and sanitation, an increase of 3 percentage point in access to improved sanitation and of 25 percentage points in access to improved water sources in treatment communities. We find reductions in the time to reach improved water sources (2 minutes), increases in ownership and use of improved water and sanitation services, 28 percentage points more likely to use tap water as a principal source for drinking water, increases in the reliability of service with 16.5 hours per week more of service in treatment communities. Other impacts include: Increases in satisfaction with the water system in the community, reductions in the perceived riskiness of drinking water from water systems. We find a decrease the probability of having bacterial contamination at the source. Treatment households are between 16 and 19 percentage points less likely to have E.coli in their water source after treatment, but there are no effects on the water stored or at the point of consumption. This indicates that drinking water is being contaminated between the source and the point of consumption.

We also find that expenditure on water increased by 1.87 USD per month, on average, among beneficiary households following the installation of metered water taps. We find no effects on the total quantity of water consumed but we detect increases in water from taps and a decrease in water from wells and other unimproved sources. The reductions in the time spent carrying water and doing laundry outside the home were significant. On average, individuals saved 1.41 hours per week carrying water thanks to the interventions 
and up to 2.75 for households that report being direct beneficiaries. The decrease in time spent doing laundry outside the home was on average 1.79 hours per week, a concentrated and significant benefit for females.

Exploring how these effects differ by the amount of time beneficiary households were connected to the new or improved system, we find that these effects occur within the first months of being connected and that among households that were connected for a longer time-period, these effects persist. These findings indicate the sustainability of community-demand driven rural water and sanitation infrastructure projects. The findings from the three essays help to draw conclusions and important policy implications for future studies. We highlight the problems of endogeneity and placement bias that plague observational studies in infrastructure evaluations when these are not well grounded in theory, or that did not use appropriate methods to control for these problems. 


\section{ACKNOWLEDGEMENTS}

I am indebted to Maximo Torero for his initial and continued support and serving as a co-supervisor for this work. This work would not have been possible without his support and guidance and the opportunities he afforded me during his time at the International Food Policy Research Institute (IFPRI).

My understanding of the topics in this dissertation have greatly benefited from countless discussions with Eduardo Nakasone; I am lucky to have him as a colleague and a friend.

I would like to thank my coauthors Maureen Cropper and Raymond Guiteras. This work was greatly improved by the comments they provided. Their trust in my ability meant the world to me when I most needed reassurance.

I would like to thank my supervisor Prof. Qaim for his guidance, advice, and the opportunity to pursue this PhD under his supervision. I also want to thank Prof. Brümmer for his time and effort in the examination of this thesis.

I would like to thanks Maribel Elias for her support and guidance using spatial data.

The funding for the impact evaluations in this dissertation by the Millennium Challenge Corporation is gratefully acknowledged.

I am thankful to family and friends for their unwavering moral support in this journey. 
To my grandmother, Maria, my example;

my mother, Xiomara, my biggest fan;

my sister, Xiomy, my best friend;

my brother, Victor, my first care;

my niece, Ixchel, my latest care. 


\section{TABLE OF CONTENTS}

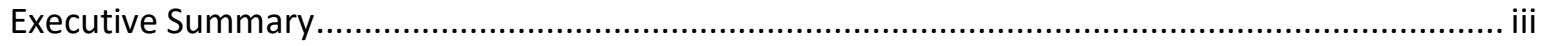

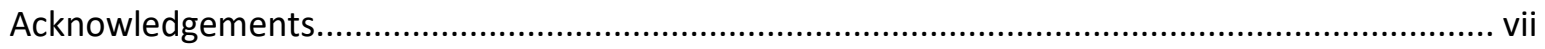

Chapter 1 - Introduction and General Presentation .............................................................. 1

Chapter 2 - Distributional Effects of Growth and Public Expenditures in Africa ............................. 3

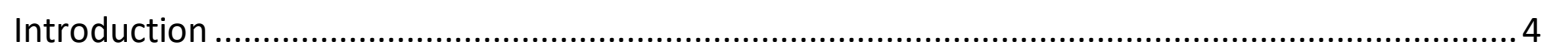

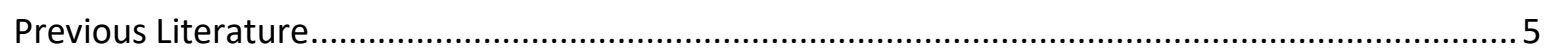

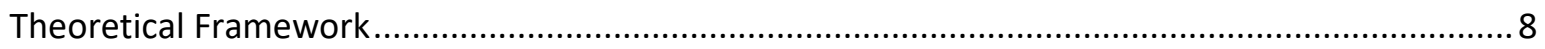

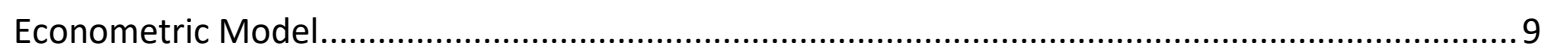

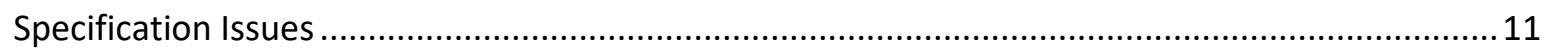

Data

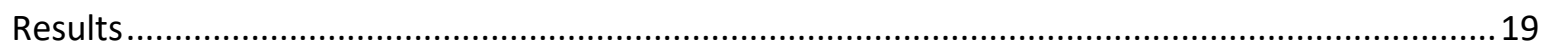

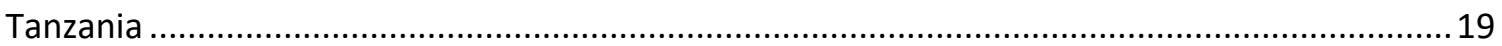

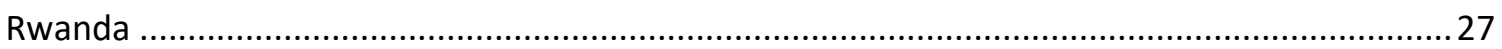

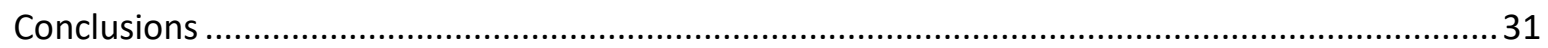

Chapter 3 - Impact Evaluation Of The Northern Transnational Highway Of El Salvador ...............33

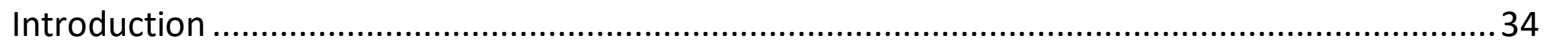

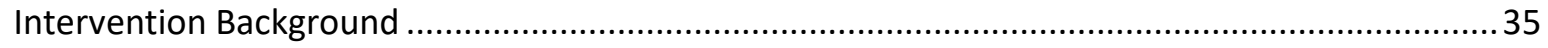

Rural Roads and Development: A Literature Review.................................................................3

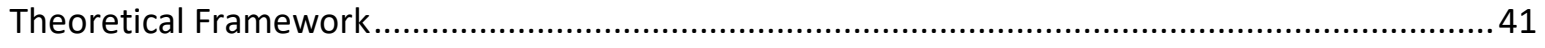

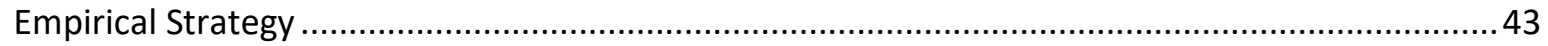

Reduced Form Design: Difference-in-Difference Pipeline Estimator.......................................... 44

Structural Time to Market Design: a Continuous Treatment Approach ........................................46

Comparison across educed Form and Structural Methodologies ..............................................50

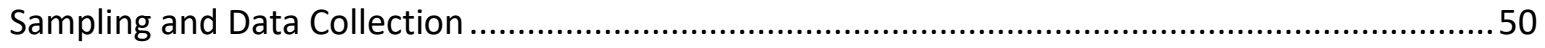

Baseline Balance and Validation of Assumptions .........................................................................51

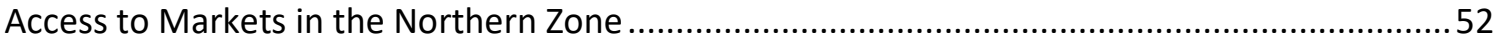

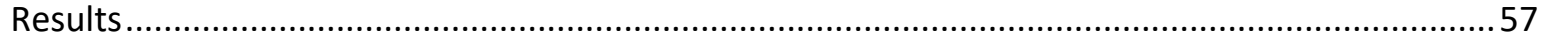

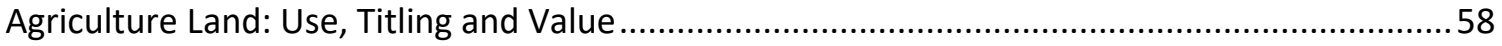

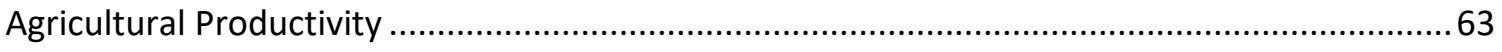

Road quality and Income: Agriculture and Non-Agriculture Sectors..........................................71

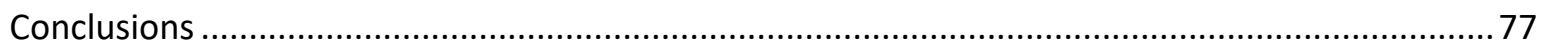

Chapter 4 - Impact Evaluation of the Rural Water and Sanitation Projects in Northern El Salvador ...79

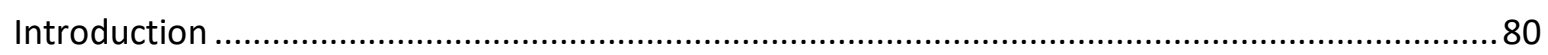

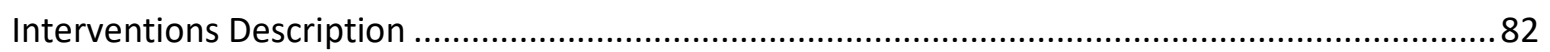




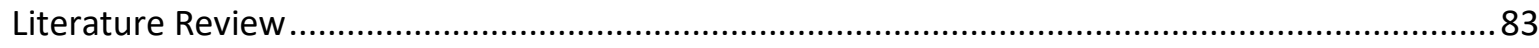

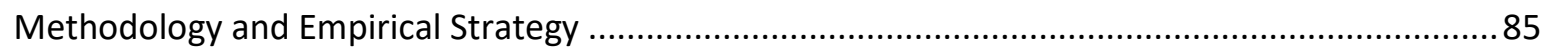

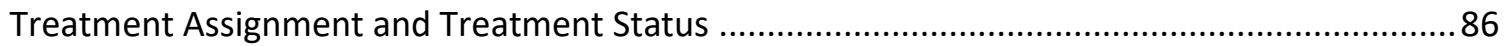

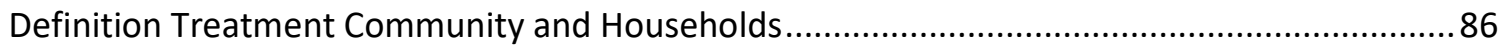

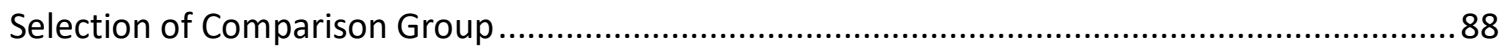

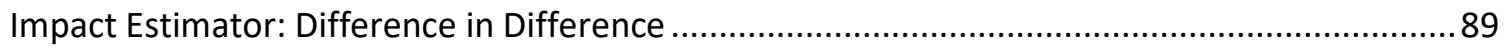

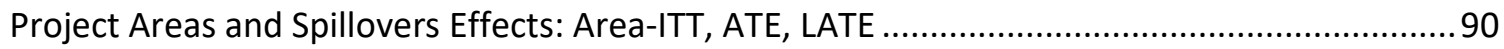

Heterogenous effects: Socioeconomic, Sex and Initial Water Access ........................................91

Sustainability of Impacts and Heterogeneity in Exposure Period to Treatment ..........................91

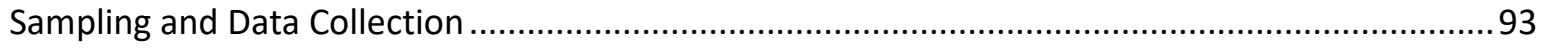

Baseline Balance and Matching Assumptions …........................................................................... 95

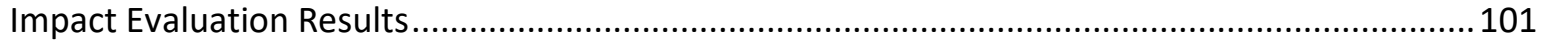

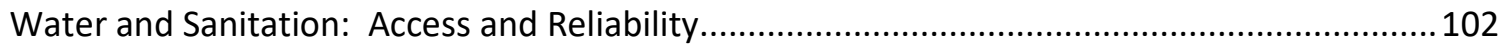

Water Systems: Reliability, and Perceptions of Risks and Quality..........................................116

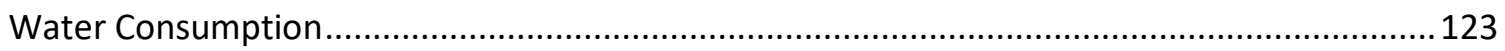

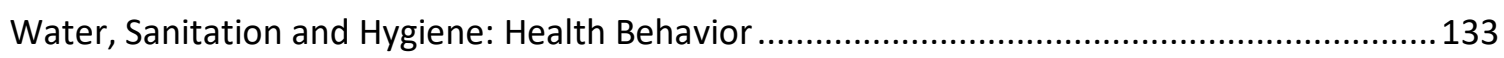

Water Contamination: Water Supply and the Point of Consumption ....................................... 140

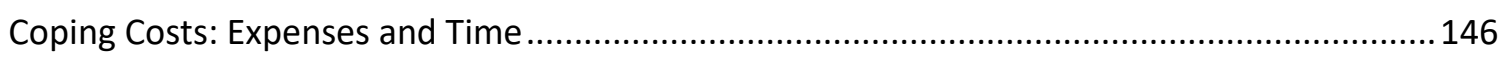

Individual Time Coping Costs: Age, Gender and Socio-economic Heterogeneity ......................159

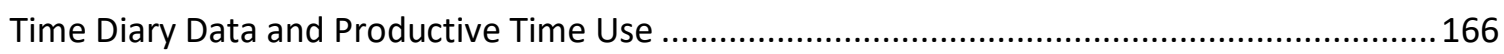

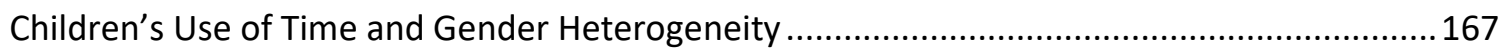

Sustainability of Impacts and Heterogeneity by Exposure to Treatment.................................173

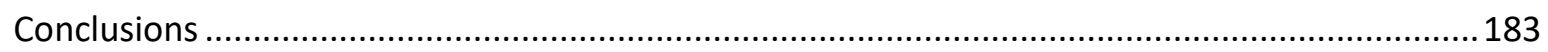

Lessons and Recommendations for Future WASH Interventions.............................................. 184

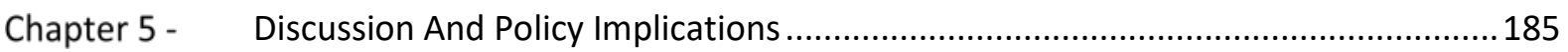

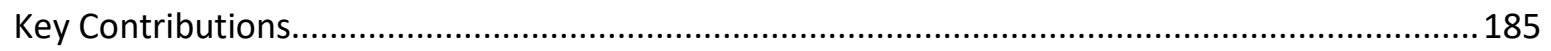

Growth and Government Expenditure Distributional Effects ..................................................186

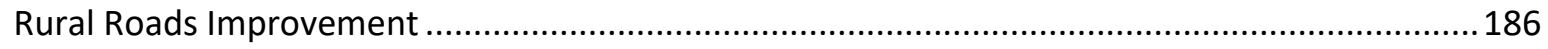

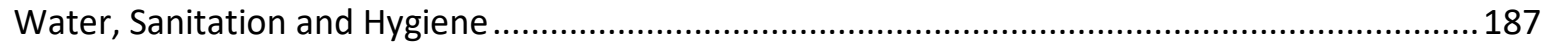

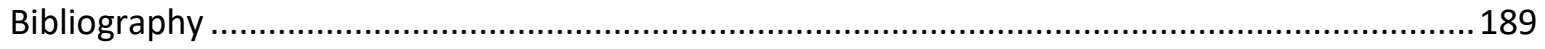

References on Distributional Effects of Growth and Public Expenditures ...............................189

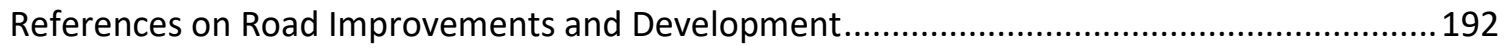

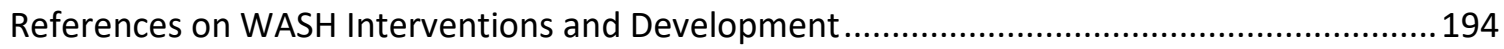

Annex 1 -Calculating the Time and Cost of Travel: Accessibility Model .......................................199

Annex 2- Additional Results: Road Improvement Impacts ...........................................................204 
Annex 3 Additional Results: WASH Impacts

Time Diary Minor Sample 208

Hygiene

Annex 4 - Water Quality Testing Design .

Declaration about Co-authored Papers.... 


\section{LIST OF TABLES}

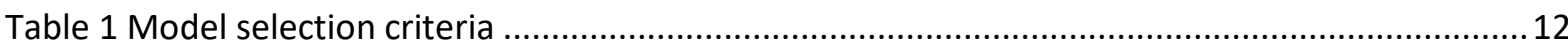

Table 2 Summary statistics for Rwanda data: Expenditures............................................................ 14

Table 3 Summary statistics for Rwanda data: Mean growth and expenditure shares.........................14

Table 4 Summary statistics for Tanzania data: Expenditures ............................................................ 15

Table 5 Summary statistics for Tanzania data: Mean growth and expenditure shares ......................16

Table 6 Tanzania: Rate of growth of per capita group expenditure (unrestricted estimates) .............20

Table 7 Tanzania: Rate of growth of per capita group expenditure (restricted estimates) .................21

Table 8 Tanzania: Model parameters based on expenditure (unrestricted estimates) .......................23

Table 9 Tanzania: Elasticities of group expenditures for all districts (unrestricted estimates) ............24

Table 10 Tanzania: Elasticities of group expenditures for bottom expenditure districts......................26

Table 11 Tanzania: Elasticities of group expenditures for top expenditure districts ..........................26

Table 12 Rwanda: Rate of growth of per capita group expenditure (unrestricted estimates) ............27

Table 13 Rwanda: Rate of growth of per capita group expenditure (restricted estimates)................28

Table 14 Rwanda: Model parameters based on expenditure (unrestricted estimates).......................29

Table 15 Rwanda: Elasticities of group expenditures for all districts ................................................30

Table 16 Rwanda: Elasticities of group expenditures for bottom expenditure districts ......................31

Table 17 Rwanda: Elasticities of group expenditures for top expenditure districts.............................31

Table 18 NTH Construction Timeline: Initial and Actual ..................................................................

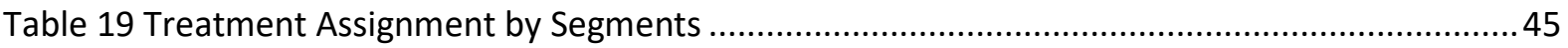

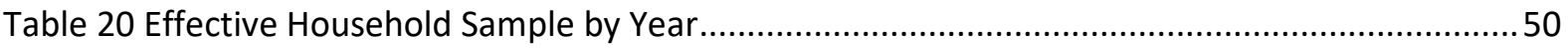

Table 21 Baseline or Pre-Improvement Period Balance …................................................................52

Table 22 Impact to Travel Times to Markets in Minutes: ChalatenangO …........................................53

Table 23 Impact to Travel Times to Markets in Minutes: Metapan ...................................................54

Table 24 Impact to Travel Times to Markets in Minutes: San Salvador ...............................................55

Table 25 Impact of Time in Minutes to Nearest Market ......................................................................56

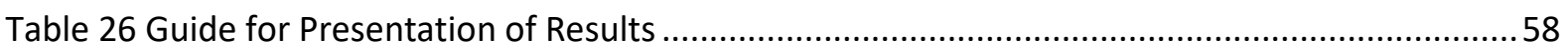

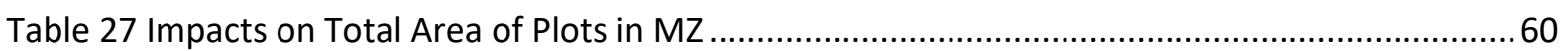

Table 28 Impacts on Land Titling: Propability of owning a plot with a title ........................................61

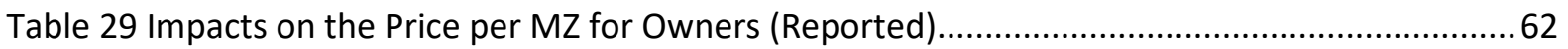

Table 30 Agricultural Production Impacts: Probability of Growing Cash Crops ..................................64

Table 31 Agricultural Production Impacts: Probability of producing Fruits and Vegetables...............65

Table 32 Agricultural Production Impacts: Probability of Selling Agricultural Production ....................66

Table 33 Agricultural Production Impacts: Total Agriculture products Sales $(\$)$.................................67

Table 34 Agricultural Production Impacts: Basic Grains Production Quantities (Kgs)........................69 
Table 35 Agricultural Production Impacts: Auto-consumption (\$) ................................................... 70

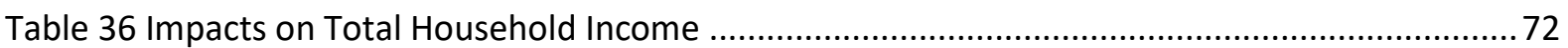

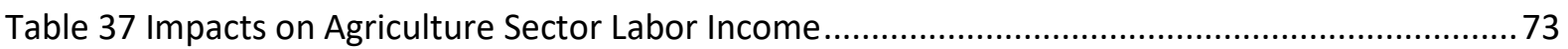

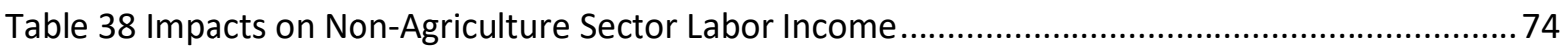

Table 39 Impacts on Agriculture Sector Independent/Business Income............................................75

Table 40 Impacts on Non-Agriculture Independent/Business Income ................................................ 76

Table 41 Sample Size Description: Households ................................................................................. 94

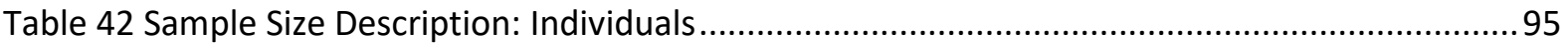

Table 43 Logistic Regression and Matching Equation and Results .....................................................96

Table 44 Matched and Unmatched Samples - Balancing Tests at 2011 Baseline ...............................97

Table 45 Matched and Unmatched Samples and Bias Distribution Statistics - Tests at 2011 Baseline98

Table 46 Ex-ante Matching Variables as Measured in the Baseline .................................................. 101

Table 47 Sanitation Uptake: Probability of Having an Improved Latrine ..........................................104

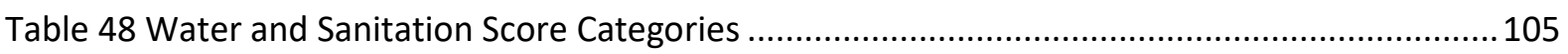

Table 49 Improve Water Services Uptake: Probability of Having a Household Tap ...........................107

Table 50 Improve Water Services Uptake:: Increases in Best Water Source Score ...........................108

Table 51 Average Travel Times to Water Sources at Baseline (Minutes) ...........................................109

Table 52 Average Time in Minutes to Access Water Sources.............................................................110

Table 53 Time in Minutes to Access Water Sources: Best Source Used...........................................111

Table 54 Descriptive Statistics: Hours and Days per Week that Household has Access to Tap Water

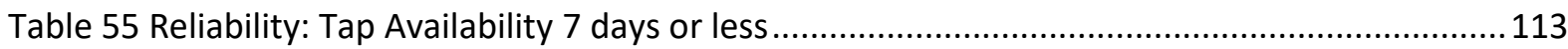

Table 56 Reliability: Tap Availability in Hours per Week ..............................................................114

Table 57 Reliability for Households with Taps at Baseline: Hours and Days per Week with Access to

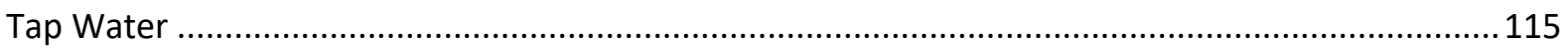

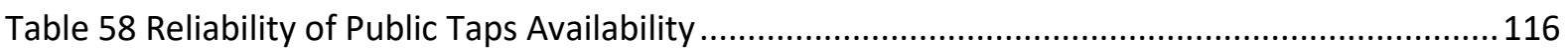

Table 59 Risk Perceptions of Best Water Source Used ...............................................................118

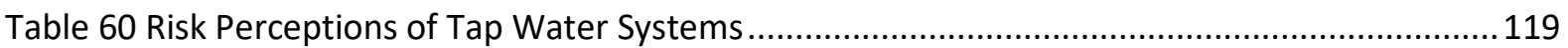

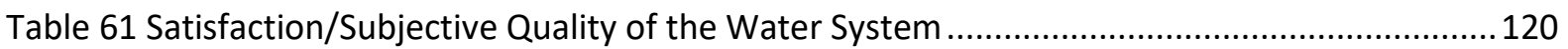

Table 62 Household Water Consumption (Liters/Week): Total Consumption Across Sources...........124

Table 63 Household Water Consumption (Liters/Week): Public Taps and Neighbors .......................126

Table 64 Household Water Consumption (Liters/Week): Private wells and Springs .........................127

Table 65 Household Water Consumption (Liters/Week): Trucks and Bottled ...................................128

Table 66 Household Water Consumption (Liters/Week): Consumption from Metered Private Taps130

Table 67 Household Water Consumption (Liters/Week): Metered Private Taps................................132

Table 68 Hygiene and Health Knowledge: Diarrhea Prevention and Hand Washing ........................134 
Table 69 Hygiene Practices: Treatment of Drinking Water and Use of Soap 136

Table 70 Residual Chlorine enumerator test

Table 71 Tap Water in Effective Use: Drinking 138

Table 72 Tap Water in Effective Use: Cooking 139

Table 73 Tap Water in Effective Use: Washing 140

Table 74 MPN Index and 95 Percent Confidence Intervals

Table 75 Water Contamination: Fecal Coliforms and E.coli Presence.

Table 76 Residual Chlorine - Mg/Liter (Laboratory)

Table 77 Coping Costs: Total Monthly Cash Expenses in Water.

Table 78 Coping Costs: Monthly Expenses in Water from Neighbors and Trucks......

Table 79 Coping Costs: Monthly Expense in Taps.

Table 80 Coping Costs: Chemicals and Filters

Table 81 Household Time Coping Costs: Probability and Number Carrying Water from Outside .....154

Table 82 Household Time Coping Costs: Probability and Number Doing Laundry Outside 155

Table 83 Household Time Coping Costs: Time Spent Carrying Water from Outside (Hours/Week)..157

Table 84 Household Time Coping Costs: Time Spent Doing Laundry Outside (Hours/Week).... 158

Table 85 Gender Time Coping Costs: Individual Probability of Carrying Water and Hours per Week Spent

Table 86 Gender Time Coping Costs: Individual Probability of Doing Laundry Outside and Hours per Week 163

Table 87 Time Diary, Education: Time Spent in Minutes, Individuals Ages 5-18. 169

Table 88 Results per Road Classification. 201

Table 89 Sample Size for Water Quality Tests. 220 


\section{LIST OF FIGURES}

Figure 1 Rwanda: Consumption growth for the top 20 percent and the bottom 20 percent of the expenditure distribution

Figure 2 Tanzania: Consumption growth for the top 20 percent and the bottom 20 percent of the

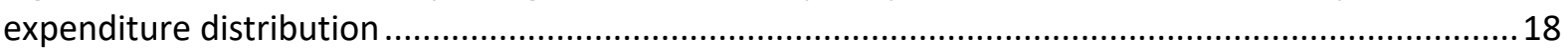

Figure 3 NTH and Pan-American Highway with Respect to the Northern Zone..................................37

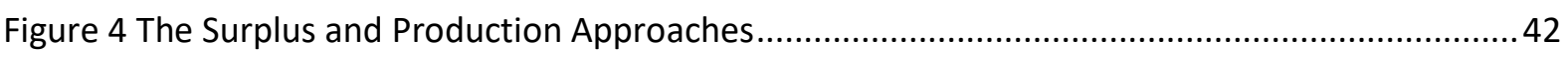

Figure 5 Roll-out of NTH and Comparison Groups for DID in the Northern Zone ...............................44

Figure 6 Hypothetical Transportation Routes of Households in Adjacent Segments...........................47

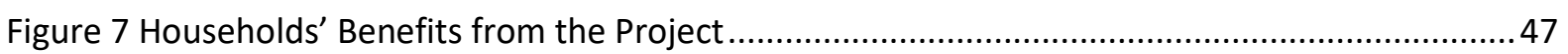

Figure 8 Geographical Distribution of Sample and Segment Assignment ...........................................51

Figure 9 Hypothetical Case of Transportation with Feeder Roads and NTH ......................................78

Figure 10 Number of Weeks Connected to Improved Systems at 2011 Baseline ...............................92

Figure 11 Number of Weeks Connected to Improved Systems at 2012 Follow-up..............................92

Figure 12 Number of Weeks Connected to Improved Systems at 2013 Endline.................................93

Figure 13 Geographical Distribution of Treatment and Comparison Segments..................................94

Figure 14 Distribution of Propensity Scores Before Matching.......................................................99

Figure 15 Distribution of Propensity Scores After Matching 2011 ..................................................100

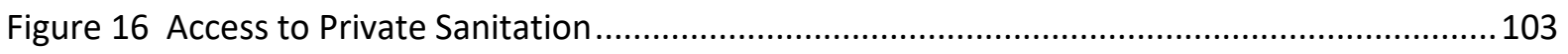

Figure 17 Distribution of Improved Sanitation Scores at Baseline ..................................................103

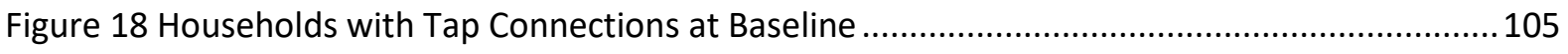

Figure 19 Distribution of Improved Water Scores at Baseline ........................................................ 106

Figure 20 Uptake: Probability of Having a Tap by Initial Water Source............................................ 108

Figure 21 Distribution of Travel Times to Sources at Baseline ........................................................109

Figure 22 Gender in Uptake: Probability of Having an Improved Latrine......................................... 121

Figure 23 Gender in Uptake: Probability of Having a Household Tap .............................................121

Figure 24 Socio-Economic in Uptake: Probability of having an Improved Latrine .............................122

Figure 25 Socio-Economic in Uptake: Probability of Having a Household Tap..................................122

Figure 26 Presence of Fecal Coliforms in Stored Water ................................................................. 142

Figure 27 Presence of Fecal Coliforms in Stored Water by Drinking Water Source ..........................142

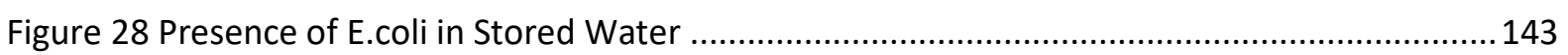

Figure 29 Presence of E.coli in Stored Water by Drinking Water Source ..........................................143

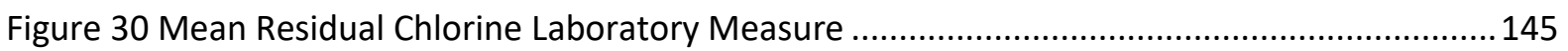

Figure 31 Gender Heterogeneity in Coping Costs: Total Expenses on Water ..................................152

Figure 32 Coping Costs by Quintile: Total Cash Expenses on Water .............................................153

Figure 33 Individual Time Coping Costs: Probability of Carrying Water by Age and Gender .............161 
Figure 34 Individual Time Coping Costs: Time Spent Carrying Water by Age and Gender 161

Figure 35 Individual Time Coping Costs: Probability of doing Laundry outside Water by Age and

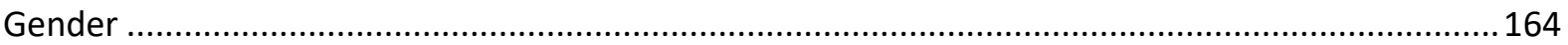

Figure 36 Individual Time Coping Costs: Time Spent Carrying Water by Age and Gender ................164

Figure 37 Individual Time Coping Costs: Time Spent Carrying Water by Age .................................165

Figure 38 Individual Time Coping Costs: Time Spent doing Laundry by Quintile ..............................166

Figure 39 Time Diary, All Activities: Participation, Individuals Ages 5-18 ......................................167

Figure 40 Time Diary, All Activities: Time Spent in Minutes, Individuals Ages 5-18 ..........................168

Figure 41 Time Diary, All Activities: Females, Time Spent in Minutes, Individuals Ages 5-18...........170

Figure 42 Time Diary, All Activities: Males, Time Spent in Minutes, Individuals Ages 5-18 ..............171

Figure 43 Time Diary, Participation in Activities: Women Ages 19+.................................................172

Figure 44 Time Diary, Time Spent: Minutes per day, Women Ages 19+ .........................................172

Figure 45 Sustainability of Impacts: Access to Improved Sanitation ................................................174

Figure 46 Sustainability of Impacts: Access to Improved Water Systems .........................................174

Figure 47 Sustainability of Impacts: Reliability, Probability of $<7$ days of service ...............................175

Figure 48 Sustainability of Impacts: Reliability, Days of Service.....................................................176

Figure 49 Sustainability of Impacts: Reliability, Hours per Week Availability ..................................176

Figure 50 Sustainability of Impacts: Satisfaction with Water Systems ............................................177

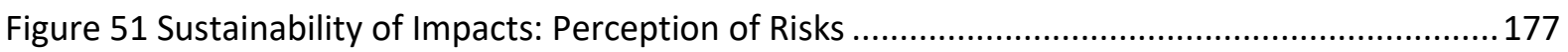

Figure 52 Sustainability of Impacts: Effective Use, Water for Drinking............................................. 178

Figure 53 Sustainability of Impacts: Total Water Consumption ....................................................... 178

Figure 54 Sustainability of Impacts: Tap Water Consumption .....................................................179

Figure 55 Sustainability of Impacts: Household Tap Expenses ...................................................... 180

Figure 56 Sustainability of Impacts: Coping, Probability of Carrying Water.....................................180

Figure 57 Sustainability of Impacts: Coping, Probability of doing Laundry Outside the Home..........181

Figure 58 Sustainability of Impacts: Coping, Time Spent Carrying Water ........................................ 181

Figure 59 Sustainability of Impacts: Coping, Time Spent doing Laundry Outside the Home .............182

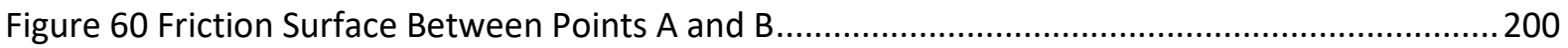

Figure 61 Values Indicating the Difficulty of Crossing a "Cell" ........................................................200

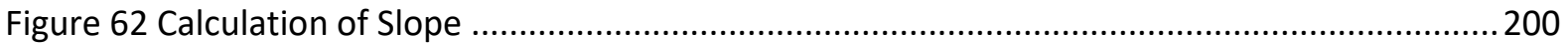

Figure 63 Times Calculated only with the Off-path Walking Velocity …...........................................201

Figure 64 Times Calculated with the Three Variations of Walking Velocity and Fixed Speed Road

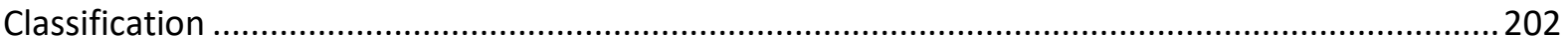

Figure 65 Time to Markets Before and After the Transnational Highway Improvement..................203 


\section{ABbreviations}

$\begin{array}{ll}\text { IFPRI } & \text { International Food Policy Research Institute } \\ \text { MCC } & \text { Millennium Challenge Corporation } \\ \text { MPN } & \text { Most Probable Number } \\ \text { NCR } & \text { Network of Connecting Roads } \\ \text { NTH } & \text { Northern Transnational Highway } \\ \text { OLS } & \text { Ordinary Least Squares } \\ \text { PPP } & \text { Purchasing Power Parity } \\ \text { PSM } & \text { Propensity Score Matching } \\ \text { SD } & \text { Standard Deviation } \\ \text { TFP } & \text { Total Factor Productivity } \\ \text { USD } & \text { United States Dollar } \\ \text { VIP } & \text { Ventilated Improved Pit } \\ \text { WASH } & \text { Water, Sanitation and Hygiene } \\ \text { WHO } & \text { World Health Organization }\end{array}$





\section{Chapter 1 - INTROduction AND General PRESENTATION}

The general objective of this dissertation is to understand the relationship between economic growth, government expenditure in public services and infrastructure on different sectors of the population. This objective is pursued in in three essays in this dissertation explicitly highlighting the importance of data, theory and methodology in the interpretation of findings in a literature that has few examples that provide rigorous evidence on the effects of growth and infrastructure. This dissertation attempts to tackle the problems of endogeneity and placement bias that plague observational studies in infrastructure evaluations when these are not well grounded in theory. We discuss some appropriate methods to control for these problems and provide some new methodological insights on how these problems can be addressed empirically.

The first essay in Chapter 2 tackles the questions of how do growth and government expenditures affect different socio-economic groups in Rwanda and Tanzania. This essay provides a distributional framework through which we can better understand the effects of government expenditure and group by explicitly modeling the household sector and the government sector and deriving restrictions that allow us to estimate the elasticities of different types of expenditures (for example, social and non-social expenditures) across each quintile of the expenditure distribution in Rwanda and Tanzania.

The second and third essays evaluate the impact of infrastructure projects in Northern Zone of El Salvador. In November of 2006, the Millennium Challenge Corporation, a US foreign aid agency, made and agreement with the government of El Salvador (GOES) to improve the lives of Salvadorans through strategic investments. The goal was to combine infrastructure development with technical assistance aimed at connecting northern El Salvador with the rest of the country, helping to create opportunities for the region's residents through increased access to markets through the east-west highway, increased access to electricity through expansions of the electrical grid and distribution of solar panels, increased access to water and sanitation facilities to decrease disease in the region, and other interventions in education, agriculture, and other productive activities.

The Northern Zone of El Salvador contains half of El Salvador's poorest municipalities and suffered more damage from the country's internal conflict during the 1980s than any other region. Economic and social indicators in the Northern Zone are currently worse than the national average: In 2011, 48.4 percent of households in the Northern Zone were poor, compared with the 40.6 percent national estimate; 18.7 percent of households in the region lived in extreme poverty in 2011 compared with 11.2 percent at the national level. Human capital development is also lower in this region than in any other. The average level of schooling in El Salvador was 6.2 years in 2011, while the average in the Northern Zone was only 4.7. The percentage of illiterate people in the Northern Zone was 21.9 percent in 2011 versus a 12.8 national average ${ }^{1}$. The goal of the agreement was to reduce rural poverty by increasing regional economic growth through a five-year program of strategic investments and technical assistance in various sectors.

We had the opportunity to design the evaluation for the road improvement and water and sanitation investments. To accomplish this, we designed two separate panel surveys in the northern zone. One with a focus on market access, agricultural productivity and income to evaluate the impact of the rehabilitations of the Northern Transnational Highway (NTH); a two-lane paved road which serves as a transport artery within the Northern Zone. The second panel survey focused on quantifying water consumption from different sources, and quantifying the costs in time and money experience by households as they cope with lack of access to safe and adequate water and sanitation infrastructure. The water and sanitation investment consisted in the construction of potable water and sanitation systems, technical assistance for community

${ }^{1}$ DIGESTYC (2012) 
capacity building to improve water management-both environmental and financial-to ensure sustainability and maintenance of the systems, and community education related to appropriate health, hygiene and sanitation practices.

The second essay, in Chapter 3, assesses the extent to which the NTH achieved its goal of "connecting northern El Salvador with the rest of the country, helping to create opportunities for the region's residents through increased access to markets," and identifies which bottlenecks might have hindered achieving this goal, and which aspects might have aided in achieving it.

We evaluate the main impacts of the improvement of the NTH with two parallel approaches that use a panel household survey to exploit variation in the improvement of the road across time through a novel reduced form based on difference-in-difference and pipeline design, and a continuous treatment structural design that exploits the variation induce in market access by the timing of the improvements of the road and the spatial distribution of households in the Northern Zone of El Salvador. This is one of the few rigorous evaluations of road improvements in the literature and provides an impact evaluation strategy based on a sound theoretical framework that can be used by future evaluation of rural roads projects.

The third essay, in chapter 4, quantifies the benefits of water, sanitation and hygiene (WASH) interventions of the agreement. These interventions followed a community demand-driven model that allowed us to design a rigorous impact evaluation that provides reliable estimates that are not plagued by placement bias and omitted variable bias that characterizes much of the evidence in the literature. We propose a rigorous quasiexperimental design that incorporates matching on pre-baseline census data, panel data and difference-indifference estimation. This study contributes to the WASH literature in three ways. First, we examine the effect of an at-scale community demand-driven WASH intervention across a comprehensive set of indicators in a setting where the interventions mainly increase the quantity and quality of water and sanitation access. The evidence in this study from rural areas in El Salvador provides context and the opportunity to adjust the expectation on the effect of WASH intervention in other parts of Latin America and the world where the initial conditions of water and sanitation access are similar. Second, we provide evidence on the literature on the importance of research design at the early stages of impact evaluation to avoid relying on ex-post statistical methods selection, which have been recently showed to perform poorly in replicating known experimental impacts. The combination of pre-baseline matching and panel data in this study provides a methodologically well-grounded example of the impacts of WASH interventions in a literature that is plagued by shortcomings due to intervention placement bias and the endogeneity of households' WASH choices that are a function of where they live. Third, we present novel evidence on the effects of WASH interventions on the quality of drinking water at the source and at the point of consumption. Contamination of drinking water from the source to the point of consumption is a persistent problem in developing countries. This study is one of the few in the literature that estimates the effects of WASH interventions on source and stored water over time and with significantly larger sample size.

The key contributions and policy implications of the three essays are discussed in chapter 5 . The limitations and avenues for future research are discussed. 


\title{
Chapter 2 - Distributional Effects of Growth AND PUBLIC EXPENDITURES IN AFRICA
}

Estimates for Tanzania and Rwanda

with Maximo Torero

\begin{abstract}
Summary
In this essay, we explore the effects of fiscal policies and growth on measures of household welfare across the distribution of expenditures for two African countries: Rwanda and Tanzania. We explore the effect of government expenditures on expenditure growth in each quintile of the expenditure distribution and the effect of growth for each group. We find that the benefits of growth are concentrated among the better-off sectors of the population in these two countries (perhaps to the detriment of the poorer sectors) by looking at the effects within a country and across different groups of households and administrative entities. We exploit variation in expenditures and growth across and within regions of each country to estimate the elasticities of expenditure with respect to fiscal expenditure and mean expenditure growth at different points of the expenditure distribution, using household survey data and government expenditure data at the district level. We find that, overall, mean expenditure growth benefits the top expenditure groups. The welfare spillovers are mostly present for the top $20 \%$ of the expenditure distribution, with the middle of the distribution in Tanzania responding slightly to these spillovers. Public/social expenditures do not appear to affect inequality considerably, but do tend to work toward decreasing inequality. However, mean expenditure growth is related to increases in inequality because the richest sectors of the population benefit the most from growth. The growth elasticity of expenditure is only above one for the top quintile in both countries. In Tanzania, a $1 \%$ increase in average household expenditure is related to a $1.96 \%$ expenditure growth in the top quintile and $0.43 \%$ in the third quintile. In Rwanda, a $1 \%$ increase in average household expenditure is related to a $1.93 \%$ increase in household expenditure in the top $20 \%$ of the distribution.
\end{abstract}

Keywords: Tanzania, Rwanda, growth, inequality, fiscal policy

This is a reprint of the article of the same name published in World Development, Vol. 95, pp. 177-195, 2017 http://dx.doi.org/10.1016/j.worlddev.2017.02.019 


\section{INTRODUCTION}

The potential of using fiscal policies as a way of reducing poverty and inequality cannot be understated. These policies, however, are often mismanaged and, when the results are disappointing, many argue that the problem is intrinsically one of the weaknesses of fiscal policy as an instrument to achieve these goals. There is little dispute that overall growth can reduce poverty, but the potential for growth effects to be amplified or dampened by complementary fiscal policies is less understood. We explore these linkages and how their effects are reflected in the expenditure distribution, bringing attention not only to the power of growth and fiscal policies as poverty reduction tools, but also to the kind of effects on inequality these have; namely, the extent to which fiscal policies in developing countries can decrease inequality.

The literature on the efficiency of government expenditures in developed countries is nuanced-depending on the types of expenditures analyzed, results point to different, but mostly positive, levels of inefficiency (Arjona et al. 2003; Folster and Henrekson 2001; Schaltegger and Torgler 2004). However, the case for developing countries might be very different. In contrast to developed countries, government expenditures in developing countries may be more easily influenced by powerful interest groups, or suffer from political volatility. These, and other factors, make it more likely for public and social expenditures to suffer from inefficiencies in targeting. Benefits aimed at the poor may instead reach non-poor or powerful social classes (World Bank 2006). For example, Bose, Haque, and Osborn (2003) find that only capital expenditures and education outlays are significantly correlated with growth in a sample of developing countries, suggesting that more direct forms of aid may not reach their intended recipients.

In this essay, we explore the effects of fiscal policies and growth on measures of the household welfare across the distribution of household expenditure for two African countries: Rwanda and Tanzania. We look at effects within each country as well as across different groups of households and administrative entities. We prefer this method in lieu of estimating parameters at the mean across different countries, since it can provide a better picture of which groups are driving the dynamics of inequality and growth, while simultaneously allowing heterogeneity across countries.

Rwanda and Tanzania present exceptional cases for studying these issues. Both have gone through a decentralization process, where more responsibilities in the provision of public goods and general administration have been transferred to regional and communal institutions. This is key to our identification strategy because we exploit variation in expenditures and growth across and within regions of each country to estimate the elasticities of expenditure with respect to these fiscal outlays at different points of the expenditure distribution. In addition, East Africa has been on a solid growth path in the last years; in Rwanda, the average per capita GDP growth between 2000 and 2005 was above 4.5 percent and above 3 percent in Tanzania. However, in Rwanda and Tanzania, growth has been accompanied by budgetary deficits and increasing in government expenditures from 11 percent of GDP in 2000 to 18 percent in Rwanda and to 16 percent in Tanzania (World Bank, 2016). This paper looks to provide evidence as to what type of budgetary allocation can compensate for the effects growth has across different income groups to improve equity.

The paper presents the results for each country separately using a common framework and the specific fiscal outlays reported in each country. Given this, the exercise in this paper looks to describe the implications of the framework for each country and not to quantitatively compare the results across countries.

We use household survey data to characterize the distribution of expenditure of each country. For Tanzania, we use the Household Budget Survey (HBS) for 2000-2001 and 2007, while for Rwanda we use the Household Living Conditions Survey for 2000-2001 (EICV1) and 2005-2006 (EICV2). We use administrative data on public expenditures to characterize the government sector's expenditures. These consist of budget reports that describe the amount and the types of projects to which the government has made outlays. For Tanzania, we use data from district-level budget reports for the 2001-2007 period, and for Rwanda we use provincial- and 
regional-level budget reports for the 2004-2005 period. While more recent household-level data are available, we used these waves to mirror the period for which the budget data were available and for which the changes in public expenditures are plausibly related to the changes observed in the household sector.

Typical evaluations focus on single measures of inequality such as the GINI coefficient or the poverty headcount ratio. In contrast, we first estimate a model within a comprehensive distributional framework, and subsequently evaluate the distributional impact of public expenditures. We separate government expenditures into two large groups: public/social goods expenditures, which include health, education, and infrastructure; and other expenditures, which include administrative expenses and expenditures in sectors where positive social externalities are limited or nonexistent. We further disaggregate these variables as a function of the source of financing (for example, development grants) and/or by the type of sector within each group of expenditure. This separation is largely determined by the availability of budget data at the regional or district level in each country. Having different categories in each country serves to illustrate the flexibility of the distributional framework we use and allows us to explore if there are different implications depending on the source of financing and the purpose of government expenditures. We part from the premise, considered especially true for developing countries, that an essential part of a government's responsibility is to provide public goods targeted to the poor. The accuracy of this premise is an empirical question that we address in this paper.

This paper tries to fill some gaps in the literature by applying a common theoretical framework to examine how the benefits of economic growth spill into the household sector and how such benefits affect the distribution of income within the household sector and to what extent fiscal policy contributes to increase social equity and to decrease poverty in Rwanda and Tanzania.

\section{PREVIOUS LITERATURE}

In theory, proper public expenditure can be effective in promoting economic growth within an endogenous growth framework (Barro 1990; Jones et al. 1993; Stokey and Rebelo 1993). Since governments can provide a large array of goods and services such as national defense, justice services, public infrastructure, primary education, etc., the allocation of public expenditure is what determines whether the public expenditure is productive or not (Devarajan et al. 1996; Agénor and Neanidis 2011). Measuring the impact of public expenditure on economic growth allows us to evaluate the effectiveness of certain public expenditure strategies. More importantly, measuring the impact of public expenditure on different income groups can provide valuable information on the effectiveness of public expenditure to improve the living conditions of those in the bottom of the income distribution (that is, pro-poor public expenditure).

Studies that link aggregate public expenditure to economic growth, in general, have not yielded consistent results and have focused on developed economies. Some have found that aggregate public spending is associated negatively with economic growth (Landau 1986; Levine and Renelt 1992; Folster et al. 2001; Schaltegger and Torgler 2004), while others have found the opposite (Ram 1986; Sattar 1993; Bose, Haque, and Osborn 2003), or claim a neutral relationship (Kormendi and Meguire 1985). A similar trend is found in studies testing the effects of particular components of public expenditure (public investment, education expenditure, defense expenditure, etc.) on economic growth. Again, some suggest that public sector consumption is negatively related with economic growth (Barro 1991; Levine and Renelt 1992; Kneller et al. 1999), while others find the opposite (Devarajan 1996). Even though many assume public investment to axiomatically have a positive impact on private productivity, some studies agree (Aschauer 1989; Barro 1991; Easterly and Rebelo 1993; Kneller et al. 1999) while others find evidence to contradict this claim (Devarajan 1996). Education indicators also yield conflicting results. Barro (1991), Mankiw et al. (1992), and Easterly and 
Rebelo (1993) all find a positive association between human capital investment and economic growth; in contrast, Islam (1995) and Caselli et al. (1996) use panel data to address endogeneity problems, and find a negative relationship between economic growth and measures of human capital. These contradictory results may be partly explained by scholars ignoring the impact of other economic policies which coincide with fiscal policy, differences in each study's set of explanatory variables (Levine and Renelt 1992), or the omission of government budget constraints (Kneller et al. 1999).

Though the relationship between government expenditure and economic growth may be contested, most scholars contend that economic growth is a key factor in poverty reduction. However, the rate at which poverty falls with growth, and the extent to which different income groups benefit from economic growth remains an open question.

Some consensus exists regarding the power of economic growth to reduce poverty among developing countries (Dollar and Kraay 2002, 2004), less agreement exists about the role of economic growth on other aspects of income distribution, its effect on the welfare of the middle class (Deininger and Squire 1996; Chen and Ravallion, 1997). Earlier studies have mainly focused on the effect of growth on the poor, but there are no empirical studies that systematically look at the effects of growth on the complete distribution of income. The need for fiscal policy as a complementary instrument to reduce inequality in a growing economy is, in general, not well understood.

Ravallion (2004) found that, depending on the initial level of inequality, a 1 percent increase in income levels could result in poverty reductions ranging from 0.6 percent (with high inequality) to 4.3 percent (with low inequality). Similarly, David Dollar and associates show that economic growth is good for the poor, meaning that the elasticity of the level of per capita income of the poor vis-à-vis the level of per capita GDP is about one or even higher; the incomes of the poor rise at the same rate as average incomes (Gallup et al. 1999; Dollar and Kraay 2002; Dollar, Kleineberg and Kraay 2016). These results are an average for many countries, from very poor to upper middle income countries. It remains unclear whether the results are driven by groups of countries, and whether we can generalize them to a specific context. Additionally, Dollar and Kraay (2002) and Dollar, Kleineberg and Kraay (2016) focus mainly on the incomes of poor households as measured by head count measures, but they do not evaluate the impact of growth within a comprehensive distributional framework that encompasses other important social groups. In contrast, Foster and Székely (2008) suggest that the income of the poor does not rise one-for-one with increases in the average income. In large part, these papers and others fail to systematically examine the role of fiscal policy as a mechanism that may alter the impact of growth on social distribution.

In the intersection between growth, inequality and fiscal policies, Balakrishnan, Steinberg and Syed (2013) study how pro-poor and inclusive growth has been in Asia. They find that growth has been less inclusive and less-pro poor and suggest fiscal policies, such as increasing expenditures on health and education, social safety nets, and labor market reforms to broaden the benefits of growth in the region. Afonso, Schuknecht and Tanzi (2010) looks at relationship between different types of public expenditure and Gini coefficients of OECD countries and find that inequality in the income distribution, as measured by the Gini coefficient, could be attained with reduced public social spending, implying that with the same level of public social spending one could in principle increase income equality.

The rising income inequality in advanced and developing economies and the use of fiscal policies for income redistribution when fiscal budgetary restraints are necessary highlights the importance of studying these issues jointly. Our paper aims to estimate the joint effect of economic growth and the structure of government expenditures on household expenditure distribution. To the best of our knowledge, this question has not been systematically explored before in the empirical literature despite its obvious importance and policy relevance. Existing studies on public expenditure and inequality may be roughly categorized into three main themes: 
First, the relationships between different measures of social capital and their relationship to government actions and inequality; second, papers that try to test the median voter hypothesis and its implications for fiscal policy; and third, studies that specifically consider the effects on inequality by redistributive public spending (specifically education and health).

Within the first thematic group, the main objective is to capture national or jurisdictional tastes for redistributive and collective goods. Highly unequally distributed wealth in conjunction with unduly concentrated political power can prevent institutions from enforcing broad-based personal and property rights, and lead to skewed provisioning of public services and functioning of markets.

The second line of research examines the way in which inequality may affect growth through political channels. The degree of inequality could affect the median voter's desired pattern of policies or it could determine individuals' ability to access political markets and social spending, and to participate in costly lobbying (Deininger and Squire 1998). These studies rely on some version of the median voter theorem (Persson and Tabellini 1994; Bertola 1993), which in its simplest and most widespread version assumes democratic determination of tax rates. Most of the empirical implementation of these papers ${ }^{2}$ is motivated by the relationship between measures of inequality (median income levels, share of the median income, Gini coefficients) and growth, but they focus on the impact of inequality on the decision-making process of the median voter. In addition, Moene and Wallerstein (2001), Bradley et al. (2003), and Kenworthy and Pontusson (2005) address similar issues but using empirical specifications that often yield more robust results.

The third strand of the literature focuses on inequality and growth as they are both affected by redistributive public spending, particularly health and education. ${ }^{3}$ Most of these studies conclude that there is no direct link between inequality and public spending on health and education.

Our empirical strategy departs from the literature above in two main ways. First, we measure the impact of public expenditures in the different parts of the distribution directly by looking at the impacts over expenditure growth at each quintile of the distribution instead of focusing on single measures of distribution such as the Gini coefficient or head count poverty as is commonly done. This approach helps us to disentangle the relationship between changes in public expenditure and economic growth across several income groups, exploiting both the cross-regional and time-series variation in the data.

Second, the relationship between economic inequality and social spending is one of mutual interdependency; it may be crucial to distinguish specific types of social spending, which in turn differentially affect and are affected by different aspects of economic inequality. Moreover, different kinds of social expenditure-cash (income, maintenance, and social insurance), health and education, infrastructure, and others-may have different political determinants. We classify the public expenditure into two key categories (expenditures in public/social goods and other expenditures), and estimate the effect of changes in these categories on income growth across different income groups. We also take the source of financing and type of expense within each category into account when the data allow (for example, infrastructure, health and education, funds from development grants, etc.). Our paper develops a more comprehensive distributional framework that may allow us to evaluate the effects of economic growth on several social groups including the poor, middle class, and upper class groups.

\footnotetext{
2 For example, Arjona et al. (2003), Turnbull and Djoundourian (2005), Milanovic (2000), Bassett et al. (1999), Alesina and La Ferrara (2005, and Kristov et al. (1992).

${ }^{3}$ For example, Ross and Wu (1995), Perroti (1992, 1996), Bassett et al. (1999), Persson and Tabellini (1994), Alesina and Rodrik (1994), Osberg (1995), Sala-i-Martin (1997), Benabou (1996, 2000), Castello and Domenech (2002), and, most recently, van der Ploeg (2003), Gylafson and Zoega (2003), and Deaton (2003).
} 
One of the few papers that attempts a similar exercise is Wikstrom (1999). He estimates the income distribution effects from local public expenditures in Swedish municipalities by estimating a model where quintile income shares are explained by municipality-specific determinants. He also uses three categories of local public spending: social expenditures, primary and secondary education expenditures, and recreational expenditures. The paper finds that while social expenditure affects the distribution of income within a municipality, no effects can be found for education or recreation. Larger social expenditures appear to decrease the portion of income in the lowest quintile and the portion of income in the highest quintile, thereby concentrating income toward the middle classes.

\section{THEORETICAL FRAMEWORK}

We use a comprehensive distributional framework to evaluate the impact of public expenditures instead of focusing on single measures of distribution. We work with annual growth rates instead of levels, which at least in part mitigates the problems of unbalanced panels and different lag lengths between observations that have affected some earlier studies (Ashley 2006).

The effect of GDP growth on the per capita income of social groups (including the poor) is quite complex. We can separate the analysis of this effect into two stages.

- Stage 1: Estimating the effect of per capita GDP on per capita mean household expenditure as an indicator of the degree by which the benefits of economic growth spill into the household sector. Public policies, including government expenditure level and composition, may play a role in affecting this relationship. For example, government tighter tax policies or a more pro-ordinary citizen (less pro-elite) public expenditure composition may reduce the gap between per capita GDP and per capita household income. This is particularly so if these policies would reduce the income of the very rich who, as discussed below, are not likely to be represented in the household surveys.

- Stage 2: Measuring the effect of changes in average per capita household income on the per capita income of the various social groups to reflect the within-household distribution of household income growth. Given the mean per capita household income, there is also a pure distribution effect of public policy among the various social groups represented in the household surveys. That is, government expenditure composition may cause a reallocation of income across the (mostly non-rich) groups represented in the household surveys.

We distinguish between per capita GDP, which is a measure of real output produced in the regions, and mean per capita household income, which in most existing household surveys is after tax income accruing to the households. There are many reasons other than taxes for why household income is likely to diverge from GDP. Part of GDP is directed to pay foreigners, part of it stays within the corporate sector as non-distributed profits, and certain households (particularly the richest) may not be represented in the national surveys. Rich households that are in the survey may severely under report their income.

Consistent with the above two-stage procedure, we propose a multiple equation model and derive crosssector restrictions to jointly estimate the equations and circumvent the need of first estimating the impact of GDP growth on the growth of per capita income of the mean household. This allows us to estimate the effect of growth of the average per capita household income on the per capita income of the poor, middle, and upper class groups represented in the household surveys, while also controlling for public expenditure policies and other covariates. 


\section{ECONOMETRIC MODEL}

We divide the total household population of a country into $M$ social groups to reflect the income distribution ${ }^{4}$. We assume that the per capita household income of a particular group $i$ at time $t$ in district $j, y_{i j t}$, is determined by the household average per capita income in the district, $Y_{j t}$, by a vector reflecting the stock of various government-provided goods, which is in turn related to the government expenditure level and composition $E_{j t},{ }^{5}$ and by unobserved effects specific to the social group and district $\psi_{i j}$, unobserved time effects, $v_{t}$, and a random disturbance $\varepsilon_{i j t}$.

Thus, if there are $M$ household groups, we have $M$ equations, such as

$$
y_{i j t}=\psi_{i j}+\alpha_{1 i} E_{j t}+\alpha_{2 i} Y_{j t}+v_{t}+\varepsilon_{i j t} \quad \text { for } \quad i=1 \ldots . M
$$

We note that the parameter vectors $\alpha_{1 i}$ and $\alpha_{2 i}$ can be different for each of the $M$ groups considered to allow for differential effects of the stocks of government-provided goods and average household income on the per capita income of each group. We also note that the fixed effects $\psi_{i j}$ allow for intrinsic or unobserved variability not just across districts but across income groups as well.

In addition, the average per capita household income of the whole district is related to the group per capita income as follows:

$$
Y_{j t}=\sum_{i=1}^{M} \frac{n_{i j}}{N_{j}} y_{i j t}
$$

where $n_{i j}$ is the size of group $i$ in district $j$ and $N_{j}$ is the total population in district $j$. This implies the following restrictions to the coefficients in Equation 1:

$$
\sum_{i=1}^{M} \frac{n_{i j}}{N_{j}} \alpha_{1 i}=0 \quad \text { (2b) } \quad \sum_{i=1}^{M} \frac{n_{i j}}{N_{j}} \alpha_{2 i}=1
$$

$$
\sum_{i=1}^{M} \frac{n_{i j}}{N_{j}} v_{t}=0
$$

These restrictions imply that Equation 1 needs to be jointly estimated using a system estimation. ${ }^{6}$ While we have data on the flows of government expenditures for various key components, we do not have reliable measures of their respective stock levels as would be needed to directly estimate Equation 1, nor a measure for district-level GDP. We thus express the system of Equation 1 in absolute or proportional differences. Each of course has different stochastic properties and requires different assumptions. Expressed in absolute changes over time the system is

$$
\Delta y_{i j t}=\alpha_{1 i} \Delta E_{j t}+\alpha_{2 i} \Delta Y_{j t}+\Delta v_{t}+\Delta \varepsilon_{i j t} \quad \text { for } \quad i=1 \ldots . M
$$

The use of the "difference" approach permits us to use the flows of public expenditures as proxies for the changes in the stocks of goods that may affect the changes in group income. Moreover, the goods provided by the government typically comprise a mix of durable and investment goods such as education or infrastructure,

\footnotetext{
${ }^{4}$ The discussion of the framework is center around the income distribution. However, the empirical results presented are those of the expenditure distribution.

${ }^{5}$ Another important determinant of group income is the level and composition of taxes, which could also be part of the vector $E_{j t}$.

${ }^{6}$ If a system like Equation 1 were estimated then given the above restrictions one would only need to estimate $\mathrm{M}-1$ equations of the system while the remaining one could be identified through the restrictions. However, for reasons we explain below we do not directly estimate Equation 1.
} 
which mainly exhibit a stock effect, along with other goods such as social assistance which may affect household income directly through their flow effects as well.

Another advantage of using a difference model is that it is naturally independent of the district and group fixed effects. This, as we shall see, allows us to use the region effects as valid instruments for some explanatory variables. Mean per capita household income is, in turn, related to per capita GDP as well as to a number of other factors that alter the relationship between household income and GDP discussed earlier. Thus, we postulate the following household income to GDP relationship

$$
Y_{j t}=\beta_{1} Z_{j t}+\beta_{2} E_{j t}+u_{j}+\phi_{t}+\eta_{\mathrm{jt}}
$$

where $Z_{j t}$ is GDP per capita for district $j$ in $t, E_{j t}$ is a vector of public policy variables that may affect the relationship between household income and GDP (including public expenditures and taxes); $u_{j}$ and $\phi_{t}$ are fixed district and time effects and $\eta_{j t}$ is the stochastic error term. The $u_{j}$ allows for other unobserved sources of divergence between per capita GDP and per capita household income that are district specific. The district effects may, among other things, control for peculiarities to the way in which the household survey income is measured across districts.

Expressing Equation 4 in relative or absolute differences:

$$
\Delta Y_{j t}=\beta_{1} \Delta Z_{j t}+\beta_{2} \Delta E_{j t}+\Delta \phi_{t}+\Delta \eta_{\mathrm{jt}}
$$

The specification in Equation 4 or Equation 4' captures some of the main sources of discrepancy between household per capita income as measured from household surveys and the district's per capita GDP as would be measured by national accounts. First is the level of per capita GDP itself; that is, we allow for a one dollar increase in per capita GDP to affect average household income by more, or less than a dollar. This is the reason why we do not a priori impose $\beta_{1}=1$ and in fact test for such a result.

Instead of directly estimating the system Equation 3 and Equation 4', we insert Equation 4' into Equation 3 and obtain:

$$
\Delta y_{i j t}=\gamma_{i} \Delta Z_{j t}+\theta_{i} \Delta E_{j t}+\sigma_{t}+\omega_{\mathrm{ijt}} \quad \text { for } \quad i=1 \ldots . M
$$

where we have redefined the parameter vectors as

$$
\gamma_{i}=\alpha_{2 i} \beta_{1} \quad \text { and } \quad \theta_{i}=\alpha_{1 i}+\alpha_{2 i} \beta_{2} \text {. }
$$

Using the restrictions given by Equations $2 a$ and $2 b$, we can identify the original parameter as follows:

$$
\text { (6a) } \quad \sum_{i \in I} \frac{n_{i j}}{N_{j}} \gamma_{i}=\beta_{1} \underbrace{\sum_{i \in I} \frac{n_{i j}}{N_{j}} \alpha_{2 i}}_{1}=\beta_{1}
$$

(6b) $\quad \sum_{i \in I} \frac{n_{i j}}{N_{j}} \theta_{i}=\sum_{i \in I} \frac{n_{i j}}{N_{j}}\left(\alpha_{1 i}+\alpha_{2 i} \beta_{2}\right)=\underbrace{\sum_{i \in I} \frac{n_{i j}}{N_{j}} \alpha_{1 i}}_{0}+\beta_{2} \underbrace{\sum_{i \in I} \frac{n_{i j}}{N_{j}} \alpha_{2 i}}_{1}=\beta_{2}$

Given the $\beta$ parameters we can further identify the $\alpha$ parameters. The income distribution parameters are $\alpha_{2 i}=\frac{\gamma_{i}}{\beta_{1}}$ and the fiscal distribution parameters are $\alpha_{1 i}=\theta_{i}-\alpha_{2 i} \beta_{2}$. Standard errors for the coefficients $\beta, \alpha$ can be obtained using the variance covariance matrix of the estimated parameters $\theta, \gamma$ by the delta method.

In the estimation, we mainly look at five social groups, although we experimented with different disaggregation methods. We divide the households by quintile: 
- The "bottom poor," defined as the bottom 20 percent of the households.

- The "poor," defined as the next 20 percent of the households.

- The "lower middle class," defined as the next 20 percent of the households.

- The "upper middle class," defined as the next 20 percent of the households.

- The "upper class," defined as the remaining 20 percent of the households.

We considered alternative cuts across the distribution, such as a 40-40-20 type of grouping and 40-20-30-10. The results are qualitatively similar, but we opt to present the results by quintile to shed light on the differences of these effects across more points in the distribution of expenditure.

Given the restrictions in Equations $2 \mathrm{a}$ to $2 \mathrm{c}$, the parameters $\alpha_{1 i}$ associated with the fiscal variables reflect changes in income distribution within the household sector. That is, the parameters measure how the composition of the government expenditures affects the per capita household income of the various social groups given a fixed level of the mean per capita household income. By contrast, the parameters $\theta_{i}$ measure the total or uncompensated impact of the fiscal variables on the per capita income of the various household groups. The effect of a change in government expenditures in public infrastructure, for example, on a particular social group can be separated into two components: it may affect the per capita mean household income of all households and it may affect the distribution of income across the household groups for a given level of mean household income.

In addition, we are interested in measuring how economic growth affects the distribution of income among the five social groups considered. We consider the effect of per capita GDP growth on the groups' household income growth through the effect of average household income growth. The $\gamma_{i}$ coefficients measure the total effect of GDP growth on the per capita income of group $i$, while the coefficients $\alpha_{2 i}$ measure how an increase in the average household per capita income is distributed across the groups.

\section{SPECIFICATION ISSUES}

In estimating Equation 5, we need to be concerned about potential specification problems. The estimated parameters may be biased due to reverse causality, omitted variables, and/or measurement errors in the explanatory variables. To mitigate possible biases due to omitted variables, we use first differences instead of levels of the variables, and use instrumental variables to circumvent problems arising from reverse causality.

The use of first differences eliminates the district fixed effects as well as the group fixed effects. Therefore, while the district dummies are part of Equation 1, they are not part of the right-hand-side variables of Equation 5 . We use regional dummies ${ }^{7}$ and GIS variables as instruments for the fiscal expenditure and growth variables, namely the annual mean, standard deviation, and absolute deviations of rainfall and temperature during the study period in each district. We test for the exclusion of these dummies and GIS variables from Equation 5. The model without the region fixed effects reports higher (in absolute value) AIC (Akaike Information Criterion) for Rwanda and the BIC (Bayesian Information Criterion) is higher for both countries, providing evidence that the regional fixed effects and GIS variables are not jointly omitted variables in the equations. Table 1 presents the results.

\footnotetext{
${ }^{7}$ A region comprises multiple districts in each country. Note that the district effects subsume a regional effect that also is differentiated out. The choice of using regional dummies as instruments is to prevent a problem of weak instruments and low power due to the amount of degrees of freedom needed.
} 


\begin{tabular}{|c|c|c|}
\hline Expenditure Equation & Unrestricted model & Including instruments \\
\hline \multicolumn{3}{|l|}{ Rwanda } \\
\hline AIC & $-2,111.7$ & $-2,073.2$ \\
\hline $\mathrm{BIC}$ & $-2,049.2$ & $-1,748.2$ \\
\hline \multicolumn{3}{|l|}{ Tanzania } \\
\hline AIC & $-2,314.046$ & $-2,322.542$ \\
\hline $\mathrm{BIC}$ & $-2,209.839$ & $-1,840.586$ \\
\hline
\end{tabular}

In addition, regional dummies are highly correlated with the government expenditure variables considered. Hence, the fact that regional dummies have no explanatory power in the main regressions but are nonetheless correlated with the government expenditure variables allows us to use the regional dummies as valid instruments.

We also need to correct for the fact that in the relative differences model we may have built in heteroskedasticity, given that the disturbances in Equation 5 are divided by $y_{i j t-1}$ in the estimation since we use the growth rates of expenditure in each quintile group. Therefore, we need to use appropriate procedures to obtain the corrected (robust) standard errors.

\section{DATA}

We need two types of data to estimate the model: household survey data for the household sector variables and public expenditure data. We separate government expenditures into two large groups: public/social goods expenditures, which include health, education and infrastructure; and other expenditures, which include administrative expenses and expenditures in sectors where positive social externalities are limited or nonexistent. We further disaggregate these variables as a function of the source of financing (for example, development grants) and/or by the type of sector within each group of expenditure. This categorization of public expenditures is largely due to the level of detail in the budget reports in each country; this prevent us from using a unique set of public expenditures variables for both countries, but allows to explore contextualize the implications of the framework based on the different types of fiscal measures. Namely, source of funding and administrative variables in Tanzania, and more specific sectors (like infrastructure, and health and education) in Rwanda.

For Tanzania, we use the Household Budget Survey (HBS) for 2000-2001 and 2007. The 2001 survey is representative of 20 regions in mainland Tanzania and the 2007 survey is representative of three strata in mainland Tanzania. For Rwanda, we use the Household Living Conditions Survey from 2000-2001 (EICV1) based on the 1991 Rwanda census and from 2005-2006 (EICV2) based on the 2002 Rwanda census.

These data are not representative at the district level, but they are a useful gauge of the growth in each district. ${ }^{8}$ In Tanzania, we can construct the measures for 100 districts in the mainland. For Rwanda, we can construct 90 conglomerates of districts within each region to calculate a district-level measure. In the case of Rwanda, there were changes in the boundaries of districts in the time between the two surveys, so a one-toone matching across surveys was not possible. We use GIS information to allocate the districts in the EICV1 to the districts as they stood in the 2002 census. We also map the location of each household in the EICV2 to the

8 In addition, our use of first differences and IV gives us more meaningful measures while accounting for the measurement error. 
district classification of the 2002 census to consider boundary changes in 2006 . The measures we calculate using the household-level data consist of the average income and expenditure per capita of each district and the mean income and expenditure of each quintile in the district. This results in a dataset with one observation per time period per district.

In Tanzania, we use data from district-level budget reports for 2001 to 2007 and construct annualized growth measures for each public expenditure type used in the analysis, as not all budget items had information for 2001. We calculate the average growth rate of each expenditure variable between 2007 and the earliest available year for which we have data in our survey period (2001 to 2006). Assuming a geometric growth rate, for any year $t$ before 2007, the average growth rate between 2007 and year $t$ is given by:

$$
r=\left(\frac{Y_{2007}}{Y t}\right)^{\frac{1}{2007-t}}-1
$$

In the case of Rwanda, we use provincial- and regional-level budget reports for 2004-2005. Given that the data were only available at the regional level and we require them at the district level, we use the formulas used by the national government to allocate the national budget to different districts (Shirima 2004). To some extent, the allocation is an idealized allocation rule for available funds, but it does reflect infrastructure needs, poverty levels, and the political reality at the time.

We use the World Development Indicators to transform all currency variables to purchasing power parity (PPP) constant dollars in the last year of the household survey for each country (2005 PPP dollars for Rwanda and 2007 PPP dollars for Tanzania).

Table 2 through Table 5 show the summary statistics of the variables used for each country in the study. In each table, we divide districts into two groups: those that fall above the median household expenditure ( $\$ 352$ per capita for Rwanda and \$661 per capita in Tanzania) in the last year of the household survey (high columns) and those that are below (low columns).

Rwanda's districts are characterized by wide income disparities even across adjacent groups of the expenditure distribution. The expenditures of the poor are considerably lower than other groups. Over all districts, the top quintile has almost three times the annual expenditure per capita of the fourth quintile. The situation of the poor in Rwanda (Table 2) is very similar in districts both above and below the median per capita income. We note that the expenditure levels are well below the one dollar a day poverty line even for the third quintile. ${ }^{9}$ On the government expenditure side, poorer districts spend only slightly more in health and education; and health and education is the highest fiscal spending category in the data.

In Table 3, we can see the average growth rate across groups for our expenditure variables in Rwanda. Average expenditure growth is greatest for the top quintile and growth rates are higher for richer districts. In contrast, growth rates are much lower and similar across the bottom 80 percent of the distribution. The lower levels of growth among the poor suggest that the benefits of growth are concentrated at the top quintiles. We note that poorer districts (and poorer households) start from much lower levels of expenditure in contrast to their middle-class peers, and thus have more room to increase their wealth. The shares of expenditure concentrated among the top quintile of the distribution are above 50 percent, with even larger concentrations among the districts above the median per capita expenditure.

\footnotetext{
${ }^{9}$ With the caveat that as is well known the "very wealthy" are not usually represented in household surveys.
} 


\begin{tabular}{|c|c|c|c|c|c|c|}
\hline & \multicolumn{6}{|c|}{ District Category } \\
\hline & \multicolumn{2}{|l|}{ High } & \multicolumn{2}{|l|}{ Low } & \multicolumn{2}{|l|}{ All } \\
\hline & Mean & SD & Mean & SD & Mean & SD \\
\hline \multicolumn{7}{|c|}{$\begin{array}{l}\text { Yearly Per Capita Government } \\
\text { Expenditures }\end{array}$} \\
\hline Infrastructure & 1.14 & 0.69 & 1.12 & 0.33 & 1.13 & 0.54 \\
\hline Health and Education & 16.05 & 2.49 & 16.56 & 2.27 & 16.30 & 2.38 \\
\hline General Expenses & 4.33 & 2.77 & 3.92 & 2.21 & 4.12 & 2.50 \\
\hline \multicolumn{7}{|c|}{$\begin{array}{l}\text { Yearly Per Capita Household } \\
\text { Expenditure }\end{array}$} \\
\hline Quintile 1 & 81.65 & 11.99 & 81.34 & 9.84 & 81.50 & 10.92 \\
\hline Quintile 2 & 153.13 & 5.64 & 154.47 & 8.11 & 153.80 & 6.98 \\
\hline Quintile 3 & 237.60 & 9.73 & 239.81 & 10.46 & 238.70 & 10.11 \\
\hline Quintile 4 & 401.89 & 29.35 & 402.25 & 24.99 & 402.07 & 27.08 \\
\hline Quintile 5 & $1,175.43$ & 537.60 & 818.12 & 299.70 & $1,000.84$ & 470.95 \\
\hline
\end{tabular}

Source: Household averages were obtained using 2005 EICV data.

Note: All figures are in 2005 PPP dollars.

TABLE 3 SUMMARY STATISTICS FOR RWANDA DATA: MEAN GROWTH AND EXPENDITURE SHARES

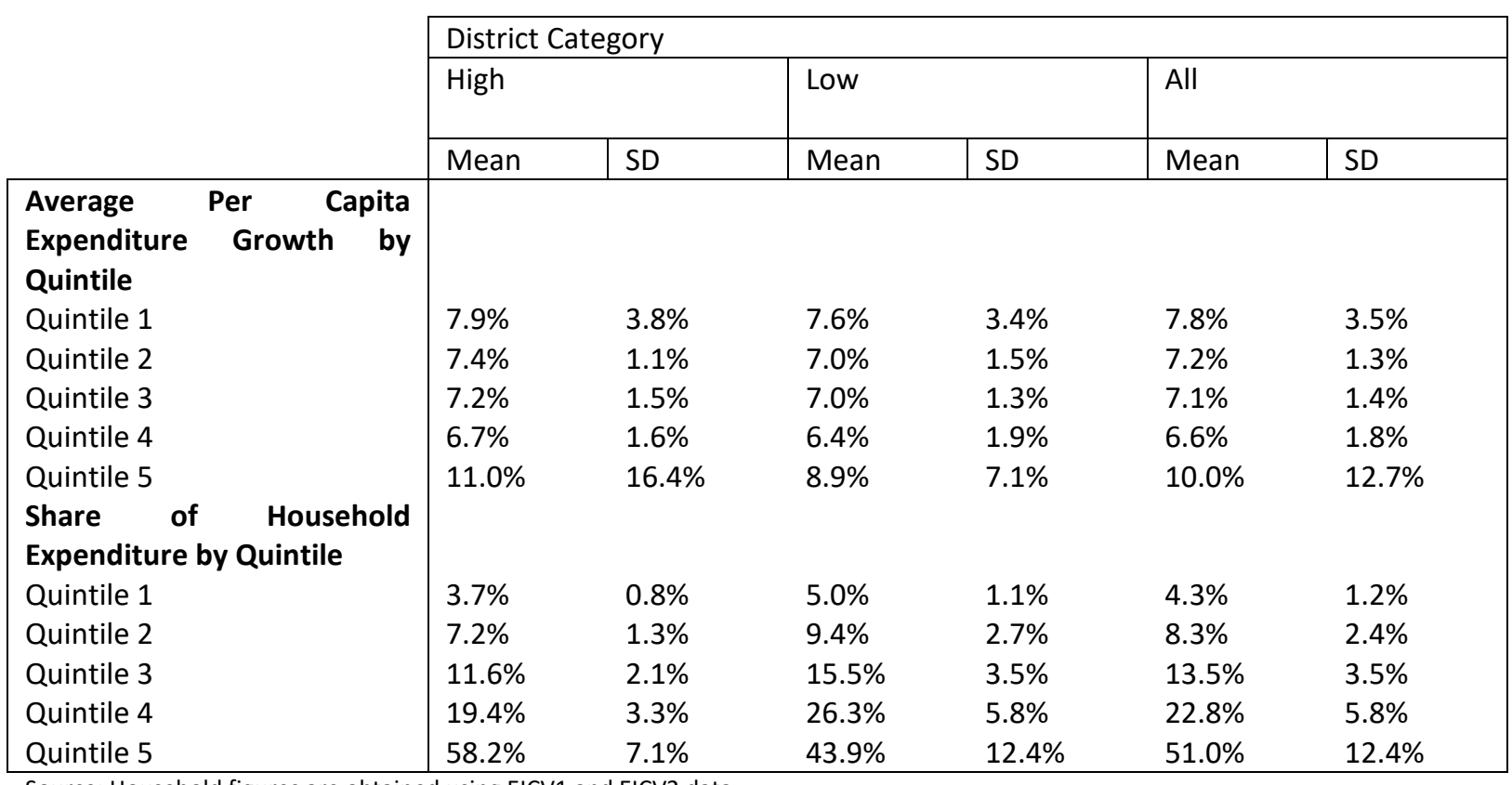

Source: Household figures are obtained using EICV1 and EICV2 data.

Note: Annualized growth rates are reported for years 2000-2005.

In Tanzania, the situation is similar but with higher overall levels of expenditure (Table 4 and Table 5). Unlike Rwanda, there is a significant gap in social expenditures between poorer and richer districts. In Tanzania, the higher fiscal expenditures are given by social expenditures, and, on average, expenditure growth rates are similar across quintiles. 


\begin{tabular}{|c|c|c|c|c|c|c|}
\hline & \multicolumn{6}{|c|}{ District Category } \\
\hline & \multicolumn{2}{|l|}{ High } & \multicolumn{2}{|l|}{ Low } & \multicolumn{2}{|l|}{ All } \\
\hline & Mean & SD & Mean & SD & Mean & SD \\
\hline \multicolumn{7}{|l|}{$\begin{array}{l}\text { Per Capita Government Expenditures } \\
\text { Social Expenditures }\end{array}$} \\
\hline Expenditures from development funds & 11.82 & 11.80 & 16.63 & 32.46 & 14.22 & 24.42 \\
\hline Expenditures on salaries and charges & 48.36 & 49.88 & 69.72 & 159.29 & 59.04 & 117.92 \\
\hline \multicolumn{7}{|l|}{ Non-Social Expenditures } \\
\hline Expenditures from development funds & 4.71 & 5.27 & 5.51 & 8.24 & 5.11 & 6.89 \\
\hline Expenditures on salaries and charges & 4.07 & 5.21 & 7.00 & 16.51 & 5.53 & 12.27 \\
\hline Taxes and Levies & 5.15 & 9.45 & 4.21 & 12.62 & 4.68 & 11.10 \\
\hline Total collected revenue & 6.67 & 9.79 & 5.54 & 13.59 & 6.11 & 11.80 \\
\hline \multicolumn{7}{|l|}{ Per Capita Household Expenditure } \\
\hline Quintile 1 & 193.08 & 24.49 & 192.50 & 22.54 & 192.79 & 23.42 \\
\hline Quintile 2 & 334.73 & 14.68 & 332.33 & 15.77 & 333.53 & 15.21 \\
\hline Quintile 3 & 495.65 & 18.84 & 495.74 & 21.37 & 495.70 & 20.05 \\
\hline Quintile 4 & 750.50 & 34.96 & 745.35 & 51.97 & 747.92 & 44.14 \\
\hline Quintile 5 & $1,839.21$ & 967.12 & $1,456.84$ & 300.55 & $1,648.02$ & 737.95 \\
\hline
\end{tabular}

Source: Household averages were obtained using HBS 2007 data.

Note: All figures are in 2007 PPP dollars. 


\begin{tabular}{|c|c|c|c|c|c|c|c|}
\hline & & \multicolumn{6}{|c|}{ District Category } \\
\hline & & \multicolumn{2}{|c|}{ High } & \multicolumn{2}{|c|}{ Low } & \multicolumn{2}{|c|}{ All } \\
\hline & & Mean & SD & Mean & SD & Mean & SD \\
\hline \multicolumn{8}{|c|}{$\begin{array}{l}\text { Average Per Capita Expenditure } \\
\text { Growth by Quintile }\end{array}$} \\
\hline Quintile 1 & & $9.8 \%$ & $3.4 \%$ & $9.5 \%$ & $3.5 \%$ & $9.7 \%$ & $3.4 \%$ \\
\hline Quintile 2 & & $11.2 \%$ & $1.1 \%$ & $11.2 \%$ & $1.1 \%$ & $11.2 \%$ & $1.1 \%$ \\
\hline Quintile 3 & & $11.9 \%$ & $0.9 \%$ & $11.7 \%$ & $1.2 \%$ & $11.8 \%$ & $1.1 \%$ \\
\hline Quintile 4 & & $12.6 \%$ & $1.8 \%$ & $12.5 \%$ & $2.1 \%$ & $12.6 \%$ & $2.0 \%$ \\
\hline Quintile 5 & & $11.3 \%$ & $6.9 \%$ & $12.7 \%$ & $6.3 \%$ & $12.0 \%$ & $6.6 \%$ \\
\hline \multicolumn{8}{|c|}{$\begin{array}{l}\text { Share of Household Expenditure by } \\
\text { Quintile }\end{array}$} \\
\hline Quintile 1 & & $5.5 \%$ & $0.8 \%$ & $6.3 \%$ & $0.6 \%$ & $5.9 \%$ & $0.8 \%$ \\
\hline Quintile 2 & & $9.7 \%$ & $0.9 \%$ & $11.2 \%$ & $0.6 \%$ & $10.4 \%$ & $1.0 \%$ \\
\hline Quintile 3 & & $14.3 \%$ & $1.2 \%$ & $16.5 \%$ & $0.7 \%$ & $15.4 \%$ & $1.5 \%$ \\
\hline Quintile 4 & & $21.5 \%$ & $2.0 \%$ & $24.3 \%$ & $1.3 \%$ & $22.9 \%$ & $2.2 \%$ \\
\hline Quintile 5 & & $49.1 \%$ & $4.4 \%$ & $41.8 \%$ & $1.9 \%$ & $45.5 \%$ & $5.0 \%$ \\
\hline
\end{tabular}

Source: Household figures are obtained using HBS 2001 and 2007 data.

Note: Annualized growth rates are reported for years 2001-2007.

In Figure 1 and Figure 2 we can see that the districts that have higher expenditure growth of the bottom quintile are often not the ones with the higher growth in the top quintile. This suggests significant heterogeneity in growth rates both across districts as well as between income groups. Considering differences between and within districts, we estimate our model separately for low- and high-income districts to explore heterogeneity in the effects of our fiscal variables. 
FIGURE 1 RWANDA: CONSUMPTION GROWTH FOR THE TOP 20 PERCENT AND THE BOTTOM 20 PERCENT OF THE EXPENDITURE DISTRIBUTION
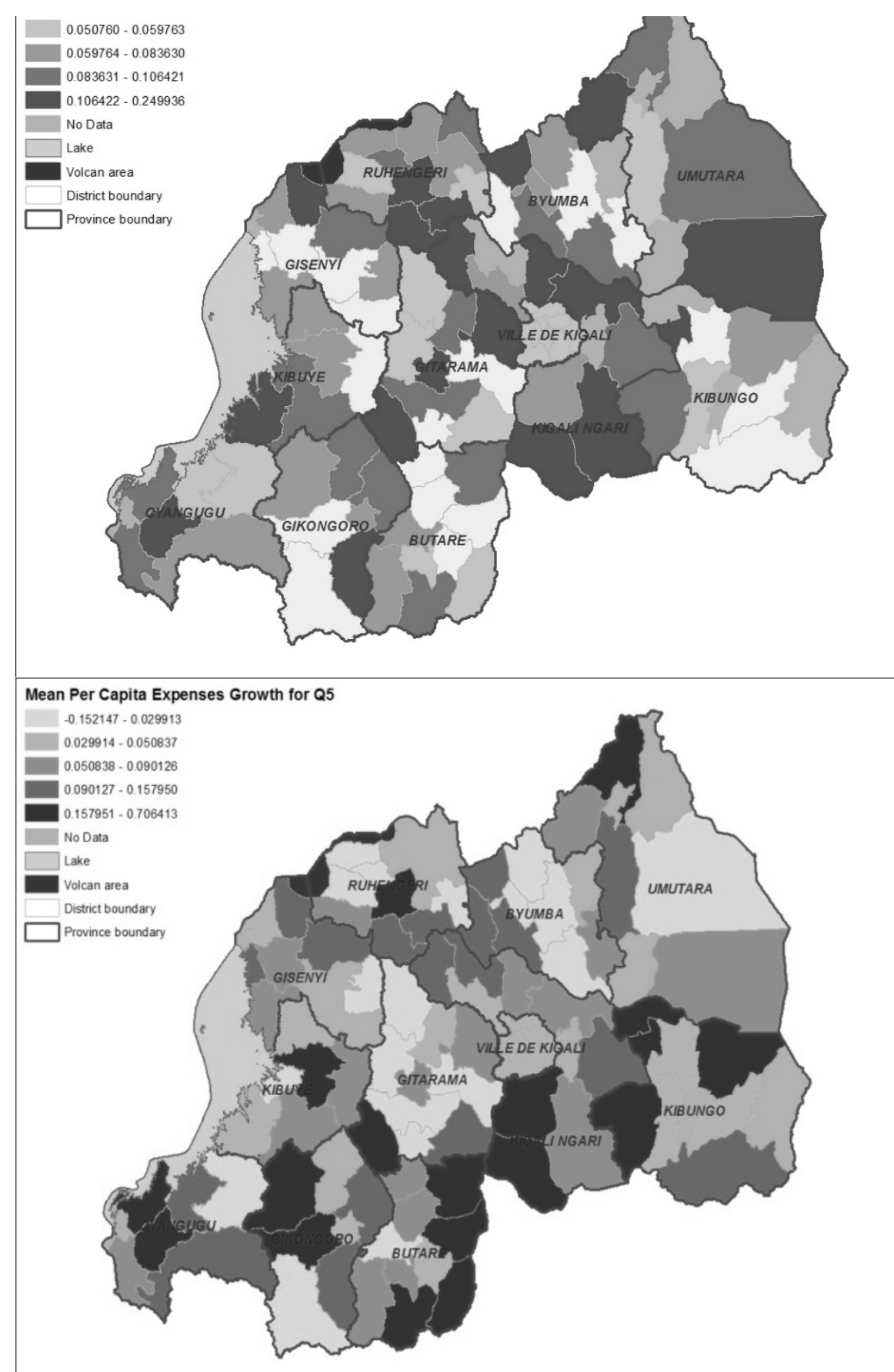

Source: Created by authors 
FIGURE 2 TANZANIA: CONSUMPTION GROWTH FOR THE TOP 20 PERCENT AND THE BOTTOM 20 PERCENT OF THE EXPENDITURE DISTRIBUTION
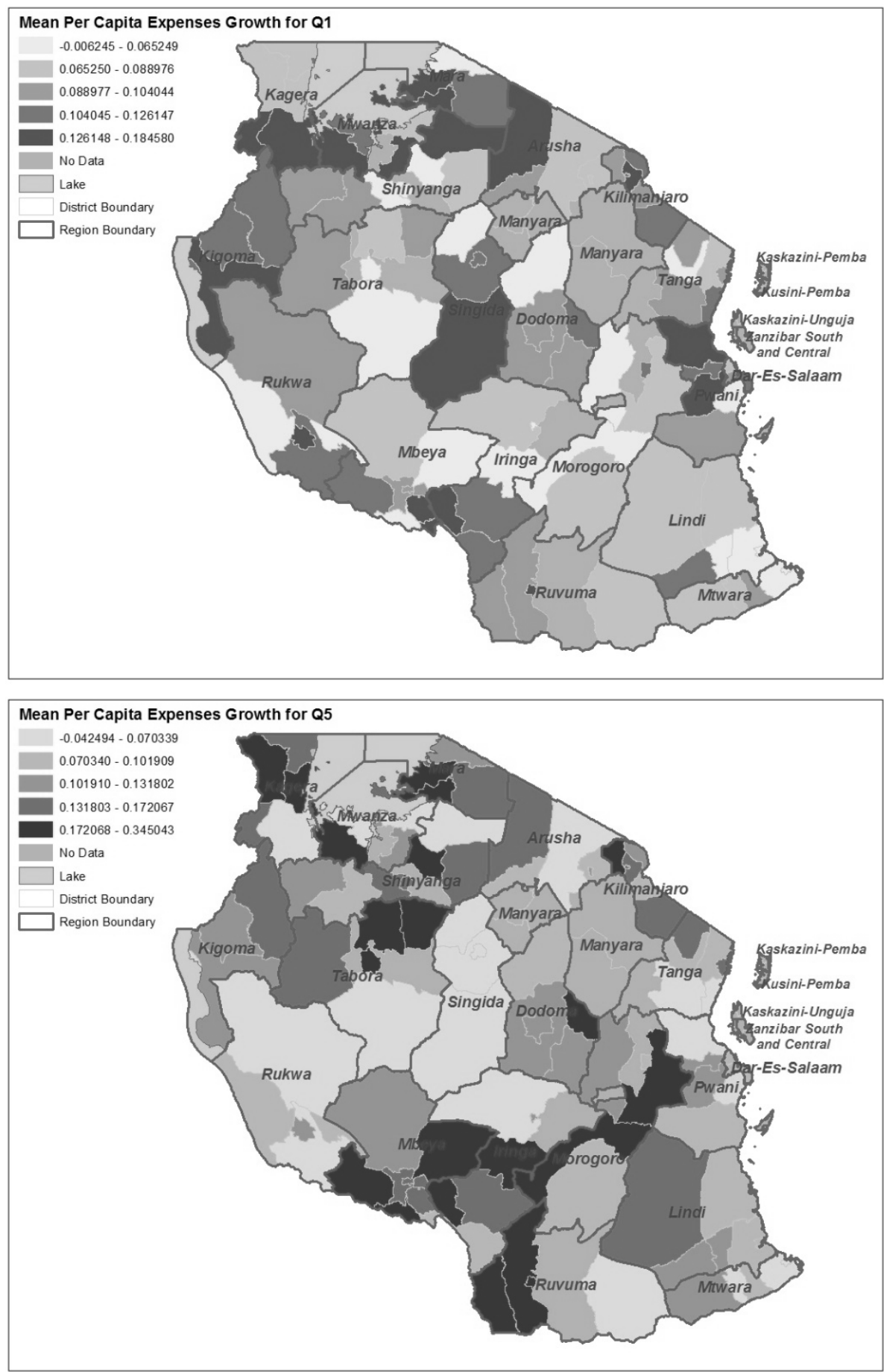

Source: Created by authors 


\section{RESULTS}

We present the results for the estimation of Equation 5 for Rwanda and Tanzania. We focus on the expenditure per capita growth variables because we believe that expenditure variables better reflect the economic well-being of household and are less susceptible to measurement error than income computed from household surveys. Though we also estimate Equation 5 with net and gross income variables, we do not present the results as they are qualitatively similar. As fiscal variables, we have expenditure in infrastructure, health and education, and general expenses in Rwanda. In Tanzania, we divide the fiscal expenditure variables in social (health and education) and non-social expenditures (incudes agricultural, energy, and roads expenditure); the variables differentiate between expenditures from development funds and expenditures for salaries and charges in the sector). In addition, the fiscal sector in the estimation includes taxes and levies collected by the districts, total own revenue for Tanzania. The effect of average GDP growth is included through mean expenditure growth in the district.

As discussed earlier, the effect of an increase in government expenditures on a particular social group can be separated into two components: it may affect the per capita mean household income of all households in a given district as well as the distribution of income across all groups for a given level of mean household income. Our estimates show the total effect of the fiscal expenditure variables in each expenditure group.

\section{TANZANIA}

Table 6 presents the coefficients from Equation 5 without using the restrictions in Equations $2 \mathrm{a}$ and $2 \mathrm{~b}$. These estimates reflect the total effect of a change in government expenditure, allowing for both redistribution of household income as well as changes in the district's average household income. Fiscal expenditures from development funds in social goods benefit the bottom quintile, but this effect is counteracted by non-social public goods' effects, which are negative and larger. The negative effect of non-social public goods is also significant for the second quintile group. In contrast, social expenditures from development funds are negatively associated with expenditure growth of the top quintile. However, note that mean expenditure growth disproportionately benefits the top 20 percent of the income distribution, with relatively large and significant estimates for the third and fifth quintile equations ${ }^{10}$. The effects of other fiscal activities, proxy by taxes and the ability to collect revenue are not significant at conventional levels.

${ }^{10}$ Statistical significance and relative size of the coefficients is what should be noted in the reduced form estimation. The magnitude implied by this effect of the effects is given by the structural parameters. 
TABLE 6 TANZANIA: RATE OF GROWTH OF PER CAPITA GROUP EXPENDITURE (UNRESTRICTED ESTIMATES)

\begin{tabular}{|c|c|c|c|c|c|}
\hline & $\underline{\text { Q1 }}$ & $\underline{\text { Q2 }}$ & $\underline{\text { Q3 }}$ & $\underline{\mathrm{Q}}$ & $\underline{\mathrm{Q} 5}$ \\
\hline \multicolumn{6}{|l|}{ Social Expenditures } \\
\hline \multirow[t]{2}{*}{ Expenditures from development funds } & 0.203 & -0.004 & -0.018 & 0.234 & -3.639 \\
\hline & {$[0.116]^{*}$} & [0.067] & [0.099] & {$[0.260]$} & {$[1.424]^{* *}$} \\
\hline \multirow[t]{2}{*}{ Expenditures on salaries and charges } & -0.28 & -0.013 & 0.121 & -0.203 & 2.65 \\
\hline & {$[0.162]^{*}$} & [0.092] & [0.139] & {$[0.360]$} & [1.965] \\
\hline \multicolumn{6}{|l|}{ Non-Social Expenditures } \\
\hline \multirow[t]{2}{*}{ Expenditures from development funds } & -0.53 & -0.299 & -0.139 & -0.874 & -0.025 \\
\hline & {$[0.317]^{*}$} & {$[0.177]^{*}$} & {$[0.256]$} & [0.705] & [3.989] \\
\hline \multirow[t]{2}{*}{ Expenditures on salaries and charges } & 0.29 & 0.281 & 0.293 & 2.389 & -1.166 \\
\hline & {$[0.818]$} & {$[0.516]$} & {$[0.748]$} & [2.039] & {$[9.797]$} \\
\hline \multirow[t]{2}{*}{ Taxes and levies } & 3.33 & -1.547 & -5.1 & 6.28 & -78.856 \\
\hline & {$[3.471]$} & [1.964] & {$[2.833]^{*}$} & {$[8.095]$} & {$[42.183]^{*}$} \\
\hline \multirow[t]{2}{*}{ Total collected revenue } & -2.046 & 2.636 & 6.16 & -5.701 & 52.028 \\
\hline & [3.154] & {$[1.790]$} & {$[2.601]^{* *}$} & {$[7.341]$} & {$[38.801]$} \\
\hline \multirow[t]{2}{*}{ Growth in $\mathrm{HH}$ expenditure/income } & 0.064 & 0.023 & 0.1 & 0.065 & 2.4 \\
\hline & {$[0.033]^{*}$} & {$[0.023]$} & {$[0.032]^{* * *}$} & {$[0.085]$} & {$[0.418]^{* * *}$} \\
\hline \multirow[t]{2}{*}{ Constant } & 0.075 & 0.109 & 0.105 & 0.119 & 0.014 \\
\hline & {$[0.013]^{* * *}$} & {$[0.005]^{* * *}$} & {$[0.005]^{* * *}$} & {$[0.008]^{* * *}$} & {$[0.021]$} \\
\hline $\mathrm{N}$ & 100 & & & & \\
\hline
\end{tabular}

Source: Authors' calculations.

Notes: Standard errors in brackets. The dependent variable in each column is the income growth for each quintile. The sample consists of all districts _ and the estimates are obtained using seemingly unrelated regression systems with instruments for government expenditures and expenditure growth. The instruments consist of regional indicators and geographical (GIS) data.

$* p<0.10, * * p<0.05, * * * p<0.01$

In Table 7, we impose the restrictions to obtain the pure redistribution effects within the household sector of the fiscal variables in the estimation in Equation 1 -namely, that $\beta_{1}=1$, average household income is affected one-to-one by GDP increases, and that the $\beta_{2}$ 's are zero-to isolate the distributive effects of fiscal expenditures on household income. The estimates in Table 7 are precisely the $\alpha_{1 i}$ and $\alpha_{2 i}$ of Equation $1 .{ }^{11}$ The redistributive effects within the household sector of social expenditures from development funds promote growth toward the bottom and middle of the expenditure distribution, with the persistent negative effects on the top quintile we saw in the unrestricted estimates. District average expenditure growth benefits the top income bracket more than the other income groups, and the evidence suggests that the poor benefit from mean income growth but less so than higher income groups. The negative distortion to the high-income groups seems to increase when we allow for both redistribution within the household sector and for changes in the average household income (in Table 6), in comparison to the point estimates for social expenditures from development funds in Table 7; the effects of the expenditure variables on this group is reflected more through their effects on average expenditure than on their pure distribution effects.

${ }^{11}$ Note that under these restrictions $\alpha_{2 i}=\gamma_{i}$ and $\alpha_{1 i}=\theta_{i}$. 20 
TABLE 7 TANZANIA: RATE OF GROWTH OF PER CAPITA GROUP EXPENDITURE (RESTRICTED ESTIMATES)

\begin{tabular}{|c|c|c|c|c|c|}
\hline & $\underline{\mathbf{Q 1}}$ & $\underline{\text { Q2 }}$ & $\underline{\text { Q3 }}$ & $\underline{\text { Q4 }}$ & $\underline{Q 5}$ \\
\hline \multicolumn{6}{|l|}{ Social Expenditures } \\
\hline \multirow[t]{2}{*}{ Expenditures from development funds } & 0.262 & 0.064 & 0.164 & 0.483 & -0.974 \\
\hline & {$[0.110]^{* *}$} & {$[0.072]$} & [0.101] & {$[0.277]^{*}$} & {$[0.373]^{* * *}$} \\
\hline \multirow[t]{2}{*}{ Expenditures on salaries and charges } & -0.307 & -0.049 & 0.003 & -0.362 & 0.714 \\
\hline & {$[0.153]^{* *}$} & [0.099] & [0.142] & [0.384] & [0.517] \\
\hline \multicolumn{6}{|l|}{ Non-Social Expenditures } \\
\hline \multirow[t]{2}{*}{ Expenditures from development funds } & -0.453 & -0.241 & 0.021 & -0.634 & 1.307 \\
\hline & {$[0.300]$} & [0.191] & {$[0.265]$} & {$[0.757]$} & [1.017] \\
\hline \multirow[t]{2}{*}{ Expenditures on salaries and charges } & 0.232 & 0.077 & -0.265 & 1.346 & -1.39 \\
\hline & [0.773] & [0.549] & [0.755] & [2.134] & [2.785] \\
\hline \multirow[t]{2}{*}{ Taxes and levies } & 4.077 & -0.515 & -2.032 & 9.001 & -10.53 \\
\hline & {$[3.281]$} & [2.108] & [2.907] & [8.577] & {$[11.275]$} \\
\hline \multirow[t]{2}{*}{ Total collected revenue } & -2.407 & 1.87 & 3.888 & -7.77 & 4.419 \\
\hline & [2.983] & [1.924] & [2.665] & [7.794] & [10.278] \\
\hline \multirow[t]{2}{*}{ Growth in $\mathrm{HH}$ expenditure/income } & 0.104 & 0.091 & 0.274 & 0.359 & 4.172 \\
\hline & {$[0.031]^{* * *}$} & {$[0.024]^{* * *}$} & {$[0.034]^{* * *}$} & {$[0.090]^{* * *}$} & {$[0.120]^{* * *}$} \\
\hline \multirow[t]{2}{*}{ Constant } & 0.061 & 0.095 & 0.081 & 0.091 & -0.066 \\
\hline & {$[0.012]^{* * *}$} & {$[0.005]^{* * *}$} & {$[0.005]^{* * *}$} & {$[0.009]^{* * *}$} & {$[0.010]^{* * *}$} \\
\hline $\mathrm{N}$ & 100 & & & & \\
\hline \multicolumn{6}{|c|}{$\begin{array}{l}\text { Notes: Standard errors in brackets. The dependent variable in each column is the income growth for each quintile. The sample consists of al } \\
\text { districts and the estimates are obtained using seemingly unrelated regression systems with instruments for government expenditures anc } \\
\text { expenditure growth. The instruments consist of regional indicators and geographical (GIS) data. We impose a restriction that } \beta=1 \text {, or that } \\
\text { average household income is affected one-to-one by GDP increases. } \\
* \mathrm{p}<0.10,{ }^{* *} p<0.05, * * * p<0.01\end{array}$} \\
\hline
\end{tabular}


The next step is to use the unrestricted estimated parameters, which allow for both redistribution within the household sector and for changes in the average household income, and use the restrictions to recuperate the structural parameters in Equations 1 and 4. Table 8 shows the structural parameter estimates using the point estimates from the regressions that use observations for all districts (in Table 6). We also include the structural parameter estimates for districts below (bottom districts) and above (top districts) the median average per capita household expenditure; these parameters are obtained from the unrestricted regressions (analogous to Table 6) that only use observations for each group

The $\beta$ model parameters show the total effect of public expenditure and mean per capita expenditure across the distribution (note that Equation 4 is a district-level equation); we call this fiscal diffusion effects. The model parameters show that the public expenditure $\left(\beta^{\prime}\right.$ s) diffusion effects are significant and negative for the social expenditures from development funds because of the distortions to the top quintile, especially in the below median districts. The effect of mean per capita expenditure growth or consumption growth diffusion effects are significant for both bottom and top districts and larger for top districts; the parameter estimate is well below one, so that $\beta_{1} \neq 1$ and average household expenditure is not affected one-to-one by GDP increases.

Consumption multipliers $\left(\alpha_{2}^{\prime} s\right)$ measure how an increase in the average household per capita expenditure is distributed across the groups. These effects tend to affect the top quintile of the expenditure distribution, while for the rest of the groups they are much smaller and significant near the middle of the distribution, specifically in the third quintile.

An important result is that the differences across top and bottom districts arise from the $\beta$ coefficients, which are statistically significant, but not from differences in the $\alpha_{2}$ 's, which are practically identical across; meaning that the differences between poor and rich districts are due to difference in the responsiveness of the household sector to macroeconomic conditions. 
TABLE 8 TANZANIA: MODEL PARAMETERS BASED ON EXPENDITURE (UNRESTRICTED ESTIMATES)

\begin{tabular}{|c|c|c|c|}
\hline$\beta$ Parameters & All Districts & Bottom Districts & Top Districts \\
\hline \multicolumn{4}{|l|}{ Social Expenditures } \\
\hline Expenditures from development funds & $\begin{array}{l}-0.645 \\
{[0.293]^{* *}}\end{array}$ & $\begin{array}{l}-0.698 \\
{[0.199]^{* * *}}\end{array}$ & $\begin{array}{l}-0.416 \\
{[0.364]}\end{array}$ \\
\hline Expenditures on salaries and charges & $\begin{array}{l}0.455 \\
{[0.404]}\end{array}$ & $\begin{array}{l}0.157 \\
{[0.260]}\end{array}$ & $\begin{array}{l}0.459 \\
{[0.594]}\end{array}$ \\
\hline \multicolumn{4}{|l|}{ Non-Social Expenditures } \\
\hline Expenditures from development funds & $\begin{array}{l}-0.373 \\
{[0.817]}\end{array}$ & $\begin{array}{l}2.301 \\
{[0.609]^{* * *}}\end{array}$ & $\begin{array}{l}-1.05 \\
{[0.633]^{*}}\end{array}$ \\
\hline Expenditures on salaries and charges & $\begin{array}{l}0.418 \\
{[2.022]}\end{array}$ & $\begin{array}{l}-0.169 \\
{[1.017]}\end{array}$ & $\begin{array}{l}6.744 \\
{[16.373]}\end{array}$ \\
\hline Taxes and levies & $\begin{array}{l}-15.178 \\
{[8.664]^{*}}\end{array}$ & $\begin{array}{l}-11.666 \\
{[7.220]}\end{array}$ & $\begin{array}{l}-5.535 \\
{[6.301]}\end{array}$ \\
\hline Total collected revenue & $\begin{array}{l}10.615 \\
{[7.966]}\end{array}$ & $\begin{array}{l}10.127 \\
{[6.461]}\end{array}$ & $\begin{array}{l}8.676 \\
{[6.225]}\end{array}$ \\
\hline Growth in $\mathrm{HH}$ expenditure/income & $\begin{array}{l}0.53 \\
{[0.086]^{* * *}}\end{array}$ & $\begin{array}{l}0.183 \\
{[0.059]^{* * *}}\end{array}$ & $\begin{array}{l}0.427 \\
{[0.072]^{* * *}}\end{array}$ \\
\hline \multicolumn{4}{|l|}{$\alpha_{2}$ Parameters } \\
\hline Quintile 1 & $\begin{array}{l}0.12 \\
{[0.061]^{* *}}\end{array}$ & $\begin{array}{l}0.381 \\
{[0.213]^{*}}\end{array}$ & $\begin{array}{l}0.142 \\
{[0.066]^{* *}}\end{array}$ \\
\hline Quintile 2 & $\begin{array}{l}0.044 \\
{[0.042]}\end{array}$ & $\begin{array}{l}0.201 \\
{[0.149]}\end{array}$ & $\begin{array}{l}-0.013 \\
{[0.037]}\end{array}$ \\
\hline Quintile 3 & $\begin{array}{l}0.188 \\
{[0.055]^{* * *}}\end{array}$ & $\begin{array}{l}0.257 \\
{[0.165]}\end{array}$ & $\begin{array}{l}0.123 \\
{[0.048]^{* * *}}\end{array}$ \\
\hline Quintile 4 & $\begin{array}{l}0.122 \\
{[0.161]}\end{array}$ & $\begin{array}{l}0.19 \\
{[0.527]}\end{array}$ & $\begin{array}{l}0.104 \\
{[0.136]}\end{array}$ \\
\hline Quintile 5 & $\begin{array}{l}4.526 \\
{[0.187]^{* * *}}\end{array}$ & $\begin{array}{l}3.972 \\
{[0.657]^{* * *}}\end{array}$ & $\begin{array}{l}4.644 \\
{[0.173]^{* * *}}\end{array}$ \\
\hline $\mathrm{N}$ & 100 & 50 & 50 \\
\hline
\end{tabular}

Source: Author's calculations.

Notes: Standard errors in brackets. Columns show the structural parameters estimates using all districts and those dividing the sample in districts above and below the median. $\beta^{\prime}$ s show the effect of the variable on the household sector and the $\alpha_{2}$ represent the distribution effect within the household sector.

${ }^{*} \mathrm{p}<0.10, * * \mathrm{p}<0.05, * * * \mathrm{p}<0.01$

The message is clear: multipliers are reflected among the higher income groups, and the poor might not have the resources to respond to (positive) shocks; moreover, the spillovers are disproportionately reflected in the top quintile group. There is also some evidence that toward the middle of the distribution, there are spillover effects of smaller magnitude.

The final step to gauge the effect of these variables across the expenditure distribution is to compute the elasticities of group expenditure with respect to each of these variables. The elasticities of per capita group expenditure with respect to the fiscal expenditure variables $\left(E_{j t}\right)$ for each group $i$ can be obtained using Equation 1:

$\varepsilon_{E}^{i}=\mathbf{E}\left(\frac{E_{j t}}{y_{i j t}}\right) * \alpha_{1 i}=\mathbf{E}\left(\frac{E_{j t}}{y_{i j t}}\right) *\left(\theta_{i}-\alpha_{2 i} \beta_{2}\right)=\mathbf{E}\left(\frac{E_{j t}}{y_{i j t}}\right) *\left(\theta_{i}-\frac{\gamma_{i}}{\beta_{1}} \beta_{2}\right)$

Where $\beta_{2}$ is the beta parameter vector for the expenditure variables, $i$ is the quintile group or the mean, and $\mathbf{E}()$ is the expectation operator. In addition, the elasticity of per capita group expenditure with respect to average district income is: 
$\varepsilon_{y}^{i}=\mathbf{E}\left(\frac{Y_{j t}}{y_{i j t}}\right) * \alpha_{2 i}=\mathbf{E}\left(\frac{Y_{j t}}{y_{i j t}}\right) * \frac{\gamma_{i}}{\beta_{1}}$

Standard errors can be obtained using the delta method ${ }^{12}$.

Table 9 shows the estimated elasticities for each expenditure group using observations for all districts. The elasticities are evaluated at the average value of the ratios of Equations 6 and $7 .{ }^{13}$ The effects for social expenditures (health and education) from development funds are small but positive and significant for quintile 1 , implying that an increase of 10 percent in social expenditures would be reflected as a 0.2 percent increase in the mean expenditure of the quintile 1 group. It is interesting to note that this effect is negative for the top quintile group; this is because of the distortions in the top quintile we mentioned before. The elasticity of social expenditures in salaries and other charges is negative for the bottom quintile. Together, we can conclude that expenditures in social goods, namely health and education, tend to increase the share of the household sector in the economy. This can be regarded as a pro-equity effect, meaning that it promotes growth toward the bottom of the distribution.

TABLE 9 TANZANIA: ELASTICITIES OF GROUP EXPENDITURES FOR ALL DISTRICTS (UNRESTRICTED ESTIMATES)

\begin{tabular}{|c|c|c|c|c|c|c|c|c|}
\hline Expenditure & $\begin{array}{c}\text { Quintile } \\
1\end{array}$ & & $\begin{array}{c}\text { Quintile } \\
2\end{array}$ & $\begin{array}{c}\text { Quintile } \\
3\end{array}$ & & $\begin{array}{l}\text { Quintil } \\
\text { e } 4\end{array}$ & $\begin{array}{l}\text { Quintil } \\
\text { e } 5\end{array}$ & \\
\hline \multicolumn{9}{|l|}{ Social Expenditures } \\
\hline Expenditures from development funds & $\begin{array}{l}0.021 \\
(0.009)\end{array}$ & $* *$ & $\begin{array}{l}0.001 \\
(0.003)\end{array}$ & $\begin{array}{l}0.003 \\
(0.003)\end{array}$ & & $\begin{array}{l}0.006 \\
(0.005)\end{array}$ & $\begin{array}{l}-0.007 \\
(0.003)\end{array}$ & $* *$ \\
\hline Expenditures on salaries and charges & $\begin{array}{l}-0.102 \\
(0.049)\end{array}$ & $* *$ & $\begin{array}{l}-0.006 \\
(0.016)\end{array}$ & $\begin{array}{l}0.004 \\
(0.015)\end{array}$ & & $\begin{array}{l}-0.021 \\
(0.029)\end{array}$ & $\begin{array}{l}0.023 \\
(0.017)\end{array}$ & \\
\hline \multicolumn{9}{|l|}{ Non-Social Expenditures } \\
\hline Expenditures from development funds & $\begin{array}{l}-0.013 \\
(0.008)\end{array}$ & & $\begin{array}{l}-0.004 \\
(0.003)\end{array}$ & $\begin{array}{l}-0.001 \\
(0.002)\end{array}$ & & $\begin{array}{l}-0.006 \\
(0.005)\end{array}$ & $\begin{array}{l}0.006 \\
(0.003)\end{array}$ & $* *$ \\
\hline Expenditures on salaries and charges & $\begin{array}{l}0.007 \\
(0.023)\end{array}$ & & $\begin{array}{l}0.004 \\
(0.008)\end{array}$ & $\begin{array}{l}0.002 \\
(0.007)\end{array}$ & & $\begin{array}{l}0.017 \\
(0.015)\end{array}$ & $\begin{array}{l}-0.011 \\
(0.008)\end{array}$ & \\
\hline Taxes and levies & $\begin{array}{l}0.120 \\
(0.077)\end{array}$ & & $\begin{array}{l}-0.012 \\
(0.026)\end{array}$ & $\begin{array}{l}-0.021 \\
(0.023)\end{array}$ & & $\begin{array}{l}0.051 \\
(0.049)\end{array}$ & $\begin{array}{l}-0.030 \\
(0.027)\end{array}$ & \\
\hline Total collected revenue & $\begin{array}{l}-0.101 \\
(0.092)\end{array}$ & & $\begin{array}{l}0.039 \\
(0.032)\end{array}$ & $\begin{array}{l}0.051 \\
(0.029)\end{array}$ & $*$ & $\begin{array}{l}-0.057 \\
(0.059)\end{array}$ & $\begin{array}{l}0.015 \\
(0.033)\end{array}$ & \\
\hline Growth in $\mathrm{HH}$ expenditure/income & $\begin{array}{l}0.434 \\
(0.220)\end{array}$ & $* *$ & $\begin{array}{l}0.090 \\
(0.087)\end{array}$ & $\begin{array}{l}0.260 \\
(0.076)\end{array}$ & $* * *$ & $\begin{array}{l}0.112 \\
(0.147)\end{array}$ & $\begin{array}{l}1.963 \\
(0.081)\end{array}$ & $* * *$ \\
\hline
\end{tabular}

Source: Authors' calculations.

Notes: Standard errors in parentheses. Elasticities are estimated at the respective means and use the structural estimates to calculate the effect of a 1 percent increase in the expenditure variable on the mean expenditure of each quintile group.

$* \mathrm{p}<0.10, * * \mathrm{p}<0.05, * * * \mathrm{p}<0.01$

For non-social expenditures, the only significant elasticity is that of the expenditures that come from development funds for the top quintile. These effects affect the distribution within the household sector concentrating growth to the top of the distribution, contrary to that found with the social expenditures. This is shown by the fact that restricted or compensated estimates of the effect of the non-social expenditure variables are jointly and individually insignificant for the bottom quintiles in Table 7.

\footnotetext{
12 The delta method approximates the standard errors using a Taylor approximation around the true parameter and asymptotic theory to obtain a close form expression for the standard errors.

${ }^{13}$ Note $\mathbf{E}\left(\frac{X}{Z}\right) \neq \frac{\mathbf{E}(X)}{\mathbf{E}(Z)}$ and we use $\mathbf{E}\left(\frac{X}{Z}\right)$ as presented in Equations 6 and 7 as it seems a more natural approach. We calculated the elasticities using the ratio of the expected values and the results are almost identical. 
Taxes and levies have no discernible effects on the household income of the quintile groups. While not precisely estimated, these effects seem to be counteracted by total revenue of the district. The implication is that districts with high average income might use revenue from taxes with a progressive distributive purpose.

All coefficients of household consumption growth are positive and significant as expected in Table 6 and Table 7. However, the elasticities of all groups' income with respect to per capita household consumption are positive and only significant for quintiles 1,3 , and 5, reflecting the results in Table 6 . The household expenditure growth elasticity is well above one for the top quintile. This implies that mean expenditure growth is not reflected one-to-one among the poorest sections of the population and disproportionally benefits the better-off sectors of the population. When analyzing the distributional effects within the household sector the neutrality is rejected; meaning that the larger coefficients in the unrestricted model (Table 6) for the higher income groups are reflected differently across the expenditure distribution, as the elasticities are different among all income groups. Moreover, it implies that given large differences between the GDP and household income in these districts, household income for all groups except for the top quintile will tend to catch up slowly.

Table 10 and Table 11 show similar results, now separating the sample into those below the median expenditure districts and those above. The effects for social expenditures from development funds are only positive and significant in quintile 1 for the bottom districts and are similarly significant for the top districts. In general, we can see that among the bottom districts significant effects are concentrated among non-social public expenditures from development funds and benefiting the top of the expenditure distribution, while for top districts they are concentrated in the social expenditures from development funds and tend to be positive for the bottom quintiles. The evidence suggests that the richer districts are perhaps more efficient in their targeting of social expenditures toward the poorer sectors of the population, even though these elasticities are very small. 
TABLE 10 TANZANIA: ELASTICITIES OF GROUP EXPENDITURES FOR BOTTOM EXPENDITURE DISTRICTS

\begin{tabular}{|c|c|c|c|c|c|c|c|c|}
\hline Expenditure & $\begin{array}{l}\text { Quintile } \\
1\end{array}$ & & $\begin{array}{l}\text { Quintile } \\
2\end{array}$ & & $\begin{array}{l}\text { Quintile } \\
\mathbf{3}\end{array}$ & $\begin{array}{l}\text { Quintile } \\
4\end{array}$ & $\begin{array}{l}\text { Quintile } \\
5\end{array}$ & \\
\hline \multicolumn{9}{|l|}{ Social Expenditures } \\
\hline Expenditures from development funds & $\begin{array}{l}0.035 \\
(0.017)\end{array}$ & $* *$ & $\begin{array}{l}0.010 \\
(0.007)\end{array}$ & & $\begin{array}{l}0.005 \\
(0.005)\end{array}$ & $\begin{array}{l}0.006 \\
(0.011)\end{array}$ & $\begin{array}{l}-0.011 \\
(0.007)\end{array}$ & $*$ \\
\hline Expenditures on salaries and charges & $\begin{array}{l}-0.040 \\
(0.066)\end{array}$ & & $\begin{array}{l}-0.029 \\
(0.022)\end{array}$ & & $\begin{array}{l}0.013 \\
(0.017)\end{array}$ & $\begin{array}{l}-0.022 \\
(0.035)\end{array}$ & $\begin{array}{l}0.018 \\
(0.022)\end{array}$ & \\
\hline \multicolumn{9}{|l|}{ Non-Social Expenditures } \\
\hline Expenditures from development funds & $\begin{array}{l}-0.037 \\
(0.019)\end{array}$ & $* *$ & $\begin{array}{l}-0.013 \\
(0.007)\end{array}$ & $*$ & $\begin{array}{l}-0.006 \\
(0.006)\end{array}$ & $\begin{array}{l}-0.005 \\
(0.012)\end{array}$ & $\begin{array}{l}0.012 \\
(0.007)\end{array}$ & $*$ \\
\hline Expenditures on salaries and charges & $\begin{array}{l}-0.004 \\
(0.022)\end{array}$ & & $\begin{array}{l}0.006 \\
(0.008)\end{array}$ & & $\begin{array}{l}0.002 \\
(0.006)\end{array}$ & $\begin{array}{l}-0.007 \\
(0.014)\end{array}$ & $\begin{array}{l}0.002 \\
(0.008)\end{array}$ & \\
\hline Taxes and levies & $\begin{array}{l}0.249 \\
(0.151)\end{array}$ & $*$ & $\begin{array}{l}0.066 \\
(0.057)\end{array}$ & & $\begin{array}{l}-0.003 \\
(0.043)\end{array}$ & $\begin{array}{l}0.000 \\
(0.093)\end{array}$ & $\begin{array}{l}-0.045 \\
(0.056)\end{array}$ & \\
\hline Total collected revenue & $\begin{array}{l}-0.291 \\
(0.178)\end{array}$ & & $\begin{array}{l}-0.064 \\
(0.067)\end{array}$ & & $\begin{array}{l}0.024 \\
(0.051)\end{array}$ & $\begin{array}{l}-0.002 \\
(0.109)\end{array}$ & $\begin{array}{l}0.044 \\
(0.066)\end{array}$ & \\
\hline Growth in $\mathrm{HH}$ expenditure/income & $\begin{array}{l}1.372 \\
(0.769)\end{array}$ & $*$ & $\begin{array}{l}0.413 \\
(0.307)\end{array}$ & & $\begin{array}{l}0.355 \\
(0.228)\end{array}$ & $\begin{array}{l}0.174 \\
(0.483)\end{array}$ & $\begin{array}{l}1.723 \\
(0.285)\end{array}$ & $* * *$ \\
\hline
\end{tabular}

Source: Authors' calculations.

Notes: Standard errors in parentheses. Elasticities are estimated at the respective means and use the structural estimates to calculate the effect of a 1 percent increase in the expenditure variable on the mean expenditure of each quintile group. Estimates are presented for bottom expenditure districts.

$* \mathrm{p}<0.10, * * \mathrm{p}<0.05, * * * \mathrm{p}<0.01$

TABLE 11 TANZANIA: ELASTICITIES OF GROUP EXPENDITURES FOR TOP EXPENDITURE DISTRICTS

\begin{tabular}{|c|c|c|c|c|c|c|c|c|c|}
\hline Expenditure & $\begin{array}{l}\text { Quintil } \\
\text { e } 1\end{array}$ & & $\begin{array}{l}\text { Quintile } \\
\mathbf{2}\end{array}$ & & $\begin{array}{l}\text { Quintil } \\
\text { e } 3\end{array}$ & & $\begin{array}{l}\text { Quintile } \\
4\end{array}$ & $\begin{array}{l}\text { Quintil } \\
\text { e } 5\end{array}$ & \\
\hline \multicolumn{10}{|l|}{ Social Expenditures } \\
\hline Expenditures from development funds & $\begin{array}{l}0.025 \\
(0.012)\end{array}$ & $* *$ & $\begin{array}{l}-0.001 \\
(0.004)\end{array}$ & & $\begin{array}{l}0.000 \\
(0.003)\end{array}$ & & $\begin{array}{l}0.004 \\
(0.006)\end{array}$ & $\begin{array}{l}-0.005 \\
(0.004)\end{array}$ & \\
\hline Expenditures on salaries and charges & $\begin{array}{l}-0.070 \\
(0.086)\end{array}$ & & $\begin{array}{l}0.054 \\
(0.025)\end{array}$ & $* *$ & $\begin{array}{l}0.023 \\
(0.022)\end{array}$ & & $\begin{array}{l}-0.037 \\
(0.044)\end{array}$ & $\begin{array}{l}0.008 \\
(0.027)\end{array}$ & \\
\hline \multicolumn{10}{|l|}{ Non-Social Expenditures } \\
\hline Expenditures from development funds & $\begin{array}{l}-0.003 \\
(0.007)\end{array}$ & & $\begin{array}{l}-0.002 \\
(0.002)\end{array}$ & & $\begin{array}{l}0.000 \\
(0.002)\end{array}$ & & $\begin{array}{l}-0.005 \\
(0.004)\end{array}$ & $\begin{array}{l}0.003 \\
(0.002)\end{array}$ & \\
\hline Expenditures on salaries and charges & $\begin{array}{l}-0.186 \\
(0.216)\end{array}$ & & $\begin{array}{l}-0.049 \\
(0.060)\end{array}$ & & $\begin{array}{l}-0.065 \\
(0.052)\end{array}$ & & $\begin{array}{l}-0.023 \\
(0.100)\end{array}$ & $\begin{array}{l}0.066 \\
(0.063)\end{array}$ & \\
\hline Taxes and levies & $\begin{array}{l}0.076 \\
(0.068)\end{array}$ & & $\begin{array}{l}-0.005 \\
(0.020)\end{array}$ & & $\begin{array}{l}0.000 \\
(0.017)\end{array}$ & & $\begin{array}{l}0.014 \\
(0.035)\end{array}$ & $\begin{array}{l}-0.015 \\
(0.021)\end{array}$ & \\
\hline Total collected revenue & $\begin{array}{l}-0.080 \\
(0.090)\end{array}$ & & $\begin{array}{l}0.056 \\
(0.028)\end{array}$ & $* *$ & $\begin{array}{l}0.011 \\
(0.023)\end{array}$ & & $\begin{array}{l}-0.022 \\
(0.048)\end{array}$ & $\begin{array}{l}0.005 \\
(0.029)\end{array}$ & \\
\hline Growth in $\mathrm{HH}$ expenditure/income & $\begin{array}{l}0.511 \\
(0.237)\end{array}$ & $* *$ & $\begin{array}{l}-0.027 \\
(0.077)\end{array}$ & & $\begin{array}{l}0.170 \\
(0.066)\end{array}$ & $* * *$ & $\begin{array}{l}0.096 \\
(0.125)\end{array}$ & $\begin{array}{l}2.014 \\
(0.075)\end{array}$ & $* * *$ \\
\hline
\end{tabular}

Source: Authors' calculations.

Notes: Standard errors in parentheses. Elasticities are estimated at the respective means and use the structural estimates to calculate the effect of a 1 percent increase in the expenditure variable on the mean expenditure of each quintile group. Estimates are presented for the top expenditure districts.

${ }^{*} \mathrm{p}<0.10,{ }^{* *} \mathrm{p}<0.05, * * * \mathrm{p}<0.01$ 


\section{RWANDA}

We now present the results for Rwanda. The dependent variables are the group per capita growth rates as before. The fiscal expenditure growth variables are: social expenditures, where we have expenditures in infrastructure and the health and education sectors; and non-social expenditures, which are general expenses. In this latter category, we have expenditures for other public goods like good governance, industrial development, and agricultural management, among others.

The estimates in Table 12 reflect the total effect allowing for both redistribution within the household sector and for changes in the average household income as well. Expenditures in social and non-social public goods do not seem to benefit the poor and middle classes. There are significant negative effects for the bottom quintile (Q1) and only a large positive effect but not significant of infrastructure for the top quintile. Mean expenditure growth, disproportionately, benefits the top 20 percent of the income distribution, with large positive estimates for the fifth quintile equation.

TABLE 12 RWANDA: RATE OF GROWTH OF PER CAPITA GROUP EXPENDITURE (UNRESTRICTED ESTIMATES)

\begin{tabular}{|c|c|c|c|c|c|}
\hline & $\underline{\text { Q1 }}$ & $\underline{\text { Q2 }}$ & Q3 & Q4 & Q5 \\
\hline \multicolumn{6}{|l|}{ Social Expenditures } \\
\hline \multirow[t]{2}{*}{ Infrastructure } & -8.79 & -2.55 & -4.35 & -4.68 & 54.9 \\
\hline & {$[3.13]^{* * *}$} & {$[2.18]$} & {$[3.41]$} & {$[7.40]$} & {$[61.6]$} \\
\hline \multirow[t]{2}{*}{ Health and Education } & -1.09 & 0.5 & -0.018 & 0.44 & -4.35 \\
\hline & {$[0.60]^{*}$} & {$[0.46]$} & {$[0.74]$} & {$[1.57]$} & {$[11.3]$} \\
\hline \multicolumn{6}{|l|}{ Non-Social Expenditures } \\
\hline \multirow[t]{2}{*}{ General Expenses } & -1.06 & -0.62 & -1.13 & -0.77 & 0.039 \\
\hline & {$[0.56]^{*}$} & {$[0.40]$} & {$[0.64]^{*}$} & {$[1.36]$} & {$[10.6]$} \\
\hline \multirow[t]{2}{*}{ Growth in $\mathrm{HH}$ expenditure/income } & 0.014 & -0.0061 & -0.0046 & 0.055 & 3.84 \\
\hline & {$[0.021]$} & {$[0.016]$} & {$[0.025]$} & {$[0.053]$} & {$[0.52]^{* * *}$} \\
\hline \multirow[t]{2}{*}{ Constant } & 0.082 & 0.076 & 0.075 & 0.064 & -0.033 \\
\hline & {$[0.0080]^{* * *}$} & {$[0.0030]^{* * *}$} & {$[0.0031]^{* * *}$} & {$[0.0039]^{* * *}$} & {$[0.018]^{*}$} \\
\hline $\mathrm{N}$ & \multicolumn{5}{|l|}{90} \\
\hline
\end{tabular}

In Table 13 we impose the restrictions discussed above to reflect the pure redistribution effects within the household sector of the fiscal variables estimated and the results are similar. Social expenditures in infrastructure promote expenditure growth at the top quintile of the distribution, with negative effects on the bottom quintile as with the unrestricted estimates in the previous table. Total average expenditure growth benefits the top income and the evidence suggests that the poor do not benefit as much from growth in expenditures and the effect is only significant for the top quintile. 
TABLE 13 RWANDA: RATE OF GROWTH OF PER CAPITA GROUP EXPENDITURE (RESTRICTED ESTIMATES)

\begin{tabular}{|c|c|c|c|c|c|}
\hline & $\underline{\text { Q1 }}$ & $\underline{\mathbf{Q 2}}$ & $\underline{\mathrm{Q3}}$ & $\underline{\mathrm{Q} 4}$ & $\underline{\mathrm{Q} 5}$ \\
\hline \multicolumn{6}{|l|}{ Social Expenditures } \\
\hline \multirow[t]{2}{*}{ Infrastructure } & -8.96 & -2.64 & -4.5 & -5.14 & 21.2 \\
\hline & {$[3.07]^{* * *}$} & {$[2.18]$} & [3.52] & {$[8.25]$} & {$[10.8]^{* *}$} \\
\hline \multirow[t]{2}{*}{ Health and Education } & -1.06 & 0.52 & 0.036 & 0.59 & -0.082 \\
\hline & {$[0.59]^{*}$} & {$[0.46]$} & {$[0.76]$} & {$[1.74]$} & {$[2.27]$} \\
\hline \multicolumn{6}{|l|}{ Non-Social Expenditures } \\
\hline \multirow[t]{2}{*}{ General Expenses } & -1.04 & -0.6 & -1.1 & -0.65 & 3.4 \\
\hline & {$[0.55]^{*}$} & {$[0.40]$} & {$[0.66]^{*}$} & {$[1.51]$} & {$[1.98]^{*}$} \\
\hline \multirow[t]{2}{*}{ Growth in $\mathrm{HH}$ expenditure/income } & 0.019 & -0.0017 & 0.0034 & 0.079 & 4.9 \\
\hline & {$[0.021]$} & {$[0.016]$} & {$[0.026]$} & {$[0.060]$} & {$[0.079]^{* * *}$} \\
\hline \multirow[t]{2}{*}{ Constant } & 0.081 & 0.076 & 0.074 & 0.062 & -0.067 \\
\hline & {$[0.0079]^{* * *}$} & {$[0.0030]^{* * *}$} & {$[0.0032]^{* * *}$} & {$[0.0044]^{* * *}$} & {$[0.0083]^{* * *}$} \\
\hline $\mathrm{N}$ & 90 & & & & \\
\hline
\end{tabular}

Source: Authors' calculations.

Notes: Standard errors in brackets. The dependent variable in each column is the income growth for each quintile. The sample consists of all districts with and the estimates are obtained using seemingly unrelated regressions system with instruments for government expenditures and expenditure growth. The instruments consist of regional indicators and geographical (GIS) data. We impose the restriction that $\beta=1$, or that household income is affected by GDP increases in a one-to-one ratio.

${ }^{*} \mathrm{p}<0.10, * * \mathrm{p}<0.05, * * * \mathrm{p}<0.01$

Table 14 shows the model structural parameters estimates using the unrestricted equations coefficients and the model restrictions to recover the structural parameters in Equation 1. As before, we present the estimated structural parameters for the estimations with all districts, the districts with mean expenditure below the median (bottom districts), and those above the median (top districts).

The fiscal diffusion effects $\left(\beta^{\prime} \mathrm{s}\right)$ show that the public expenditure variables are not significant, and the effect of mean per capita expenditure growth or consumption growth diffusion effects are significant for both bottom and top districts and slightly larger for top districts. The parameter estimate is below one, so that we reject that $\beta_{1}=1$ average household income is not affected one-to-one by GDP increases. The consumption multipliers $\left(\alpha_{2}\right.$ 's) show that increases in the average household per capita expenditure is concentrated in the top quintile. 
TABLE 14 RWANDA: MODEL PARAMETERS BASED ON EXPENDITURE (UNRESTRICTED ESTIMATES)

\begin{tabular}{|c|c|c|c|}
\hline & All Districts & Bottom Districts & Top Districts \\
\hline \multicolumn{4}{|l|}{$\beta$ Parameters } \\
\hline \multirow[t]{2}{*}{ Infrastructure } & 6.9 & 11.7 & -12.7 \\
\hline & [12.2] & {$[16.1]$} & {$[13.1]$} \\
\hline \multirow[t]{2}{*}{ Health and Education } & -0.9 & -0.25 & -1.98 \\
\hline & {$[2.25]$} & [3.22] & {$[2.11]$} \\
\hline \multirow[t]{2}{*}{ General Expenses } & -0.71 & -0.16 & -1.82 \\
\hline & {$[2.11]$} & {$[2.60]$} & {$[2.12]$} \\
\hline \multirow[t]{2}{*}{ Growth in $\mathrm{HH}$ expenditure/income } & 0.78 & 0.65 & 0.77 \\
\hline & {$[0.10]^{* * *}$} & {$[0.12]^{* * *}$} & {$[0.063]^{* * *}$} \\
\hline \multicolumn{4}{|l|}{$\alpha$ Parameters } \\
\hline \multirow[t]{2}{*}{ Quintile 1} & 0.018 & 0.015 & 0.044 \\
\hline & {$[0.027]$} & {$[0.052]$} & {$[0.027]$} \\
\hline \multirow[t]{2}{*}{ Quintile 2} & -0.0079 & 0.015 & -0.01 \\
\hline & {$[0.020]$} & [0.049] & {$[0.017]$} \\
\hline \multirow[t]{2}{*}{ Quintile 3} & -0.0059 & -0.042 & -0.02 \\
\hline & [0.032] & {$[0.082]$} & {$[0.029]$} \\
\hline \multirow[t]{2}{*}{ Quintile 4} & 0.071 & 0.21 & 0.022 \\
\hline & {$[0.069]$} & {$[0.16]$} & {$[0.064]$} \\
\hline \multirow[t]{2}{*}{ Quintile 5} & 4.92 & 4.81 & 4.96 \\
\hline & {$[0.089]^{* * *}$} & {$[0.20]^{* * *}$} & {$[0.086]^{* * *}$} \\
\hline $\mathrm{N}$ & 90 & 45 & 45 \\
\hline
\end{tabular}

Source: Authors' calculations.

Notes: Standard errors in brackets. The dependent variable in each column is the income growth for each quintile. The sample consists of all districts and the estimates are obtained using seemingly unrelated regression systems with instruments for government expenditures and expenditure growth. The instruments consist of regional indicators and geographical (GIS) data. We present estimates for the top and bottom expenditure districts.

$* \mathrm{p}<0.10, * * \mathrm{p}<0.05, * * * \mathrm{p}<0.01$

Table 15 shows the estimated elasticities for each expenditure group using observations for all districts. The elasticities are evaluated at the average value of the ratios of Equations 6 and 7 as before. The effects for expenditures in infrastructure are significant for quintile 1 and quintile 5, but with opposite effects: promoting growth in the top quintile and reducing it at the bottom quintile. The elasticity of health and education expenditures is negative for the bottom quintile, concentrating growth toward the middle of the distribution. The expenditures in social goods tend to be neutral in the aggregate, as the growth that is promoted among a group tends to be neutralized by decreases elsewhere. For example, the results suggest that a 10 percent increase in infrastructure spending is reflected as an increase of 0.26 percent among the top quintile and a decrease of 1.25 percent among the bottom quintile; considering the different levels of mean income among these groups, the effects cancel one another.

In the case of health and education expenditures the situation is similar, but we cannot detect significant positive effects elsewhere in the distribution. The points to draw from these results are the different nature of 
health and education expenditures and infrastructure expenditures. As we mentioned before, these effects also reflect the differential capacity of these groups to benefit from these investments, which are dictated by their initial conditions. So the poorest groups are less likely to experience mean expenditure growth through investments in infrastructure that are reflected in the fiscal expenditure data.

General expenses have a positive and significant effect on the average household income of the top quintile and negative effects on the household income of the other groups. The elasticities of household consumption growth are only positive and significant for the top quintile and the household expenditure growth elasticity is only above one for the top quintile. This implies that mean expenditure growth is not reflected among the poorest sections of the population and is better reflected among the top quintile of the expenditure distribution in Rwanda.

TABLE 15 RWANDA: ELASTICITIES OF GROUP EXPENDITURES FOR ALL DISTRICTS

\begin{tabular}{|c|c|c|c|c|c|c|c|c|}
\hline Expenditure & Quintile 1 & & Quintile 2 & Quintile 3 & & Quintile 4 & Quintile 5 & \\
\hline \multirow[t]{2}{*}{ Infrastructure } & -0.125 & $* * *$ & -0.018 & -0.020 & & -0.015 & 0.026 & $* *$ \\
\hline & $(0.04)$ & & $(0.02)$ & $(0.02)$ & & $(0.02)$ & $(0.01)$ & \\
\hline \multirow[t]{2}{*}{ Health and Education } & -0.218 & $*$ & 0.052 & -0.002 & & 0.021 & 0.002 & \\
\hline & $(0.12)$ & & $(0.05)$ & $(0.05)$ & & $(0.06)$ & $(0.04)$ & \\
\hline \multirow[t]{2}{*}{ General Expenses } & -0.053 & $*$ & -0.017 & -0.020 & $*$ & -0.007 & 0.016 & $* *$ \\
\hline & $(0.03)$ & & $(0.01)$ & $(0.01)$ & & $(0.01)$ & $(0.01)$ & \\
\hline \multirow[t]{2}{*}{ HH Expenditure } & 0.085 & & -0.019 & -0.009 & & 0.065 & 1.933 & $* * *$ \\
\hline & $(0.12)$ & & $(0.05)$ & $(0.05)$ & & $(0.06)$ & $(0.04)$ & \\
\hline
\end{tabular}

Source: Authors' calculations. effect of a 1 percent increase in the expenditure variable on the mean expenditure of each quintile group.

$* \mathrm{p}<0.10, * * \mathrm{p}<0.05, * * * \mathrm{p}<0.01$

Separating the estimation of the elasticities by the average expenditure levels of each district, as presented in Table 16 and Table 17, shows a more nuanced picture of the effects discussed. These estimates show that the negative elasticity found above for infrastructure expenditure for the bottom quintile is coming from the poorer districts, while the positive effect observed for the top quintile comes from the richer districts. In the top districts mean income growth benefits the bottom of the distribution but the estimate is considerably smaller for the bottom quintile. 
TABLE 16 RWANDA: ELASTICITIES OF GROUP EXPENDITURES FOR BOTTOM EXPENDITURE DISTRICTS

\begin{tabular}{|c|c|c|c|c|c|c|c|}
\hline Expenditure & Quintile 1 & Quintile 2 & & Quintile 3 & Quintile 4 & Quintile 5 & \\
\hline \multirow[t]{2}{*}{ Infrastructure } & -0.063 & -0.022 & & -0.036 & -0.032 & 0.033 & $*$ \\
\hline & $(0.06)$ & $(0.03)$ & & $(0.03)$ & $(0.03)$ & $(0.02)$ & \\
\hline \multirow[t]{2}{*}{ Health and Education } & -0.199 & -0.003 & & -0.005 & 0.029 & 0.007 & \\
\hline & $(0.16)$ & $(0.08)$ & & $(0.08)$ & (0.10) & $(0.06)$ & \\
\hline \multirow[t]{2}{*}{ General Expenses } & -0.045 & -0.030 & $* *$ & -0.008 & 0.010 & 0.007 & \\
\hline & $(0.03)$ & $(0.02)$ & & $(0.02)$ & $(0.02)$ & $(0.01)$ & \\
\hline \multirow[t]{2}{*}{ HH Expenditure } & 0.069 & 0.035 & & -0.065 & 0.190 & 1.887 & $* * *$ \\
\hline & $(0.24)$ & $(0.12)$ & & $(0.13)$ & $(0.14)$ & $(0.08)$ & \\
\hline
\end{tabular}

Source: Authors' calculation.

Notes: Standard errors in parentheses. Elasticities are estimated at the respective means and use the structural estimates to calculate the effect of a 1 percent increase in the expenditure variable on the mean expenditure of each quintile group. We present elasticities for the bottom expenditure districts.

$* \mathrm{p}<0.10, * * \mathrm{p}<0.05, * * * \mathrm{p}<0.01$

TABLE 17 RWANDA: ELASTICITIES OF GROUP EXPENDITURES FOR TOP EXPENDITURE DISTRICTS

\begin{tabular}{|c|c|c|c|c|c|c|c|}
\hline Expenditure & Quintile 1 & & Quintile 2 & Quintile 3 & Quintile 4 & Quintile 5 & \\
\hline \multirow[t]{2}{*}{ Infrastructure } & -0.179 & $* * *$ & -0.013 & -0.014 & -0.001 & 0.023 & \\
\hline & $(0.06)$ & & $(0.02)$ & $(0.02)$ & $(0.03)$ & $(0.02)$ & \\
\hline \multirow[t]{2}{*}{ Health and Education } & -0.176 & & 0.062 & 0.001 & 0.030 & -0.009 & \\
\hline & $(0.18)$ & & $(0.08)$ & $(0.06)$ & $(0.09)$ & $(0.05)$ & \\
\hline \multirow[t]{2}{*}{ General Expenses } & -0.089 & $* *$ & -0.011 & -0.019 & -0.005 & 0.017 & \\
\hline & $(0.04)$ & & $(0.02)$ & $(0.01)$ & $(0.02)$ & $(0.01)$ & \\
\hline \multirow[t]{2}{*}{ HH Expenditure } & 0.201 & $*$ & -0.024 & -0.030 & 0.020 & 1.948 & $* * *$ \\
\hline & $(0.12)$ & & $(0.05)$ & $(0.04)$ & $(0.06)$ & $(0.03)$ & \\
\hline
\end{tabular}

Source: Authors' calculations.

Notes: Standard errors in parentheses. Elasticities are estimated at the respective means and use the structural estimates to calculate the effect of a 1 percent increase in the expenditure variable on the mean expenditure of each quintile group. We present results for the top expenditure districts.

$* \mathrm{p}<0.10, * * \mathrm{p}<0.05, * * * \mathrm{p}<0.01$

\section{CONCLUSIONS}

In this paper, we explore the effects of fiscal policies and growth on measures of the household welfare across the distribution of expenditure for Rwanda and Tanzania. The purpose is to better understand what groups are benefiting more from growth and public investment in these countries. We explore how government expenditures and growth affects different sectors of the population by looking at the effects within a country and across different groups of households and administrative entities.

We find contrasting results in the two countries we study. In Tanzania, the benefits of growth are reflected in a wider range of the expenditure distribution but with benefits concentrated on the top income bracket. Mean expenditure growth is not reflected one-to-one among the poorest sections of the population and disproportionally benefits the better-off sectors of the population, implying that the distributional effects of growth within the household sector do not reduce inequality. When comparing better and worse-off districts, we find that districts that have mean expenditure above the national median may be more efficient in their targeting of social expenditures toward the poorer sectors of the population, even though the effects are very small. Public expenditures tend to have small effects and most of the effects are neutralized in the aggregate by distortions to the top quintiles in the expenditure distribution. The distributional effects of social expenditures tend to increase the share of the household sector in the economy, which can be regarded as a pro-equity effect, meaning that it promotes growth toward the bottom of the distribution. 
In the case of Rwanda, we find that mean expenditure growth disproportionally benefits the top quintile. We find that the public expenditure variables do not promote growth for the poor and middle classes. We find small positive effects only for the top quintile of the expenditure distribution.

The welfare spillovers are mostly present for top 20 percent of the expenditure distribution in both countries, with the bottom and middle of the distribution in Tanzania responding slightly to these spillovers. The elasticities of household consumption growth are only positive, significant, and above one for the top quintile. Public expenditures do not affect inequality in a considerable manner, but tend to concentrate growth toward the middle of the distribution, which can be seen as a pro-equity effect. On the other hand, growth is related to "increases" in inequality in the sense that the poorest sectors of the population benefit the least from growth. We find that the growth elasticity of expenditure for the bottom quintile is well below one in both countries.

In summary, the results show that the better-off sectors of the population in these two countries benefit more from growth, with growth increasing the importance of the household sector. These effects differ from those found in the literature that finds that growth tends to be pro-poor and inclusive, that is that reduces poverty and does not disadvantages the poor (Dollar and Kray, 2002 and Dollar, Kleineberg and Kraay, 2016). These studies, rely on cross-country differences and mainly focused on the effect of growth on the poor, while our study shows the effects of growth on the complete distribution of income based on within country differences.

The fiscal sector contributes very little to increase equity among the households that are represented in the surveys, although it does affect the income of the household sector vis-à-vis the rest of the economy. Public expenditures contribute modestly to increase the household per capita income and some components of the expenditures have a small effect on the distribution within the household sector. Government expenditures in the non-social category leave little or no significant effect on average household income and tend to be regressive.

Government expenditures in social goods, on the other hand, have a positive effect on the middle groups of household income, and their distribution effect tends to be progressive.

East Africa has been on a solid growth path in the last years, but in Rwanda and Tanzania, growth has been accompanied by budgetary deficits. Our results have several implications as to what type of budgetary allocation can compensate for the unequal effects growth has across different income groups. Social expenditures, such as health and education, should be better targeted toward the poor to achieve a higher pass-through from the fiscal to the household sector among the poorer sectors of the population. Finally, the possible distortionary effects that fiscal outlays can have among the better-off group can be buffered by the higher incidence of the benefits of growth on this group.

The limitations of the empirical strategy and the distributional framework are mainly due to the data availability and possible changes in administrative limits in the countries (as was the case in Rwanda during the study period). Ideally, we would want higher frequency survey data to construct annual growth measures and have more than one growth observation per district. In the same spirit, the fiscal expenditure data would ideally provide more detailed categories and provide district-level outlays that can be matched to each yearly growth rate computed from the household surveys. In contrast to the previous literature that uses crosscountry data, the finding that expenditure growth in the bottom quintiles is slower than average expenditure growth for these two countries in the period studied highlights the importance of exploring the implications of growth within a country and how they are reflected across the household sector. 


\section{Chapter 3 - Impact Evaluation Of The Northern TRANSNATIONAL HighWAY Of El SALVAdor}

Impact Estimates using Panel Data from 2009 to 2014

with Maximo Torero and Eduardo Nakasone

\section{Summary}

Roads are a basic input for all economic sectors and have a large potential impact on development. In rural areas, roads help households to integrate into markets, which allow them to increase their monetary income, access better inputs, coordinate with other actors along the value chain, and purchase goods to expand their consumption basket. The government of El Salvador and the Millennium Challenge Corporation, a foreign aid agency, with the aim of improving the economic conditions in the Norther Zone through strategic investments in infrastructure rehabilitated the Northern Transnational Highway (NTH), a two-lane paved road which serves as a transport artery within the Northern Zone of the country.

In this essay, we evaluate the main impacts of the improvement of the NTH using two parallel approaches that use a panel household survey to exploit variation in the improvement of the road across time through a novel difference-in-difference estimator and a continuous treatment structural estimator that exploits the variation induce to market access by the timing of the improvements and the spatial distribution of households in the Northern Zone of El Salvador.

Our results suggest that the improvement of the NTH in El Salvador had modest impacts in the short run. We find clear evidence of improvement in market access through shorter times and cost of moving products to existing markets. Across the population in the Northern Zone, the traveling time to the nearest market decreased between 16 and 18 minutes on average. The evidence suggests modest effects, if any, on agricultural productivity and no effects in the value of land. We find limited effects on the probability of having a title for an agricultural plot in some areas along the NTH; an increase between 18 and 32 percentage points on the households in the west side of the road. Some of the more salient effects of the road improvements is an in the probability of commercialization in agriculture. Households are 10 percentage points more likely to sell after the road improvement. We find some indication of an increase in stored grains; the value of agriculture production designated for auto-consumption, increased between 40 to 53 USD. These effects vary depending on the methodology used.

Interestingly, we find negative impact on household income of 140 USD per year or $5 \%$ of annual income. This effect can be traced to dependent labor in the agriculture sector income and to independent/business income in the non-agriculture sector. We posit that these short-run effects might be due to a reallocation of dependent labor supply across sectors and an increase in business competition from areas that become newly accessible with ease following the road improvement.

Keywords: roads, impact evaluation, structural, market access, panel data, El Salvador 


\section{INTRODUCTION}

Roads are a basic input for all economic sectors and have a large potential impact on development. Transportation determines an important portion of transaction costs, which have several economy-wide implications. High transaction costs hinder competition, arbitrage between markets, market integration, labor mobility, and the creation of value chains.

In rural areas, roads help households to integrate into markets, which allow them to increase their monetary income, access better inputs, coordinate with other actors along the value chain, and purchase goods to expand their consumption basket. In El Salvador, about half of the road infrastructure is unpaved ${ }^{14}$. This limits transportation ability and inhibits economic development in El Salvador. The situation for rural Salvadoran households is even more critical because they are usually located in remote areas where dirt roads become impassable during the rainy season (which accounts for nearly half of the year).

In November of 2006, the Millennium Challenge Corporation (MCC) made and agreement with the government of El Salvador (GOES) to improve The Northern Transnational Highway (NTH), a two-lane paved road which serves as a transport artery within the Northern Zone. The NTH connects with roads to southern EI Salvador, to the Pacific Ocean port at La Union in eastern El Salvador, and to the Caribbean ports of Puerto Barrios in Guatemala and Puerto Cortez in Honduras.

The Northern Zone of El Salvador contains half of El Salvador's poorest municipalities and suffered more damage from the country's internal conflict during the 1980s than any other region. Economic and social indicators in the Northern Zone are currently worse than the national average. Thus, the goal of this investment was to connect northern El Salvador with the rest of the country, helping to create opportunities for the region's residents through increased access to markets through the east-west highway. Over five years, the project constructed, improved, or rehabilitated $223.3 \mathrm{~km}$ of the NTH, with GOES completing the rehabilitation of an additional segment of $43.7 \mathrm{~km}$, allowing the highway to provide contiguous and reliable access to communities in the Northern Zone, as well as to main transportation corridors. In addition, three large bridges and twenty smaller bridges were rehabilitated or constructed in northern El Salvador to help improve connectivity with the rest of the country.

In this essay, we evaluate the main impacts of the improvement of the NTH using two parallel approaches that use a panel household survey to exploit variation in the improvement of the road across time through a novel difference-in-difference estimator and a continuous treatment structural estimator that exploits the variation induce to market access by the timing of the improvements and the spatial distribution of households in the Northern Zone of El Salvador.

The first approach takes advantage of the sequence in which the different segments of the NTH were constructed by combining a difference-in-difference (DID) and pipeline design. The DID exploits a discontinuity in market access at the boundaries of the different segments and sub-segments of the NTH due the characteristics of the different contractors, the terrain and level of work completion at different point in time. This is coupled with a pipeline design that exploits the different planned construction dates to categorize adjacent segments of the road to treatment and comparison areas and create groups of treatment and comparison segment pairs across the road that could be impacted at different points in time.

The second approach exploits variations in the time to the nearest markets affect by the NTH improvement and model these changes as changes in the intensity of treatment. These variations result from the fact that over time, the NTH will provide different degrees of accessibility to the households located along the road and

${ }^{14}$ The World Bank's World Development Indicators estimate that the paved share of the total road network in El Salvador was 54.1 percent in 2009 and 46.9 percent in 2010. 
gains would depend on what portion of the road household's use to go to different markets and how the quality of the road enters the decision of what market to go to.

Both methodologies exploit the panel structure of the data to measure the change in outcomes for households around the area of influence of the NTH; households around the NTH and the network of connecting roads surrounding it. We focus on the following expected impacts: the reduction of transportation costs and transportation time, changes in agricultural productivity and changes in income across agriculture and nonagriculture sectors.

There are very few rigorous evaluations of rural road projects. This evaluation contributes to the literature on the effects of improvement of rural roads by providing empirical estimates based on a sound theoretical framework. The framework informs the empirical strategy and provides a reduced form and a structural interpretation of the results that future rural roads evaluation can use to predict the impacts of rural roads improvements in similar contexts.

\section{INTERVENTION BACKGROUND}

The NTH is a two-lane paved road which serves as a transport artery within the Northern Zone and connects with roads to southern El Salvador, to Honduras in the east and Guatemala to the west and northwest. The project constructed, improved, or rehabilitated $223.3 \mathrm{~km}$ of the NTH, along with an additional $43.7 \mathrm{~km}$ rehabilitated by GOES, allowing the highway to provide contiguous and reliable access to communities in the Northern Zone, as well as to main transportation corridors. These improvements include, in addition, three large bridges and twenty smaller bridges across the NTH. This should enable the Northern Zone to participate more fully in the national and regional economy.

Reduction of the transportation costs within the Northern Zone to the rest of the country and to neighboring countries could facilitate access to markets, promote territorial development, increase productive use of land, and attract new investments. The increase in accessibility could also improve access to health and education services. Together these effects are expected to cause an overall improvement of welfare of beneficiary households.

The road improvements can affect the livelihood of the poor in the area through different pathways. First, through the income-market access pathway, increases in access in the form of shorter times and lower cost of moving products to existing markets are expected to promote agricultural productivity and participation in non-agricultural activities, by the availability of better and cheaper inputs for agricultural activities and the increased demand for non-agricultural labor from new and more accessible existing markets. These changes imply income flows that are more diverse and perhaps less volatile promoting resilience in those that exit out of poverty. Second, improvements in the roads could also improve the access to existing health services, education services, and other existing public infrastructure. This can increase the use of health facilities and school enrollment, increasing the human capital of a wide range of the population, specifically among more vulnerable members such as children, women, and the elderly. These two pathways compound their effect to achieve the objective of promoting inclusive and sustainable growth in the region.

Before the Connectivity project, road conditions and, in some places, the lack of roads exacerbated the isolation of the Northern Zone; with twenty-three of the fifty-seven municipalities in the zone of influence of the road having only unpaved dirt roads. During periods of heavy rain, these roads - especially unpaved roads - can become impassable. In the Northern Zone, many neighboring communities do not have direct, reliable transport routes connecting them, so community members must travel great distances, or over difficult conditions, to access services or markets in neighboring communities. 
The NTH improvement provided significantly greater access to alleviate these difficulties, as well as decrease travel time and vehicle operation and maintenance costs.

The construction of the NTH was split in sections or segments whose approximate lengths, expected timeline for completion, and realized timeline for completion are presented in Table 18. A seventh segment that was not initially planned to be constructed was added later to the timeline of the compact.

TABLE 18 NTH CONSTRUCTION TIMELINE: INITIAL AND ACTUAL

INITIAL

SEGMENTS
T1
T2
T3
T4
T5
T6
T7
BRIDGES

ACTUAL

APPROXIMATE

LENGTH IN KM

$\begin{array}{ll}\begin{array}{l}\text { Scheduled } \\ \text { Start Date }\end{array} & \begin{array}{c}\text { Schedul } \\ \text { End Date }\end{array} \\ \text { Will not be constructed } \\ \text { May-09 } & \text { Oct-10 } \\ \text { Dec-09 } & \text { Oct-11 } \\ \text { Jan-10 } & \text { Jan-12 } \\ \text { Oct-09 } & \text { Aug-11 } \\ \text { Oct-09 } & \text { Aug-11 } \\ \text { Will not be constructed }\end{array}$

Will not be constructed

\section{Start Date $\quad$ End Date}

Will not be constructed

May-09 Sep-10 43

Dec-09 Aug-12 41

Jan-10 Nov-12 53

Oct-09 Aug-12 32

Oct-09 Aug-12 35

Sep-11 Sep-12 21

Figure 3 shows a map of El Salvador with the Northern Zone outlines in bold and the different segments of the NTH displayed in various colors. It also highlights the Pan-American Highway (in red) and the accessibility of the whole country before and after the construction of the NTH. 


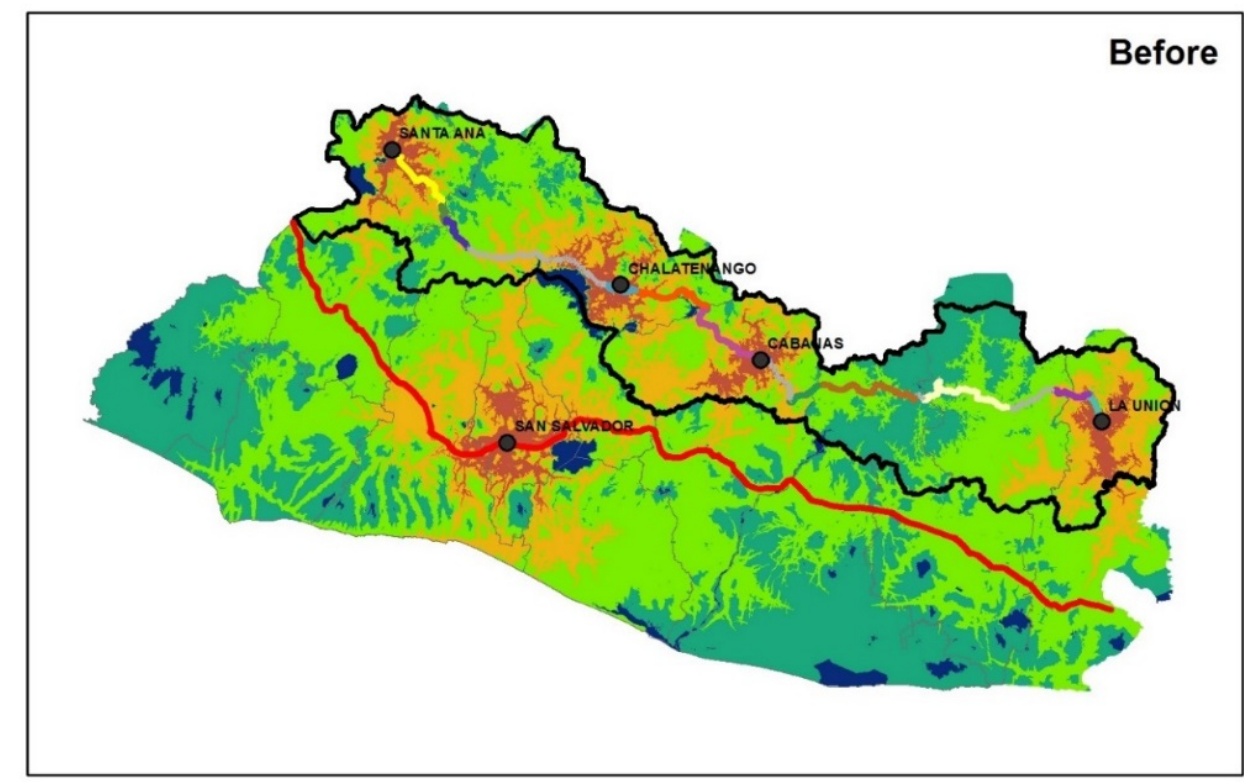

Northern Transnational Highway Tramo

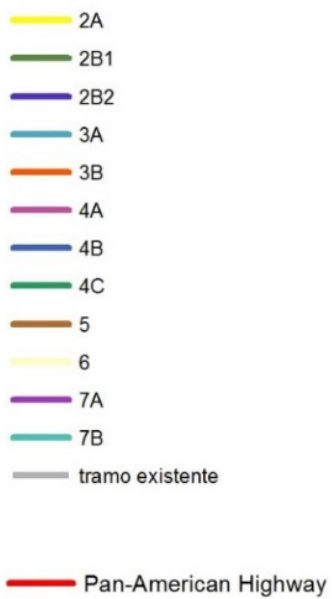

Time to markets

\begin{tabular}{l}
\hline$<30 \mathrm{~min}$ \\
$30 \mathrm{~min}-1 \mathrm{hr}$ \\
$1 \mathrm{hr}-2 \mathrm{hr}$ \\
$2 \mathrm{hr}-4 \mathrm{hr}$ \\
$>4 \mathrm{hr}$
\end{tabular}

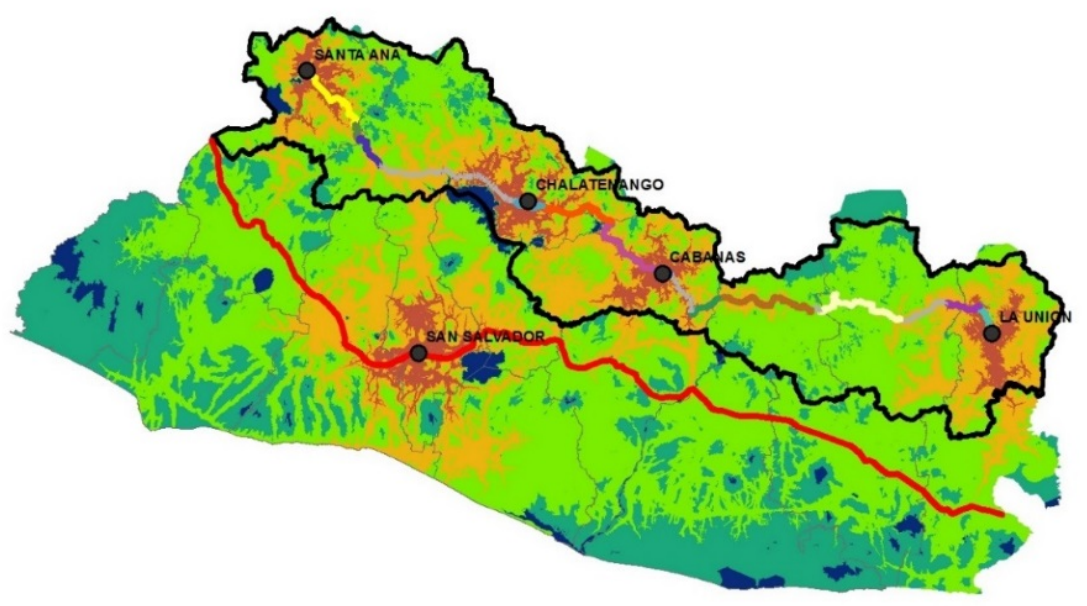




\section{RuRal Roads AND DeVElopment: A Literature ReVIEW}

Early work on roads attempted to establish a relationship between the stock of public infrastructure and productivity. Antle (1983) used infrastructure as an input in a Cobb-Douglas function to explain cross-country differences in agricultural output. In a similar study in rural India, Antle (1984) found a positive impact of roads, telecommunications infrastructure, and human capital on agricultural productivity. However, this study fails to account for possible reverse causality between output and capital. Also, common trends in infrastructure and output may reflect a spurious correlation that is related to the underlying time trend. Binswanger et al (1993) correct for reverse causality with a fixed effects model with time trend variables on a panel of 85 districts in 13 states in India. They describe the process through which areas that have favorable agro-climatic conditions attract roads and financial institutions, ultimately resulting in higher investment and agricultural productivity. They are among the first to model the endogenous processes through which roads may lead to higher output. Fan and Zhang (2003), also in India, apply the Generalized Method of Moments (GMM) to account for reverse causality and find significant effects of road density and irrigation on agricultural total factor productivity (TFP).

More recent work on roads evaluates the paving of existing or the construction of new roads. Most impact evaluations on rural road construction find positive effects across a wide array of measures. Some papers measure the increased property values (Gonzalez-Navarro and Quintana-Domeneque 2012, Jacoby 2000), lower transport costs (Jacoby and Minten 2008), agricultural productivity (Dong 2000), effects on crop prices (Khandker et al. 2009, Casaburi et al. 2013), increases in income and non-farm employment (Rand 2011, Jacoby and Minten 2009, Gachassin et al. 2010), consumption (Jalan and Ravallion 2002, Gibson and Rozelle 2003), specialization (Qin and Zhang 2012), and access to health and education services (Valdivia 2009). These results point to the multiplicity of possible mechanisms and interactions through which roads may contribute to poverty reduction.

While studies tend to find positive average effects, the distribution of the benefits of road improvement has favored men. There has been an increased recognition that men's and women's gender-defined roles and responsibilities lead to different patterns of transport access, needs, and use (World Bank 2012). Women are less likely to own motorized transportation and more likely to walk (Peters 2001). In all countries, there are fewer women than men working in transport-related jobs (Duchene 2011). Despite a recognition that women have different transport needs, few studies have taken gender into account when assessing the impact of roads. Khandker et al. (2009) examine the effect of paving feeder roads and upgrading market infrastructure in rural Bangladesh on men's and women's agricultural and non-agricultural labor supply and found the number of days worked in the previous month increased for men and decreased for women. Valdivia (2009) analyzed a road maintenance program in Peru and found that in communities that received the program, women reduced their participation as unpaid workers at the family farm in favor of outside agricultural work. Males appeared to have better access to waged non-agricultural jobs.

There is mixed evidence on whether wealthier households are better positioned to benefit from road improvement. Mu and Van de Walle (2011), in a study of feeder road rehabilitation in Vietnam, found communities where roads were improved were more likely to switch from agricultural to non-agricultural activities and primary school completion rates increased with higher impacts in poorer communities. Lokshin and Yemtsov (2005) evaluated rehabilitation of schools, roads and bridges, and water systems in Georgia. They divided their sample into poor and non-poor households and found that off-farm employment improved solely for non-poor households, while female wage employment increased for poor women only, though their results were not statistically significant. Khandker et al. (2009) estimate the effects of feeder roads on different parts of the income distribution with a quantile regression. They found that the program increased household per capita expenditure and that these effects were larger in poor communities. However, Khandker and Koolwal (2011) in a follow-up survey estimate the long-term effects of road construction and found that its pro-poor 
benefits diminish over time. They find that the benefits were not captured by the poorest in their sample but rather by individuals in the $50^{\text {th }}$ through $75^{\text {th }}$ percentiles of their sample income distribution.

The Khandker papers underscore the point that impacts may take a while to immerge and can be different over time. Similarly, Mu and Van de Walle (2011) found that number of schools and availability of food-related goods increased in the short-term while expansion of markets and non-food goods took longer to emerge. Van de Walle (2009) emphasizes that evaluation should allow sufficient time for impacts to manifest and acknowledge the differences between short-term and long-term impacts. However, she adds that the longer the period in which an evaluation takes place, the more likely it is to suffer from sample attrition, confounding exogenous shocks, and spillover effects.

Van de Walle (2009) also highlights the fact that people do not derive utility from roads but rather through the opportunities for extra consumption that they facilitate. This makes the impact of roads likely to be dependent on other investments, infrastructure, and community characteristics. Gachassin et al. (2010) explore this idea using instrumental variables on a cross section of 11,533 households in Cameroon. They find no significant effect of proximity to tarred road on consumption but they do find a significant effect of access to labor market activities which they describe as an indirect benefit of roads. They strongly advocate against "investing uniformly for roads in Africa" and emphasize that roads are only effective in so far as they consider the needs of road users. Raballand et al. (2010), drawing on case studies in Burkina Faso, Cameroon, and Uganda, highlight that most evaluations of rural road programs are performed without examination of local transport economics. The authors challenge the assumption that the presence of high quality roads will increase mobility and allow farmers to truck their produce to market because farmers may not have adequate surplus or there may be collusion in the trucking industry. Because roads interact with many factors, it is important to understand potential complementarities when designing an impact pathway.

The literature acknowledges that roads may not be sufficient to ensure poverty reduction and their impact may depend on access to other assets. Yamauchi et al. (2013) examined survey data on village road quality in rural Indonesia and found that asphalt roads are complementary with education. Post-primary education significantly increased the number of days worked in non-agricultural labor and non-agricultural income growth in areas that received road improvement. Similarly, Escobal and Torero (2005) estimate the interaction effects between traditional infrastructure such as roads, electricity, and sewage, with "human-capital generating" public services such as education and access to health, as well as access to communication infrastructure. Using a simulation based on survey data from Peru, they found that investment in a combination of roads, telecommunication infrastructure, and schools leads to a higher expected increase in expenditures among the poor than the sum of the individual effects of these investments alone.

Endogenous road placement makes attributing the causal benefits of rural roads difficult. Road placement is not random and factors linked to the decision to build are likely correlated with outcome variables. For example, if an area is selected to receive a road because of its high agricultural potential, then estimates of the impacts of the road will be upwardly biased. Furthermore, there may be unobserved individual characteristics such as the household decision to locate near a road which are likely correlated with program placement. Gonzalez-Navarro and Quintana-Domeneque (2012) are able to randomly assign road pavement to households. They conduct a first-time asphalting of residential non-arterial streets in a peri-urban setting in Mexico and found that two years post-intervention, households who had received the treatment increased their use of collateralized credit which led to higher consumption of consumer durables and automobiles. However, they are unable to determine whether the increase in collateral-based credit was the result of an increase in the demand or supply of credit. They also found that pavement did not significantly increase consumption of non-durables, labor supplied, income, school attendance or self-reported health. 
Other evaluations of road construction employ quasi-experimental techniques to deal with endogeneity. Rand (2011) implements a matched double-difference approach controlling for factors that influence the placement of the roads and subsequent employment growth rates to evaluate the construction of tertiary roads in Nicaragua. He estimates that hours worked increased in communities that received roads between 9.5 and 12.3 hours per week relative to comparison communities. Escobal and Ponce (2002) use propensity score matching at the town level to evaluate a rehabilitation program in Peru and find that the program increased income through access to wage opportunities. However, consumption did not increase because the road improvement was "seen as transitory." Mu and Van de Walle (2011) and Lokshin and Yemtsov (2005) also implement double differences and propensity score matching on pre-intervention covariates. Khandker et al. (2009) use a fixed effects estimator and attempt to control for initial endowments of communities and households. They controlled for the number of banks, schools, and hospitals serving the village; distance from the village to the nearest paved road; and the average short-term interest rate in the village.

Casaburi et al. (2013) evaluate the paving of feeder roads in Sierra Leone. They perform an DID by creating cutoff points with the exact methodology and data that the managing consultant used to prioritize which roads would be built first. The presence of a road reduced transport costs and market prices of rice and cassava. The authors then test alternative theoretical models to explain their results and find that they are most consistent with the search-cost framework developed by Mortensen (2003). In this framework, higher transportation costs associated with being far away from a city lower the net price available to traders which leads to fewer traders entering the market and increases traders' monopsony power. Because markets are difficult to reach and the timing of interactions are uncertain this generates search frictions because farmers and traders "may not end up in a given rural market at the same time." Road construction decreased this cost with larger effects in the most remote markets.

Instrumental variables have also been used to evaluate the effect of roads in the absence of an intervention or new construction. Gachassin et al. (2010) use the presence of "gendarmerie" police stations as well as provincial tarred road density lagged one year as instruments for road placement in a cross sectional survey in Cameroon. Dercon et al. (2008) use a GMM instrumental variable estimator with household fixed effects to account for endogeneity in a growth model. Their sample consists of survey data from fifteen Ethiopian villages whose residents have access to roads of different quality. Using log of fertile land holdings, log number of adult equivalents, and log number of livestock holdings as instruments, they find access to all-weather roads reduces poverty by 7.6 percent and increases consumption growth by 16.3 percent.

Evaluations of highway construction use instrumental variables for road placement based on the timing of construction or project specific features. Datta (2011) argues that the while the endpoints of highways are endogenously placed, the intermediate points are plausibly exogenous. His assessment of the construction of the Golden Quadrilateral highway in India exploits the fact that the route was chosen to be the most direct between the four largest cities in India. He compares firms in cities that received the highway to those which already had a major highway and found that the former reduced their inventory as a result of the road. Gibson and Rozelle (2003) use the year that a district receives a national highway as an instrument to explain variation in travel time to roads in Papua New Guinea. They assume that highway construction will naturally lead to a proliferation of feeder roads and argue that the construction is not correlated with a region's wealth or productivity because they were built starting at the coast and proceeding inland. They find time to nearest road to be a significant determinant of poverty and simulate the poverty reduction effects of road construction. Cutting the time to nearest road to three hours for those who were more than three hours away would reduce the percent of people living below the poverty line by 5.36 percent. Faber (2014) uses least cost path spanning networks as an instrument to evaluate highways intended to connect provincial capitals with cities of greater than 500,000 people in China. He found that the project reduced inter-regional trade costs which led to a decrease in Gross Domestic Product (GDP) growth in non-targeted rural counties. Road infrastructure led to a reduction in industrial growth in non-connected areas relative to connected ones. 


\section{THEORETICAL FRAMEWORK}

Our empirical approach relies on how changes in transportation demand due to improvement in road quality can be thought of as an input in the production function of rural households. In this light, we develop a simple model to inform our empirical strategy.

Assume that $x$ is transportation and $F(x)$ determines the level of production $Y$ that corresponds to each level of this input ${ }^{15}$. The demand for factor $\mathrm{x}$ is then determined by its marginal productivity (i.e. $F^{\prime}(x)$ ); the farmer's willingness to pay for an additional unit of $\mathrm{x}$ is precisely what this additional unit would produce.

Figure 4 depicts hypothetical schedules for a production function $F(x)$ and the input demand for $x$. The input demand is determined by the slope of $F(x)$ throughout the range of $x: F^{\prime}(x)$. When the price of factor $\mathrm{x}$ is $P_{0}$, the farmer demands units of $\mathrm{x}$ until $F^{\prime}\left(x_{0}\right)=P_{0}$ (analogously, when the price reduces $F^{\prime}\left(x_{1}\right)=P_{1}$ ).

Rather than estimating the demand curve (or making any assumptions) for transportation, we estimate the difference between $Y_{1}=F\left(x_{1}\right)$ and $Y_{0}=F\left(x_{0}\right)$. Because the demand curve for $x$ is its marginal productivity, the area under $F^{\prime}(x)$ between $x_{0}$ and $x_{1}$ is equivalent to $Y_{1}-Y_{0}: \int_{0}^{x_{1}} F^{\prime}(x) d x-\int_{0}^{x_{0}} F^{\prime}(x) d x=F\left(x_{1}\right)-$ $F\left(x_{0}\right)$.

Thus, our methodology relies on directly measuring the change in production (or income, from the different rounds of surveys we collected) derived from the NTH rehabilitation and improvement. This approach has several advantages. First, we can gauge the benefits of the project from observed changes in income, which does not require any assumptions about the input demand function (or the production function). Second, we do not need to rely on assumptions regarding depreciation factors or to measure households' time savings. Third, instead of capturing benefits from traffic flows (which include foreign companies, large firms in the cities, etc.), we restrict our analysis to the population of interest: rural households in the NTH's area of influence.

${ }^{15}$ As usual, we assume that the production function is increasing and concave. We normalize the output price to one so that $F(x)$ is also a revenue function. However, assuming any other output price does not affect this idea. 

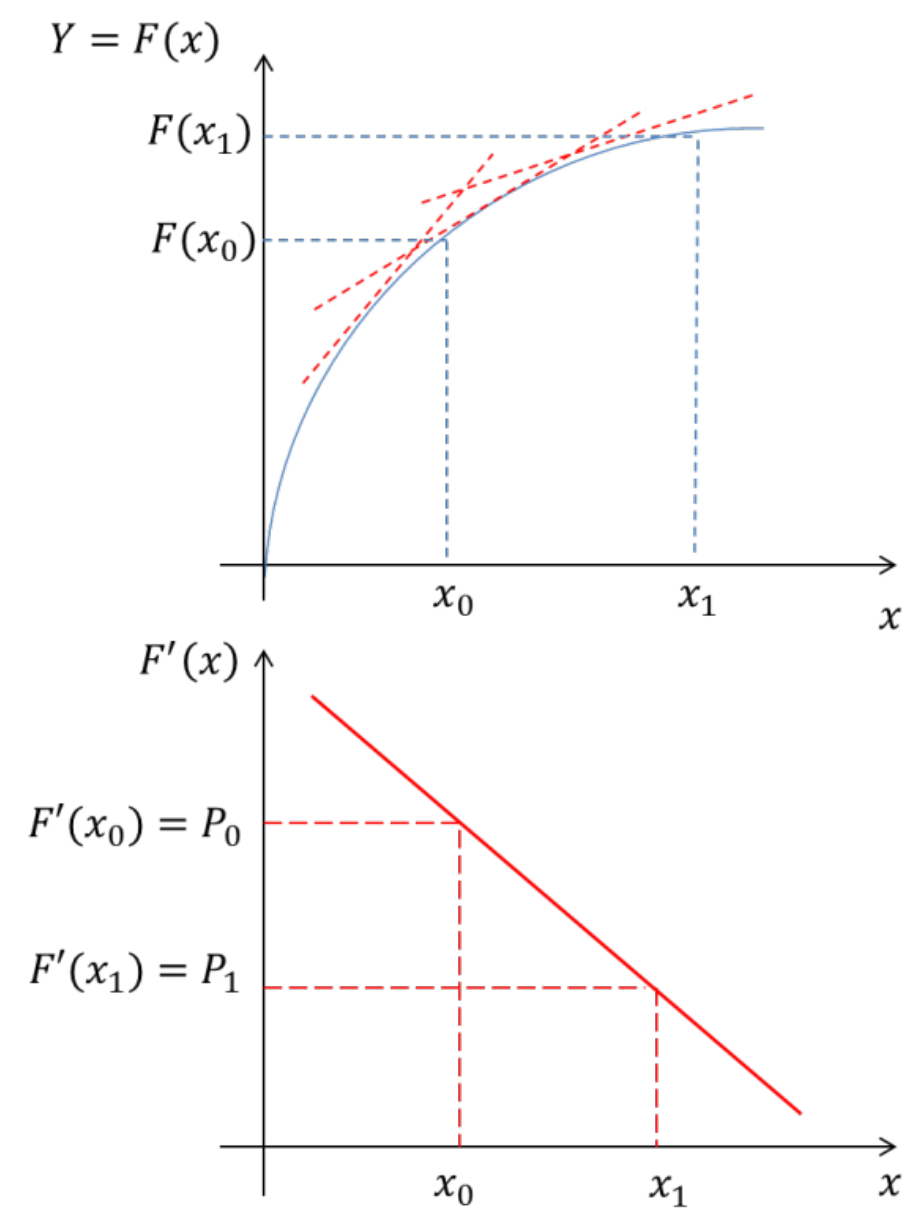

The outcomes that we study are informed by this simple model. For example, the project might increase land values through two potential channels. The first is land as an agricultural input $(x)$ in the model outlined above. As such, an increase for this production factor can improve land values. Second, better markets access can also lead to changes in land use due to the expansion of sub- and peri-urban areas (with further increases in land demand).

Furthermore, the impact on total income resulting from increased access to markets and reduced transportation costs can be separated by farm and non-farm activities. To illustrate the case for the impacts on on-farm activities through agriculture productivity, assume a household that purchases $x$ units of farm inputs, with a unit cost of $c$. This unit cost includes the price of the direct cost of the input as well as a transportation cost (e.g. the farmer has to travel to an input market and bring the input back to the farm). Its agricultural production function is given by $Q=F(x)$. If the household decides to sell its production in the market, it receives a price of $p$ but incurs an output transportation cost of $t$. The household can also decide to selfconsume some (or even all) of its production instead of selling it; in this case, we denote self-consumption as $q$ so that the households' sales volume is $F(x)-q$. Assume that the household's utility function is quasi-linear in income so that its maximization problem is:

$$
\operatorname{Max} U(x, q \mid p, t, c)=(p-t)(F(x)-q)-c x+V(q)
$$

where $F(x)$ and $V(x)$ are increasing and concave functions (i.e. $F^{\prime}()>0,. F^{\prime \prime}()<0,. V^{\prime}()>$.0 and $V^{\prime \prime}()<$. $0)$. The optimal values $x^{*}$ and $q^{*}$ satisfy: 


$$
\begin{aligned}
& F^{\prime}\left(x^{*}\right)=\frac{c}{(p-t)} \\
& U^{\prime}\left(q^{*}\right)=(p-t)
\end{aligned}
$$

We posit that the project should have two effects on households' agricultural activities. The first is a potential reduction in $c$. If households have better connectivity, they can have better access to input markets (which reduces the transportation portion of $c)$. In such a case, it can be shown that $d x / d c=1 /((P-$ t) $\left.F^{\prime \prime}(x)\right)<0$. Thus, reductions in $c$ should lead to both increases in input demand and higher outputs. Second (and more importantly), the project also leads to reductions in output transportation costs.

$$
\begin{gathered}
\frac{d F(x)}{d t}=\frac{\mathrm{F}^{\prime}(\mathrm{x})}{(p-t) F^{\prime \prime}(\mathrm{x})}<0 \\
\frac{d q}{d t}=-\frac{1}{U^{\prime \prime}(q)}>0
\end{gathered}
$$

In this line, we expect that reductions in transportation costs will lead to enhanced profitability of households' sales. Thus, the household will be both induced to increase its production and to sell more (through more active market participation and reductions in self-consumption). In addition, better access to roads could allow household members to commute more readily to non-farm jobs, enlarge markets for their non-farm products, and generate more opportunities for income diversification.

\section{EMPIRICAL STRATEGY}

As discussed previously, the current literature is plagued by endogeneity problems and omitted variables biases. "Roads are clearly not randomly placed, and it is highly likely that the factors that led to the road placement will also affect outcomes" [ (van de Walle \& Cratty, 2002)]. For example, if relatively well-off areas with higher levels of non-agriculture activity attract more infrastructure projects, then the positive correlation we observe between road infrastructure and income would not be causal due to the endogenous placement of the project. In the same way, if infrastructure is placed in areas with higher unobserved productivity levels, any estimated effect would be biased because of these unobserved factors.

Given that full randomization is not feasible, we implement quasi-experimental assessment methods; noting that none of these methods offers a perfect solution [ (Ravallion, 2007)]. We use a combination of methods to obtain valid inferences about the various household-level impacts of the road improvement. The framework serving as a guideline for our empirical analysis is the Roy-Rubin model [ (Roy, 1951) (Rubin, 1974), (Rubin, 1977), (Rubin, 1979), (Rosenbaum \& Rubin, 1983)] and includes carefully selecting our analytical samples of the population affected and non-affected to be as similar as possible in terms of their observable characteristics prior to the road improvement based on the timing of construction and the geographic distribution of the road.

We implement two quasi-experimental designs: (a) a reduced form, Difference-in-Difference Pipeline design, that exploits a discontinuity in market access at the boundaries of adjacent segments due to the improvement of the NTH across time; and (b) a "small" structural time to market design, a continuous treatment approach, that exploits the structural relationship between market access and road quality; the variation in travel times and choice of markets induced by the timing and progress of the road improvement and the spatial distribution of households. 


\section{Reduced Form Design: Difference-in-Difference Pipeline Estimator}

The improvement process of the NTH was scheduled to take place between May 2009 and November 2012 and involved the improvement of six out of seven defined construction segments. These segments were mostly determined by cost effectiveness concerns (e.g. the presence of natural barriers, engineering factors, etc.). The idea of the DID approach is to exploit these discontinuities, take advantage of the roll-out of the construction of the NTH, and compare households in adjacent segments.

This methodology assumes that households do not self-select into either side of the segment boundaries. Thus, the households on both sides are essentially comparable; they just happen to be divided by an engineering discontinuity that determines the timing in which they benefit from the NTH construction. In this line, the segments can be used as a quasi-random assignment of households into treatment and comparison groups over time.

While considerably more complicated in practice (because of the multiplicity of segments and implementation dates), this is the basic idea of the DID design. Figure 5 shows the schedule and actual dates of the construction of the different segments. Based on the scheduled construction dates and the proximity of segments, we create appropriate comparison groups to implement our DID design. For example, Segment 2 (scheduled for construction between May 2009 and September 2010) lies to the right of Segment 1 (which was not constructed). These segments comprise the first comparison group. We estimate the intervention's effects by assessing the differences between Segments 1 and 2 in several rounds of the survey (i.e. one, two, three, or four years after the intervention, using the 2010, 2011, 2012, and 2013 rounds of the survey). A similar approach allows us to determine four other comparison groups for the DID estimation.

\section{FIGURE 5 ROLL-OUT OF NTH AND COMPARISON GROUPS FOR DID IN THE NORTHERN ZONE}

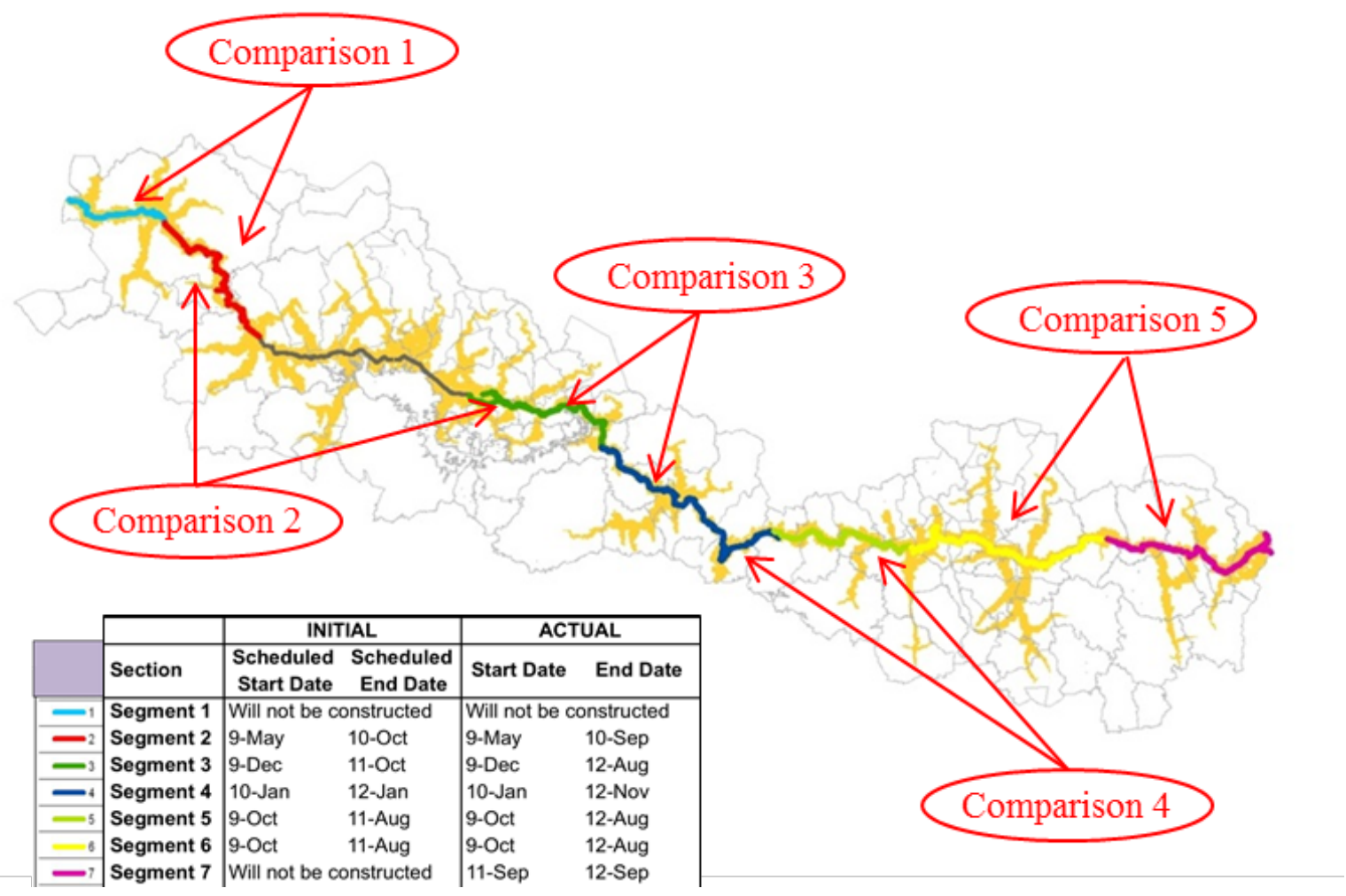


In this approach, we compare households in adjacent segments where the NTH is rehabilitated in different periods (or is not rehabilitated at all). Consider the following group assignments $\left(W_{k}\right)$ between pairs of segments, where one is assigned to a treatment group if $S_{k}=1$ and the other is used as a comparison if $S_{k}=$ 0 . For each of these group we define Post $t_{t}^{k}$, an indicator for the period after the finalization of the road improvement. Post $t_{t}^{k}=1$ in the survey years after the completion of the road work and implies that the baseline comparison level for different groups uses multiple waves of the data. The complete treatment assignment and time indicator for the DID approach is presented in Table 19.

TABLE 19 TREATMENT ASSIGNMENT BY SEGMENTS

\begin{tabular}{llllll}
\hline Treat Assignment & $\begin{array}{l}\text { Treatment } \\
\text { Segment (Sk) }\end{array}$ & $\begin{array}{l}\text { Comparison } \\
\text { Segment }\end{array}$ & Post $_{\boldsymbol{t}}^{\boldsymbol{k}}=\mathbf{1}$ after & $\begin{array}{l}\text { Survey } \\
\text { Years } \\
\text { Pre-Period }\end{array}$ & $\begin{array}{l}\text { Survey } \\
\text { Years } \\
\text { Post- } \\
\text { Period }\end{array}$ \\
\hline Group 1, $\boldsymbol{W}_{\mathbf{1}}$ & Segment 2 & Segment 1 & September 2010 & 2009 & 2010-2014 \\
\hline Group 2, $\boldsymbol{W}_{\mathbf{2}}$ & Segment 2 & Segment 3 & September 2010 & 2009 & 2010-2014 \\
\hline Group 3, $\boldsymbol{W}_{\mathbf{3}}$ & Segment 3 & Segment 4 & August 2012 & 2009-2011 & 2012-2014 \\
\hline Group 4, $\boldsymbol{W}_{\mathbf{4}}$ & Segment 5 & Segment 4 & August 2012 & 2009-2011 & 2012-2014 \\
\hline Group 5, $\boldsymbol{W}_{\mathbf{5}}$ & Segment 6 & Segment 7 & August 2012 & 2009-2011 & 2012-2014 \\
\hline
\end{tabular}

The effect of the treatment in each treatment assignment can estimated through:

$$
Y_{i t}=\boldsymbol{\theta}_{k} \cdot S_{k} \cdot \text { Post }_{t}^{k}+\lambda \cdot \text { Post }_{t}^{k}+\gamma D_{t}+\alpha_{i}+\varepsilon_{i t} \quad \text { if } i \in W_{k}, k=1, \ldots, 5
$$

Where

$S_{k}$ is the indicator for the treatment segment in group $\mathrm{k}$

Post $_{t}^{k}$ is the post improvement indicator for group $\mathrm{k}$

$D_{t}$ are survey year indicator variables for $\mathrm{t}=1 \ldots 5$;

$\alpha_{i}$ are household-specific fixed effects (that capture any time-invariant unobservable heterogeneity)

$\varepsilon_{i t} \sim D\left(0, \sigma^{2}\right)$ is an error term.

$W_{k}$ denotes the set of households in each $\mathrm{k}$ group assignment for which we estimate separate regressions. Note that $W_{k}$ includes all households in both segments of each treatment assignment.

Household fixed effects allows us to control for any time-invariant differences between the treatment and comparison units in each comparison group. Additionally, to account for common shocks that affect household living in the same location and sampling design, we clustered the error term at the census segment level. Due to the fixed-effects specification, the segment DID pipeline impact estimate is for group k on outcome $Y, \boldsymbol{\theta}_{k}$ exploits the within-household variation among treatment and comparison groups before and after the road improvement within each group $k$. Therefore, this methodology allows for the possibility of the NTH having differential effects within comparison groups and time periods.

\section{DiD With Construction Progress Administrative Data}

Noting that, while the construction of Segment 2 followed the initial schedule, there were significant delays in the construction of other parts of the NTH. Public works were delayed and most segments were only ready between August and November, 2012. Our DID identification strategy exploits the staggered roll-out of different segments of the NTH (i.e. in any given year, we would like to compare the outcomes of households in 
a segment with access to the highway with households in segment that did not). While there are still some differences in their construction dates, most segments were ready about the same time. Therefore, the variability in construction dates is somewhat smaller than originally expected.

To tackle this challenge, we exploit another source of variability. While project delays pushed the dates in which segments were available to August-November 2012, the delays were not uniform across segments. Using detailed administrative data of the construction progress of different sub-segments, we can determine the completion progress during our evaluation period. These data allow identify sub-segments in each segment and determine, at any given point of time, the percentage of the sub-segment was constructed. We match this information with our household surveys using the middle point of each data collection period (e.g. if the survey was collected between December and March of a year, we match the survey with the percentage of the households' sub-segment that was constructed by mid-January of that year). Therefore, beyond exploiting the variability in the initial and final dates of construction, we are also able to exploit differential delays in the public works of each segment. With this additional piece of information, we estimate two variants of the DID estimator.

The Sub-segment DID estimator $\left(\boldsymbol{\theta}^{\prime}{ }_{k}\right)$

$$
Y_{i t}=\boldsymbol{\theta}_{k}^{\prime} \cdot \text { Improved }_{s t}+\gamma D_{t}+\alpha_{i}+\varepsilon_{i t} \quad \text { if } i \in W_{k}, k=1, \ldots, 5 \text { and } s \in k
$$

where Improved $_{s t}$ is an indicator for the sub-segment $s$ (inside $k$ ) improvement being finalized in survey year $t$.

The Sub-segment Progress DID estimator $\left(\boldsymbol{\psi}_{k}\right)$

$$
Y_{i t}=\boldsymbol{\psi}_{k} \cdot \text { Progress }_{s t}+\gamma D_{t}+\alpha_{i}+\varepsilon_{i t} \quad \text { if } i \in W_{k}, k=1, \ldots, 5 \text { and } s \in k
$$

where Progress $_{s t}$ is the percentage of sub-segment $s$ (inside $k$ ) that was constructed in survey year $t$.

The processing of the administrative data of the construction progress of different sub-segments proved to be a difficult task. We invested a great amount of effort to extract uniform data from different implementers and contractors and then match these to the geographic information system (GIS) data to better update the accessibility data when we visited El Salvador. In the end, this data proved to be essential to improve the impact evaluation design after the delays in construction decreased the identifying variation in some comparisons group in the DID approach.

These DID specification are a "reduced form" of the continuous time to market treatment approach below, in that the variation in the construction across space and time are linked to changes in travel times that are in turn related to the outcomes of interest.

\section{Structural Time to Market Design: a Continuous Treatment Approach}

The goal of the previous approach is to capture the difference in outcomes between households in areas with and without roads. While the simplicity of this approach is appealing, in this continuous time to market approach we need to determine the intensity of treatment for each household, which is not evident in this context. For example, consider two households (Figure 6) that go to a nearby market (blue " $X$ " on the bottom of the graph) to sell their harvests. Household A lives in Segment 6 (where NTH was constructed between October 2009 and August 2012) and Household B lives in Segment 7 (where NTH was only constructed in the last year of the project). The dashed line indicates the path that each household would travel to reach target $X$.

The DID approach would have assigned A to the treatment and B to the comparison group for the period in which Segment 7 was still not constructed. However, even before the construction of Segment 7, Household B is not totally unaffected by the NTH. While most of its route to the market will go through the unimproved 46 
(green) section of the road (and thus see no changes in its travel time), B's route does include a small section of the improved road (brown); it will therefore save some time from improvement of the NTH. Household A lives in a segment with an improved section of the road and will thus spend more time on the NTH than Household B.

Assume that transportation time to the market is inversely related to households' agricultural income. This hypothetical relationship is the depicted by the function $Y=F$ (travel time) in Figure 7. The figure shows that Households' A's reduction in travel time will translate into larger increases in its agricultural income. While more modest, Household B will also experience some improvement in income.

The continuous time to market approach does not assign households to a treatment and comparison group but instead exploits variations in the degree to which NTH reduces households' transportation time and the extent to which these reductions translate into enhanced welfare outcomes.

\section{FIGURE 6 HYPOTHETICAL TRANSPORTATION ROUTES OF HOUSEHOLDS IN ADJACENT SEGMENTS}
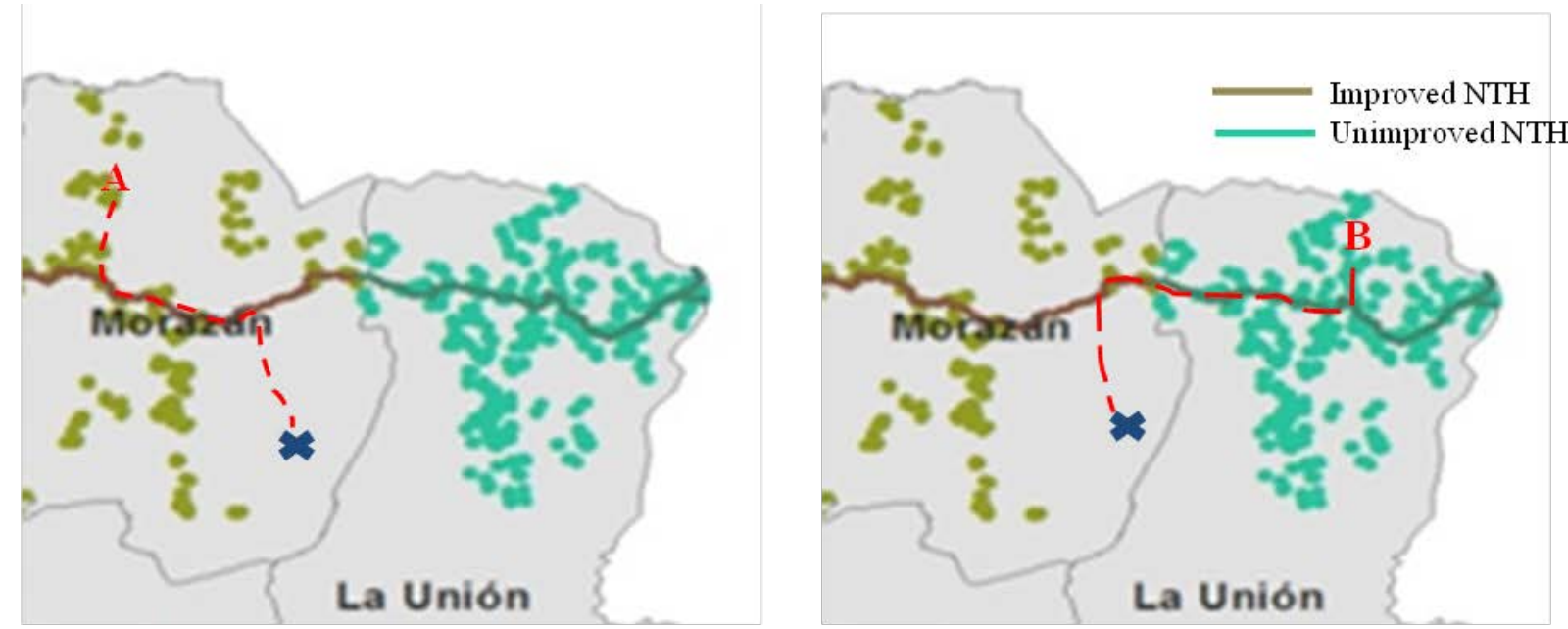

FIGURE 7 HOUSEHOLDS' BENEFITS FROM THE PROJECT

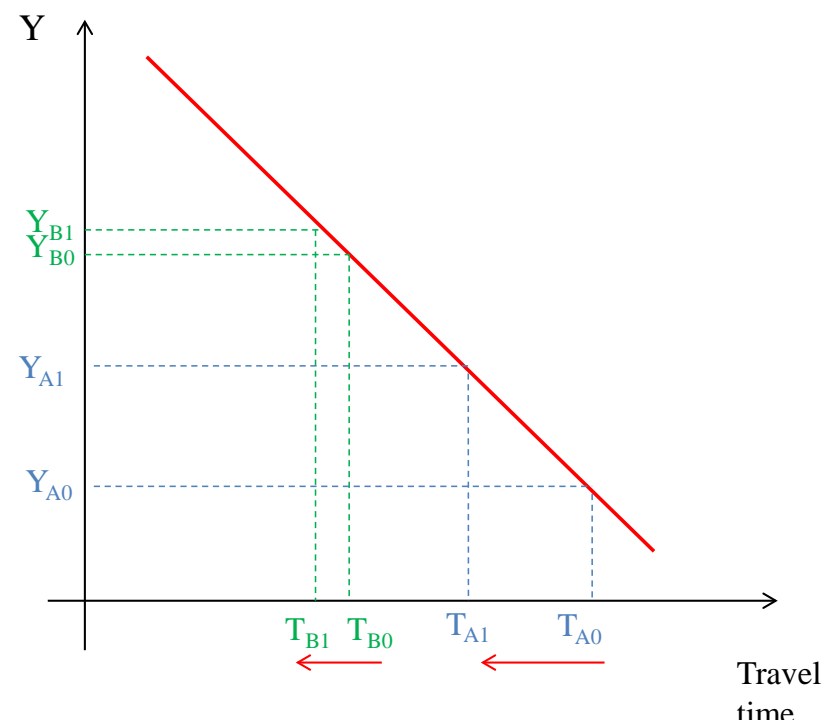


The continuous approach is conducted in several different stages:

1. First, we determine a set of relevant destinations in a given area. While agricultural markets are not the only potential targets, they represent an obvious candidate due to their economic relevance for rural households. These would also encompass the peri-urban areas that are relevant to rural households.

2. Once the relevant targets have been defined, we estimate each household's travel time. For this purpose, we will apply a GIS raster analysis ${ }^{16}$. This method calculates the shortest time from any household to relevant local or regional markets. It considers the availability of different road surfaces (e.g. paved road, dirt road, no road, etc.) and their respective impedance factors, which reflects traveling speeds on different quality roads and on variously sloped terrains through which the road passes. This procedure allows us to calculate travel times to different markets and determine for each household the market with the shortest travel time. Using distribution and characteristics of the road system in the baseline, this procedure provides us with an initial "optimal" travel time for each household.

3. Third, we measure the average speed across the NTH and re-estimate households' travel time after the implementation of the project. Using this updated data, we re-estimate the "optimal" travel time under these new conditions and estimate the travel times for each period altering the impedance factor of the segment of the NTH that has been improved as a function of the percentage of the segment that was completed in each period (which captures road enhancement and higher speeds of transit).

4. Fourth, we use the variation in travel time experienced by each household in a regression setting to determine its effect on households' income and other welfare indicators.

While the DID approach allows for simpler and more intuitive calculations of the impact of the project, the continuous approach exploits a more detailed source of variability in transportation time resulting from the NTH.

In the continuous treatment, rather than exploiting differences between segments, the aim is to capture the impact of reductions in travel time on income and other outcomes using the structure of the accessibility model. We estimate the following regression:

$$
Y_{i s t}=\boldsymbol{\rho} \cdot V_{i s t}+\gamma D_{t}+\alpha_{i s}+\varepsilon_{i s t}
$$

where $Y_{i s t}$ is the income of the $\mathrm{i}$-th household in segment $\mathrm{s}$ and time $\mathrm{t}, D_{t}$ are indicator variables for each survey year, $\alpha_{i s}$ are household-specific fixed effects (to account for time-invariant observables and unobservables), and $\varepsilon_{i s t} \sim D\left(0, \sigma^{2}\right) . V_{i s t}$ is travel time to a relevant market for each household estimated using raster analysis and administrative data on the progress of construction in each year of the survey. This approach considers overall reductions in travel time as the NTH rehabilitation progresses. However, it also considers that households will be differentially affected depending on their specific location (because segments are improved in different periods). In this light, the coefficient of interest is $\boldsymbol{\rho}$, which measures the impact of reducing transportation time to the nearest market by one minute due to the improvement in the NTH; the estimate exploits within-household variation in market access across time. The identifying assumption is that conditional on the household fixed effects the outcome is only affected by the improvement in the highway through the increase in market access (the reduction in the time to the nearest market and market choice).

\footnotetext{
${ }^{16}$ Refer to "Annex 1 -Calculating the Time and Cost of Travel: Accessibility Model" for a detailed discussion of the raster analysis.
} 
In addition, we explicitly calculate the instrumental variable estimate of equation (4). In these regressions, we instrument the time to the nearest market variable as a function of (a) the treatment assignment and post improvement indicator and (b) using the sub-segment construction progress variable. This makes explicit the reduced form nature of our previous DID design.

Explicitly, we model the structural relationship between the time to the nearest market and the road improvement by estimating the system of equations in (4a) and (4b) by two stage least squares:

$Y_{i s t}=\boldsymbol{\rho}^{\prime} \cdot V_{i s t}+\gamma D_{t}+\alpha_{i s}+\varepsilon_{i s t}$

$V_{i s t}=\boldsymbol{v} \cdot S_{k} \cdot$ Post $_{t}^{k}+\lambda \cdot$ Post $_{t}^{k}+\gamma D_{t}+\alpha_{i s}+\varepsilon_{i s t}$

where the exclude instrument is $S_{k} \cdot$ Post $_{t}^{k}$

$Y_{i s t}=\boldsymbol{\rho}^{\prime \prime} \cdot V_{i s t}+\gamma D_{t}+\alpha_{i s}+\varepsilon_{i s t}$

$V_{i s t}=\boldsymbol{\sigma} \cdot$ Progress $_{s t}+\gamma D_{t}+\alpha_{i s}+\varepsilon_{i s t}$

where the excluded instrument is Progress $_{s t}$

This structural approach, in principle, can be used to estimate the effect of future road improvement in a similar context. Taking the model of estimates, we can predict how a future road project that reduces travel time (albeit to a similar destination) by $\mathrm{x}$ will increase income given a menu of markets in the Norther Zone. More generally, the estimation on the relationship between time to nearest market and income allows us to contribute external validity to the impacts that could be used as lessons for other rural projects. 


\section{Comparison across educed Form and Structural Methodologies}

We note that with this continuous treatment methodology, we can also derive estimates that can be compared with those calculated through the DID approach. Consider the same treatment assignment in Table 19. We can estimate the following regression:

$$
Y_{i s t}=\boldsymbol{\rho}_{\boldsymbol{k}} V_{i s t}+\gamma D_{t}+\alpha_{i s}+\varepsilon_{i s t} \quad \text { if } i \in W_{k}, k=1, \ldots, 5
$$

These regressions allow us to estimate a set of coefficients $\rho_{k}$ for each comparison group $k$. Then we can use the average travel time for each segment in different periods to estimate the average treatment effect in each group across the NTH. For example, consider comparison group $k=1$, where we compare outcomes in segments 2 and 1 . The difference in outcome $Y$ attributable to the NTH is: $-\rho_{1}\left(\bar{V}_{s=2, \text { Post }_{t}=1}-\bar{V}_{s=1, \text { Post }_{t}=0}\right)$.

These calculations are not strictly equivalent because, as mentioned, both methods exploit different sources of variability. However, they provide alternative impact estimates that speak to the robustness of the results and a useful comparison of the results under both methodologies.

As noted before, the variation exploited in the DID approach and the continuous treatment approach is coming from the same source: variation in market access due to the NTH improvement. The impact estimates from the IV estimation will be similar to the reduced form DID across groups from the structural interpretation of the continuous market access design.

\section{SAMPLING AND DATA COLLECTION}

The data collection activities were performed in the period from November to February each starting in 2009. The baseline survey included 4,800 respondents, which re-interviewed in the follow-up survey. The analysis sample consists of a panel of households that were successfully interviewed in 2009 (baseline) and in at least one of the follow-up surveys from 2010 to 2013/14. The sample spans the departments of Cabañas, Chalatenango, La Unión, Morazán, San Miguel and Santa Ana. As Table 20 shows, there was high attrition in the first follow-up survey (2010), with few of the households lost in the follow-up being regained in 2011/12. In the 2012/13 round, we implemented a farther-reaching tracking of the baseline households and could recover more households, bringing the effective sample size in the 2012/13 survey to 4,3115 households and finalizing in 2013/14 with 4,220 household for a total attrition of 12 percent in the panel in 5 years. Figure 8 shows the geographic distribution of households in the sample across the Northern Zone and the different segment to which they were assigned given their proximity to the NTH.

\section{TABLE 20 EFFECTIVE HOUSEHOLD SAMPLE BY YEAR}

\begin{tabular}{llll}
\hline Survey & Effective Sample & Total Attrition & Rolling Attrition \\
& & & \\
\hline $\mathbf{2 0 0 9 / 1 0}$ & 4,667 & $3 \%$ & - \\
$\mathbf{2 0 1 0 / 1 1}$ & 4,128 & $14 \%$ & $11.55 \%$ \\
$\mathbf{2 0 1 1 / 1 2}$ & 4,080 & $15 \%$ & $1.16 \%$ \\
$\mathbf{2 0 1 2 / 1 3}$ & 4,311 & $10 \%$ & $-5.66 \%$ \\
$\mathbf{2 0 1 3 / 1 4}$ & 4,220 & $12 \%$ & $2.11 \%$ \\
\hline
\end{tabular}




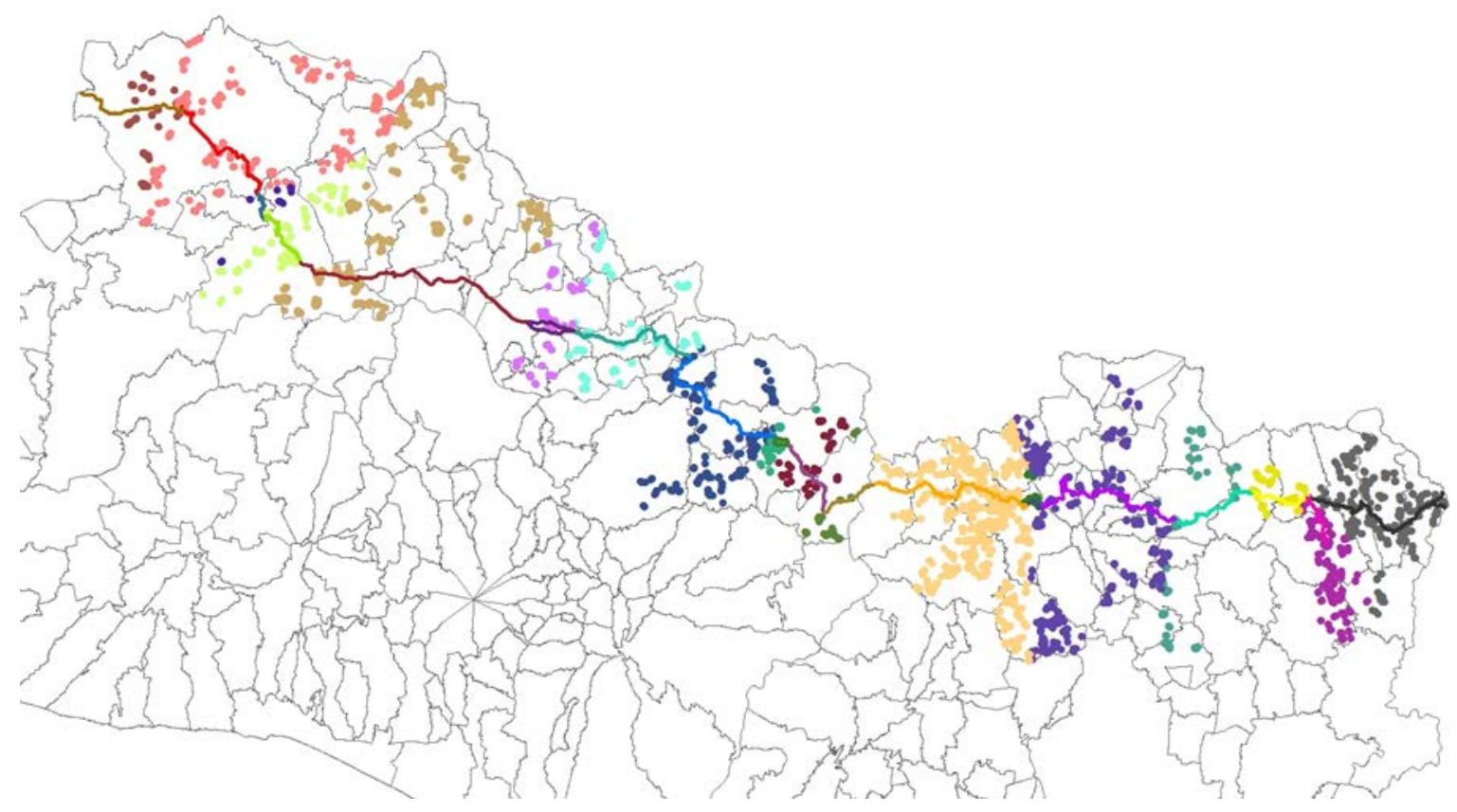

\section{BASELINE BALANCE AND VALIDATION OF ASSUMPTIONS}

Both impact evaluation designs rely on the expectation the rehabilitation of the NTH will reduce transportation costs and enable households to extend their labor activities and diversify their income sources. The first step is then to empirically verify that the DID groups are balanced in the baseline characteristics before the road improvement and for the continuous time to market design, verify the reduction in time to markets or the first stage that provides the identifying variation in both design. This amounts to verifying that the evolution of the NTH improvement facilitates access to markets in the Northern Zone.

Table 21 shows the test of difference between the treatment segment and the comparison segment in each group of the DID for our main outcomes. The test consists of a regression of the outcomes on a treatment indicator and adjusted for survey year using the pre-improvement period observations. Ideally, all the differences in column 1 through 5 would not be significant. This would imply that households in treatment segments are observationally equivalent in the period before the improvement; lending some evidence for the parallel trends assumption on which any DID estimate rests. In our case, the table highlights some successes and some shortcoming in the DID design. First, the time to the nearest market variable is well balanced for groups 1 through 3 is balance in the period before the improvement; however, we find significant differences in groups 4 and 5 . The implication here is that the households in the treatment segment in these groups (segment 5 and segment 6, respectively) have more to gain from the road improvement as they are on average farther from markets in the baseline. These differences might be due to natural barriers and lack bridges in these areas. The difference in column 6 , does not related directly to the parallel trends assumption but helps us interpret the DID results across the NTH. On average, households in the segments that were improved were farther from markets, as expected; the quality of the NTH segments before the improvement hindered the access to markets for these households.

On other outcomes, such as, labor income and business/independent income from agricultural and nonagricultural activities, and total income; groups 2 and 3 are balanced in most of the indicators. The significant 
differences observed in the table highlight the importance of having a longitudinal data for the DID design. Time invariant heterogeneity across households will be controlled for with the households fixed effects.

TABLE 21 BASELINE OR PRE-IMPROVEMENT PERIOD BALANCE

\begin{tabular}{|c|c|c|c|c|c|c|}
\hline & $\begin{array}{c}\text { (1) } \\
\text { Group } 1\end{array}$ & $\begin{array}{c}(2) \\
\text { Group } 2\end{array}$ & $\begin{array}{c}\text { (3) } \\
\text { Group } 3\end{array}$ & $\begin{array}{c}(4) \\
\text { Group } 4\end{array}$ & $\begin{array}{l}\text { (5) } \\
\text { Group } 5\end{array}$ & $\begin{array}{c}\text { (6) } \\
\text { Full Sample }\end{array}$ \\
\hline $\begin{array}{l}\text { Time to nearest market } \\
\text { (Minutes) }\end{array}$ & $\begin{array}{l}-3.2 \\
{[5.08]}\end{array}$ & $\begin{array}{l}7.77 \\
{[4.92]}\end{array}$ & $\begin{array}{l}2.26 \\
{[3.51]}\end{array}$ & $\begin{array}{l}90.7 \\
{[3.24]^{* * *}}\end{array}$ & $\begin{array}{l}23.7 \\
{[6.71]^{* * *}}\end{array}$ & $\begin{array}{l}16.3 \\
{[3.85]^{* * *}}\end{array}$ \\
\hline $\begin{array}{l}\text { Annual income from Business, } \\
\text { transfers, and labor }\end{array}$ & $\begin{array}{l}563.2 \\
{[263.8]^{* *}}\end{array}$ & $\begin{array}{l}499 \\
{[289.0]^{*}}\end{array}$ & $\begin{array}{l}19.5 \\
{[347.3]}\end{array}$ & $\begin{array}{l}-818.3 \\
{[213.4]^{* * *}}\end{array}$ & $\begin{array}{l}291.3 \\
{[229.2]}\end{array}$ & $\begin{array}{l}208.8 \\
{[151.8]}\end{array}$ \\
\hline $\begin{array}{l}\text { Annual income derived from } \\
\text { labor in agriculture }\end{array}$ & $\begin{array}{l}-136.2 \\
{[55.8]^{* *}}\end{array}$ & $\begin{array}{l}-68.2 \\
{[42.7]}\end{array}$ & $\begin{array}{l}-26.8 \\
{[29.9]}\end{array}$ & $\begin{array}{l}102.4 \\
{[31.8]^{* * *}}\end{array}$ & $\begin{array}{l}36.7 \\
{[29.7]}\end{array}$ & $\begin{array}{l}-81.4 \\
{[30.6]^{* * *}}\end{array}$ \\
\hline $\begin{array}{l}\text { Annual income derived from } \\
\text { labor in non-agriculture }\end{array}$ & $\begin{array}{l}33.5 \\
{[128.1]}\end{array}$ & $\begin{array}{l}-239.8 \\
{[168.1]}\end{array}$ & $\begin{array}{l}356.2 \\
{[254.3]}\end{array}$ & $\begin{array}{l}-475 \\
{[134.5]^{* * *}}\end{array}$ & $\begin{array}{l}441.6 \\
{[145.5]^{* * *}}\end{array}$ & $\begin{array}{l}199.4 \\
{[74.8]^{* * *}}\end{array}$ \\
\hline $\begin{array}{l}\text { Annual income derived from } \\
\text { business in agriculture }\end{array}$ & $\begin{array}{l}13.7 \\
{[145.9]}\end{array}$ & $\begin{array}{l}154.8 \\
{[125.5]}\end{array}$ & $\begin{array}{l}-9.91 \\
{[69.1]}\end{array}$ & $\begin{array}{l}10.8 \\
{[58.9]}\end{array}$ & $\begin{array}{l}14.5 \\
{[35.2]}\end{array}$ & $\begin{array}{l}-34.8 \\
{[63.2]}\end{array}$ \\
\hline $\begin{array}{l}\text { Annual income derived from } \\
\text { business in non- agriculture }\end{array}$ & $\begin{array}{l}447.6 \\
{[219.3]^{* *}}\end{array}$ & $\begin{array}{l}295 \\
{[224.5]}\end{array}$ & $\begin{array}{l}-222.5 \\
{[238.6]}\end{array}$ & $\begin{array}{l}-525.5 \\
{[192.6]^{* * *}}\end{array}$ & $\begin{array}{l}220.1 \\
{[179.1]}\end{array}$ & $\begin{array}{l}306.4 \\
{[110.9]^{* * *}}\end{array}$ \\
\hline
\end{tabular}

Standard errors in brackets

Std. errors are clustered at the census segment level.

$* \mathrm{p}<0.10, * * \mathrm{p}<0.05, * * * \mathrm{p}<0.01$

\section{ACCESS to MARKetS IN THE Northern Zone}

The next step is to verify the change in markets access during the study period for the continuous treatment approach. This step gauges the success of the project by examining the improvement in the direct outcome of the NTH improvement: reductions in access time to markets in the Northern Zone. We examine the changes in access to different markets in the area of influence of the NTH: Metapan, Chalatenango, Sesuntepeque, Ana Moros and San Salvador. While the effects of measures such as time to nearest market or access to a specific market are evident, it is necessary to empirically verify these changes, given that the IE design relies on these. Essentially, these first regressions illustrate the intensity of treatment across different groups and across the complete road.

Table 22 through Table 24 show the results for impact on the traveling times for markets around the NTH and San Salvador ${ }^{17}$. As expected, we see reductions in travel time for all markets and the magnitude depends on the proximity of the group to each market. For example, the travel time to the market in Chalatenango was reduced by 32 to 52 minutes thanks to the improvement of the NTH for the full sample. Groups 1 and 2 include the households that are the nearest to Chalatenango. Thus, have lower reductions in travel times, between 7.08 and 14.8 minutes. Similar effects are present for the travel time to Metapan. The reduction in time to San Salvador is the most homogeneous across groups, since San Salvador is not connected by the NTH. Being the capital, it is the most important market and we included in the menu of markets available for households in

\footnotetext{
${ }^{17}$ For brevity, we show the discuss the results for the biggest markets and include the estimation for the other markets in "Annex 2Additional Results"

The "\#" in the tables denotes the interaction between the indicator variables. For example, A\#B is equal to one when both $\mathrm{A}$ and $\mathrm{B}$ are equal to one, if not it is zero.
} 
the Northern Zone. Households in the northern zone had a reduction between 7.81 minutes 12.2 minutes in travel times to San Salvador because of the improvement in the NTH.

TABLE 22 IMPACT TO TRAVEL TIMES TO MARKETS IN MINUTES: CHALATENANGO

Time to Chalatenango Market (minutes)

(1) (2) (3) (4) (5) (6)

Group 1 Group 2 Group 3 Group 4 Group 5 Sample

\begin{tabular}{lllllll}
\hline First Stage and Segment Difference in Difference & \multicolumn{1}{l}{} \\
\hline \hline Treatment\#Post Road Improvement & -14.2 & -13.2 & 27.3 & -43.1 & -77.6 & -32 \\
& {$[1.08]^{* * *}$} & {$[1.11]^{* * *}$} & {$[2.48]^{* * *}$} & {$[2.83]^{* * *}$} & {$[2.42]^{* * *}$} & {$[1.20]^{* * *}$} \\
Post Road Improvement & 1.62 & 0.88 & -32.6 & -36.5 & -2.7 & 23.1 \\
& {$[0.24]^{* * *}$} & {$[0.22]^{* * *}$} & {$[2.35]^{* * *}$} & {$[2.28]^{* * *}$} & {$[0.32]^{* * *}$} & {$[1.23]^{* * *}$} \\
Construction Administrative Data & & & & & \\
Improved Sub-Segment & -10.1 & -7.08 & -7.16 & -40 & -77.6 & -42.2 \\
& {$[0.75]^{* * *}$} & {$[0.59]^{* * *}$} & {$[3.02]^{* *}$} & {$[3.31]^{* * *}$} & {$[2.42]^{* * *}$} & {$[1.93]^{* * *}$} \\
Post Road Improvement & -4.64 & -4.21 & -15.2 & -33.2 & -2.7 & \\
& {$[0.65]^{* * *}$} & {$[0.54]^{* * *}$} & {$[2.94]^{* * *}$} & {$[3.00]^{* * *}$} & {$[0.32]^{* * *}$} & \\
\% of Sub-segment Improved & -14.8 & -9.37 & -24.1 & -57.4 & -81.5 & -52.4 \\
& {$[1.13]^{* * *}$} & {$[0.89]^{* * *}$} & {$[2.43]^{* * *}$} & {$[3.74]^{* * *}$} & {$[2.62]^{* * *}$} & {$[2.02]^{* * *}$} \\
Post Road Improvement & 0.12 & -1.87 & 0.4 & -9.47 & -0.23 & \\
& {$[0.057]^{* *}$} & {$[0.31]^{* * *}$} & {$[0.87]$} & {$[2.86]^{* * *}$} & {$[0.18]$} \\
\hline Mean of Comp. at Pre-Period & 74.8 & 41.9 & 105.6 & 105.6 & 278 & 164.8 \\
SD of Comp. at Pre-Period & 39.7 & 27.9 & 19.7 & 19.7 & 30.6 & 88.1 \\
Number of Clusters & 113 & 142 & 96 & 138 & 135 & 410 \\
Number of Households & 1,219 & 1,496 & 1,006 & 1,652 & 1,415 \\
Observations & 5,549 & 6,795 & 4,560 & 7,639 & 6,490 \\
\hline \hline
\end{tabular}

Standard errors in brackets

Std. errors are clustered at the census segment level.

All equations include household and year fixed effects. Columns(1)-(5) shows the impact for each treatment Assignment group along the NTH. Column (6) shows impact across the whole NTH.

* $\mathrm{p}<0.10, * * \mathrm{p}<0.05, * * * \mathrm{p}<0.01$ 
TABLE 23 IMPACT TO TRAVEL TIMES TO MARKETS IN MINUTES: METAPAN

Time to Metapan Market (minutes)

(1)

(2)

(3)

(4)

(5)

(6)

Group 1

Group 2 Group 3 Group 4 Group 5 Full Sample

\begin{tabular}{|c|c|c|c|c|c|c|}
\hline \multicolumn{7}{|c|}{ First Stage and Segment Difference in Difference } \\
\hline Treatment\#Post Road Improvement & -8.29 & -1.17 & 23.2 & -35.9 & -84.7 & -38.3 \\
\hline & {$[1.02]^{* * *}$} & {$[1.37]$} & {$[3.09]^{* * *}$} & {$[3.73]^{* * *}$} & {$[2.42]^{* * *}$} & {$[1.33]^{* * *}$} \\
\hline \multirow[t]{2}{*}{ Post Road Improvement } & 0.45 & -2.85 & -55.7 & -59.5 & -2.95 & 28.5 \\
\hline & {$[0.11]^{* * *}$} & {$[0.51]^{* * *}$} & {$[3.05]^{* * *}$} & {$[2.96]^{* * *}$} & {$[0.34]^{* * *}$} & {$[1.39]^{* * *}$} \\
\hline \multicolumn{7}{|l|}{ Construction Administrative Data } \\
\hline Improved Sub-Segment & {$[0.76]^{* * *}$} & {$[0.98]^{* * *}$} & {$[4.07]^{* * *}$} & {$[5.03] * * *$} & {$[2.42]^{* * *}$} & {$[2.29]^{* * *}$} \\
\hline \multirow[t]{2}{*}{ Post Road Improvement } & -3.11 & -1.61 & -32.3 & -51.7 & -2.95 & \\
\hline & {$[0.36]^{* * *}$} & {$[0.31]^{* * *}$} & {$[4.52]^{* * *}$} & {$[4.62] * * *$} & {$[0.34]^{* * *}$} & \\
\hline \multirow[t]{2}{*}{$\%$ of Sub-segment Improved } & -9 & -20.1 & -50.7 & -79 & -89 & -64.7 \\
\hline & {$[1.03]^{* * *}$} & {$[1.06]^{* * *}$} & {$[2.34]^{* * *}$} & {$[3.19]^{* * *}$} & {$[2.63]^{* * *}$} & {$[2.03]^{* * *}$} \\
\hline Post Road Improvement & -0.27 & 3.81 & 0.3 & -7.49 & -0.24 & \\
\hline Mean of Comp. at Pre-Period & 94.5 & 124.3 & 220.9 & 220.9 & 375.9 & 239.5 \\
\hline SD of Comp. at Pre-Period & 43.1 & 28.8 & 19.1 & 19.1 & 29.7 & 121.2 \\
\hline Number of Clusters & 113 & 142 & 96 & 138 & 135 & 410 \\
\hline Number of Households & 1,219 & 1,496 & 1,006 & 1,652 & 1,415 & 4,667 \\
\hline Observations & 5,549 & 6,795 & 4,560 & 7,639 & 6,490 & 21,406 \\
\hline
\end{tabular}

Standard errors in brackets

Std. errors are clustered at the census segment level.

All equations include household and year fixed effects. Columns(1)-(5) shows the impact for each treatment Assignment group along the NTH. Column (6) shows impact across the whole NTH.

$* \mathrm{p}<0.10, * * \mathrm{p}<0.05, * * * \mathrm{p}<0.01$ 
TABLE 24 IMPACT TO TRAVEL TIMES TO MARKETS IN MINUTES: SAN SALVADOR

Time to San Salvador Market (minutes)

(1)

(2)

(3)

(4)

(5)

(6)

Full

Group 1 Group 2 Group 3 Group $4 \quad$ Group 5 Sample

\begin{tabular}{|c|c|c|c|c|c|c|}
\hline \multicolumn{7}{|c|}{ First Stage and Segment Difference in Difference } \\
\hline \multirow[t]{2}{*}{ Treatment\#Post Road Improvement } & -5.82 & -3.95 & -6.53 & -19.4 & -14 & -7.81 \\
\hline & {$[0.76]^{* * *}$} & {$[0.82]^{* * *}$} & {$[0.87]^{* * *}$} & {$[1.69]^{* * *}$} & {$[1.48]^{* * *}$} & {$[0.50]^{* * *}$} \\
\hline \multirow[t]{2}{*}{ Post Road Improvement } & 0.66 & -0.31 & -1.64 & -2.75 & -0.43 & 5.4 \\
\hline & {$[0.13]^{* * *}$} & {$[0.17]^{*}$} & {$[0.33]^{* * *}$} & {$[0.35]^{* * *}$} & {$[0.093]^{* * *}$} & {$[0.43]^{* * *}$} \\
\hline \multicolumn{7}{|l|}{ Construction Administrative Data } \\
\hline \multirow[t]{2}{*}{ Improved Sub-Segment } & -4.15 & -4.62 & -1.06 & -12.8 & -14 & -10.2 \\
\hline & {$[0.53]^{* * *}$} & {$[0.37]^{* * *}$} & {$[0.53]^{* *}$} & {$[1.26]^{* * *}$} & {$[1.48]^{* * *}$} & {$[0.71]^{* * *}$} \\
\hline \multirow[t]{2}{*}{ Post Road Improvement } & -1.9 & -1.47 & -3.22 & -5.24 & -0.43 & \\
\hline & {$[0.32]^{* * *}$} & {$[0.30]^{* * *}$} & {$[0.85]^{* * *}$} & {$[0.54]^{* * *}$} & {$[0.093]^{* * *}$} & \\
\hline \multirow[t]{2}{*}{$\%$ of Sub-segment Improved } & -6.09 & -7.05 & -3.4 & -11.7 & -14.4 & -12.2 \\
\hline & {$[0.79]^{* * *}$} & {$[0.57]^{* * *}$} & {$[0.48]^{* * *}$} & {$[1.68]^{* * *}$} & {$[1.56]^{* * *}$} & {$[0.79]^{* * *}$} \\
\hline \multirow[t]{2}{*}{ Post Road Improvement } & 0.054 & 0.4 & -1.06 & -3.96 & -0.21 & \\
\hline & [0.033] & {$[0.20]^{* *}$} & {$[0.51]^{* *}$} & {$[1.20]^{* * *}$} & {$[0.11]^{* *}$} & \\
\hline Mean of Comp. at Pre-Period & 113.3 & 110.6 & 108.6 & 108.6 & 243.3 & 165.3 \\
\hline SD of Comp. at Pre-Period & 30.8 & 21.8 & 17.7 & 17.7 & 29.7 & 55.5 \\
\hline Number of Clusters & 113 & 142 & 96 & 138 & 135 & 410 \\
\hline Number of Households & 1,219 & 1,496 & 1,006 & 1,652 & 1,415 & 4,667 \\
\hline Observations & 5,549 & 6,795 & 4,560 & 7,639 & 6,490 & 21,406 \\
\hline
\end{tabular}

Standard errors in brackets

Std. errors are clustered at the census segment level.

All equations include household and year fixed effects. Columns(1)-(5) shows the impact for each treatment Assignment group along the NTH. Column (6) shows impact across the whole NTH.

$* p<0.10, * * p<0.05, * * * p<0.01$

Increases in accessibility do not only decrease the time that it takes to access a given market. They also provide the possibility of changing markets given the time it takes to reach it. Next, we combine the effects across market choice and travel time and calculate impact of the road improvement on the time to the nearest market, allowing households to switch markets due to the improvements in segments of the highway each year. This is our continuous treatment variable in the markets access design and these results also serve as the first stage of the instrumental variable estimations of equations $4 \mathrm{a}$ and $4 \mathrm{~b}$.

Table 25 shows that across the sample the highway construction improved travel times to markets between 4 and 42 minutes; with treatment segments in groups 4 and 5 experiencing the largest decreases in travel time to markets. These two groups had larger average traveling times at baseline, as discussed before. On average, across the population in the Northern Zone, the traveling time to the nearest market decreased between sixteen and eighteen minutes on average. Note that the post improvement indicator in each group is negative, indicating that all households experience increases in market access as we discussed in the methodology section. We note that the estimate for group 3 is not significant when using the DID specification with the dichotomous variables but it significant with the progress DID variable (in addition, note that this group experience an improvement just not a significant one between treatment segment and comparison segment). Group 3 compares segments three and four, for which there is significant overlap in the construction dates- 
the start dates only differ by one month and the end dates by three months. When using the percentage of the segment constructed (which captures differential delays in the construction phase), the results are consistent with the effects that we find in other groups. The significant impacts on travel in the table indicate that we the treatment assignment and progress variables are strong instruments for the reduction in travel times to the nearest markets.

TABLE 25 IMPACT OF TIME IN MINUTES TO NEAREST MARKET

(2)

(3)

(4)

(5)

(6)

Group 1

Group 2

Group 3

Group 4

Group 5

Full

First Stage and Segment Difference in Difference

\begin{tabular}{|c|c|c|c|c|c|c|}
\hline \multirow[t]{2}{*}{ Treatment\#Post Road Improvement } & -4.79 & -3.83 & -0.33 & -36.1 & -17.8 & -11.5 \\
\hline & {$[0.60]^{* * *}$} & {$[0.66]^{* * *}$} & {$[1.34]$} & {$[1.66]^{* * *}$} & {$[2.06]^{* * *}$} & {$[0.72]^{* * *}$} \\
\hline \multirow[t]{2}{*}{ Post Road Improvement } & 0.24 & -0.24 & -4.01 & -6.16 & -0.17 & 8.33 \\
\hline & {$[0.057]^{* * *}$} & {$[0.14]^{*}$} & {$[0.90]^{* * *}$} & {$[0.91]^{* * *}$} & {$[0.072]^{* *}$} & {$[0.64]^{* * *}$} \\
\hline \multicolumn{7}{|l|}{ Construction Administrative Data } \\
\hline \multirow{2}{*}{ Improved Sub-Segment } & -3.76 & -3.06 & 0.83 & -23.8 & -17.8 & -15.9 \\
\hline & {$[0.46]^{* * *}$} & {$[0.36]^{* * *}$} & {$[0.82]$} & {$[1.66]^{* * *}$} & {$[2.06]^{* * *}$} & {$[1.07]^{* * *}$} \\
\hline \multirow[t]{2}{*}{ Post Road Improvement } & -1.81 & -1.57 & -4.91 & -10.7 & -0.17 & \\
\hline & {$[0.22]^{* * *}$} & {$[0.21]^{* * *}$} & {$[1.21]^{* * *}$} & {$[1.12]^{* * *}$} & {$[0.072]^{* *}$} & \\
\hline \multirow[t]{2}{*}{$\%$ of Sub-segment Improved } & -5.25 & -4.65 & -3.42 & -22.4 & -17.6 & -18.4 \\
\hline & {$[0.61]^{* * *}$} & {$[0.62]^{* * *}$} & {$[0.80]^{* * *}$} & {$[2.95]^{* * *}$} & {$[2.12]^{* * *}$} & {$[1.18]^{* * *}$} \\
\hline \multirow[t]{2}{*}{ Post Road Improvement } & -0.16 & -0.34 & -0.97 & -7.76 & -0.34 & \\
\hline & {$[0.058]^{* * *}$} & {$[0.23]$} & {$[0.49]^{*}$} & {$[2.33]^{* * *}$} & {$[0.16]^{* *}$} & \\
\hline Mean of Comp. at Pre-Period & 52.9 & 41.9 & 21 & 21 & 54.7 & 64.5 \\
\hline SD of Comp. at Pre-Period & 26.1 & 27.9 & 17 & 17 & 33.7 & 44.3 \\
\hline Number of Clusters & 113 & 142 & 96 & 138 & 135 & 410 \\
\hline Number of Households & 1,219 & 1,496 & 1,006 & 1,652 & 1,415 & 4,667 \\
\hline Observations & 5,549 & 6,795 & 4,560 & 7,639 & 6,490 & 21,406 \\
\hline
\end{tabular}

Standard errors in brackets

Std. errors are clustered at the census segment level.

All equations include household and year fixed effects. Columns(1)-(5) shows the impact for each treatment Assignment group along the NTH. Column (6) shows impact across the whole NTH.

$* p<0.10, * * p<0.05, * * * p<0.01$ 


\section{RESULTS}

The results from both methodologies are presented in the Table 26 using the same notation as in the methodology section. Panel A, shows the estimates from the DID pipeline design format and the DID with construction progress. The bottom part panel $A$ uses the administrative data on the construction progress of sub-segments using an indicator for the construction of the sub segment being finalized and the percentage of the sub segment that was finalized. Panel B shows the estimations using the continuous time to market methodology, where all households experience improvements in travel times due to the improvement in the roads in the accessibility model. Panel B shows the results from the continuous market to access methodology, first the direct estimates for the time to nearest market and at the bottom the estimates from the two-stage least squares that use (a) the treatment assignment and timing, and (b) the construction progress variable as instruments for the time to the nearest market.

All equations include household and year fixed effects. Columns (1)-(5) shows the impact for each treatment Assignment group along the NTH. These five estimates are the main results for the segment DID design $\left(\theta_{k}{ }^{\prime} \mathrm{s}\right)$. Column (6) shows impact across the whole NTH, in the case of the DID design, it represents a weighted average of the impact estimates of each of the groups; the weights $\left(w_{k}\right)$ depend on the size and precision of the estimate in each group.

In panel $B$, the estimates in each column give us a way to compare the estimates from the continuous treatment design with the DID design. The full sample uses all observations to compute the estimates. This is the main result for the continuous time to market design $(\boldsymbol{\rho})$.

The result tables show the mean and std. deviation of the outcome variable for the comparison in each group before the road improvement; and the baseline mean in the full sample column. The rows labeled time to market reduction show average difference before and after the improvement for the treatment group in each group; and the difference for households in improved segments between the end line and the baseline for the full sample column. Rows labeled "K-P rk Wald F" are the F statistic for weak identification test (Cragg-Donald or Kleibergen-Paap) of the excluded instruments (the interactions of the treatment Assignment and post indicators in (a), and the percentage of the segment improved in (b)). We include the number of clusters, households, and time-household observations in each regression at the end of each table. 


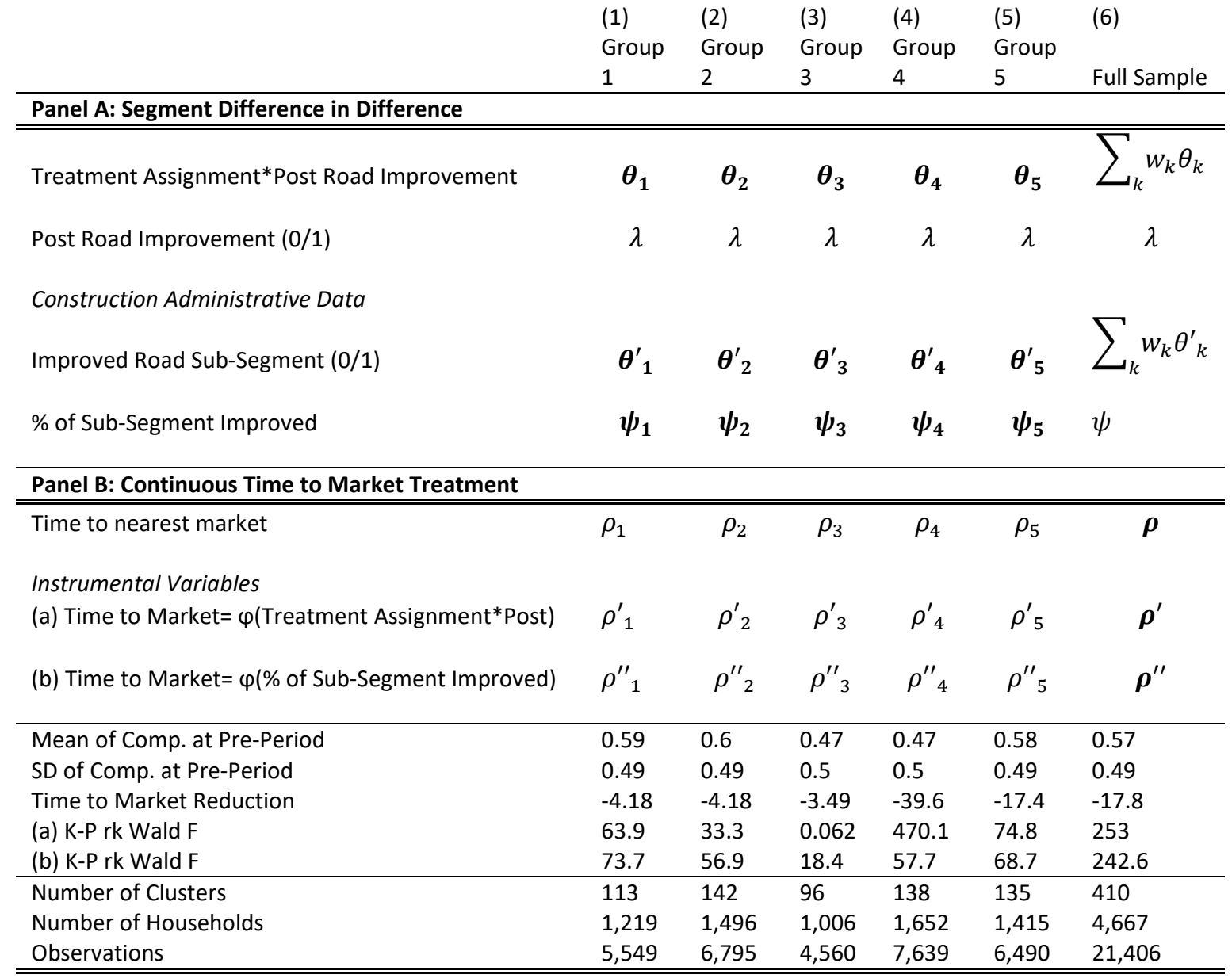

Standard errors in brackets

Std. errors are clustered at the census segment level.

$* \mathrm{p}<0.10, * * \mathrm{p}<0.05, * * * \mathrm{p}<0.01$

\section{Agriculture LAND: USE, TitLing AND VALUe}

The construction of the NTH and roads improvement in general can increase land values. Given the low frequency of land sales in the northern zone we observed; estimating the effect of the NTH improvement using transaction data is to feasible. We estimate the changes in the land values by exploring proxies of the channels through which an increase in market access, due to road improvements, can affect land values. We consider changes in the amount of land used as an agricultural input, be it new land or changes in land use due to the expansion of sub- and peri-urban areas (with further increases in land demand) and the price of land as reported by survey respondents.

Table 27 shows the impact estimates for the total area in hectares to which the household has access for agriculture. The estimates suggest a decrease in the land use for agriculture for group 1 and 2 and a positive impact on group 3 from the DID estimates in panel A. The DID estimates that use the sub-segment construction progress data present a similar story and on the full sample we find that households in the improved segments of the roads decrease their use of land after the road improvement relative with the households living in adjacent segment where the segment was improved. 
The continuous market access approach in panel $B$, the main results in column 7 suggest a significant impact estimate, with the relationship between agricultural land use and market access estimated at 0.013 hectares per minute. The average time reduction in the sample between baseline and end line being 19.7 minutes, implies a 0.26 hectare average impact of the NTH improvement on land use in the Northern Zone. From the IV estimates the impacts are larger, 0.43 hectare decrease on average. Comparing these effects with the full sample effect of the DID we see they are similar, a reduction 0.23 and 0.44 hectares on average ${ }^{18}$. The impact estimates are consistent with an increase in the value of land through a movement along the demand curve caused by a decrease in the supply of agricultural land; or a decrease in the value of land due to decrease in the demand for land.

To explore more the effects of the NTH construction on land titling and land values. Table 28 shows the impact of land titling using an indicator for the probability of having a plot with a formal title. We estimate the impact on an indicator for having a land title as a proxy for investments in owned land that would facilitate transactions in the formal land market and/or increase the value of land and access to formal credit markets. We find significant effect on group 1 and 2, with household in the improved segment of the road being more likely to report having a title for agriculture plot, 18 percentage point in group 1 and 22 percentage points in group 2. In group 3, we find opposite effects; a decrease of 23 percentage points between the households that live near the treatment segment in the period after the improvement, relative to the adjacent comparison segment in the period before the improvement. The implied impacts from the continuous approach from the IV estimates are larger, and increase of 25 percentage points for group 1 and 32 percentage points for group 2.

Finally, we estimate the effects on a proxy for the value of land. We used the responses of landowner households to the question, "If you would have to sell this plot, for how much would you sell it?" Using this and the area of the plot we calculate a price per hectare for these households. The impacts on this outcome are presented in Table 29. We find no significant impacts on the price per hectare. We note that the sample are much smaller in this case because many households do not know the value of their land, in part because of the few transaction in the land markets of these rural areas.

${ }^{18}$ Note that this is expected since the estimates in Panel A are a reduced form version of the structural relationships in panel $B$. 
Total size of plots in hectares

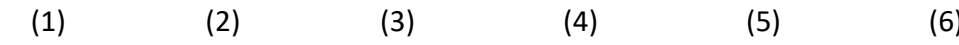

Group 1 Group 2 Group 3 Group $4 \quad$ Group 5 Full Sample

\begin{tabular}{|c|c|c|c|c|c|c|}
\hline \multicolumn{7}{|l|}{ Panel A: Segment Difference in Difference } \\
\hline Treatment Assignment\#Post Road Improvement & $\begin{array}{l}-0.56 \\
{[0.26]^{* *}}\end{array}$ & $\begin{array}{l}-0.59 \\
{[0.25]^{* *}}\end{array}$ & $\begin{array}{l}0.26 \\
{[0.12]^{* *}}\end{array}$ & $\begin{array}{l}-0.28 \\
{[0.16]^{*}}\end{array}$ & $\begin{array}{l}-0.17 \\
{[0.14]}\end{array}$ & $\begin{array}{l}-0.063 \\
{[0.11]}\end{array}$ \\
\hline Post Road Improvement (0/1) & $\begin{array}{l}-0.14 \\
{[0.083]^{*}}\end{array}$ & $\begin{array}{l}-0.075 \\
{[0.071]}\end{array}$ & $\begin{array}{l}-0.25 \\
{[0.12]^{* *}}\end{array}$ & $\begin{array}{l}-0.1 \\
{[0.14]}\end{array}$ & $\begin{array}{l}-0.15 \\
{[0.14]}\end{array}$ & $\begin{array}{l}-0.24 \\
{[0.088]^{* * *}}\end{array}$ \\
\hline \multicolumn{7}{|l|}{ Construction Administrative Data } \\
\hline Improved Road Sub-Segment (0/1) & $\begin{array}{l}-0.2 \\
{[0.12]}\end{array}$ & $\begin{array}{l}-0.12 \\
{[0.084]}\end{array}$ & $\begin{array}{l}-0.011 \\
{[0.10]}\end{array}$ & $\begin{array}{l}-0.33 \\
{[0.12]^{* * *}}\end{array}$ & $\begin{array}{l}-0.17 \\
{[0.14]}\end{array}$ & $\begin{array}{l}-0.23 \\
{[0.070]^{* * *}}\end{array}$ \\
\hline$\%$ of Sub-Segment Improved & $\begin{array}{l}-0.46 \\
{[0.21]^{* *}}\end{array}$ & $\begin{array}{l}-0.25 \\
{[0.13]^{*}}\end{array}$ & $\begin{array}{l}-0.26 \\
{[0.14]^{*}}\end{array}$ & $\begin{array}{l}-0.62 \\
{[0.17]^{* * *}}\end{array}$ & $\begin{array}{l}-0.18 \\
{[0.15]}\end{array}$ & $\begin{array}{l}-0.44 \\
{[0.10]^{* * *}}\end{array}$ \\
\hline \multicolumn{7}{|l|}{ Panel B: Continuous Time to Market Treatment } \\
\hline Time to nearest market & $\begin{array}{l}0.035 \\
{[0.037]}\end{array}$ & $\begin{array}{l}0.019 \\
{[0.019]}\end{array}$ & $\begin{array}{l}0.031 \\
{[0.019]}\end{array}$ & $\begin{array}{l}0.0092 \\
{[0.0039]^{* *}}\end{array}$ & $\begin{array}{l}0.016 \\
{[0.0061]^{* *}}\end{array}$ & $\begin{array}{l}0.013 \\
{[0.0031]^{* * *}}\end{array}$ \\
\hline \multicolumn{7}{|l|}{ Instrumental Variables } \\
\hline (a) Time to Market $=\varphi($ Treatment Assignment\#Post $)$ & $\begin{array}{l}0.12 \\
{[0.058]^{* *}}\end{array}$ & $\begin{array}{l}0.16 \\
{[0.073]^{* *}}\end{array}$ & $\begin{array}{l}1.1 \\
{[6.86]}\end{array}$ & $\begin{array}{l}0.0082 \\
{[0.0045]^{*}}\end{array}$ & $\begin{array}{l}0.0087 \\
{[0.0072]}\end{array}$ & $\begin{array}{l}0.005 \\
{[0.0089]}\end{array}$ \\
\hline (b) Time to Market $=\varphi(\%$ of Sub-Segment Improved) & $\begin{array}{l}0.088 \\
{[0.042]^{* *}}\end{array}$ & $\begin{array}{l}0.056 \\
{[0.030]^{*}}\end{array}$ & $\begin{array}{l}0.064 \\
{[0.034]^{*}}\end{array}$ & $\begin{array}{l}0.024 \\
{[0.0069]^{* * *}}\end{array}$ & $\begin{array}{l}0.0096 \\
{[0.0078]}\end{array}$ & $\begin{array}{l}0.022 \\
{[0.0051]^{* * *}}\end{array}$ \\
\hline Mean of Comp. at Pre-Period & 0.77 & 0.84 & 0.95 & 0.95 & 0.99 & 1.04 \\
\hline SD of Comp. at Pre-Period & 1.05 & 2.5 & 2.4 & 2.4 & 2.47 & 2.79 \\
\hline Time to Market Reduction & -4.21 & -4.21 & -4.05 & -39.2 & -16.3 & -19.7 \\
\hline (a) K-P rk Wald F & 57.3 & 31.1 & 0.025 & 334.5 & 58 & 215.3 \\
\hline (b) K-P rk Wald F & 63.2 & 52.4 & 18.6 & 76.7 & 51.5 & 202.5 \\
\hline Number of Clusters & 107 & 132 & 85 & 130 & 132 & 390 \\
\hline Number of Households & 707 & 887 & 582 & 1,068 & 889 & 2,905 \\
\hline Observations & 2,704 & 3,399 & 2,238 & 4,232 & 3,398 & 11,260 \\
\hline
\end{tabular}

Standard errors in brackets clustered at the segment level.

$* \mathrm{p}<0.10, * * \mathrm{p}<0.05, * * * \mathrm{p}<0.01$

Notes: All equations include household and year fixed effects. Columns (1)-(5) shows the impact for each treatment Assignment group along the NTH.

Column (6) shows impact across the whole NTH. Panel A shows the estimations using the difference in difference between segments methodology, where adjacent segments are compare before and after the treatment segment is improved. The bottom part panel $A$ uses the administrative data on the construction progress of sub-segments. Panel B shows the estimations using the continuous time to market methodology, where all households experience improvements in travel times due to the improvement in the roads in the accessibility model. The bottom of panel B shows the instrumental variable estimation where the time to market is instrumented with the timeline of construction. The table shows the mean and std. deviation of the outcome variable for the comparison in each group before the road improvement and the baseline mean in the full sample column. Time to market reduction shows the difference before and after the improvement for the treatment group in each column and the difference for households in improved segments between the end line and the baseline. K-P rk Wald F is the F statistic for weak identification test(Cragg-Donald or Kleibergen-Paap) of the excluded instruments 
TABLE 28 IMPACTS ON LAND TITLING: PROPABILITY OF OWNING A PLOT WITH A TITLE

Any Plot -Plot with title

$\begin{array}{lllll}\text { (1) } & \text { (2) } & \text { (3) } & \text { (4) } & \text { (5) }\end{array}$

Group 1 Group 2 Group $3 \quad$ Group $4 \quad$ Group $5 \quad$ Sample

\begin{tabular}{|c|c|c|c|c|c|c|}
\hline \multicolumn{7}{|l|}{ Panel A: Segment Difference in Difference } \\
\hline Treatment Assignment\#Post Road Improvement & $\begin{array}{l}0.18 \\
{[0.085]^{* *}}\end{array}$ & $\begin{array}{l}0.22 \\
{[0.075]^{* * *}}\end{array}$ & $\begin{array}{l}-0.23 \\
{[0.077]^{* * *}}\end{array}$ & $\begin{array}{l}-0.076 \\
{[0.062]}\end{array}$ & $\begin{array}{l}0.015 \\
{[0.068]}\end{array}$ & $\begin{array}{l}0.061 \\
{[0.051]}\end{array}$ \\
\hline Post Road Improvement (0/1) & $\begin{array}{l}-0.023 \\
{[0.087]}\end{array}$ & $\begin{array}{l}-0.087 \\
{[0.067]}\end{array}$ & $\begin{array}{l}0.044 \\
{[0.049]}\end{array}$ & $\begin{array}{l}0.01 \\
{[0.062]}\end{array}$ & $\begin{array}{l}-0.078 \\
{[0.063]}\end{array}$ & $\begin{array}{l}-0.11 \\
{[0.048]^{* *}}\end{array}$ \\
\hline \multicolumn{7}{|l|}{ Construction Administrative Data } \\
\hline Improved Road Sub-Segment (0/1) & $\begin{array}{l}0.014 \\
{[0.078]}\end{array}$ & $\begin{array}{l}-0.061 \\
{[0.064]}\end{array}$ & $\begin{array}{l}-0.13 \\
{[0.076]^{*}}\end{array}$ & $\begin{array}{l}-0.011 \\
{[0.057]}\end{array}$ & $\begin{array}{l}0.015 \\
{[0.068]}\end{array}$ & $\begin{array}{l}0.0084 \\
{[0.033]}\end{array}$ \\
\hline$\%$ of Sub-Segment Improved & $\begin{array}{l}0.14 \\
{[0.089]}\end{array}$ & $\begin{array}{l}0.04 \\
{[0.068]}\end{array}$ & $\begin{array}{l}-0.17 \\
{[0.11]}\end{array}$ & $\begin{array}{l}-0.062 \\
{[0.10]}\end{array}$ & $\begin{array}{l}-0.0048 \\
{[0.068]}\end{array}$ & $\begin{array}{l}0.025 \\
{[0.038]}\end{array}$ \\
\hline \multicolumn{7}{|l|}{ Panel B: Continuous Time to Market Treatment } \\
\hline Time to nearest market & $\begin{array}{l}-0.011 \\
{[0.010]}\end{array}$ & $\begin{array}{l}-0.01 \\
{[0.0078]}\end{array}$ & $\begin{array}{l}-0.0061 \\
{[0.0055]}\end{array}$ & $\begin{array}{l}0.0012 \\
{[0.0015]}\end{array}$ & $\begin{array}{l}-0.00087 \\
{[0.0022]}\end{array}$ & $\begin{array}{l}-0.00059 \\
{[0.00098]}\end{array}$ \\
\hline Instrumental Variables & & & & & & \\
\hline (a) Time to Market $=\varphi$ (Treatment Assignment\#Post) & $\begin{array}{l}-0.045 \\
{[0.022]^{* *}}\end{array}$ & $\begin{array}{l}-0.059 \\
{[0.022]^{* * *}}\end{array}$ & $\begin{array}{l}-0.076 \\
{[0.051]}\end{array}$ & $\begin{array}{l}0.0022 \\
{[0.0018]}\end{array}$ & $\begin{array}{l}-0.00072 \\
{[0.0032]}\end{array}$ & $\begin{array}{l}-0.0045 \\
{[0.0039]}\end{array}$ \\
\hline (b) Time to Market $=\varphi(\%$ of Sub-Segment Improved $)$ & $\begin{array}{l}-0.03 \\
{[0.020]}\end{array}$ & $\begin{array}{l}-0.011 \\
{[0.019]}\end{array}$ & $\begin{array}{l}0.035 \\
{[0.025]}\end{array}$ & $\begin{array}{l}0.0021 \\
{[0.0033]}\end{array}$ & $\begin{array}{l}0.00024 \\
{[0.0034]}\end{array}$ & $\begin{array}{l}-0.0012 \\
{[0.0018]}\end{array}$ \\
\hline Mean of Comp. at Pre-Period & 0.77 & 0.81 & 0.73 & 0.73 & 0.72 & 0.72 \\
\hline SD of Comp. at Pre-Period & 0.42 & 0.39 & 0.45 & 0.45 & 0.45 & 0.45 \\
\hline Time to Market Reduction & -5.57 & -5.57 & 1.79 & -41.3 & -18.7 & -21.9 \\
\hline (a) K-P rk Wald F & 29.4 & 24.8 & 3.08 & 263.4 & 45.3 & 150.4 \\
\hline (b) K-P rk Wald F & 35.1 & 31.6 & 14.4 & 63.4 & 39.3 & 142.9 \\
\hline Number of Clusters & 79 & 100 & 57 & 100 & 107 & 306 \\
\hline Number of Households & 175 & 224 & 150 & 315 & 300 & 855 \\
\hline Observations & 524 & 647 & 417 & 963 & 922 & 2,583 \\
\hline
\end{tabular}

Standard errors in brackets clustered at the segment level.

$* \mathrm{p}<0.10, * * \mathrm{p}<0.05, * * * \mathrm{p}<0.01$

Notes: All equations include household and year fixed effects. Columns (1)-(5) shows the impact for each treatment Assignment group along the NTH.

Column (6) shows impact across the whole NTH. Panel A shows the estimations using the difference in difference between segments methodology,

where adjacent segments are compare before and after the treatment segment is improved. The bottom part panel A uses the administrative data on

the construction progress of sub-segments. Panel B shows the estimations using the continuous time to market methodology, where all households experience improvements in travel times due to the improvement in the roads in the accessibility model. The bottom of panel B shows the instrumental variable estimation where the time to market is instrumented with the timeline of construction. The table shows the mean and std. deviation of the outcome variable for the comparison in each group before the road improvement and the baseline mean in the full sample column. Time to market reduction shows the difference before and after the improvement for the treatment group in each column and the difference for households in improved segments between the end line and the baseline. K-P rk Wald F is the F statistic for weak identification test(Cragg-Donald or Kleibergen-Paap) of the excluded instruments 
TABLE 29 IMPACTS ON THE PRICE PER MZ FOR OWNERS (REPORTED)

Price of land per hectare

(1) (2) (3) (4) (6) (6)

Full

$\begin{array}{llllll}\text { Group } 1 & \text { Group } 2 & \text { Group } 3 & \text { Group } 4 & \text { Group } 5 & \text { Sample }\end{array}$

\begin{tabular}{|c|c|c|c|c|c|c|}
\hline & & & & & & \\
\hline \multicolumn{7}{|l|}{ Panel A: Segment Difference in Difference } \\
\hline \multirow[t]{2}{*}{ Treatment Assignment\#Post Road Improvement } & 1242 & 1312.9 & -4193.8 & 547.7 & 1110.2 & 1359.7 \\
\hline & [7944.7] & [7306.9] & [2729.9] & [2365.3] & {$[3065.8]$} & [3496.4] \\
\hline \multirow[t]{2}{*}{ Post Road Improvement (0/1) } & -3736.9 & -4753.6 & -1515.2 & -4748.1 & -4127.3 & -4960.9 \\
\hline & [4778.8] & [3826.8] & [2817.5] & {$[2497.6]^{*}$} & [3309.8] & [3091.1] \\
\hline \multicolumn{7}{|l|}{ Construction Administrative Data } \\
\hline \multirow[t]{2}{*}{ Improved Road Sub-Segment (0/1) } & 1067.9 & -2430.3 & -5485.1 & -2809.7 & 1110.2 & 112.7 \\
\hline & [4442.0] & [3661.0] & {$[2757.9]^{*}$} & [3052.7] & {$[3065.8]$} & [1826.7] \\
\hline \multirow[t]{2}{*}{$\%$ of Sub-Segment Improved } & 1359.8 & -1547.8 & -6643.8 & -4170.7 & 863.1 & 317.3 \\
\hline & [7617.0] & [5046.7] & [4612.7] & [5117.1] & [3364.4] & [2402.6] \\
\hline \multicolumn{7}{|l|}{ Panel B: Continuous Time to Market Treatment } \\
\hline \multirow[t]{2}{*}{ Time to nearest market } & -863.4 & -552.6 & 65.9 & -22.1 & -10.4 & -38.8 \\
\hline & [589.1] & [413.7] & [195.0] & {$[56.7]$} & {$[62.8]$} & {$[42.4]$} \\
\hline \multicolumn{7}{|l|}{ Instrumental Variables } \\
\hline \multirow[t]{2}{*}{ (a) Time to Market $=\varphi$ (Treatment Assignment\#Post) } & -375.3 & -431.8 & -1786.5 & -15.4 & -49.9 & -94.7 \\
\hline & [2400.6] & [2399.7] & [1791.1] & {$[66.5]$} & [138.3] & [243.9] \\
\hline \multirow[t]{2}{*}{ (b) Time to Market $=\varphi(\%$ of Sub-Segment Improved $)$} & -341.7 & 492.8 & 1444 & 130.3 & -40.2 & -13.9 \\
\hline & [1910.9] & [1628.6] & [1090.1] & {$[165.0]$} & [156.9] & [104.9] \\
\hline Mean of Comp. at Pre-Period & 20989.2 & 20960.1 & 13491.3 & 13491.3 & 15670.2 & 18464.6 \\
\hline SD of Comp. at Pre-Period & 34240.7 & 31846.9 & 19589.6 & 19589.6 & 21378.8 & 26309.6 \\
\hline Time to Market Reduction & -0.24 & -0.24 & 1.57 & -41.1 & -21.8 & -22.5 \\
\hline (a) K-P rk Wald F & 18.9 & 15.3 & 1.7 & 271.3 & 49.6 & 140.5 \\
\hline (b) K-P rk Wald F & 22.4 & 20.9 & 12.9 & 75.4 & 42 & 139.5 \\
\hline Number of Clusters & 69 & 86 & 52 & 98 & 99 & 283 \\
\hline Number of Households & 139 & 182 & 127 & 285 & 254 & 730 \\
\hline Observations & 401 & 511 & 344 & 832 & 728 & 2,100 \\
\hline
\end{tabular}

Standard errors in brackets clustered at the segment level.

$* \mathrm{p}<0.10, * * \mathrm{p}<0.05, * * * \mathrm{p}<0.01$

Notes: All equations include household and year fixed effects. Columns (1)-(5) shows the impact for each treatment Assignment group along the NTH. Column (6) shows impact across the whole NTH. Panel A shows the estimations using the difference in difference between segments methodology, where adjacent segments are compare before and after the treatment segment is improved. The bottom part panel A uses the administrative data on the construction progress of sub-segments. Panel B shows the estimations using the continuous time to market methodology, where all households experience improvements in travel times due to the improvement in the roads in the accessibility model. The bottom of panel B shows the instrumenta variable estimation where the time to market is instrumented with the timeline of construction. The table shows the mean and std. deviation of the outcome variable for the comparison in each group before the road improvement and the baseline mean in the full sample column. Time to market reduction shows the difference before and after the improvement for the treatment group in each column and the difference for households in improved segments between the end line and the baseline. K-P rk Wald F is the F statistic for weak identification test(Cragg-Donald or Kleibergen-Paap) of the excluded instruments 


\section{Agricultural Productivity}

The evidence in the preceding sections points to a reduction in transport costs through increased market access or decreased travel times-the time to the nearest markets and the larger relevant markets in the Northern Zone was significantly lower. Increases in market access can increase the productivity of farmers through access to better inputs and/or technologies. These increases in access can also increase market participation, as easier access to markets might incentivize households to sell some or more of their production.

In this section, we will explore the impacts of the NTH on agriculture-related outcomes. Namely changes in the probability of producing fruits and vegetables and cash crops, participation in agriculture market sales and changes in the agriculture productivity and commercialization of basic grains.

Table 30 shows the impact on the probability of cultivating cash crops (defined as coffee, sugar cane, and coconut) and Table 31 for the probability of producing fruits and vegetables. We choose these indicators to explicitly isolate an effect among crops that are more likely affected by an increase in market access. We find no consistent pattern of significant effects across methodologies on the probability of growing cash crops or growing fruits and vegetables.

In Table 32 we estimate the impact on market participation or commercialization. We use an indicator for having sold any of the household production in a nearby market. While we find that there was an overall increase in the probability of participating in commercialization in the full sample (10 percentage points more likely to sell after the road improvement), we only find differential impacts in group 1 and 2, where the households in treatment segment were less likely than their counterparts in adjacent road segments; indicating that in this section of the NTH the effect on market participation was smaller. Indeed, these groups are on the west of the NTH where there is less commercial activity and the segment connecting to Guatemala was never constructed. The IV estimates from the continuous treatment design in panel B are similar to those in of the DID in panel A. The impact estimates are 10 percentage points in group one and 12 percentage points in group 2, given the estimated relationship between the time to the nearest market and the probability of participating in commercialization ( 0.25 and 0.03 ) and a reduction of 4.7 minutes on average among these groups. On the intensive margin of the value of agricultural sales, we do not find significant impacts as evidence in Table 33 
Household produces cash crops (coffee, sugar cane, coconut).

(3)

Group 5

Panel A: Segment Difference in Difference

Group 1 Group 2

Group 3

Group 4 Full Sample

\begin{tabular}{|c|c|c|c|c|c|c|}
\hline Treatment Assignment\#Post Road Improvement & $\begin{array}{l}0.0086 \\
{[0.0092]}\end{array}$ & $\begin{array}{l}0.0062 \\
{[0.0068]}\end{array}$ & $\begin{array}{l}0.00061 \\
{[0.0018]}\end{array}$ & $\begin{array}{l}-0.0019 \\
{[0.0018]}\end{array}$ & $\begin{array}{l}0.00072 \\
{[0.0046]}\end{array}$ & $\begin{array}{l}0.0055 \\
{[0.0055]}\end{array}$ \\
\hline Post Road Improvement $(0 / 1)$ & $\begin{array}{l}-0.018 \\
{[0.0097]^{*}}\end{array}$ & $\begin{array}{l}-0.015 \\
{[0.0067]^{* *}}\end{array}$ & $\begin{array}{l}-0.0013 \\
{[0.00077]}\end{array}$ & $\begin{array}{l}-0.0031 \\
{[0.0012]^{* *}}\end{array}$ & $\begin{array}{l}-0.012 \\
{[0.0055]^{* *}}\end{array}$ & $\begin{array}{l}-0.013 \\
{[0.0055]^{* *}}\end{array}$ \\
\hline \multicolumn{7}{|l|}{ Construction Administrative Data } \\
\hline Improved Road Sub-Segment (0/1) & $\begin{array}{l}0.011 \\
{[0.0071]}\end{array}$ & $\begin{array}{l}0.0063 \\
{[0.0051]}\end{array}$ & $\begin{array}{l}-0.00063 \\
{[0.00068]}\end{array}$ & $\begin{array}{l}-0.0024 \\
{[0.0012]^{*}}\end{array}$ & $\begin{array}{l}0.00072 \\
{[0.0046]}\end{array}$ & $\begin{array}{l}0.0012 \\
{[0.0023]}\end{array}$ \\
\hline$\%$ of Sub-Segment Improved & $\begin{array}{l}0.011 \\
{[0.0093]}\end{array}$ & $\begin{array}{l}0.003 \\
{[0.0057]}\end{array}$ & $\begin{array}{l}0.00071 \\
{[0.0010]}\end{array}$ & $\begin{array}{l}-0.005 \\
{[0.0022]^{* *}}\end{array}$ & $\begin{array}{l}0.0016 \\
{[0.0048]} \\
\end{array}$ & $\begin{array}{l}-0.00079 \\
{[0.0028]} \\
\end{array}$ \\
\hline \multicolumn{7}{|l|}{ Panel B: Continuous Time to Market Treatment } \\
\hline Time to nearest market & $\begin{array}{l}-0.00026 \\
{[0.00064]}\end{array}$ & $\begin{array}{l}0.000014 \\
{[0.00031]}\end{array}$ & $\begin{array}{l}-0.000028 \\
{[0.000060]}\end{array}$ & $\begin{array}{l}0.000043 \\
{[0.000048]}\end{array}$ & $\begin{array}{l}0.00029 \\
{[0.00019]}\end{array}$ & $\begin{array}{l}0.00013 \\
{[0.000064]^{* *}}\end{array}$ \\
\hline \multicolumn{7}{|l|}{ Instrumental Variables } \\
\hline (a) Time to Market $=\varphi($ Treatment Assignment\#Post $)$ & $\begin{array}{l}-0.0018 \\
{[0.0019]}\end{array}$ & $\begin{array}{l}-0.0016 \\
{[0.0018]}\end{array}$ & $\begin{array}{l}-0.0018 \\
{[0.0090]}\end{array}$ & $\begin{array}{l}0.000052 \\
{[0.000050]}\end{array}$ & $\begin{array}{l}-0.00004 \\
{[0.00026]}\end{array}$ & $\begin{array}{l}-0.00048 \\
{[0.00048]}\end{array}$ \\
\hline (b) Time to Market $=\varphi(\%$ of Sub-Segment Improved $)$ & $\begin{array}{l}-0.0021 \\
{[0.0018]} \\
\end{array}$ & $\begin{array}{l}-0.00065 \\
{[0.0012]} \\
\end{array}$ & $\begin{array}{l}-0.00021 \\
{[0.00032]}\end{array}$ & $\begin{array}{l}0.00022 \\
{[0.00011]^{* *}}\end{array}$ & $\begin{array}{l}-0.000089 \\
{[0.00027]} \\
\end{array}$ & $\begin{array}{l}0.000043 \\
{[0.00015]}\end{array}$ \\
\hline Mean of Comp. at Pre-Period & 0.019 & 0.015 & 0.00058 & 0.00058 & 0.012 & 0.013 \\
\hline SD of Comp. at Pre-Period & 0.14 & 0.12 & 0.024 & 0.024 & 0.11 & 0.11 \\
\hline Time to Market Reduction & -4.18 & -4.18 & -3.49 & -39.6 & -17.4 & -17.8 \\
\hline (a) K-P rk Wald F & 63.9 & 33.3 & 0.062 & 470.1 & 74.8 & 253 \\
\hline (b) K-P rk Wald F & 73.7 & 56.9 & 18.4 & 57.7 & 68.7 & 242.6 \\
\hline Number of Clusters & 113 & 142 & 96 & 138 & 135 & 410 \\
\hline Number of Households & 1,219 & 1,496 & 1,006 & 1,652 & 1,415 & 4,667 \\
\hline Observations & 5,549 & 6,795 & 4,560 & 7,639 & 6,490 & 21,406 \\
\hline
\end{tabular}

Standard errors in brackets clustered at the segment level. ${ }^{*} p<0.10,{ }^{* *} p<0.05,{ }^{* * *} p<0.01$

Notes: All equations include household and year fixed effects. Columns (1)-(5) shows the impact for each treatment Assignment group along the NTH. Column (6) shows impact across the whole NTH. Pane A shows the estimations using the difference in difference between segments methodology, where adjacent segments are compare before and after the treatment segment is improved. The bottom part panel A uses the administrative data on the construction progress of sub-segments. Panel B shows the estimations using the continuous time to market methodology, where all households experience improvements in travel times due to the improvement in the roads in the accessibility model. The bottom of panel B shows the instrumental variable estimation where the time to market is instrumented with the timeline of construction. K-P rk Wald F is the F statistic for weak identification test(Cragg-Donald or Kleibergen-Paap) of the excluded instruments 
TABLE 31 AGRICULTURAL PRODUCTION IMPACTS: PROBABILITY OF PRODUCING FRUITS AND VEGETABLES

\section{Household produces fruits and vegetables}

\begin{tabular}{|c|c|c|c|c|c|c|}
\hline & $\begin{array}{c}\text { (1) } \\
\text { Group } 1\end{array}$ & $\begin{array}{c}\text { (2) } \\
\text { Group } 2\end{array}$ & $\begin{array}{c}\text { (3) } \\
\text { Group } 3\end{array}$ & $\begin{array}{c}\text { (4) } \\
\text { Group } 4\end{array}$ & $\begin{array}{c}\text { (5) } \\
\text { Group } 5\end{array}$ & $\begin{array}{c}\text { (6) } \\
\text { Full Sample }\end{array}$ \\
\hline \multicolumn{7}{|l|}{ Panel A: Segment Difference in Difference } \\
\hline Treatment Assignment\#Post Road Improvement & $\begin{array}{l}-0.00045 \\
{[0.0090]}\end{array}$ & $\begin{array}{l}-0.0021 \\
{[0.0088]}\end{array}$ & $\begin{array}{l}0.015 \\
{[0.012]}\end{array}$ & $\begin{array}{l}0.0072 \\
{[0.0092]}\end{array}$ & $\begin{array}{l}-0.006 \\
{[0.0062]}\end{array}$ & $\begin{array}{l}0.0024 \\
{[0.0051]}\end{array}$ \\
\hline Post Road Improvement (0/1) & $\begin{array}{l}0.038 \\
{[0.012]^{* * *}}\end{array}$ & $\begin{array}{l}0.041 \\
{[0.011]^{* * *}}\end{array}$ & $\begin{array}{l}-0.019 \\
{[0.0081]^{* *}}\end{array}$ & $\begin{array}{l}-0.016 \\
{[0.0079]^{*}}\end{array}$ & $\begin{array}{l}-0.0026 \\
{[0.0047]}\end{array}$ & $\begin{array}{l}0.052 \\
{[0.0066]^{* * *}}\end{array}$ \\
\hline \multicolumn{7}{|l|}{ Construction Administrative Data } \\
\hline Improved Road Sub-Segment (0/1) & $\begin{array}{l}-0.00033 \\
{[0.0097]}\end{array}$ & $\begin{array}{l}-0.0013 \\
{[0.0077]}\end{array}$ & $\begin{array}{l}0.013 \\
{[0.0092]}\end{array}$ & $\begin{array}{l}0.01 \\
{[0.0083]}\end{array}$ & $\begin{array}{l}-0.006 \\
{[0.0062]}\end{array}$ & $\begin{array}{l}-0.0032 \\
{[0.0042]}\end{array}$ \\
\hline$\%$ of Sub-Segment Improved & $\begin{array}{l}-0.0019 \\
{[0.0086]}\end{array}$ & $\begin{array}{l}-0.0022 \\
{[0.0084]}\end{array}$ & $\begin{array}{l}0.016 \\
{[0.016]}\end{array}$ & $\begin{array}{l}0.02 \\
{[0.015]}\end{array}$ & $\begin{array}{l}-0.0044 \\
{[0.0063]}\end{array}$ & $\begin{array}{l}-0.01 \\
{[0.0052]^{* *}}\end{array}$ \\
\hline \multicolumn{7}{|l|}{ Panel B: Continuous Time to Market Treatment } \\
\hline Time to nearest market & $\begin{array}{l}0.00026 \\
{[0.00082]}\end{array}$ & $\begin{array}{l}0.00032 \\
{[0.00071]}\end{array}$ & $\begin{array}{l}0.00095 \\
{[0.0011]}\end{array}$ & $\begin{array}{l}-0.00013 \\
{[0.00022]}\end{array}$ & $\begin{array}{l}0.000069 \\
{[0.00016]}\end{array}$ & $\begin{array}{l}0.00021 \\
{[0.00015]}\end{array}$ \\
\hline \multicolumn{7}{|l|}{ Instrumental Variables } \\
\hline (a) Time to Market $=\varphi($ Treatment Assignment\#Post $)$ & $\begin{array}{l}0.000093 \\
{[0.0019]}\end{array}$ & $\begin{array}{l}0.00054 \\
{[0.0023]}\end{array}$ & $\begin{array}{l}-0.045 \\
{[0.19]}\end{array}$ & $\begin{array}{l}-0.0002 \\
{[0.00025]}\end{array}$ & $\begin{array}{l}0.00034 \\
{[0.00035]}\end{array}$ & $\begin{array}{l}-0.00021 \\
{[0.00044]}\end{array}$ \\
\hline (b) Time to Market $=\varphi(\%$ of Sub-Segment Improved $)$ & $\begin{array}{l}0.00036 \\
{[0.0016]}\end{array}$ & $\begin{array}{l}0.00048 \\
{[0.0018]}\end{array}$ & $\begin{array}{l}-0.0047 \\
{[0.0049]}\end{array}$ & $\begin{array}{l}-0.00089 \\
{[0.00066]}\end{array}$ & $\begin{array}{l}0.00025 \\
{[0.00036]}\end{array}$ & $\begin{array}{l}0.00056 \\
{[0.00028]^{* *}}\end{array}$ \\
\hline Mean of Comp. at Pre-Period & 0.04 & 0.036 & 0.046 & 0.046 & 0.013 & 0.019 \\
\hline SD of Comp. at Pre-Period & 0.2 & 0.19 & 0.21 & 0.21 & 0.11 & 0.14 \\
\hline Time to Market Reduction & -4.18 & -4.18 & -3.49 & -39.6 & -17.4 & -17.8 \\
\hline (a) K-P rk Wald F & 63.9 & 33.3 & 0.062 & 470.1 & 74.8 & 253 \\
\hline (b) K-P rk Wald F & 73.7 & 56.9 & 18.4 & 57.7 & 68.7 & 242.6 \\
\hline Number of Clusters & 113 & 142 & 96 & 138 & 135 & 410 \\
\hline Number of Households & 1,219 & 1,496 & 1,006 & 1,652 & 1,415 & 4,667 \\
\hline Observations & 5,549 & 6,795 & 4,560 & 7,639 & 6,490 & 21,406 \\
\hline
\end{tabular}

Standard errors in brackets clustered at the segment level. ${ }^{*} p<0.10,{ }^{* *} p<0.05,{ }^{* * *} p<0.01$

Notes: All equations include household and year fixed effects. Columns (1)-(5) shows the impact for each treatment Assignment group along the NTH. Column (6) shows impact across the whole NTH. Panel A shows the estimations using the difference in difference between segments methodology, where adjacent segments are compare before and after the treatment segment is improved. The bottom part panel $A$ uses the administrative data on the construction progress of sub-segments. Panel B shows the estimations using the continuous time to market methodology, where all households experience improvements in travel times due to the improvement in the roads in the accessibility model. The bottom of panel $B$ shows the instrumental variable estimation where the time to market is instrumented with the timeline of construction. K-P rk Wald F is the F statistic for weak identification test(Cragg-Donald or Kleibergen-Paap) of the excluded instruments 
TABLE 32 AGRICULTURAL PRODUCTION IMPACTS: PROBABILITY OF SELLING AGRICULTURAL PRODUCTION

Household sells part agriculture output

$\begin{array}{lllll}(1) & (2) & \text { (3) } & \text { (4) } & \text { (4) }\end{array}$

Group $1 \quad$ Group $2 \quad$ Group $3 \quad$ Group $4 \quad$ Group 5 Full Sample

\begin{tabular}{|c|c|c|c|c|c|c|}
\hline \multicolumn{7}{|l|}{ Panel A: Segment Difference in Difference } \\
\hline \multirow[t]{2}{*}{ Treatment Assignment\#Post Road Improvement } & -0.11 & -0.11 & 0.011 & -0.0048 & -0.03 & -0.027 \\
\hline & {$[0.049]^{* *}$} & {$[0.046]^{* *}$} & [0.052] & [0.034] & [0.031] & {$[0.025]$} \\
\hline \multirow[t]{2}{*}{ Post Road Improvement $(0 / 1)$} & 0.15 & 0.017 & 0.062 & 0.095 & -0.0037 & 0.1 \\
\hline & {$[0.038]^{* * *}$} & [0.035] & [0.040] & {$[0.032]^{* * *}$} & {$[0.027]$} & {$[0.023]^{* * *}$} \\
\hline \multicolumn{7}{|l|}{ Construction Administrative Data } \\
\hline \multirow[t]{2}{*}{ Improved Road Sub-Segment (0/1) } & -0.012 & -0.031 & -0.096 & -0.052 & -0.03 & -0.025 \\
\hline & [0.037] & [0.028] & {$[0.049]^{*}$} & [0.042] & [0.031] & [0.017] \\
\hline \multirow[t]{2}{*}{$\%$ of Sub-Segment Improved } & -0.084 & -0.044 & 0.0071 & 0.01 & -0.037 & -0.015 \\
\hline & {$[0.045]^{*}$} & [0.035] & [0.078] & [0.077] & [0.033] & {$[0.020]$} \\
\hline \multicolumn{7}{|l|}{ Panel B: Continuous Time to Market Treatment } \\
\hline \multirow[t]{2}{*}{ Time to nearest market } & 0.0079 & 0.0056 & 0.0048 & -0.000051 & 0.00067 & -0.0000095 \\
\hline & {$[0.0052]$} & {$[0.0035]$} & [0.0030] & {$[0.00081]$} & {$[0.00091]$} & {$[0.00052]$} \\
\hline \multicolumn{7}{|l|}{ Instrumental Variables } \\
\hline \multirow[t]{2}{*}{ (a) Time to Market $=\varphi($ Treatment Assignment\#Post $)$} & 0.025 & 0.03 & 0.053 & 0.00014 & 0.0015 & 0.0021 \\
\hline & {$[0.011]^{* *}$} & {$[0.013]^{* *}$} & {$[0.40]$} & [0.00099] & {$[0.0016]$} & {$[0.0020]$} \\
\hline \multirow[t]{2}{*}{ (b) Time to Market $=\varphi(\%$ of Sub-Segment Improved $)$} & 0.016 & 0.0097 & -0.0017 & -0.00039 & 0.002 & 0.00072 \\
\hline & {$[0.0090]^{*}$} & [0.0077] & [0.019] & {$[0.0030]$} & {$[0.0018]$} & {$[0.00096]$} \\
\hline Mean of Comp. at Pre-Period & 0.34 & 0.32 & 0.4 & 0.4 & 0.18 & 0.32 \\
\hline SD of Comp. at Pre-Period & 0.47 & 0.47 & 0.49 & 0.49 & 0.39 & 0.46 \\
\hline Time to Market Reduction & -4.01 & -4.01 & -4.37 & -39.3 & -16.6 & -19.8 \\
\hline (a) K-P rk Wald F & 57.5 & 30.1 & 0.02 & 331.5 & 57.8 & 210.4 \\
\hline (b) K-P rk Wald F & 63 & 51.9 & 18.7 & 70.2 & 51 & 200.1 \\
\hline Number of Clusters & 107 & 131 & 82 & 128 & 132 & 387 \\
\hline Number of Households & 697 & 873 & 574 & 1,060 & 878 & 2,872 \\
\hline Observations & 2,629 & 3,308 & 2,194 & 4,162 & 3,337 & 11,032 \\
\hline
\end{tabular}

Standard errors in brackets clustered at the segment level.

$* \mathrm{p}<0.10, * * \mathrm{p}<0.05, * * * \mathrm{p}<0.01$

Notes: All equations include household and year fixed effects. Columns (1)-(5) shows the impact for each treatment Assignment group along the NTH.

Column (6) shows impact across the whole NTH. Panel A shows the estimations using the difference in difference between segments methodology, where adjacent segments are compare before and after the treatment segment is improved. The bottom part panel $A$ uses the administrative data on the construction progress of sub-segments. Panel B shows the estimations using the continuous time to market methodology, where all households experience improvements in travel times due to the improvement in the roads in the accessibility model. The bottom of panel $B$ shows the instrumental variable estimation where the time to market is instrumented with the timeline of construction. The table shows the mean and std. deviation of the outcome variable for the comparison in each group before the road improvement and the baseline mean in the full sample column. Time to market reduction shows the difference before and after the improvement for the treatment group in each column and the difference for households in improved segments between the end line and the baseline. K-P rk Wald F is the F statistic for weak identification test(Cragg-Donald or Kleibergen-Paap) of the excluded instruments 
TABLE 33 AGRICULTURAL PRODUCTION IMPACTS: TOTAL AGRICULTURE PRODUCTS SALES (\$)

Total Amount sold (USD)
(1)
(2)
(3)
(4)
(5)
(6)

Group 1 Group 2 Group 3 Group 4 Group 5 Sample

\begin{tabular}{|c|c|c|c|c|c|c|}
\hline \multicolumn{7}{|l|}{ Panel A: Segment Difference in Difference } \\
\hline \multirow[t]{2}{*}{ Treatment Assignment\#Post Road Improvement } & -106.9 & -82.3 & 13.4 & 7.66 & 59.9 & -30.1 \\
\hline & {$[80.9]$} & [77.4] & [58.9] & [47.2] & [67.3] & [54.5] \\
\hline \multirow[t]{2}{*}{ Post Road Improvement (0/1) } & -163.2 & -200.3 & -105.1 & -74 & 18.7 & -149.2 \\
\hline & {$[71.2]^{* *}$} & {$[57.8]^{* * *}$} & {$[57.4]^{*}$} & {$[50.2]$} & {$[72.8]$} & {$[52.4]^{* * *}$} \\
\hline \multicolumn{7}{|l|}{ Construction Administrative Data } \\
\hline \multirow{2}{*}{ Improved Road Sub-Segment (0/1) } & -2.54 & 24.5 & 53 & 7.72 & 59.9 & 21.9 \\
\hline & {$[50.0]$} & [35.7] & [56.3] & [45.9] & [67.3] & {$[25.2]$} \\
\hline \multirow[t]{2}{*}{$\%$ of Sub-Segment Improved } & -78.7 & -24.2 & -3.3 & -48.6 & 62 & -27.7 \\
\hline & [71.7] & [48.3] & [77.5] & {$[83.3]$} & {$[72.1]$} & [32.7] \\
\hline \multicolumn{7}{|l|}{ Panel B: Continuous Time to Market Treatment } \\
\hline \multirow[t]{2}{*}{ Time to nearest market } & -7.23 & -3.55 & 2.35 & -0.36 & -1.78 & -0.53 \\
\hline & {$[8.13]$} & [5.64] & [3.41] & [1.32] & [2.73] & {$[0.91]$} \\
\hline \multicolumn{7}{|l|}{ Instrumental Variables } \\
\hline \multirow[t]{2}{*}{ (a) Time to Market $=\varphi$ (Treatment Assignment\#Post $)$} & 19.9 & 18.9 & 370.2 & -0.28 & -3.96 & 3.68 \\
\hline & {$[15.6]$} & [18.5] & [14483.6] & {$[1.74]$} & [4.54] & {$[6.71]$} \\
\hline \multirow[t]{2}{*}{ (b) Time to Market $=\varphi(\%$ of Sub-Segment Improved $)$} & 13.3 & 5.14 & 1.13 & 2.78 & -4.36 & 2.23 \\
\hline & {$[12.4]$} & {$[10.3]$} & [26.3] & {$[4.80]$} & {$[5.17]$} & {$[2.64]$} \\
\hline Mean of Comp. at Pre-Period & 549.4 & 477.7 & 385.8 & 385.8 & 292.4 & 473.8 \\
\hline SD of Comp. at Pre-Period & 506.4 & 449.8 & 406.3 & 406.3 & 337.8 & 487.3 \\
\hline Time to Market Reduction & -7.62 & -7.62 & -1.51 & -32.4 & -15.1 & -14.5 \\
\hline (a) K-P rk Wald F & 43.6 & 22.4 & 0.00063 & 73.4 & 40.8 & 87.6 \\
\hline (b) K-P rk Wald F & 52.9 & 51 & 8.54 & 34.6 & 33.1 & 106.5 \\
\hline Number of Clusters & 96 & 118 & 74 & 104 & 86 & 311 \\
\hline Number of Households & 406 & 477 & 288 & 393 & 180 & 1,092 \\
\hline Observations & 1,243 & 1,419 & 812 & 1,097 & 451 & 3,105 \\
\hline
\end{tabular}

Standard errors in brackets clustered at the segment level.

$* \mathrm{p}<0.10, * * \mathrm{p}<0.05, * * * \mathrm{p}<0.01$

Notes: All equations include household and year fixed effects. Columns (1)-(5) shows the impact for each treatment Assignment group along the NTH. Column (6) shows impact across the whole NTH. Panel A shows the estimations using the difference in difference between segments methodology, where adjacent segments are compare before and after the treatment segment is improved. The bottom part panel A uses the administrative data on the construction progress of sub-segments. Panel B shows the estimations using the continuous time to market methodology, where all households experience improvements in travel times due to the improvement in the roads in the accessibility model. The bottom of panel B shows the instrumental variable estimation where the time to market is instrumented with the timeline of construction. The table shows the mean and std. deviation of the outcome variable for the comparison in each group before the road improvement and the baseline mean in the full sample column. Time to market reduction shows the difference before and after the improvement for the treatment group in each column and the difference for households in improved segments between the end line and the baseline. K-P rk Wald F is the F statistic for weak identification test(Cragg-Donald or Kleibergen-Paap) of the excluded instruments 
Next, we present results on the intensive margin of agricultural production: quantities of basic grains production and the total value of agricultural production and sales. Table 34 shows the impacts on agriculture production quantities for basic grains (corn, beans and sorghum). These are the staple crops in the Norther Zone and given the lack of significant changes in the probability of producing cash crops and fruits and vegetables, we explore in this section increases in productivity for staple crops. We do not find differences in agricultural productivity for basic grains ${ }^{19}$ due to the improvement of the NTH.

We find significant increases in the value of quantities designated for auto consumption in the previous year. From the DID estimations, we find significant effects among group 4, with an increase of 40 to 53 USD in the amount of agriculture production use for consumption in the household or auto-consumption. In regressions (not-shown) we can trace the effect to increases in the stored quantities of corn. The estimates from full sample using the continuous approach shows a marginally significant effect of 8.4 USD on average across the NTH.

${ }^{19}$ We estimated the effect for each staple crop separately and the conclusion estimates are qualitatively similar. 
TABLE 34 AGRICULTURAL PRODUCTION IMPACTS: BASIC GRAINS PRODUCTION QUANTITIES (KGS)

Basic grains quantity produced $(\mathrm{Kg})$

$\begin{array}{lllll}(1) & (2) & \text { (3) } & \text { (4) }\end{array}$

Full

Group 1 Group 2 Group 3 Group 4 Group 5 Sample

\begin{tabular}{|c|c|c|c|c|c|c|}
\hline \multicolumn{7}{|l|}{ Panel A: Segment Difference in Difference } \\
\hline Treatment Assignment\#Post Road Improvement & $\begin{array}{l}-107.1 \\
{[116.0]}\end{array}$ & $\begin{array}{l}-109.7 \\
{[107.3]}\end{array}$ & $\begin{array}{l}-110.7 \\
{[91.5]}\end{array}$ & $\begin{array}{l}-52.7 \\
{[72.3]}\end{array}$ & $\begin{array}{l}29.8 \\
{[51.8]}\end{array}$ & $\begin{array}{l}18.2 \\
{[50.1]}\end{array}$ \\
\hline Post Road Improvement $(0 / 1)$ & $\begin{array}{l}62.3 \\
{[84.2]}\end{array}$ & $\begin{array}{l}56.2 \\
{[67.9]}\end{array}$ & $\begin{array}{l}120.1 \\
{[82.0]}\end{array}$ & $\begin{array}{l}88.8 \\
{[82.9]}\end{array}$ & $\begin{array}{l}102.5 \\
{[52.0]^{*}}\end{array}$ & $\begin{array}{l}61.3 \\
{[47.7]}\end{array}$ \\
\hline \multicolumn{7}{|l|}{ Construction Administrative Data } \\
\hline Improved Road Sub-Segment (0/1) & $\begin{array}{l}16.4 \\
{[99.1]}\end{array}$ & $\begin{array}{l}-25.8 \\
{[73.1]}\end{array}$ & $\begin{array}{l}-124 \\
{[104.7]}\end{array}$ & $\begin{array}{l}-140.2 \\
{[84.9]}\end{array}$ & $\begin{array}{l}29.8 \\
{[51.8]}\end{array}$ & $\begin{array}{l}-7.8 \\
{[40.8]}\end{array}$ \\
\hline$\%$ of Sub-Segment Improved & $\begin{array}{l}-95.3 \\
{[122.8]}\end{array}$ & $\begin{array}{l}-84.4 \\
{[82.2]}\end{array}$ & $\begin{array}{l}-113.3 \\
{[156.3]}\end{array}$ & $\begin{array}{l}-157.1 \\
{[154.4]}\end{array}$ & $\begin{array}{l}46.9 \\
{[54.7]}\end{array}$ & $\begin{array}{l}-27.1 \\
{[44.7]} \\
\end{array}$ \\
\hline \multicolumn{7}{|l|}{ Panel B: Continuous Time to Market Treatment } \\
\hline Time to nearest market & $\begin{array}{l}-9.33 \\
{[16.9]}\end{array}$ & $\begin{array}{l}-0.072 \\
{[8.89]}\end{array}$ & $\begin{array}{l}-1.69 \\
{[8.95]}\end{array}$ & $\begin{array}{l}2.27 \\
{[1.40]}\end{array}$ & $\begin{array}{l}-0.3 \\
{[1.56]}\end{array}$ & $\begin{array}{l}0.37 \\
{[0.83]}\end{array}$ \\
\hline
\end{tabular}

Instrumental Variables

(a) Time to Market $=\varphi($ Treatment

Assignment\#Post)

$\begin{array}{llllll}23 & 28.9 & -533 & 1.52 & -1.55 & -1.43\end{array}$

(b) Time to Market $=\varphi(\%$ of Sub-Segment

$\left[\begin{array}{llllll}{[25.2]} & {[28.7]} & {[3714.7]} & {[2.10]} & {[2.69]} & {[3.92]}\end{array}\right.$

Improved) 18.5

\begin{tabular}{llllll}
18.5 & 18.7 & 28.7 & 6.08 & -2.5 & 1.33 \\
{$[24.1]$} & {$[18.7]$} & {$[39.8]$} & {$[6.11]$} & {$[2.93]$} & {$[2.19]$} \\
\hline 1375.6 & 1292.9 & 1482.1 & 1482.1 & 892.6 & 1258.6 \\
1251 & 1082.1 & 1137.1 & 1137.1 & 779.2 & 1177.2 \\
-4.48 & -4.48 & -4.33 & -39.3 & -17 & -20.1 \\
57.2 & 32.8 & 0.02 & 331.1 & 56.4 & 205.1 \\
62.4 & 49.9 & 17.9 & 68.1 & 49.8 & 196.7 \\
105 & 129 & 82 & 128 & 132 & 385 \\
683 & 859 & 570 & 1,053 & 861 & 2,834 \\
2,561 & 3,236 & 2,174 & 4,113 & 3,268 & 10,841 \\
\hline
\end{tabular}

Mean of Comp. at Pre-Period

SD of Comp. at Pre-Period

Time to Market Reduction

\begin{tabular}{lllllll} 
(a) K-P rk Wald F & 57.2 & 32.8 & 0.02 & 331.1 & 56.4 & 205.1 \\
(b) K-P rk Wald F & 62.4 & 49.9 & 17.9 & 68.1 & 49.8 & 196.7 \\
\hline Number of Clusters & 105 & 129 & 82 & 128 & 132 & 385 \\
Number of Households & 683 & 859 & 570 & 1,053 & 861 & 2,834 \\
Observations & 2,561 & 3,236 & 2,174 & 4,113 & 3,268 & 10,841 \\
\hline \hline
\end{tabular}

Standard errors in brackets clustered at the segment level.

$* \mathrm{p}<0.10, * * \mathrm{p}<0.05, * * * \mathrm{p}<0.01$

Notes: All equations include household and year fixed effects. Columns (1)-(5) shows the impact for each treatment Assignment group along the NTH. Column (6) shows impact across the whole NTH. Panel A shows the estimations using the difference in difference between segments methodology, where adjacent segments are compare before and after the treatment segment is improved. The bottom part panel A uses the administrative data on the construction progress of sub-segments. Panel B shows the estimations using the continuous time to market methodology, where all households experience improvements in travel times due to the improvement in the roads in the accessibility model. The bottom of panel B shows the instrumental variable estimation where the time to market is instrumented with the timeline of construction. The table shows the mean and std. deviation of the outcome variable for the comparison in each group before the road improvement and the baseline mean in the full sample column. Time to market reduction shows the difference before and after the improvement for the treatment group in each column and the difference for households in improved segments between the end line and the baseline. K-P rk Wald F is the F statistic for weak identification test(Cragg-Donald or Kleibergen-Paap) of the excluded instruments 
TABLE 35 AGRICULTURAL PRODUCTION IMPACTS: AUTO-CONSUMPTION (\$)

Total Amount consumed (USD)

$\begin{array}{lllll}(1) & (2) & (3) & \text { (4) }\end{array}$

Full

Group 1 Group 2 Group 3 Group 4 Group 5 Sample

Panel A: Segment Difference in Difference

Treatment Assignment\#Post Road Improvement

$\begin{array}{llllll}26.8 & 8.14 & 54.1 & 53 & -0.41 & 16.4\end{array}$

$[29.1][26.5] \quad[23.8]^{* *} \quad[19.4]^{* * *} \quad[15.0] \quad[14.7]$

Post Road Improvement (0/1)

$\begin{array}{llllll}-118.1 & -95.4 & -145.2 & -20.5 & -117.2\end{array}$

Construction Administrative Data

Improved Road Sub-Segment (0/1)

$[22.5]^{* * *} \quad[18.2]^{* * *} \quad[23.3]^{* * *} \quad[20.6]^{* * *} \quad[15.5] \quad[13.8]^{* * *}$

$\begin{array}{llllll}31.2 & 22.5 & 20.7 & 40.4 & -0.41 & 24.4\end{array}$

$\%$ of Sub-Segment Improved

[24.4]

[19.1]

[26.2]

$[19.2]^{* *} \quad[15.0]$

24.4

30.3

30.5

$-34.3$

$-47.8$

$-2.63$

$[9.74]^{* *}$

[32.0]

[22.1]

[37.3]

[37.6]

[16.0]

Panel B: Continuous Time to Market Treatment

Time to nearest market

$\begin{array}{llllll}-6.53 & -4.5 & -3.34 & -0.63 & -0.61 & -0.42 \\ {[3.92]^{*}} & {[2.08]^{* *}} & {[1.87]^{*}} & {[0.42]} & {[0.40]} & {[0.23]^{*}}\end{array}$

Instrumental Variables

(a) Time to Market $=\varphi($ Treatment

Assignment\#Post)

245.3

$-1.53$

0.021

$-1.27$

(b) Time to Market $=\varphi(\%$ of Sub-Segment

[6.95]

[1651.6]

$[0.56]^{* * *}$

[0.77] Improved)

$$
-5.96
$$

$-6.83$

8.85

1.84

0.14

$-0.21$

[6.19] [4.7

Mean of Comp. at Pre-Period

368.1

[10.2]

[1.52]

[0.84]

[0.57]

SD of Comp. at Pre-Period

279

Time to Market Reduction

279

$368.1 \quad 405.2$

$405.2 \quad 297.1 \quad 348$

(a) K-P rk Wald F

57.2

274.8

274.8

(b) K-P rk Wald F

Number of Clusters

$64.8 \quad 49$

33.1

$-3.97$

$-39.4$

$-17.3$

Number of Clusters

$105 \quad 129$

0.023

331.9

57

$-20$

$4.3 \quad 17.4$

66.4

$678 \quad 85$

Observations

2,502

852
3,164

81

127

196.5

tandard errors in brackets clustered at the segment level.

$* \mathrm{p}<0.10, * * \mathrm{p}<0.05, * * * \mathrm{p}<0.01$

Notes: All equations include household and year fixed effects. Columns (1)-(5) shows the impact for each treatment Assignment group along the NTH. Column (6) shows impact across the whole NTH. Panel A shows the estimations using the difference in difference between segments methodology, where adjacent segments are compare before and after the treatment segment is improved. The bottom part panel A uses the administrative data on the construction progress of sub-segments. Panel B shows the estimations using the continuous time to market methodology, where all households experience improvements in travel times due to the improvement in the roads in the accessibility model. The bottom of panel B shows the instrumental variable estimation where the time to market is instrumented with the timeline of construction. The table shows the mean and std. deviation of the outcome variable for the comparison in each group before the road improvement and the baseline mean in the full sample column. Time to market reduction shows the difference before and after the improvement for the treatment group in each column and the difference for households in improved segments between the end line and the baseline. K-P rk Wald F is the F statistic for weak identification test(Cragg-Donald or Kleibergen-Paap) of the excluded instruments 


\section{RoAd Quality AND InCOME: Agriculture AND Non-Agriculture SeCtORS}

As discussed in the theoretical framework, the main impacts of the road improvement we are evaluating rely on the changes in the marginal returns of production that would be reflected as changes in income. In the previous section, the evidence suggests some increase in market participation in some areas of the NTH. In this section, we explore the impacts on household income making a distinction between agriculture (farm) and non-agriculture(non-farm) income and the explore impacts on consumption or expenditure as a summary of household economic welfare.

We start with the effects on total household income. We construct total household income from information on the labor market activities of all household members, business or independent productive activities income, and transfers. Table 36 shows the impact estimates for this measure of total household income. The DID impacts in panel A show no significant effects across groups. On panel B, the continuous treatment approach estimates the relationship between market access changes and income is positive (on the cross section the relationship is negative, households farther from markets tend to have lower income). The implication that taking the structural interpretation the relationship between income and market access is positive and the improvement in markets access had a negative impact on total income in the short run. The implied impact estimates suggest that an improvement of the road reflected through a reduction of 17.8 minutes in accessing the nearest market caused a reduction of 140 USD per year, calculating the impact with the 7.92 USD/Minute estimate and 361 USD per year with the 20.3 USD per minute IV estimate. This could be because of increased competition from surrounding areas now that more remote areas are more accessible or a reallocation of labor to other activities that might initially be less lucrative.

To explore the possibility that the increase in market access could affect the allocation of labor across activities and the returns to these activities, we estimate the impact of the road improvement for dependent and independent income for the agriculture and non-agriculture sectors.

The impact estimates are presented in Table 37 for dependent labor income in the agriculture sector and in Table 38 for the non-agriculture sector. For dependent labor income, the negative impact is in the agriculture sector and the relationship is smaller. The implied effects are a reduction of 18 USD in annual agriculture labor income due to a decrease of 17.8 minutes in the access to the nearest market, using the 1.03 USP per minute decrease in time to the nearest market. The impacts on the dependent income in the non-agriculture sector are only marginally significant.

The impact estimates are presented in Table 39 for independent/business income in the agriculture sector and in Table 40 for the non-agriculture sector. For independent/business income, the negative impact is in the non-agriculture sector and the relationship is smaller. The implied effects are a reduction of 93 USD in annual non-agriculture independent income due to a decrease of 17.8 minutes in the access to the nearest market, using the 5.25 USP per minute decrease in time to the nearest market in panel $B$. The impacts on the independent income in the agriculture sector are only marginally significant.

Together this suggest that competition from surrounding areas are one of the mechanism through which road improvements affect the economic well-being of household in rural areas. The estimates suggest decreases in (dependent) labor supply to the agriculture sector (perhaps signaling movement towards non-ag sector dependent work in newly accessible areas) and a decrease in the returns for the non-agricultural business sector, as increased market access increases competition from outsiders in previously remote areas. 
$\begin{array}{lllll}(1) & \text { (2) }\end{array}$

Full

Group 1 Group 2 Group 3 Group 4 Group 5 Sample

Panel A: Segment Difference in Difference

Treatment Assignment\#Post Road Improvement

Group 1

Post Road Improvement (0/1)

Construction Administrative Data

Improved Road Sub-Segment (0/1)

$\%$ of Sub-Segment Improved

$\begin{array}{llllll}-206 & -386.8 & -66.3 & -276.7 & -68.6 & 36.3 \\ {[224.6]} & {[225.7]^{*}} & {[227.8]} & {[179.3]} & {[169.3]} & {[127.4]} \\ -524.2 & -219.9 & 1270.9 & 1109.3 & 1163.5 & -155.4 \\ {[199.1]^{* * *}} & {[184.1]} & {[188.2]^{* * *}} & {[171.6]^{* * *}} & {[157.2]^{* * *}} & {[121.0]}\end{array}$

Panel B: Continuous Time to Market Treatment

\begin{tabular}{llllll}
171.3 & -44.8 & 62.9 & 63.6 & -68.6 & -144.5 \\
{$[193.9]$} & {$[154.0]$} & {$[228.5]$} & {$[212.8]$} & {$[169.3]$} & {$[90.8]$} \\
-72.7 & -271.7 & -632.4 & -789.2 & -113.3 & -374.6 \\
{$[234.7]$} & {$[169.8]$} & {$[290.9]^{* *}$} & {$[311.5]^{* *}$} & {$[175.5]$} & {$[102.5]^{* * *}$} \\
\hline-3.42 & -26.8 & -19 & 5.41 & 14.4 & 7.92 \\
{$[29.1]$} & {$[17.3]$} & {$[20.5]$} & {$[4.03]$} & {$[3.97]^{* * *}$} & {$[2.49]^{* * *}$}
\end{tabular}

Instrumental Variables

(a) Time to Market $=\varphi$ (Treatment Assignment\#Post

\begin{tabular}{llllll}
43 & 101 & 198.9 & 7.67 & 3.85 & -3.15 \\
{$[47.4]$} & {$[63.4]$} & {$[1143.0]$} & {$[4.98]$} & {$[9.42]$} & {$[11.1]$} \\
13.8 & 58.4 & 184.9 & 35.2 & 6.45 & 20.3 \\
{$[44.8]$} & {$[38.3]$} & {$[92.1]^{* *}$} & {$[14.9]^{* *}$} & {$[9.83]$} & {$[5.64]^{* * *}$} \\
\hline 2505.7 & 2569.9 & 2962.2 & 2962.2 & 2543.7 & 2497.7 \\
3664.1 & 3716.7 & 3833.7 & 3833.7 & 3579.8 & 3515.5 \\
-4.18 & -4.18 & -3.49 & -39.6 & -17.4 & -17.8 \\
63.9 & 33.3 & 0.062 & 470.1 & 74.8 & 253 \\
73.7 & 56.9 & 18.4 & 57.7 & 68.7 & 242.6 \\
113 & 142 & 96 & 138 & 135 & 410 \\
1,219 & 1,496 & 1,006 & 1,652 & 1,415 & 4,667 \\
5,549 & 6,795 & 4,560 & 7,639 & 6,490 & 21,406 \\
\hline
\end{tabular}

(b) Time to Market $=\varphi(\%$ of Sub-Segment Improved $)$

Mean of Comp. at Pre-Period

SD of Comp. at Pre-Period

Time to Market Reduction

(a) K-P rk Wald F

(b) K-P rk Wald F

Number of Clusters

Number of Households

Observations

Standard errors in brackets clustered at the segment level.

${ }^{*} \mathrm{p}<0.10, * * \mathrm{p}<0.05, * * * \mathrm{p}<0.01$

Notes: All equations include household and year fixed effects. Columns (1)-(5) shows the impact for each treatment Assignment group along the NTH.

Column (6) shows impact across the whole NTH. Panel A shows the estimations using the difference in difference between segments methodology, where adjacent segments are compare before and after the treatment segment is improved. The bottom part panel A uses the administrative data on the construction progress of sub-segments. Panel B shows the estimations using the continuous time to market methodology, where all households experience improvements in travel times due to the improvement in the roads in the accessibility model. The bottom of panel $B$ shows the instrumental variable estimation where the time to market is instrumented with the timeline of construction. The table shows the mean and std. deviation of the outcome variable for the comparison in each group before the road improvement and the baseline mean in the full sample column. Time to market reduction shows the difference before and after the improvement for the treatment group in each column and the difference for households in improved segments between the end line and the baseline. K-P rk Wald F is the F statistic for weak identification test(Cragg-Donald or Kleibergen-Paap) of the excluded instruments 
TABLE 37 IMPACTS ON AGRICULTURE SECTOR LABOR INCOME

\section{Annual income derived from labor in agriculture}

(1)

(2)

(3)

(4)

(5)

(6)

Full

Group $1 \quad$ Group 2 $\quad$ Group $3 \quad$ Group 4 $\quad$ Group $5 \quad$ Sample

\begin{tabular}{|c|c|c|c|c|c|c|}
\hline \multicolumn{7}{|l|}{ Panel A: Segment Difference in Difference } \\
\hline Treatment Assignment\#Post Road Improvement & $\begin{array}{l}-147.5 \\
{[47.7]^{* * *}}\end{array}$ & $\begin{array}{l}-103.8 \\
{[39.0]^{* * *}}\end{array}$ & $\begin{array}{l}98.3 \\
{[43.6]^{* *}}\end{array}$ & $\begin{array}{l}-12.1 \\
{[30.4]}\end{array}$ & $\begin{array}{l}-47.6 \\
{[29.8]}\end{array}$ & $\begin{array}{l}-54.6 \\
{[27.5]^{* *}}\end{array}$ \\
\hline Post Road Improvement $(0 / 1)$ & $\begin{array}{l}159.7 \\
{[41.5]^{* * *}}\end{array}$ & $\begin{array}{l}102.5 \\
{[30.0]^{* * *}}\end{array}$ & $\begin{array}{l}78.3 \\
{[32.8]^{* *}}\end{array}$ & $\begin{array}{l}84.5 \\
{[26.7]^{* * *}}\end{array}$ & $\begin{array}{l}125.2 \\
{[30.0]^{* * *}}\end{array}$ & $\begin{array}{l}158.4 \\
{[26.3]^{* * *}}\end{array}$ \\
\hline \multicolumn{7}{|l|}{ Construction Administrative Data } \\
\hline Improved Road Sub-Segment (0/1) & $\begin{array}{l}-78.3 \\
{[36.1]^{* *}}\end{array}$ & $\begin{array}{l}-29.3 \\
{[31.2]}\end{array}$ & $\begin{array}{l}54.4 \\
{[42.2]}\end{array}$ & $\begin{array}{l}13.3 \\
{[42.2]}\end{array}$ & $\begin{array}{l}-47.6 \\
{[29.8]}\end{array}$ & $\begin{array}{l}-31.7 \\
{[17.8]^{*}}\end{array}$ \\
\hline$\%$ of Sub-Segment Improved & $\begin{array}{l}-139.4 \\
{[47.3]^{* * *}}\end{array}$ & $\begin{array}{l}-46.3 \\
{[36.8]} \\
\end{array}$ & $\begin{array}{l}69.4 \\
{[93.1]} \\
\end{array}$ & $\begin{array}{l}43.3 \\
{[88.5]} \\
\end{array}$ & $\begin{array}{l}-48.4 \\
{[31.4]}\end{array}$ & $\begin{array}{l}-60.2 \\
{[20.4]^{* * *}}\end{array}$ \\
\hline \multicolumn{7}{|l|}{ Panel B: Continuous Time to Market Treatment } \\
\hline Time to nearest market & $\begin{array}{l}10.6 \\
{[5.92]^{*}}\end{array}$ & $\begin{array}{l}-4.95 \\
{[5.44]}\end{array}$ & $\begin{array}{l}-11.6 \\
{[3.61]^{* * *}}\end{array}$ & $\begin{array}{l}-0.56 \\
{[0.65]}\end{array}$ & $\begin{array}{l}2.13 \\
{[1.06]^{* *}}\end{array}$ & $\begin{array}{l}1.03 \\
{[0.47]^{* *}}\end{array}$ \\
\hline \multicolumn{7}{|l|}{ Instrumental Variables } \\
\hline \multirow[t]{2}{*}{ (a) Time to Market $=\varphi$ (Treatment Assignment\#Post) } & 30.8 & 27.1 & -295 & 0.34 & 2.67 & 4.73 \\
\hline & {$[10.4]^{* * *}$} & {$[11.2]^{* *}$} & [1132.0] & {$[0.85]$} & [1.67] & {$[2.43]^{*}$} \\
\hline \multirow[t]{2}{*}{ (b) Time to Market $=\varphi(\%$ of Sub-Segment Improved) } & 26.6 & 9.95 & -20.3 & -1.93 & 2.76 & 3.27 \\
\hline & {$[9.37]^{* * *}$} & [8.10] & {$[27.5]$} & [4.01] & {$[1.77]$} & {$[1.11]^{* * *}$} \\
\hline Mean of Comp. at Pre-Period & 322.5 & 254.4 & 173.4 & 173.4 & 233.7 & 186.3 \\
\hline SD of Comp. at Pre-Period & 704 & 622.7 & 552.5 & 552.5 & 637.9 & 542.2 \\
\hline Time to Market Reduction & -4.18 & -4.18 & -3.49 & -39.6 & -17.4 & -17.8 \\
\hline (a) K-P rk Wald F & 63.9 & 33.3 & 0.062 & 470.1 & 74.8 & 253 \\
\hline (b) K-P rk Wald F & 73.7 & 56.9 & 18.4 & 57.7 & 68.7 & 242.6 \\
\hline Number of Clusters & 113 & 142 & 96 & 138 & 135 & 410 \\
\hline Number of Households & 1,219 & 1,496 & 1,006 & 1,652 & 1,415 & 4,667 \\
\hline Observations & 5,549 & 6,795 & 4,560 & 7,639 & 6,490 & 21,406 \\
\hline
\end{tabular}

Standard errors in brackets clustered at the segment level.

${ }^{*} p<0.10,{ }^{* *} p<0.05,{ }^{* * *} p<0.01$

Notes: All equations include household and year fixed effects. Columns (1)-(5) shows the impact for each treatment Assignment group along the NTH. Column (6) shows impact across the whole NTH. Panel A shows the estimations using the difference in difference between segments methodology, where adjacent segments are compare before and after the treatment segment is improved. The bottom part panel A uses the administrative data on the construction progress of sub-segments. Panel B shows the estimations using the continuous time to market methodology, where all households experience improvements in travel times due to the improvement in the roads in the accessibility model. The bottom of panel B shows the instrumental variable estimation where the time to market is instrumented with the timeline of construction. The table shows the mean and std. deviation of the outcome variable for the comparison in each group before the road improvement and the baseline mean in the full sample column. Time to market reduction shows the difference before and after the improvement for the treatment group in each column and the difference for households in improved segments between the end line and the baseline. $\mathrm{K}$ $\mathrm{P}$ rk Wald $\mathrm{F}$ is the $\mathrm{F}$ statistic for weak identification test(Cragg-Donald or Kleibergen-Paap) of the excluded instruments 
Annual income derived from labor in non- agriculture

\begin{tabular}{|c|c|c|c|c|c|c|}
\hline & $\begin{array}{c}(1) \\
\text { Group } \\
1 \\
\end{array}$ & $\begin{array}{c}\text { (2) } \\
\text { Group } 2\end{array}$ & Group 3 & Group 4 & $\begin{array}{c}\text { (5) } \\
\text { Group } 5\end{array}$ & $\begin{array}{c}(6) \\
\text { Full } \\
\text { Sample } \\
\end{array}$ \\
\hline \multicolumn{7}{|l|}{ Panel A: Segment Difference in Difference } \\
\hline Treatment Assignment\#Post Road Improvement & $\begin{array}{l}-50.8 \\
{[84.5]}\end{array}$ & $\begin{array}{l}-50 \\
{[84.3]}\end{array}$ & $\begin{array}{l}49.9 \\
{[147.0]}\end{array}$ & $\begin{array}{l}-122.4 \\
{[69.4]^{*}}\end{array}$ & $\begin{array}{l}-13 \\
{[77.6]}\end{array}$ & $\begin{array}{l}38.3 \\
{[49.8]}\end{array}$ \\
\hline Post Road Improvement (0/1) & $\begin{array}{l}103.3 \\
{[63.7]}\end{array}$ & $\begin{array}{l}85.7 \\
{[67.0]}\end{array}$ & $\begin{array}{l}315.6 \\
{[95.2]^{* * *}}\end{array}$ & $\begin{array}{l}316.9 \\
{[67.4]^{* * *}}\end{array}$ & $\begin{array}{l}313.3 \\
{[60.3]^{* * *}}\end{array}$ & $\begin{array}{l}163.3 \\
{[45.5]^{* * *}}\end{array}$ \\
\hline \multicolumn{7}{|l|}{ Construction Administrative Data } \\
\hline Improved Road Sub-Segment (0/1) & $\begin{array}{l}7.28 \\
{[68.3]}\end{array}$ & $\begin{array}{l}-9.14 \\
{[71.4]}\end{array}$ & $\begin{array}{l}-24.9 \\
{[106.6]}\end{array}$ & $\begin{array}{l}-138.9 \\
{[63.6]^{* *}}\end{array}$ & $\begin{array}{l}-13 \\
{[77.6]}\end{array}$ & $\begin{array}{l}-67.9 \\
{[36.5]^{*}}\end{array}$ \\
\hline$\%$ of Sub-Segment Improved & $\begin{array}{l}-38.4 \\
{[85.5]} \\
\end{array}$ & $\begin{array}{l}-25.2 \\
{[97.6]} \\
\end{array}$ & $\begin{array}{l}65 \\
{[89.5]}\end{array}$ & $\begin{array}{l}-54.8 \\
{[71.5]}\end{array}$ & $\begin{array}{l}3.22 \\
{[82.9]} \\
\end{array}$ & $\begin{array}{l}-76.9 \\
{[44.2]^{*}}\end{array}$ \\
\hline \multicolumn{7}{|l|}{ Panel B: Continuous Time to Market Treatment } \\
\hline Time to nearest market & $\begin{array}{l}-0.7 \\
{[8.51]}\end{array}$ & $\begin{array}{l}2.75 \\
{[10.7]}\end{array}$ & $\begin{array}{l}-1.8 \\
{[6.56]}\end{array}$ & $\begin{array}{l}1.19 \\
{[1.60]}\end{array}$ & $\begin{array}{l}-0.019 \\
{[2.52]}\end{array}$ & $\begin{array}{l}1.9 \\
{[1.05]^{*}}\end{array}$ \\
\hline \multicolumn{7}{|l|}{ Instrumental Variables } \\
\hline (a) Time to Market $=\varphi$ (Treatment Assignment\#Post) & $\begin{array}{l}10.6 \\
{[17.7]}\end{array}$ & $\begin{array}{l}13.1 \\
{[22.3]}\end{array}$ & $\begin{array}{l}-149.9 \\
{[735.4]}\end{array}$ & $\begin{array}{l}3.4 \\
{[1.95]^{*}}\end{array}$ & $\begin{array}{l}0.73 \\
{[4.36]}\end{array}$ & $\begin{array}{l}-3.32 \\
{[4.33]}\end{array}$ \\
\hline (b) Time to Market $=\varphi(\%$ of Sub-Segment Improved $)$ & $\begin{array}{l}7.31 \\
{[16.3]} \\
\end{array}$ & $\begin{array}{l}5.41 \\
{[21.0]} \\
\end{array}$ & $\begin{array}{l}-19 \\
{[26.5]}\end{array}$ & $\begin{array}{l}2.44 \\
{[3.21]}\end{array}$ & $\begin{array}{l}-0.18 \\
{[4.72]} \\
\end{array}$ & $\begin{array}{l}4.17 \\
{[2.41]^{*}}\end{array}$ \\
\hline Mean of Comp. at Pre-Period & 644.2 & 917.5 & 970.1 & 970.1 & 600.6 & 686.2 \\
\hline SD of Comp. at Pre-Period & 1611.8 & 2220.5 & 2140.4 & 2140.4 & 1675.6 & 1804.7 \\
\hline Time to Market Reduction & -4.18 & -4.18 & -3.49 & -39.6 & -17.4 & -17.8 \\
\hline (a) K-P rk Wald F & 63.9 & 33.3 & 0.062 & 470.1 & 74.8 & 253 \\
\hline (b) K-P rk Wald F & 73.7 & 56.9 & 18.4 & 57.7 & 68.7 & 242.6 \\
\hline Number of Clusters & 113 & 142 & 96 & 138 & 135 & 410 \\
\hline Number of Households & 1,219 & 1,496 & 1,006 & 1,652 & 1,415 & 4,667 \\
\hline Observations & 5,549 & 6,795 & 4,560 & 7,639 & 6,490 & 21,406 \\
\hline
\end{tabular}

Standard errors in brackets clustered at the segment level.

$* \mathrm{p}<0.10, * * \mathrm{p}<0.05, * * * \mathrm{p}<0.01$

Notes: All equations include household and year fixed effects. Columns (1)-(5) shows the impact for each treatment Assignment group along the NTH. Column (6) shows impact across the whole NTH. Panel A shows the estimations using the difference in difference between segments methodology, where adjacent segments are compare before and after the treatment segment is improved. The bottom part panel A uses the administrative data on the construction progress of sub-segments. Panel B shows the estimations using the continuous time to market methodology, where all households experience improvements in travel times due to the improvement in the roads in the accessibility model. The bottom of panel B shows the instrumental variable estimation where the time to market is instrumented with the timeline of construction. The table shows the mean and std. deviation of the outcome variable for the comparison in each group before the road improvement and the baseline mean in the full sample column. Time to market reduction shows the difference before and after the improvement for the treatment group in each column and the difference for households in improved segments between the end line and the baseline. K-P rk Wald $\mathrm{F}$ is the $\mathrm{F}$ statistic for weak identification test(Cragg-Donald or Kleibergen-Paap) of the excluded instruments 
TABLE 39 IMPACTS ON AGRICULTURE SECTOR INDEPENDENT/BUSINESS INCOME

\section{Annual income derived from business in agriculture}

(1)

(2)

(3)

(4)

(5)

(6)

Ful

Group 1 Group 2 Group 3 Group $4 \quad$ Group $5 \quad$ Sample

\begin{tabular}{|c|c|c|c|c|c|c|}
\hline \multicolumn{7}{|l|}{ Panel A: Segment Difference in Difference } \\
\hline \multirow[t]{2}{*}{ Treatment Assignment\#Post Road Improvement } & 56.8 & -57.8 & -69 & -90.4 & 15.2 & 61.9 \\
\hline & [153.4] & [130.2] & [87.8] & [73.4] & [42.1] & [64.8] \\
\hline \multirow[t]{2}{*}{ Post Road Improvement (0/1) } & -296 & -131.8 & -100.8 & -66.2 & -119.3 & -104.8 \\
\hline & {$[123.2]^{* *}$} & [90.8] & {$[57.4]^{*}$} & [81.4] & {$[39.7]^{* * *}$} & {$[61.6]^{*}$} \\
\hline \multicolumn{7}{|l|}{ Construction Administrative Data } \\
\hline \multirow[t]{2}{*}{ Improved Road Sub-Segment (0/1) } & 29.7 & -0.96 & 13.7 & -153.7 & 15.2 & -51.6 \\
\hline & [106.0] & [79.8] & [107.9] & [114.9] & [42.1] & [39.4] \\
\hline \multirow[t]{2}{*}{$\%$ of Sub-Segment Improved } & 39 & -54.8 & -68 & -179.9 & -1.68 & -83.2 \\
\hline & {$[149.5]$} & {$[100.0]$} & {$[119.1]$} & [132.3] & [46.3] & {$[48.7]^{*}$} \\
\hline \multicolumn{7}{|l|}{ Panel B: Continuous Time to Market Treatment } \\
\hline \multirow[t]{2}{*}{ Time to nearest market } & -23.5 & -11.8 & 8.09 & 3.62 & -0.12 & 1.86 \\
\hline & {$[12.4]^{*}$} & {$[6.60]^{*}$} & {$[6.93]$} & {$[1.62]^{* *}$} & {$[1.32]$} & {$[1.06]^{*}$} \\
\hline \multicolumn{7}{|l|}{ Instrumental Variables } \\
\hline \multirow[t]{2}{*}{ (a) Time to Market= $\varphi$ (Treatment Assignment\#Post) } & -11.8 & 15.1 & 207.1 & 2.51 & -0.86 & -5.37 \\
\hline & [31.9] & [34.5] & [871.3] & [2.02] & [2.37] & [5.63] \\
\hline \multirow[t]{2}{*}{ (b) Time to Market $=\varphi(\%$ of Sub-Segment Improved) } & -7.43 & 11.8 & 19.9 & 8.03 & 0.096 & 4.51 \\
\hline & [28.4] & [21.8] & [34.1] & [6.18] & [2.64] & {$[2.65]^{*}$} \\
\hline Mean of Comp. at Pre-Period & 570.3 & 429.2 & 279.6 & 279.6 & 153.5 & 346.5 \\
\hline SD of Comp. at Pre-Period & 2378 & 1965.3 & 1411.7 & 1411.7 & 785.7 & 1618.5 \\
\hline Time to Market Reduction & -4.18 & -4.18 & -3.49 & -39.6 & -17.4 & -17.8 \\
\hline (a) K-P rk Wald F & 63.9 & 33.3 & 0.062 & 470.1 & 74.8 & 253 \\
\hline (b) K-P rk Wald F & 73.7 & 56.9 & 18.4 & 57.7 & 68.7 & 242.6 \\
\hline Number of Clusters & 113 & 142 & 96 & 138 & 135 & 410 \\
\hline Number of Households & 1,219 & 1,496 & 1,006 & 1,652 & 1,415 & 4,667 \\
\hline Observations & 5,549 & 6,795 & 4,560 & 7,639 & 6,490 & 21,406 \\
\hline
\end{tabular}

Standard errors in brackets clustered at the segment level.

$* \mathrm{p}<0.10, * * \mathrm{p}<0.05, * * * \mathrm{p}<0.01$

Notes: All equations include household and year fixed effects. Columns (1)-(5) shows the impact for each treatment Assignment group along the NTH. Column (6) shows impact across the whole NTH. Panel A shows the estimations using the difference in difference between segments methodology, where adjacent segments are compare before and after the treatment segment is improved. The bottom part panel A uses the administrative data on the construction progress of sub-segments. Panel B shows the estimations using the continuous time to market methodology, where all households experience improvements in travel times due to the improvement in the roads in the accessibility model. The bottom of panel B shows the instrumental variable estimation where the time to market is instrumented with the timeline of construction. The table shows the mean and std. deviation of the outcome variable for the comparison in each group before the road improvement and the baseline mean in the full sample column. Time to market reduction shows the difference before and after the improvement for the treatment group in each column and the difference for households in improved segments between the end line and the baseline. K-P rk Wald F is the F statistic for weak identification test(Cragg-Donald or Kleibergen-Paap) of the excluded instruments 
TABLE 40 IMPACTS ON NON-AGRICULTURE INDEPENDENT/BUSINESS INCOME

Annual income derived from business in non-agriculture

$\begin{array}{llllll}\text { (1) } & (2) & \text { (3) } & \text { (4) } & \text { (5) }\end{array}$

$\begin{array}{lccccc}1 & 2 & \text { Group } 3 & \text { Group } 4 & \text { Group } 5 & \text { Sample }\end{array}$

\begin{tabular}{|c|c|c|c|c|c|c|}
\hline \multicolumn{7}{|l|}{ Panel A: Segment Difference in Difference } \\
\hline Treatment Assignment\#Post Road Improvement & $\begin{array}{l}129.4 \\
{[213.8]}\end{array}$ & $\begin{array}{l}70.3 \\
{[207.5]}\end{array}$ & $\begin{array}{l}1.37 \\
{[234.0]}\end{array}$ & $\begin{array}{l}-127.3 \\
{[149.9]}\end{array}$ & $\begin{array}{l}104.2 \\
{[168.0]}\end{array}$ & $\begin{array}{l}-22.5 \\
{[109.1]}\end{array}$ \\
\hline Post Road Improvement (0/1) & $\begin{array}{l}56.7 \\
{[168.8]}\end{array}$ & $\begin{array}{l}93.1 \\
{[153.8]}\end{array}$ & $\begin{array}{l}638.3 \\
{[189.8]^{* * *}}\end{array}$ & $\begin{array}{l}551.6 \\
{[146.9]^{* * *}}\end{array}$ & $\begin{array}{l}466.1 \\
{[133.1]^{* * *}}\end{array}$ & $\begin{array}{l}251.6 \\
{[100.0]^{* *}}\end{array}$ \\
\hline Construction Administrative Data & & & & & & \\
\hline Improved Road Sub-Segment (0/1) & $\begin{array}{l}56.8 \\
{[172.9]}\end{array}$ & $\begin{array}{l}-52.9 \\
{[153.7]}\end{array}$ & $\begin{array}{l}7.88 \\
{[214.5]}\end{array}$ & $\begin{array}{l}185.1 \\
{[163.9]}\end{array}$ & $\begin{array}{l}104.2 \\
{[168.0]}\end{array}$ & $\begin{array}{l}4.18 \\
{[81.4]}\end{array}$ \\
\hline$\%$ of Sub-Segment Improved & $\begin{array}{l}117.6 \\
{[215.3]}\end{array}$ & $\begin{array}{l}10.5 \\
{[171.2]}\end{array}$ & $\begin{array}{l}213.4 \\
{[438.4]}\end{array}$ & $\begin{array}{l}230.3 \\
{[359.0]}\end{array}$ & $\begin{array}{l}131.6 \\
{[173.9]}\end{array}$ & $\begin{array}{l}-15.2 \\
{[92.9]} \\
\end{array}$ \\
\hline \multicolumn{7}{|l|}{ Panel B: Continuous Time to Market Treatment } \\
\hline Time to nearest market & $\begin{array}{l}-7.12 \\
{[29.0]}\end{array}$ & $\begin{array}{l}-25.7 \\
{[19.0]}\end{array}$ & $\begin{array}{l}-23 \\
{[19.5]}\end{array}$ & $\begin{array}{l}3.28 \\
{[3.49]}\end{array}$ & $\begin{array}{l}11.6 \\
{[3.98]^{* * *}}\end{array}$ & $\begin{array}{l}5.25 \\
{[2.25]^{* *}}\end{array}$ \\
\hline Instrumental Variables & & & & & & \\
\hline (a) Time to Market $=\varphi$ (Treatment Assignment\#Post) & $\begin{array}{l}-27 \\
{[44.7]}\end{array}$ & $\begin{array}{l}-18.4 \\
{[54.2]}\end{array}$ & $\begin{array}{l}-4.1 \\
{[700.4]}\end{array}$ & $\begin{array}{l}3.53 \\
{[4.15]}\end{array}$ & $\begin{array}{l}-5.85 \\
{[9.60]}\end{array}$ & $\begin{array}{l}1.95 \\
{[9.46]}\end{array}$ \\
\hline (b) Time to Market $=\varphi(\%$ of Sub-Segment Improved $)$ & $\begin{array}{l}-22.4 \\
{[41.1]} \\
\end{array}$ & $\begin{array}{l}-2.26 \\
{[36.8]}\end{array}$ & $\begin{array}{l}-62.4 \\
{[127.1]}\end{array}$ & $\begin{array}{l}-10.3 \\
{[16.2]} \\
\end{array}$ & $\begin{array}{l}-7.5 \\
{[10.1]}\end{array}$ & $\begin{array}{l}0.82 \\
{[5.03]} \\
\end{array}$ \\
\hline Mean of Comp. at Pre-Period & 441.7 & 594.3 & 1162.8 & 1162.8 & 837.1 & 704.2 \\
\hline SD of Comp. at Pre-Period & 2871.9 & 3360.1 & 4110.5 & 4110.5 & 3522.9 & 3113 \\
\hline Time to Market Reduction & -4.18 & -4.18 & -3.49 & -39.6 & -17.4 & -17.8 \\
\hline (a) K-P rk Wald F & 63.9 & 33.3 & 0.062 & 470.1 & 74.8 & 253 \\
\hline (b) K-P rk Wald F & 73.7 & 56.9 & 18.4 & 57.7 & 68.7 & 242.6 \\
\hline Number of Clusters & 113 & 142 & 96 & 138 & 135 & 410 \\
\hline Number of Households & 1,219 & 1,496 & 1,006 & 1,652 & 1,415 & 4,667 \\
\hline Observations & 5,549 & 6,795 & 4,560 & 7,639 & 6,490 & 21,406 \\
\hline
\end{tabular}

Standard errors in brackets clustered at the segment level.

$* \mathrm{p}<0.10, * * \mathrm{p}<0.05, * * * \mathrm{p}<0.01$

Notes: All equations include household and year fixed effects. Columns (1)-(5) shows the impact for each treatment Assignment group along the NTH. Column (6) shows impact across the whole NTH. Panel A shows the estimations using the difference in difference between segments methodology, where adjacent segments are compare before and after the treatment segment is improved. The bottom part panel A uses the administrative data on the construction progress of sub-segments. Panel B shows the estimations using the continuous time to market methodology, where all households experience improvements in travel times due to the improvement in the roads in the accessibility model. The bottom of panel B shows the instrumental variable estimation where the time to market is instrumented with the timeline of construction. The table shows the mean and std. deviation of the outcome variable for the comparison in each group before the road improvement and the baseline mean in the full sample column. Time to market reduction shows the difference before and after the improvement for the treatment group in each column and the difference for households in improved segments between the end line and the baseline. K-P rk Wald F is the F statistic for weak identification test(Cragg-Donald or Kleibergen-Paap) of the excluded instruments 


\section{CONCLUSIONS}

Our results suggest that the improvement of the NTH in El Salvador had modest impacts in the short run. While we find clear evidence of improvement in market access, we find no changes in land values nor agriculture productivity. Limited effects on the probability of having a title in some segments of the NTH, increase in the probability of commercialization in agriculture, and in the value of agriculture production designated for auto-consumption.

On the other hand, we find negative impact on household income and find an interesting pattern in the impacts across the agriculture and non-agriculture sector. Namely, the negative impacts on household income are through dependent labor in the agriculture sector and independent/business income in the nonagriculture sector. We posit that these short run effects, might be due to a reallocation of dependent labor supply across sectors and an increase business competition from newly easily accessible areas after the road improvement.

There are important limitations to our evaluation. Our evaluation was restricted to the impact of the NTH. While the project originally included improvements of feeder roads, this additional component was not implemented due to financial constraints. Feeder roads play a crucial role in rural infrastructure, and the impact of a rural road is likely to depend on these complementary investments. While highways might be key investments to reduce transportation costs and transaction costs, their effects can be stifled if households cannot easily access them through adequate feeder roads.

For example, consider the following hypothetical situation (illustrated in Figure 9). A farmer is located north of the NTH, and is trying to reach a market in the south. He will travel through the feeder road to the NTH, but will only spend a little time on the highway. He will then take other feeder roads to the market he is trying to reach. While he will experience some reductions in travel time with the construction of the NTH, the bulk of his trip will depend on the conditions of the smaller roads around the highway.

In this spirit, the impact of the NTH might have been boosted with the rehabilitation of the adjacent feeder roads (as originally envisaged by the project). This question should be part of a future research agenda considering that government of El Salvador rehabilitated part of network of feeder roads after the end line survey. 


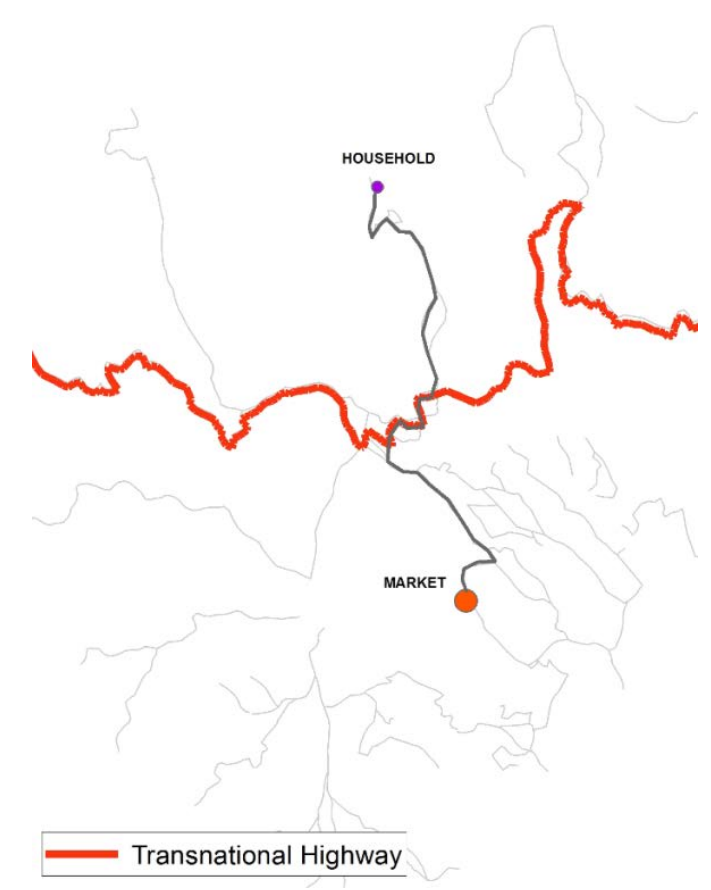

Our results might be limited by delays in the construction of the NTH. Our identification strategy exploited the rollout of the highway, where different segments would be constructed in different dates over a forty-month period. Our estimates are driven by the comparison between segments that had and had not benefited from the road construction in each survey round. However, due to construction delays, most segments were constructed in the later stages of the project. This reduces our main source of variability and limits the ability of our design to detect small impacts in other outcomes. In addition, these delays mean that most segments were only constructed in the later stages of the project, our results mostly capture short-run effects of the NTH. Segments 2-7 were only ready by August-November 2012, and our final round of data was collected in late 2013.

It is difficult to assess the impact of a project like the rehabilitation of the NTH when so little time has elapsed since its full completion. Road benefits might take some time to materialize if households have to adapt their behavior, change agricultural marketing patterns, become aware of non-farm employment opportunities, etc. Therefore, while the NTH might play a larger role in household welfare in the long run, the delays in public works restrict our ability to explore this possibility more thoroughly. 


\title{
Chapter 4 - IMPAct Evaluation of the RuRal Water AND SANitation PROJects in NORTHERN El SALVADOR
}

Impact Estimates Using Panel Data from 2011 to 2013

\author{
with Maureen Cropper and Raymond Guiteras
}

\section{Summary}

Adequate and dependable access to water and sanitation is needed to sustain humanity and to promote growth and development. For the rural poor access to water is essential both for basic needs and for productive purposes. Safe drinking-water and sanitation are crucial to human welfare. The Millennium Development Declaration in 2000 called for the world to halve, by 2015 , the proportion of people without access to safe drinking water as well as the proportion of people who do not have access to basic sanitation. Yet in 2015, millions still did not have access to improved drinkingwater sources or have access to improved sanitation, such as toilets or latrines.

This essay quantifies the benefits of a set of water, sanitation and hygiene interventions, that included community training campaigns, and the construction or improvement of water and sanitation systems in communities across the Northern Zone of El Salvador between 2006 and 2012 to advance this millennium development goal. The goal of the water and sanitation investments was to enhance access to water systems and to improve sanitation services for the poorest by providing piped water or (in a few cases) public taps for households that previously did not have access to this level of service and latrines to all water project participants who do not already have improved sanitation. The impact of the interventions was measured using a rigorous quasi-experimental methodology that used a matched difference-indifferences estimator with a three-year (2011-2013) panel household survey specifically designed to evaluate the impact these investments.

Our impact analysis suggests that the water, sanitation and hygiene interventions resulted in significant improvements in access to safe water and improved sanitation. We found robust and significant benefits across measures of access to water and sanitation, an increase of 3 percentage point in access to improved sanitation and of 25 percentage points in access to improved water sources in treatment communities. We found reductions in the time to reach improved water sources ( 2 minutes), increases in ownership and use of improved water and sanitation services, 28 percentage points more likely to use tap water as a principal source for drinking water, increases in the reliability of service with 16.5 hours per week more of service in treatment communities. Other impacts include: increases in satisfaction with the water system in the community, reductions in the perceived riskiness of drinking water from water systems.

We found a decrease the probability of having bacterial contamination at the source. Treatment households are between 16 and 19 percentage points less likely to have E.coli in their water source after but there are no effects on the water stored or at the point of consumption. This indicates the drinking water is being contaminated between the source and the point of consumption. We also found that expenditure on water increased by 1.87 USD per month, on average, among beneficiary households following the installation of metered water taps. The reductions in the time spent carrying water and doing laundry outside the home were significant. On average, individuals saved 1.41 hours per week carrying water thanks to the interventions and up to 2.75 for households that report being direct beneficiaries. The decrease in time spent doing laundry outside the home was on average 1.79 hours per week were concentrated and significant for females.

Exploring how these effects differ by the amount of time beneficiary households were connected to the new or improved system, we found that these effects occur within the first months of being connected and that among households that were connected for a longer time-period, these effects persist; indicative of the sustainability of community-demand driven rural water and sanitation infrastructure projects.

Keywords: water and sanitation, impact evaluation, matching, panel data, El Salvador 


\section{INTRODUCTION}

The importance of water and sanitation infrastructure for economic growth and development in general has long been recognized. Throughout history people have settled near water sources to use this resource for human consumption, sanitation services, irrigation and food production, etc. The economic and social returns from investments in water and sanitation systems are high and reflected through increased economic security and reductions in health risks, increased resilience of the poor to disease and climate shocks, and ultimately poverty reduction. For the rural poor, who make up some $75 \%$ of the world's poorest people, access to water is essential both for basic needs and for productive purposes. The consumption of unsafe water impairs human health through illnesses such as diarrhea, and untreated sewage can contaminate drinking-water supplies and the environment, creating a heavy burden on communities.

The Millennium Development Declaration in 2000 called $^{20}$ for the world to halve, by 2015, the proportion of people without access to safe drinking water as well as the proportion of people who do not have access to basic sanitation. However, by 2015, the WHO/UNICEF Joint Monitoring Programme (JMP) estimated that 660 million people still did not have access to improved drinking-water sources, 1.8 billion people were estimated to drink water that is faecally contaminated and over 2.4 billion people do not have access to improved sanitation, such as toilets or latrines ${ }^{21}$.

This essay quantifies the benefits of a set of water, sanitation and hygiene interventions, that included community training campaigns, and the construction or improvement of water and sanitation systems in communities across the Northern Zone of El Salvador between 2006 and 2012 to advance this millennium development goal.

The conditions in the area were these interventions took place were some of the worst in the country. Half of the poorest municipalities in El Salvador are in the Northern Zone and suffered more damage from the country's internal conflict during the 1980s than any other region. In 2007, the economic and social indicators in the Northern Zone were worse than the national average: 44.7 percent of households in the Northern Zone were poor, compared with the 34.6 percent national estimate; 17.2 percent of households in the region lived in extreme poverty in 2007 compared with 10.8 percent at the national level. Human capital development was also lower in this region than in any other. The average level of schooling in El Salvador was 5.9 years in 2007, while the average in the Northern Zone was only 4.3 years. The percentage of illiterate people in the Northern Zone was 18.3 percent in 2007 versus an 11.1 percent national average. ${ }^{22}$

The goal of these water and sanitation and hygiene (WASH) interventions was to enhance access to water systems and to improve sanitation services for the poorest by providing piped water or (in a few cases) public taps for households that previously did not have access to this level of service and latrines to all water project participants who do not already have improved sanitation. In addition, the interventions included greases traps for all beneficiary households to manage gray waters.

Household water demand for different uses is determined by the time, labor and financial costs required to access water. Since households in the Northern Zone had access to multiple sources of water and different levels of service, in this evaluation, we gave priority to the measurement of changes in expenses to access water of adequate quality for different needs and the time costs associated with lack of access adequate quality water sources. One reason for this is that these costs accounted for the bulk of the expected benefits of

\footnotetext{
${ }^{20}$ United Nations Millennium Development Goals. 2000. http://www.un.org/millenniumgoals/

${ }^{21}$ http://www.un.org/sustainabledevelopment/water-and-sanitation

${ }^{22}$ Source: (DIGESTYC, 2007).
} 
water supply interventions in the economic analysis underlying the program ${ }^{23}$. We did not focus on the effects on health because the diarrhea rates in El Salvador dropped substantially in the years leading up to the intervention. This makes measuring changes in rates more difficult and costlier, and is likely to mean lowerthan-expected benefits from health improvements in these projects. We would have needed a very large sample size to detect any impact on self-reported health outcomes

Given the different types of interventions included in this WASH package, we included outcome indicators that would be affected by different aspects of the interventions and evaluate the impact of the interventions as a package. We included indicators such as expenses in water and time spent dealing with lack of access to reliable water sources, as mentioned before, and reliability, satisfaction of water services and water contamination for the water infrastructure component; for the sanitation infrastructure component, we included access to improved sanitation infrastructure; and for the hygiene campaign component we included frequency of hand washing, knowledge of diarrhea prevention and food handling practices.

This essay lays out the results of the impact evaluation of the WASH interventions. Using a baseline and two follow-up surveys, specifically designed to evaluate the impact these investments, that was administered ${ }^{24}$ from March to April of 2011, 2012, and 2013, respectively. The benefits of the water and sanitation projects are measured with a rigorous quasi-experimental design that incorporates matching, a panel survey and difference-in-differences (DID) estimations. To the extent possible, we examined the distribution of benefits and outcomes across gender and socio-economic groups.

In addition, we exploit the different dates that the WASH interventions were finalized to explore the sustainability of the observed impacts. By the time of the first follow-up survey in 2012, not all projects had been finalized and by the end line survey while all interventions were finalized. This implies that treatment households were connected to the new and/or improved systems for different lengths of time, which allows us to explore differences in the time between finalization of the interventions and the dates of the survey. This analysis allows us to explore the sustainability of the benefits and of the observed impacts.

This study contributes to the WASH literature in three ways. First, we examine the effect of an at-scale community-demand driven WASH intervention across a comprehensive set of indicators in a setting where the interventions mainly increase the quantity and quality of water and sanitation access. The examples in the WASH literature are often in the context of open defecation and were access to water is mainly through natural water sources. Our study present novel evidence on the effects of improving water and sanitation access through WASH intervention in a setting where water system existed but not of adequate quality. The evidence in this study from rural areas in El Salvador provides context and the opportunity to adjust the expectation on the effect of WASH intervention in other part of Latin America and the world where the initial condition of water and sanitation access are similar. By focusing on the costs of collecting, storing, and treating water, the perceptions and satisfaction of the beneficiaries, and the dynamics of the time reallocation caused by increased access to adequate water, we provide evidence on different mechanisms and benefits of WASH interventions that can be included in the cost benefit calculus of decision-makers at the time of deciding what interventions to fund.

Second, we provide evidence on the literature on the importance of research design at the early stages of impact evaluation to avoid relying on ex-post statistical methods selection, which have been recently showed to perform poorly in replicating known experimental impacts. The combination of pre-baseline matching and

\footnotetext{
${ }^{23}$ In the economic analysis prepared for the water and sanitation component, three-quarters of the expected benefits were attributed to reductions in coping costs, specifically the time costs associated with collecting water and the monetary cost of relying on alternative water sources (such as vendors) and storage systems.

${ }^{24}$ Data collection for the panel survey was implemented by the Dirección General de Estadísticas y Censos General (DIGESTYC) , the statistical agency of El Salvador.
} 
panel data in this study provides a methodologically well-grounded example of the impacts of WASH interventions in a literature that is plagued by short-comings due to intervention placement bias and the endogeneity of households' WASH choices that are a function of where they live.

Third we present novel evidence on the effects of WASH interventions on the quality of drinking water at the source and at the point of consumption. Contamination of drinking water from the source to the point of consumption is a persistent problem in developing countries. This study is one of the few in the literature that estimates the effects of WASH interventions on source and stored water over time and with significantly larger sample size. In addition, to identifying this bottleneck in the provision of safe water in a diverse set of rural communities, we provide evidence on how this point of distribution to point of consumption contamination is affected by WASH interventions. To our knowledge, this study is the first that estimates the impact of a large WASH intervention on the degree of contamination at the source versus at the point of consumption.

\section{INTERVENTIONS DESCRIPTION}

The WASH intervention in this study consisted in the construction of potable water and sanitation systems, technical assistance for community capacity building to improve water management-both environmental and financial-to ensure sustainability and maintenance of the systems, and community education related to appropriate health, hygiene and sanitation practices. The goal of the WASH interventions was to improve the lives of the poorest inhabitants of the Northern Zone of El Salvador through enhanced access to potable water systems, by improving quality, reliability, and building of new systems; and improving sanitation services for the households in these poor areas. These interventions were financed by the Millennium Challenge Corporation (MCC) and the government of El Salvador and were completed in September of 2012.

The water infrastructure projects consisted of 15 community taps and water systems connecting 26 wells and 19 water sources to an estimated 32,929 beneficiaries with 7,624 new metered household tap connections providing access to new or improved water distribution systems. The sanitation infrastructure projects built 1,702 composting latrines and 108 improved-hole latrines, and repaired 212 composting latrines in the households that were connected to the water system. In addition, it included the construction 7,142 greasetraps to dispose of gray waters.

The infrastructure projects were selected using a community demand-driven approach aimed at empowering the communities and promote community ownership of the projects. Communities in 62 municipalities in the Northern Zone, classified as either "Extreme Moderate Poverty" or "Extreme High Poverty" by the national poverty map, were invited to submit proposals for water and sanitation projects needed in their communities.

To be considered eligible for the proposals had to meet the following criteria: (1) the community and municipality had to be willing to make a financial commitment of 10 percent of the cost to the project (in cash or in-kind), (2) the community had to have a community development committee or organization (with legal documentation or willingness to organize) to ensure community commitment in the management, operation, and maintenance of the works, (3) the estimated cost of the project could not exceed 850 USD per beneficiary, (4) communities needed to agree on the provision of a sustainable monthly fee paid to be established in set community-municipality-contractor that would cover the costs of operating and maintaining the system.

After projects that did not meet the eligibility criteria were excluded, a list of 68 feasible projects remained. Our study includes 45 of these projects in the Northern Zone: 25 installed water in communities that did not previously have improved water services and remaining 20 projects improved and extended to additional households existing water systems. 


\section{LITERATURE REVIEW}

The importance of providing improved water and sanitation to promote development has long been recognized. From the effects on child mortality, to school attendance and work productivity gains, water and sanitation can improve the well-being of people throughout their life span [ (WHO/UNICEF, 2005)]. Recognizing this potential, one of the millennium goals is to halve the proportion of the population without sustainable access to safe drinking water and basic sanitation by 2015. In the developing world, the lack of access to safe water and improved sanitation service has clear implications for the health status of the poor and their economic life. Lack of access to water and sanitation not only exposes people to infectious waterborne disease-decreasing the probability of survival at young and old ages-it also imposes a burden on their economic life by reducing the amount of time spent on productive activities due to illness, time spent fetching and storing water, and water treatment costs.

The health impacts of water and sanitation programs have been studied frequently [see (Fewtrell, et al., 2005); (Pattanayak, et al., 2008); (Pattanayak, et al., 2010); (Newman, et al., 2002); and (Galiani, et al., 2005) (Galiani, et al., 2009); (Devoto, et al., 2012); (Jalan \& Ravallion, 2003); (Gamper-Rabindran, et al., 2010)]. Very few studies measured other important outcomes, such as changes in the household's costs of collecting, storing, and treating water, or the income losses due to water-borne and water-washed illnesses [ (Pattanayak, et al., 2008)].

To give a brief overview of the rigorous impact evaluations in the water and sanitation sector, we follow (Bosch, et al., 2000) that categorized water and sanitation impacts on program participants into four groups: health improvement, education, gender and social inclusion, and income and consumption.

On the health side, impact evaluations primarily focus on child mortality. Specifically, given that diarrheal disease is the second leading cause of death in children under five years old and a leading cause of malnutrition [ (WHO, 2013)], the health impact of water and sanitation tend to focus on this measure. (Newman, et al., 2002) evaluated the investments in small water and sanitation projects in Bolivia, and found that community level training was needed to have effects on water quality. They also found effects of infant mortality-bringing forward the importance of "hardware" interventions coupled with "software" interventions to achieve goals. (Galiani, et al., 2005) found that child mortality in Argentina fell eight percent due to access to increased access to water (through privatization), with the poorest benefiting the most. (Kremer, et al., 2011) found positive effects in child health from a randomized experiment in Kenya that protected water sources, while (Devoto, et al., 2012) found effects on child health from an intervention that provided tap connections to an urban sample in Morocco. These two studies highlight an important issue regarding the effects of water supply infrastructure: that it is important to distinguish between increases in quantity and quality of water. (Kremer, et al., 2011) evaluated the impact of an increase in the water quality available to treatment group by protecting the water sources, while (Devoto, et al., 2012) evaluate the impact of increasing the quantity of water available to households in an urban area. ${ }^{25}$ Similarly, (Devoto, et al., 2012) did not find education impacts; however, this is probably due to children no longer being involved in water fetching activities. In rural Pakistan, (Rauniyar, et al., 2011) found that water and sanitation projects improved access to the water supply and improved attendance among girls; they found no effects on the labor supply or water-borne diseases.

Other studies explored the link between water and child health. (Mangyo, 2008), using panel data and an instrumental variable ${ }^{26}$ methodology, found that access to in-yard water sources in China positively impacted

\footnotetext{
${ }^{25}$ No changes in quality were expected in this setting since these households obtained water from this network before the intervention.

${ }^{26}$ (Lamichhane \& Mangyo, 2011) warrant against the IV methodology due to endogenous project placement.
} 
child health for children of educated mothers. Using propensity score matching (PSM) methods, (Jalan \& Ravallion, 2003) found that piped water can lower the prevalence and duration of diarrhea among children under five in rural India. (Gamper-Rabindran, et al., 2010) used panel data to estimate a quantile treatment effect for the provision of piped water on infant mortality in Brazil. They found that piped water benefits are larger for areas with higher infant mortality. On the other side of the spectrum of the effects of health outcome, (Klasen, et al., 2011) evaluated the impact of increased access to piped water supply in Yemen and found that it worsens health outcomes when water rationing is frequent, likely due to pollution in the network. They found that connections to piped sewers can lead to health improvements but that these benefits are not cleared when compared to water supply through water vendors. (Fan \& Mahal, 2011) found non-robust positive effects of water and sanitation on dysentery and significant reductions of diarrhea for children under five due to hygienic practices (hand washing).

An important issue in the literature is the complementarities of water and sanitation projects. For example, (Esrey, 1996) found that improved water quality can improve child health if sanitation is also provided. Some rigorous evaluations, like (Pattanayak, et al., 2009) and (Pattanayak, et al., 2008), found that a community demand driven water and sanitation intervention in India had positive effects on the level of access to piped water and sanitary services, but no discernible health or education impacts.

Water quality at the source and quality at the point of consumption may differ dramatically. This finding in the public health literature, that water quantity and water quality might have different effects depending on the level of sanitation and hygienic practices [ (Esrey, et al., 1991), (Fewtrell, et al., 2005)], is a persistent problem in developing countries. Many studies find that delivery of safe water is not the same as access to improved water sources since storing water in the household leads to a deterioration of water quality because of recontamination in the home even households have access to adequate and safe sources. A systematic review of 57 studies measuring bacteria counts for source water and stored water in the home by (Wright, et al., 2004) concluded that bacteriologic quality of drinking water significantly declines after collection, although they noted considerable variability between community settings and greater contamination at the point of consumption when the contamination of the source was low.

Studies show that hygiene education, better point-of-use treatment and storage options, and in-house water connections are complement each other and are needed to effectively increase water to safe water. These studies tend to suffer from small samples size and generally limited to identifying this bottleneck in the provision of safe water and not on how this point-to-point contamination is affected by WASH interventions. (Levy, et al., 2008)] studies the role of initial source water conditions in determining household water quality, and how levels of contamination of drinking water change over time, in a rural setting in Ecuador, and found reductions of microbiologic indicators between the source of drinking water and drinking water stored in the households indicating some treatment at the household level; however, these reductions were followed by recontamination during storage and use. Comparing the importance of the distinction between improved sources and safe sources, (Clasen \& Bastable, 2003) found that fecal contamination at the household level was higher than at the point of distribution for non-improved sources and that even for improved sources, while they found no contamination at the source, fecal contamination at the household level was frequent and extensive. Other studies that demonstrate drinking water contamination even when safe water during collection is available and the need of hygiene and water-handling education are: (Simonne Rufener, et al., 2010) in Bolivia, shows ineffectiveness of home-based interventions in disinfection of water because of recontamination; (Oswald, et al., 2007) in peri-urban communities in Peru, found that boiled water was more frequently contaminated when served in a drinking cup than when stored; (Firth, et al., 2010) in South India, that found that chlorine reduced microbiological contamination to potable levels, but was less acceptable to participants. 
Some studies found limited effects on consumption and income indicator [ (Chase, 2002), (Lokshin \& Yemtsov, 2005), (Kremer, et al., 2011), (Pattanayak, et al., 2008), (Pattanayak, et al., 2010), (Devoto, et al., 2012)]. Impacts on consumption and income are achieved through changes in the costs related to access water of adequate quality, both time and expenses. These impacts can be measured through indicators of expenditure on water and sanitation services; coping costs more generally, as in (Pattanayak, et al., 2005).

The evidence of the effects of water and sanitation on gender and social inclusion is limited. The impacts on gender and social inclusion refer to the extent that minorities, the poor, or other vulnerable populations benefit from the water and sanitation interventions. The effects might be larger for some of these populations because of non-linear treatment effects. For example, if women disproportionately participate in fetching water, they would have larger benefits from a project that provides tap-water [ (Koolwal \& van de Walle, 2013)]. However, if the contribution is large, poorer and older-age ${ }^{27}$ households might not be able to afford the connection and, thus, not benefit from the project, even if targeted [ (Zwane \& Kremer, 2007)].

There are few studies that quantify the impact of water access on productivity in either agriculture or in the labor market. The mechanisms through which these effects can exist are evident: (1) the decrease in time fetching water provides time that can be allocated to productive activities, and (2) the decrease in waterborne illness provides for a healthier population that can be more productive. However, these effects were only recently explored in the literature and, to date, no discernible effects are found. For example, in (Devoto, et al., 2012), no changes in the time allocation to productive activities are found, and (Koolwal \& van de Walle, 2013) did not find that access to water comes with greater off-farm work for women.

\section{Methodology AND EMPIRICAL StRATEgy}

An impact evaluation studies the changes in outcomes that measure aspects of well-being which can be attributed to a specific intervention. Impact evaluations require a credible and rigorously defined counterfactual, which estimates what would have happened to the beneficiaries absent the project. The key to measuring the impacts caused by the water and sanitation interventions is to compare conditions with the interventions to conditions that would have prevailed without them. The counterfactual state is not naturally observable-we can never know what change would have occurred in program participants (the treatment group) if the interventions were not implemented.

As it was not possible to apply randomization in the selection of communities that would received the WASH interventions the impact evaluation uses a rigorous quasi-experimental design that incorporates matching on prebaseline census data, pre-and-post-implementation data collection and difference in difference (DID) estimation. This required selecting a comparison group-households that are observationally similar to beneficiary households but do not participate in the program-and observing both sets of households before and after the program was implemented.

We use matching to selected the communities that would serve as a comparison group. Matching represents a credible, non-experimental option for identifying comparison groups. We used propensity score matching (PSM) [ (Rubin, 1974); (Rubin, 1979); (Rosenbaum \& Rubin, 1983); (Dehejia \& Wahba, 1994); (Heckman, et al., 1997); (Heckman, et al., 1998); (Heckman, et al., 1998) ] using data from the 2007 census to match the treatment communities to comparable communities before program implementation. PSM identifies comparison communities that have a similar probability of receiving the treatment and are similar to the treatment communities in terms of observable characteristics. Accordingly, they provide measures of indicators in communities that are similar, except for the treatment; thus, addressing selection on observables and addressing the project placement bias that is common in impact evaluation on infrastructure projects.

\footnotetext{
${ }^{27}$ Older-age individuals are less able to contribute to the labor force and are thus constrained physically and economically.
} 
By collecting data before and after program implementation, can use DID estimator [ (Heckman, et al., 1998)]. This estimator measures the treatment effect as the difference between the changes in indicators before and after the program among treatment recipients, on the one hand, and the changes in indicators before and after the program among comparison units, on the other. DID estimation helps control for residual confounding due to imperfect matches and selection bias from time-invariant unobservable factors, which differ between treatment and comparison communities and which may have an influence on the impact variables of interest. To implement the DID estimator, we conducted a panel survey in which the same households were interviewed a baseline in 2011, and two follow-ups in 2012, and 2013 during the same period in the year.

\section{Treatment AssignMent AND Treatment Status}

There are numerous different ways to define the "treatment" that beneficiary communities received in the WASH interventions. We could consider defining different treatments differentiating between project types: introduction of systems or improvement of existing systems. The implication of defining multiple treatments, however, is that it requires a research design that measures the program impact for each type of treatment, which in this case would mean close to doubling (in the case of two treatments) the sample size required for the survey.

Of the potential differences in treatment effects that we could analyze in this study, we considered that the most policy relevant and least studied in the existing literature is the potential differential effects between access to a new piped potable water system and the access to improved quality water systems. Communities in Latin American developing countries find themselves in need of what could be called a third stage of water supply improvements, where quality and reliability take a center stage. They passed the first stage of installing public point sources and a second stage of installing individual piped connections, namely increasing access to potable water. The third stage of improvements needs to address system failures and population growth; households are not receiving the quality and reliability of service they demand, or some new households are excluded from connecting to the existing systems.

In addition, the hygiene and sustainability components of the interventions added another layer of complexity if we wanted to separately estimate the effects of these different treatments. We opted for the simplest approach in this design and estimate the benefits of the full WASH interventions as a single treatment, thus ignoring the differences between the interventions in each community. In this case the treatment effect is an average effect across all types of interventions.

\section{Definition TREATMENT COMMUNITY AND HOUSEHOLDS}

Treated "communities" were difficult to define in this case. The concept of community in rural El Salvador is associated with caseríos, which are residential areas that have a collective identity. Caseríos are not formal administrative units and do not exist in all areas. Each caserío is part of a "canton," 28 and a group of cantons forms a municipality. Most of the projects were intended to serve a single caserío, but some projects served multiple caseríos. Thus, "project areas" were not equivalent to either caseríos, cantons, or municipalities, and the water systems were not necessarily based in one "community."

In addition to the conceptual problems involved in defining community, we faced a practical constraint in defining treatment communities for sampling purposes: there was no information available about households at the caserío level or at the project area level. The lowest level at which census information is gathered is the census segment. ${ }^{29}$ Each canton has one or more census segments. ${ }^{30}$ In some cases, census segments are larger

\footnotetext{
${ }^{28}$ With some caseríos falling in more than one canton.

${ }^{29}$ This is the primary sampling unit for sample surveys in El Salvador. Its boundaries do not correspond to any political boundaries in most cases.

${ }^{30}$ In theory, each census segment is located in a single canton, but in practice there is debate about canton boundaries. We found
} 
than project areas, and in some cases they are smaller. According to the information we were given before selecting the sample, census segments generally include about 100-125 households. ${ }^{31}$

In this study, we chose to define treatment "community" at the level of the census segment. The advantages to defining community at the census segment level rather than at the project level or canton level are:

- While "project area" would, in many ways, be the ideal choice of treatment community, we did not have the equivalent unit in comparison communities. ${ }^{32}$

- A canton is usually much larger than a project area and will include many more non-beneficiary households than a census segment would.

- 2007 census data was available at the census segment level, so we had significant information available for matching treatment and comparison communities at this level.

A census segment was considered a "treatment segment" if any households in the segment was inside the project area; that is, the household was included in the area described in the community project proposal. To identify which census segment in the Northern Zone were "treatment segments" we used the project descriptions to identify the cantons and communities where the projects where going to be implemented. Cartographers from the statistics institute visited these communities and identified the segments corresponding to each community and the number of households that were expected to be beneficiaries of the interventions.

There were not many more treatment segments than the number required for this design. There were 100 treatment segments in the sample frame and the power calculations indicated we needed at least 65 . We chose instead to use clear criteria to reduce the set of possible treatment segments to the 65 that we needed to comply with the power calculations. We eliminated segments: were the project associated with the treatment segment was very small (had fewer than 100 participants); the segment had fewer than 55 identified households, since it would be hard to select a sample of at least 18 occupied houses; and if the segment was also included in other surveys (which would make selection of households for the water survey difficult) and elimination of the segment would not eliminate the entire project area from the survey sample.

This process of systematic elimination did not significantly alter the distribution of segments across project types or across departments ${ }^{33}$.

"Treated" households-or households that have received the treatment-are defined as those households who had the potential to benefit from these water and sanitation interventions. This means that they live within the service area of the new or improved water (and/or sanitation) system or the intervention community in the project proposal. Households that live within the service area, but do not connect to the service, or see no change in their water or sanitation service after the project (e.g. water reliability, quality, or hours of service from existing connection did not improve), are still considered treated households. This approach to defining treated households has additional implications for this impact evaluation: projects that do not inspire households to connect or to agree to build latrines will have lower impacts than projects that

that a number of census segments span several cantons, at least according to the residents of the area.

${ }^{31}$ The rural census segments had about 120 houses, but the recent census showed that up to 20 percent of those houses can be unoccupied. For the purposes of the evaluation design, we assumed 100 households per census segment.

32 We made an effort to identify projects that have been formulated, but not submitted for funding. This could have served as comparison "projects" for the study. However, there were not enough formulated but un-submitted projects to have this be the nontreated pool for the matching.

${ }^{33}$ We also eliminated one treatment segment from each of the two largest project areas (the treatment segment from each project that contained the smallest number of households). 
achieve full coverage. One of the aspects of the project evaluated is the "take up" and use of the services that is offered.

The definition of treatment community as a segment, the project area and the connection decision of households imply that the estimate impact is an intention-to-treat (ITT) effect and a lower bound for the effects of the WASH interventions. There are four reasons why our main estimate is a lower bound:

1. Treatment Segments are not all contained within the project area. Thus, households inside treatment segments and outside the project area, are considered as treated but do not receive the benefits; decreasing the treatment mean.

2. Households in comparison segments adjacent to projects areas that are inside the project areas at the end of the interventions or spillover effect. These households are considered as not-treated but are inside the project area and/or choose to receive the benefits; increasing the comparison mean.

3. Households in treatment segments and inside project areas that decide not to connect or noncompliance effect. These households are considered as treated but choose not to receive the benefits, decreasing the treatment mean.

4. Households in comparison segments could have received WASH interventions from other sources or contamination effect. These households are considered as not-treated but are receiving benefits from similar interventions; increasing the comparison mean.

\section{Selection OF Comparison GROUP}

Comparison segments were selected prior to the intervention using propensity score matching (PSM) [ (Rosenbaum \& Rubin, 1983); (Dehejia \& Wahba, 1994); (Heckman, et al., 1997); (Heckman, et al., 1998) (Heckman, et al., 1998) ]. The PSM procedure allowed us to select a comparison unit $j$ that is very like a treatment unit $i$ in all observable aspects except for treatment status, thus providing a proper counterfactual of the situation of $i$ without the treatment. A "propensity score" is the probability that a given unit participates in the program given certain observable characteristics $Z$. Thus, the propensity score is given by the probability that a unit is treated conditional on having observed the set of characteristics $Z$, that is $P(T=1 \mid Z)$.

$$
P(T=1 \mid Z)=\Phi(Z \hat{\alpha})
$$

where the function $\Phi($.$) is the cumulative normal distribution (probit) or the logistic distribution (logit) and$ $\hat{\alpha}$ are the estimated coefficients.

We implemented PSM using data from the 2007 census to match the treatment communities (segments) to comparable communities (segments) before program implementation. Once we estimated the propensity score function, we estimated the propensity score $P(T=1 \mid Z)$ for all treatment segments and all possible comparison segments. We assigned an appropriate comparison segment to each treatment segment in the sample using nearest neighbor matching without replacement. Specifically, we found a segment $j$ among the segments with $T=0$ for each segment $i$ with $T=1$, so that the pair $(i, j)$ satisfies

$$
\min _{\mathrm{j} \in\{\mathrm{T}=0\}}\left\|P_{i}-P_{j}\right\|
$$

According to the PSM method, the comparison segment $j$ is selected such that its probability of participation in the program is as similar as possible to beneficiary $i$ 's participation probability. Intuitively, PSM creates the observational analogue of a randomized control group in which comparison units and beneficiary units have the same probability of participation.

The comparison group was determined by matching the identified treatment segments with similar census segments located within the municipalities that were eligible for the water and sanitation program. PSM was used to identify the comparison segments that were most similar to treatment segments on observable 88 
variables thought to predict the likelihood of being chosen for inclusion in a water and sanitation project area. When using the propensity score, it is important to use variables that are strong predictors of selection into treatment. These variables usually consist of measures of the rules or the eligibility criteria in the program design.

Alternative specifications of the selection model were judged based on their prediction rates and their ability to reduce bias between comparison and treatment groups. All specifications of the matching equation used variables that paralleled the eligibility criteria used in the project selection stage, were predetermined, and/or were correlated with the water availability in the segment. The final model used the following variables to predict whether or not a census segment would be a treatment segment (i.e. the probability of being a census segment that participates in the WASH interventions):

1) Indicators of location

a. Average temperature

b. Dummy variables for department

2) Characteristics of population and location

a. Population of municipality in which segment is located

b. Density of settlement

c. Percent of surface area occupied by water bodies (an indicator of access to surface water)

d. \% of households in segment relying on private well for water

e. Average household size (which is highly correlated with "rural area")

f. Average number of household members who had emigrated (an indicator of external resources available to the community)

g. \% of households in segment with in-home business (an indicator of economic diversity and non-residential demand for water services)

3) Indicators of inadequate water and/or sanitation

a. \% of households in segment relying on unimproved water source

b. \% of households in segment with piped water, but not receiving water every day

c. \% of households in segment with no improved sanitation facilities

d. \% of households in segment with composting latrines

\section{IMPACT ESTIMATOR: DifFERENCE IN DIFFERENCE}

Although PSM can ensure that treatment segments are compared to non-recipients who are similar in terms of probability of treatment, there still may be both observable and unobservable differences between treatment and comparison segments that may bias the results. To eliminate these biases, we used a DID approach to control for "selection on unobservables" [ (Heckman, et al., 1998)].

Our main impact estimator is the DID estimator at household level data and controls for matched pairs fixed effects from the comparison segment selection stage. To estimate the impact of the WASH interventions on the outcome variable of interest $Y$ at the household level, we estimate the following equation:

$$
Y_{i j t}=\alpha_{p}+\lambda_{t}+\Delta_{Y} \cdot T_{j} \cdot \text { Post }_{t}+\varepsilon_{i j t}
$$

Where:

$i$ indexes households

$j$ indexes communities or segments

$t$ indexes survey wave $(2011,2012,2013)$

$\alpha_{p}$ are matched-pair fixed effects

$\lambda_{t}$ is a vector of time period indicators, which are equal to one in year $t$

$T_{j}$ is the treatment indicator, equal to one for households living in treatment segment 
Post $_{t}$ is and indicator equal to one for the follow-up and end line surveys

$\Delta_{Y}$ is the impact estimate for outcome $Y$

$\varepsilon_{i j t}$ is a random disturbance with mean zero and positive finite variance, that is allowed to be correlated across survey rounds within a segment

The estimate compares the difference between the average of outcome in the follow-up surveys and the baseline for the treatment and comparison households within each matched pair. The identifying assumption is that that conditional on the matched pair the treatment and comparison groups trends are parallel before the WASH interventions and aggregate shocks do not differentially affect each group.

This impact estimate assesses the effects of the WASH interventions as a "package," meaning that the treatment status was determined by the segment being in the communities where the WASH interventions took place. In other words, we conducted an "intention to treat" analysis, as explained previously in treatment assignment section. Since the uptake of water and/or sanitation services at the household level was endogenous and not all treatment segments were contained inside the project areas, all households in treated segments were defined as treated, regardless of whether there were direct beneficiaries.

Similarly, all households in comparison segments are classified as non-beneficiaries, even though they may have obtained piped water (by other means or by expansion of the interventions from adjacent treatment segments). These results, therefore, provided lower bound estimates of the impact that could be realized if all complied with the treatment and there was no comparison group contamination. These are the main results that appear in the column (3) in the results section, marked DD-Pair ${ }^{34}$.

The standard errors were clustered at the segment level to allow observations to be correlated within segments and to allow for segment level shocks that are correlated across time.

\section{Project Areas and Spillovers Effects: Area-ITT, ATE, LATE}

To explore the effects of compliance, we also present results defining treatment as a living in an area where that was covered by the project by the end line survey. In the end line survey, we asked the enumerators to identify the sample households that were inside the communities identified in the project proposal for each treatment and comparison segment. This variable presents a more flexible definition of what households are inside a project area. The comparison group and the treatment group using this variable, instead of $T_{j}$ in the previous equation, provides a project area ITT. These are the results that appear in the column (4) in the results section, marked RF-Area-ITT for Reduced Form Area intention to Treat. We present the instrumental variable estimate in column (5) of the results tables, where we used the segment treatment assignment as an instrument for inside the project area. Both estimates rely on the identifying assumption that conditional of the pair effects treatment assignment at the segment levels is "as good as" random and only affects the outcomes through changes in the probability of being in the catchment area of the WASH interventions.

In addition, we asked respondents in the in the end line survey if they were direct beneficiaries of the WASH interventions financed by MCC. The financing of the WASH interventions was salient since the interventions placed signs in the community and branded the material used in the education campaigns. As above, we used the segment treatment assignment as an instrument for a household reporting being a direct beneficiary of the WASH interventions. This treatment variable varies at the household level and gives us a sense of the local average treatment effect (LATE), or the affect among households that connected to the new systems because they were inside the catchment area, compliers. The identifying assumption is that conditional of the pair

\footnotetext{
${ }^{34}$ Columns (1) and (2) in the main results table show a pooled DID and a Fixed effects-DID to contrast with simpler estimators that do not rely on the pre-matching design.
} 
effects, treatment assignment at the segment levels is "as good as" random and only affects the outcomes through increased access to WASH interventions. These are the results that appear in the column (6) in the results section, marked RF-ATE for Reduced Form- Average Treatment Effect. The instrumental variable estimate appears in column (7), marker IV-LATE for Instrumental Variable- Local Average Treatment Effect. These effects are the largest and reflect the spill over effects of the projects, as all households that benefited from the WASH interventions are included as "treated".

\section{Heterogenous efFects: SOCIOeConomic, SeX ANd INITIAL WATER AcCesS}

To explore heterogeneity, for example by sex of household head and socio-economic status, we estimate the DID for each sub-sample identified by the characteristic

$$
Y_{i j t}=\alpha_{p}+\lambda_{t}+\Delta_{Y} \cdot T_{j} \cdot \text { Post }_{t}+\varepsilon_{i j t} \quad \text { if } i \in Z_{i j}
$$

and triple difference regressions interacted by these characteristics, $Z_{i j}$,

$$
Y_{i j t}=\alpha_{p}+\lambda_{t}+\Delta_{Y} \cdot T_{j} \cdot \text { Post }_{t}+\delta_{Y} \cdot T_{j} \cdot \text { Post }_{t} \cdot Z_{i j}+\varepsilon_{i j t}
$$

Where $\delta_{Y}$ gives us the additional effect for the households with (baseline) characteristics $Z_{i j}$.

For example, if $Z_{i j}$ is a poverty status indicator, equal to one if the household was below the poverty line at baseline and zero otherwise; the impact for the poor is given by $\Delta_{Y}+\delta_{Y}$ and for the non-poor at baseline by $\Delta_{Y}$.

\section{SuStaINABILITY of IMPACTS AND Heterogeneity In EXPOSURE PERIOd to TREATMENT}

Figure 10 shows the timing of the baseline survey with respect to when the project was completed in the community (week 0). Most of the surveys in the treatment segments were done by the time the project was finalized. ${ }^{35}$ By the time of the first follow-up (March-May 2012), not all projects were finalized. As such, some treatment households were not receiving water from the improved systems by the time the survey was administered. The distribution of the number of weeks that treated households where connected to the new or improved water system can be seen in Figure 11. Some households that were receiving water from the improved water systems had been connected to the new systems for as little as one month, while others had been connected for as long as 12 months. By the time of the end line in March-April 2013, all beneficiary households were connected to the improved systems and had been exposed to the treatment for different lengths of time; some as long as two years and a few others as little as six months. As can be seen in Figure 12 , most of the households had been connected to the new or improved water system more than 10 months when the end line survey was administered.

${ }^{35}$ We note that there might be a delay between project finalization date and the actual day of service. We corroborated in the data that these households reported the project being ready but not functioning yet. 
FIGURE 10 NUMBER OF WEEKS CONNECTED TO IMPROVED SYSTEMS AT 2011 BASELINE

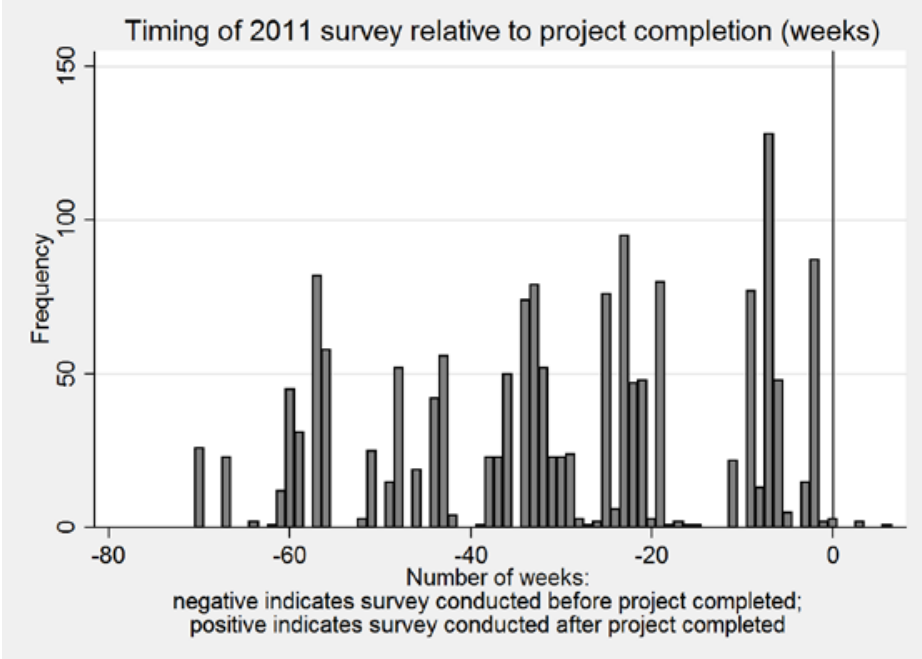

FIGURE 11 NUMBER OF WEEKS CONNECTED TO IMPROVED SYSTEMS AT 2012 FOLLOW-UP

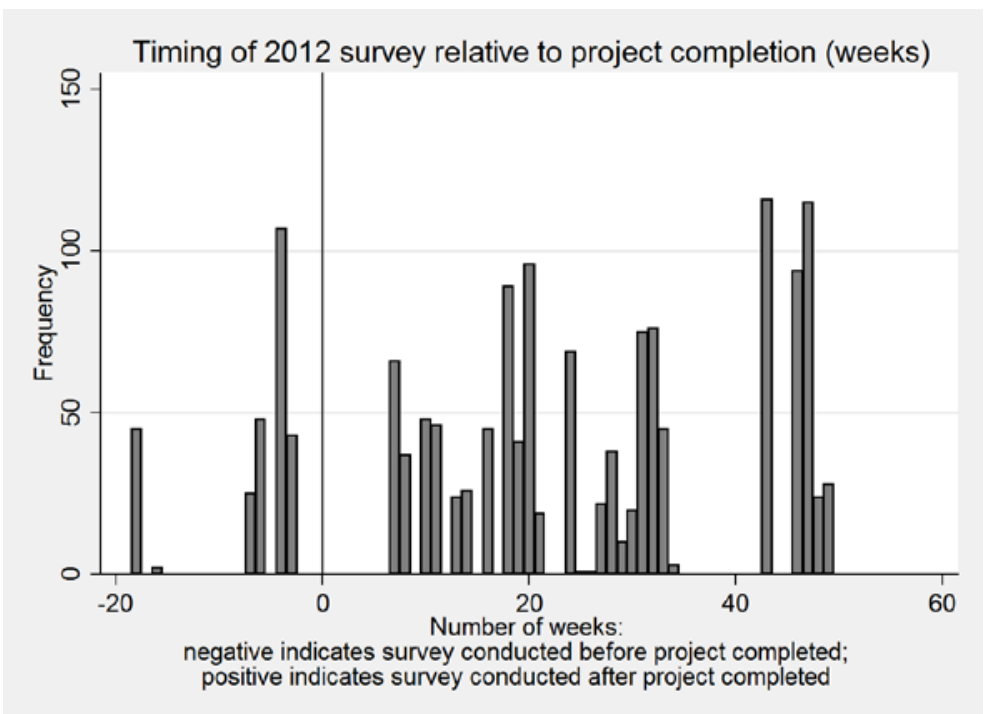




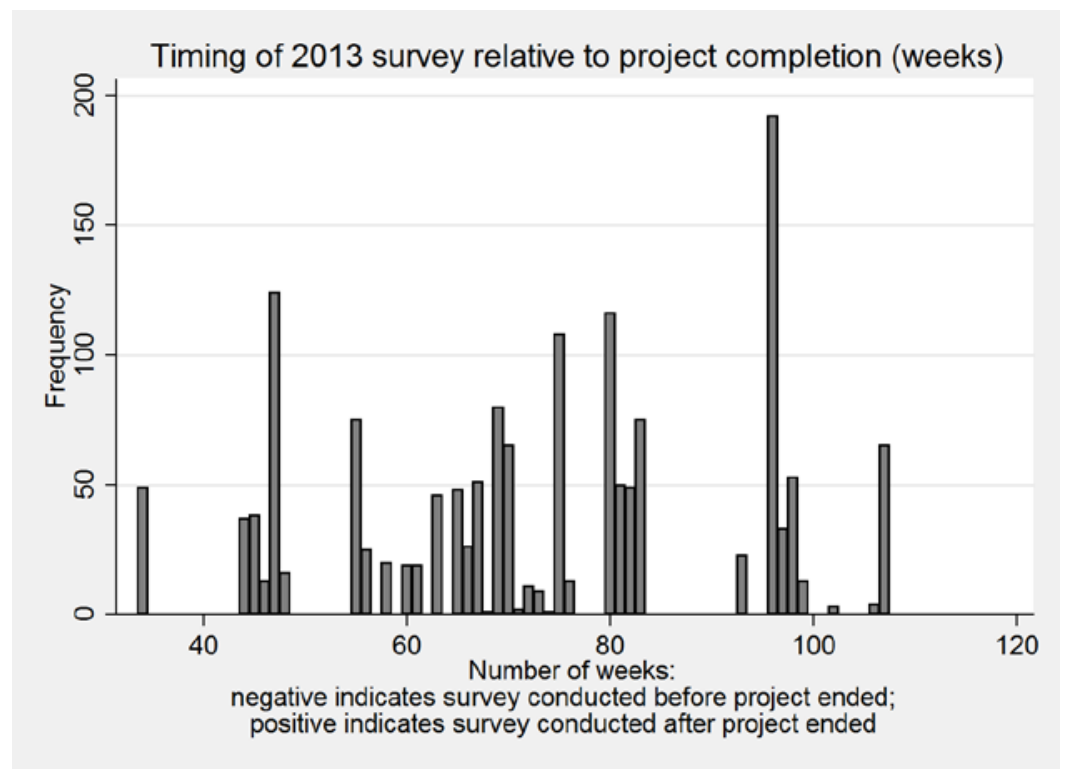

Given the varied exposure time, we also present a graphical analysis that illustrates the evolution of the main impact indicators and allow the beneficiaries to learn and change their behavior-allowing for the expected impacts to manifest in the data at later rounds and explore how sustainable or persistent are the impacts observed. We do this by estimating a flexible functional form, namely a fractional-polynomial prediction of the outcome variable with respect the number of weeks between the survey date and the date of finalization of the projects for each segment pair ${ }^{36}$. That is the treatment segment experienced an "event" when this variable is zero, and their comparison counterpart did not. The effect on the comparison group of this time to finalization of the project variables is a placebo and the impact at different points from the date of finalization would be observed as the difference between the prediction for the treatment group and the comparison group. ${ }^{37}$

\section{SAMPLING AND DATA COLLECTION}

The sample consists of a panel of households that were successfully interviewed in 2011 and in at least one of the follow-up surveys in 2012 and 2013 in the departments of Cabañas, Chalatenango, Cuscatlán, La Unión, Morazán, San Miguel, and Santa Ana. Table 41 shows the resulting household sample. Of the 3,291 households interviewed in 2011, we excluded seven households in a census segment in Nueva Trinidad, as the mayor did not allow us to implement the survey in his municipality, for a total baseline survey of 3,287 . In the follow-up surveys, we successfully located 3,104 in 2012 and 3,155 in 2013. After excluding households for which we only had a baseline observation, the panel consisted of 3,222 households in 2011; 3,104 households in 2012; and 3,155 households in 2013. Female headed households account for around 30 percent of the households in the sample. Figure 13 shows the distribution of the treatment (in orange) and comparison segments (in green) in the Northern Zone of El Salvador.

${ }^{36}$ This is done with the fpfit Stata command. This fits a fractional polynomial of degree 2 with powers chosen from -the vector (2, $-1,-.5,0, .5,1,2,3)$. This provides a flexible parametric approximation of the outcome variable with respect to the time between the survey date and the contract end date.

${ }^{37}$ We note that this analysis gives credence to the parallel trends before treatment on which DID estimators depend. That is, we would expect that the trends on the negative side of the $x$-axis will be parallel (or that the confidence bands intersect); adding to the balancing of the means in the treatment and comparison groups discussed previously. 


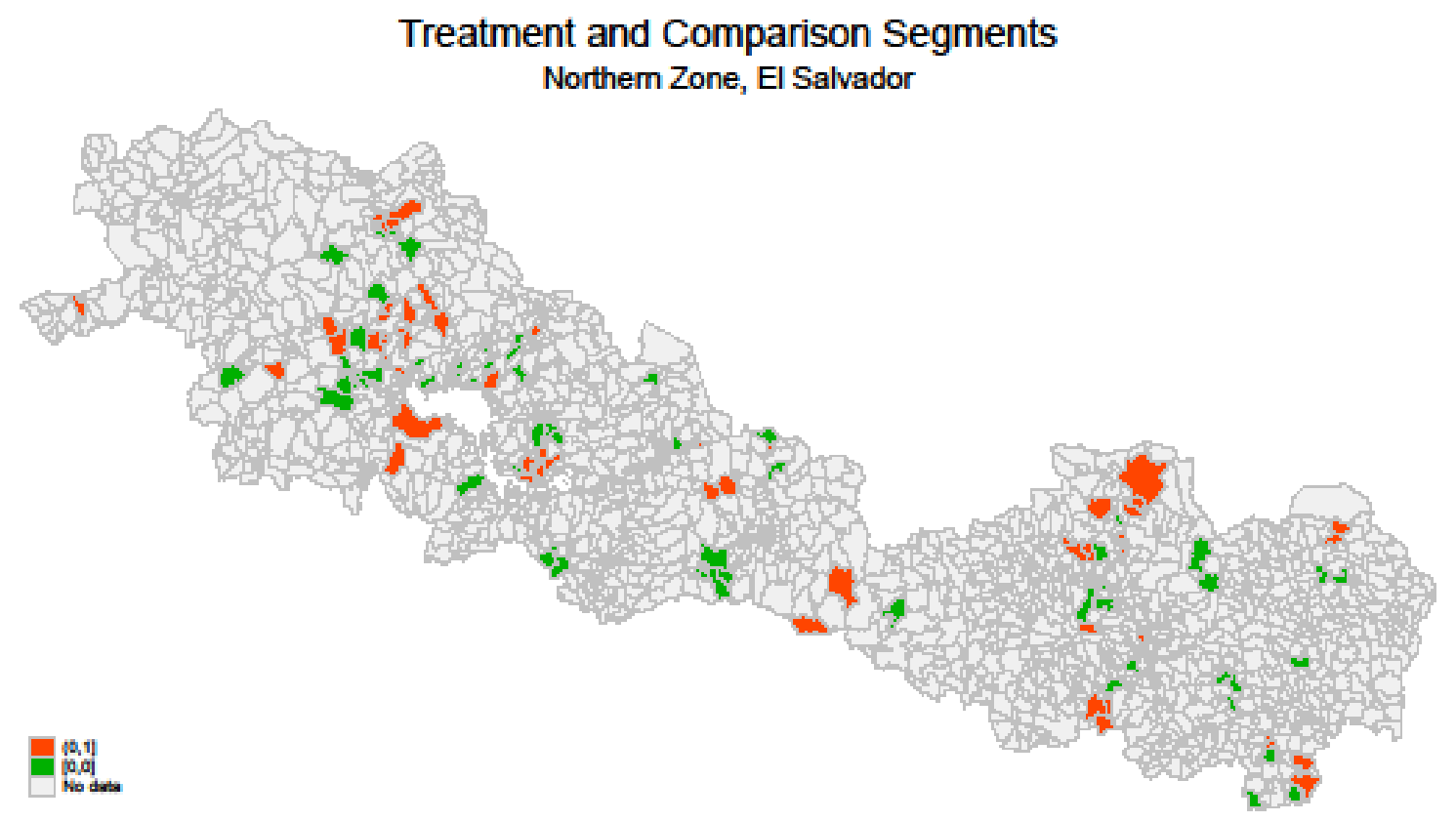

In all three years, enumerators tested the residual chlorine levels in the drinking water of all interviewed households. Parallel to the household survey, a private firm tested a sub-sample of households for bacterial contamination in drinking water (at the household level) and at a selection of sources in the community.

Table 42 shows the individual level observations in the panel used for analysis. The sample represents 13,072 individuals in 2011; 13,158 in 2012; and 13,143 in 2013. After excluding individuals for which we only have one observation, the panel used for analysis represents 12,857 individuals in 2011; 12,943 in 2012; and 12,497 in 2013.

TABLE 41 SAMPLE SIZE DESCRIPTION: HOUSEHOLDS

\begin{tabular}{llll}
$\begin{array}{l}\text { Survey } \\
\text { Year }\end{array}$ & Baseline & $\begin{array}{l}\text { Excluding } \\
\text { Nueva } \\
\text { Trinidad }\end{array}$ & $\begin{array}{l}\text { Excluding } \\
\text { Households } \\
\text { Baseline Only }\end{array}$ with \\
\hline 2011 & 3,291 & 3,284 & 3,222 \\
2012 & 3,104 & 3,104 & 3,104 \\
2013 & 3,155 & 3,155 & 3,155 \\
\hline Total & 9,550 & 9,543 & 9,481 \\
\hline \multicolumn{5}{r}{} \\
\hline Household Disaggregation by Sex of Head of Household \\
\hline 2011 & Male & Female & Total \\
2012 & 2,218 & 1,004 & 3,222 \\
2013 & 2,091 & 1,013 & 3,104 \\
\hline Total & 2,097 & 1,058 & 3,155 \\
\hline \hline
\end{tabular}


TABLE 42 SAMPLE SIZE DESCRIPTION: INDIVIDUALS

\begin{tabular}{llll} 
Survey Year & Male & Female & Total \\
\hline 2011 & 6,709 & 6,993 & 13,702 \\
2012 & 6,432 & 6,726 & 13,158 \\
2013 & 6,400 & 6,743 & 13,143 \\
\hline \multicolumn{4}{l}{ Excluding Individuals a Single Observation } \\
\hline 2011 & 6,306 & 6,551 & 12,857 \\
2012 & 6,322 & 6,621 & 12,943 \\
2013 & 6,084 & 6,413 & 12,497 \\
\hline
\end{tabular}

\section{BASELINE BALANCE AND MATCHING ASSUMPTIONS}

The logistic regression results as well as tables showing how the matching reduces bias, for the initial (the revised (2011) treatment assignment of segments. The estimation of the propensity score using the census data is presented in Table 43 and the test before and after matching in Table 44. Table 44 and Table 45 show that the PSM methodology was able to balance all the variables available in the census data with the treatment assignment of 2011. 
TABLE 43 LOGISTIC REGRESSION AND MATCHING EQUATION AND RESULTS

\begin{tabular}{|c|c|}
\hline \multirow[t]{2}{*}{ Municipal Population 2005} & -0.007 \\
\hline & {$[0.0018]^{* * *}$} \\
\hline \multirow[t]{2}{*}{ Density } & -0.0013 \\
\hline & {$[0.00061]^{*}$} \\
\hline \multirow[t]{2}{*}{ Surface Area Occupied by Water } & 0.69 \\
\hline & [0.37] \\
\hline \multirow[t]{2}{*}{ Average Temperature } & -0.12 \\
\hline & {$[0.064]$} \\
\hline \multirow[t]{2}{*}{ Household Size } & -0.96 \\
\hline & {$[0.30]^{* *}$} \\
\hline \multirow[t]{2}{*}{ Unimproved Water } & 1.37 \\
\hline & {$[0.74]$} \\
\hline \multirow[t]{2}{*}{ Private Well } & 2.44 \\
\hline & {$[0.70]^{* * *}$} \\
\hline \multirow[t]{2}{*}{ Piped Water } & 0.94 \\
\hline & {$[0.51]$} \\
\hline \multirow[t]{2}{*}{ No Sanitation } & -0.066 \\
\hline & [0.97] \\
\hline \multirow[t]{2}{*}{ Composting Latrine } & 1.88 \\
\hline & {$[0.63]^{* *}$} \\
\hline \multirow[t]{2}{*}{$\%$ in-Home Business } & -3.24 \\
\hline & {$[1.63]^{*}$} \\
\hline \multirow[t]{2}{*}{ Number Emigrated } & -0.044 \\
\hline & {$[0.45]$} \\
\hline \multirow[t]{2}{*}{ Dep_1 } & -0.62 \\
\hline & {$[0.88]$} \\
\hline \multirow[t]{2}{*}{ Dep_2 } & -0.26 \\
\hline & {$[0.40]$} \\
\hline \multirow[t]{2}{*}{ Dep_7 } & -2.3 \\
\hline & {$[1.09]^{*}$} \\
\hline \multirow[t]{2}{*}{ Dep_8 } & -0.71 \\
\hline & {$[0.45]$} \\
\hline \multirow[t]{2}{*}{ Dep_9 } & -0.9 \\
\hline & {$[0.55]$} \\
\hline \multirow[t]{2}{*}{ Constant } & 5.25 \\
\hline & {$[2.44]^{*}$} \\
\hline Observations & 1047 \\
\hline
\end{tabular}


TABLE 44 MATCHED AND UNMATCHED SAMPLES - BALANCING TESTS AT 2011 BASELINE

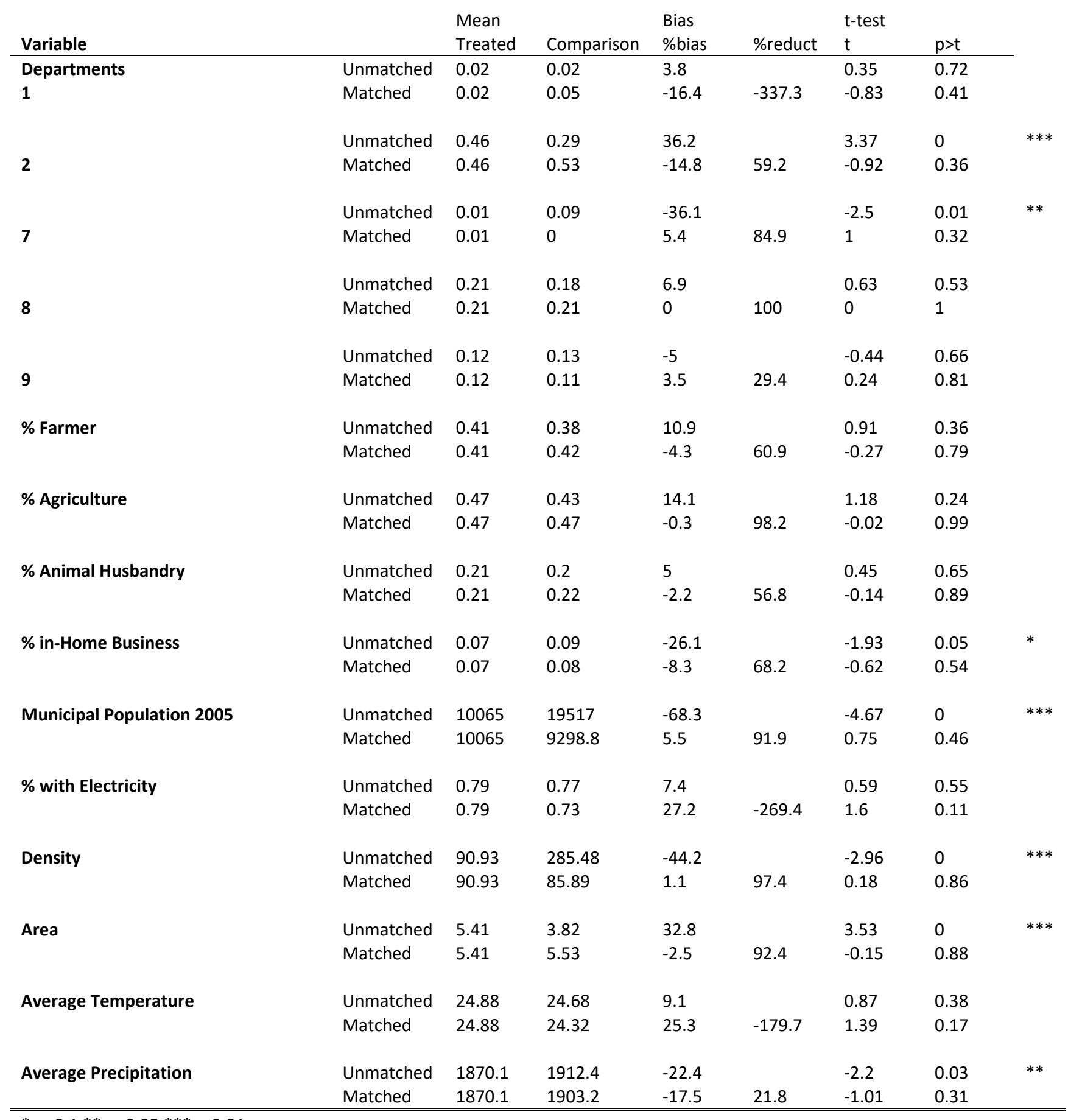

* $p<0.1 * * p<0.05 * * * p<0.01$ 
TABLE 45 MATCHED AND UNMATCHED SAMPLES AND BIAS DISTRIBUTION STATISTICS - TESTS AT 2011 BASELINE

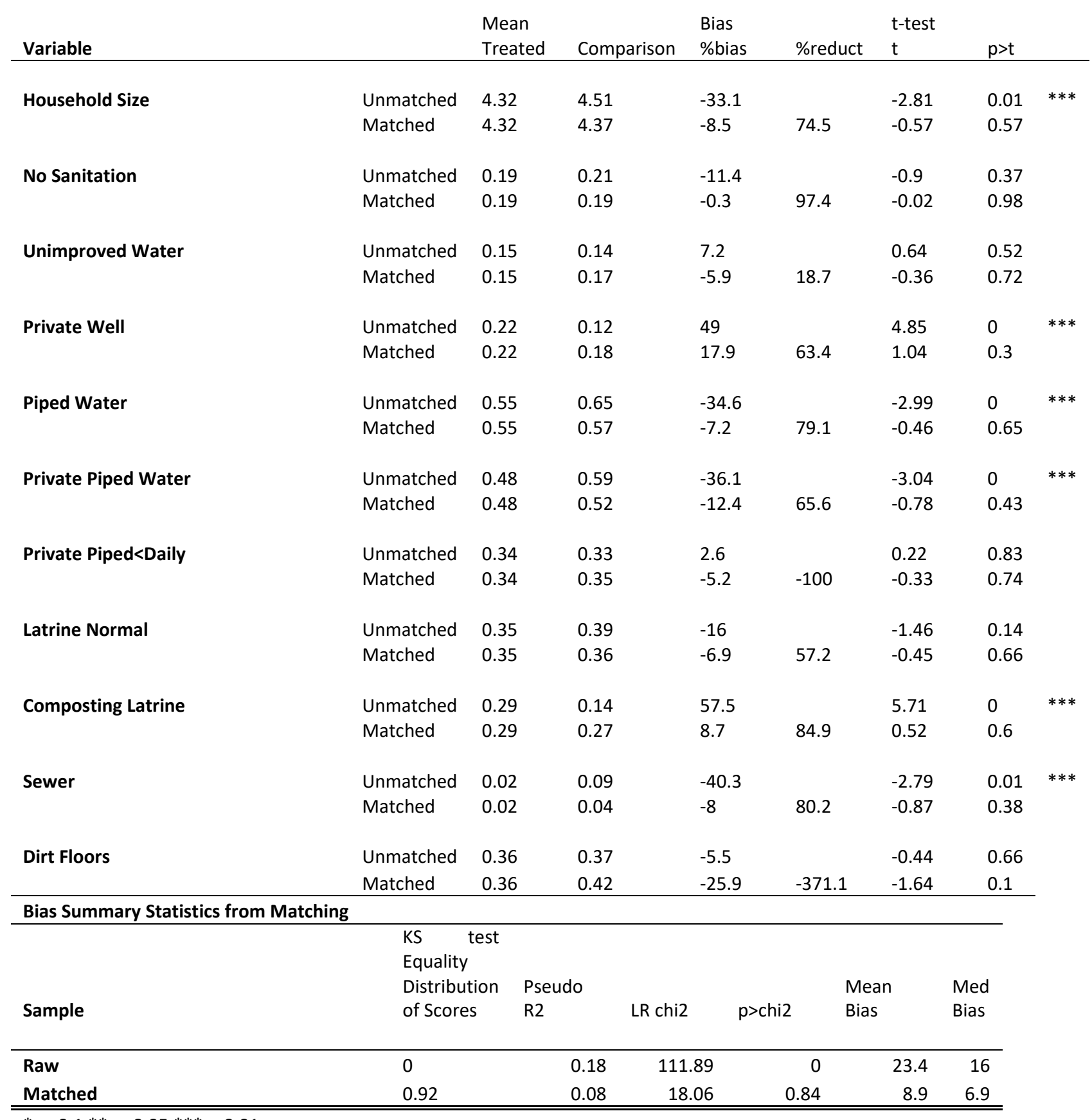

${ }^{*} p<0.1 * * p<0.05 * * * p<0.01$ 
The main assumptions of the PSM methodology to calculate the average treatment on the treated were [ (Heckman, et al., 1998) ]:

(1) Conditional on a set of covariates or conditional on the propensity score treatment status is mean independent of the outcome of interest,

$$
E\left[Y_{0} \mid P(Z), T=1\right]=E\left[Y_{0} \mid P(Z), T=0\right]=E\left[Y_{0} \mid P(Z)\right]
$$

(2) That the propensity score is bounded away from one, to allow us to find appropriate matches for each treated unit. This is called the 'common support' requirement.

$$
P(T=1 \mid Z)<1
$$

Below we present the estimated propensity score distribution before and after matching and direct the reader to the baseline report for further evidence of the comparability between the treatment and comparison groups. Figure 14 shows the estimated propensity scores for the segments included in the propensity score estimation. In Figure 15, we can see the initial distribution of the propensity scores in, for the matched sample of segments. We can see the considerable overlap of the probabilities of treatment for the selected sample after selecting the comparison segments using nearest neighbor matching. The propensity scores after matching are very similar and have a wide overlap in their support. All comparison segments were selected from the region of common support. Two sample Kolmogorov-Smirnov tests do not reject the hypothesis that the distribution of propensity scores of the treatment and comparison segments selected come from the same underlying distribution ( $\mathrm{p}$-value 0.920).

FIGURE 14 DISTRIBUTION OF PROPENSITY SCORES BEFORE MATCHING

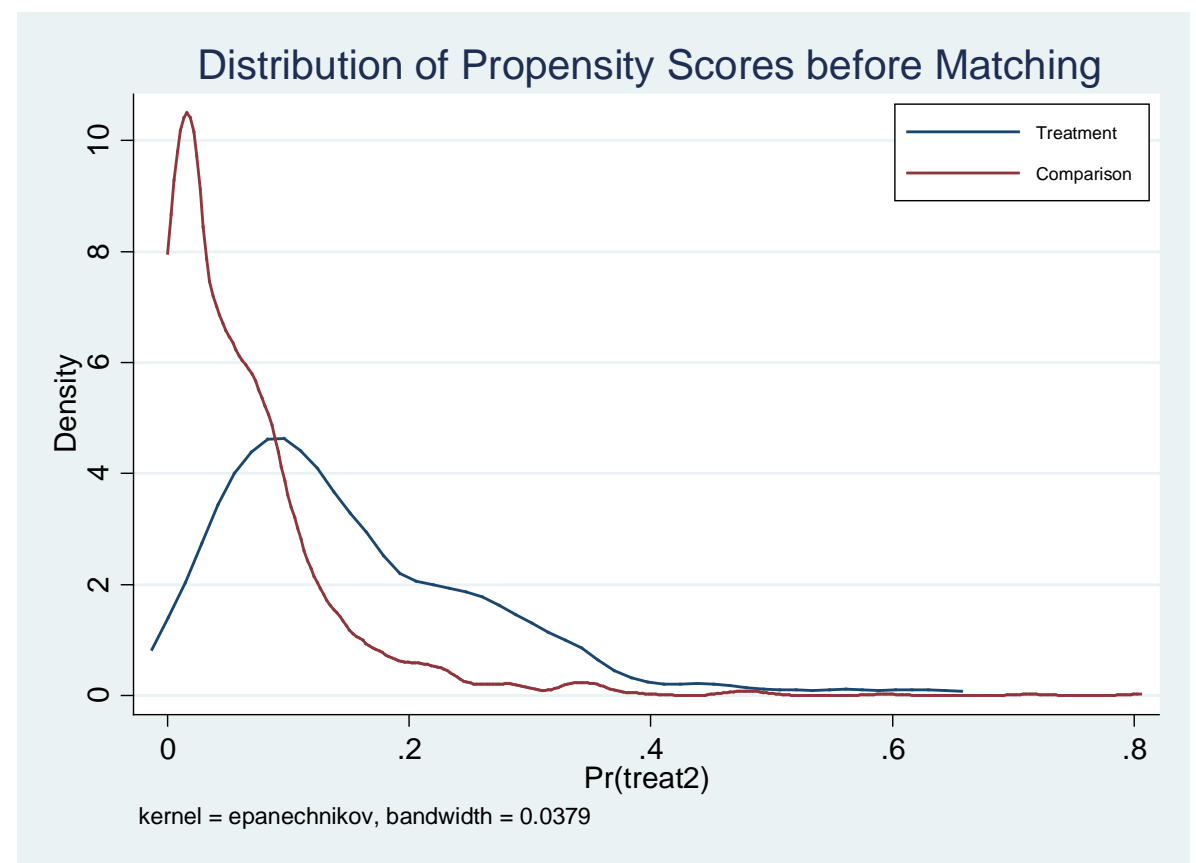




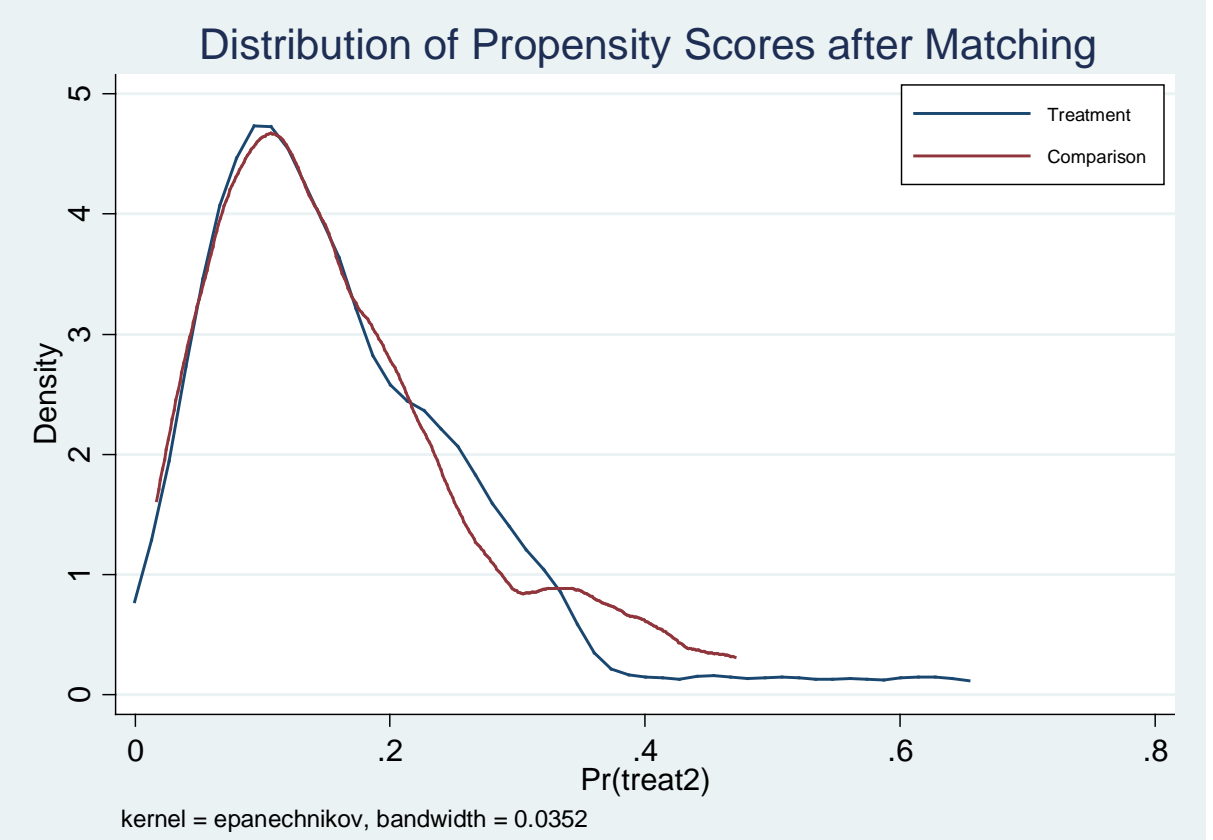

While we do not have information on all these variables (as measured in the census), we show a comparison of similar variables within our sample at baseline. Table 46 shows these variables and the $p$-value associated with the test that the means/proportions are the same across treatment status. The results show that the matching procedure balances these observables very well in our baseline data. 
TABLE 46 EX-ANTE MATCHING VARIABLES AS MEASURED IN THE BASELINE

\begin{tabular}{|c|c|c|c|c|c|c|}
\hline \multirow[b]{2}{*}{ Departments } & \multicolumn{2}{|c|}{ Comparison } & \multicolumn{2}{|l|}{ Treatment } & \multirow[b]{2}{*}{ Difference } & \multirow[b]{2}{*}{ p-value } \\
\hline & Mean & SE & Mean & SE & & \\
\hline SANTA ANA & - & - & 0.031 & 0.022 & - & 0.496 \\
\hline CHALATENANGO & 0.477 & 0.062 & 0.477 & 0.062 & - & 1 \\
\hline CUSCATLAN & 0.015 & 0.015 & 0.062 & 0.03 & - & 0.365 \\
\hline CABAÑAS & 0.185 & 0.048 & 0.077 & 0.033 & - & 0.117 \\
\hline SAN MIGUEL & 0.015 & 0.015 & - & - & - & 1 \\
\hline MORAZAN & 0.2 & 0.05 & 0.246 & 0.054 & - & 0.674 \\
\hline LA UNION & 0.108 & 0.039 & 0.108 & 0.039 & - & 1 \\
\hline Unimproved & 0.017 & 0.004 & 0.018 & 0.004 & -0.001 & 0.889 \\
\hline Natural Sources & 0.139 & 0.021 & 0.137 & 0.02 & 0.002 & 0.937 \\
\hline Poliducts, Wells & 0.294 & 0.038 & 0.298 & 0.035 & -0.003 & 0.946 \\
\hline Public Taps & 0.021 & 0.007 & 0.03 & 0.009 & -0.009 & 0.462 \\
\hline Backyard Tap, Neighbors & 0.389 & 0.039 & 0.399 & 0.033 & -0.01 & 0.84 \\
\hline In=house Tap & 0.139 & 0.017 & 0.118 & 0.015 & 0.021 & 0.363 \\
\hline Unimproved, Open Air & 0.123 & 0.017 & 0.088 & 0.014 & 0.035 & 0.105 \\
\hline Latrine, Common or Neighbor & 0.041 & 0.005 & 0.05 & 0.006 & -0.009 & 0.256 \\
\hline Backyard Latrine, Hole & 0.296 & 0.027 & 0.269 & 0.025 & 0.027 & 0.461 \\
\hline Backyard Latrine, Compost/Solar & 0.312 & 0.033 & 0.323 & 0.033 & -0.011 & 0.814 \\
\hline Inside Latrine, Hole & 0.016 & 0.004 & 0.023 & 0.005 & -0.008 & 0.193 \\
\hline Inside Latrine, Compost/Solar & 0.012 & 0.005 & 0.02 & 0.004 & -0.008 & 0.192 \\
\hline Backyard Toilet & 0.086 & 0.012 & 0.086 & 0.011 & 0.001 & 0.962 \\
\hline Inside Toilet & 0.114 & 0.014 & 0.141 & 0.019 & -0.027 & 0.255 \\
\hline Household Size & 4.267 & 0.082 & 4.189 & 0.076 & 0.078 & 0.483 \\
\hline Average Number of Members Abroad & 0.452 & 0.043 & 0.376 & 0.035 & 0.076 & 0.173 \\
\hline
\end{tabular}

Observations: 130 Segments

$* p<0.1 * * p<0.05 * * * p<0.01$

\section{IMPACT EVALUATION RESULTS}

The principal outcomes of the WASH intervention included improved access to potable water and sanitation infrastructure as well as improved availability and quality of the water supply. These outcomes are reflected in indicators such as: the proportion of households with piped water and sanitation facilities and the distance to the water source to measure access; cubic meters of water consumed and hours of service to measure availability; and chlorination rates at the source to measure the quality of the service and of stored water to measure household storing behavior.

We divided the primary evaluation questions in different categories: access, quality and reliability of water and sanitation services, water consumption, coping costs in cash and time, hygiene practices and behavior and finally water contamination. In each section that follows, we disaggregate the effects by initial water source access, gender of the household head and by the expenditure quintile of the household (at baseline) to explore heterogeneous treatment effects.

In the following tables, we present different specification based on the discussion in the empirical strategy section. Columns (1)-(3) are DID estimations where the treatment is defined as living in a treatment assigned segment; (1) is the pooled difference in difference (DID), (2) includes households fixed effects (DID-FE) and (3) is our preferred specification that included matched-pairs from the PSM matching in the impact evaluation design (DID-Pairs). In columns (4)-(5), we estimate an intention to treat where the treatment assignment 
variables is defined as living inside the project area within the matched pairs, with a reduced form (RF-AreaITT) where the treatment is included directly in the estimations and an instrumental variable (IV-Area-ITT) where the interaction of treatment assignment and the post period indicator is instrumented with the interaction of the segment level treatment assignment from the design and the post period indicator. Finally, in columns (6)-(7) we estimate a similar reduced form and IV impact estimate where the treatment is defined as having reported being beneficiary of the WASH project within the matched pairs (RF-ATE and IV-LATE); this specification address the possibility of spillover effects due to expansion of the projects to part of the comparison segments and differences in the definitions of treatment segments and project areas, where not everyone living in the segment was a beneficiary of the WASH interventions. Together these estimates give us a range of plausible impacts for each outcome of interest and serve as a robustness check, from a lower bound in the ITT in (3) to an average treatment effect (ATE) in (6) and LATE in (7).

How the benefits of water and sanitation interventions are distributed across categories of participants is a question that remains to be studied through a rigorous impact analyses. For this study, we collected information on the gender and age of household members as well as on the relative socio-economic status of households. This information is used to analyze, to the extent feasible with the sample available, differences in selected impacts and outcomes across gender and socio-economic groups. In the case of gender, we paid attention to differential impacts in time use and in the case of socio-economic groups, we looked at differences in access and coping costs. Heterogeneity estimates (Triple DID) are presented graphically with together with the DID estimates in the following discussion of the results. The points specific point estimates are presented in "Annex 3 Additional".

\section{Water And SANitation: Access and ReliabiLIty}

The first step in gauging the success of the projects was to examine the improvement in direct outcomes. Namely, to examine the changes in access to water and sanitation services in treatment segments versus comparison segments.

To estimate the effects on sanitation access we first call a sanitation facility "improved" if it hygienically separates human excreta from human contact. We categorize and ordered households that have access to flush/pour-flush pit latrines, ventilated improved pit (VIP) latrines, and composting or solar latrines post intervention in different groups; with access to flush/pour-flush pit latrines having a higher order. Figure 16 shows the proportion of households that had access to private sanitation facilities at baseline. As we can see from the figure, over 80 percent of households already had access to private sanitation facilities, with treatment and comparison groups well balanced. In Figure 17, we disaggregated the access to sanitation for both groups at baseline. In this figure, we can see the kind of sanitation facilities these households were using at baseline. Among the households that had sanitation facilities, the most common were latrines (both hole and solar/composting) that were detached from the home.

Table 47 presents the impact estimates of the WASH interventions on the accessibility to improved sanitation facilities or the change in the percentage of households that had and improved sanitation facility, such as a composting latrine or an improved-hole latrine. In column (1) we estimate a three percent increase in treatment segments' availability of improved sanitation facilities relative to comparison segments; with our preferred specification in column (3) estimating that 3.1 percent more households have access to private sanitation services in treatment segments than would be the case if the WASH interventions would have not occurred. We note that the access to sanitation was high in the intervention areas at baseline, around 85 percent as can be seen in Figure 16, so the possible effects would be small.

When we consider differences in treatment assignment using the area treatment assignment indicator in columns (4) and (5) and the spillovers in (6)-(7), the estimates increase to 4 and 5 percent, respectively. That is 
households that report participating in the WASH interventions are 5 percentage points more likely to have access to improved private sanitation facilities after the WASH intervention was completed.

FIGURE 16 ACCESS TO PRIVATE SANITATION

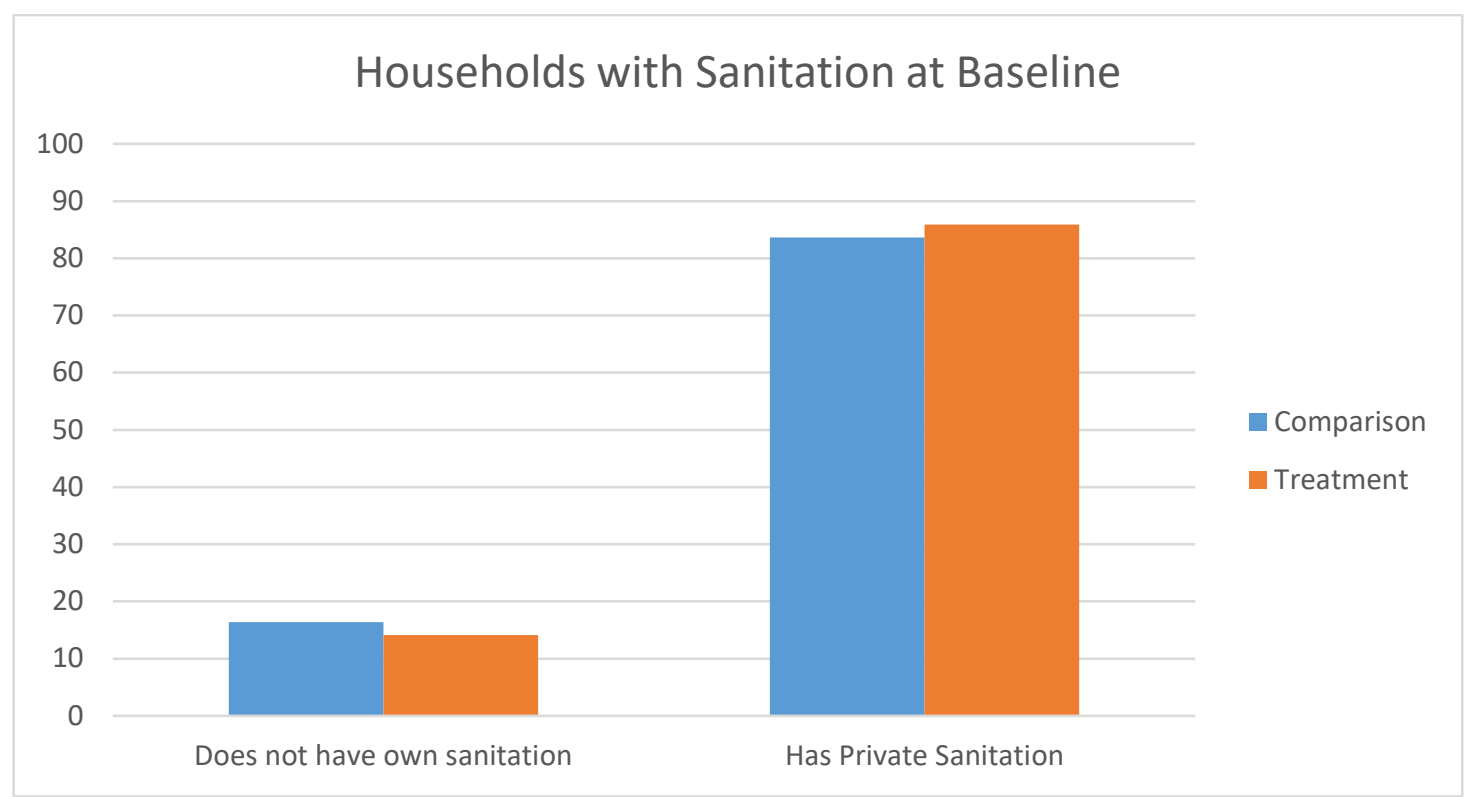

FIGURE 17 DISTRIBUTION OF IMPROVED SANITATION SCORES AT BASELINE

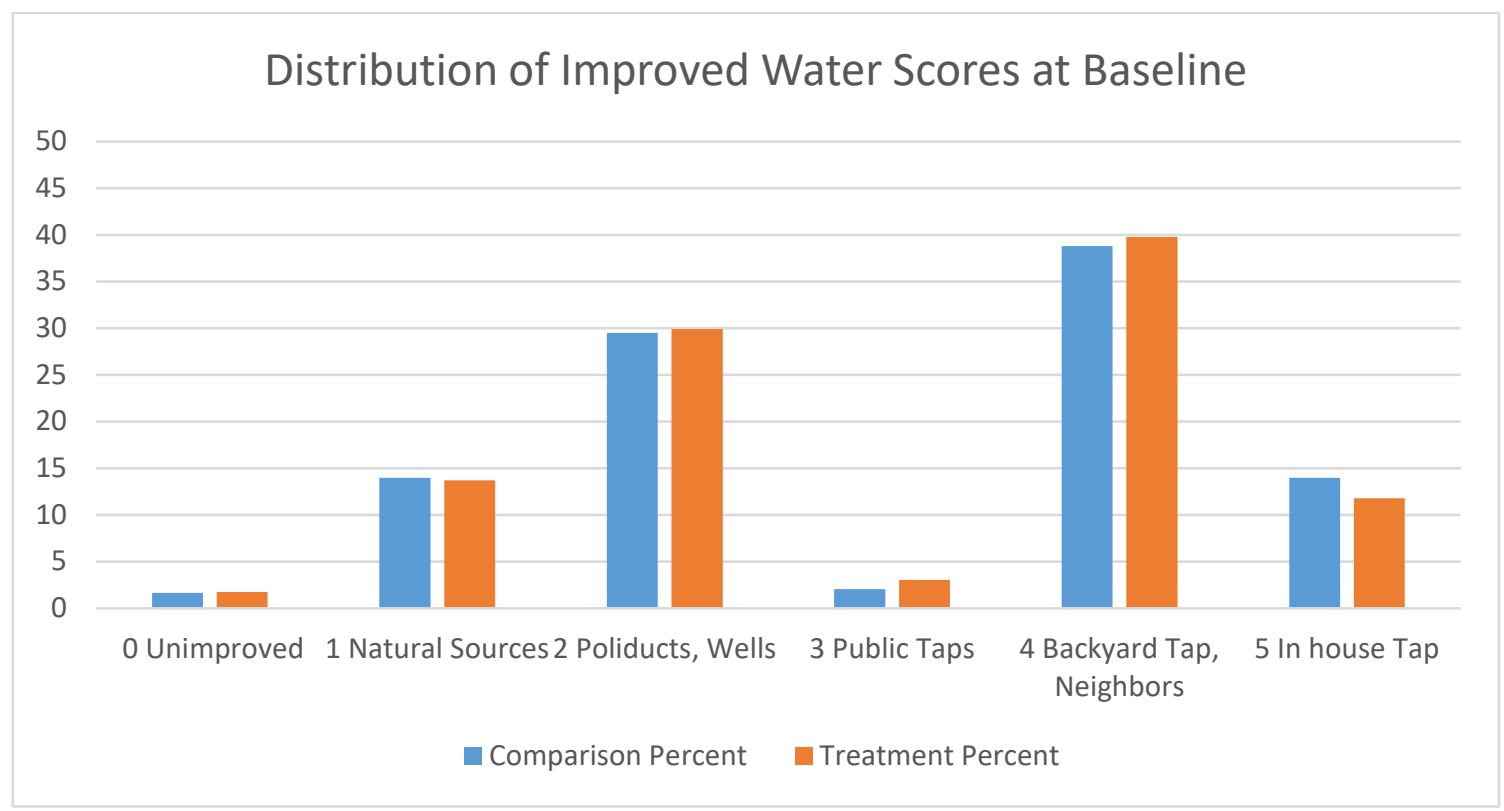


TABLE 47 SANITATION UPTAKE: PROBABILITY OF HAVING AN IMPROVED LATRINE

\begin{tabular}{|c|c|c|c|c|c|c|c|}
\hline & $(1)$ & $(2)$ & (3) & (4) & (5) & (6) & (7) \\
\hline & DID & DID-FE & DID-Pairs & $\begin{array}{l}\text { RF-Area- } \\
\text { ITT }\end{array}$ & 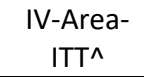 & RF-ATE & IV-LATE^ \\
\hline Treatment \# Post Period & $\begin{array}{l}0.031 \\
{[0.012]^{* *}}\end{array}$ & $\begin{array}{l}0.029 \\
{[0.012]^{* *}}\end{array}$ & $\begin{array}{l}0.031 \\
{[0.012]^{* *}}\end{array}$ & & & & \\
\hline Inside Project Area \# Post Period & & & & $\begin{array}{l}0.036 \\
{[0.014]^{* *}}\end{array}$ & & & \\
\hline Inside Project Area-ITT in Post Period & & & & & $\begin{array}{l}0.041 \\
{[0.019]^{* *}}\end{array}$ & & \\
\hline Beneficiary \# Post Period & & & & & & $\begin{array}{l}0.051 \\
{[0.017]^{* * *}}\end{array}$ & \\
\hline Beneficiary-LATE in Post Period & & & & & & & $\begin{array}{l}0.05 \\
{[0.022]^{* *}}\end{array}$ \\
\hline Pairs Indicators & NO & NO & YES & YES & NO & YES & NO \\
\hline Mean of Comp. at Baseline & 0.84 & 0.84 & 0.84 & 0.83 & 0.83 & 0.83 & 0.83 \\
\hline SD of Comp. at Baseline & 0.37 & 0.37 & 0.37 & 0.38 & 0.38 & 0.38 & 0.38 \\
\hline Number of Clusters & 128 & 128 & 128 & 128 & 128 & 128 & 128 \\
\hline Observations & 9,325 & 9,325 & 9,325 & 9,208 & 9,208 & 9,208 & 9,208 \\
\hline K-P rk Wald F & & & & & 249.6 & & 129.9 \\
\hline
\end{tabular}

Standard errors in brackets

Std. errors are clustered at the census segment level.

All equations include year fixed effects. Equations are DID, in (1)-(3) the treatment is defined as living in a treatment assigned segment, (4)-(5) treatment is defined as living inside the project area within the matched pairs, (6)-(7) treatment is defined as having reported being beneficiary of the WASH project within the matched pairs. Equations (4)-(7) control for initial treatment assignment.

Equation (2) includes household fixed effects. Pair dummies indicated in the table are based in on nearest neighbor matching propensity score matching based on 2007 census segment data.

IV estimates in columns (5) and (7) use the census segment treatment assignment to instrument for indicators for being in a project area in 20122013 (5); and the households reporting being a beneficiary of the WASH projects from MCC in (7)

^IV estimates partial out the indicators for pairs to compute the std. errors of the coefficients of interest. We report the K-P rk Wald F statistic following the results in Stock and Yogo (2005)

$* \mathrm{p}<0.10, * * \mathrm{p}<0.05, * * * \mathrm{p}<0.01$

To measure access to improved water we defined a 'tap connection,' a water source that derives from a formal water distribution system and permits households to connect their internal (house/patio) water system to the distribution system. To deal with households that might use multiple water sources we defined a 'water score' that measures the quality/type of the best service a household had access to. ${ }^{38}$ For example, the water score dealt with the possibility of overlap across water sources by assigning a number between zero and five to reflect the most improved water source they used. If a household reported using public taps and the tap of a neighbor, this household would get a score of four because getting water from a neighbor is more convenient than walking to the community tap. Changes in the water sources used are reflected in the scores. Households that have access to potable/tap connections post intervention will have higher water scores even if they did not abandon their use of unimproved water sources as their best source will be a tap connection. Table 48 shows the categories for each value of the water score.

\footnotetext{
${ }^{38}$ In the water and sanitation score, missing data is coded as zero, that is, we assume the worst score. There are few observations in this category for the water score.
} 


\section{TABLE 48 WATER AND SANITATION SCORE CATEGORIES}

\begin{tabular}{ll} 
Best Water Source & Score \\
\hline Unimproved/Missing & 0 \\
Natural Sources & 1 \\
Poliducts, Wells & 2 \\
Public Taps & 3 \\
Backyard Tap, Neighbors & 4 \\
In-house Tap & 5 \\
\hline \hline
\end{tabular}

Figure 18 shows the proportion of households that had access to a tap connection in their home or backyard at baseline. As we can see from the figure, around 50 percent of households already had a tap connection and the treatment and comparison groups were well balanced. In Figure 19, we disaggregated the improved water score for both groups at baseline. In this figure, we get a sense of the kind of sources these households were using at baseline; most of the households with access to tap connections had it in their backyard (as opposed to inside the house plumbing) and for those that did not have access to taps, natural sources and wells were the most used.

\section{FIGURE 18 HOUSEHOLDS WITH TAP CONNECTIONS AT BASELINE}

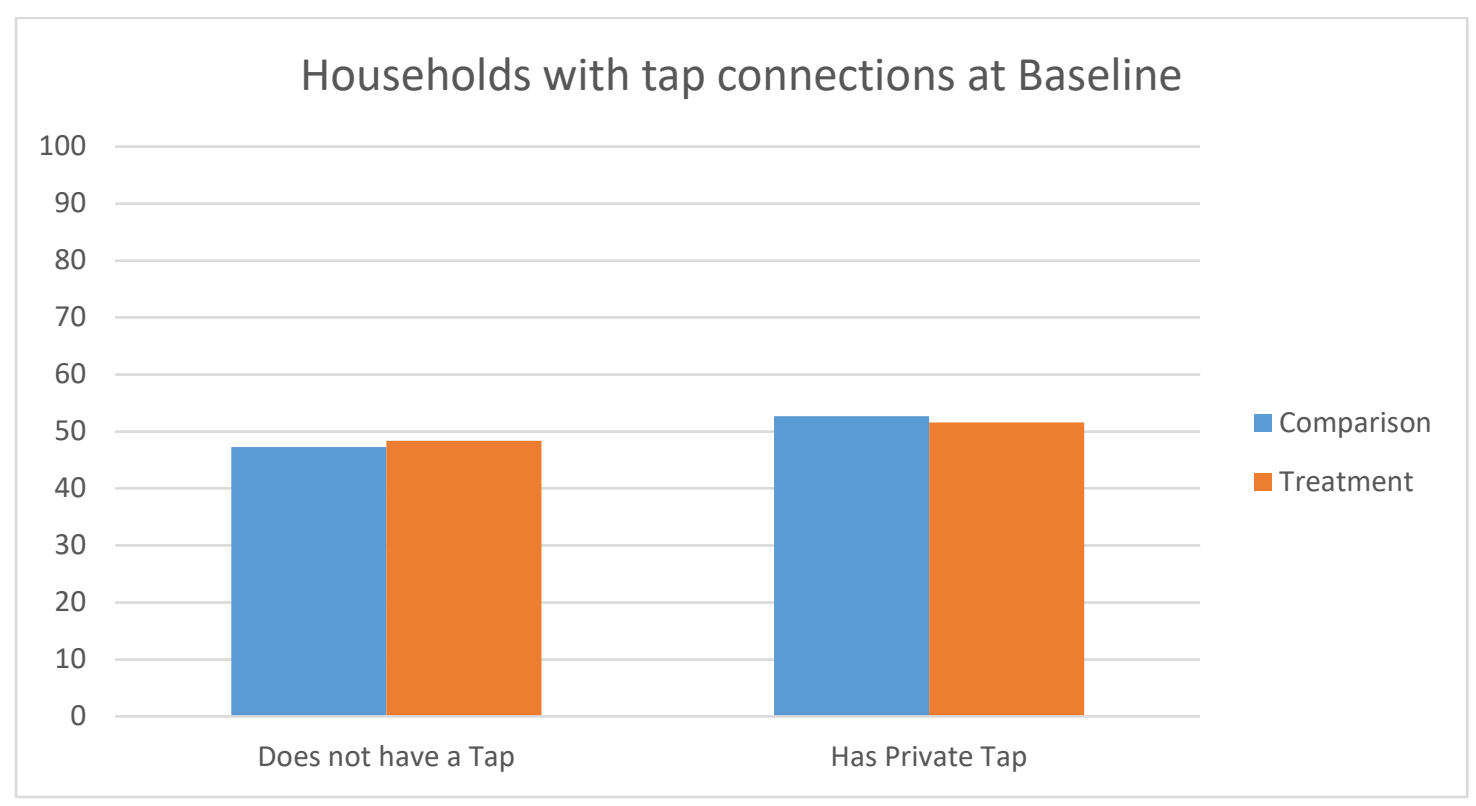




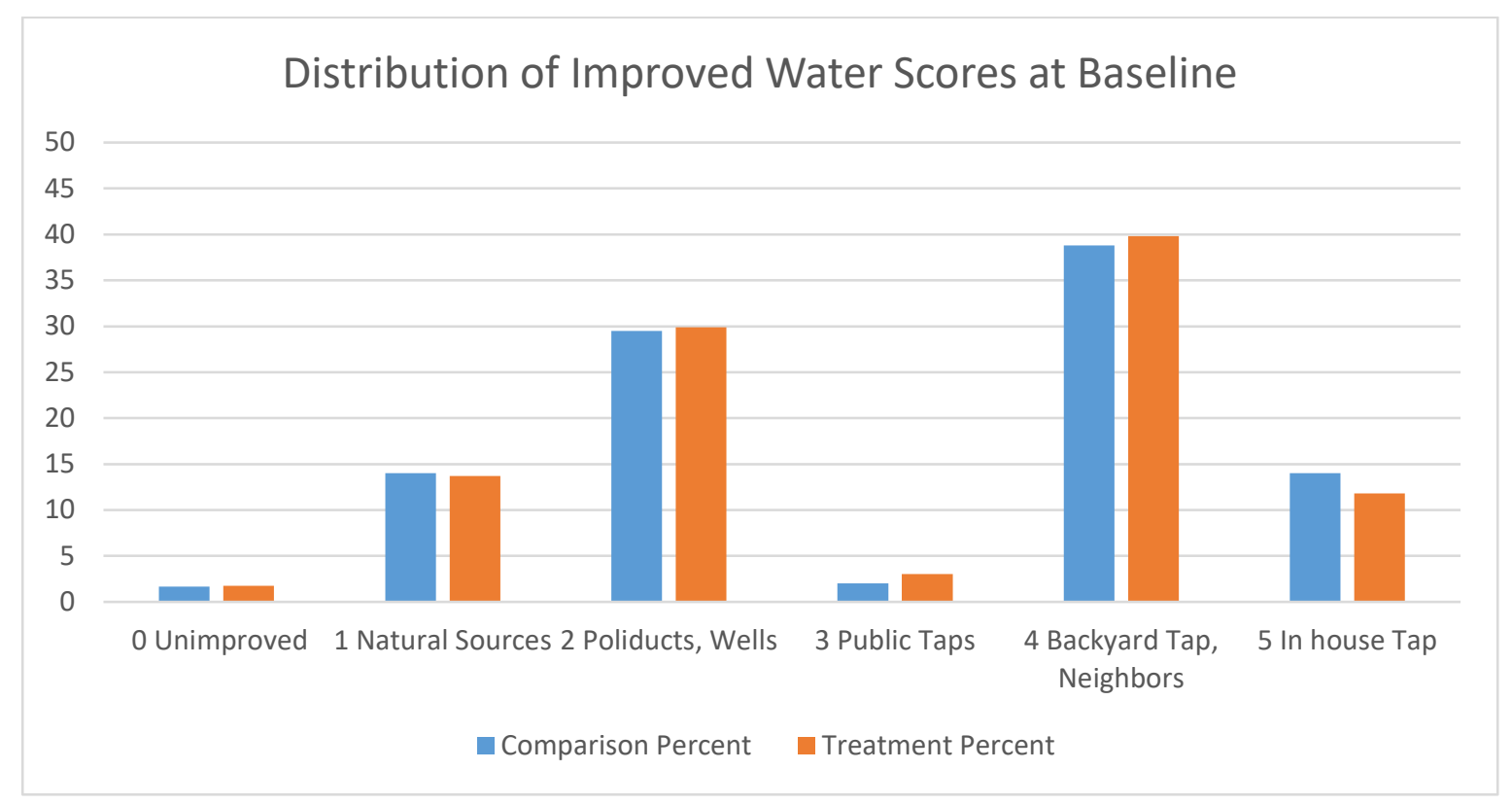

To quantify this effect, we estimate the impact of the WASH interventions on the probability of having a tap connection and for the water score described above. Table 49 presents the results for the probability of having a household tap and Table 50, the improved water scores show significant positive effects, implying that households moved from lower scores towards higher scores and that households also entered the maximum score category of having a tap connection in their house. We estimate that treatment households experienced an increase in the average score of 0.61 units to 1.05 units; 20 percent of the average score.

In Figure 20, we explore heterogeneity across baseline water source to identify if the households that used worse water sources are the ones that are connecting to the new projects. The estimates show that the increase in access to private taps was driven by households that used public taps, public wells, and trucks. Households living in treatment segments and using public taps at baseline were 66 percentage points more likely to have a private tap after the WASH interventions when compared to similar households in the comparison group. Consistent with these results, we find larger impacts on the improved water score for the households using natural sources, poliducts, and wells at baseline. 
TABLE 49 IMPROVE WATER SERVICES UPTAKE: PROBABILITY OF HAVING A HOUSEHOLD TAP

\begin{tabular}{|c|c|c|c|c|c|c|c|}
\hline & (1) & $(2)$ & (3) & (4) & (5) & $(6)$ & (7) \\
\hline & DID & DID-FE & DID-Pairs & $\begin{array}{l}\text { RF-Area- } \\
\text { ITT }\end{array}$ & 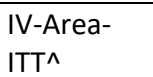 & RF-ATE & IV-LATE^ \\
\hline Treatment \# Post Period & $\begin{array}{l}0.25 \\
{[0.039]^{* * *}}\end{array}$ & $\begin{array}{l}0.24 \\
{[0.039]^{* * *}}\end{array}$ & $\begin{array}{l}0.25 \\
{[0.039]^{* * *}}\end{array}$ & & & & \\
\hline Inside Project Area \# Post Period & & & & $\begin{array}{l}0.35 \\
{[0.045]^{* * *}}\end{array}$ & & & \\
\hline Inside Project Area-ITT in Post & & & & & & & \\
\hline Period & & & & & $\begin{array}{l}0.36 \\
{[0.055]^{* * *}}\end{array}$ & & \\
\hline Beneficiary \# Post Period & & & & & & $\begin{array}{l}0.42 \\
{[0.051]^{* * *}}\end{array}$ & \\
\hline Beneficiary-LATE in Post Period & & & & & & & $\begin{array}{l}0.42 \\
{[0.064]^{* * *}}\end{array}$ \\
\hline Pairs Indicators & NO & NO & YES & YES & NO & YES & NO \\
\hline SD of Comp. at Baseline & 0.5 & 0.5 & 0.5 & 0.5 & 0.5 & 0.5 & 0.5 \\
\hline Number of Clusters & 128 & 128 & 128 & 128 & 128 & 128 & 128 \\
\hline Observations & 9,325 & 9,325 & 9,325 & 9,208 & 9,208 & 9,208 & 9,208 \\
\hline K-P rk Wald F & & & & & 249.6 & & 129.9 \\
\hline
\end{tabular}

\section{Standard errors in brackets}

Std. errors are clustered at the census segment

level.

All equations include year fixed effects. Equations are DID, in (1)-(3) the treatment is defined as living in a treatment assigned segment, (4)-(5) treatment is defined as living inside the project area within the matched pairs, (6)-(7) treatment is defined as having reported being beneficiary of the WASH project within the matched pairs. Equations (4)-(7) control for initial treatment assignment. Equation (2) includes household fixed effects. Pair dummies indicated in the table are based in on nearest neighbor matching propensity score matching based on 2007 census segment data.

IV estimates in columns (5) and (7) use the census segment treatment assignment to instrument for indicators for being in a project area in 2012-2013 (5); and the households reporting being a beneficiary of the WASH projects from MCC in (7)

^IV estimates partial out the indicators for pairs to compute the std. errors of the coefficients of interest. We report the K-P rk Wald $F$ statistic following the results in Stock and Yogo (2005)

$* p<0.10, * * p<0.05, * * * p<0.01$ 
TABLE 50 IMPROVE WATER SERVICES UPTAKE:: INCREASES IN BEST WATER SOURCE SCORE

\begin{tabular}{|c|c|c|c|c|c|c|c|}
\hline & (1) & $(2)$ & (3) & (4) & (5) & (6) & (7) \\
\hline & DID & DID-FE & DID-Pairs & $\begin{array}{l}\text { RF-Area- } \\
\text { ITT }\end{array}$ & 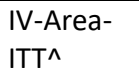 & RF-ATE & IV-LATE^ \\
\hline Treatment \# Post Period & $\begin{array}{l}0.61 \\
{[0.10]^{* * *}}\end{array}$ & $\begin{array}{l}0.6 \\
{[0.10]^{* * *}}\end{array}$ & $\begin{array}{l}0.61 \\
{[0.10]^{* * *}}\end{array}$ & & & & \\
\hline Inside Project Area \# Post Period & & & & $\begin{array}{l}0.86 \\
{[0.12]^{* * *}}\end{array}$ & & & \\
\hline Inside Project Area-ITT in Post Period & & & & & $\begin{array}{l}0.88 \\
{[0.15]^{* * *}}\end{array}$ & & \\
\hline Beneficiary \# Post Period & & & & & & $\begin{array}{l}1.02 \\
{[0.14]^{* * *}}\end{array}$ & \\
\hline Beneficiary-LATE in Post Period & & & & & & & $\begin{array}{l}1.05 \\
{[0.17]^{* * *}}\end{array}$ \\
\hline Pairs Indicators & NO & NO & YES & YES & NO & YES & NO \\
\hline Mean of Comp. at Baseline & 3.07 & 3.07 & 3.07 & 3.08 & 3.08 & 3.06 & 3.06 \\
\hline Number of Clusters & 128 & 128 & 128 & 128 & 128 & 128 & 128 \\
\hline Observations & 9,325 & 9,325 & 9,325 & 9,208 & 9,208 & 9,208 & 9,208 \\
\hline K-P rk Wald F & & & & & 249.6 & & 129.9 \\
\hline
\end{tabular}

Standard errors in brackets

Std. errors are clustered at the census segment level.

All equations include year fixed effects. Equations are DID, in (1)-(3) the treatment is defined as living in a treatment assigned segment, (4)-(5) treatment is defined as living inside the project area within the matched pairs, (6)-(7) treatment is defined as having reported being beneficiary of the WASH project within the matched pairs. Equations (4)-(7) control for initial treatment assignment.

Equation (2) includes household fixed effects. Pair dummies indicated in the table are based in on nearest neighbor matching propensity score matching based on 2007 census segment data.

IV estimates in columns (5) and (7) use the census segment treatment assignment to instrument for indicators for being in a project area in $2012-2013$

(5); and the households reporting being a beneficiary of the WASH projects from MCC in (7)

IV estimates partial out the indicators for pairs to compute the std. errors of the coefficients of interest. We report the K-P rk Wald $\mathrm{F}$ statistic

following the results in Stock and Yogo (2005)

$* \mathrm{p}<0.10, * * \mathrm{p}<0.05, * * * \mathrm{p}<0.01$

FIGURE 20 UPTAKE: PROBABILITY OF HAVING A TAP BY INITIAL WATER SOURCE

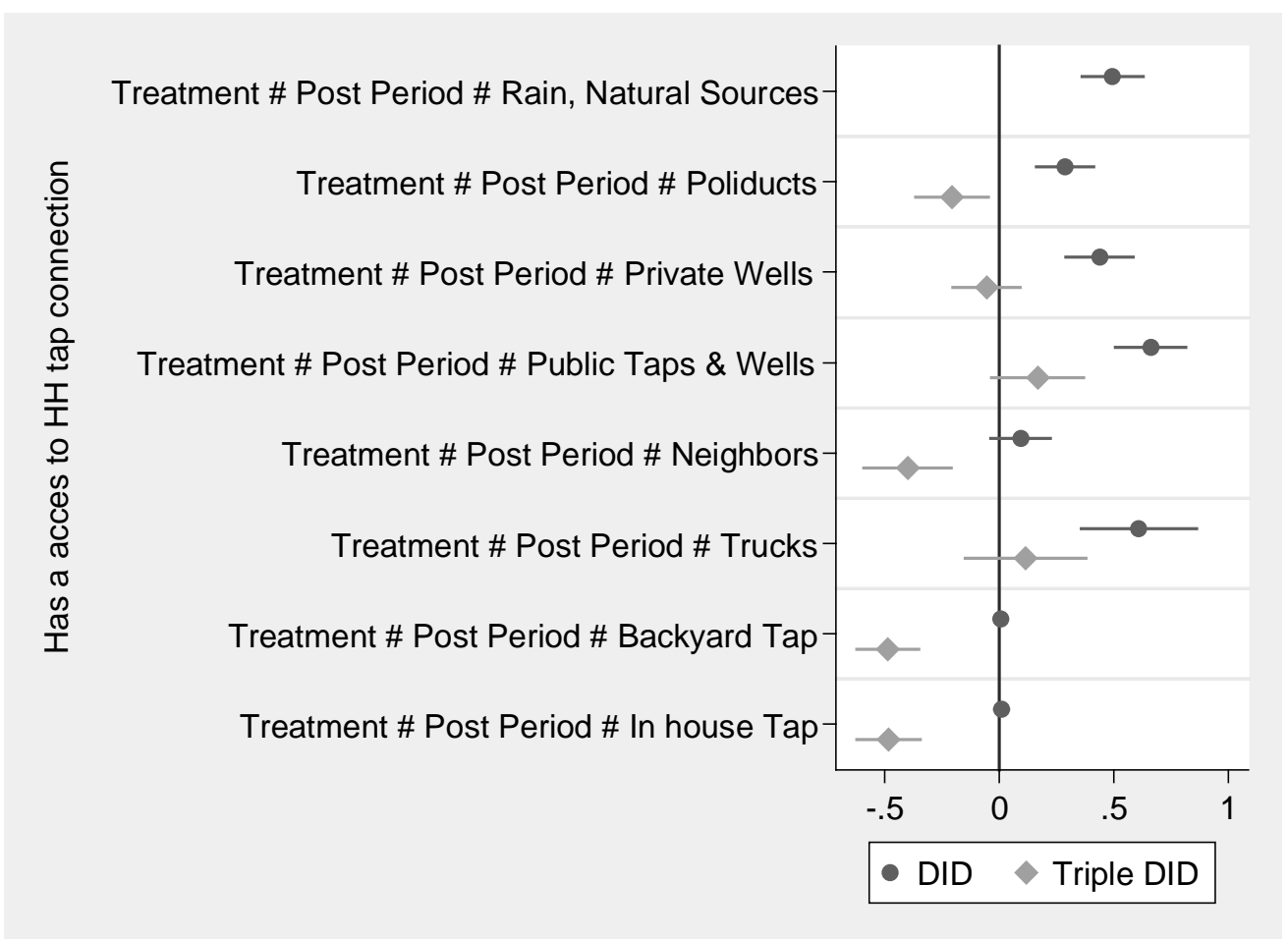


Improvements in access to water services are also reflected as decreases in time to specific sources, such as public, neighbors', and private taps. Table 51 shows the average traveling time across water sources for specific sources at baseline. The average travel time to all the sources available to the households is eight minutes each way. The sources that are the farthest are springs and other natural sources, which are around 12 minutes each way. While these are not extremely large times to collect water, households tend to make multiple trips per week to fetch water and store it. This, coupled with poorer households being larger and the distribution of travel times as seen in Figure 21, implies that there is room for the water projects to generate considerable time savings.

TABLE 51 AVERAGE TRAVEL TIMES TO WATER SOURCES AT BASELINE (MINUTES)

\begin{tabular}{lccc} 
& Mean & Standard Error & Observations \\
\hline \multicolumn{1}{c}{ Comparison } & & & \\
Average & 8.0 & 0.2 & 1,654 \\
Public Tap & 6.4 & 0.4 & 259 \\
Other Sources & 11.9 & 0.4 & 881 \\
Public Well & 9.0 & 0.8 & 95 \\
Springs & 11.4 & 0.5 & 568 \\
$\quad$ Treatment & & & \\
Average & 8.1 & 0.3 & 1,637 \\
Public Tap & 6.0 & 0.4 & 240 \\
Other Sources & 12.9 & 0.5 & 848 \\
Public Well & 7.3 & 0.5 & 170 \\
Springs & 11.5 & 0.4 & 711 \\
\hline \hline
\end{tabular}

FIGURE 21 DISTRIBUTION OF TRAVEL TIMES TO SOURCES AT BASELINE

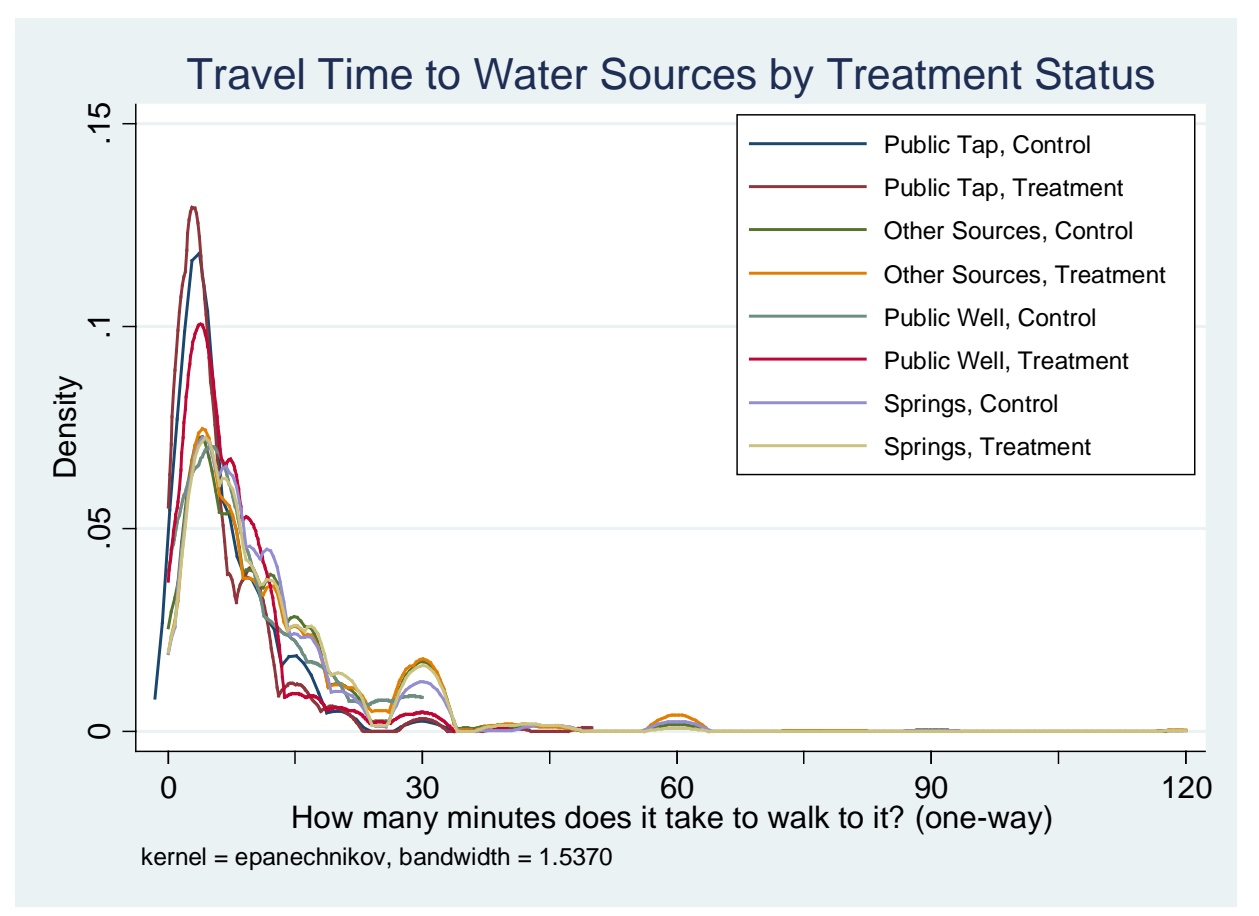

Table 52 presents the results for the average travel time for all sources that households used and for the travel time to the best source the households used. We did not detect effects on the average time to all sources; this 
is likely due to households that continued to use other sources even if they have a tap connection. The number of non-tap sources ranges from one to four; at baseline, households used 1.15 non-tap sources on average (households that used only tap are counted as zero). Excluding the households that only used a tap connection, the average is 1.56 non-tap sources.

In Table 53, we address this issue by using the travel time that corresponds to the best type of water source that the household used; namely the time to travel to the source defined by the improved water score. We can see that treatment households experienced some time savings while travelling to water sources, with a savings of 1.78 minutes per trip per person in the ITT estimate (3) and over 3 minutes per trip in IV specification with the reported treatment assignment (7).

TABLE 52 AVERAGE TIME IN MINUTES TO ACCESS WATER SOURCES

\begin{tabular}{|c|c|c|c|c|c|c|c|}
\hline & $(1)$ & $(2)$ & (3) & $(4)$ & $(5)$ & $(6)$ & (7) \\
\hline & DID & DID-FE & DID-Pairs & $\begin{array}{l}\text { RF-Area- } \\
\text { ITT }\end{array}$ & 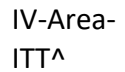 & RF-ATE & IV-LATE^ \\
\hline Treatment \# Post Period & $\begin{array}{l}-0.075 \\
{[0.67]}\end{array}$ & $\begin{array}{l}-0.063 \\
{[0.67]}\end{array}$ & $\begin{array}{l}-0.088 \\
{[0.67]}\end{array}$ & & & & \\
\hline \multicolumn{2}{|c|}{ Inside Project Area \# Post Period } & & & $\begin{array}{l}-0.4 \\
{[0.68]}\end{array}$ & & & \\
\hline \multicolumn{2}{|c|}{ Inside Project Area-ITT in Post Period } & & & & $\begin{array}{l}-0.039 \\
{[1.01]}\end{array}$ & & \\
\hline \multicolumn{2}{|l|}{ Beneficiary \# Post Period } & & & & & $\begin{array}{l}-0.34 \\
{[0.68]}\end{array}$ & \\
\hline \multicolumn{2}{|c|}{ Beneficiary-LATE in Post Period } & & & & & & $\begin{array}{l}0.13 \\
{[1.19]}\end{array}$ \\
\hline Pairs Indicators & NO & NO & YES & YES & NO & YES & NO \\
\hline Mean of Comp. at Baseline & 7.97 & 7.97 & 7.97 & 8.29 & 8.29 & 8.15 & 8.15 \\
\hline SD of Comp. at Baseline & 9.76 & 9.76 & 9.76 & 10.3 & 10.3 & 10.2 & 10.2 \\
\hline Number of Clusters & 128 & 128 & 128 & 128 & 128 & 128 & 128 \\
\hline Observations & 9,325 & 9,325 & 9,325 & 9,208 & 9,208 & 9,208 & 9,208 \\
\hline K-P rk Wald F & & & & & 249.6 & & 129.9 \\
\hline
\end{tabular}

Standard errors in brackets

Std. errors are clustered at the census segment level.

All equations include year fixed effects. Equations are DID, in (1)-(3) the treatment is defined as living in a treatment assigned segment, (4)-(5) treatment is defined as living inside the project area within the matched pairs, (6)-(7) treatment is defined as having reported being beneficiary of the WASH project within the matched pairs. Equations (4)-(7) control for initial treatment assignment.

Equation (2) includes household fixed effects. Pair dummies indicated in the table are based in on nearest neighbor matching propensity score matching based on 2007 census segment data.

IV estimates in columns (5) and (7) use the census segment treatment assignment to instrument for indicators for being in a project area in 2012-2013 (5); and the households reporting being a beneficiary of the WASH projects from MCC in (7)

NIV estimates partial out the indicators for pairs to compute the std. errors of the coefficients of interest. We report the K-P rk Wald $F$ statistic following the results in Stock and Yogo (2005)

${ }^{*} \mathrm{p}<0.10, * * \mathrm{p}<0.05, * * * \mathrm{p}<0.01$ 
TABLE 53 TIME IN MINUTES TO ACCESS WATER SOURCES: BEST SOURCE USED

\begin{tabular}{|c|c|c|c|c|c|c|c|}
\hline & $(1)$ & $(2)$ & (3) & (4) & $(5)$ & $(6)$ & (7) \\
\hline & DID & DID-FE & DID-Pairs & $\begin{array}{l}\text { RF-Area- } \\
\text { ITT }\end{array}$ & $\begin{array}{l}\text { IV-Area- } \\
\mathrm{ITT}^{\wedge}\end{array}$ & RF-ATE & IV-LATE^ \\
\hline Treatment \# Post Period & $\begin{array}{l}-1.71 \\
{[0.52]^{* * *}}\end{array}$ & $\begin{array}{l}-1.7 \\
{[0.47]^{* * *}}\end{array}$ & $\begin{array}{l}-1.78 \\
{[0.53]^{* * *}}\end{array}$ & & & & \\
\hline Inside Project Area \# Post Period & & & & $\begin{array}{l}-2.43 \\
{[0.58]^{* * *}}\end{array}$ & & & \\
\hline Inside Project Area-ITT in Post Period & & & & & $\begin{array}{l}-2.62 \\
{[0.77]^{* * *}}\end{array}$ & & \\
\hline Beneficiary \# Post Period & & & & & & $\begin{array}{l}-2.67 \\
{[0.60]^{* * *}}\end{array}$ & \\
\hline Beneficiary-LATE in Post Period & & & & & & & $\begin{array}{l}-3.01 \\
{[0.86]^{* * *}}\end{array}$ \\
\hline Pairs Indicators & NO & NO & YES & YES & NO & YES & NO \\
\hline Mean of Comp. at Baseline & 3.4 & 3.4 & 3.4 & 3.32 & 3.32 & 3.37 & 3.37 \\
\hline SD of Comp. at Baseline & 8.3 & 8.3 & 8.3 & 8.45 & 8.45 & 8.5 & 8.5 \\
\hline Number of Clusters & 128 & 128 & 128 & 128 & 128 & 128 & 128 \\
\hline Observations & 7,808 & 7,808 & 7,808 & 7,722 & 7,722 & 7,722 & 7,722 \\
\hline K-P rk Wald F & & & & & 135.9 & & 123.1 \\
\hline
\end{tabular}

Standard errors in brackets

Std. errors are clustered at the census segment level.

All equations include year fixed effects. Equations are DID, in (1)-(3) the treatment is defined as living in a treatment assigned segment, (4)-(5) treatment is defined as living inside the project area within the matched pairs, (6)-(7) treatment is defined as having reported being beneficiary of the WASH project within the matched pairs. Equations (4)-(7) control for initial treatment assignment.

Equation (2) includes household fixed effects. Pair dummies indicated in the table are based in on nearest neighbor matching propensity score matching based on 2007 census segment data.

IV estimates in columns (5) and (7) use the census segment treatment assignment to instrument for indicators for being in a project area in 20122013 (5); and the households reporting being a beneficiary of the WASH projects from MCC in (7)

IIV estimates partial out the indicators for pairs to compute the std. errors of the coefficients of interest. We report the K-P rk Wald F statistic following the results in Stock and Yogo (2005)

$* \mathrm{p}<0.10, * * \mathrm{p}<0.05, * * * \mathrm{p}<0.01$

Another outcome central to the improvement in access to WASH services is the reliability of the water systems in the communities. We measured reliability by the numbers of days and hours per week that households that have taps could obtain water and by the number of days and hours per week that public taps were available.

Table 54 shows some descriptive statistics for these variables. For the households that had a tap at baseline, we see that they had water for five days a week, on average, and over 50 percent of these households had water seven days a week.

In what follows, we first estimate the impact for the complete sample and then limit the estimation to the households that had tap connections at baseline. The purpose is to disentangle the extensive margin from the intensive margin. For example, on the extensive margin, a household that did not have a tap and then began receiving the water service would create an upward pressure in the full sample estimates, as they go from having zero days of service to five days of service. In the second set of results, we get the pure intensive margin impact; households that were already connected and now might be receiving better service. 
TABLE 54 DESCRIPTIVE STATISTICS: HOURS AND DAYS PER WEEK THAT HOUSEHOLD HAS ACCESS TO TAP WATER

\begin{tabular}{|c|c|c|c|c|c|c|c|c|}
\hline & \multicolumn{4}{|c|}{ Comparison } & \multicolumn{4}{|c|}{ Treatment } \\
\hline \multicolumn{9}{|c|}{2011} \\
\hline Household tap is available $<7$ & 0.47 & 0.5 & 0 & 853 & 0.5 & 0.5 & 1 & 828 \\
\hline Hours per week Household Tap is Available & 77.4 & 68.3 & 49 & 769 & 59.3 & 67.8 & 21 & 652 \\
\hline Number of days Household Tap Available & 5.04 & 2.48 & 7 & 822 & 5.23 & 2.49 & 7 & 804 \\
\hline Household Tap is Available $<7$ & 0.43 & 0.49 & 0 & 822 & 0.37 & 0.48 & 0 & 804 \\
\hline Hours per Week Household Tap is Available & 80.4 & 69.5 & 48 & 741 & 70.6 & 69.6 & 28 & 733 \\
\hline \multicolumn{9}{|c|}{2013} \\
\hline Number of days Household Tap Available & 4.94 & 2.45 & 7 & 834 & 4.99 & 2.52 & 7 & 810 \\
\hline Number of Days Household Tap Available & 5 & 2.46 & 7 & 2509 & 4.86 & 2.67 & 7 & 2442 \\
\hline Household Tap is Available $<7$ & 0.45 & 0.5 & 0 & 2509 & 0.44 & 0.5 & 0 & 2442 \\
\hline Hours per Week Household Tap is Available & 77.6 & 69.2 & 42 & 2261 & 67.9 & 70 & 24.5 & 2119 \\
\hline
\end{tabular}

*Sample with a connection at baseline. 
Table 55 shows that households in treatment segments were around 20 percent less likely to report having tap water available less than seven days a week. This table shows the coupled effects on the extensive and intensive margins. Table 56 shows that household in treatment segments had 16.5 to 24.3 more hours of available service per week after the completion of the WASH interventions than households living in comparison segments.

In addition, we estimate these effects on the sample of households that had a tap at baseline to isolate the effects on the intensive margin, presented in Table 57. We find effects of similar size that are concentrated in households that had access to a backyard tap at baseline (as opposed to internal house plumbing); although not always significant at the 5 percent confidence level. Coupled with the results in Table 56, we conclude that there was a general increase in the reliability measures for households that had potable water for the first time and for those that had tap water previously, where the projects improved the existing system.

TABLE 55 RELIABILITY: TAP AVAILABILITY 7 DAYS OR LESS

\begin{tabular}{|c|c|c|c|c|c|c|c|}
\hline & (1) & $(2)$ & (3) & (4) & (5) & (6) & (7) \\
\hline & DID & DID-FE & DID-Pairs & $\begin{array}{c}\text { RF-Area- } \\
\text { ITT }\end{array}$ & $\begin{array}{c}\text { IV-Area- } \\
\text { ITT }^{\wedge}\end{array}$ & RF-ATE & IV-LATE^^ \\
\hline Treatment \# Post Period & -0.2 & -0.2 & -0.2 & & & & \\
\hline & {$[0.045]^{* * *}$} & {$[0.045]^{* * *}$} & {$[0.045]^{* * *}$} & & & & \\
\hline Inside Project Area \# Post Period & & & & -0.29 & & & \\
\hline & & & & {$[0.049]^{* * *}$} & & & \\
\hline Inside Project Area-ITT in Post & & & & & & & \\
\hline Period & & & & & -0.3 & & \\
\hline & & & & & {$[0.064]^{* * *}$} & & \\
\hline Beneficiary \# Post Period & & & & & & -0.35 & \\
\hline & & & & & & {$[0.055]^{* * *}$} & \\
\hline Beneficiary-LATE in Post Period & & & & & & & -0.36 \\
\hline & & & & & & & {$[0.075]^{* * *}$} \\
\hline Pairs Indicators & NO & NO & YES & YES & NO & YES & NO \\
\hline Mean of Comp. at Baseline & 0.71 & 0.71 & 0.71 & 0.71 & 0.71 & 0.72 & 0.72 \\
\hline SD of Comp. at Baseline & 0.45 & 0.45 & 0.45 & 0.45 & 0.45 & 0.45 & 0.45 \\
\hline Number of Clusters & 128 & 128 & 128 & 128 & 128 & 128 & 128 \\
\hline Observations & 9,325 & 9,325 & 9,325 & 9,208 & 9,208 & 9,208 & 9,208 \\
\hline K-P rk Wald F & & & & & 249.6 & & 129.9 \\
\hline
\end{tabular}

Standard errors in brackets

Std. errors are clustered at the census segment level.

All equations include year fixed effects. Equations are DID, in (1)-(3) the treatment is defined as living in a treatment assigned segment, (4)-(5) treatment is defined as living inside the project area within the matched pairs, (6)-(7) treatment is defined as having reported being beneficiary of the WASH project within the matched pairs. Equations (4)-(7) control for initial treatment assignment.

Equation (2) includes household fixed effects. Pair dummies indicated in the table are based in on nearest neighbor matching propensity score matching based on 2007 census segment data.

IV estimates in columns (5) and (7) use the census segment treatment assignment to instrument for indicators for being in a project area in 20122013 (5); and the households reporting being a beneficiary of the WASH projects from MCC in (7)

IIV estimates partial out the indicators for pairs to compute the std. errors of the coefficients of interest. We report the K-P rk Wald F statistic

following the results in Stock and Yogo (2005)

$* \mathrm{p}<0.10, * * \mathrm{p}<0.05, * * * \mathrm{p}<0.01$ 
TABLE 56 RELIABILITY: TAP AVAILABILITY IN HOURS PER WEEK

\begin{tabular}{|c|c|c|c|c|c|c|c|}
\hline & (1) & $(2)$ & (3) & (4) & (5) & (6) & (7) \\
\hline & DID & DID-FE & DID-Pairs & $\begin{array}{c}\text { RF-Area- } \\
\text { ITT }\end{array}$ & 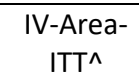 & RF-ATE & IV-LATE^ \\
\hline \multirow[t]{2}{*}{ Treatment \# Post Period } & 17.1 & 14.4 & 16.5 & & & & \\
\hline & {$[7.91]^{* *}$} & {$[6.32]^{* *}$} & {$[6.79]^{* *}$} & & & & \\
\hline \multirow[t]{2}{*}{ Inside Project Area \# Post Period } & & & & 20.2 & & & \\
\hline & & & & {$[7.65]^{* * *}$} & & & \\
\hline \multirow[t]{2}{*}{ Inside Project Area-ITT in Post Period } & & & & & 23.1 & & \\
\hline & & & & & {$[9.40]^{* *}$} & & \\
\hline \multirow[t]{2}{*}{ Beneficiary \# Post Period } & & & & & & 22.6 & \\
\hline & & & & & & {$[8.24]^{* * *}$} & \\
\hline \multirow[t]{2}{*}{ Beneficiary-LATE in Post Period } & & & & & & & 24.3 \\
\hline & & & & & & & {$[9.99]^{* *}$} \\
\hline Pairs Indicators & NO & NO & YES & YES & NO & YES & NO \\
\hline Mean of Comp. at Baseline & 77.5 & 77.5 & 77.5 & 77.3 & 77.3 & 76.7 & 76.7 \\
\hline Number of Clusters & 122 & 122 & 122 & 122 & 122 & 122 & 122 \\
\hline Observations & 5,316 & 5,316 & 5,316 & 5,273 & 5,273 & 5,273 & 5,273 \\
\hline K-P rk Wald F & & & & & 92.5 & & 86.3 \\
\hline
\end{tabular}

Standard errors in brackets

Std. errors are clustered at the census segment level.

All equations include year fixed effects. Equations are DID, in (1)-(3) the treatment is defined as living in a treatment assigned segment, (4)-(5) treatment is defined as living inside the project area within the matched pairs, (6)-(7) treatment is defined as having reported being beneficiary of the WASH project within the matched pairs. Equations (4)-(7) control for initial treatment assignment.

Equation (2) includes household fixed effects. Pair dummies indicated in the table are based in on nearest neighbor matching propensity score matching based on 2007 census segment data.

IV estimates in columns (5) and (7) use the census segment treatment assignment to instrument for indicators for being in a project area in $2012-2013$ (5); and the households reporting being a beneficiary of the WASH projects from MCC in (7)

^IV estimates partial out the indicators for pairs to compute the std. errors of the coefficients of interest. We report the K-P rk Wald $\mathrm{F}$ statistic following the results in Stock and Yogo (2005)

${ }^{*} \mathrm{p}<0.10, * * \mathrm{p}<0.05, * * * \mathrm{p}<0.01$ 
TABLE 57 RELIABILITY FOR HOUSEHOLDS WITH TAPS AT BASELINE: HOURS AND DAYS PER WEEK WITH ACCESS TO TAP WATER

\begin{tabular}{|c|c|c|c|c|c|}
\hline & (1) & (2) & (3) & (4) & (5) \\
\hline & DID & DID-FE & $\begin{array}{l}\text { DID- } \\
\text { Pairs }\end{array}$ & $\begin{array}{c}\text { RF-Area- } \\
\text { ITT }\end{array}$ & RF-ATE \\
\hline \multirow[t]{2}{*}{ Treatment \# Post Period \# Backyard Tap } & 13.2 & 14.3 & 14 & & \\
\hline & {$[6.96]^{*}$} & {$[6.61]^{* *}$} & {$[6.73]^{* *}$} & & \\
\hline \multirow[t]{2}{*}{ Treatment \# Post Period \# In house Tap } & 10.8 & 14.8 & 12.7 & & \\
\hline & {$[8.77]$} & {$[8.42]^{*}$} & {$[8.54]$} & & \\
\hline \multirow[t]{2}{*}{ Inside Project Area \# Post Period \# Backyard Tap } & & & & 12.2 & \\
\hline & & & & {$[8.11]$} & \\
\hline \multirow[t]{2}{*}{ Inside Project Area \# Post Period \# In house Tap } & & & & 18.3 & \\
\hline & & & & {$[10.4]^{*}$} & \\
\hline \multirow[t]{2}{*}{ Beneficiary \# Post Period \# Backyard Tap } & & & & & 15.4 \\
\hline & & & & & {$[8.77]^{*}$} \\
\hline \multirow[t]{2}{*}{ Beneficiary \# Post Period \# In house Tap } & & & & & 25.6 \\
\hline & & & & & {$[11.0]^{* *}$} \\
\hline Pairs Indicators & NO & NO & YES & YES & YES \\
\hline Mean of Comp. at Baseline & 77.5 & 77.5 & 77.5 & 77.3 & 76.7 \\
\hline SD of Comp. at Baseline & 68.3 & 68.3 & 68.3 & 68.8 & 69.2 \\
\hline Number of Clusters & 122 & 122 & 122 & 122 & 122 \\
\hline Observations & 5,316 & 5,316 & 5,316 & 5,273 & 5,273 \\
\hline
\end{tabular}

Standard errors in brackets

Std. errors are clustered at the census segment level.

All equations include year fixed effects. Equations are DID, in (1)-(3) the treatment is defined as living in a treatment assigned segment, (4) treatment is defined as living inside the project area within the matched pairs, (5) treatment is defined as having reported being beneficiary of the WASH project within the matched pairs. Equations (4)-(5) control for initial treatment assignment.

Equation (2) includes household fixed effects. Pair dummies indicated in the table are based in on nearest neighbor matching propensity score matching based on 2007 census segment data.

Impact estimates represent the DID estimates for households that had the same baseline water source

$* \mathrm{p}<0.10, * * \mathrm{p}<0.05, * * * \mathrm{p}<0.01$

The WASH interventions also included the construction of public taps; although not many). The impact on indicators for public taps access and reliability are not precisely estimated in Table 58. This is for two reasonsfirst because there were few households reporting the use of public taps, and second, because the main purpose of the water and sanitation intervention was not to improve access to public taps but to household taps, as the evidence suggests. As mentioned before, only 15 public taps were constructed. The impact estimates suggest that public taps in treatment segment had increased service, increasing by almost 50 percent or 30.3 hours per week in segments where the WASH interventions took place. 
TABLE 58 RELIABILITY OF PUBLIC TAPS AVAILABILITY

\begin{tabular}{|c|c|c|c|c|c|c|c|}
\hline & $(1)$ & $(2)$ & (3) & (4) & (5) & (6) & (7) \\
\hline & DID & DID-FE & DID-Pairs & $\begin{array}{c}\text { RF-Area- } \\
\text { ITT }\end{array}$ & $\begin{array}{l}\text { IV-Area- } \\
\text { ITT^ }^{\wedge}\end{array}$ & RF-ATE & $\begin{array}{c}\text { IV- } \\
\text { LATE^ }^{\wedge}\end{array}$ \\
\hline Treatment \# Post Period & $\begin{array}{l}-10.7 \\
{[31.0]}\end{array}$ & $\begin{array}{l}-1.11 \\
{[19.6]}\end{array}$ & $\begin{array}{l}30.3 \\
{[14.5]^{* *}}\end{array}$ & & & & \\
\hline Inside Project Area \# Post Period & & & & $\begin{array}{l}30.1 \\
{[16.5]^{*}}\end{array}$ & & & \\
\hline Inside Project Area-ITT in Post Period & & & & & $\begin{array}{l}39.9 \\
{[18.5]^{* *}}\end{array}$ & & \\
\hline Beneficiary \# Post Period & & & & & & $\begin{array}{l}26.7 \\
{[15.9]}\end{array}$ & \\
\hline Beneficiary-LATE in Post Period & & & & & & & $\begin{array}{l}63.7 \\
{[33.2]^{*}}\end{array}$ \\
\hline Pairs Indicators & NO & NO & YES & YES & NO & YES & NO \\
\hline Mean of Comp. at Baseline & 79.4 & 79.4 & 79.4 & 78.6 & 78.6 & 79.1 & 79.1 \\
\hline Number of Clusters & 40 & 40 & 40 & 40 & 40 & 40 & 40 \\
\hline Observations & 360 & 360 & 360 & 353 & 353 & 353 & 353 \\
\hline K-P rk Wald F & & & & & 34.6 & & 8.16 \\
\hline
\end{tabular}

Standard errors in brackets

Std. errors are clustered at the census segment level.

All equations include year fixed effects. Equations are DID, in (1)-(3) the treatment is defined as living in a treatment assigned segment, (4)-(5) treatment is defined as living inside the project area within the matched pairs, (6)-(7) treatment is defined as having reported being beneficiary of the WASH project within the matched pairs. Equations (4)-(7) control for initial treatment assignment.

Equation (2) includes household fixed effects. Pair dummies indicated in the table are based in on nearest neighbor matching propensity score matching based on 2007 census segment data.

IV estimates in columns (5) and (7) use the census segment treatment assignment to instrument for indicators for being in a project area in $2012-2013$

(5); and the households reporting being a beneficiary of the WASH projects from MCC in (7)

^IV estimates partial out the indicators for pairs to compute the std. errors of the coefficients of interest. We report the K-P rk Wald $\mathrm{F}$ statistic following the results in Stock and Yogo (2005)

$* \mathrm{p}<0.10, * * \mathrm{p}<0.05, * * * \mathrm{p}<0.01$

\section{WATER SYSTEMS: Reliability, ANd PeRCEPTIONS Of RISKS AND QUALITY}

Increases in access may be accompanied by changes in the risk perceptions of water sources that are effectively used by households. To explore these changes in subjective quality, we constructed a risk score for each household. The score used the responses to the questions "How likely is a person to get sick from drinking the water from [...]?" for each water source that the household used. The responses were on a scale of no chance, some chance, and high chance. The risk score measured the risk perception of the best water that the household used. For example, a household that used a poliduct ${ }^{39}$ and a well would get the score of the source they believed was the safest; while a household that used a well and a household tap would get the score for the riskiness of the tap water system. Sources that are in the same 'quality' category received the score of the safest because a rational decision maker would select the safest source as a drinking source. If the sources were in different 'quality' categories, they received the score of the better-quality source. The purpose was not to have to rank similar sources arbitrarily. In the ideal situation of improvement and trust in the water services provided, we would see the risk score at "no chance" for all households, in that every household had a source which they thought was safe to drink. Improvements in the risk perception of water sources are reflected as decreases in the risk score. ${ }^{40}$

Table 59 presents the impact estimates from the linear probability models for the probability of responding "no chance" in panel A and responding "high chance" in panel B. The results confirm that treatment households were 15 percentage points more likely to report that there was no chance of getting sick from

\footnotetext{
${ }^{39} \mathrm{~A}$ poliduct is a long system of hoses that brings water to the household from a natural water source.

${ }^{40}$ See Annex 6: Risk Score Allocation Example for a hypothetical situation mapping out risk scores for several households.
} 
consuming the water from their best source after the projects were implemented. Treatment households, similarly were 17 percentage points less likely to responding there was a high chance of getting sick from drinking the water from the system.

We estimated the impact on this risk measures for the sample of households that lives in communities with water systems. For these households, we have their perceptions of the likelihood of getting sick from consuming water from these systems even if they are not connected to the systems. The negative coefficients in panel B of Table 59 confirms that households living in treatment segments perceived the water projects as a safe source of drinking water.

Next, we present the impact estimates for the level of satisfaction with the water system used. This is a subjective measure of the quality of the water system in the community both from a health and reliability standpoint. The level of satisfaction was given by the household response to the question. "How satisfied are you with the tap-water service?" on a scale from zero to three, with three being very satisfied and zero being very unsatisfied. As seen in Table 60, treatment households were more likely to report being very satisfied with the water systems after the water projects were implemented in comparison to similar households in segments where no water projects were implemented. The impact comes from a lower probability of reporting their dissatisfaction and higher probability of reporting that they are very satisfied with the systems (13 percent in column 3 ). 
TABLE 59 RISK PERCEPTIONS OF BEST WATER SOURCE USED

(1) (2)

DID
(3)

(4)

RF-AreaITT

(5)

(6)

(7)

\begin{tabular}{|c|c|c|c|c|c|c|c|}
\hline & DID & DID-FE & DID-Pairs & $\begin{array}{c}\text { RF-Area- } \\
\text { ITT }\end{array}$ & 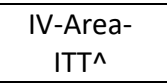 & RF-ATE & IV-LATE^^ \\
\hline \multicolumn{8}{|l|}{ Panel A: No chance } \\
\hline Treatment \# Post Period & $\begin{array}{l}0.15 \\
{[0.038]^{* * *}}\end{array}$ & $\begin{array}{l}0.15 \\
{[0.039]^{* * *}}\end{array}$ & $\begin{array}{l}0.15 \\
{[0.039]^{* * *}}\end{array}$ & & & & \\
\hline Inside Project Area \# Post Period & & & & $\begin{array}{l}0.25 \\
{[0.037]^{* * *}}\end{array}$ & & & \\
\hline Inside Project Area-ITT in Post Period & & & & & $\begin{array}{l}0.22 \\
{[0.053]^{* * *}}\end{array}$ & & \\
\hline Beneficiary \# Post Period & & & & & & $\begin{array}{l}0.26 \\
{[0.040]^{* * *}}\end{array}$ & \\
\hline Beneficiary-LATE in Post Period & & & & & & & $\begin{array}{l}0.25 \\
{[0.065]^{* * *}}\end{array}$ \\
\hline Pairs Indicators & NO & NO & YES & YES & NO & YES & NO \\
\hline Mean of Comp. at Baseline & 0.37 & 0.37 & 0.37 & 0.4 & 0.4 & 0.39 & 0.39 \\
\hline SD of Comp. at Baseline & 0.48 & 0.48 & 0.48 & 0.49 & 0.49 & 0.49 & 0.49 \\
\hline Number of Clusters & 128 & 128 & 128 & 128 & 128 & 128 & 128 \\
\hline Observations & 9,188 & 9,188 & 9,188 & 9,073 & 9,073 & 9,073 & 9,073 \\
\hline K-P rk Wald F & & & & & 213.6 & & 129.3 \\
\hline \multicolumn{8}{|l|}{ Panel B: High Chance } \\
\hline Treatment \# Post Period & $\begin{array}{l}-0.17 \\
{[0.035]^{* * *}}\end{array}$ & $\begin{array}{l}-0.17 \\
{[0.035]^{* * *}}\end{array}$ & $\begin{array}{l}-0.17 \\
{[0.035]^{* * *}}\end{array}$ & & & & \\
\hline Inside Project Area \# Post Period & & & & $\begin{array}{l}-0.22 \\
{[0.041]^{* * *}}\end{array}$ & & & \\
\hline Inside Project Area-ITT in Post Period & & & & & $\begin{array}{l}-0.25 \\
{[0.050]^{* * *}}\end{array}$ & & \\
\hline Beneficiary \# Post Period & & & & & & $\begin{array}{l}-0.23 \\
{[0.044]^{* * *}}\end{array}$ & \\
\hline Beneficiary-LATE in Post Period & & & & & & & $\begin{array}{l}-0.29 \\
{[0.060]^{* * *}}\end{array}$ \\
\hline Pairs Indicators & NO & NO & YES & YES & NO & YES & NO \\
\hline Mean of Comp. at Baseline & 0.26 & 0.26 & 0.26 & 0.25 & 0.25 & 0.26 & 0.26 \\
\hline SD of Comp. at Baseline & 0.44 & 0.44 & 0.44 & 0.43 & 0.43 & 0.44 & 0.44 \\
\hline Number of Clusters & 128 & 128 & 128 & 128 & 128 & 128 & 128 \\
\hline Observations & 9,188 & 9,188 & 9,188 & 9,073 & 9,073 & 9,073 & 9,073 \\
\hline K-P rk Wald F & & & & & 213.6 & & 129.3 \\
\hline
\end{tabular}

Standard errors in brackets

Std. errors are clustered at the census segment level.

All equations include year fixed effects. Equations are DID, in (1)-(3) the treatment is defined as living in a treatment assigned segment, (4)-(5) treatment is defined as living inside the project area within the matched pairs, (6)-(7) treatment is defined as having reported being beneficiary of the WASH project within the matched pairs. Equations (4)-(7) control for initial treatment assignment.

Equation (2) includes household fixed effects. Pair dummies indicated in the table are based in on nearest neighbor matching propensity score matching based on 2007 census segment data.

IV estimates in columns (5) and (7) use the census segment treatment assignment to instrument for indicators for being in a project area in 2012-2013 (5); and the households reporting being a beneficiary of the WASH projects from MCC in (7)

^IV estimates partial out the indicators for pairs to compute the std. errors of the coefficients of interest. We report the K-P rk Wald F statistic following the results in Stock and Yogo (2005)

${ }^{*} \mathrm{p}<0.10,{ }^{* *} \mathrm{p}<0.05$, *** $\mathrm{p}<0.01$ 
TABLE 60 RISK PERCEPTIONS OF TAP WATER SYSTEMS

\begin{tabular}{|c|c|c|c|c|c|c|c|}
\hline & $(1)$ & $(2)$ & (3) & (4) & (5) & (6) & (7) \\
\hline & DID & DID-FE & DID-Pairs & $\begin{array}{c}\text { RF-Area- } \\
\text { ITT }\end{array}$ & $\begin{array}{c}\text { IV-Area- } \\
\text { ITT }^{\wedge}\end{array}$ & RF-ATE & IV-LATE^ \\
\hline \multicolumn{8}{|l|}{ Panel A: No chance } \\
\hline \multirow[t]{2}{*}{ Treatment \# Post Period } & 0.14 & 0.13 & 0.13 & & & & \\
\hline & {$[0.053]^{* * *}$} & {$[0.054]^{* *}$} & {$[0.052]^{* *}$} & & & & \\
\hline \multirow[t]{2}{*}{ Inside Project Area \# Post Period } & & & & 0.22 & & & \\
\hline & & & & {$[0.047]^{* * *}$} & & & \\
\hline \multirow[t]{2}{*}{ Inside Project Area-ITT in Post Period } & & & & & 0.18 & & \\
\hline & & & & & {$[0.067]^{* * *}$} & & \\
\hline \multirow[t]{2}{*}{ Beneficiary \# Post Period } & & & & & & 0.22 & \\
\hline & & & & & & {$[0.048]^{* * *}$} & \\
\hline \multirow[t]{2}{*}{ Beneficiary-LATE in Post Period } & & & & & & & 0.21 \\
\hline & & & & & & & {$[0.082]^{* *}$} \\
\hline Pairs Indicators & NO & NO & YES & YES & NO & YES & NO \\
\hline Mean of Comp. at Baseline & 0.46 & 0.46 & 0.46 & 0.48 & 0.48 & 0.47 & 0.47 \\
\hline SD of Comp. at Baseline & 0.5 & 0.5 & 0.5 & 0.5 & 0.5 & 0.5 & 0.5 \\
\hline Number of Clusters & 125 & 125 & 125 & 124 & 124 & 124 & 124 \\
\hline Observations & 6,609 & 6,609 & 6,609 & 6,546 & 6,546 & 6,546 & 6,546 \\
\hline K-P rk Wald F & & & & & 115.9 & & 115.8 \\
\hline \multicolumn{8}{|l|}{ Panel B: High Chance } \\
\hline \multirow[t]{2}{*}{ Treatment \# Post Period } & -0.14 & -0.12 & -0.14 & & & & \\
\hline & {$[0.046]^{* * *}$} & {$[0.045]^{* * *}$} & {$[0.044]^{* * *}$} & & & & \\
\hline \multirow[t]{2}{*}{ Inside Project Area \# Post Period } & & & & -0.15 & & & \\
\hline & & & & {$[0.051]^{* * *}$} & & & \\
\hline \multirow[t]{2}{*}{ Inside Project Area-ITT in Post Period } & & & & & -0.19 & & \\
\hline & & & & & {$[0.059]^{* * *}$} & & \\
\hline \multirow[t]{2}{*}{ Beneficiary \# Post Period } & & & & & & -0.15 & \\
\hline & & & & & & {$[0.053]^{* * *}$} & \\
\hline \multirow[t]{2}{*}{ Beneficiary-LATE in Post Period } & & & & & & & -0.22 \\
\hline & & & & & & & {$[0.071]^{* * *}$} \\
\hline Pairs Indicators & NO & NO & YES & YES & NO & YES & NO \\
\hline Mean of Comp. at Baseline & 0.15 & 0.15 & 0.15 & 0.15 & 0.15 & 0.15 & 0.15 \\
\hline SD of Comp. at Baseline & 0.35 & 0.35 & 0.35 & 0.35 & 0.35 & 0.35 & 0.35 \\
\hline Number of Clusters & 125 & 125 & 125 & 124 & 124 & 124 & 124 \\
\hline Observations & 6,609 & 6,609 & 6,609 & 6,546 & 6,546 & 6,546 & 6,546 \\
\hline K-P rk Wald F & & & & & 115.9 & & 115.8 \\
\hline
\end{tabular}

Standard errors in brackets

Std. errors are clustered at the census segment level.

All equations include year fixed effects. Equations are DID, in (1)-(3) the treatment is defined as living in a treatment assigned segment, (4)-(5) treatment is defined as living inside the project area within the matched pairs, (6)-(7) treatment is defined as having reported being beneficiary of the WASH project within the matched pairs. Equations (4)-(7) control for initial treatment assignment.

Equation (2) includes household fixed effects. Pair dummies indicated in the table are based in on nearest neighbor matching propensity score matching based on 2007 census segment data.

IV estimates in columns (5) and (7) use the census segment treatment assignment to instrument for indicators for being in a project area in 2012-2013 (5); and the households reporting being a beneficiary of the WASH projects from MCC in (7)

AIV estimates partial out the indicators for pairs to compute the std. errors of the coefficients of interest. We report the K-P rk Wald F statistic following the results in Stock and Yogo (2005)

${ }^{*} \mathrm{p}<0.10,{ }^{* *} \mathrm{p}<0.05, * * * \mathrm{p}<0.01$ 
TABLE 61 SATISFACTION/SUBJECTIVE QUALITY OF THE WATER SYSTEM

\begin{tabular}{|c|c|c|c|c|c|c|c|}
\hline & (1) & $(2)$ & (3) & (4) & (5) & (6) & (7) \\
\hline & DID & DID-FE & DID-Pairs & $\begin{array}{c}\text { RF-Area- } \\
\text { ITT }\end{array}$ & $\begin{array}{c}\text { IV-Area- } \\
\text { ITT }^{\wedge}\end{array}$ & RF-ATE & IV-LATE^ \\
\hline \multicolumn{8}{|l|}{ Very dissatisfied } \\
\hline \multirow[t]{2}{*}{ Treatment \# Post Period } & -0.047 & -0.066 & -0.049 & & & & \\
\hline & {$[0.032]$} & {$[0.030]^{* *}$} & {$[0.031]$} & & & & \\
\hline \multirow[t]{2}{*}{ Inside Project Area \# Post Period } & & & & -0.086 & & & \\
\hline & & & & {$[0.035]^{* *}$} & & & \\
\hline \multirow[t]{2}{*}{ Inside Project Area-ITT in Post Period } & & & & & -0.067 & & \\
\hline & & & & & {$[0.041]$} & & \\
\hline \multirow[t]{2}{*}{ Beneficiary \# Post Period } & & & & & & -0.13 & \\
\hline & & & & & & {$[0.039]^{* * *}$} & \\
\hline \multirow[t]{2}{*}{ Beneficiary-LATE in Post Period } & & & & & & & -0.082 \\
\hline & & & & & & & {$[0.048]^{*}$} \\
\hline Pairs Indicators & NO & NO & YES & YES & NO & YES & NO \\
\hline Mean of Comp. at Baseline & 0.13 & 0.13 & 0.13 & 0.12 & 0.12 & 0.12 & 0.12 \\
\hline SD of Comp. at Baseline & 0.34 & 0.34 & 0.34 & 0.32 & 0.32 & 0.33 & 0.33 \\
\hline Number of Clusters & 125 & 125 & 125 & 124 & 124 & 124 & 124 \\
\hline Observations & 6,765 & 6,765 & 6,765 & 6,700 & 6,700 & 6,700 & 6,700 \\
\hline K-P rk Wald F & & & & & 124.4 & & 118.9 \\
\hline \multicolumn{8}{|l|}{ Very satisfied } \\
\hline \multirow[t]{2}{*}{ Treatment \# Post Period } & 0.13 & 0.11 & 0.13 & & & & \\
\hline & {$[0.037]^{* * *}$} & {$[0.038]^{* * *}$} & {$[0.037]^{* * *}$} & & & & \\
\hline \multirow[t]{2}{*}{ Inside Project Area \# Post Period } & & & & 0.16 & & & \\
\hline & & & & {$[0.035]^{* * *}$} & & & \\
\hline \multirow[t]{2}{*}{ Inside Project Area-ITT in Post Period } & & & & & 0.17 & & \\
\hline & & & & & {$[0.049]^{* * *}$} & & \\
\hline \multirow[t]{2}{*}{ Beneficiary \# Post Period } & & & & & & 0.21 & \\
\hline & & & & & & {$[0.038]^{* * *}$} & \\
\hline \multirow[t]{2}{*}{ Beneficiary-LATE in Post Period } & & & & & & & 0.21 \\
\hline & & & & & & & {$[0.057]^{* * *}$} \\
\hline Pairs Indicators & NO & NO & YES & YES & NO & YES & NO \\
\hline Mean of Comp. at Baseline & 0.22 & 0.22 & 0.22 & 0.21 & 0.21 & 0.2 & 0.2 \\
\hline SD of Comp. at Baseline & 0.42 & 0.42 & 0.42 & 0.41 & 0.41 & 0.4 & 0.4 \\
\hline Number of Clusters & 125 & 125 & 125 & 124 & 124 & 124 & 124 \\
\hline Observations & 6,765 & 6,765 & 6,765 & 6,700 & 6,700 & 6,700 & 6,700 \\
\hline K-P rk Wald F & & & & & 124.4 & & 118.9 \\
\hline
\end{tabular}

Standard errors in brackets

Std. errors are clustered at the census segment level.

All equations include year fixed effects. Equations are DID, in (1)-(3) the treatment is defined as living in a treatment assigned segment, (4)-(5) treatment is defined as living inside the project area within the matched pairs, (6)-(7) treatment is defined as having reported being beneficiary of the WASH project within the matched pairs. Equations (4)-(7) control for initial treatment assignment.

Equation (2) includes household fixed effects. Pair dummies indicated in the table are based in on nearest neighbor matching propensity score matching based on 2007 census segment data.

IV estimates in columns (5) and (7) use the census segment treatment assignment to instrument for indicators for being in a project area in $2012-2013$

(5); and the households reporting being a beneficiary of the WASH projects from MCC in (7)

^IV estimates partial out the indicators for pairs to compute the std. errors of the coefficients of interest. We report the K-P rk Wald F statistic following the results in Stock and Yogo (2005)

* $\mathrm{p}<0.10,{ }^{*} \mathrm{p}<0.05, * * * \mathrm{p}<0.01$ 


\section{GENDER AND SOCIO-ECONOMIC HETEROGENEITY IN ACCESS}

We explored heterogeneity of effects across gender of the head of household and across socio-economic status using the expenditure quintile at baseline to disaggregate the impact estimates on access and reliability presented above.

Figure 22 and Figure 23 show that male headed households and female headed households had similar on access to sanitation and tap water. The impact for male vs. female headed household is not statistically different from each other as evidence by the triple difference estimate in the figures.

FIGURE 22 GENDER IN UPTAKE: PROBABILITY OF HAVING AN IMPROVED LATRINE

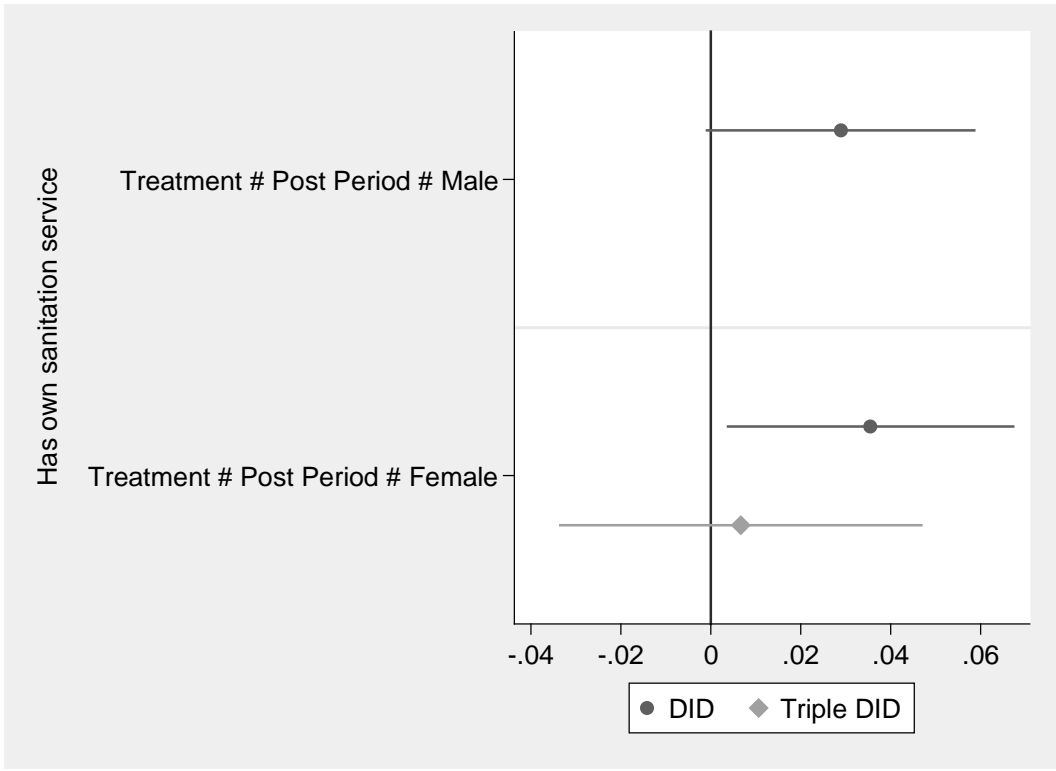

FIGURE 23 GENDER IN UPTAKE: PROBABILITY OF HAVING A HOUSEHOLD TAP

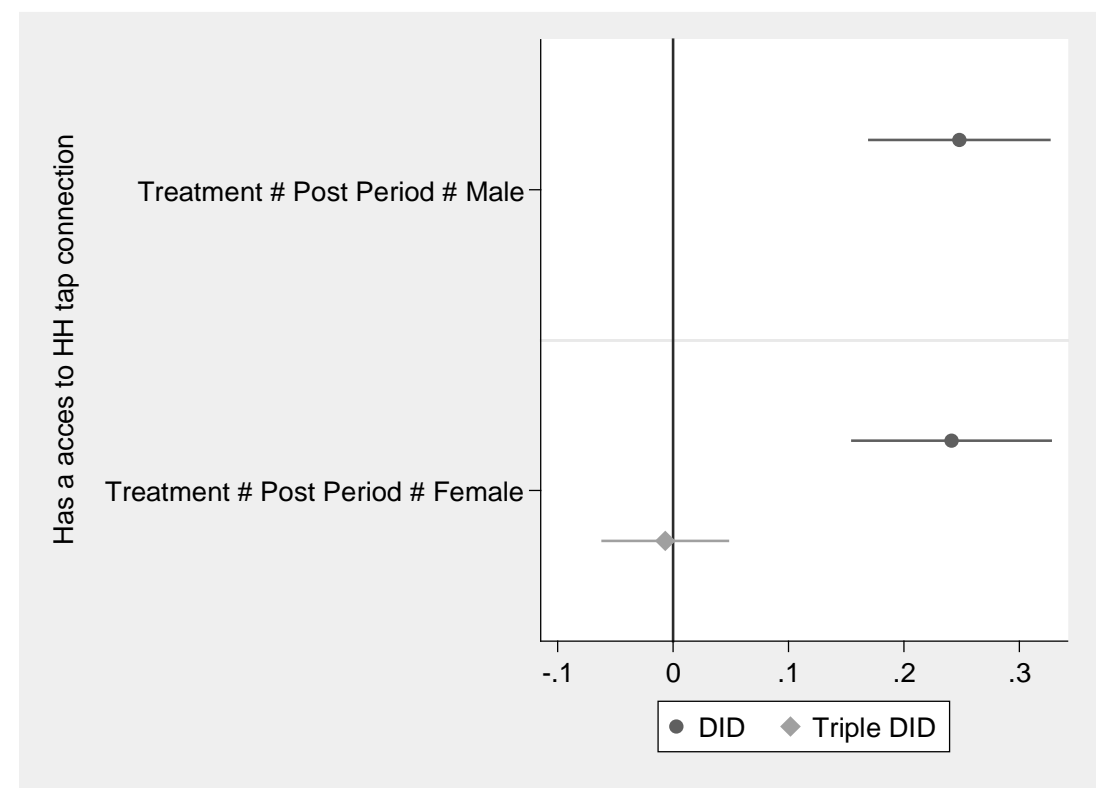

In the case of socio-economic differences in access, the results imply that households in higher quintiles benefitted more (with DID estimates slightly larger) but not significantly different as shown by the triple difference estimates in Figure 24 for sanitation and Figure 25 for access to tap water. 


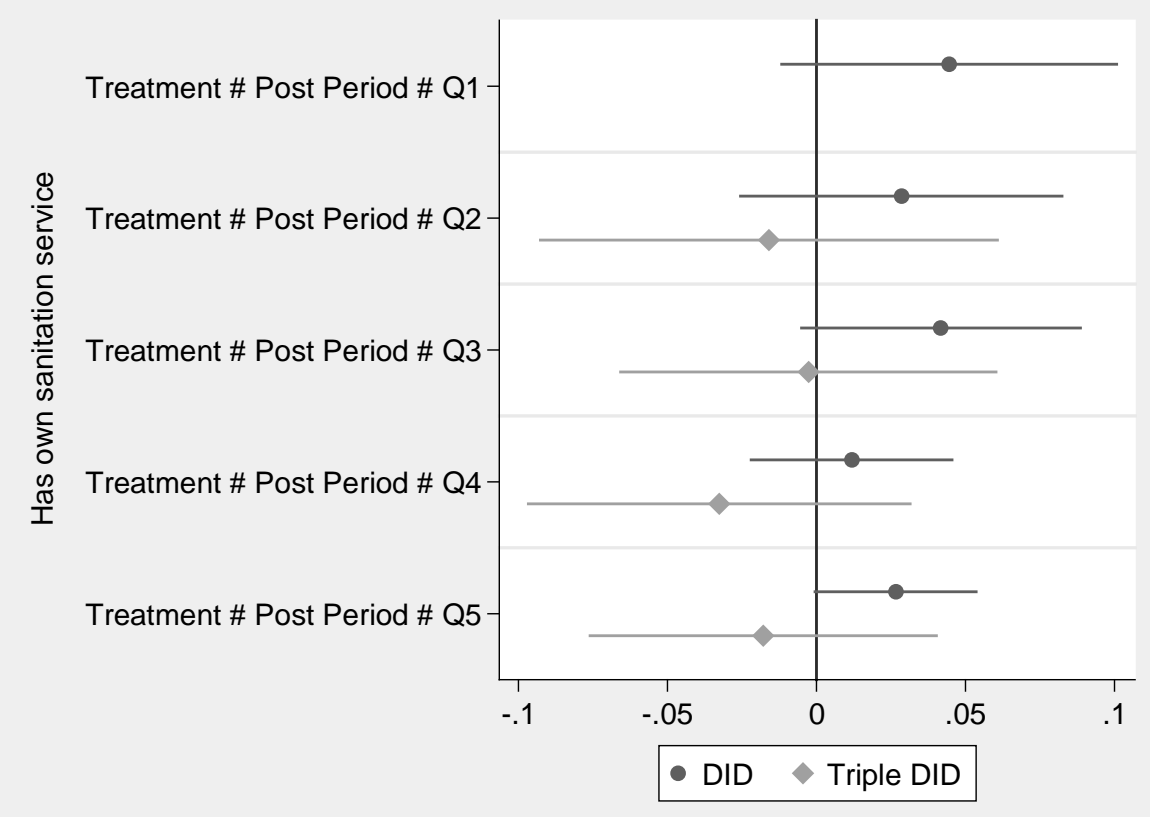

FIGURE 25 SOCIO-ECONOMIC IN UPTAKE: PROBABILITY OF HAVING A HOUSEHOLD TAP

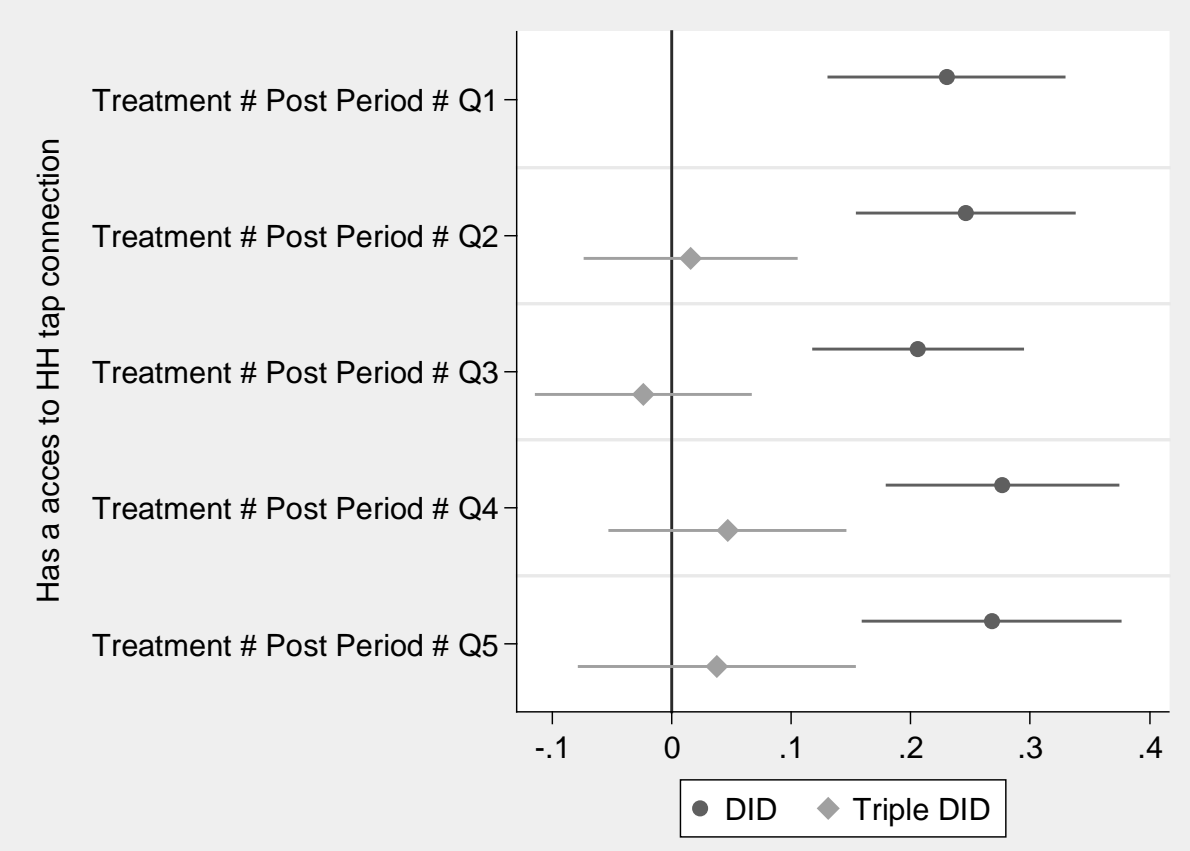




\section{WATER CONSUMPTION}

In this section, we discuss the water consumption patterns of the households in the sample. Theoretically, the availability of an improved water system has an ambiguous impact on the volume of water that a household consumes. A water system that places meters in households where no meters previously existed could, in principle, decrease water consumption depending on how water is priced. Under block pricing, this is not necessarily the case, as households do not face an increasing marginal price for the water they consume. In this case, it might be optimal for the household to increase their water consumption to just below the quantity where the block price increases-essentially creating 'bunching' at the kinks of the price schedule. The endogeneity of price under a block pricing schedule makes it difficult to estimate the water demand curve. For this reason, we did not estimate a water demand function per se. We focus, instead, on estimating the impact of projects on water consumption patterns of treatment households.

The survey was designed to measure water consumption across all the sources that a household has available. These include poliducts, public taps, storage systems, and hoses. We created a comprehensive water consumption measure that includes all reported sources, including taps. This measure was likely a noisy estimate of the water consumption of the household, and more so for households where there are no metered taps. To correct this, and as a robustness check, we also conducted the analysis using the sub-sample of households with metered tap connections and only for the water consumed from the tap. This means that households with no tap are assigned a zero consumption of tap water in those estimates. In addition, we conducted the analysis conditional on having reported in at least one survey having a tap. We followed this procedure for each type of source, as described below.

We proceed to estimate the impact of the WASH interventions on the water consumption of households living in the treatment segments. Table 62 shows the impact estimates for total liters per week consumed by the household in panel $A$ and the log transformation in panel $B$ to address the skewedness of the distribution. We expected the quantity of water used by households to increase with reliable piped service [see (Strand \& Walker, 2005)]. However, we detect no effect on the total amount of water consumed by the household across all sources. This might be due to reallocating water consumption across sources, decreasing consumption from some sources, and increasing their consumption from others. The estimate is positive but not precisely estimated (i.e., not significantly different from zero), hence we cannot conclude in what direction the pattern of water consumption is moving. 
TABLE 62 HOUSEHOLD WATER CONSUMPTION (LITERS/WEEK): TOTAL CONSUMPTION ACROSS SOURCES

\begin{tabular}{|c|c|c|c|c|c|c|c|}
\hline & (1) & $(2)$ & (3) & (4) & (5) & (6) & (7) \\
\hline & DID & DID-FE & $\begin{array}{l}\text { DID- } \\
\text { Pairs }\end{array}$ & $\begin{array}{l}\text { RF- } \\
\text { Area- } \\
\text { ITT }\end{array}$ & 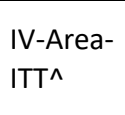 & RF-ATE & $\begin{array}{l}\text { IV- } \\
\text { LATE^ }^{\wedge}\end{array}$ \\
\hline \multicolumn{8}{|c|}{ Panel A: Total Water Consumption Lts./Week } \\
\hline Treatment \# Post Period & $\begin{array}{l}502.5 \\
{[324.5]}\end{array}$ & $\begin{array}{l}524.5 \\
{[325.6]}\end{array}$ & $\begin{array}{l}496.9 \\
{[325.3]}\end{array}$ & & & & \\
\hline Inside Project Area \# Post Period & & & & $\begin{array}{l}5.16 \\
{[306.9]}\end{array}$ & & & \\
\hline Inside Project Area-ITT in Post Period & & & & & $\begin{array}{l}750 \\
{[506.3]}\end{array}$ & & \\
\hline Beneficiary \# Post Period & & & & & & $\begin{array}{l}-102.6 \\
{[309.9]}\end{array}$ & \\
\hline Beneficiary-LATE in Post Period & & & & & & & $\begin{array}{l}841.6 \\
{[555.4]}\end{array}$ \\
\hline Mean of Comp. at Baseline & 2359.8 & 2359.8 & 2359.8 & 2215.7 & 2215.7 & 2187.1 & 2187.1 \\
\hline SD of Comp. at Baseline & 6451.7 & 6451.7 & 6451.7 & 5952.7 & 5952.7 & 5703.6 & 5703.6 \\
\hline Number of Clusters & 128 & 128 & 128 & 128 & 128 & 128 & 128 \\
\hline Observations & 9,208 & 9,208 & 9,208 & 9,092 & 9,092 & 9,092 & 9,092 \\
\hline K-P rk Wald F & & & & & 213.1 & & 130.1 \\
\hline \multicolumn{8}{|c|}{ Panel B: Log-Total Water Consumption Lts./Week } \\
\hline Treatment \# Post Period & $\begin{array}{l}0.06 \\
{[0.094]}\end{array}$ & $\begin{array}{l}0.085 \\
{[0.094]}\end{array}$ & $\begin{array}{l}0.064 \\
{[0.095]}\end{array}$ & & & & \\
\hline Inside Project Area \# Post Period & & & & $\begin{array}{l}0.18 \\
{[0.097]^{*}}\end{array}$ & & & \\
\hline Inside Project Area-ITT in Post Period & & & & & $\begin{array}{l}0.11 \\
{[0.14]}\end{array}$ & & \\
\hline Beneficiary \# Post Period & & & & & & $\begin{array}{l}0.2 \\
{[0.10]^{*}}\end{array}$ & \\
\hline Pairs Indicators & NO & NO & YES & YES & NO & YES & NO \\
\hline Mean of Comp. at Baseline & 6.82 & 6.82 & 6.82 & 6.78 & 6.78 & 6.77 & 6.77 \\
\hline SD of Comp. at Baseline & 1.55 & 1.55 & 1.55 & 1.51 & 1.51 & 1.51 & 1.51 \\
\hline Number of Clusters & 128 & 128 & 128 & 128 & 128 & 128 & 128 \\
\hline Observations & 9,208 & 9,208 & 9,208 & 9,092 & 9,092 & 9,092 & 9,092 \\
\hline K-P rk Wald F & & & & & 213.1 & & 130.1 \\
\hline
\end{tabular}

Standard errors in brackets

Std. errors are clustered at the census segment level.

All equations include year fixed effects. Equations are DID, in (1)-(3) the treatment is defined as living in a treatment assigned segment, (4)-(5) treatment is defined as living inside the project area within the matched pairs, (6)-(7) treatment is defined as having reported being beneficiary of the WASH project within the matched pairs. Equations (4)-(7) control for initial treatment assignment.

Equation (2) includes household fixed effects. Pair dummies indicated in the table are based in on nearest neighbor matching propensity score matching based on 2007 census segment data.

IV estimates in columns (5) and (7) use the census segment treatment assignment to instrument for indicators for being in a project area in 2012-

2013 (5); and the households reporting being a beneficiary of the WASH projects from MCC in (7)

AIV estimates partial out the indicators for pairs to compute the std. errors of the coefficients of interest. We report the K-P rk Wald F statistic

following the results in Stock and Yogo (2005)

${ }^{*} \mathrm{p}<0.10,{ }^{* *} \mathrm{p}<0.05, * * * \mathrm{p}<0.01$ 
In what follows, we show the number of liters of water per week consumed by households for different sources to explore if the pattern in sources used changed in the treatment households after the implementation of the WASH interventions. This serves to disentangle if the non-significant effect on total water consumption was due to household re-optimizing their consumption across sources. We present each source with the number of liters consumed per week for the subsample of households that reported using that source in any round of the survey. This reduces the amount of zero effects that go into the impact estimate by only including households for which the source was available and used in the study period.

Table 63 shows the impact estimates for the consumption of water from public taps and neighbors' taps. We find significant decreases in the amount of water consumed from public taps, namely decreases of 458.5 liters per week in the sample that reported using public taps at any point from 2011 to 2013; the estimate increases to 697 liters per week for the households that report being part of the program in column (7) using the treatment assignment as an instrument for receiving a connection. In water consumption from neighbors', we detect no significant impact across the specifications.

Table 64 shows the impact estimates for the consumption of water from private wells and springs. In the consumption from private wells, we do not detect consistent significant decreases in water consumption. These results are not surprising when one considers that the cost of these sources is a sunk cost. Even though a sunk cost should not affect the optimal decision of a rational household, once it is available, we would expect that the household would continue to use them even if they have access to tap water. The reason for this behavior is that there are purposes for which water from wells or springs could be cheaper or easier to use; for example, to extract large quantities quickly, or because they are not metered, or when there is no water in the tap system.

Table 65 shows the impact estimates for the consumption of water from trucks and bag/bottled water. Households living in treatment segments consumed 10 liters per week of bottled water than households living in comparison segments and we find no significant effects on water from truck for general purpose. 
TABLE 63 HOUSEHOLD WATER CONSUMPTION (LITERS/WEEK): PUBLIC TAPS AND NEIGHBORS

\begin{tabular}{|c|c|c|c|c|c|c|c|}
\hline & (1) & $(2)$ & (3) & (4) & (5) & (6) & (7) \\
\hline & DID & DID-FE & DID-Pairs & RF-Area-ITT & IV-Area-ITT^^ & RF-ATE & IV-LATE^ \\
\hline \multicolumn{8}{|c|}{ Liters/Week from Total from Public Tap } \\
\hline \multirow[t]{2}{*}{ Treatment \# Post Period } & -463.4 & -446.4 & -458.5 & & & & \\
\hline & {$[129.9]^{* * *}$} & {$[130.8]^{* * *}$} & {$[133.8]^{* * *}$} & & & & \\
\hline \multirow[t]{2}{*}{ Inside Project Area \# Post Period } & & & & -236.5 & & & \\
\hline & & & & {$[169.4]$} & & & \\
\hline \multirow[t]{2}{*}{ Inside Project Area-ITT in Post Period } & & & & & -594.2 & & \\
\hline & & & & & {$[250.3]^{* *}$} & & \\
\hline \multirow[t]{2}{*}{ Beneficiary \# Post Period } & & & & & & -312.3 & \\
\hline & & & & & & {$[156.8]^{*}$} & \\
\hline \multirow[t]{2}{*}{ Beneficiary-LATE in Post Period } & & & & & & & -696.9 \\
\hline & & & & & & & {$[239.2]^{* * *}$} \\
\hline Pairs Indicators & NO & NO & YES & YES & NO & YES & NO \\
\hline Mean of Comp. at Baseline & 246 & 246 & 246 & 346.6 & 346.6 & 315.3 & 315.3 \\
\hline SD of Comp. at Baseline & 517.5 & 517.5 & 517.5 & 598.6 & 598.6 & 568.3 & 568.3 \\
\hline Number of Clusters & 38 & 38 & 38 & 38 & 38 & 38 & 38 \\
\hline Observations & 642 & 642 & 642 & 632 & 632 & 632 & 632 \\
\hline K-P rk Wald F & & & & & 71.4 & & 27.2 \\
\hline \multicolumn{8}{|l|}{ Liters/Week from Neighbors } \\
\hline \multirow[t]{2}{*}{ Treatment \# Post Period } & -134.5 & -149.5 & -135.9 & & & & \\
\hline & [265.0] & [266.9] & [277.6] & & & & \\
\hline \multirow[t]{2}{*}{ Inside Project Area \# Post Period } & & & & -243.7 & & & \\
\hline & & & & [261.7] & & & \\
\hline \multirow[t]{2}{*}{ Inside Project Area-ITT in Post Period } & & & & & -269.1 & & \\
\hline & & & & & [442.0] & & \\
\hline \multirow[t]{2}{*}{ Beneficiary \# Post Period } & & & & & & -671.3 & \\
\hline & & & & & & {$[258.4]^{* *}$} & \\
\hline \multirow[t]{2}{*}{ Beneficiary-LATE in Post Period } & & & & & & & -441 \\
\hline & & & & & & & {$[701.0]$} \\
\hline Pairs Indicators & NO & NO & YES & YES & NO & YES & NO \\
\hline Mean of Comp. at Baseline & 861.1 & 861.1 & 861.1 & 797.1 & 797.1 & 750.8 & 750.8 \\
\hline SD of Comp. at Baseline & 2229.8 & 2229.8 & 2229.8 & 2113.7 & 2113.7 & 1961.9 & 1961.9 \\
\hline Number of Clusters & 83 & 83 & 83 & 83 & 83 & 83 & 83 \\
\hline Observations & 667 & 667 & 667 & 656 & 656 & 656 & 656 \\
\hline K-P rk Wald F & & & & & 28.9 & & 18.6 \\
\hline
\end{tabular}

Standard errors in brackets

Std. errors are clustered at the census segment level.

All equations include year fixed effects. Equations are DID, in (1)-(3) the treatment is defined as living in a treatment assigned segment, (4)-(5) treatment is defined as living inside the project area within the matched pairs, (6)-(7) treatment is defined as having reported being beneficiary of the WASH project within the matched pairs. Equations (4)-(7) control for initial treatment assignment.

Equation (2) includes household fixed effects. Pair dummies indicated in the table are based in on nearest neighbor matching propensity score matching based on 2007 census segment data.

IV estimates in columns (5) and (7) use the census segment treatment assignment to instrument for indicators for being in a project area in $2012-2013$ (5); and the households reporting being a beneficiary of the WASH projects from MCC in (7)

AIV estimates partial out the indicators for pairs to compute the std. errors of the coefficients of interest. We report the K-P rk Wald F statistic following the results in Stock and Yogo (2005)

$* \mathrm{p}<0.10, * * \mathrm{p}<0.05, * * * \mathrm{p}<0.01$ 
TABLE 64 HOUSEHOLD WATER CONSUMPTION (LITERS/WEEK): PRIVATE WELLS AND SPRINGS

\begin{tabular}{|c|c|c|c|c|c|c|c|}
\hline & $(1)$ & $(2)$ & (3) & (4) & (5) & $(6)$ & (7) \\
\hline & DID & DID-FE & DID-Pairs & RF-Area-ITT & IV-Area-ITT^^ & RF-ATE & $\begin{array}{l}\text { IV- } \\
\text { LATE^ }^{\wedge}\end{array}$ \\
\hline \multicolumn{8}{|l|}{ Liters/Week from Private Wells } \\
\hline \multirow[t]{2}{*}{ Treatment \# Post Period } & 164.6 & 181.7 & 180.7 & & & & \\
\hline & {$[1139.6]$} & {$[1131.1]$} & {$[1161.3]$} & & & & \\
\hline \multirow[t]{2}{*}{ Inside Project Area \# Post Period } & & & & -2180.1 & & & \\
\hline & & & & {$[1078.1]^{* *}$} & & & \\
\hline \multirow[t]{2}{*}{ Inside Project Area-ITT in Post Period } & & & & & 295.6 & & \\
\hline & & & & & {$[1561.1]$} & & \\
\hline \multirow[t]{2}{*}{ Beneficiary \# Post Period } & & & & & & -2800.7 & \\
\hline & & & & & & {$[1047.5]^{* * *}$} & \\
\hline \multirow[t]{2}{*}{ Beneficiary-LATE in Post Period } & & & & & & & 285.2 \\
\hline & & & & & & & {$[1871.0]$} \\
\hline Pairs Indicators & NO & NO & YES & YES & $\mathrm{NO}$ & YES & NO \\
\hline Mean of Comp. at Baseline & 3485 & 3485 & 3485 & 3374.7 & 3374.7 & 3331.7 & 3331.7 \\
\hline SD of Comp. at Baseline & 7594.5 & 7594.5 & 7594.5 & 7262 & 7262 & 6867.8 & 6867.8 \\
\hline Number of Clusters & 89 & 89 & 89 & 89 & 89 & 89 & 89 \\
\hline Observations & 2,348 & 2,348 & 2,348 & 2,318 & 2,318 & 2,318 & 2,318 \\
\hline K-P rk Wald F & & & & & 258 & & 95.3 \\
\hline \multicolumn{8}{|l|}{ Liters/Week from Springs } \\
\hline \multirow[t]{2}{*}{ Treatment \# Post Period } & -91.5 & -91.9 & -95.5 & & & & \\
\hline & [209.1] & [210.4] & [215.0] & & & & \\
\hline \multirow[t]{2}{*}{ Inside Project Area \# Post Period } & & & & -284 & & & \\
\hline & & & & [184.7] & & & \\
\hline \multirow[t]{2}{*}{ Inside Project Area-ITT in Post Period } & & & & & -129.9 & & \\
\hline & & & & & [323.8] & & \\
\hline \multirow[t]{2}{*}{ Beneficiary \# Post Period } & & & & & & -254.6 & \\
\hline & & & & & & {$[155.2]$} & \\
\hline \multirow[t]{2}{*}{ Beneficiary-LATE in Post Period } & & & & & & & -92.7 \\
\hline & & & & & & & {$[359.9]$} \\
\hline Pairs Indicators & NO & NO & YES & YES & NO & YES & NO \\
\hline Mean of Comp. at Baseline & 751.9 & 751.9 & 751.9 & 654.8 & 654.8 & 667.7 & 667.7 \\
\hline SD of Comp. at Baseline & 1767.9 & 1767.9 & 1767.9 & 1553.3 & 1553.3 & 1566.2 & 1566.2 \\
\hline Number of Clusters & 104 & 104 & 104 & 104 & 104 & 104 & 104 \\
\hline Observations & 1,949 & 1,949 & 1,949 & 1,925 & 1,925 & 1,925 & 1,925 \\
\hline K-P rk Wald F & & & & & 113.1 & & 56.2 \\
\hline
\end{tabular}

Standard errors in brackets

Std. errors are clustered at the census segment level.

All equations include year fixed effects. Equations are DID, in (1)-(3) the treatment is defined as living in a treatment assigned segment, (4)-(5) treatment is defined as living inside the project area within the matched pairs, (6)-(7) treatment is defined as having reported being beneficiary of the WASH project within the matched pairs. Equations (4)-(7) control for initial treatment assignment.

Equation (2) includes household fixed effects. Pair dummies indicated in the table are based in on nearest neighbor matching propensity score matching based on 2007 census segment data.

IV estimates in columns (5) and (7) use the census segment treatment assignment to instrument for indicators for being in a project area in 2012-2013 (5); and the households reporting being a beneficiary of the WASH projects from MCC in (7)

^IV estimates partial out the indicators for pairs to compute the std. errors of the coefficients of interest. We report the K-P rk Wald F statistic following the results in Stock and Yogo (2005)

${ }^{*} \mathrm{p}<0.10,{ }^{* *} \mathrm{p}<0.05,{ }^{* * *} \mathrm{p}<0.01$ 
TABLE 65 HOUSEHOLD WATER CONSUMPTION (LITERS/WEEK): TRUCKS AND BOTTLED

\begin{tabular}{|c|c|c|c|c|c|c|c|}
\hline & (1) & $(2)$ & (3) & (4) & (5) & (6) & (7) \\
\hline & DID & DID-FE & $\begin{array}{l}\text { DID- } \\
\text { Pairs }\end{array}$ & RF-Area-ITT & $\begin{array}{l}\text { IV-Area- } \\
\text { ITT^^}\end{array}$ & RF-ATE & $\begin{array}{l}\text { IV- } \\
\text { LATE^ }\end{array}$ \\
\hline \multicolumn{8}{|l|}{ Liters/Week from Trucks } \\
\hline \multirow[t]{2}{*}{ Treatment \# Post Period } & -268.9 & -273.9 & -274.1 & & & & \\
\hline & {$[197.2]$} & [202.4] & [218.6] & & & & \\
\hline \multirow[t]{2}{*}{ Inside Project Area \# Post Period } & & & & -335.4 & & & \\
\hline & & & & [211.9] & & & \\
\hline \multirow[t]{2}{*}{ Inside Project Area-ITT in Post Period } & & & & & -329.7 & & \\
\hline & & & & & [259.7] & & \\
\hline \multirow[t]{2}{*}{ Beneficiary \# Post Period } & & & & & & -346.5 & \\
\hline & & & & & & [217.9] & \\
\hline \multirow[t]{2}{*}{ Beneficiary-LATE in Post Period } & & & & & & & -346.4 \\
\hline & & & & & & & [274.2] \\
\hline Pairs Indicators & NO & NO & YES & YES & NO & YES & NO \\
\hline Mean of Comp. at Baseline & 462 & 462 & 462 & 435 & 435 & 426.9 & 426.9 \\
\hline SD of Comp. at Baseline & 812 & 812 & 812 & 799 & 799 & 785.3 & 785.3 \\
\hline Number of Clusters & 21 & 21 & 21 & 21 & 21 & 21 & 21 \\
\hline Observations & 122 & 122 & 122 & 120 & 120 & 120 & 120 \\
\hline K-P rk Wald F & & & & & . & & 22.7 \\
\hline \multicolumn{8}{|l|}{ Liters/Week from Bottled Water } \\
\hline \multirow{2}{*}{ Treatment \# Post Period } & -10.8 & -10.4 & -10.7 & & & & \\
\hline & {$[4.00]^{* * *}$} & {$[4.05]^{* *}$} & {$[4.12]^{* *}$} & & & & \\
\hline \multirow[t]{2}{*}{ Inside Project Area \# Post Period } & & & & -12 & & & \\
\hline & & & & {$[3.72]^{* * *}$} & & & \\
\hline \multirow[t]{2}{*}{ Inside Project Area-ITT in Post Period } & & & & & -13.1 & & \\
\hline & & & & & {$[4.97]^{* *}$} & & \\
\hline \multirow[t]{2}{*}{ Beneficiary \# Post Period } & & & & & & -16.2 & \\
\hline & & & & & & {$[4.19]^{* * *}$} & \\
\hline \multirow[t]{2}{*}{ Beneficiary-LATE in Post Period } & & & & & & & -14.7 \\
\hline & & & & & & & {$[5.81]^{* *}$} \\
\hline Pairs Indicators & NO & NO & YES & YES & NO & YES & NO \\
\hline Mean of Comp. at Baseline & 18 & 18 & 18 & 18.1 & 18.1 & 17.5 & 17.5 \\
\hline SD of Comp. at Baseline & 29.8 & 29.8 & 29.8 & 29 & 29 & 28.5 & 28.5 \\
\hline Number of Clusters & 75 & 75 & 75 & 75 & 75 & 75 & 75 \\
\hline Observations & 864 & 864 & 864 & 853 & 853 & 853 & 853 \\
\hline K-P rk Wald F & & & & & 65.3 & & 72.8 \\
\hline
\end{tabular}

Standard errors in brackets

Std. errors are clustered at the census segment level.

All equations include year fixed effects. Equations are DID, in (1)-(3) the treatment is defined as living in a treatment assigned segment, (4)-(5) treatment is defined as living inside the project area within the matched pairs, (6)-(7) treatment is defined as having reported being beneficiary of the WASH project within the matched pairs. Equations (4)-(7) control for initial treatment assignment.

Equation (2) includes household fixed effects. Pair dummies indicated in the table are based in on nearest neighbor matching propensity score matching based on 2007 census segment data.

IV estimates in columns (5) and (7) use the census segment treatment assignment to instrument for indicators for being in a project area in 2012-2013 (5); and the households reporting being a beneficiary of the WASH projects from MCC in (7)

^IV estimates partial out the indicators for pairs to compute the std. errors of the coefficients of interest. We report the K-P rk Wald F statistic following the results in Stock and Yogo (2005)

${ }^{*} \mathrm{p}<0.10, * * \mathrm{p}<0.05, * * * \mathrm{p}<0.01$ 
Given the difficulty in measuring water consumption from all sources we estimate the impact of consumption from household taps for households that have a meter (as all households in the treatment area have a metered connection). The advantages of using these data are at least twofold. First, the quality of the water consumption measure is better for the sub-sample of households with meters we collected the information from their water bill. Second, these households are charged depending on their consumption ${ }^{41}$ so that they have the information necessary to adjust their behavior.

However, restricting the analysis to these households presents some difficulties. First, before the projects, many households did not have a meter, so their consumption of metered water was a "real" zero that should be included in the estimation. The presence of so many zeroes in the data presents a problem to address the skewness of the water consumption distribution. Second, the availability of the metered data is correlated with treatment; all the households that received a tap connection also received a meter, so the treatment group is more likely to have this data than the comparison and the measurement error in water consumption is correlated with the treatment.

Giving these issues, we opt to first present a descriptive analysis of these data. Table 66 shows some descriptive measures for each year and each group. We present three measures: (1) a measure with the full sample, with zeroes for those that do not have a tap or a measurement of consumption in their bill; (2) a measure with only the households for which we have at least one bill in any year (and zero for the years where we do not); and (3) just a measure with the sample with non-missing and non-zero data. We can see the effects of the issues mentioned above. Sample size, in that the number of treatment households that have a bill at baseline, jumps from 39 in 2011 to 587 in 2012 and to 741 in 2013 . The comparisons jump from 89 in 2011 to 203 in 2012. Part of the jump from 2011 to 2012 was due to our diligence in procuring the information from the bill. However, this was done independently of the household being in a treated or comparison segment. The increase in the treatment areas was also due to the new systems providing a bill and the amount of water consumed. The full sample and conditional measures in the table show the effect of the zeroes, with the average mean from the full sample being much lower and the median being zero. It also illustrates that the number of zeroes that enters the calculation of the average also depends on the treatment. In both measures, comparison segments are more likely to have more zeroes than treatment segments, thus depressing the average impact estimate. These figures show that while the data has its limitations, the pattern of the number of observations and increase in water consumption for treatment households from 2011 to 2012 is indicative of the projects having taken place with the installation of meters. In addition, this information is being used in the administration of the systems (for billing, cost recovery, etc.).

${ }^{41}$ In some cases, there was a meter but the households paid a fixed fee. In most cases, they were on an increase block pricing schedule. 
TABLE 66 HOUSEHOLD WATER CONSUMPTION (LITERS/WEEK): CONSUMPTION FROM METERED PRIVATE TAPS

\begin{tabular}{|c|c|c|c|c|c|c|c|c|}
\hline \multirow[b]{2}{*}{ Liters/Week Consumed (from Bill) } & \multicolumn{4}{|c|}{ Comparison } & \multicolumn{4}{|c|}{ Treatment } \\
\hline & Mean & SD & Median & Observations & Mean & SD & Median & Observations \\
\hline \multicolumn{9}{|l|}{2011} \\
\hline Full Sample & 222.4 & 1174.7 & 0 & 1618 & 108.6 & 858.7 & 0 & 1604 \\
\hline Conditional on Having a Tap in Any Year & 1323.1 & 2602.4 & 0 & 272 & 209.4 & 1183.8 & 0 & 832 \\
\hline Non-missing Data & 4043.5 & 3119.6 & 3500 & 89 & 4466.3 & 3336.6 & 3750 & 39 \\
\hline \multicolumn{9}{|l|}{2012} \\
\hline Full Sample & 507.5 & 1613.5 & 0 & 1560 & 1438.1 & 2470.3 & 0 & 1544 \\
\hline Conditional on Having a Tap in Any Year & 3010.4 & 2815.4 & 2750 & 263 & 2734.6 & 2839.1 & 2500 & 812 \\
\hline Non-missing Data & 3900.2 & 2606.4 & 3500 & 203 & 3782.8 & 2680.2 & 3500 & 587 \\
\hline \multicolumn{9}{|l|}{2013} \\
\hline Full Sample & 548.4 & 1531.1 & 0 & 1583 & 1605.9 & 2326 & 0 & 1572 \\
\hline Conditional on Having a Tap in Any Year & 3239.3 & 2267.3 & 3000 & 268 & 3082.4 & 2415.3 & 2750 & 819 \\
\hline Non-missing Data & 3444.9 & 2181 & 3000 & 252 & 3406.9 & 2311.2 & 3000 & 741 \\
\hline
\end{tabular}


Table 67 shows the impact estimates for the consumption of water from household taps as retrieved from the monthly bill before the survey; in levels in panel A and logs in panel B. We see significant increases in the amount of water consumed from household taps. Households living in the treatment segment consumed $1,071.5$ liters per week more water from private taps than households living in comparison segments. This figure increases over 1,300 liters per week in treatment areas and over 1,400 liters per week among households that report being connected to the new water systems. These increases imply a 100 percent increase in tap water from baseline levels.

To finalize our discussion on water consumption, we note that the previous result shows the increase in water consumption from private household taps. However, this consumption could have come directly from the tap if the household believed that the service would be present anytime they needed it, or from previously stored water. The results for water stored per week are similar to those of the water consumed in the previous tables. This is indicative of households still using their existing storage systems to store water when the household tap is available. This has implications for the expected effects on water contamination at the point of consumption versus at the source, as the mismanagement of stored water opens the possibility of contaminating the water. 
TABLE 67 HOUSEHOLD WATER CONSUMPTION (LITERS/WEEK): METERED PRIVATE TAPS

\begin{tabular}{|c|c|c|c|c|c|c|c|}
\hline & (1) & $(2)$ & (3) & (4) & (5) & (6) & (7) \\
\hline & DID & DID-FE & DID-Pairs & $\begin{array}{l}\text { RF-Area- } \\
\text { ITT }\end{array}$ & $\begin{array}{l}\text { IV-Area- } \\
\text { ITT^^}\end{array}$ & RF-ATE & IV-LATE^ \\
\hline \multicolumn{8}{|c|}{ Panel A: Liters/Week from Bill from HH Tap } \\
\hline \multirow[t]{2}{*}{ Treatment \# Post Period } & 1067 & 1076 & 1071.5 & & & & \\
\hline & {$[515.5]^{* *}$} & {$[519.9]^{* *}$} & {$[520.2]^{* *}$} & & & & \\
\hline \multirow[t]{2}{*}{ Inside Project Area \# Post Period } & & & & 1352.4 & & & \\
\hline & & & & {$[465.3]^{* * *}$} & & & \\
\hline \multirow[t]{2}{*}{ Inside Project Area-ITT in Post Period } & & & & & 1363.7 & & \\
\hline & & & & & {$[660.7]^{* *}$} & & \\
\hline \multirow[t]{2}{*}{ Beneficiary \# Post Period } & & & & & & 1401.5 & \\
\hline & & & & & & {$[396.0]^{* * *}$} & \\
\hline \multirow[t]{2}{*}{ Beneficiary-LATE in Post Period } & & & & & & & 1408.2 \\
\hline & & & & & & & {$[695.3]^{* *}$} \\
\hline Pairs Indicators & NO & NO & YES & YES & NO & YES & NO \\
\hline Mean of Comp. at Baseline & 1474.1 & 1474.1 & 1474.1 & 1686.5 & 1686.5 & 1428.7 & 1428.7 \\
\hline SD of Comp. at Baseline & 4189.7 & 4189.7 & 4189.7 & 4241 & 4241 & 3916.6 & 3916.6 \\
\hline Number of Clusters & 79 & 79 & 79 & 79 & 79 & 79 & 79 \\
\hline Observations & 3,260 & 3,260 & 3,260 & 3,231 & 3,231 & 3,231 & 3,231 \\
\hline K-P rk Wald F & & & & & 71.1 & & 287.7 \\
\hline \multicolumn{8}{|c|}{ Panel B: Log-Metered Water Consumption Lts./Week } \\
\hline \multirow[t]{2}{*}{ Treatment \# Post Period } & 2.02 & 2.04 & 2.03 & & & & \\
\hline & {$[0.79]^{* *}$} & {$[0.79]^{* *}$} & {$[0.80]^{* *}$} & & & & \\
\hline \multirow[t]{2}{*}{ Inside Project Area \# Post Period } & & & & 2.6 & & & \\
\hline & & & & {$[0.69]^{* * *}$} & & & \\
\hline \multirow[t]{2}{*}{ Inside Project Area-ITT in Post Period } & & & & & 2.54 & & \\
\hline & & & & & {$[0.98]^{* *}$} & & \\
\hline \multirow[t]{2}{*}{ Beneficiary \# Post Period } & & & & & & 2.8 & \\
\hline & & & & & & {$[0.61]^{* * *}$} & \\
\hline \multirow[t]{2}{*}{ Beneficiary-LATE in Post Period } & & & & & & & 2.64 \\
\hline & & & & & & & {$[1.12]^{* *}$} \\
\hline Pairs Indicators & NO & NO & YES & YES & NO & YES & NO \\
\hline Mean of Comp. at Baseline & 2.83 & 2.83 & 2.83 & 3.15 & 3.15 & 2.66 & 2.66 \\
\hline SD of Comp. at Baseline & 4.13 & 4.13 & 4.13 & 4.26 & 4.26 & 4.08 & 4.08 \\
\hline Number of Clusters & 79 & 79 & 79 & 79 & 79 & 79 & 79 \\
\hline Observations & 3,260 & 3,260 & 3,260 & 3,231 & 3,231 & 3,231 & 3,231 \\
\hline K-P rk Wald F & & & & & 71.1 & & 287.7 \\
\hline
\end{tabular}

Standard errors in brackets

Std. errors are clustered at the census segment level.

All equations include year fixed effects. Equations are DID, in (1)-(3) the treatment is defined as living in a treatment assigned segment, (4)-(5) treatment is defined as living inside the project area within the matched pairs, (6)-(7) treatment is defined as having reported being beneficiary of the WASH project within the matched pairs. Equations (4)-(7) control for initial treatment assignment.

Equation (2) includes household fixed effects. Pair dummies indicated in the table are based in on nearest neighbor matching propensity score matching based on 2007 census segment data.

IV estimates in columns (5) and (7) use the census segment treatment assignment to instrument for indicators for being in a project area in $2012-2013$

(5); and the households reporting being a beneficiary of the WASH projects from MCC in (7)

^IV estimates partial out the indicators for pairs to compute the std. errors of the coefficients of interest. We report the K-P rk Wald $\mathrm{F}$ statistic following the results in Stock and Yogo (2005)

${ }^{*} \mathrm{p}<0.10,{ }^{* *} \mathrm{p}<0.05, * * * \mathrm{p}<0.01$ 


\section{Water, Sanitation and Hygiene: Health Behavior}

For all households in the study, we monitored the understanding of good hygiene behavior and disease prevention knowledge. The purpose was to examine whether sanitation facilities were being used, drinking water was being treated, and hand washing was being practiced. Since the WASH interventions, apart from providing access to infrastructure, also provided information on hygienic best practices and community-led water sources protection initiatives we included questions in the survey relating to water treatment practices (boiling, filtering, and use of chlorine additives) as well as test drinking water samples for residual chlorine levels in all surveyed households. In addition, the access to improved water and sanitation services might have created incentives for the household members to seek information on how the appropriate use of these services can reduce the incidence of water-borne illnesses.

We start by presenting the results on the knowledge of disease and hygiene behavior in Table 68. We counted the numbers of correct practices to prevent diarrhea that the respondent in the household identified (washing hands, burying feces, treat drinking water, etc.) and the number of situations in which the respondent thought most appropriate or necessary to wash hands (before eating, after using sanitary services, etc.).

We found marginally significant effects for the knowledge of preventing diarrhea. The estimates suggest that households living in treatment segments mentioned 0.16 more ways, out of 10 total, to prevent diarrhea or five percent more correct ways than households living in comparison segments. On the washing hands behavior, we found no significant effects. 
TABLE 68 HYGIENE AND HEALTH KNOWLEDGE: DIARRHEA PREVENTION AND HAND WASHING

\begin{tabular}{|c|c|c|c|c|c|c|c|}
\hline & $(1)$ & $(2)$ & (3) & (4) & (5) & $(6)$ & (7) \\
\hline & DID & DID-FE & DID-Pairs & $\begin{array}{l}\text { RF-Area- } \\
\text { ITT }\end{array}$ & 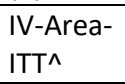 & RF-ATE & $\begin{array}{l}\text { IV- } \\
\text { LATE^ }^{\wedge}\end{array}$ \\
\hline \multicolumn{8}{|c|}{ Panel A: No. ways to prevent diarrhea mentioned } \\
\hline Treatment \# Post Period & $\begin{array}{l}0.16 \\
{[0.087]^{*}}\end{array}$ & $\begin{array}{l}0.16 \\
{[0.086]^{*}}\end{array}$ & $\begin{array}{l}0.16 \\
{[0.087]^{*}}\end{array}$ & & & & \\
\hline \multicolumn{8}{|l|}{ Inside Project Area \# Post } \\
\hline Period & & & & $\begin{array}{l}0.03 \\
{[0.084]}\end{array}$ & & & \\
\hline \multicolumn{8}{|l|}{ Inside Project Area-ITT in } \\
\hline Post Period & & & & & $\begin{array}{l}0.25 \\
{[0.13]^{*}}\end{array}$ & & \\
\hline Beneficiary \# Post Period & & & & & & $\begin{array}{l}0.054 \\
{[0.078]}\end{array}$ & \\
\hline $\begin{array}{l}\text { Beneficiary-LATE in Post } \\
\text { Period }\end{array}$ & & & & & & & $\begin{array}{l}0.3 \\
{[0.16]^{*}} \\
\end{array}$ \\
\hline Pairs Indicators & NO & NO & YES & YES & NO & YES & NO \\
\hline Mean of Comp. at Baseline & 3.25 & 3.25 & 3.25 & 3.21 & 3.21 & 3.22 & 3.22 \\
\hline SD of Comp. at Baseline & 1.09 & 1.09 & 1.09 & 1.1 & 1.1 & 1.1 & 1.1 \\
\hline Number of Clusters & 128 & 128 & 128 & 128 & 128 & 128 & 128 \\
\hline Observations & 9,325 & 9,325 & 9,325 & 9,208 & 9,208 & 9,208 & 9,208 \\
\hline K-P rk Wald F & & & & & 249.6 & & 129.9 \\
\hline \multicolumn{8}{|c|}{ Panel B: No. situations mentioned when washing hands } \\
\hline Treatment \# Post Period & $\begin{array}{l}0.057 \\
{[0.059]}\end{array}$ & $\begin{array}{l}0.054 \\
{[0.059]}\end{array}$ & $\begin{array}{l}0.057 \\
{[0.059]}\end{array}$ & & & & \\
\hline \multicolumn{8}{|l|}{ Inside Project Area \# Post } \\
\hline Period & & & & $\begin{array}{l}0.011 \\
{[0.054]}\end{array}$ & & & \\
\hline \multicolumn{8}{|l|}{ Inside Project Area-ITT in } \\
\hline Post Period & & & & & $\begin{array}{l}0.085 \\
{[0.088]}\end{array}$ & & \\
\hline Beneficiary \# Post Period & & & & & & $\begin{array}{l}-0.012 \\
{[0.052]}\end{array}$ & \\
\hline Beneficiary-LATE in Post & & & & & & & \\
\hline Period & & & & & & & $\begin{array}{l}0.1 \\
{[0.11]}\end{array}$ \\
\hline Pairs Indicators & NO & NO & YES & YES & NO & YES & NO \\
\hline Mean of Comp. at Baseline & 1.39 & 1.39 & 1.39 & 1.36 & 1.36 & 1.36 & 1.36 \\
\hline SD of Comp. at Baseline & 0.82 & 0.82 & 0.82 & 0.82 & 0.82 & 0.82 & 0.82 \\
\hline Number of Clusters & 128 & 128 & 128 & 128 & 128 & 128 & 128 \\
\hline Observations & 9,325 & 9,325 & 9,325 & 9,208 & 9,208 & 9,208 & 9,208 \\
\hline K-P rk Wald F & & & & & 249.6 & & 129.9 \\
\hline
\end{tabular}

Standard errors in brackets

Std. errors are clustered at the census

segment level.

All equations include year fixed effects. Equations are DID, in (1)-(3) the treatment is defined as living in a treatment assigned segment, (4)-(5) treatment is defined as living inside the project area within the matched pairs, (6)-(7) treatment is defined as having reported being beneficiary of the WASH project within the matched pairs. Equations (4)-(7) control for initial treatment assignment.

Equation (2) includes household fixed effects. Pair dummies indicated in the table are based in on nearest neighbor matching propensity score matching based on 2007 census segment data.

IV estimates in columns (5) and (7) use the census segment treatment assignment to instrument for indicators for being in a project area in 2012-2013 (5); and the households reporting being a beneficiary of the WASH projects from MCC in (7)

IIV estimates partial out the indicators for pairs to compute the std. errors of the coefficients of interest. We report the K-P rk Wald

$F$ statistic following the results in Stock and Yogo (2005)

* $\mathrm{p}<0.10, * * \mathrm{p}<0.05, * * *$

$p<0.01$ 
Given these positive effects on the knowledge of ways of preventing diarrhea, we were interested in seeing if these effects were reflected as behavior changes. To see changes in actual hygienic behaviors, we used an indicator for the households that treated their water before drinking it. We defined 'treatment of water' as using chlorine additives, boiling, water filtering, or sun/UV exposure since these were the modes of treatment identified in the written materials distributed in the community. Table 69 shows the results for this indicator in panel $A$. We found a decrease in the probability of treating water before drinking it of 6 percentage points after the WASH interventions; for household that report being direct beneficiaries the increases to 10 percentage points from a 20 percent baseline. This does not necessarily reflect unsafe drinking water, as the beneficiary households should have decreased "at home treatment" if they trusted the quality of the water provided by the water projects; and, our previous results indicate that there was an increase in household perception of how safe is the water in the systems. In addition, we inquire about the presence of soap in the place where household members most wash their hands and create an indicator to estimate the impact on the probability that there was soap at the time of the survey, the results are presented in Table 69, panel B, but we do not find significant effects on this indicator.

We conducted residual chlorine tests in all households of the sample. We tested for residual chlorine in the drinking water at the time of the survey. This test provided us with a categorical indicator of the levels of chlorine: less than $0.3 \mathrm{mg} / \mathrm{liter}, 0.3-0.5 \mathrm{mg} /$ Liter, 0.5-1.0 mg/liter, $1.0-1.5 \mathrm{mg} / \mathrm{liter}$, and 1.5-3.0 mg/liter. The test measured the chlorine level at the tap for households that drank water directly from the tap and at the container/cup for those that did not. We expected the chlorination rates in treatment segments to increase in the water used to drink; even the households that did not drink directly from the tap were receiving chlorinated/potable water in the treatment segments and information through the hygiene campaign. The results are presented in Table 70, panel A uses the categorical result as a dependent variable and panel B an indicator for the chlorine level being $0.3 \mathrm{mg} /$ liter and above. Households living in treatment segments had higher levels of chlorine because of the WASH interventions, but the levels of chlorine remained lower than the recommendable amount. Households living in treatment segments are 9.7 percentage points more likely than similar household in comparison segments to have some chlorine in their drinking water and this estimate increases to 22 percentage points among the households that report being direct beneficiaries of the WASH interventions. The World Health Organization recommends residual chlorine of at least $0.5 \mathrm{mg} / \mathrm{liter}$ [ (World Health Organization, 1997) $]^{42}$ and the probability of having a chlorine result above $0.5 \mathrm{mg} / \mathrm{liter}$ is only marginally significant for 2012 (non-shown results) ${ }^{43}$.

${ }^{42}$ However, this level is most likely not adequate to maintain the quality of the water when this water is stored in the home.

${ }^{43}$ In non-presented regression (Annex 2 Additional Results tables) we explore the impacts on the hygienic habits of children in the household and food handling in the household. We did not found significant effects on the hand washing behavior of children and found marginally significant effects on the probability of using chlorine to wash vegetables. The effects on the hygienic management of latrines, such as the number of times that household emptied their latrines and if they added chemical to control odors and vectors, were also not significant. 
TABLE 69 HYGIENE PRACTICES: TREATMENT OF DRINKING WATER AND USE OF SOAP

\begin{tabular}{|c|c|c|c|c|c|c|c|}
\hline & $(1)$ & $(2)$ & (3) & (4) & (5) & (6) & (7) \\
\hline & DID & DID-FE & $\begin{array}{l}\text { DID- } \\
\text { Pairs }\end{array}$ & $\begin{array}{l}\text { RF-Area- } \\
\text { ITT }\end{array}$ & 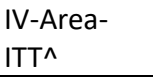 & RF-ATE & IV-LATE^ \\
\hline \multicolumn{8}{|c|}{ Panel A: Probability of Treating water before drinking } \\
\hline \multirow[t]{2}{*}{ Treatment \# Post Period } & -0.061 & -0.059 & -0.06 & & & & \\
\hline & {$[0.019]^{* * *}$} & {$[0.020]^{* * *}$} & {$[0.019]^{* *}$} & & & & \\
\hline \multirow[t]{2}{*}{ Inside Project Area \# Post Period } & & & & -0.073 & & & \\
\hline & & & & {$[0.021]^{* * *}$} & & & \\
\hline \multirow[t]{2}{*}{ Inside Project Area-ITT in Post Period } & & & & & -0.086 & & \\
\hline & & & & & {$[0.029]^{* * *}$} & & \\
\hline \multirow[t]{2}{*}{ Beneficiary \# Post Period } & & & & & & -0.088 & \\
\hline & & & & & & {$[0.026]^{* *}$} & \\
\hline \multirow[t]{2}{*}{ Beneficiary-LATE in Post Period } & & & & & & & -0.1 \\
\hline & & & & & & & {$[0.035]^{* * *}$} \\
\hline Pairs Indicators & NO & NO & YES & YES & NO & YES & NO \\
\hline Mean of Comp. at Baseline & 0.19 & 0.19 & 0.19 & 0.2 & 0.2 & 0.2 & 0.2 \\
\hline SD of Comp. at Baseline & 0.39 & 0.39 & 0.39 & 0.4 & 0.4 & 0.4 & 0.4 \\
\hline Number of Clusters & 128 & 128 & 128 & 128 & 128 & 128 & 128 \\
\hline Observations & 9,325 & 9,325 & 9,325 & 9,208 & 9,208 & 9,208 & 9,208 \\
\hline K-P rk Wald F & & & & & 249.6 & & 129.9 \\
\hline \multicolumn{8}{|c|}{ Panel B: Probability of having soap where hands are washed } \\
\hline \multirow[t]{2}{*}{ Treatment \# Post Period } & -0.025 & -0.025 & -0.025 & & & & \\
\hline & {$[0.019]$} & {$[0.019]$} & {$[0.019]$} & & & & \\
\hline \multirow[t]{2}{*}{ Inside Project Area \# Post Period } & & & & 0.0016 & & & \\
\hline & & & & {$[0.019]$} & & & \\
\hline \multirow[t]{2}{*}{ Inside Project Area-ITT in Post Period } & & & & & -0.034 & & \\
\hline & & & & & {$[0.028]$} & & \\
\hline \multirow[t]{2}{*}{ Beneficiary \# Post Period } & & & & & & 0.0044 & \\
\hline & & & & & & {$[0.016]$} & \\
\hline \multirow[t]{2}{*}{ Beneficiary-LATE in Post Period } & & & & & & & -0.041 \\
\hline & & & & & & & {$[0.034]$} \\
\hline Pairs Indicators & NO & NO & YES & YES & NO & YES & NO \\
\hline Mean of Comp. at Baseline & 0.9 & 0.9 & 0.9 & 0.91 & 0.91 & 0.91 & 0.91 \\
\hline SD of Comp. at Baseline & 0.3 & 0.3 & 0.3 & 0.29 & 0.29 & 0.29 & 0.29 \\
\hline Number of Clusters & 128 & 128 & 128 & 128 & 128 & 128 & 128 \\
\hline Observations & 9,325 & 9,325 & 9,325 & 9,208 & 9,208 & 9,208 & 9,208 \\
\hline K-P rk Wald F & & & & & 249.6 & & 129.9 \\
\hline
\end{tabular}

Standard errors in brackets

Std. errors are clustered at the census segment level.

All equations include year fixed effects. Equations are DID, in (1)-(3) the treatment is defined as living in a treatment assigned segment, (4)-(5) treatment is defined as living inside the project area within the matched pairs, (6)-(7) treatment is defined as having reported being beneficiary of the WASH project within the matched pairs. Equations (4)-(7) control for initial treatment assignment.

Equation (2) includes household fixed effects. Pair dummies indicated in the table are based in on nearest neighbor matching propensity score matching based on 2007 census segment data.

IV estimates in columns (5) and (7) use the census segment treatment assignment to instrument for indicators for being in a project area in 2012-2013 (5); and the households reporting being a beneficiary of the WASH projects from MCC in (7)

^IV estimates partial out the indicators for pairs to compute the std. errors of the coefficients of interest. We report the K-P rk Wald F statistic following the results in Stock and Yogo (2005)

${ }^{*} \mathrm{p}<0.10,{ }^{* *} \mathrm{p}<0.05,{ }^{* * *} \mathrm{p}<0.01$ 
TABLE 70 RESIDUAL CHLORINE ENUMERATOR TEST

\begin{tabular}{|c|c|c|c|c|c|c|c|}
\hline & $(1)$ & $(2)$ & (3) & $(4)$ & $(5)$ & (6) & (7) \\
\hline & DID & DID-FE & $\begin{array}{l}\text { DID- } \\
\text { Pairs }\end{array}$ & $\begin{array}{l}\text { RF- } \\
\text { Area- } \\
\text { ITT }\end{array}$ & 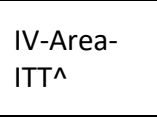 & $\begin{array}{l}\text { RF- } \\
\text { ATE }\end{array}$ & IV-LATE^ \\
\hline \multicolumn{8}{|c|}{ Panel A: Categorical Chlorine water test-Result } \\
\hline \multirow[t]{2}{*}{ Treatment \# Post Period } & 0.12 & 0.12 & 0.12 & & & & \\
\hline & {$[0.052]^{* *}$} & {$[0.052]^{* *}$} & {$[0.052]^{*}$} & & & & \\
\hline \multirow[t]{2}{*}{ Inside Project Area \# Post Period } & & & & 0.14 & & & \\
\hline & & & & {$[0.051]^{* * *}$} & & & \\
\hline \multirow[t]{2}{*}{ Inside Project Area-ITT in Post Period } & & & & & 0.18 & & \\
\hline & & & & & {$[0.078]^{* *}$} & & \\
\hline \multirow[t]{2}{*}{ Beneficiary \# Post Period } & & & & & & 0.16 & \\
\hline & & & & & & {$[0.054]^{*}$} & $* *$ \\
\hline \multirow[t]{2}{*}{ Beneficiary-LATE in Post Period } & & & & & & & 0.22 \\
\hline & & & & & & & {$[0.090]^{* *}$} \\
\hline Pairs Indicators & NO & NO & YES & YES & NO & YES & NO \\
\hline Mean of Comp. at Baseline & 1.17 & 1.17 & 1.17 & 1.15 & 1.15 & 1.15 & 1.15 \\
\hline SD of Comp. at Baseline & 0.55 & 0.55 & 0.55 & 0.51 & 0.51 & 0.5 & 0.5 \\
\hline Number of Clusters & 128 & 128 & 128 & 128 & 128 & 128 & 128 \\
\hline Observations & 9,310 & 9,310 & 9,310 & 9,194 & 9,194 & 9,194 & 9,194 \\
\hline K-P rk Wald F & & & & & 255.4 & & 129.4 \\
\hline \multicolumn{8}{|c|}{ Panel B: Probability of having at least Chlorine level above $0.3 \mathrm{mg} / \mathrm{L}$} \\
\hline \multirow[t]{2}{*}{ Treatment \# Post Period } & 0.097 & 0.099 & 0.097 & & & & \\
\hline & {$[0.030]^{* * *}$} & {$[0.030]^{* * *}$} & {$[0.030]^{*}$} & ** & & & \\
\hline \multirow[t]{2}{*}{ Inside Project Area \# Post Period } & & & & 0.13 & & & \\
\hline & & & & {$[0.029]^{* * *}$} & & & \\
\hline \multirow[t]{2}{*}{ Inside Project Area-ITT in Post Period } & & & & & 0.15 & & \\
\hline & & & & & {$[0.044]^{* * *}$} & & \\
\hline \multirow[t]{2}{*}{ Beneficiary \# Post Period } & & & & & & 0.13 & \\
\hline & & & & & & {$[0.030]^{*}$} & $* *$ \\
\hline \multirow[t]{2}{*}{ Beneficiary-LATE in Post Period } & & & & & & & 0.18 \\
\hline & & & & & & & {$[0.052]^{* * *}$} \\
\hline Pairs Indicators & NO & NO & YES & YES & NO & YES & NO \\
\hline Mean of Comp. at Baseline & 0.11 & 0.11 & 0.11 & 0.11 & 0.11 & 0.11 & 0.11 \\
\hline SD of Comp. at Baseline & 0.32 & 0.32 & 0.32 & 0.31 & 0.31 & 0.31 & 0.31 \\
\hline Number of Clusters & 128 & 128 & 128 & 128 & 128 & 128 & 128 \\
\hline Observations & 9,310 & 9,310 & 9,310 & 9,194 & 9,194 & 9,194 & 9,194 \\
\hline K-P rk Wald F & & & & & 255.4 & & 129.4 \\
\hline
\end{tabular}

Standard errors in brackets

Std. errors are clustered at the census segment level.

All equations include year fixed effects. Equations are DID, in (1)-(3) the treatment is defined as living in a treatment assigned segment, (4)-(5) treatment is defined as living inside the project area within the matched pairs, (6)-(7) treatment is defined as having reported being beneficiary of the WASH project within the matched pairs. Equations (4)-(7) control for initial treatment assignment.

Equation (2) includes household fixed effects. Pair dummies indicated in the table are based in on nearest neighbor matching propensity score matching based on 2007 census segment data.

IV estimates in columns (5) and (7) use the census segment treatment assignment to instrument for indicators for being in a project area in 2012-2013 (5); and the households reporting being a beneficiary of the WASH projects from MCC in (7)

^IV estimates partial out the indicators for pairs to compute the std. errors of the coefficients of interest. We report the K-P rk Wald $F$ statistic following the results in Stock and Yogo (2005)

$* \mathrm{p}<0.10, * * \mathrm{p}<0.05, * * * \mathrm{p}<0.01$ 
We conclude this section with the effect on "effective use" of tap water from the new and improved systems. The introduction of an improved piped system could lead to the abandonment of other unimproved sources, especially for uses that affect health, like drinking and cooking; and perhaps less so for general purposes like washing and cleaning.

Table 71 shows the impact of the WASH intervention on the principal source of water use for drinking. Households living in treatment segments were 28 percentage points more likely to use a tap as their principal water source for drinking water after the WASH interventions relative to households living in comparison segments. For households living in the catchment area of the interventions the impact increases to 37 percentage points and to 49 percentage points for the households that report being direct beneficiaries on the WASH intervention; practically increasing to 100 percent of these households.

The results in Table 72 and Table 73, show a similar impact for cooking and washing, respectively. For cooking use, households living treatment segment the impact is estimated 29 percentage points and increases to 50 percentage points for the households that report being direct beneficiaries on the WASH intervention. For washing use, households living treatment segments are 26 percentage points more likely to use tap water for washing and the impact increases to 35 percentage points in the catchment area of the project and to 45 percentage points among the households that report being direct beneficiaries on the WASH intervention. In "Annex 3 Additional" the results show that these households were also less likely to use wells, non-protected springs, and other natural sources as the principal source for all uses.

\section{TABLE 71 TAP WATER IN EFFECTIVE USE: DRINKING}

\begin{tabular}{|c|c|c|c|c|c|c|c|}
\hline & (1) & $(2)$ & (3) & (4) & (5) & (6) & (7) \\
\hline & DID & DID-FE & $\begin{array}{l}\text { DID- } \\
\text { Pairs } \\
\end{array}$ & $\begin{array}{c}\text { RF-Area- } \\
\text { ITT }\end{array}$ & 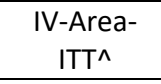 & RF-ATE & IV-LATE^ \\
\hline \multirow[t]{2}{*}{ Treatment \# Post Period } & 0.28 & 0.28 & 0.28 & & & & \\
\hline & {$[0.036]^{* * *}$} & {$[0.036]^{* * *}$} & {$[0.036]^{* * *}$} & & & & \\
\hline \multirow{2}{*}{\multicolumn{2}{|c|}{ Inside Project Area \# Post Period }} & & & 0.37 & & & \\
\hline & & & & {$[0.042]^{* * *}$} & & & \\
\hline \multirow{2}{*}{\multicolumn{2}{|c|}{ Inside Project Area-ITT in Post Period }} & & & & 0.41 & & \\
\hline & & & & & {$[0.052]^{* * *}$} & & \\
\hline \multirow{2}{*}{\multicolumn{2}{|c|}{ Beneficiary \# Post Period }} & & & & & 0.46 & \\
\hline & & & & & & {$[0.047]^{* * *}$} & \\
\hline \multirow{2}{*}{\multicolumn{2}{|c|}{ Beneficiary-LATE in Post Period }} & & & & & & 0.49 \\
\hline & & & & & & & {$[0.056]^{* * *}$} \\
\hline Pairs Indicators & NO & NO & YES & YES & NO & YES & NO \\
\hline Mean of Comp. at Baseline & 0.44 & 0.44 & 0.44 & 0.44 & 0.44 & 0.44 & 0.44 \\
\hline SD of Comp. at Baseline & 0.5 & 0.5 & 0.5 & 0.5 & 0.5 & 0.5 & 0.5 \\
\hline Number of Clusters & 128 & 128 & 128 & 128 & 128 & 128 & 128 \\
\hline Observations & 9,325 & 9,325 & 9,325 & 9,208 & 9,208 & 9,208 & 9,208 \\
\hline K-P rk Wald F & & & & & 249.6 & & 129.9 \\
\hline
\end{tabular}

Standard errors in brackets

Std. errors are clustered at the census segment level.

All equations include year fixed effects. Equations are DID, in (1)-(3) the treatment is defined as living in a treatment assigned segment, (4)-(5) treatment is defined as living inside the project area within the matched pairs, (6)-(7) treatment is defined as having reported being beneficiary of the WASH project within the matched pairs. Equations (4)-(7) control for initial treatment assignment.

Equation (2) includes household fixed effects. Pair dummies indicated in the table are based in on nearest neighbor matching propensity score matching based on 2007 census segment data.

IV estimates in columns (5) and (7) use the census segment treatment assignment to instrument for indicators for being in a project area in 2012-2013 (5); and the households reporting being a beneficiary of the WASH projects from MCC in (7)

^IV estimates partial out the indicators for pairs to compute the std. errors of the coefficients of interest. We report the K-P rk Wald $F$ statistic following the results in Stock and Yogo (2005)

$* \mathrm{p}<0.10, * * \mathrm{p}<0.05, * * * \mathrm{p}<0.01$ 
TABLE 72 TAP WATER IN EFFECTIVE USE: COOKING

\begin{tabular}{|c|c|c|c|c|c|c|c|}
\hline & (1) & (2) & (3) & (4) & (5) & (6) & (7) \\
\hline & DID & DID-FE & $\begin{array}{l}\text { DID- } \\
\text { Pairs }\end{array}$ & $\begin{array}{c}\text { RF-Area- } \\
\text { ITT }\end{array}$ & 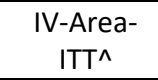 & RF-ATE & IV-LATE^ \\
\hline \multirow[t]{2}{*}{ Treatment \# Post Period } & 0.29 & 0.29 & 0.29 & & & & \\
\hline & {$[0.038]^{* * *}$} & {$[0.038]^{* * *}$} & {$[0.038]^{* * *}$} & & & & \\
\hline \multirow{2}{*}{\multicolumn{2}{|c|}{ Inside Project Area \# Post Period }} & & & 0.38 & & & \\
\hline & & & & {$[0.043]^{* * *}$} & & & \\
\hline \multirow{2}{*}{\multicolumn{2}{|c|}{ Inside Project Area-ITT in Post Period }} & & & & 0.42 & & \\
\hline & & & & & {$[0.053]^{* * *}$} & & \\
\hline \multirow{2}{*}{\multicolumn{2}{|c|}{ Beneficiary \# Post Period }} & & & & & 0.48 & \\
\hline & & & & & & {$[0.048]^{* * *}$} & \\
\hline \multirow{2}{*}{\multicolumn{2}{|c|}{ Beneficiary-LATE in Post Period }} & & & & & & 0.5 \\
\hline & & & & & & & {$[0.058]^{* * *}$} \\
\hline Pairs Indicators & NO & NO & YES & YES & NO & YES & NO \\
\hline Mean of Comp. at Baseline & 0.45 & 0.45 & 0.45 & 0.46 & 0.46 & 0.45 & 0.45 \\
\hline SD of Comp. at Baseline & 0.5 & 0.5 & 0.5 & 0.5 & 0.5 & 0.5 & 0.5 \\
\hline Number of Clusters & 128 & 128 & 128 & 128 & 128 & 128 & 128 \\
\hline Observations & 9,325 & 9,325 & 9,325 & 9,208 & 9,208 & 9,208 & 9,208 \\
\hline K-P rk Wald F & & & & & 249.6 & & 129.9 \\
\hline
\end{tabular}

Standard errors in brackets

Std. errors are clustered at the census segment level.

All equations include year fixed effects. Equations are DID, in (1)-(3) the treatment is defined as living in a treatment assigned segment, (4)-(5) treatment is defined as living inside the project area within the matched pairs, (6)-(7) treatment is defined as having reported being beneficiary of the WASH project within the matched pairs. Equations (4)-(7) control for initial treatment assignment.

Equation (2) includes household fixed effects. Pair dummies indicated in the table are based in on nearest neighbor matching propensity score matching based on 2007 census segment data.

IV estimates in columns (5) and (7) use the census segment treatment assignment to instrument for indicators for being in a project area in 2012-2013 (5); and the households reporting being a beneficiary of the WASH projects from MCC in (7)

AIV estimates partial out the indicators for pairs to compute the std. errors of the coefficients of interest. We report the K-P rk Wald $F$ statistic following the results in Stock and Yogo (2005)

$* \mathrm{p}<0.10, * * \mathrm{p}<0.05, * * * \mathrm{p}<0.01$ 
TABLE 73 TAP WATER IN EFFECTIVE USE: WASHING

\begin{tabular}{|c|c|c|c|c|c|c|c|}
\hline & $(1)$ & $(2)$ & (3) & (4) & (5) & (6) & (7) \\
\hline & DID & DID-FE & $\begin{array}{l}\text { DID- } \\
\text { Pairs }\end{array}$ & $\begin{array}{c}\text { RF-Area- } \\
\text { ITT }\end{array}$ & $\begin{array}{c}\text { IV-Area- } \\
\text { ITT }^{\wedge}\end{array}$ & RF-ATE & IV-LATE^ \\
\hline \multirow[t]{2}{*}{ Treatment \# Post Period } & 0.26 & 0.26 & 0.26 & & & & \\
\hline & {$[0.037]^{* * *}$} & {$[0.038]^{* * *}$} & {$[0.038]^{* * *}$} & & & & \\
\hline \multirow{2}{*}{\multicolumn{2}{|c|}{ Inside Project Area \# Post Period }} & & & 0.35 & & & \\
\hline & & & & {$[0.043]^{* * *}$} & & & \\
\hline \multirow{2}{*}{\multicolumn{2}{|c|}{ Inside Project Area-ITT in Post Period }} & & & & 0.38 & & \\
\hline & & & & & {$[0.053]^{* * *}$} & & \\
\hline \multirow[t]{2}{*}{ Beneficiary \# Post Period } & & & & & & 0.45 & \\
\hline & & & & & & {$[0.046]^{* * *}$} & \\
\hline \multirow{2}{*}{\multicolumn{2}{|c|}{ Beneficiary-LATE in Post Period }} & & & & & & 0.45 \\
\hline & & & & & & & {$[0.057]^{* * *}$} \\
\hline Pairs Indicators & NO & NO & YES & YES & NO & YES & NO \\
\hline Mean of Comp. at Baseline & 0.46 & 0.46 & 0.46 & 0.46 & 0.46 & 0.45 & 0.45 \\
\hline SD of Comp. at Baseline & 0.5 & 0.5 & 0.5 & 0.5 & 0.5 & 0.5 & 0.5 \\
\hline Number of Clusters & 128 & 128 & 128 & 128 & 128 & 128 & 128 \\
\hline Observations & 9,325 & 9,325 & 9,325 & 9,208 & 9,208 & 9,208 & 9,208 \\
\hline K-P rk Wald F & & & & & 249.6 & & 129.9 \\
\hline
\end{tabular}

Standard errors in brackets

Std. errors are clustered at the census segment level.

All equations include year fixed effects. Equations are DID, in (1)-(3) the treatment is defined as living in a treatment assigned segment, (4)-

(5) treatment is defined as living inside the project area within the matched pairs, (6)-(7) treatment is defined as having reported being beneficiary of the WASH project within the matched pairs. Equations (4)-(7) control for initial treatment assignment.

Equation (2) includes household fixed effects. Pair dummies indicated in the table are based in on nearest neighbor matching propensity score matching based on 2007 census segment data.

IV estimates in columns (5) and (7) use the census segment treatment assignment to instrument for indicators for being in a project area in 2012-2013 (5); and the households reporting being a beneficiary of the WASH projects from MCC in (7)

NIV estimates partial out the indicators for pairs to compute the std. errors of the coefficients of interest. We report the K-P rk Wald $F$ statistic following the results in Stock and Yogo (2005)

$* \mathrm{p}<0.10, * * \mathrm{p}<0.05, * * * \mathrm{p}<0.01$

\section{Water Contamination: Water Supply and the Point of Consumption}

There are many waterborne bacterial diseases, such as cholera, bacillary dysentery, typhoid, and paratyphoid, among others. In general, causal agents of these diseases are found in low water concentrations, which makes their isolation and identification difficult.

Some micro-organisms serve as indicators for fecal contamination. These micro-organisms are present in large amounts in human feces and in the feces of other animals. The group of bacteria usually used as indicators of fecal contamination are the coliforms. According to the WHO/UNICEF Joint Monitoring Programme for Water Supply and Sanitation, at least 1.8 billion people world-wide are estimated to drink water contaminated with fecal matter. An even greater number drink water which is delivered through a system without adequate protection against sanitary hazards.

In 66 segments, of the 135 in the sample, we contracted a laboratory to take water samples in a randomly selected sub-sample of households in our sample. The laboratory technicians visited these segments and completed a form to identify the water sources used by each household and the water they stored in the home that was used for drinking. ${ }^{44}$. For these households, they analyzed the water samples to detect the

\footnotetext{
44 “Annex 3: Water Quality Testing” presents the details of the sampling procedures.
} 
presence of total coliforms, fecal coliforms, E.coli, and residual chlorine ${ }^{45}$ at the source and at the point of consumption or the stored water used for drinking.

The test for coliform group determined the Most Probable Number (MPN) of micro-organisms existing in a water sample (number equal to the mean density of coliforms in the sample). The reading of the results was done using the tables given by the Standard Methods for the analysis of water and wastewater of the American Public Health Association, the American Water Works Association, and the Water Environment Federation. The index is presented in Table 74 for example, when no growth is observed in any of 10 tubes, the value reported by the method used is ' $<1.1 \mathrm{MPN} / \mathrm{mL}^{\prime}$ and if growth was obtained in five of the tubes, the value reported corresponds to '6.9 MPN/mL.' Guidelines for Drinking-Water Quality recommend that fecal indicator bacteria, preferably E. coli or alternatively thermotolerant coliform (TTC), should not be detectable in any 100 ml drinking water sample (WHO 2011).

TABLE 74 MPN INDEX AND 95 PERCENT CONFIDENCE INTERVALS

\begin{tabular}{|c|c|c|c|}
\hline \multirow[t]{2}{*}{$\begin{array}{c}\text { Positive } \\
\text { Tubes }\end{array}$} & \multirow[t]{2}{*}{ MPN/100ml } & \multicolumn{2}{|c|}{$\begin{array}{l}\text { 95\% Confidence } \\
\text { Interval }\end{array}$} \\
\hline & & Low & High \\
\hline 0 & $<1.1$ & - & 3.3 \\
\hline 1 & 1.1 & .05 & 5.9 \\
\hline 2 & 2.2 & .37 & 8.1 \\
\hline 3 & 3.6 & .91 & 9.7 \\
\hline 4 & 5.1 & 1.6 & 13 \\
\hline 5 & 6.9 & 2.5 & 15 \\
\hline 6 & 9.2 & 3.3 & 19 \\
\hline 7 & 12 & 4.8 & 24 \\
\hline 8 & 16 & 5.9 & 33 \\
\hline 9 & 23 & 8.1 & 53 \\
\hline 10 & $>23$ & 12 & - \\
\hline
\end{tabular}

\section{Fecal Coliforms and E. Coli Contamination}

Following the guidelines for drinking-water quality, we present the analysis using an indicator that is equal to one if the index is greater than $1.1 \mathrm{MPN} / 100 \mathrm{~mL}$, which indicates growth in the testing tubes

Figure 26 shows the laboratory results for fecal coliforms. They show that in both treatment and comparison segments, the waters were contaminated and that the proportion decreased in the follow-up years for both treatment and comparison groups. Figure 27 shows the proportion of households whose stored water for drinking had fecal coliforms present by the type of source. In general, the proportion is lower when the original water source is a tap from water system, but the proportion remains above 50 percent.

${ }^{45}$ This was only measured if the source used in the households was a water system. 


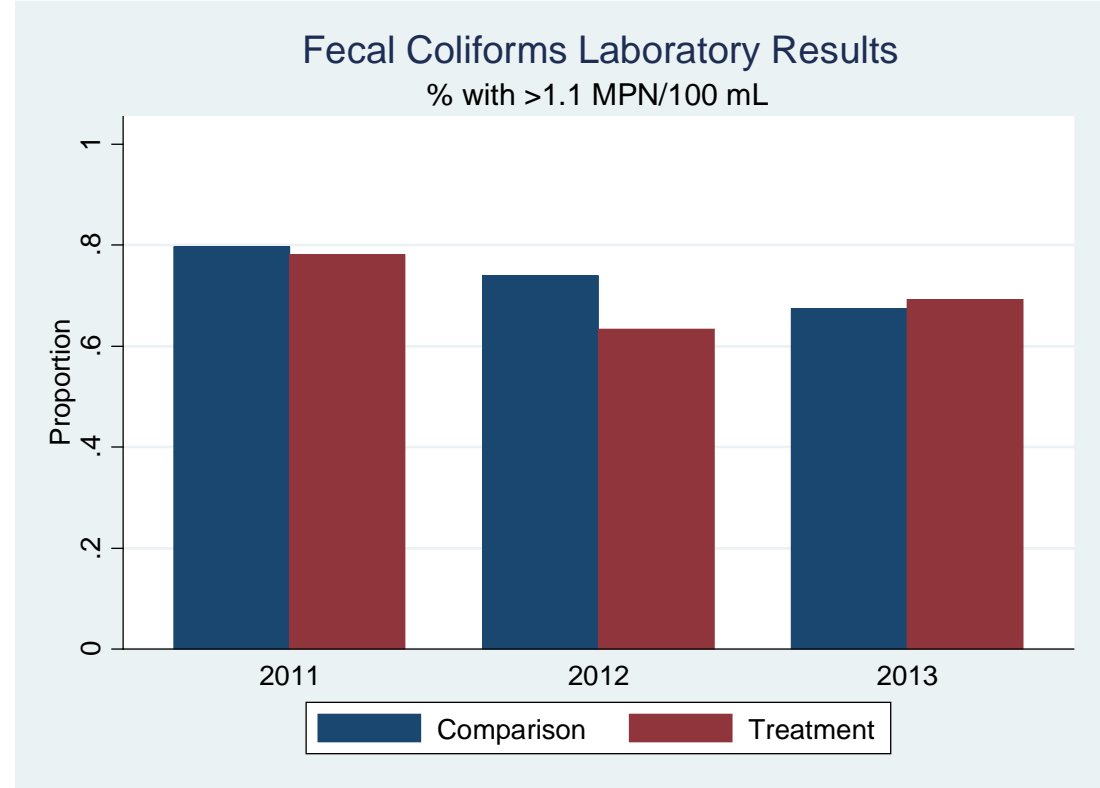

FIGURE 27 PRESENCE OF FECAL COLIFORMS IN STORED WATER BY DRINKING WATER SOURCE

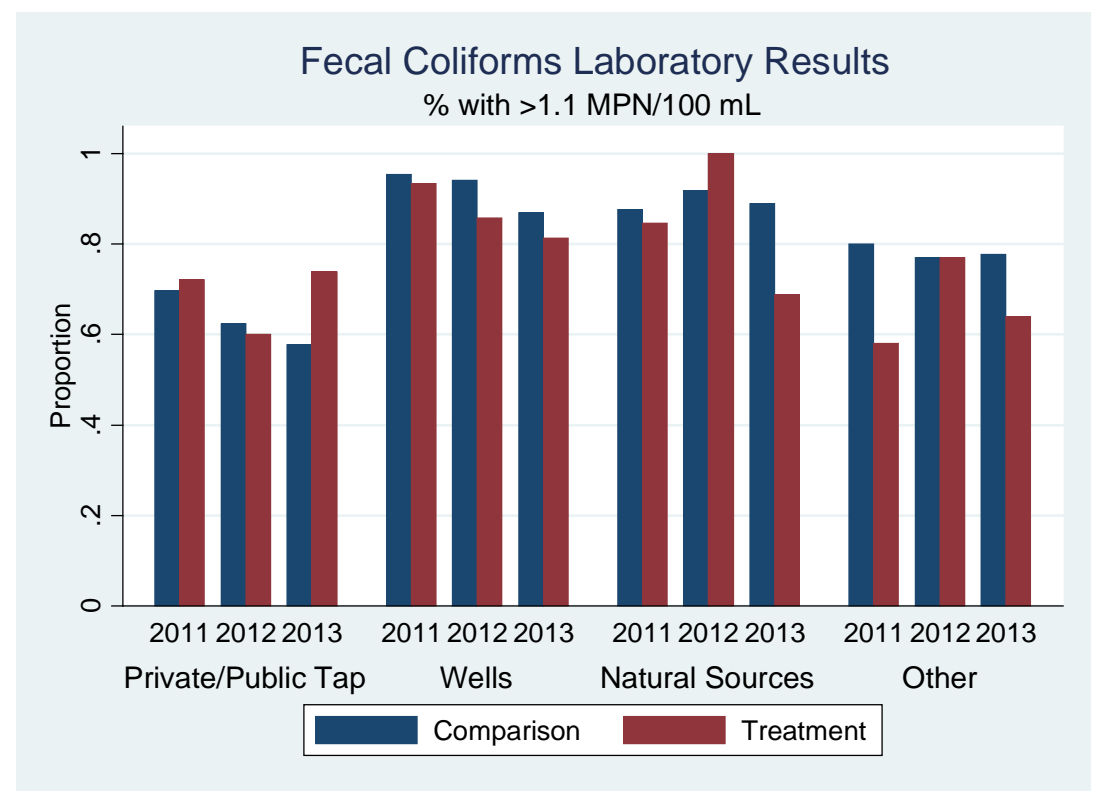

Figure 28 shows the laboratory results for E.coli indicator. The presence of E.coli was higher in the follow-up years with over 50 percent of the samples showing E.coli growth. Figure 29 shows the proportion of households that had E.coli growth in their stored water used for drinking. Similarly, to the fecal coliforms, the proportion was lower when the water source was a tap, but the proportions were very high, especially in wells. 


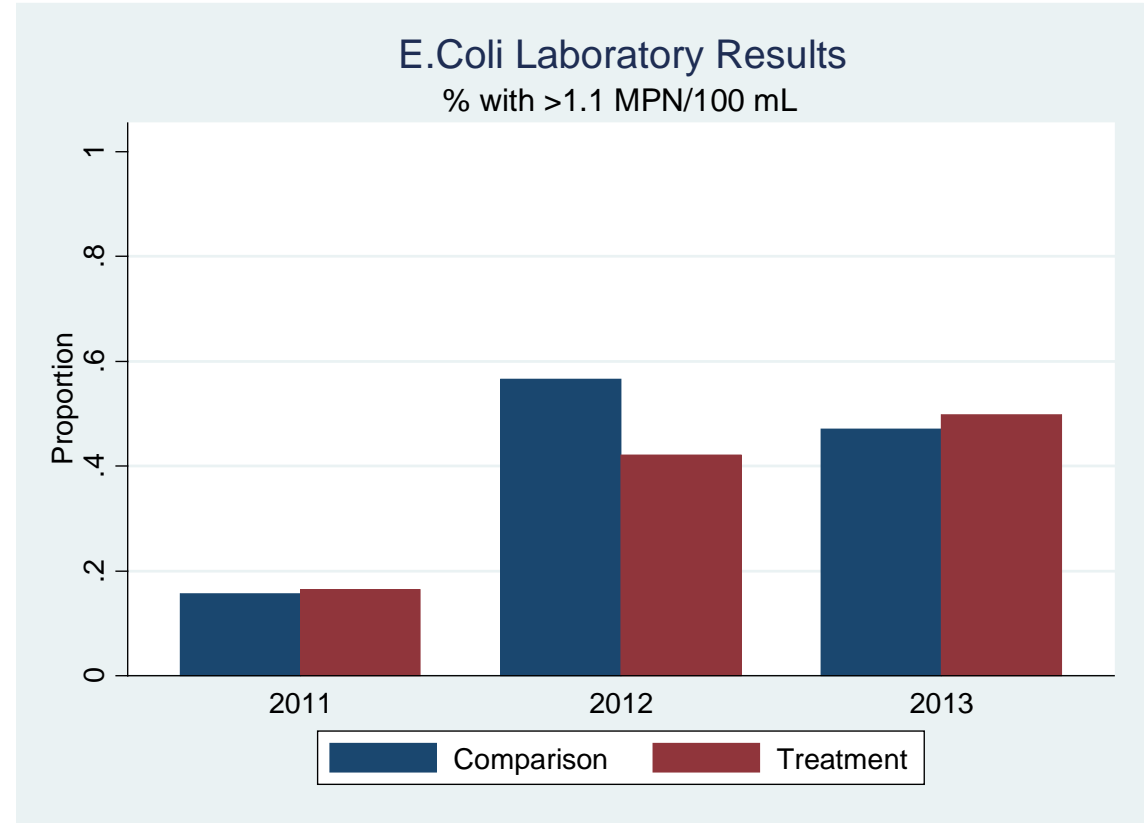

FIGURE 29 PRESENCE OF E.COLI IN STORED WATER BY DRINKING WATER SOURCE

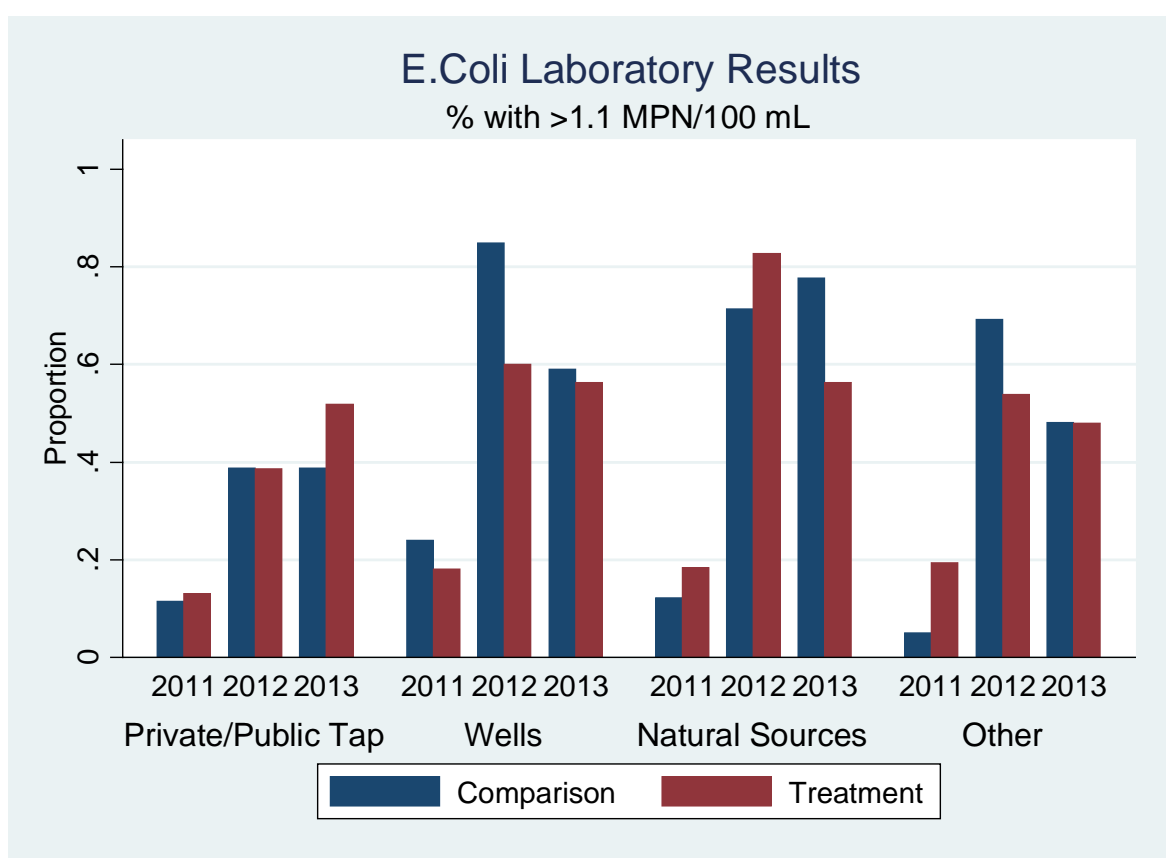

These results are indicative of contamination at the storage point and lack of appropriate treatment of the drinking water. The explore if the WASH interventions had an effect not only on the quality of water of the system but also at the final point of consumption, we present the impact estimates for this subsample of households in Table 75.

The estimated equations follow our pair matched-segment design and include year fixed effects. First we estimate a simple DID in (1), where the treatment is defined as living in a treatment assigned segment and include pairs indicators in (2). In (3) we estimate the DID with pairs indicators for the contamination outcome at the source and at the storage points. Since the presence or not of coliforms are likely different by the sourced used, in (4) we control for type of water source. 
Panel A, shows no significant effects on the probability of having fecal coliforms in treatment segments after the WASH intervention were implemented. In panel B, we find an interesting result. For the probability of having E.coli present in the water we find no significant effect; however, when differentiating between the stored water used for drinking and at the source, we find that the WASH projects successfully decrease the probability of having E.coli contamination at the source. Namely, treatment households are between 16 and 19 percentage points less likely to have E.coli in their water source after the implementation of the water systems than would have been the case without the WASH interventions. However, there are no effects on the water stored or at the point of consumption. This is evidence that drinking water is being contaminated between the source and the point of consumption.

TABLE 75 WATER CONTAMINATION: FECAL COLIFORMS AND E.COLI PRESENCE

\begin{tabular}{|c|c|c|c|c|}
\hline & $(1)$ & $(2)$ & $(3)$ & $(4)$ \\
\hline & DID & DID-Pairs & DID-Pairs-S & DID-Pairs-SS \\
\hline \multicolumn{5}{|l|}{ Panel A: Presence of Fecal Coliforms } \\
\hline \multirow[t]{2}{*}{ Treatment \# Post Period } & -0.031 & -0.036 & & \\
\hline & {$[0.064]$} & {$[0.064]$} & & \\
\hline \multirow[t]{2}{*}{ Treatment \# Post Period \# Water at the Source } & & & -0.089 & -0.058 \\
\hline & & & {$[0.077]$} & [0.078] \\
\hline \multirow[t]{2}{*}{ Treatment \# Post Period \# Stored Water } & & & -0.019 & 0.019 \\
\hline & & & [0.068] & [0.064] \\
\hline Pairs Indicators & NO & YES & YES & YES \\
\hline Source Indicators & NO & NO & NO & YES \\
\hline Mean of Comp. at Baseline & 0.82 & 0.82 & 0.82 & 0.82 \\
\hline SD of Comp. at Baseline & 0.38 & 0.38 & 0.38 & 0.38 \\
\hline Number of Clusters & 64 & 64 & 64 & 64 \\
\hline Observations & 3030 & 3030 & 3030 & 3030 \\
\hline \multicolumn{5}{|l|}{ Panel B: Presence of E.coli } \\
\hline \multirow{2}{*}{ Treatment \# Post Period } & -0.1 & -0.1 & & \\
\hline & {$[0.069]$} & [0.069] & & \\
\hline \multirow[t]{2}{*}{ Treatment \# Post Period \# Water at the Source } & & & -0.19 & -0.16 \\
\hline & & & {$[0.093]^{* *}$} & {$[0.092]^{*}$} \\
\hline \multirow[t]{2}{*}{ Treatment \# Post Period \# Stored Water } & & & -0.074 & -0.044 \\
\hline & & & {$[0.070]$} & [0.067] \\
\hline Pairs Indicators & NO & YES & YES & YES \\
\hline Source Indicators & NO & NO & NO & YES \\
\hline Mean of Comp. at Baseline & 0.15 & 0.15 & 0.15 & 0.15 \\
\hline SD of Comp. at Baseline & 0.36 & 0.36 & 0.36 & 0.36 \\
\hline Number of Clusters & 64 & 64 & 64 & 64 \\
\hline Observations & 3030 & 3030 & 3030 & 3030 \\
\hline
\end{tabular}

Standard errors in brackets

Std. errors are clustered at the census segment level.

All equations include year fixed effects. Equations are DID, where the treatment is defined as living in a treatment assigned segment. Equation (3) presents the DID estimates for the test at the water source (tap, spring, etc.) and at the point of consumption or where the households have stored their drinking water. In (4) we control for type of water source used to drink.

Pair dummies indicated in the table are based in on nearest neighbor matching propensity score matching based on 2007 census segment data.

$* \mathrm{p}<0.10, * * \mathrm{p}<0.05, * * * \mathrm{p}<0.01$ 


\section{RESIDUAL CHLORINE}

The laboratory also performed residual chlorine tests at the point of consumption (drinking water) and at different points of the water systems in segments with formal water distribution systems. These results improve on the previously discussed chlorine results in that the laboratory used an electronic colorimeter, which allows a precise estimation on the level of residual chlorine. Figure 30 shows the mean level of residual chlorine in treatment and comparison segments for each year. Treatment segments had higher levels of chlorine than comparison segments for each year after project implementation.

To corroborate these results, we estimated the impact of the projects using the specifications discussed in the previous section. The impact results are presented in Table 76. Treatment segments had a significantly larger concentration of residual chlorine, namely $0.07 \mathrm{mg} / \mathrm{L}$ more on average, or more than double of the mean at baseline. Differentiating between the water sample being taken at the source (directly from the tap of the household) and at the point or consumption (stored for drinking) in (3) yields similar impact estimates. Similarly, controlling for the source of the water sample and the condition of the storage container (e.g. directly from the tap or bottled, type of source and type of storage) the results impacts are of similar magnitude. These results are consistent with our previous findings using the chlorine kits from the household survey and suggest that while the systems are being chlorinated, perhaps not with the appropriate quantity or frequency.

FIGURE 30 MEAN RESIDUAL CHLORINE LABORATORY MEASURE

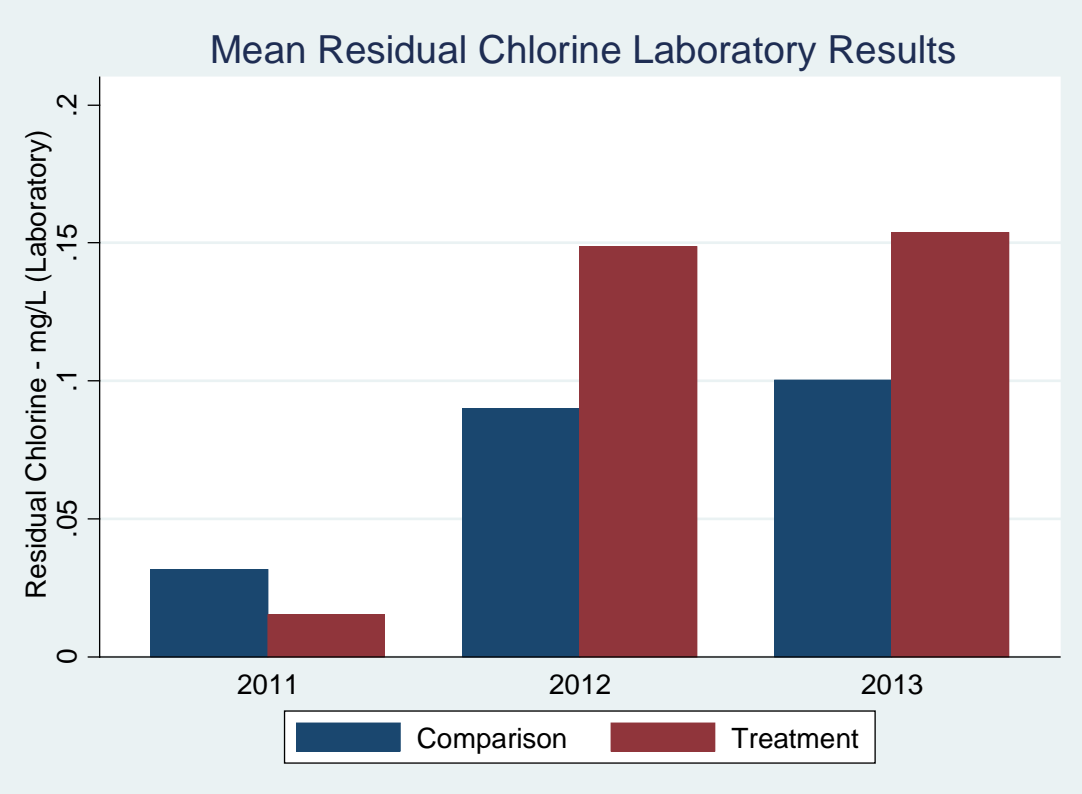


TABLE 76 RESIDUAL CHLORINE - MG/LITER (LABORATORY)

\begin{tabular}{lllll} 
& \multicolumn{1}{c}{$(1)$} & \multicolumn{1}{c}{$(2)$} & \multicolumn{1}{c}{$(3)$} & \multicolumn{1}{c}{$(4)$} \\
\hline & \multicolumn{1}{c}{ DID } & DID-Pairs & DID-Pairs-S & DID-Pairs-SS \\
\hline Treatment \# Post Period & 0.069 & 0.07 & & \\
& {$[0.023]^{* * *}$} & {$[0.023]^{* * *}$} & & \\
Treatment \# Post Period \# Water at the Source & & & 0.073 & 0.064 \\
& & & {$[0.023]^{* * *}$} & {$[0.022]^{* * *}$} \\
Treatment \# Post Period \# Stored Water & & & 0.069 & 0.056 \\
& & & {$[0.027]^{* *}$} & {$[0.026]^{* *}$} \\
\hline Pairs Indicators & NO & YES & YES & YES \\
Source Indicators & NO & NO & NO & YES \\
Mean of Comp. at Baseline & 0.026 & 0.026 & 0.026 & 0.026 \\
SD of Comp. at Baseline & 0.083 & 0.083 & 0.083 & 0.083 \\
Number of Clusters & 64 & 64 & 64 & 64 \\
Observations & 3005 & 3005 & 3005 & 3005 \\
\hline \hline
\end{tabular}

Standard errors in brackets

Std. errors are clustered at the census segment level.

All equations include year fixed effects. Equations are DID, where the treatment is defined as living in a treatment assigned segment. Equation (3) presents the DID estimates for the test at the water source (tap, spring, etc.) and at the point of consumption or where the households have stored their drinking water. In (4) we control for type of water source used to drink.

Pair dummies indicated in the table are based in on nearest neighbor matching propensity score matching based on 2007 census segment data.

$* \mathrm{p}<0.10, * * \mathrm{p}<0.05, * * * \mathrm{p}<0.01$

\section{COPING COSTS: EXPENSES AND TIME}

Coping costs are the expenditures that households make to collect, store, and treat water [ (Poulos, et al., 2006); (Strand \& Walker, 2005)]. Closer, more reliable, and better quality water is generally expected to reduce these costs. These costs include expenditures on building and maintaining alternative water sources, delivery systems, storage containers, cash expenditures on water services, water vendors, and bottled water. In addition, time spent collecting water and washing clothes at a water source outside of the home constitute a coping cost as well as.

\section{HOUSEHOLD COPING EXPENSES}

The cost of accessing water, defined as the direct payments and hauling water costs, is slightly higher. This could be expected as the beneficiaries are all using metered taps whereas before they might have used nonpaying water sources. We estimate the impact of the WASH interventions on the total monthly water expense and the expense by source. Table 77 shows that household expenses in water increased by 1.87 USD per month in treatment segments after the WASH interventions took place. 
TABLE 77 COPING COSTS: TOTAL MONTHLY CASH EXPENSES IN WATER

\begin{tabular}{|c|c|c|c|c|c|c|c|}
\hline & $(1)$ & $(2)$ & $(3)$ & $(4)$ & $(5)$ & $(6)$ & $(7)$ \\
\hline & DID & DID-FE & $\begin{array}{l}\text { DID- } \\
\text { Pairs }\end{array}$ & $\begin{array}{l}\text { RF-Area- } \\
\text { ITT }\end{array}$ & 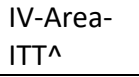 & RF-ATE & IV-LATE^^ \\
\hline \multirow[t]{2}{*}{ Treatment \# Post Period } & 1.85 & 1.87 & 1.87 & & & & \\
\hline & {$[0.72]^{* *}$} & {$[0.72]^{* * *}$} & {$[0.72]^{* *}$} & & & & \\
\hline \multirow{2}{*}{\multicolumn{2}{|c|}{ Inside Project Area \# Post Period }} & & & 2.25 & & & \\
\hline & & & & {$[0.64]^{* * *}$} & & & \\
\hline \multirow{2}{*}{\multicolumn{2}{|c|}{ Inside Project Area-ITT in Post Period }} & & & & 2.81 & & \\
\hline & & & & & {$[1.07]^{* * *}$} & & \\
\hline \multirow[t]{2}{*}{ Beneficiary \# Post Period } & & & & & & 2.32 & \\
\hline & & & & & & {$[0.66]^{* * *}$} & \\
\hline \multirow{2}{*}{\multicolumn{2}{|c|}{ Beneficiary-LATE in Post Period }} & & & & & & 3.49 \\
\hline & & & & & & & {$[1.28]^{* * *}$} \\
\hline Pairs Indicators & NO & NO & YES & YES & NO & YES & NO \\
\hline Mean of Comp. at Baseline & 9.75 & 9.75 & 9.75 & 9.37 & 9.37 & 9.39 & 9.39 \\
\hline SD of Comp. at Baseline & 12.3 & 12.3 & 12.3 & 12.1 & 12.1 & 12 & 12 \\
\hline Number of Clusters & 128 & 128 & 128 & 128 & 128 & 128 & 128 \\
\hline Observations & 9,325 & 9,325 & 9,325 & 9,208 & 9,208 & 9,208 & 9,208 \\
\hline K-P rk Wald F & & & & & 249.6 & & 129.9 \\
\hline
\end{tabular}

Standard errors in brackets

Std. errors are clustered at the census segment level.

All equations include year fixed effects. Equations are DID, in (1)-(3) the treatment is defined as living in a treatment assigned segment, (4)-(5) treatment is defined as living inside the project area within the matched pairs, (6)-(7) treatment is defined as having reported being beneficiary of the WASH project within the matched pairs. Equations (4)-(7) control for initial treatment assignment.

Equation (2) includes household fixed effects. Pair dummies indicated in the table are based in on nearest neighbor matching propensity score matching based on 2007 census segment data.

IV estimates in columns (5) and (7) use the census segment treatment assignment to instrument for indicators for being in a project area in 2012-2013 (5); and the households reporting being a beneficiary of the WASH projects from MCC in (7)

AIV estimates partial out the indicators for pairs to compute the std. errors of the coefficients of interest. We report the K-P rk Wald F statistic following the results in Stock and Yogo (2005)

$* \mathrm{p}<0.10, * * \mathrm{p}<0.05, * * * \mathrm{p}<0.01$

Table 78 and Table 79 shows the impacts on the expenses for different water sources. Parallel to the presentation of the water consumption impact, we present the result for the impacts conditional on having reported using the water source in any round of the survey. The results in Table 78 show that households in treatment segments did not spent significantly less on water from neighbors (panel A) but had a significant decrease in expenses for water from trucks (panel B). Expenses on water from trucks decreased by 4.47 USD per month in treatment segments relative to the comparison segments when we restrict the sample to households that reported using water from trucks in any round of the survey.

In addition, in Table 79 we can trace the increase in the total water monthly expense we saw before comes to increases in the water bill of households, be it a private tap (panel A) or when they share a tap with a neighbor (panel B). These figures confirm that the increase in total monthly expenses is due to households that previously did not have a household tap now pay a water bill or share the payment of a water bill, as expenditures on water from trucks or other sources decreased, as expected. The expense in private household taps increased by 2.64 USD per month after the WASH interventions in treatment segments relative to the comparison segments when we restrict the sample to households that reported using tap water in any round of the survey. 
TABLE 78 COPING COSTS: MONTHLY EXPENSES IN WATER FROM NEIGHBORS AND TRUCKS

\begin{tabular}{|c|c|c|c|c|c|c|c|}
\hline & $(1)$ & $(2)$ & (3) & $(4)$ & $(5)$ & $(6)$ & $(7)$ \\
\hline & DID & DID-FE & $\begin{array}{l}\text { DID- } \\
\text { Pairs }\end{array}$ & $\begin{array}{l}\text { RF-Area- } \\
\text { ITT }\end{array}$ & 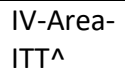 & RF-ATE & IV-LATE^ \\
\hline \multicolumn{8}{|l|}{ Panel A: Neighbor expense } \\
\hline \multirow[t]{2}{*}{ Treatment \# Post Period } & 0.21 & -0.51 & 0.093 & & & & \\
\hline & [1.19] & [1.66] & [1.43] & & & & \\
\hline \multirow[t]{2}{*}{ Inside Project Area \# Post Period } & & & & -0.12 & & & \\
\hline & & & & [1.31] & & & \\
\hline \multirow[t]{2}{*}{ Inside Project Area-ITT in Post Period } & & & & & 0.45 & & \\
\hline & & & & & [2.34] & & \\
\hline \multirow[t]{2}{*}{ Beneficiary \# Post Period } & & & & & & -1.43 & \\
\hline & & & & & & [1.27] & \\
\hline \multirow[t]{2}{*}{ Beneficiary-LATE in Post Period } & & & & & & & 0.61 \\
\hline & & & & & & & [5.27] \\
\hline Pairs Indicators & NO & NO & YES & YES & NO & YES & NO \\
\hline Mean of Comp. at Baseline & 2.59 & 2.59 & 2.59 & 2.64 & 2.64 & 2.53 & 2.53 \\
\hline SD of Comp. at Baseline & 6.88 & 6.88 & 6.88 & 7.55 & 7.55 & 7.11 & 7.11 \\
\hline Number of Clusters & 85 & 85 & 85 & 84 & 84 & 84 & 84 \\
\hline Observations & 444 & 444 & 444 & 437 & 437 & 437 & 437 \\
\hline K-P rk Wald F & & & & & 22.2 & & 7.25 \\
\hline Panel B: Water Truck expense & & & & & & & \\
\hline \multirow[t]{2}{*}{ Treatment \# Post Period } & -4.47 & -4.43 & -4.47 & & & & \\
\hline & {$[1.70]^{* *}$} & {$[1.76]^{* *}$} & {$[1.77]^{* *}$} & & & & \\
\hline \multirow[t]{2}{*}{ Inside Project Area \# Post Period } & & & & -4.66 & & & \\
\hline & & & & {$[1.67]^{* * *}$} & & & \\
\hline \multirow[t]{2}{*}{ Inside Project Area-ITT in Post Period } & & & & & -5.17 & & \\
\hline & & & & & {$[2.17]^{* *}$} & & \\
\hline \multirow[t]{2}{*}{ Beneficiary \# Post Period } & & & & & & -6.79 & \\
\hline & & & & & & {$[1.93]^{* * *}$} & \\
\hline \multirow[t]{2}{*}{ Beneficiary-LATE in Post Period } & & & & & & & -5.79 \\
\hline & & & & & & & {$[2.43]^{* *}$} \\
\hline Pairs Indicators & NO & NO & YES & YES & NO & YES & NO \\
\hline Mean of Comp. at Baseline & 8.88 & 8.88 & 8.88 & 9.03 & 9.03 & 8.65 & 8.65 \\
\hline SD of Comp. at Baseline & 15.4 & 15.4 & 15.4 & 15.1 & 15.1 & 14.7 & 14.7 \\
\hline Number of Clusters & 80 & 80 & 80 & 80 & 80 & 80 & 80 \\
\hline Observations & 915 & 915 & 915 & 902 & 902 & 902 & 902 \\
\hline K-P rk Wald F & & & & & 72.8 & & 81.9 \\
\hline
\end{tabular}

Standard errors in brackets

Std. errors are clustered at the census segment level.

All equations include year fixed effects. Equations are DID, in (1)-(3) the treatment is defined as living in a treatment assigned segment,

(4)-(5) treatment is defined as living inside the project area within the matched pairs, (6)-(7) treatment is defined as having reported being beneficiary of the WASH project within the matched pairs. Equations (4)-(7) control for initial treatment assignment.

Equation (2) includes household fixed effects. Pair dummies indicated in the table are based in on nearest neighbor matching propensity score matching based on 2007 census segment data.

IV estimates in columns (5) and (7) use the census segment treatment assignment to instrument for indicators for being in a project area in 2012-2013 (5); and the households reporting being a beneficiary of the WASH projects from MCC in (7)

^IV estimates partial out the indicators for pairs to compute the std. errors of the coefficients of interest. We report the K-P rk Wald $F$ statistic following the results in Stock and Yogo (2005)

${ }^{*} \mathrm{p}<0.10,{ }^{* *} \mathrm{p}<0.05, * * * \mathrm{p}<0.01$ 
TABLE 79 COPING COSTS: MONTHLY EXPENSE IN TAPS

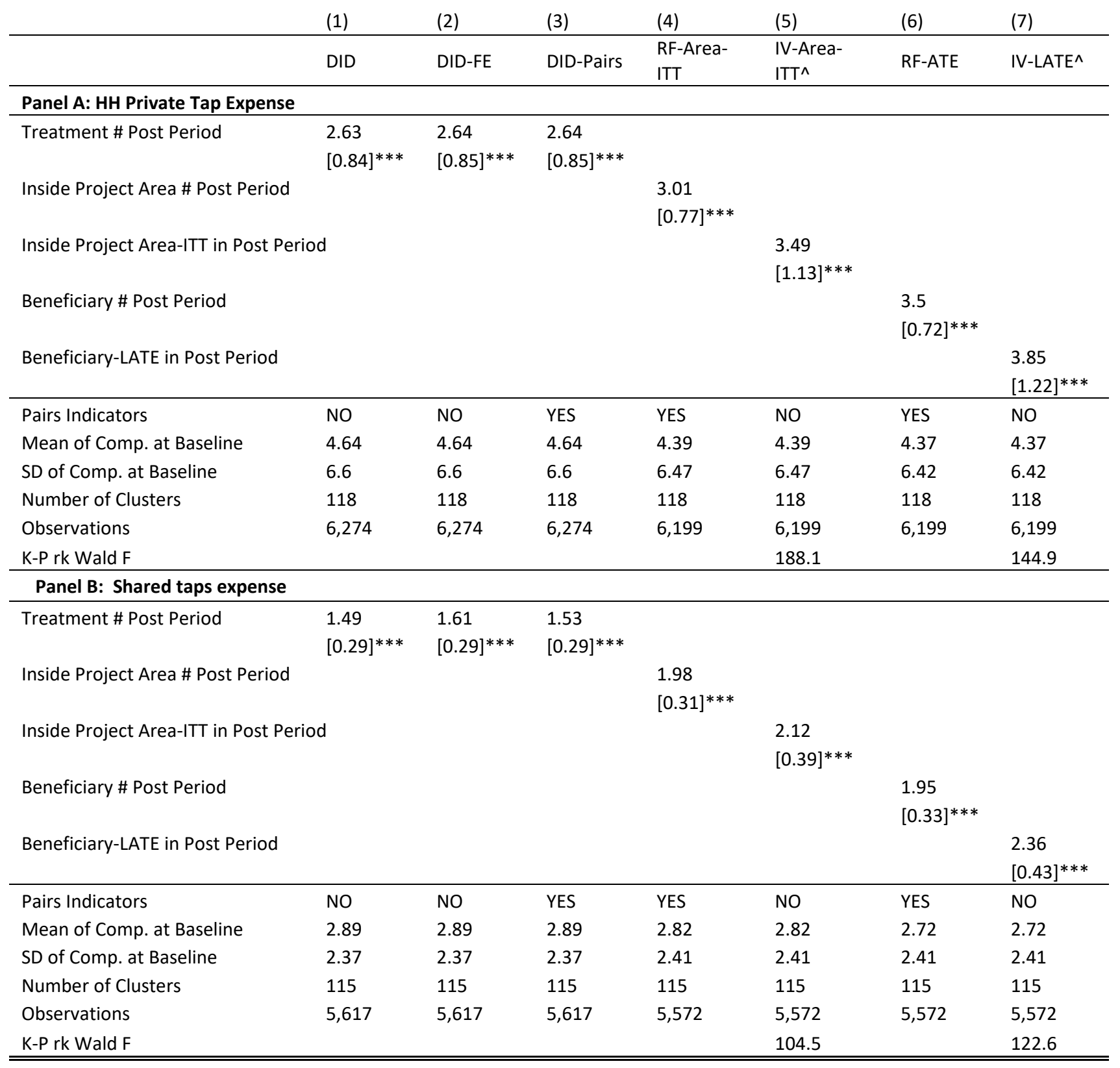

Standard errors in brackets

Std. errors are clustered at the census segment level.

All equations include year fixed effects. Equations are DID, in (1)-(3) the treatment is defined as living in a treatment assigned segment, (4)-(5) treatment is defined as living inside the project area within the matched pairs, (6)-(7) treatment is defined as having reported being beneficiary of the WASH project within the matched pairs. Equations (4)-(7) control for initial treatment assignment.

Equation (2) includes household fixed effects. Pair dummies indicated in the table are based in on nearest neighbor matching propensity score matching based on 2007 census segment data.

IV estimates in columns (5) and (7) use the census segment treatment assignment to instrument for indicators for being in a project area in 20122013 (5); and the households reporting being a beneficiary of the WASH projects from MCC in (7)

^IV estimates partial out the indicators for pairs to compute the std. errors of the coefficients of interest. We report the K-P rk Wald $\mathrm{F}$ statistic

following the results in Stock and Yogo (2005)

$* p<0.10, * * p<0.05, * * * p<0.01$ 
Other costs that households face due to the lack of access to potable water sources are costs in the treatment of water, for example in chlorine and filters to make the water appropriate for human consumption. Table 80 shows the impact on these coping costs. We find decreases in expenses in chlorine but these are not precisely estimated across specifications and no significant effects in expenses in filters. This is to be expected, as chlorine is usually supplied for free by health posts and filters are not likely to be replaced annually, especially artisanal filters. ${ }^{46}$

${ }^{46}$ In regressions not reported, we found no significant effects in the expenses on poliduct systems, hoses, and wells. This is expected, since these systems were slow to depreciate and, once the household incurred in the fixed cost to put it in place, there were few costs related to their operation. 
TABLE 80 COPING COSTS: CHEMICALS AND FILTERS

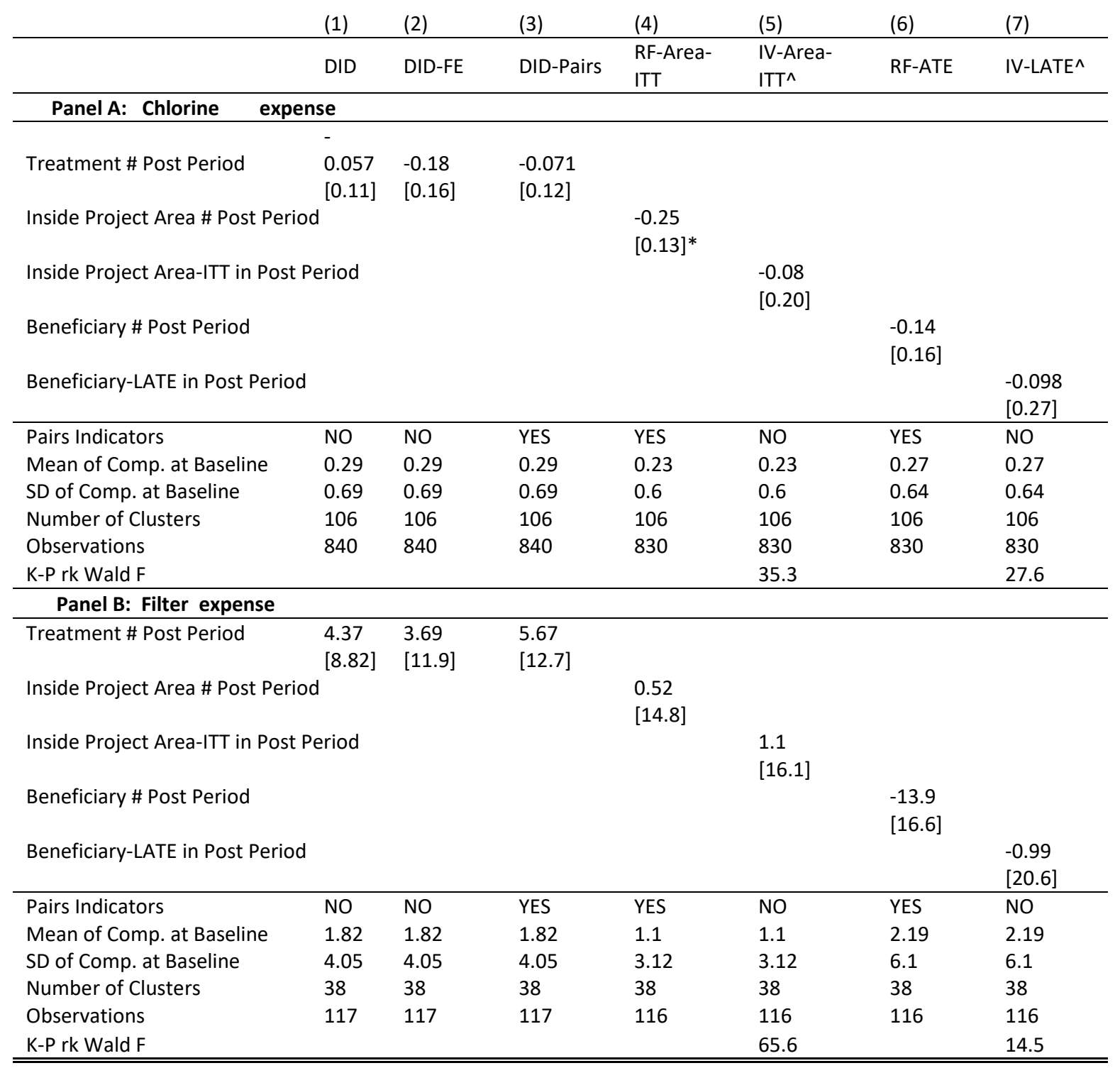

Standard errors in brackets

Std. errors are clustered at the census segment level.

All equations include year fixed effects. Equations are DID, in (1)-(3) the treatment is defined as living in a treatment assigned segment, (4)-(5) treatment is defined as living inside the project area within the matched pairs, (6)-(7) treatment is defined as having reported being beneficiary of the WASH project within the matched pairs. Equations (4)-(7) control for initial treatment assignment.

Equation (2) includes household fixed effects. Pair dummies indicated in the table are based in on nearest neighbor matching propensity score matching based on 2007 census segment data.

IV estimates in columns (5) and (7) use the census segment treatment assignment to instrument for indicators for being in a project area in 2012-2013 (5); and the households reporting being a beneficiary of the WASH projects from MCC in (7)

IIV estimates partial out the indicators for pairs to compute the std. errors of the coefficients of interest. We report the K-P rk Wald F statistic following the results in Stock and Yogo (2005)

$* p<0.10, * * p<0.05, * * * p<0.01$ 


\section{Socioeconomic Status and Gender Heterogeneity in Coping ExPENSES}

We explore the impact of gender and social status on increases in expenses for water. Figure 31 presents the impact estimates for the sample of female-headed households and for male-headed households and Figure 32 for each quintile. Figure 31 indicates an increase in total water expenditure of 2.52 USD per month in maleheaded households compared to 1.56 USD per month in female-headed households (only significant at the 10 percent confidence level). This is consistent with female-headed households being more aware of the cost and having lower incomes than male-headed households, as found in the baseline. In addition, these differences in impact are not statistically different from one another as shown by the triple difference estimate.

FIGURE 31 GENDER HETEROGENEITY IN COPING COSTS: TOTAL EXPENSES ON WATER

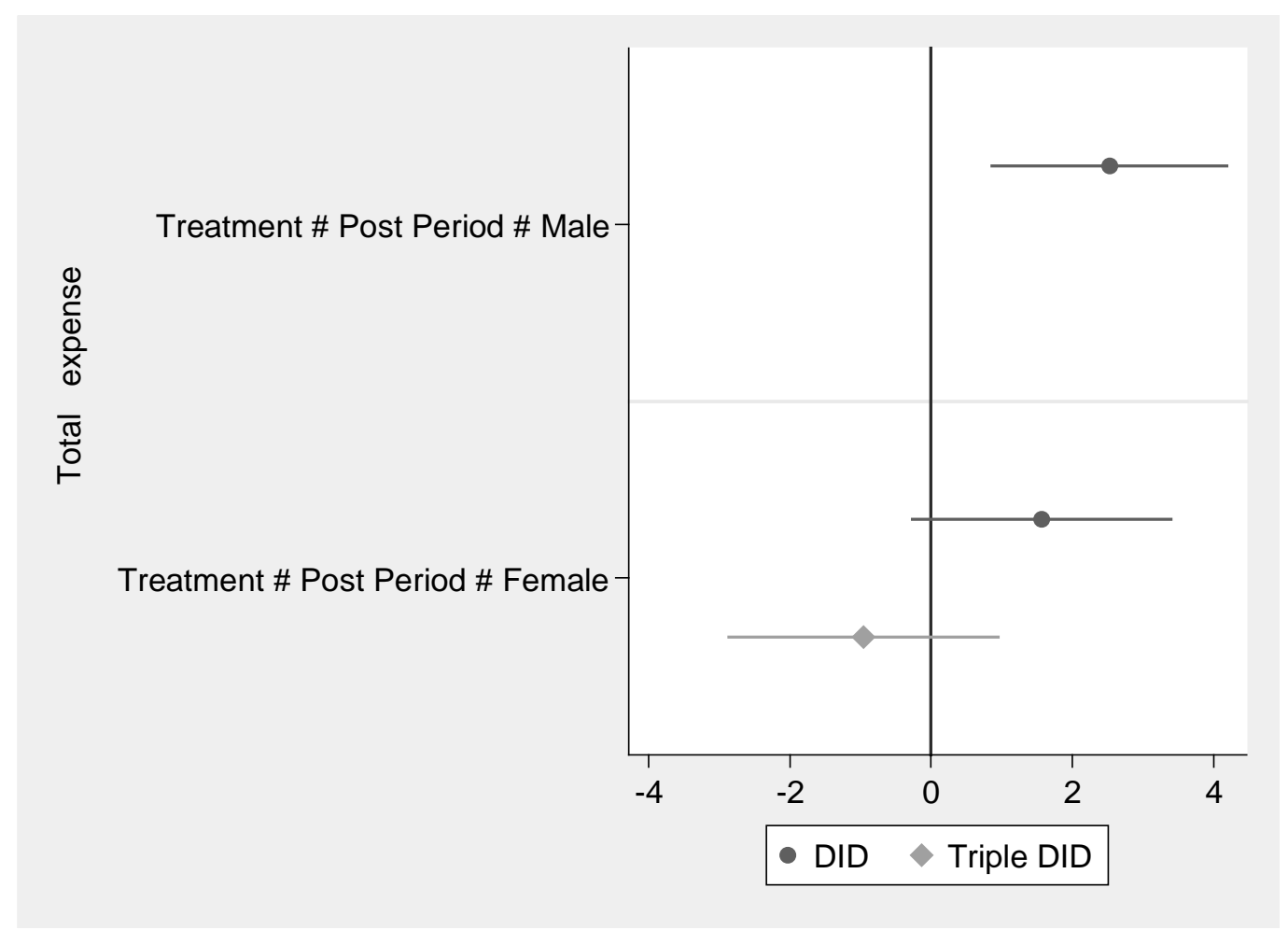

To measure impacts by socio-economic status, Figure 32 shows that the increases in water expenses for each quintile. The increase in monthly water expenses was similar across groups, but seems to be progressive; with the poor experiencing lower increases in monthly expense. Namely, with the second quintile having no significant increase in monthly expenditures. 


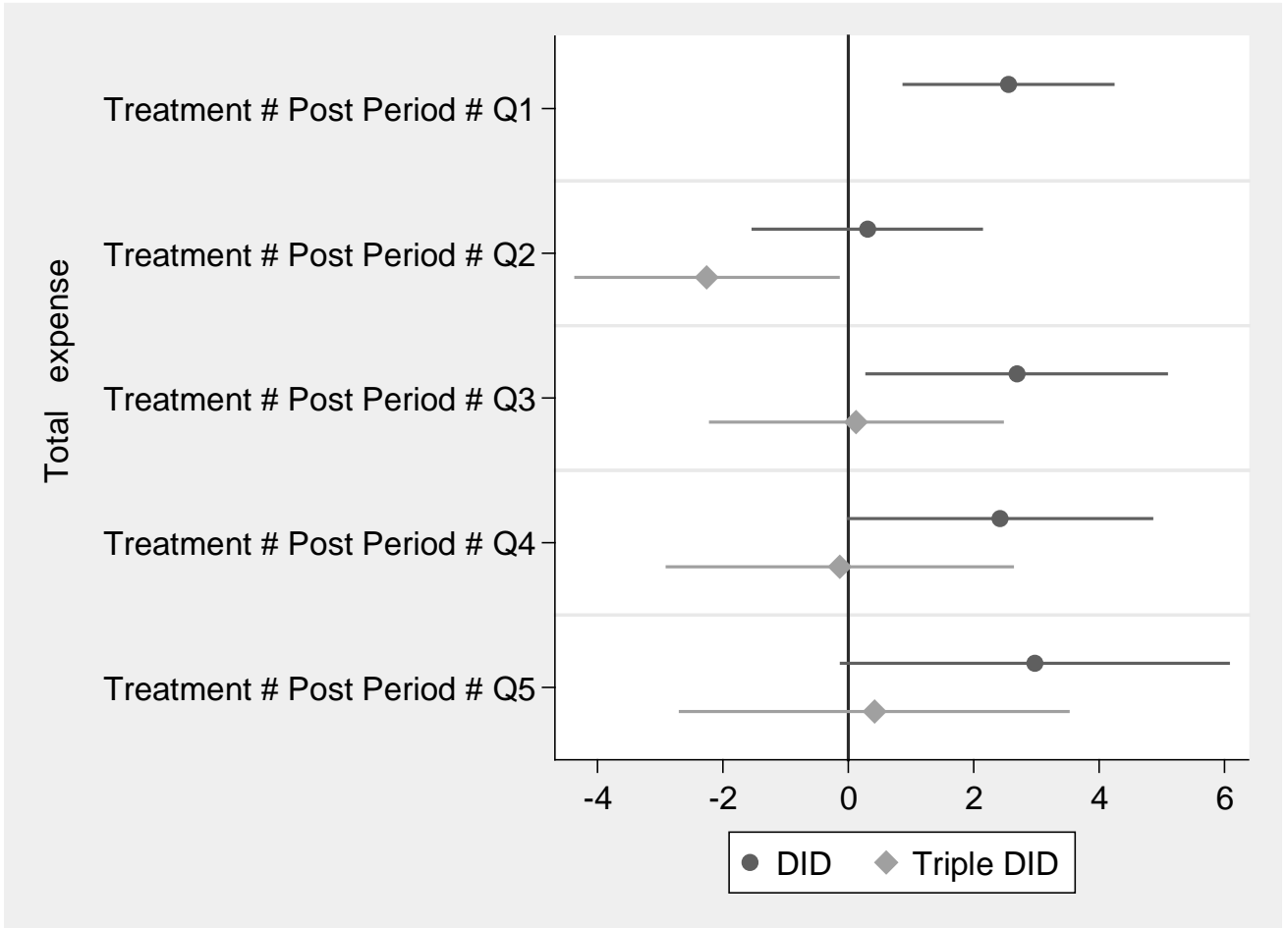

\section{Household Time Coping Costs}

One of the most important outcomes for WASH impact evaluations is time spent fetching or carrying water and doing laundry outside of the home. This section reports the time savings that the WASH interventions generated among treatment households and examines how these time savings are distributed within the household, by age and gender.

First we estimated impacts on the extensive margin, namely the change in the probability of a household having to carry water and/or doing laundry outside. Then, to explore better the variability in the data, we estimated the impact on the number of people that participated in these activities. On the probability of having to carry water in the week before the survey, in panel A, Table 81 estimates show that households living in treatment segments were 20 percent less likely to carry water from outside the home and up to 34 percentage points less likely when the household directly reports having been a beneficiary of the WASH interventions. In panel B, we modeled the number of people and find that households living in treatment segments had fewer people participating in these activities. These results together imply that households living in treatment segments almost completely stop having to carry water from outside the household when compared to comparison means at the bottom of the panel. 
TABLE 81 HOUSEHOLD TIME COPING COSTS: PROBABILITY AND NUMBER CARRYING WATER FROM OUTSIDE

\begin{tabular}{|c|c|c|c|c|c|c|c|}
\hline & (1) & $(2)$ & (3) & (4) & (5) & (6) & (7) \\
\hline & DID & DID-FE & $\begin{array}{l}\text { DID- } \\
\text { Pairs }\end{array}$ & $\begin{array}{l}\text { RF- } \\
\text { Area-ITT }\end{array}$ & 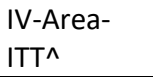 & $\begin{array}{l}\text { RF- } \\
\text { ATE }\end{array}$ & IV-LATE^ \\
\hline \multicolumn{8}{|c|}{ Panel A: Probability of household carries water from outside sources } \\
\hline Treatment \# Post Period & $\begin{array}{l}-0.2 \\
{[0.033]^{* * *}}\end{array}$ & $\begin{array}{l}-0.2 \\
{[0.033]^{* * *}}\end{array}$ & $\begin{array}{l}-0.2 \\
{[0.033]^{*}}\end{array}$ & ** & & & \\
\hline Inside Project Area \# Post Period & & & & $\begin{array}{l}-0.22 \\
{[0.039]^{* * *}}\end{array}$ & & & \\
\hline Inside Project Area-ITT in Post Period & & & & & $\begin{array}{l}-0.29 \\
{[0.050]^{* * *}}\end{array}$ & & \\
\hline Beneficiary \# Post Period & & & & & & $\begin{array}{l}-0.28 \\
{[0.042]^{*}}\end{array}$ & \\
\hline Beneficiary-LATE in Post Period & & & & & & & $\begin{array}{l}-0.34 \\
{[0.056]^{* * *}}\end{array}$ \\
\hline Pairs Indicators & NO & NO & YES & YES & NO & YES & NO \\
\hline Mean of Comp. at Baseline & 0.27 & 0.27 & 0.27 & 0.28 & 0.28 & 0.28 & 0.28 \\
\hline SD of Comp. at Baseline & 0.44 & 0.44 & 0.44 & 0.45 & 0.45 & 0.45 & 0.45 \\
\hline Number of Clusters & 128 & 128 & 128 & 128 & 128 & 128 & 128 \\
\hline Observations & 9,325 & 9,325 & 9,325 & 9,208 & 9,208 & 9,208 & 9,208 \\
\hline K-P rk Wald F & & & & & 249.6 & & 129.9 \\
\hline
\end{tabular}

Panel B: Last 7 days, number of members of the $\mathrm{HH}$ carried water from outside of the house?

Treatment \# Post Period
Inside Project Area \# Post Period
Inside Project Area-ITT in Post Period
Beneficiary \# Post Period
Beneficiary-LATE in Post Period

$\begin{array}{lll}-0.36 & -0.36 & -0.36 \\ {[0.065]^{* * *}} & {[0.065]^{* * *}} & {[0.065]^{* * *}} \\ & & \end{array}$

$\begin{array}{lll}-0.36 & -0.36 & -0.36 \\ {[0.065]^{* * *}} & {[0.065]^{* * *}} & {[0.065]^{* * *}}\end{array}$

$-0.45$

$[0.074]^{* * *}$ $-0.53$

$[0.096]^{* * *}$

$-0.55$

$[0.085]^{* * *}$

Beneficiary-LATE in Post Period

\begin{tabular}{|c|c|c|c|c|c|c|c|}
\hline & & & & & & & {$[0.11]^{* * *}$} \\
\hline Pairs Indicators & NO & NO & YES & YES & NO & YES & NO \\
\hline Mean of Comp. at Baseline & 0.48 & 0.48 & 0.48 & 0.49 & 0.49 & 0.49 & 0.49 \\
\hline SD of Comp. at Baseline & 1.01 & 1.01 & 1.01 & 1 & 1 & 1 & 1 \\
\hline Number of Clusters & 128 & 128 & 128 & 128 & 128 & 128 & 128 \\
\hline Observations & 9,325 & 9,325 & 9,325 & 9,208 & 9,208 & 9,208 & 9,208 \\
\hline K-P rk Wald F & & & & & 249.6 & & 129.9 \\
\hline
\end{tabular}

Standard errors in brackets

Std. errors are clustered at the census segment level.

All equations include year fixed effects. Equations are DID, in (1)-(3) the treatment is defined as living in a treatment assigned segment, (4)-(5) treatment is defined as living inside the project area within the matched pairs, (6)-(7) treatment is defined as having reported being beneficiary of the WASH project within the matched pairs. Equations (4)-(7) control for initial treatment assignment.

Equation (2) includes household fixed effects. Pair dummies indicated in the table are based in on nearest neighbor matching propensity score matching based on 2007 census segment data.

IV estimates in columns (5) and (7) use the census segment treatment assignment to instrument for indicators for being in a project area in 2012-2013 (5); and the households reporting being a beneficiary of the WASH projects from MCC in (7)

NIV estimates partial out the indicators for pairs to compute the std. errors of the coefficients of interest. We report the K-P rk Wald $\mathrm{F}$ statistic following the results in Stock and Yogo (2005)

${ }^{*} \mathrm{p}<0.10,{ }^{* *} \mathrm{p}<0.05,{ }^{* * *} \mathrm{p}<0.01$ 
Table 82 show the impact of the on the probability of doing laundry outside the home and the number of people that participate. We find similarly significant impacts as with the carrying water indicators; with households living in treatment segments being 13 percentage points less likely to do laundry outside and 22 percentage points more less likely among households that report being beneficiaries of the WASH projects.

TABLE 82 HOUSEHOLD TIME COPING COSTS: PROBABILITY AND NUMBER DOING LAUNDRY OUTSIDE

\begin{tabular}{|c|c|c|c|c|c|c|c|}
\hline & $(1)$ & $(2)$ & (3) & $(4)$ & (5) & (6) & $(7)$ \\
\hline & DID & DID-FE & $\begin{array}{l}\text { DID- } \\
\text { Pairs }\end{array}$ & $\begin{array}{l}\text { RF- } \\
\text { Area- } \\
\text { ITT }\end{array}$ & $\begin{array}{l}\text { IV-Area- } \\
\text { ITT^ }^{\wedge}\end{array}$ & $\begin{array}{l}\text { RF- } \\
\text { ATE }\end{array}$ & IV-LATE^ \\
\hline \multicolumn{8}{|c|}{ Panel A: Probability of household does laundry outside the home } \\
\hline Treatment \# Post Period & $\begin{array}{l}-0.13 \\
{[0.024]^{* * *}}\end{array}$ & $\begin{array}{l}-0.13 \\
{[0.024]^{* * *}}\end{array}$ & $\begin{array}{l}-0.13 \\
{[0.024]^{* *}}\end{array}$ & & & & \\
\hline Inside Project Area \# Post Period & & & & $\begin{array}{l}-0.16 \\
{[0.028]^{* * *}}\end{array}$ & & & \\
\hline Inside Project Area-ITT in Post Period & & & & & $\begin{array}{l}-0.19 \\
{[0.036]^{* * *}}\end{array}$ & & \\
\hline Beneficiary \# Post Period & & & & & & $\begin{array}{l}-0.19 \\
{[0.031]^{*}}\end{array}$ & \\
\hline Beneficiary-LATE in Post Period & & & & & & & $\begin{array}{l}-0.22 \\
{[0.041]^{* * *}}\end{array}$ \\
\hline Pairs Indicators & NO & NO & YES & YES & NO & YES & NO \\
\hline Mean of Comp. at Baseline & 0.19 & 0.19 & 0.19 & 0.2 & 0.2 & 0.21 & 0.21 \\
\hline SD of Comp. at Baseline & 0.39 & 0.39 & 0.39 & 0.4 & 0.4 & 0.41 & 0.41 \\
\hline Number of Clusters & 128 & 128 & 128 & 128 & 128 & 128 & 128 \\
\hline Observations & 9,325 & 9,325 & 9,325 & 9,208 & 9,208 & 9,208 & 9,208 \\
\hline K-P rk Wald F & & & & & 249.6 & & 129.9 \\
\hline \multicolumn{8}{|c|}{ Panel B: Last 7 days, how many members of the HH done laundry outside of the house/backyard } \\
\hline Treatment \# Post Period & $\begin{array}{l}-0.18 \\
{[0.038]^{* * *}}\end{array}$ & $\begin{array}{l}-0.18 \\
{[0.038]^{* * *}}\end{array}$ & $\begin{array}{l}-0.18 \\
{[0.039]^{* *}}\end{array}$ & & & & \\
\hline Inside Project Area \# Post Period & & & & $\begin{array}{l}-0.25 \\
{[0.044]^{* * *}}\end{array}$ & & & \\
\hline Inside Project Area-ITT in Post Period & & & & & $\begin{array}{l}-0.27 \\
{[0.057]^{* * *}}\end{array}$ & & \\
\hline Beneficiary \# Post Period & & & & & & $\begin{array}{l}-0.29 \\
{[0.047]^{*}}\end{array}$ & \\
\hline Beneficiary-LATE in Post Period & & & & & & & $\begin{array}{l}-0.33 \\
{[0.065]^{* * *}}\end{array}$ \\
\hline Pairs Indicators & NO & NO & YES & YES & NO & YES & NO \\
\hline Mean of Comp. at Baseline & 0.29 & 0.29 & 0.29 & 0.3 & 0.3 & 0.3 & 0.3 \\
\hline SD of Comp. at Baseline & 0.7 & 0.7 & 0.7 & 0.7 & 0.7 & 0.7 & 0.7 \\
\hline Number of Clusters & 128 & 128 & 128 & 128 & 128 & 128 & 128 \\
\hline Observations & 9,325 & 9,325 & 9,325 & 9,208 & 9,208 & 9,208 & 9,208 \\
\hline K-P rk Wald F & & & & & 249.6 & & 129.9 \\
\hline
\end{tabular}

Standard errors in brackets

Std. errors are clustered at the census segment level.

All equations include year fixed effects. Equations are DID, in (1)-(3) the treatment is defined as living in a treatment assigned segment, (4)(5) treatment is defined as living inside the project area within the matched pairs, (6)-(7) treatment is defined as having reported being beneficiary of the WASH project within the matched pairs. Equations (4)-(7) control for initial treatment assignment.

Equation (2) includes household fixed effects. Pair dummies indicated in the table are based in on nearest neighbor matching propensity score matching based on 2007 census segment data.

IV estimates in columns (5) and (7) use the census segment treatment assignment to instrument for indicators for being in a project area in 2012-2013 (5); and the households reporting being a beneficiary of the WASH projects from MCC in (7)

IIV estimates partial out the indicators for pairs to compute the std. errors of the coefficients of interest. We report the K-P rk Wald $\mathrm{F}$ statistic following the results in Stock and Yogo (2005)

$* \mathrm{p}<0.10, * * \mathrm{p}<0.05, * * * \mathrm{p}<0.01$ 
To explore another extensive margin of the time coping costs, we calculated the number of person-hours per week that household members spent carrying water and doing laundry. The indicators are constructed by identifying the households that reported these activities in any round of the survey and by calculating the person-hours spent in the activity in each round. For example, if 3 household members carry water from outside the home 3 times per week in the baseline, this indicator would take the value of 9 person-hours/week for that household.

In principle, a household could increase the time spent in these activities if the availability of water projects is limited or if the household did not connect to the project. Table 83 shows the impact of the projects on the time spent carrying water for the complete sample in panel $A$ (households that do not participate are included with zeros) and for the sample that reported carrying water in any round of the survey in panel $\mathrm{B}$. The impact on time spent carrying water was a reduction of 1.3 person-hours per week for the full sample and 2.94 person-hours per week for the sample that reported participating in this activity in any round of the survey. For those households that directly report being beneficiaries of the WASH interventions the impact is 2.32 person-hours per week in the full sample and up to 5.23 person hours per week conditional on having reported to carry water in any year of the survey. 
TABLE 83 HOUSEHOLD TIME COPING COSTS: TIME SPENT CARRYING WATER FROM OUTSIDE (HOURS/WEEK)

\begin{tabular}{|c|c|c|c|c|c|c|c|}
\hline & $(1)$ & $(2)$ & (3) & (4) & $(5)$ & (6) & (7) \\
\hline & DID & DID-FE & $\begin{array}{l}\text { DID- } \\
\text { Pairs }\end{array}$ & $\begin{array}{l}\text { RF-Area- } \\
\text { ITT }\end{array}$ & 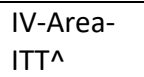 & $\begin{array}{l}\text { RF- } \\
\text { ATE }\end{array}$ & IV-LATE^ \\
\hline \multicolumn{8}{|c|}{ Panel A: Time spent carrying water, person- hrs/week } \\
\hline \multirow[t]{2}{*}{ Treatment \# Post Period } & -1.3 & -1.29 & -1.3 & & & & \\
\hline & {$[0.31]^{* * *}$} & {$[0.31]^{* * *}$} & {$[0.31]^{* * *}$} & & & & \\
\hline \multirow[t]{2}{*}{ Inside Project Area \# Post Period } & & & & -2.05 & & & \\
\hline & & & & {$[0.37]^{* * *}$} & & & \\
\hline \multirow[t]{2}{*}{ Inside Project Area-ITT in Post Period } & & & & & -1.95 & & \\
\hline & & & & & {$[0.45]^{* * *}$} & & \\
\hline \multirow[t]{2}{*}{ Beneficiary \# Post Period } & & & & & & -2.33 & \\
\hline & & & & & & {$[0.43]^{* * *}$} & \\
\hline \multirow[t]{2}{*}{ Beneficiary-LATE in Post Period } & & & & & & & -2.32 \\
\hline & & & & & & & {$[0.52]^{* * *}$} \\
\hline Pairs Indicators & NO & NO & YES & YES & NO & YES & NO \\
\hline Mean of Comp. at Baseline & 1.61 & 1.61 & 1.61 & 1.63 & 1.63 & 1.65 & 1.65 \\
\hline SD of Comp. at Baseline & 4.71 & 4.71 & 4.71 & 4.54 & 4.54 & 4.7 & 4.7 \\
\hline Number of Clusters & 128 & 128 & 128 & 128 & 128 & 128 & 128 \\
\hline Observations & 9,325 & 9,325 & 9,325 & 9,208 & 9,208 & 9,208 & 9,208 \\
\hline K-P rk Wald F & & & & & 249.6 & & 129.9 \\
\hline \multicolumn{8}{|c|}{ Panel B: Conditional - Time spent carrying water } \\
\hline \multirow[t]{2}{*}{ Treatment \# Post Period } & -2.95 & -2.94 & -2.94 & & & & \\
\hline & {$[0.65]^{* * *}$} & {$[0.66]^{* * *}$} & {$[0.66]^{* * *}$} & & & & \\
\hline \multirow[t]{2}{*}{ Inside Project Area \# Post Period } & & & & -4.64 & & & \\
\hline & & & & {$[0.74]^{* * *}$} & & & \\
\hline \multirow[t]{2}{*}{ Inside Project Area-ITT in Post Period } & & & & & -4.45 & & \\
\hline & & & & & {$[0.92]^{* * *}$} & & \\
\hline \multirow[t]{2}{*}{ Beneficiary \# Post Period } & & & & & & -5.27 & \\
\hline & & & & & & {$[0.80]^{* * *}$} & \\
\hline \multirow[t]{2}{*}{ Beneficiary-LATE in Post Period } & & & & & & & -5.26 \\
\hline & & & & & & & {$[1.03]^{* * *}$} \\
\hline Pairs Indicators & NO & NO & YES & YES & NO & YES & NO \\
\hline Mean of Comp. at Baseline & 4.08 & 4.08 & 4.08 & 4.13 & 4.13 & 4.15 & 4.15 \\
\hline SD of Comp. at Baseline & 6.8 & 6.8 & 6.8 & 6.48 & 6.48 & 6.72 & 6.72 \\
\hline Number of Clusters & 127 & 127 & 127 & 127 & 127 & 127 & 127 \\
\hline Observations & 3,859 & 3,859 & 3,859 & 3,803 & 3,803 & 3,803 & 3,803 \\
\hline K-P rk Wald F & & & & & 194.4 & & 98.7 \\
\hline
\end{tabular}

Standard errors in brackets

Std. errors are clustered at the census segment level.

All equations include year fixed effects. Equations are DID, in (1)-(3) the treatment is defined as living in a treatment assigned segment, (4)-(5) treatment is defined as living inside the project area within the matched pairs, (6)-(7) treatment is defined as having reported being beneficiary of the WASH project within the matched pairs. Equations (4)-(7) control for initial treatment assignment.

Equation (2) includes household fixed effects. Pair dummies indicated in the table are based in on nearest neighbor matching propensity score matching based on 2007 census segment data.

IV estimates in columns (5) and (7) use the census segment treatment assignment to instrument for indicators for being in a project area in 2012-2013 (5); and the households reporting being a beneficiary of the WASH projects from MCC in (7)

NIV estimates partial out the indicators for pairs to compute the std. errors of the coefficients of interest. We report the K-P rk Wald F statistic following the results in Stock and Yogo (2005)

${ }^{*} \mathrm{p}<0.10,{ }^{* *} \mathrm{p}<0.05,{ }^{* * *} \mathrm{p}<0.01$ 
For time spent doing laundry outside of the house, the impact was a reduction between 0.79 and 1.71 personhours per week in the full sample estimates and between 2.33 and 5.4 person-hours per week when we condition on having reported doing laundry outside of the home for at least one year in the panel.

TABLE 84 HOUSEHOLD TIME COPING COSTS: TIME SPENT DOING LAUNDRY OUTSIDE (HOURS/WEEK)

\begin{tabular}{|c|c|c|c|c|c|c|c|}
\hline & $(1)$ & $(2)$ & (3) & $(4)$ & (5) & (6) & (7) \\
\hline & DID & DID-FE & $\begin{array}{l}\text { DID- } \\
\text { Pairs }\end{array}$ & $\begin{array}{l}\text { RF-Area- } \\
\text { ITT }\end{array}$ & 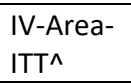 & RF-ATE & $\begin{array}{l}\text { IV- } \\
\text { LATE^ }\end{array}$ \\
\hline \multicolumn{8}{|c|}{ Panel A: Time spent doing laundry, person-hrs/week } \\
\hline Treatment \# Post Period & $\begin{array}{l}-0.81 \\
{[0.31]^{*}} \\
*\end{array}$ & $\begin{array}{l}-0.79 \\
{[0.31]^{*}} \\
*\end{array}$ & $\begin{array}{l}-0.81 \\
{[0.31]^{*}} \\
*\end{array}$ & & & & \\
\hline Inside Project Area \# Post Period & & & & $\begin{array}{l}-1.31 \\
{[0.34]^{* * *}}\end{array}$ & & & \\
\hline Inside Project Area-ITT in Post Period & & & & & $\begin{array}{l}-1.17 \\
{[0.46]^{* *}}\end{array}$ & & \\
\hline Beneficiary \# Post Period & & & & & & $\begin{array}{l}-1.71 \\
{[0.37]^{* * *}}\end{array}$ & \\
\hline Beneficiary-LATE in Post Period & & & & & & & $\begin{array}{l}-1.37 \\
{[0.56]^{*}} \\
*\end{array}$ \\
\hline Pairs Indicators & NO & NO & YES & YES & NO & YES & NO \\
\hline Mean of Comp. at Baseline & 2.04 & 2.04 & 2.04 & 2.01 & 2.01 & 2.01 & 2.01 \\
\hline SD of Comp. at Baseline & 6.66 & 6.66 & 6.66 & 6.43 & 6.43 & 6.29 & 6.29 \\
\hline Number of Clusters & 128 & 128 & 128 & 128 & 128 & 128 & 128 \\
\hline Observations & 9,325 & 9,325 & 9,325 & 9,208 & 9,208 & 9,208 & 9,208 \\
\hline K-P rk Wald F & & & & & 249.6 & & 129.9 \\
\hline \multicolumn{8}{|c|}{ Panel B: Conditional-Time spent doing laundry outside } \\
\hline Treatment \# Post Period & $\begin{array}{l}-2.33 \\
{[0.91]^{*}} \\
*\end{array}$ & $\begin{array}{l}-2.32 \\
{[0.91]^{*}} \\
*\end{array}$ & $\begin{array}{l}-2.33 \\
{[0.93]^{*}} \\
*\end{array}$ & & & & \\
\hline Inside Project Area \# Post Period & & & & $\begin{array}{l}-4 \\
{[0.95]^{* * *}}\end{array}$ & & & \\
\hline Inside Project Area-ITT in Post Period & & & & & $\begin{array}{l}-3.63 \\
{[1.40]^{* *}}\end{array}$ & & \\
\hline Beneficiary \# Post Period & & & & & & $\begin{array}{l}-5.4 \\
{[0.90]^{* * *}}\end{array}$ & \\
\hline Beneficiary-LATE in Post Period & & & & & & & $\begin{array}{l}-4.11 \\
{[1.62]^{*}} \\
*\end{array}$ \\
\hline Pairs Indicators & NO & NO & YES & YES & NO & YES & NO \\
\hline Mean of Comp. at Baseline & 6.71 & 6.71 & 6.71 & 6.41 & 6.41 & 6.36 & 6.36 \\
\hline SD of Comp. at Baseline & 10.7 & 10.7 & 10.7 & 10.2 & 10.2 & 9.87 & 9.87 \\
\hline Number of Clusters & 121 & 121 & 121 & 121 & 121 & 121 & 121 \\
\hline Observations & 2,969 & 2,969 & 2,969 & 2,935 & 2,935 & 2,935 & 2,935 \\
\hline K-P rk Wald F & & & & & 99.9 & & 96.3 \\
\hline
\end{tabular}

Standard errors in brackets

Std. errors are clustered at the census segment level.

All equations include year fixed effects. Equations are DID, in (1)-(3) the treatment is defined as living in a treatment assigned segment, (4)-(5) treatment is defined as living inside the project area within the matched pairs, (6)-(7) treatment is defined as having reported being beneficiary of the WASH project within the matched pairs. Equations (4)-(7) control for initial treatment assignment.

Equation (2) includes household fixed effects. Pair dummies indicated in the table are based in on nearest neighbor matching propensity score matching based on 2007 census segment data.

IV estimates in columns (5) and (7) use the census segment treatment assignment to instrument for indicators for being in a project area in 2012-2013 (5); and the households reporting being a beneficiary of the WASH projects from MCC in (7)

^IV estimates partial out the indicators for pairs to compute the std. errors of the coefficients of interest. We report the K-P rk Wald $\mathrm{F}$ statistic following the results in Stock and Yogo (2005)

${ }^{*} \mathrm{p}<0.10,{ }^{* *} \mathrm{p}<0.05, * * * \mathrm{p}<0.01$ 


\section{Individual Time Coping Costs: Age, Gender and Socio-economic Heterogeneity}

Given these important reductions in time coping costs, we used individual-level data to separate the effects on the intensive margin and the extensive margin by age groups and gender. The intensive margin refers to the individual probability of participating in these activities. The impact of the WASH interventions on the probability that an individual carries water was a reduction of 6.9 percentage points on average, and with a reduction of 8.5 percentage points in the female sample as opposed to 5.6 percentage points in the male sample, as shown in panel A of Table 85. In Figure 33, we present the ITT estimates for different age groups and differentiated by gender. On the extensive margin, the figure indicates that the effects are larger in the middle of the age distribution, with the largest reduction in the probability of carrying water among the 13-18 and 19-25 age groups of over 10 percentage points for these groups. The figure also shows that differences within age groups across gender are not significantly different from each other; that is, the effects among males and females of similar age are similar.

Figure 34 shows the impacts on the time spent carrying water (conditional on having reported carrying water at any point during the study period) across age groups and gender. On average, individuals saved 1.41 hours per week carrying water thanks to the WASH interventions and up to 2.75 for households that report being direct beneficiaries of the WASH interventions, as shown in panel B of Table 85. Figure 34 shows that the impacts on time spent carrying water are similar across age groups above age 12 and across gender, consistent with the decreases in probability we saw previously. In addition, we note that the estimates are significant for females in older cohorts; which is not the case for older males. 
TABLE 85 GENDER TIME COPING COSTS: INDIVIDUAL PROBABILITY OF CARRYING WATER AND HOURS PER WEEK SPENT

\begin{tabular}{|c|c|c|c|c|c|}
\hline & $(1)$ & $(2)$ & (3) & (4) & (5) \\
\hline & DID & DID-FE & $\begin{array}{l}\text { DID- } \\
\text { Pairs }\end{array}$ & RF-Area-ITT & RF-ATE \\
\hline \multicolumn{6}{|c|}{ Panel A: Heterogeneity by Gender: Individual probability of carrying water } \\
\hline \multirow[t]{2}{*}{ Treatment \# Post Period \# Male } & -0.063 & -0.062 & -0.056 & & \\
\hline & {$[0.016]^{* * *}$} & {$[0.017]^{* * *}$} & {$[0.016]^{* * *}$} & & \\
\hline \multirow[t]{2}{*}{ Treatment \# Post Period \# Female } & -0.097 & -0.097 & -0.085 & & \\
\hline & {$[0.017]^{* * *}$} & {$[0.017]^{* * *}$} & {$[0.016]^{* * *}$} & & \\
\hline \multirow[t]{2}{*}{ Inside Project Area \# Post Period \# Male } & & & & -0.072 & \\
\hline & & & & {$[0.018]^{* * *}$} & \\
\hline \multirow[t]{2}{*}{ Inside Project Area \# Post Period \# Female } & & & & -0.11 & \\
\hline & & & & {$[0.018]^{* * *}$} & \\
\hline \multirow[t]{2}{*}{ Beneficiary \# Post Period \# Male } & & & & & -0.091 \\
\hline & & & & & {$[0.020]^{* * *}$} \\
\hline \multirow[t]{2}{*}{ Beneficiary \# Post Period \# Female } & & & & & -0.12 \\
\hline & & & & & {$[0.019]^{* * *}$} \\
\hline Pairs Indicators & NO & NO & YES & YES & YES \\
\hline Mean of Comp. at Baseline & 0.11 & 0.11 & 0.1 & 0.11 & 0.11 \\
\hline SD of Comp. at Baseline & 0.31 & 0.31 & 0.31 & 0.31 & 0.31 \\
\hline Number of Clusters & 128 & 128 & 122 & 122 & 122 \\
\hline Observations & 43,784 & 43,784 & 41,678 & 41,223 & 41,223 \\
\hline \multicolumn{6}{|c|}{ Panel B: Heterogeneity by Gender: Conditional -Time spent carrying water } \\
\hline \multirow[t]{2}{*}{ Treatment \# Post Period \# Male } & -1.36 & -1.37 & -1.42 & & \\
\hline & {$[0.36]^{* * *}$} & {$[0.40]^{* * *}$} & {$[0.38]^{* * *}$} & & \\
\hline \multirow[t]{2}{*}{ Treatment \# Post Period \# Female } & -1.47 & -1.41 & -1.39 & & \\
\hline & {$[0.36]^{* * *}$} & {$[0.40]^{* * *}$} & {$[0.39]^{* * *}$} & & \\
\hline \multirow[t]{2}{*}{ Inside Project Area \# Post Period \# Male } & & & & -2.21 & \\
\hline & & & & {$[0.45]^{* * *}$} & \\
\hline \multirow[t]{2}{*}{ Inside Project Area \# Post Period \# Female } & & & & -2.43 & \\
\hline & & & & {$[0.44]^{* * *}$} & \\
\hline \multirow[t]{2}{*}{ Beneficiary \# Post Period \# Male } & & & & & -2.56 \\
\hline & & & & & {$[0.50]^{* * *}$} \\
\hline \multirow[t]{2}{*}{ Beneficiary \# Post Period \# Female } & & & & & -2.82 \\
\hline & & & & & {$[0.48]^{* * *}$} \\
\hline Pairs Indicators & NO & NO & YES & YES & YES \\
\hline Mean of Comp. at Baseline & 1.79 & 1.79 & 1.7 & 1.7 & 1.74 \\
\hline SD of Comp. at Baseline & 3 & 3 & 2.88 & 2.82 & 2.91 \\
\hline Number of Clusters & 127 & 127 & 121 & 121 & 121 \\
\hline Observations & 8,543 & 8,543 & 7,880 & 7,784 & 7,784 \\
\hline
\end{tabular}

Standard errors in brackets

Std. errors are clustered at the census segment level.

All equations include year fixed effects. Equations are DID, in (1)-(3) the treatment is defined as living in a treatment assigned segment, (4) treatment is defined as living inside the project area within the matched pairs, (5) treatment is defined as having reported being beneficiary of the WASH project within the matched pairs. Equations (4)-(5) control for initial treatment assignment. Equation (2) includes household fixed effects. Pair dummies indicated in the table are based in on nearest neighbor matching propensity score matching based on 2007 census segment data.

Impact estimates represent the DID estimates for each gender.

${ }^{*} \mathrm{p}<0.10,{ }^{* *} \mathrm{p}<0.05, * * * \mathrm{p}<0.01$ 
FIGURE 33 INDIVIDUAL TIME COPING COSTS: PROBABILITY OF CARRYING WATER BY AGE AND GENDER

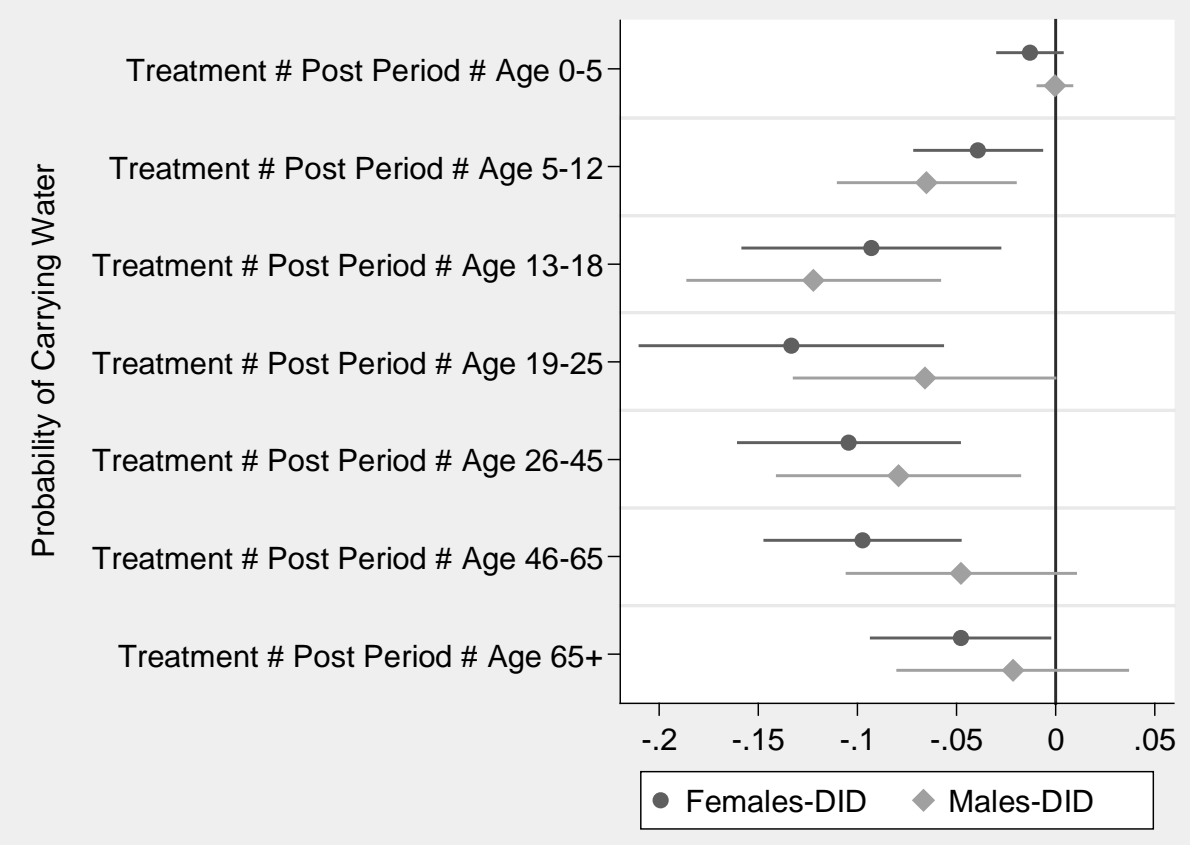

FIGURE 34 INDIVIDUAL TIME COPING COSTS: TIME SPENT CARRYING WATER BY AGE AND GENDER

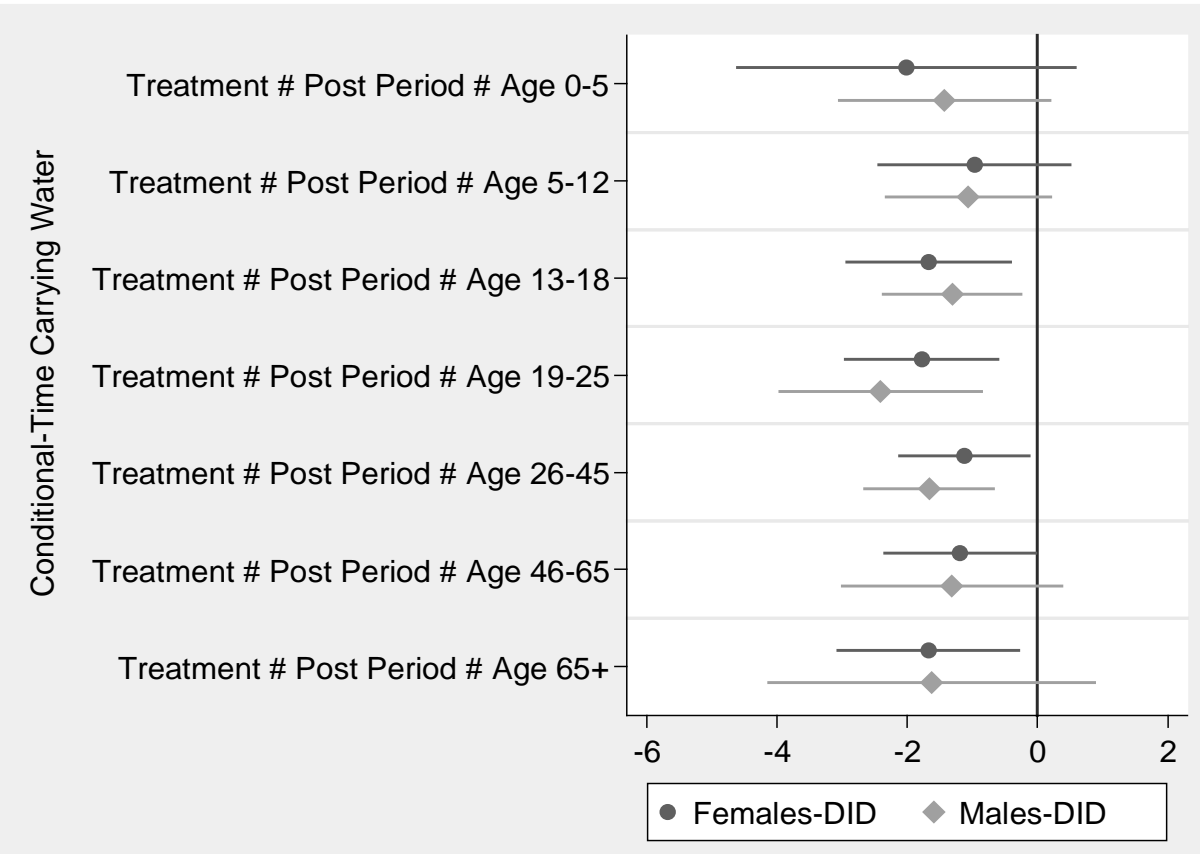


The effects on the time coping cost associated with doing laundry outside the home are presented in Table 86. Panel A shows that the effects are of different order between males and females; with the impact estimates for males being a decrease in 0.87 percentage points and 7.4 percentage points for females in the probability of doing laundry outside the home. In the case of the time spent doing this activity, panel B shows that the impacts for males are not significant and estimated as a decrease of 1.89 hours per week for females. The estimates across gender and age groups are presented in Figure 35 for the probability of doing laundry outside the home and for the time spent doing laundry outside in Figure 36. The decrease in the probability of doing laundry outside the house is markedly different from what we saw in the probability of carrying water. The effects are concentrated on individuals age 13 to 65; however, the effects are much larger and significant across the age distribution for females. For males, the estimates across age groups are below 5 percentage points when significant, while for females the estimates are above 10 percentage points for females age 13 to 45, as can be seen in Figure 35. The decrease in time spent doing laundry outside the home was on average 1.79 hours per week, and as seen in Figure 36, the effects are concentrated and significant for females age 13 to 65 . 
TABLE 86 GENDER TIME COPING COSTS: INDIVIDUAL PROBABILITY OF DOING LAUNDRY OUTSIDE AND HOURS PER WEEK

\begin{tabular}{|c|c|c|c|c|c|}
\hline & $(1)$ & $(2)$ & (3) & (4) & (5) \\
\hline & DID & DID-FE & DID-Pairs & RF-Area-ITT & RF-ATE \\
\hline \multicolumn{6}{|c|}{ Panel A: Heterogeneity by Gender: Individual Probability of doing Laundry outside } \\
\hline \multirow[t]{2}{*}{ Treatment \# Post Period \# Male } & -0.0094 & -0.0074 & -0.0087 & & \\
\hline & {$[0.0032]^{* * *}$} & {$[0.0036]^{* *}$} & {$[0.0033]^{* * *}$} & & \\
\hline \multirow[t]{2}{*}{ Treatment \# Post Period \# Female } & -0.077 & -0.076 & -0.074 & & \\
\hline & {$[0.016]^{* * *}$} & {$[0.017]^{* * *}$} & {$[0.017]^{* * *}$} & & \\
\hline \multirow[t]{2}{*}{ Inside Project Area \# Post Period \# Male } & & & & -0.0091 & \\
\hline & & & & {$[0.0036]^{* *}$} & \\
\hline \multirow[t]{2}{*}{ Inside Project Area \# Post Period \# Female } & & & & -0.098 & \\
\hline & & & & {$[0.019]^{* * *}$} & \\
\hline \multirow[t]{2}{*}{ Beneficiary \# Post Period \# Male } & & & & & -0.012 \\
\hline & & & & & {$[0.0036]^{* * *}$} \\
\hline \multirow[t]{2}{*}{ Beneficiary \# Post Period \# Female } & & & & & -0.11 \\
\hline & & & & & {$[0.021]^{* * *}$} \\
\hline Pairs Indicators & NO & NO & YES & YES & YES \\
\hline Mean of Comp. at Baseline & 0.064 & 0.064 & 0.061 & 0.062 & 0.064 \\
\hline SD of Comp. at Baseline & 0.25 & 0.25 & 0.24 & 0.24 & 0.24 \\
\hline Number of Clusters & 128 & 128 & 122 & 122 & 122 \\
\hline Observations & 43,784 & 43,784 & 41,678 & 41,223 & 41,223 \\
\hline \multicolumn{6}{|c|}{ Panel B: Heterogeneity by Gender: Conditional-Time spent doing laundry outside } \\
\hline \multirow[t]{2}{*}{ Treatment \# Post Period \# Male } & -1.32 & -1.22 & -1.47 & & \\
\hline & {$[0.81]$} & {$[0.95]$} & {$[0.90]$} & & \\
\hline \multirow[t]{2}{*}{ Treatment \# Post Period \# Female } & -1.48 & -1.54 & -1.89 & & \\
\hline & {$[0.58]^{* *}$} & {$[0.65]^{* *}$} & {$[0.58]^{* * *}$} & & \\
\hline \multirow[t]{2}{*}{ Inside Project Area \# Post Period \# Male } & & & & -2.08 & \\
\hline & & & & {$[1.15]^{*}$} & \\
\hline \multirow[t]{2}{*}{ Inside Project Area \# Post Period \# Female } & & & & -2.84 & \\
\hline & & & & {$[0.65]^{* * *}$} & \\
\hline \multirow[t]{2}{*}{ Beneficiary \# Post Period \# Male } & & & & & -3 \\
\hline & & & & & {$[1.30]^{* *}$} \\
\hline \multirow[t]{2}{*}{ Beneficiary \# Post Period \# Female } & & & & & -3.85 \\
\hline & & & & & {$[0.66]^{* * *}$} \\
\hline Pairs Indicators & NO & NO & YES & YES & YES \\
\hline Mean of Comp. at Baseline & 3.88 & 3.88 & 3.53 & 3.48 & 3.44 \\
\hline SD of Comp. at Baseline & 5.47 & 5.47 & 5.07 & 5.08 & 4.96 \\
\hline Number of Clusters & 121 & 121 & 115 & 115 & 115 \\
\hline Observations & 5,091 & 5,091 & 4,611 & 4,569 & 4,569 \\
\hline
\end{tabular}

Standard errors in brackets

Std. errors are clustered at the census segment level.

All equations include year fixed effects. Equations are DID, in (1)-(3) the treatment is defined as living in a treatment assigned segment, (4) treatment is defined as living inside the project area within the matched pairs, (5) treatment is defined as having reported being beneficiary of the WASH project within the matched pairs. Equations (4)-(5) control for initial treatment assignment.

Equation (2) includes household fixed effects. Pair dummies indicated in the table are based in on nearest neighbor matching propensity score matching based on 2007 census segment data.

Impact estimates represent the DID estimates for each gender.

${ }^{*} \mathrm{p}<0.10,{ }^{*} \mathrm{p}<0.05, * * * \mathrm{p}<0.01$ 
FIGURE 35 INDIVIDUAL TIME COPING COSTS: PROBABILITY OF DOING LAUNDRY OUTSIDE WATER BY AGE AND GENDER

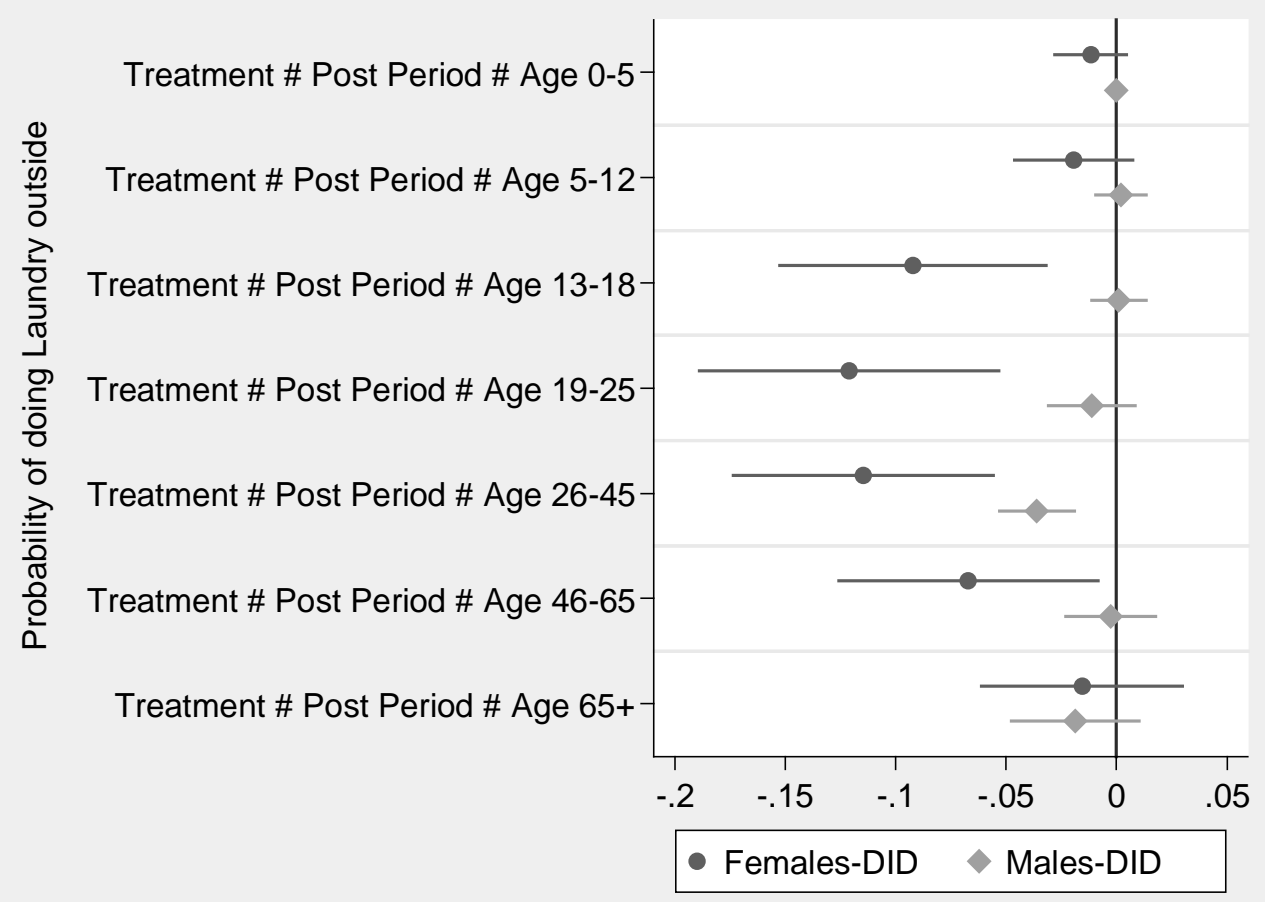

FIGURE 36 INDIVIDUAL TIME COPING COSTS: TIME SPENT CARRYING WATER BY AGE AND GENDER

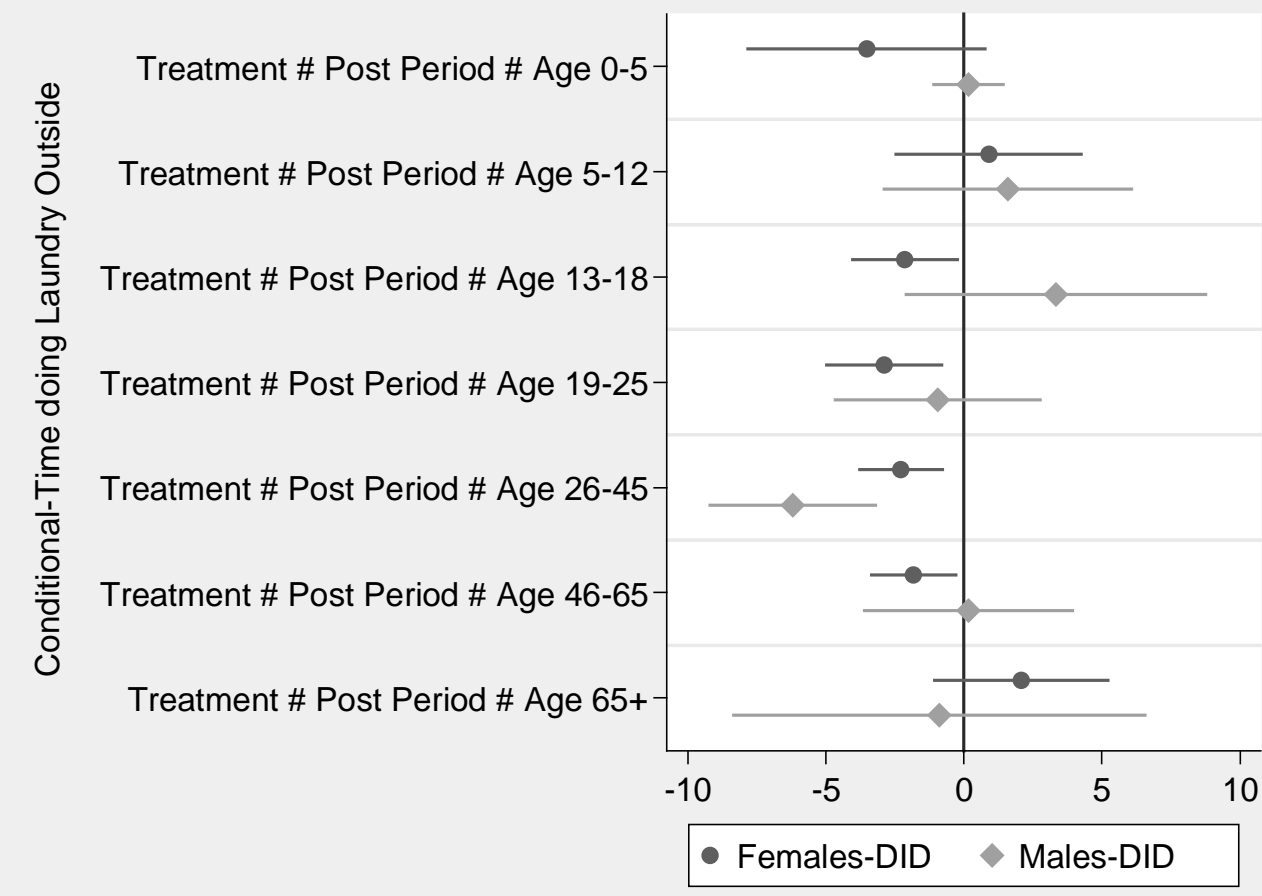


To explore heterogeneity across social economic status, we present the estimates by quintiles groups at baseline, as was done previously. We expected poor households to spend more time collecting water due to their lower opportunity cost of time and to have a lower demand for piped water services due to the constraints imposed by their lower level of resources. We find that the WASH interventions had similar impacts across quintiles in the probability and time spent by an individual having to carry water. The results on the time spent carrying water, in Figure 37, are consistent with variation in the opportunity cost of time across households: poorer households continued to carry water even when they were provided with a piped water connection, while non-poor households were more likely to stop carrying water all together.

The effects are somewhat larger for the bottom quintiles for the time spent doing laundry outside the home. These results are shown in Figure 38 for the time spent in this activity. Indeed, the figure shows that the effects are only significant for the first two quintiles.

FIGURE 37 INDIVIDUAL TIME COPING COSTS: TIME SPENT CARRYING WATER BY AGE

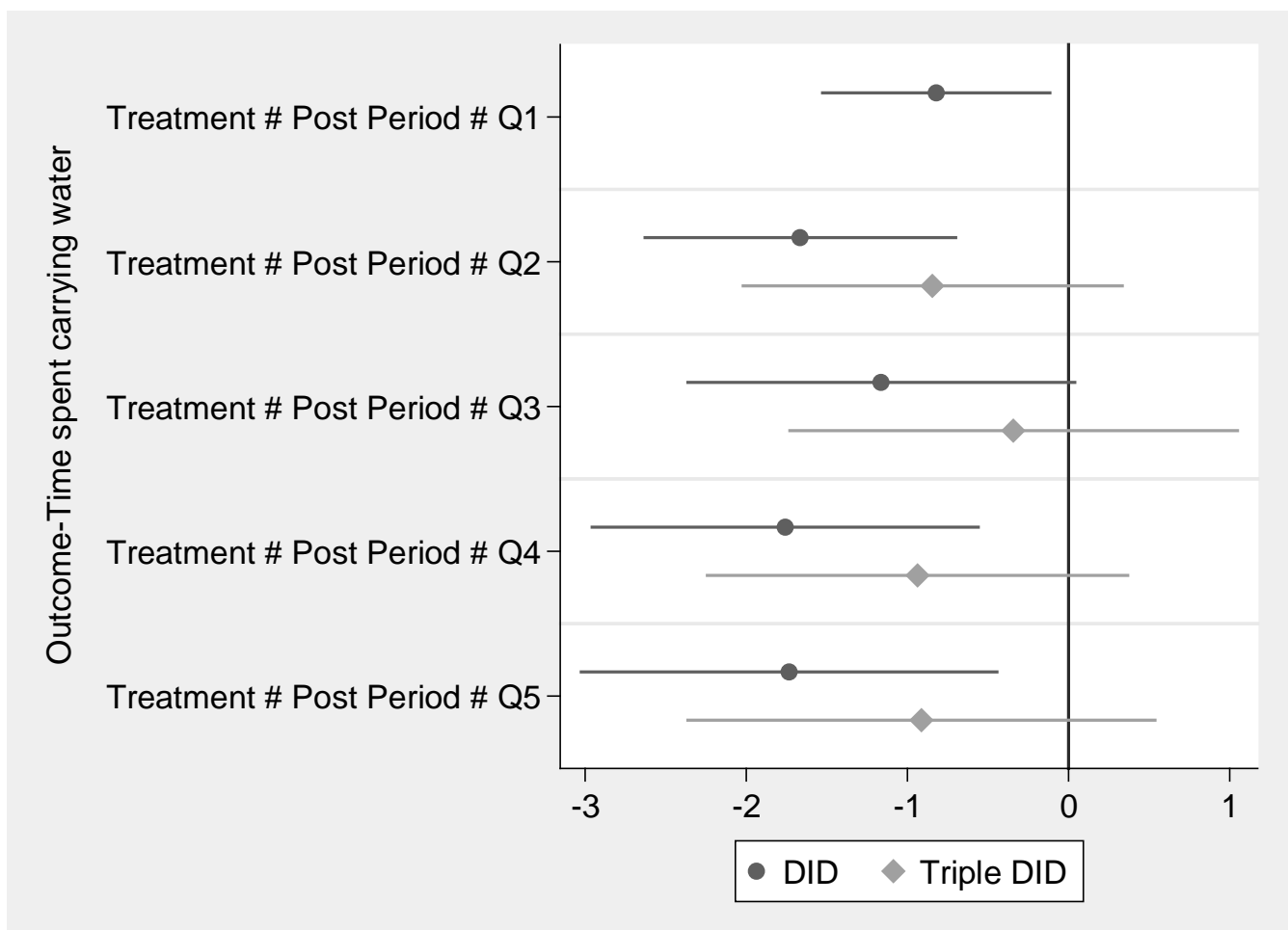




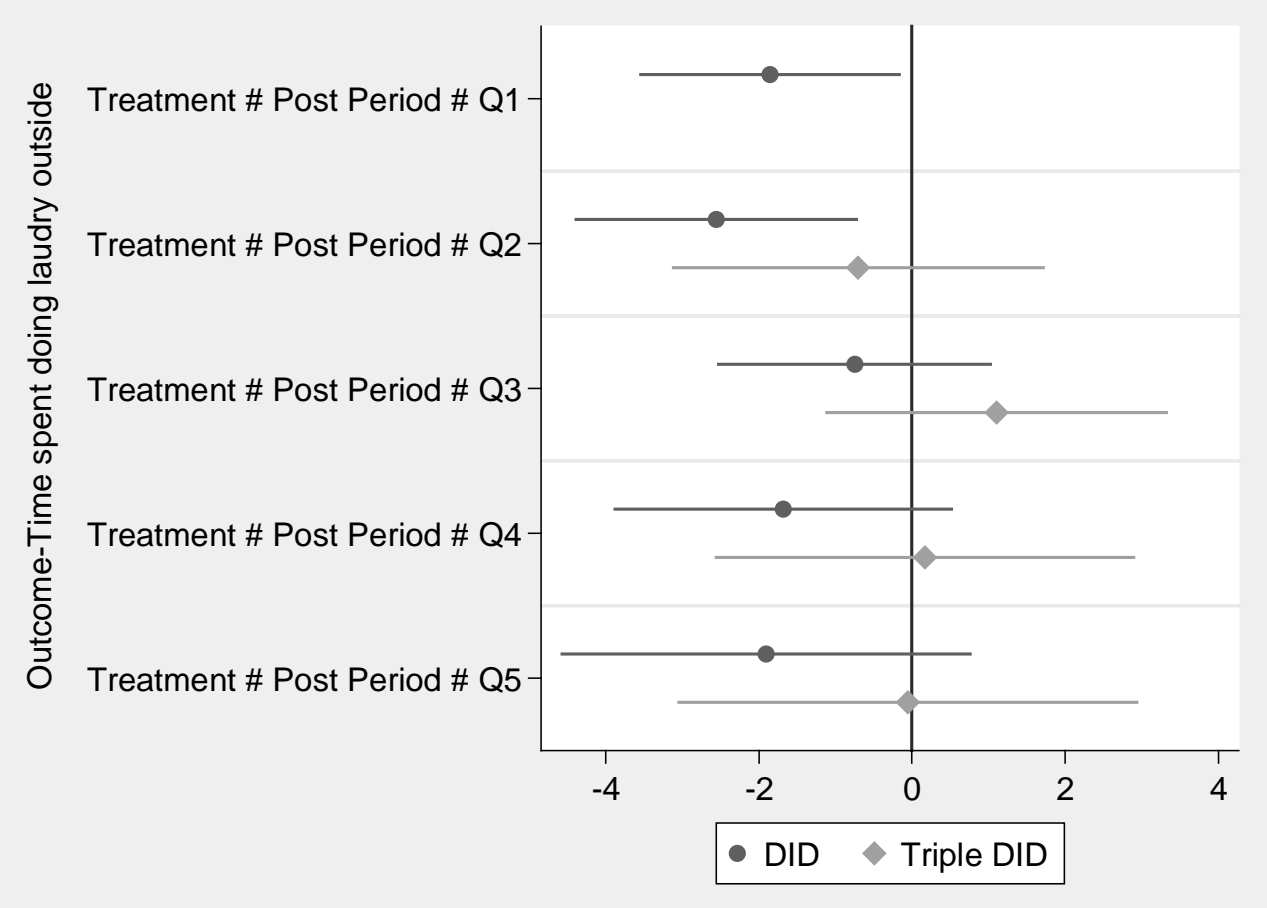

\section{Time Diary Data And Productive Time Use}

In each household, we interviewed two household members on their time use on the Monday before the day of the survey: (1) a female head of household, their spouse or a female decision maker between 16 to 55; and, (2) a child between the ages of 5 and 16 residing in the household at baseline. These data complement the results from the time coping cost impacts in the previous section, in that they shed light into what activities the time savings we detect are being invested.

In what follows, we present the impact of the WASH interventions 7 types of activities:

1) Agricultural Production - Animal care, harvesting, etc.

2) Other Work Activities - Salaried work and travel to and from work.

3) Household Activities - Cleaning, fetching water, etc.

4) Children Care - Feeding, showering, etc.

5) Time for Self-Reading, resting, eating, etc.

6) Non-labor Activities Outside the Home-Visiting friends/family, sports, social activities, etc.

7) Education - School time, homework, etc.

For each activity, we estimated the impact on 3 outcomes: (1) the probability of having spent time in the activity, (2) the time spent in the activity, and (3) the time spent in the activity conditional on having reported participated in this activity in any round of the survey. 


\section{Children's Use of Time And Gender Heterogeneity}

Given the differential impacts in time coping costs across gender and age group we will present first the general results for children age 5-18 and then explore differences in age groups and gender.

We present the coefficients across these activities in the following figures and discuss specific numeric results ${ }^{47}$. Participation of children in different activities are presented in Figure 39. We find a marginally significant (at the 10 percent level) in the probability that they participate in agricultural production, a decrease of 2.5 percentage points for children living in treatment segment after the implementation of the WASH interventions. We also observe a significant increase in the probability of participating in educational activities in the figure. In education activities, in Table 87 panel A, we find an increase of 9.2 percentage points in the probability of spending time in education for children living in treatment segments when compared to children in comparison segments. In Figure 40, we observe a significant increase only in time spent in education. The estimates for time spent in education, in Table 87 panel B, imply that children in treatment segments increase their time in education activities by 46.6 minutes on the Monday before the survey; a 12 percent increase from the comparison baseline. For children living in households that report being direct beneficiaries of the WASH interventions the estimates increase to 85 minutes in education activities, or a 22 percent increase from the comparison baseline in column (7) of panel B.

FIGURE 39 TIME DIARY, ALL ACTIVITIES: PARTICIPATION, INDIVIDUALS AGES 5-18

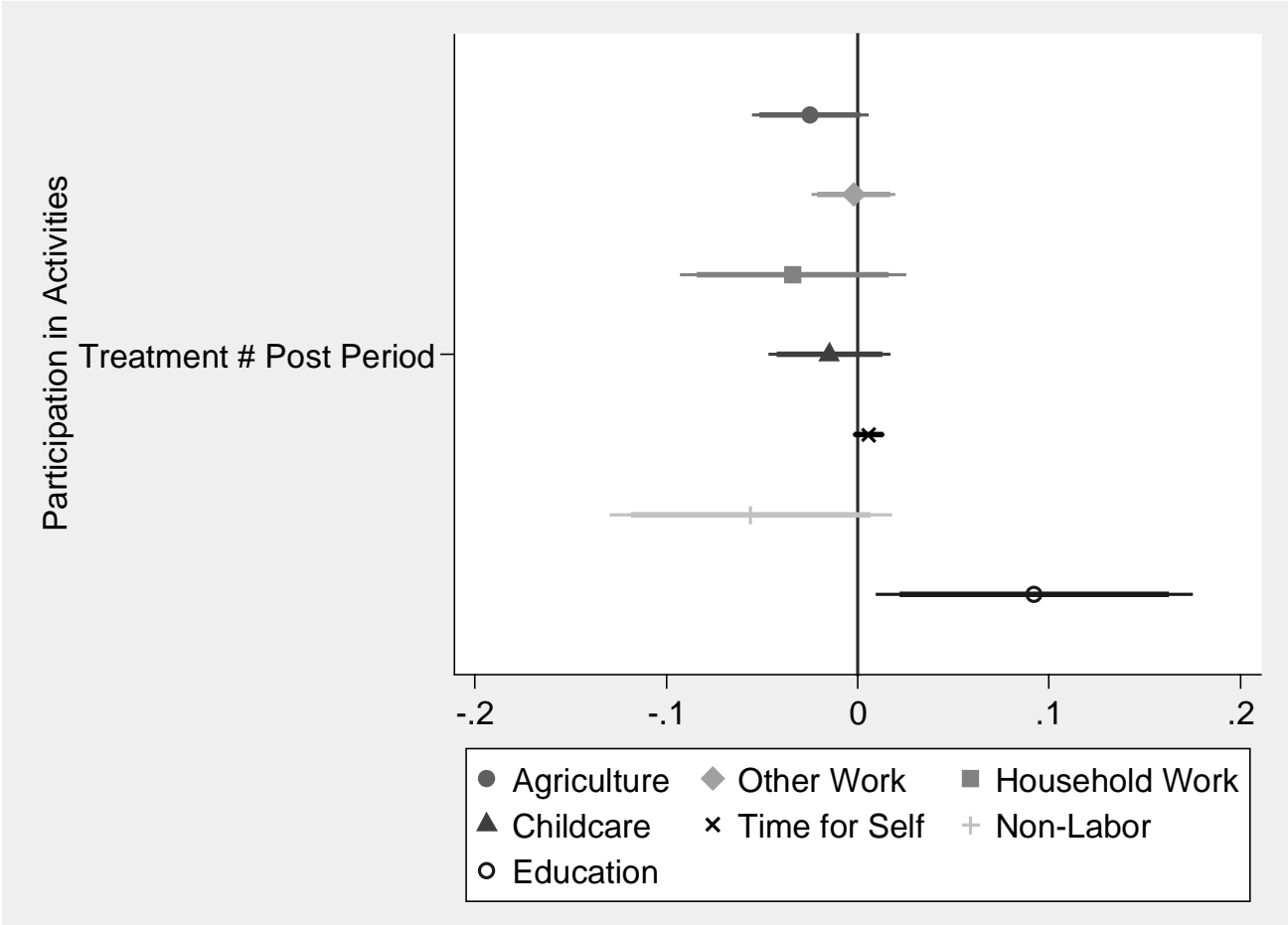

${ }^{47}$ The complete tables of results for each activity is presented in "Annex ? Additional Impact Results" 
FIGURE 40 TIME DIARY, ALL ACTIVITIES: TIME SPENT IN MINUTES, INDIVIDUALS AGES 5-18

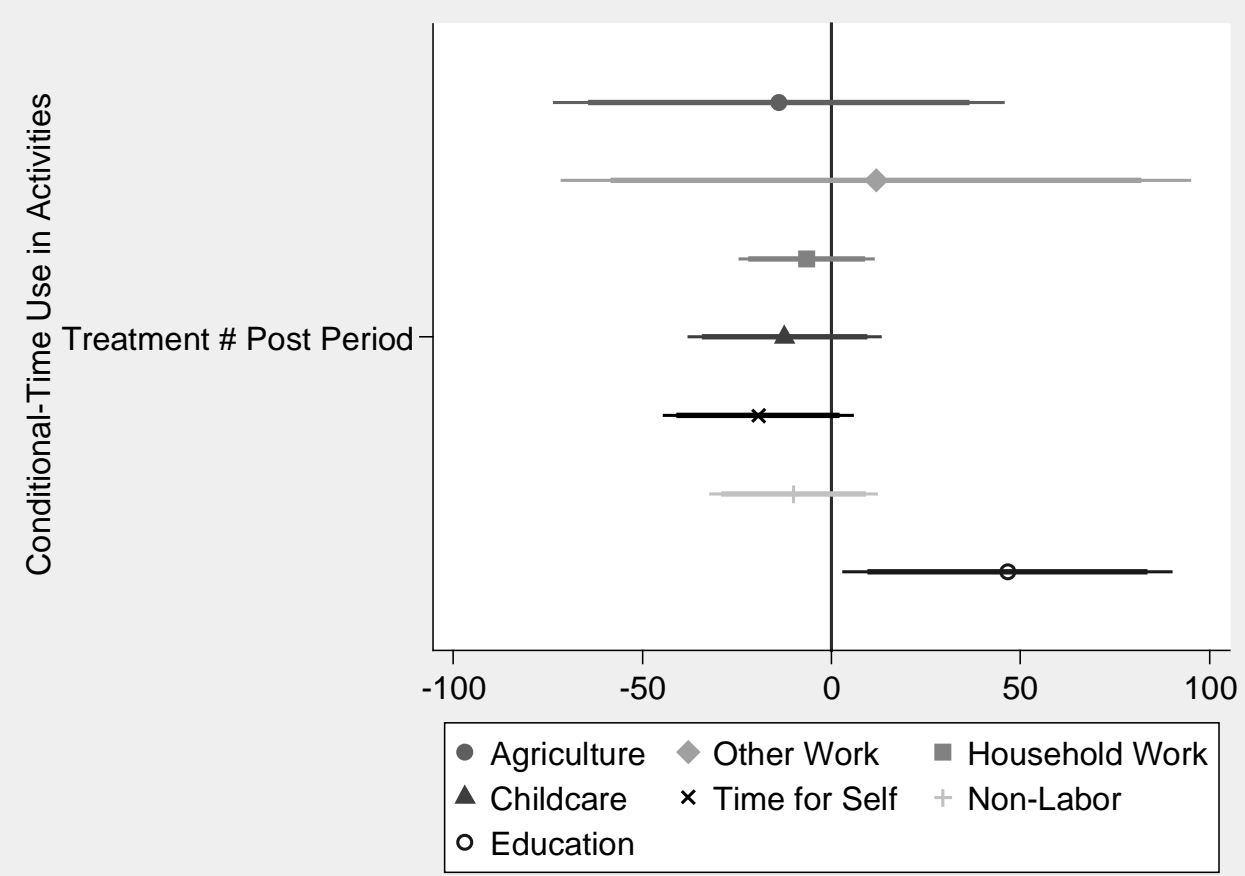


TABLE 87 TIME DIARY, EDUCATION: TIME SPENT IN MINUTES, INDIVIDUALS AGES 5-18

\begin{tabular}{|c|c|c|c|c|c|c|c|}
\hline & (1) & (2) & (3) & (4) & (5) & (6) & (7) \\
\hline & DID & DID-FE & $\begin{array}{l}\text { DID- } \\
\text { Pairs }\end{array}$ & $\begin{array}{c}\text { RF- } \\
\text { Area- } \\
\text { ITT }\end{array}$ & $\begin{array}{c}\text { IV-Area- } \\
\text { ITT^ }^{\wedge}\end{array}$ & $\begin{array}{l}\text { RF- } \\
\text { ATE }\end{array}$ & IV-LATE^ ${ }^{\wedge}$ \\
\hline \multicolumn{8}{|c|}{ Panel A: Probability of Participating in Education Activities } \\
\hline \multirow[t]{2}{*}{ Treatment \# Post Period } & 0.1 & 0.11 & 0.092 & & & & \\
\hline & {$[0.041]^{* *}$} & {$[0.052]^{* *}$} & {$[0.042]^{* *}$} & & & & \\
\hline \multirow[t]{2}{*}{ Inside Project Area \# Post Period } & & & & 0.11 & & & \\
\hline & & & & \multicolumn{2}{|l|}{$[0.038]^{* * *}$} & & \\
\hline Inside Project Area-ITT in Post & & & & & & & \\
\hline \multirow[t]{2}{*}{ Period } & & & & & 0.15 & & \\
\hline & & & & & {$[0.062]^{* *}$} & & \\
\hline \multirow[t]{2}{*}{ Beneficiary \# Post Period } & & & & & & 0.091 & \\
\hline & & & & & & {$[0.039]^{*}$} & \\
\hline \multirow[t]{2}{*}{ Beneficiary-LATE in Post Period } & & & & & & & 0.18 \\
\hline & & & & & & & {$[0.074]^{* *}$} \\
\hline Pairs Indicators & NO & NO & YES & YES & NO & YES & NO \\
\hline Mean of Comp. at Baseline & 0.77 & 0.77 & 0.77 & 0.77 & 0.77 & 0.76 & 0.76 \\
\hline SD of Comp. at Baseline & 0.42 & 0.42 & 0.42 & 0.42 & 0.42 & 0.43 & 0.43 \\
\hline Number of Clusters & 128 & 128 & 122 & 122 & 122 & 122 & 122 \\
\hline Observations & 6,265 & 6,265 & 5,966 & 5,894 & 5,894 & 5,894 & 5,894 \\
\hline K-P rk Wald F & & & & & 88.2 & & 100.5 \\
\hline \multicolumn{8}{|c|}{ Panel B: Conditional- Time Spent in Education Activities (minutes previous Monday) } \\
\hline \multirow[t]{2}{*}{ Treatment \# Post Period } & 50.9 & 52 & 46.6 & & & & \\
\hline & {$[21.8]^{* *}$} & {$[29.0]^{*}$} & {$[21.9]^{* *}$} & & & & \\
\hline \multirow[t]{2}{*}{ Inside Project Area \# Post Period } & & & & 50.1 & & & \\
\hline & & & & {$[20.0]^{* *}$} & & & \\
\hline Inside Project Area-ITT in Post & & & & & & & \\
\hline \multirow[t]{2}{*}{ Period } & & & & & 73.9 & & \\
\hline & & & & & {$[33.1]^{* *}$} & & \\
\hline \multirow[t]{2}{*}{ Beneficiary \# Post Period } & & & & & & 55.2 & \\
\hline & & & & & & {$[20.0]^{* *}$} & \\
\hline \multirow[t]{2}{*}{ Beneficiary-LATE in Post Period } & & & & & & & 84.9 \\
\hline & & & & & & & {$[38.7]^{* *}$} \\
\hline Pairs Indicators & NO & NO & YES & YES & NO & YES & NO \\
\hline Mean of Comp. at Baseline & 380.7 & 380.7 & 381 & 381.2 & 381.2 & 383.6 & 383.6 \\
\hline SD of Comp. at Baseline & 146.5 & 146.5 & 147.3 & 147.1 & 147.1 & 150.9 & 150.9 \\
\hline Number of Clusters & 128 & 128 & 122 & 122 & 122 & 122 & 122 \\
\hline Observations & 5,197 & 5,197 & 4,991 & 4,929 & 4,929 & 4,929 & 4,929 \\
\hline K-P rk Wald F & & & & & 102.1 & & 111.3 \\
\hline
\end{tabular}

Standard errors in brackets

Std. errors are clustered at the census segment level.

All equations include year fixed effects. Equations are DID, in (1)-(3) the treatment is defined as living in a treatment assigned segment, (4)-(5) treatment is defined as living inside the project area within the matched pairs, (6)-(7) treatment is defined as having reported being beneficiary of the WASH project within the matched pairs. Equations (4)-(7) control for initial treatment assignment.

Equation (2) includes household fixed effects. Pair dummies indicated in the table are based in on nearest neighbor matching propensity score matching based on 2007 census segment data.

IV estimates in columns (5) and (7) use the census segment treatment assignment to instrument for indicators for being in a project area in 2012-2013 (5); and the households reporting being a beneficiary of the WASH projects from MCC in (7)

NIV estimates partial out the indicators for pairs to compute the std. errors of the coefficients of interest. We report the K-P rk Wald F statistic following the results in Stock and Yogo (2005)

$* \mathrm{p}<0.10, * * \mathrm{p}<0.05, * * * \mathrm{p}<0.01$ 
To compare the effects of the WASH interventions across activities by gender we present the estimates for each activity for female children in Figure 41 and for male children in Figure 42. For females, we find significant differences for time spend on non-labor/social activities outside the home and education. Females children living in treatment segments spend less time in these social activities outside the home and agricultural work, and more time in education activities when compared to female children in comparison segments. The effect is estimated at $\mathbf{3 2 . 3}$ minutes in the Monday before the survey for the time in non-labor activities outside the home. The estimates are marginally significant for time in agricultural work and education. The point estimate for the time spent in agricultural work indicates a decrease of 68.6 and an increase of 53 minutes for education time among female children living in treatment segment than what would have been the case if the WASH intervention did not take place.

For male children, we also find marginally significant increase for the time spent on education and a significant decrease in the time spent for self or leisure. The estimates suggest that male children in treatment segments spend $\mathbf{4 1 . 5}$ more minutes in education than their counterparts in comparison segments after the WASH interventions; and, 37.6 fewer minutes during the day in time for leisure. The impacts on education time are not significantly different across gender. The evidence suggests that the time savings of children are towards education time. This effect is coupled with a decrease in the time spent on agricultural work for female and a decrease in leisure time for males.

FIGURE 41 TIME DIARY, ALL ACTIVITIES: FEMALES, TIME SPENT IN MINUTES, INDIVIDUALS AGES 5-18

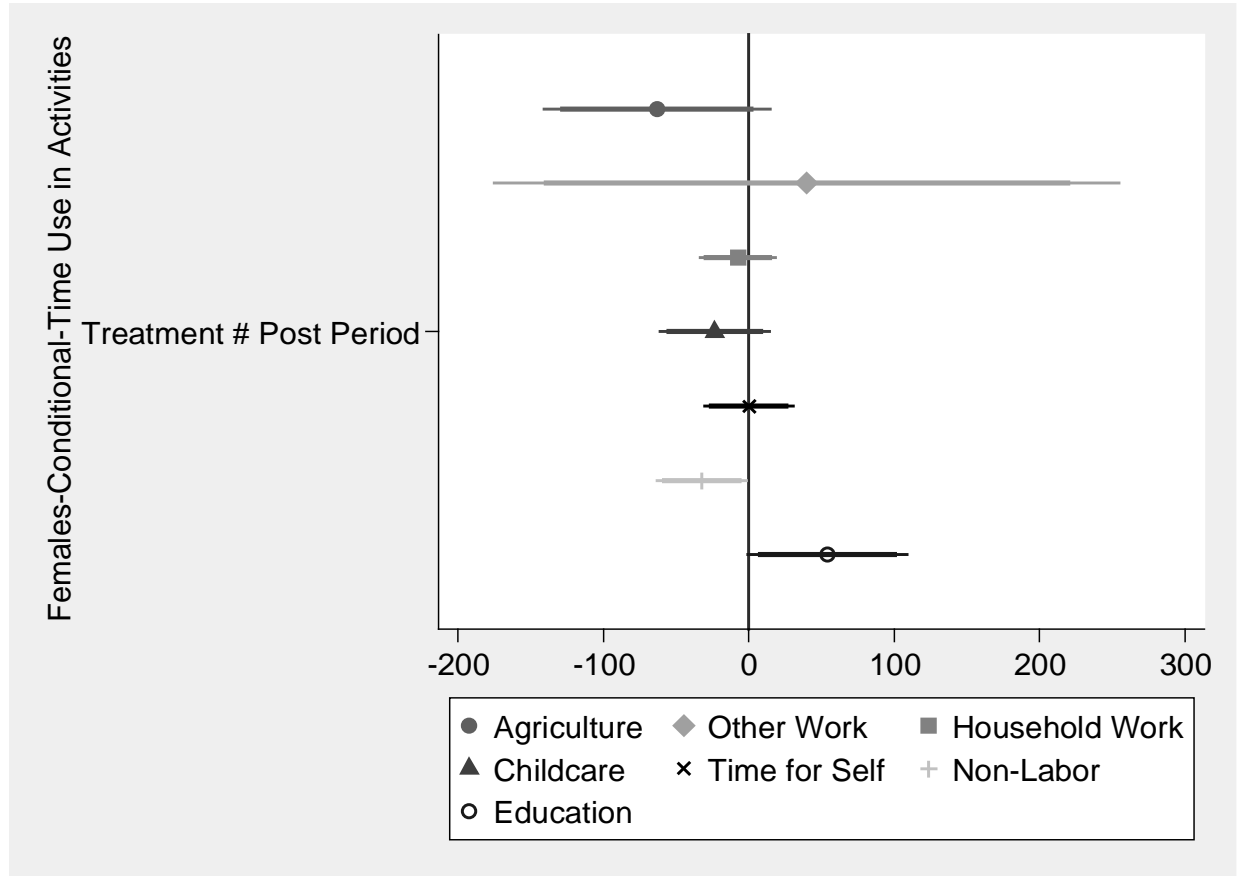




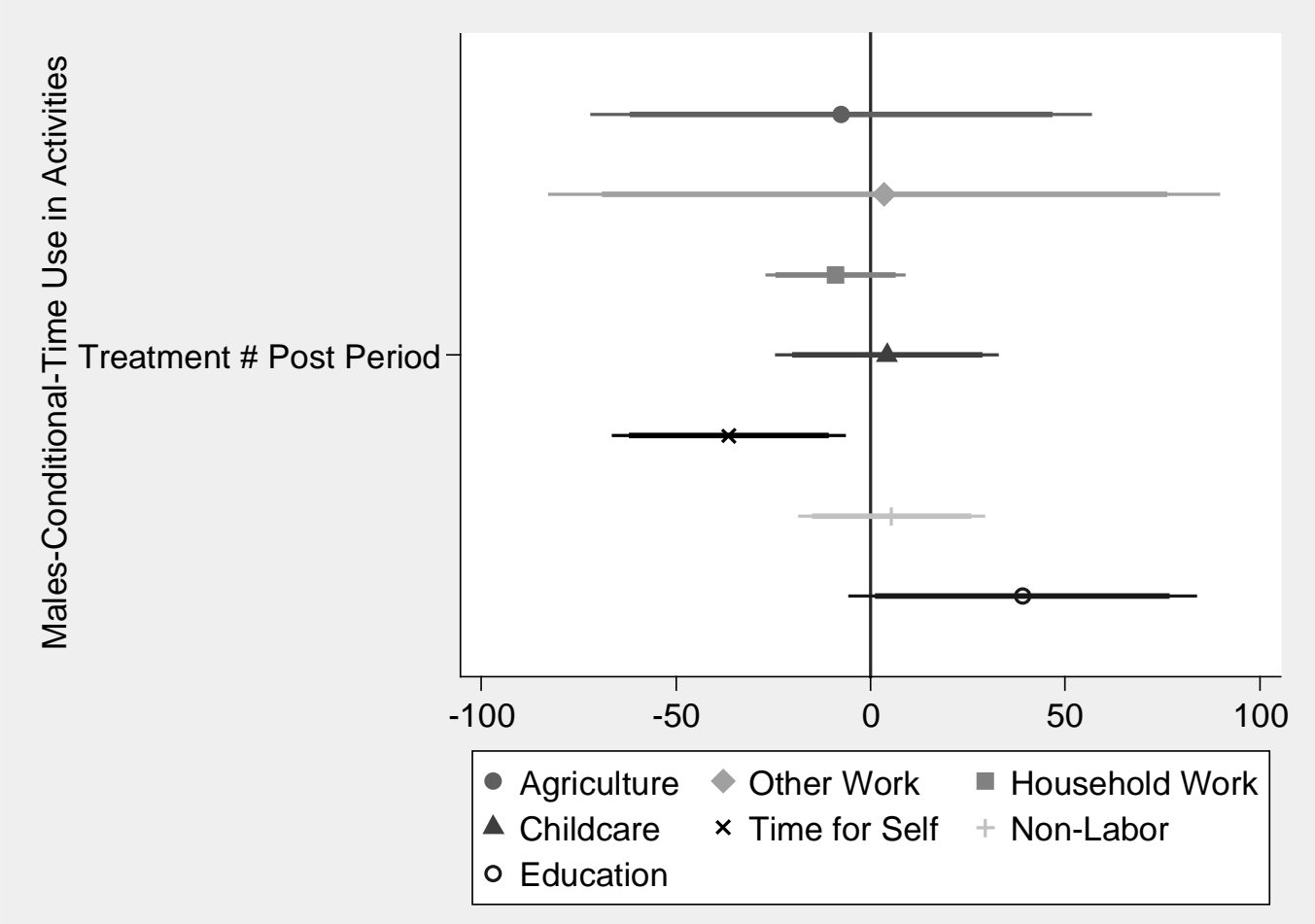

\section{ADULT WOMEN USE OF TIME}

Figure 43 present the impact estimates for the time use for the sample of women decision maker 19 years old and older. We find no significant differences in the probability of participation in any of these activities in the women living in the treatment segments that were part of the WASH intervention. In Figure 44, we explore if there are differences in the intensive margin or the time spent in each activity. On average, women spent little time in agricultural production activities, with most time spent in other productive activities, household activities, and leisure. These were the main categories where we expected impacts. We find significant impacts at the 95 percent level in Figure 44 for time-for-self or leisure and time spent in childcare. Women in treatment segment experiencing increases of 17.9 minutes in time for self on the Monday before the survey after the WASH interventions compare to the women in comparison segment. We also find marginally significant decreases in time spent in childcare in of 21 minutes for women living in treatment segments.

The time diary data gives us some evidence of what happened with the time savings due to the WASH interventions increasing access to water in the home. The estimates suggest that time savings are reflected as a reduction in time spent in childcare, perhaps through women having to spend less time bathing children and/or taking care of sick children, and allocating more time to leisure. 


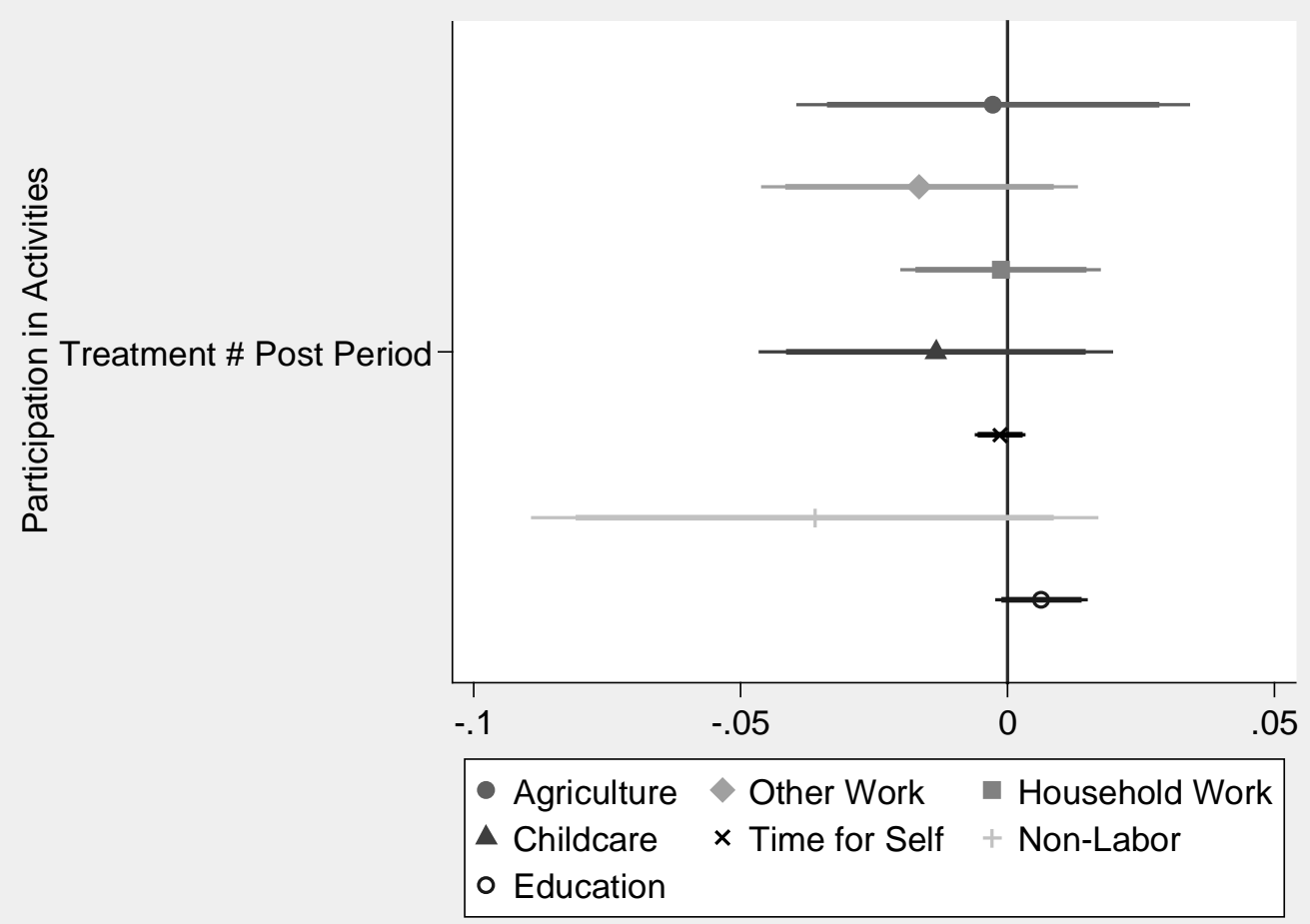

FIGURE 44 TIME DIARY, TIME SPENT: MINUTES PER DAY, WOMEN AGES 19+

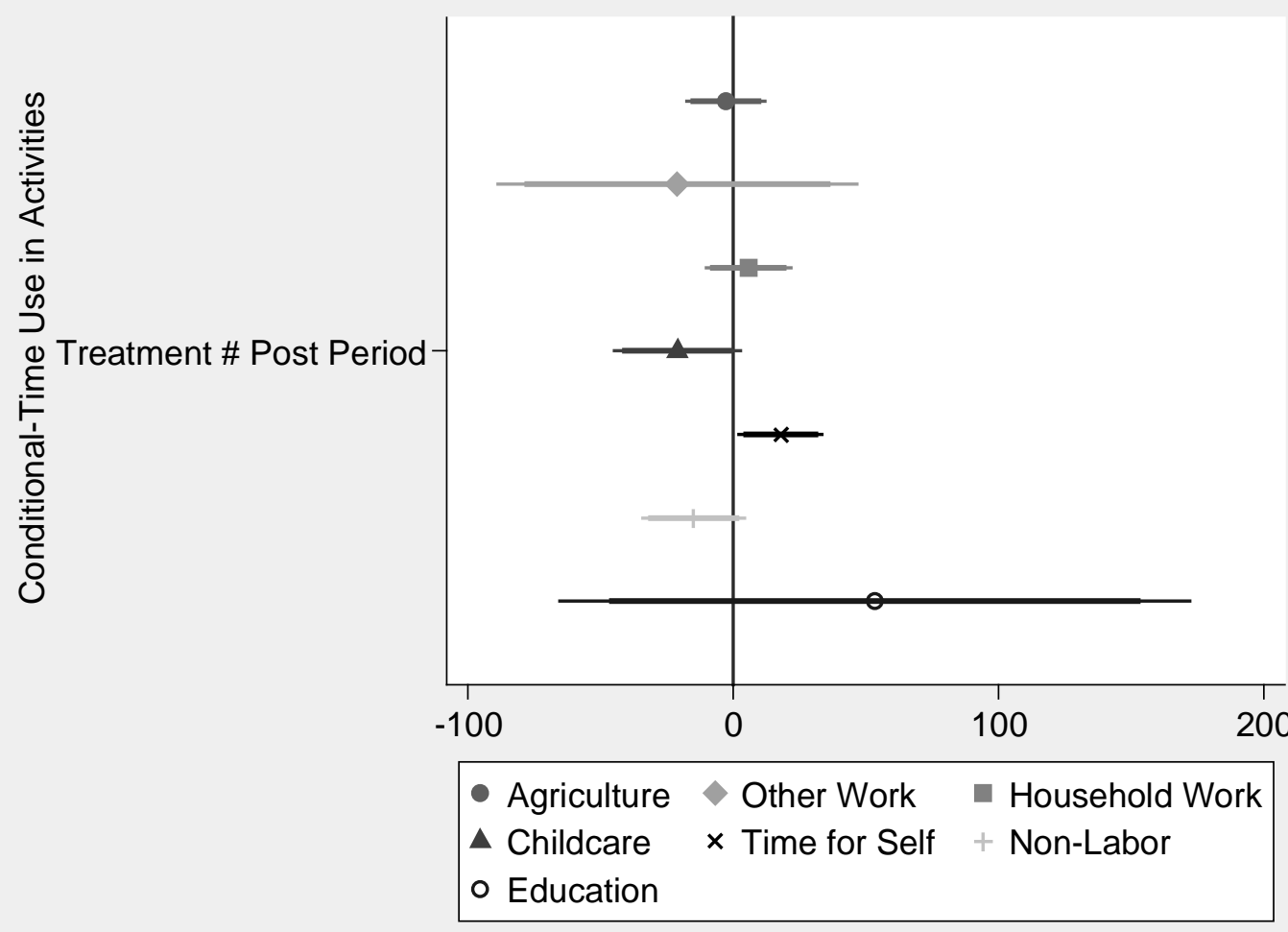




\section{SUSTAINABILITY OF IMPACTS AND HETEROGENEITY BY EXPOSURE TO TREATMENT}

While the panel survey was conducted from 2011 to 2013, the difference timing in which each project started functioning provides us with the opportunity to explore the sustainability of the infrastructure and the persistence of the impacts we observe relative to the date from which the project started functioning.

As described in the methodology section, we calculate the time between the finalization of the project (obtained from administrative data) and the day the household was surveyed. Using this information, we obtained the average duration between the finalization of the project and the survey activities for each treatment segment.

Comparison segments do not have a project finalization date, but this information is needed to make meaningful comparisons of before and after with the treatment group. The solution to this is to assigned to each comparison segment a placebo "project finalization date" that corresponds to finalization date of the treatment segment to which it was paired in the matching stage. Since for the comparison segments, this is an arbitrary date, one would expected that the difference between the survey date and this date would not influence the comparison group across years and would create a differential trend in the outcomes of the treatment group after the finalization date. We compute the difference between this date and the date of the survey for all observation, effectively pooling the panel and creating a time-to-event variable that is centered at zero, indicating the days that the WASH projects were finalized. ${ }^{48}$

The estimating procedure is similar to that used to explore heterogeneity across a categorical variable. The main difference is that the characteristic being interacted is a continuous variable (number of weeks between contract end date and the survey date) instead of a categorical variable and estimate a flexible function or prediction of the outcome based on the continuous variable.

The purpose of this section is to shed some light on the sustainability of the effects found by exploiting the variation in the time each community benefited from the WSS interventions. The impact of the WASH interventions in the following figures is reflected as a change in the slope of the treatment prediction line (solid line) after the zero point on the x-axis. The change in the slope around zero give shows the short-term impacts, as they reflect the effects in the weeks following the finalization of the WASH interventions. As we move to the right on the $x$-axis (over 100 weeks), the figures show if the effects observed in the short term are sustained as the WASH interventions have been functioning for longer time periods.

First we show the persistence of the impacts on the access to water and sanitation. Figure 45 shows the evolution of the improved sanitation rate in treatment and comparison segments. We found impacts of 3 percentage points in our main ITT specification and 5 percentage point among households that report being direct beneficiaries (ATT), and the figure shows that the impact as time passes (space between the lines) increases, suggesting that new household in treatment segments obtain improved sanitation facilities after the project implementation. In the case of access to tap water in Figure 46, we see that the 25 percentage points impact we found, reflects a persistent impact. Over 80 percent of households in treatment segments have access to tap water 100 weeks after the project end date compared to 60 percent in the comparison segments.

\footnotetext{
${ }^{48}$ While the time-to-event variable should not affect the comparison group it is possible/likely that for comparison segments adjacent to the treated segment these would be affected. This follows from our previous discussion of spillovers in the methodology section. Here we focus on the ITT based on the segment treatment assignment.
}

Note that the prediction around the beginning and end tend to be noisier, as there are fewer data points at the extremes of the time-to-event variable. 


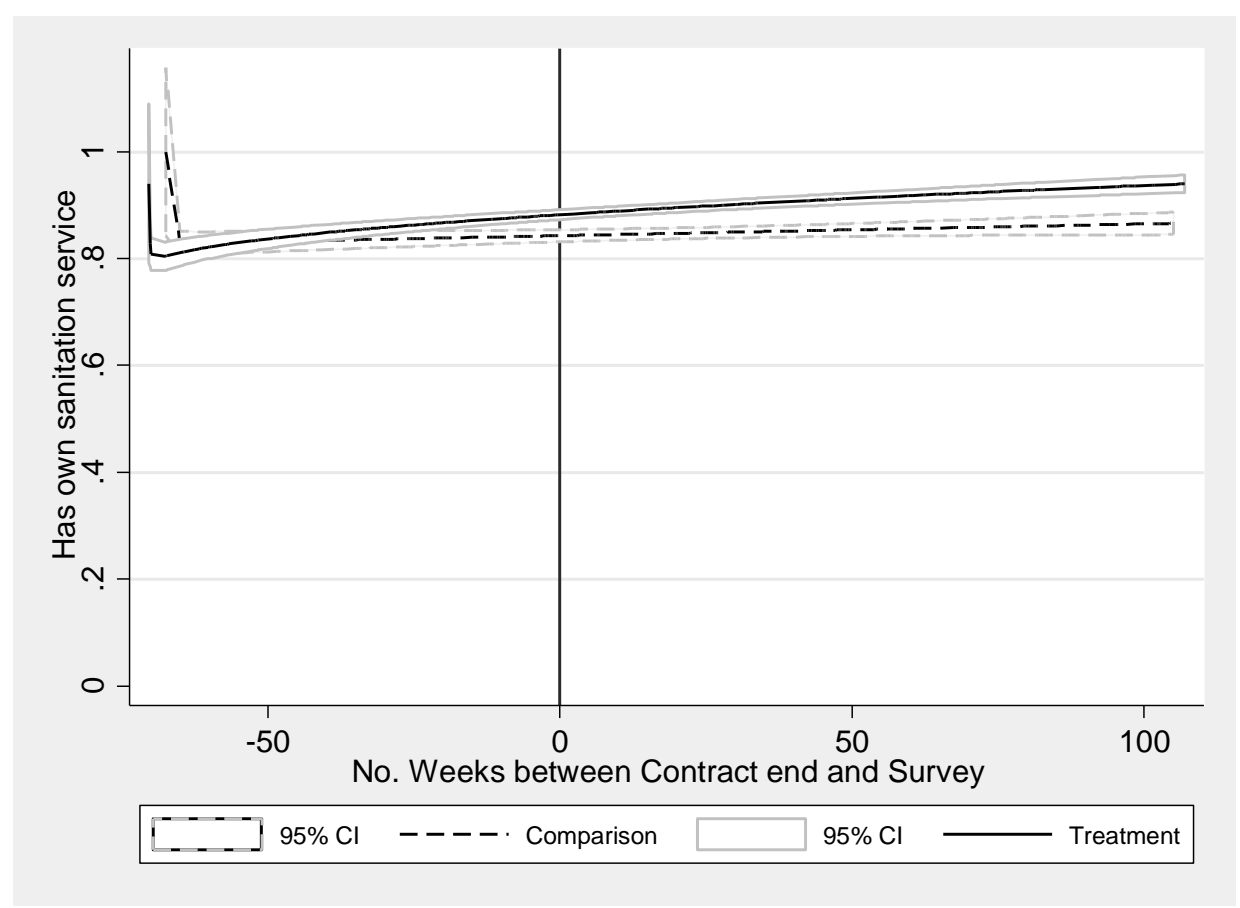

FIGURE 46 SUSTAINABILITY OF IMPACTS: ACCESS TO IMPROVED WATER SYSTEMS

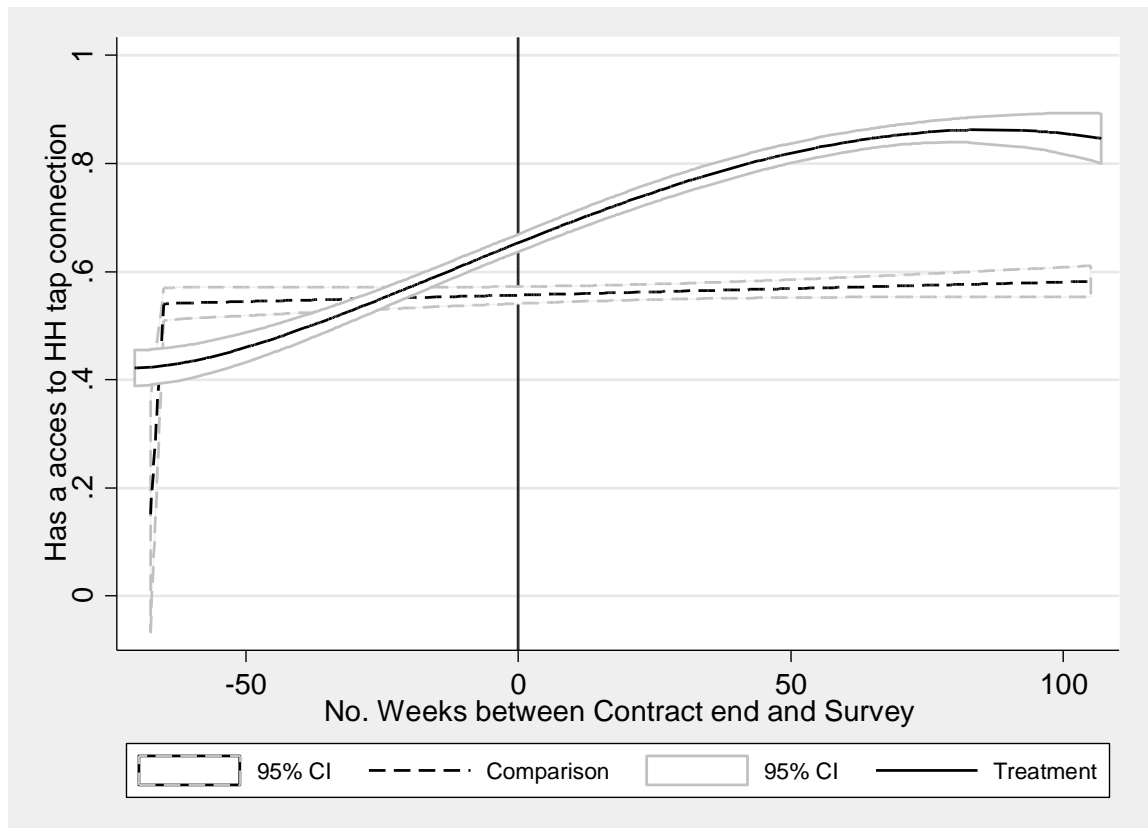

Given the effects on contamination at the point of consumption we detected before, the reliability of the new water system crucial. If the water systems reliability or the frequency of service is degraded with time or rationed, households will re-adopt behaviors, such as inadequate storage and treatment of drinking water, that opens more opportunities for contamination. Figure 47 and Figure 48 shows how the probability of having less than 7 days of service and the number of days per week of available service to explore the question of rationing and see the evolution of the water service in the treatment communities. The increase in the availability of service increased over the short term, up to week 50 after the finalization of the project. 
However, the figures show that communities might have re-adjusted the days of service provided, as they become familiar with the costs of maintaining the system.

Indeed, anecdotally, in focus groups the water committee leaders that received the training to manage the water systems part of the WASH interventions, expressed that because of the increased costs on electricity for the water pumps of the systems their communities would adjust the days and hours when the service was available. Figure 48 suggest that in treatment segments there was an initial increase in the number of days of service was reverted by the end of the study period; this is consistent with the non-significant impact we found for this indicator. While we found a significant increase in the number of hours per week the service of 16.5 hours per week, Figure 49 shows that this increase in the treatment group served to catch up the treatment to group to the levels in the comparison group. Together these results suggest that treatment communities initially had more days and hours per day of water service and then adjusted back the number of days while increasing the hours each day and maintain a higher and predictable number of hours per week than before the WASH interventions.

FIGURE 47 SUSTAINABILITY OF IMPACTS: RELIABILITY, PROBABILITY OF <7 DAYS OF SERVICE

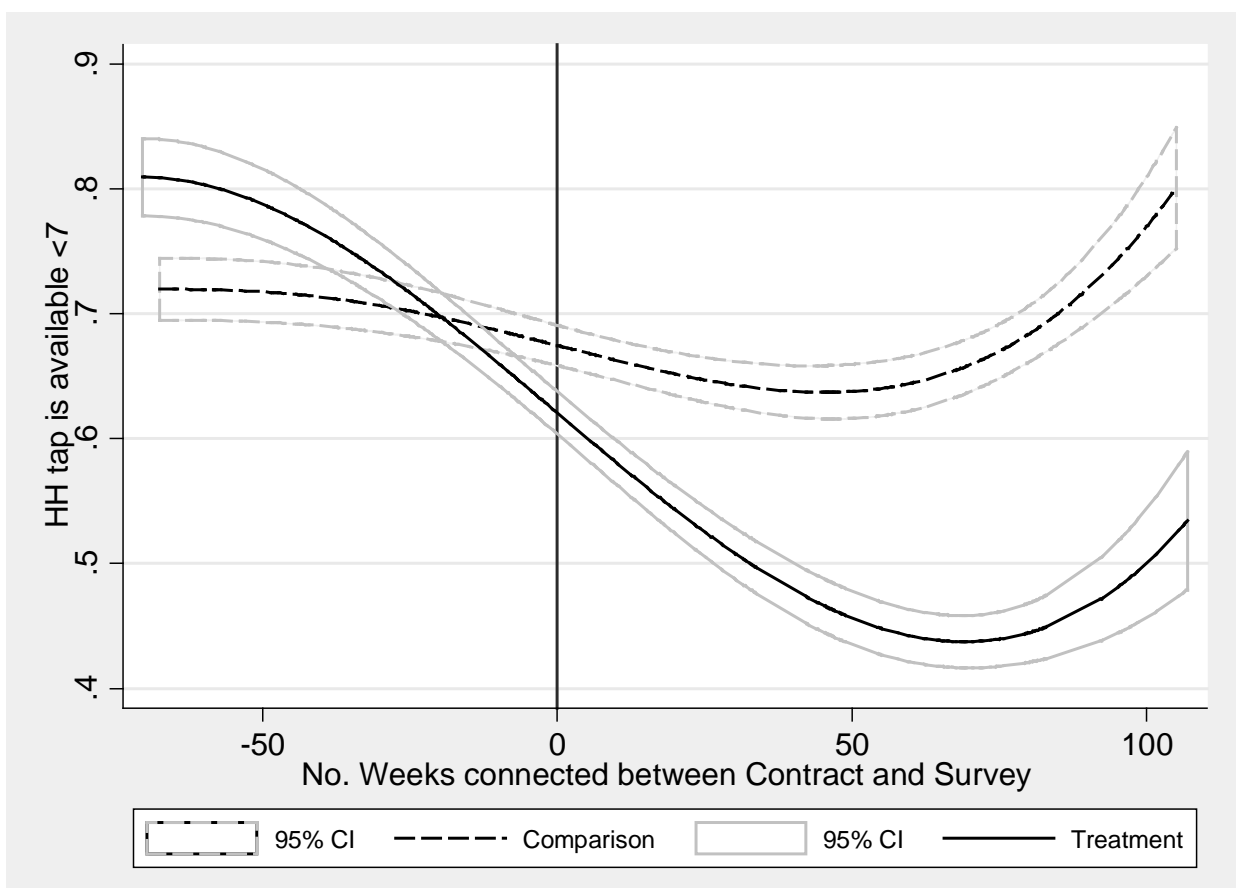




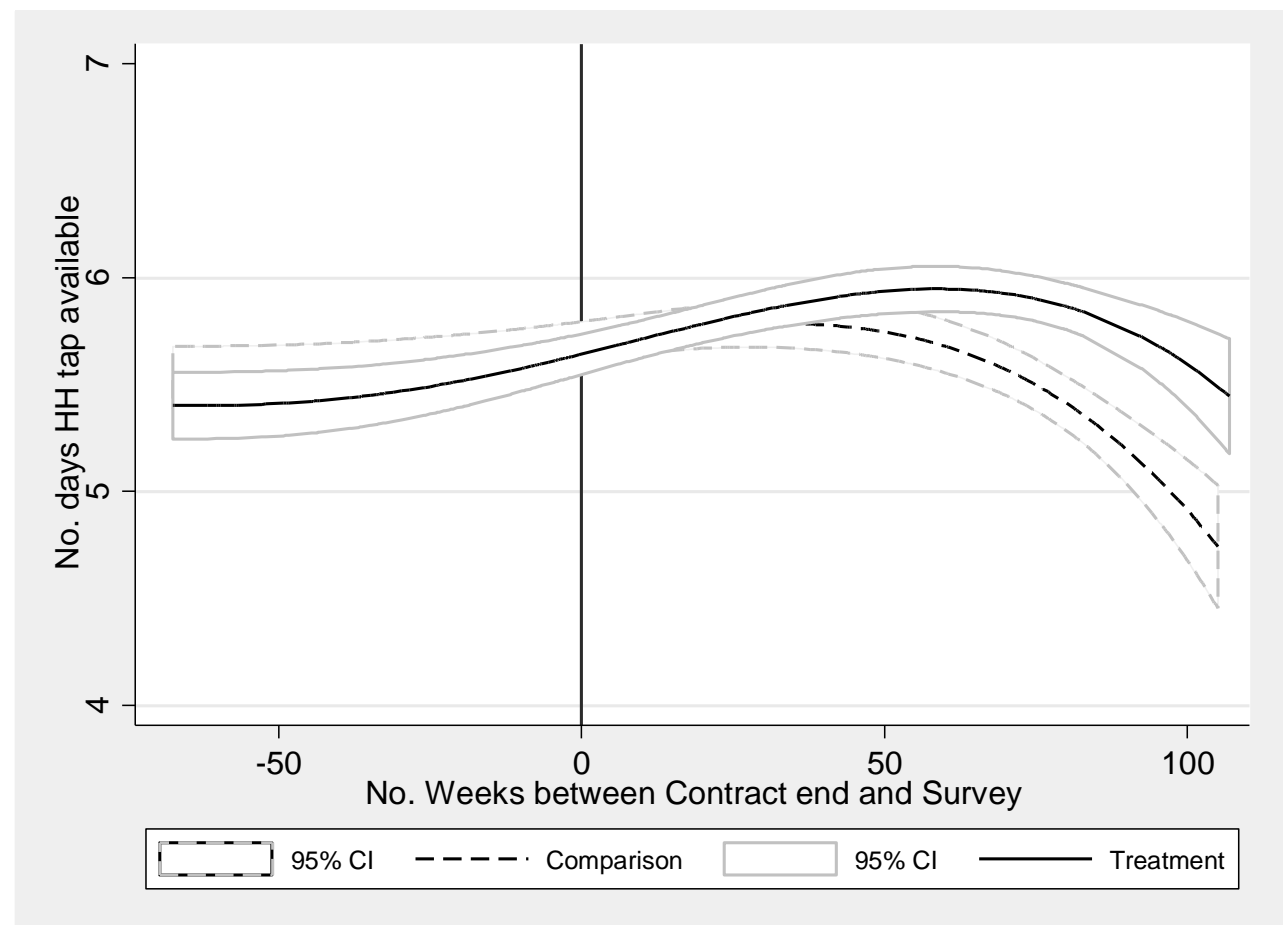

FIGURE 49 SUSTAINABILITY OF IMPACTS: RELIABILITY, HOURS PER WEEK AVAILABILITY

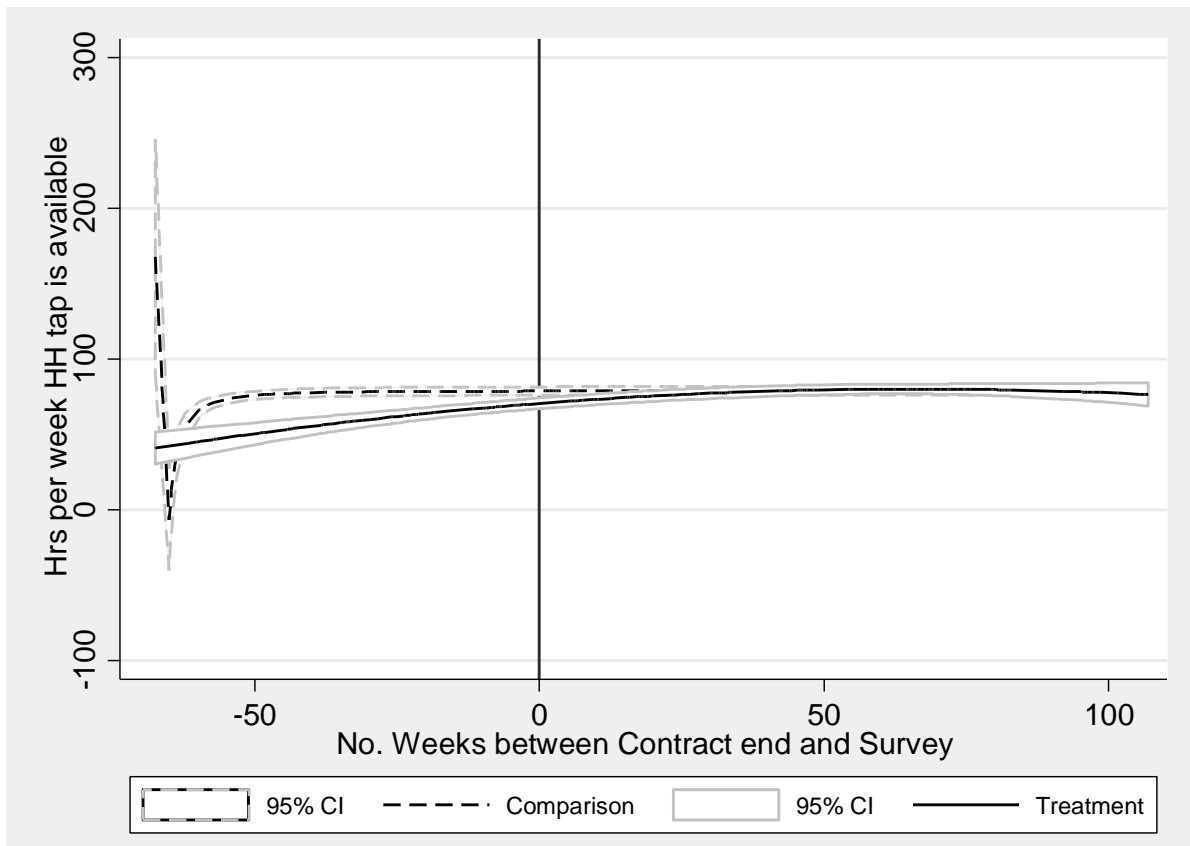

Continuing with satisfaction of household and their perception of how probable it is to get sick from drinking water from the systems. Figure 50 shows the under 25 percent of households living in treatment segments expressed to be satisfied with their water system and that this proportion increases soon after the contract end date and remains stable after 50 weeks of finalizing the WASH interventions. In the case of the probability of getting sick, households in treatment segments that were connected to the improved system for a longer 
period were more likely to respond that they were satisfied with the system. Figure 51 shows that households in treatment segments are much confident of the safety of the new systems and the proportion of household in treatment segments that perceived that is safe to drink the water directly from the system increases as they become more familiarized with the new system.

\section{FIGURE 50 SUSTAINABILITY OF IMPACTS: SATISFACTION WITH WATER SYSTEMS}

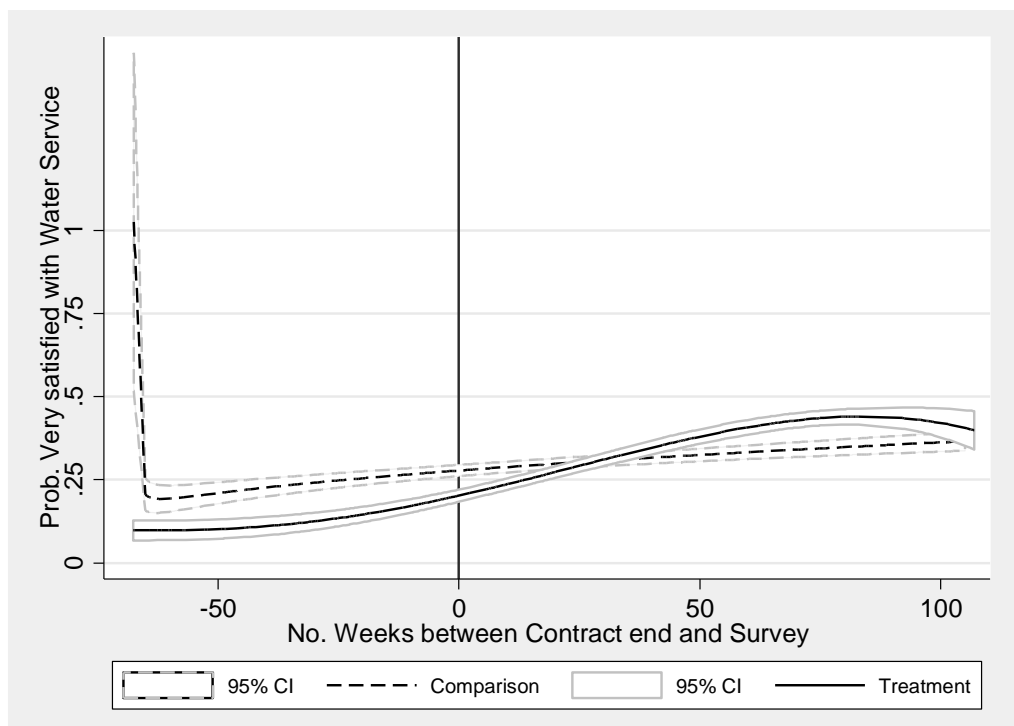

FIGURE 51 SUSTAINABILITY OF IMPACTS: PERCEPTION OF RISKS

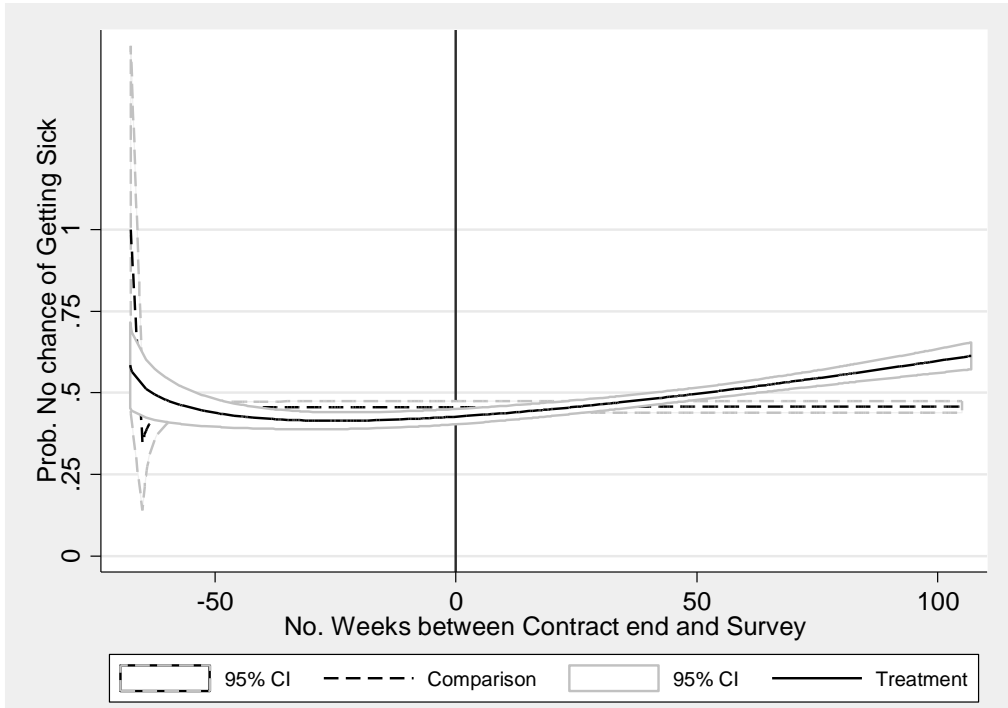

Consistent with these results, Figure 52 show the effects of duration with service on the probability of using tap water as a principal source for drinking. The duration variable has no effect for the comparison group, as expected. Then, for the treatment group in the weeks after the finalization of the projects, proportion of households using a tap as a principal source increases rapidly, from 30 percent at baseline to 70 percent 100 weeks after the projects were finalized; consistent with the 28 percentage points increase we found. 
In the main impact estimations, we did not found and effect of the WASH interventions on total water consumption and this corroborated in Figure 53. The confidence bands are wide and the prediction line in the treatment and control groups hover around 2,000 liters per week per household. Figure 54 Show the rapid increase in the water consumption from metered taps. Here we note the parallel trends and the difference in levels before the projects were finalized. After the projects are finalized in the treatment segments, their consumption increases and quickly catches up with that of the comparison group.

\section{FIGURE 52 SUSTAINABILITY OF IMPACTS: EFFECTIVE USE, WATER FOR DRINKING}

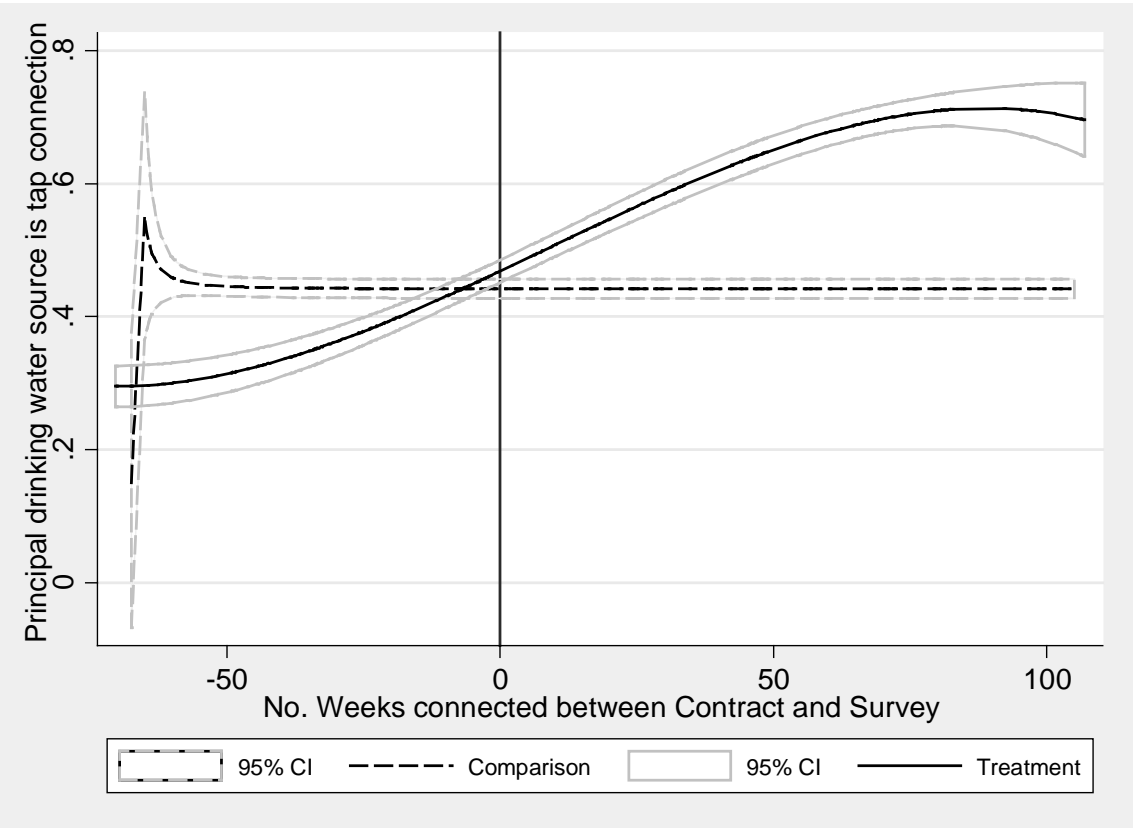

FIGURE 53 SUSTAINABILITY OF IMPACTS: TOTAL WATER CONSUMPTION

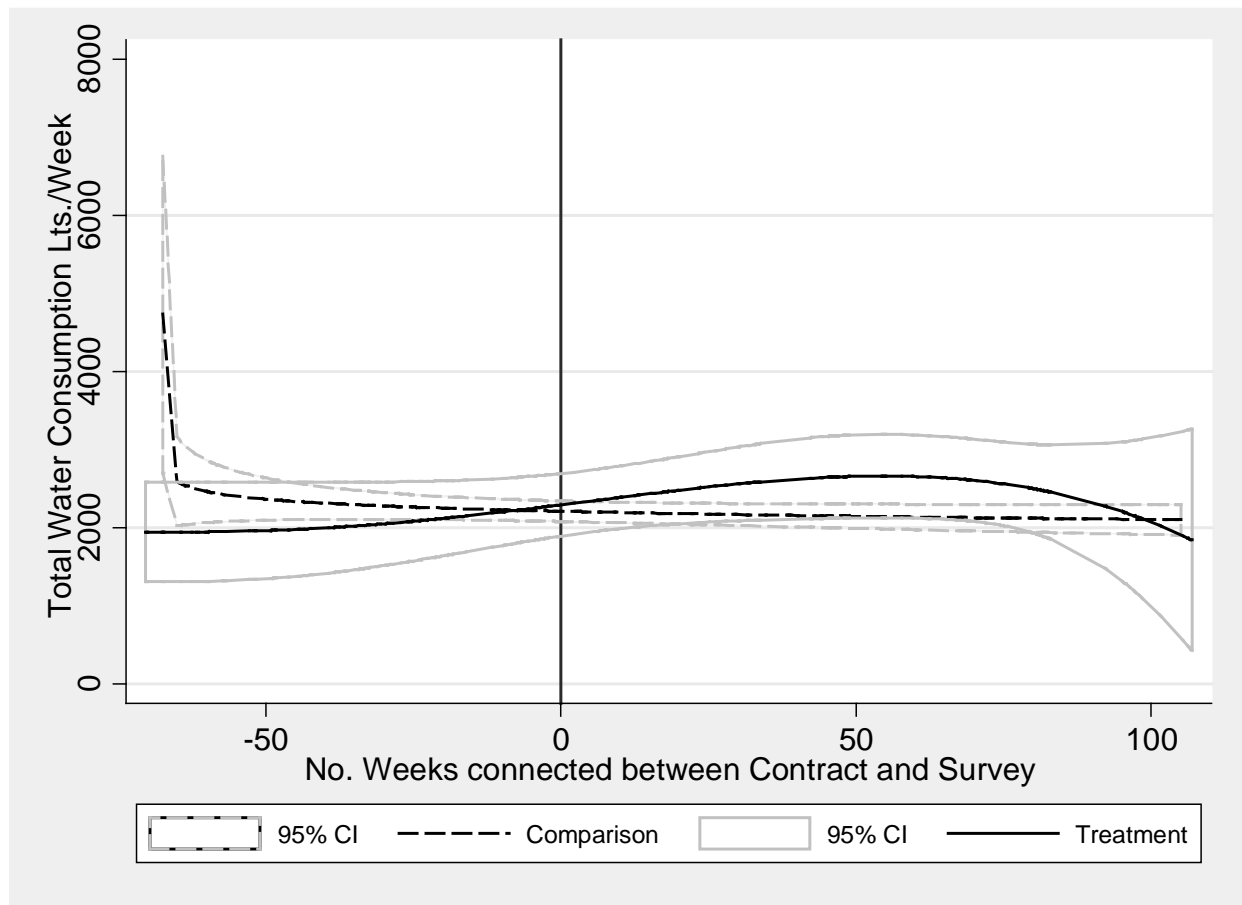




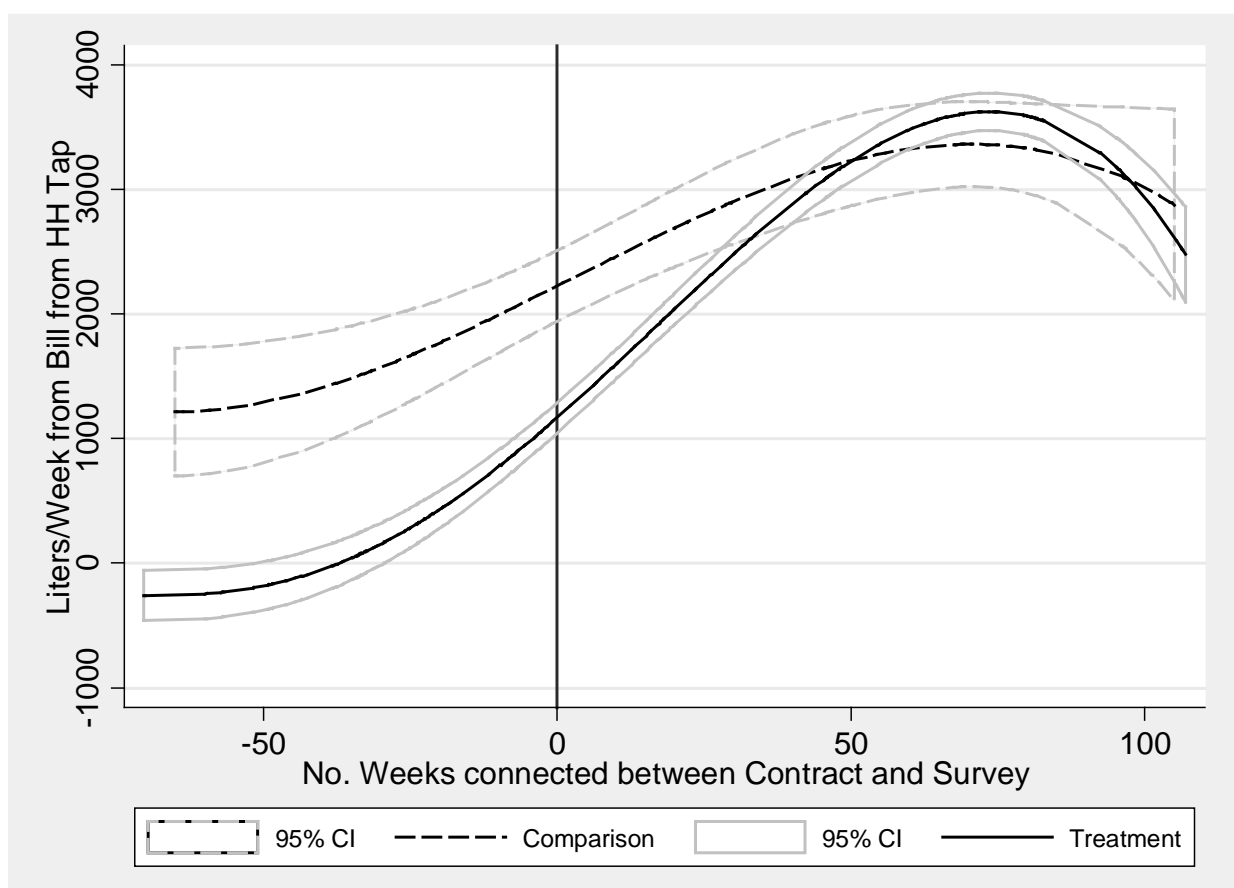

To conclude this section on the sustainability of the WASH interventions and the observed impacts, we present the effects on expenses and time coping costs. Figure 55 shows the increase in the tap expense, and we observe that the expense increases after the implementation for the treatment; due to the new expense in the water bill. The trends in both groups are similar and the increase in expenses for the treatment group, from 3 USD just before the finalization of the project, to 7 USD around 100 weeks after implementation. This provides more evidence that the communities are billing households as the training during the intervention taught them, to make sure that they could cover the maintenance cost of the projects and ensure their economic sustainability.

As before, the time coping costs are reflected on the probability of carrying water and doing laundry outside the home and the time spent in these activities. We present the results on the probability of carrying in Figure 56 and of doing laundry in Figure 57. The change in the probability of a household having to carry water decreases from almost 40 percent to almost 10 percent; however, there was a decreasing trend in the preperiod in the treatment group, which would indicate a possible upward bias if we would a pre-post difference using this adjusted time variable and this comparison group as a reference. The results in Figure 57 for the probability of doing laundry outside the home are smaller but still large, with a decrease from around 30 percent of households doing laundry outside to under 10 percent 100 weeks after the projects were finalized; consistent with the 13-percentage points impact estimate we found previously. Similar trends can be seen in Figure 58 for the time spent carrying water and in Figure 59 for the time spent doing laundry outside the house. The decrease in the time spent doing these activities imply that the WASH interventions, all but in the eliminated the time spent in these activities, particularly the time spent carrying water. 


\section{FIGURE 55 SUSTAINABILITY OF IMPACTS: HOUSEHOLD TAP EXPENSES}

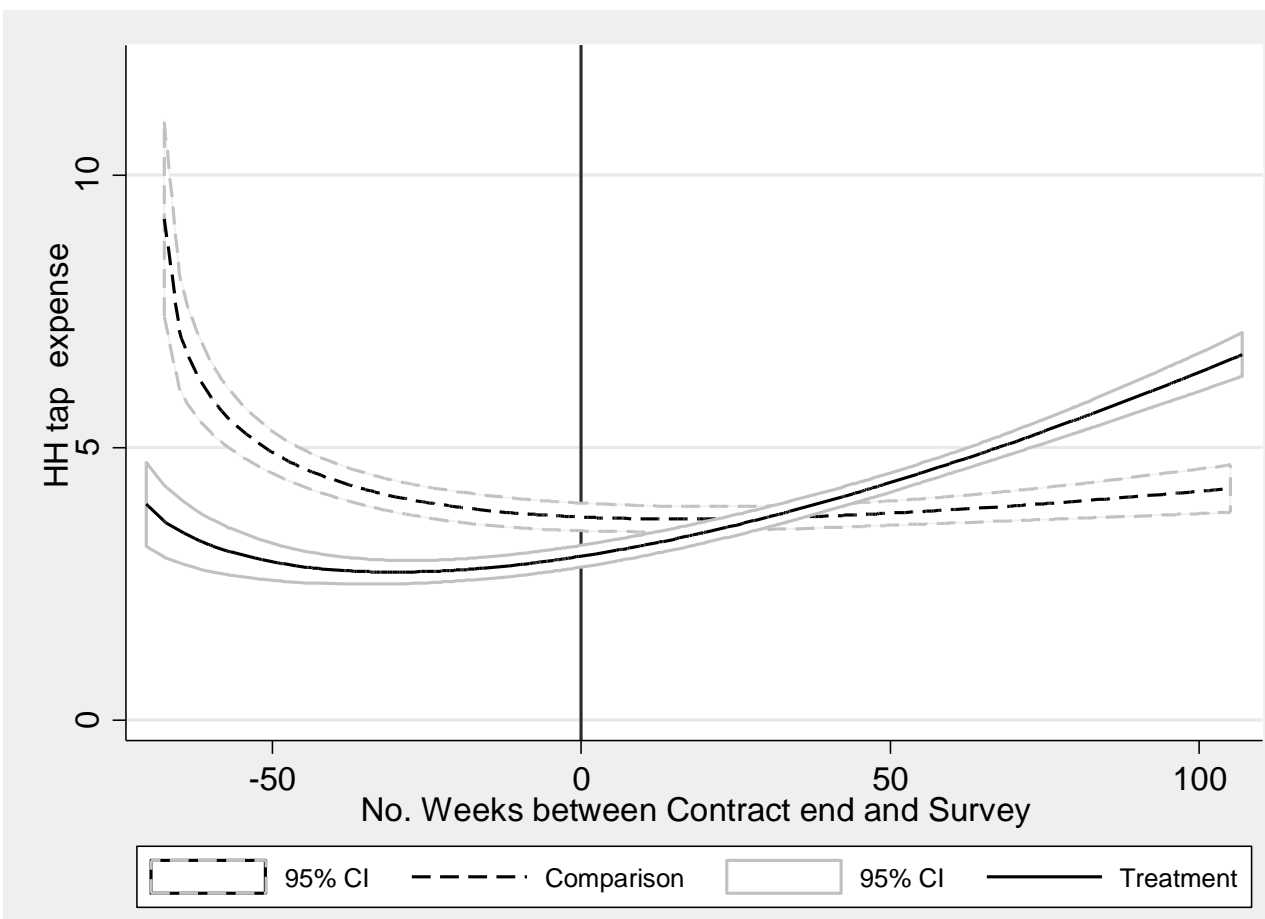

FIGURE 56 SUSTAINABILITY OF IMPACTS: COPING, PROBABILITY OF CARRYING WATER

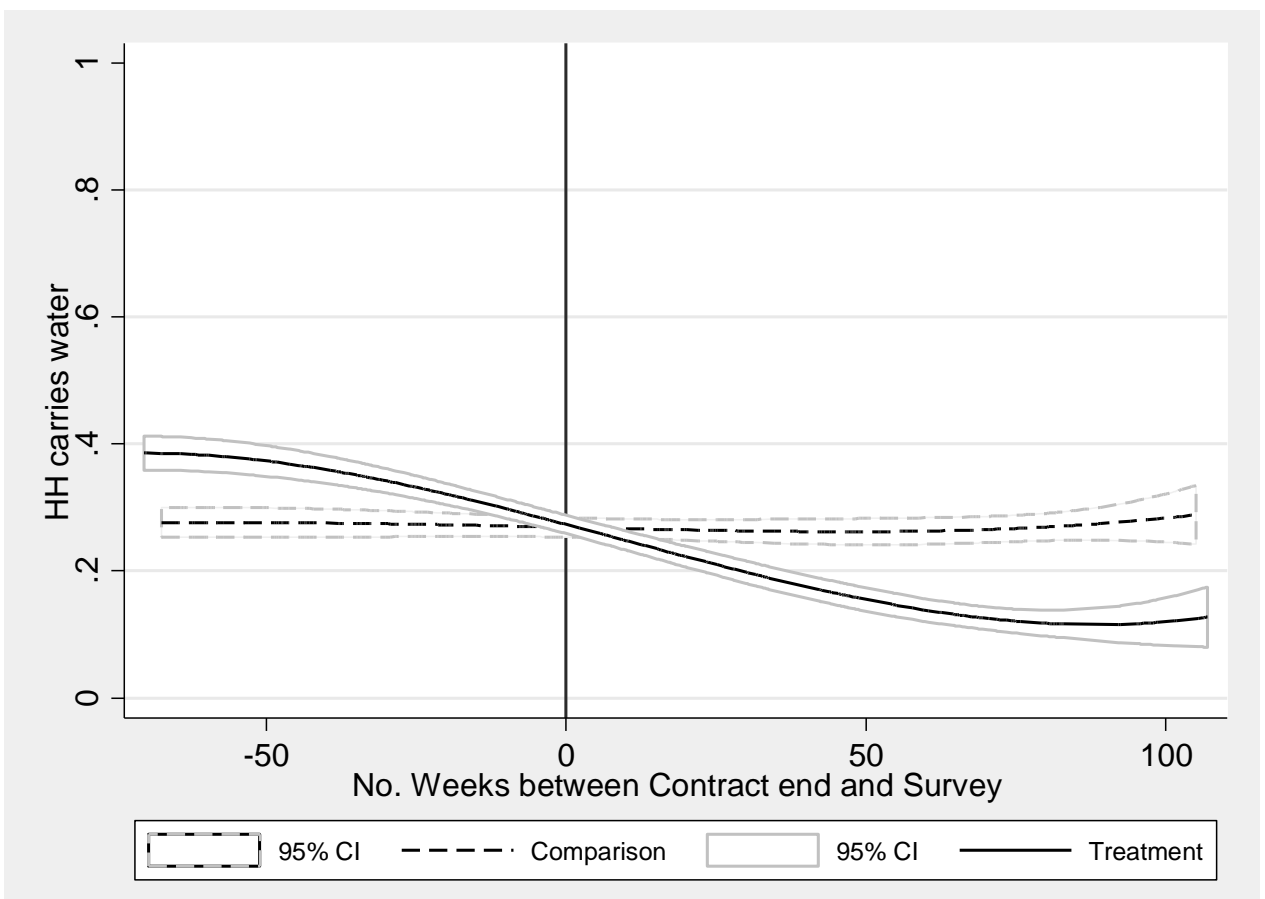


FIGURE 57 SUSTAINABILITY OF IMPACTS: COPING, PROBABILITY OF DOING LAUNDRY OUTSIDE THE HOME

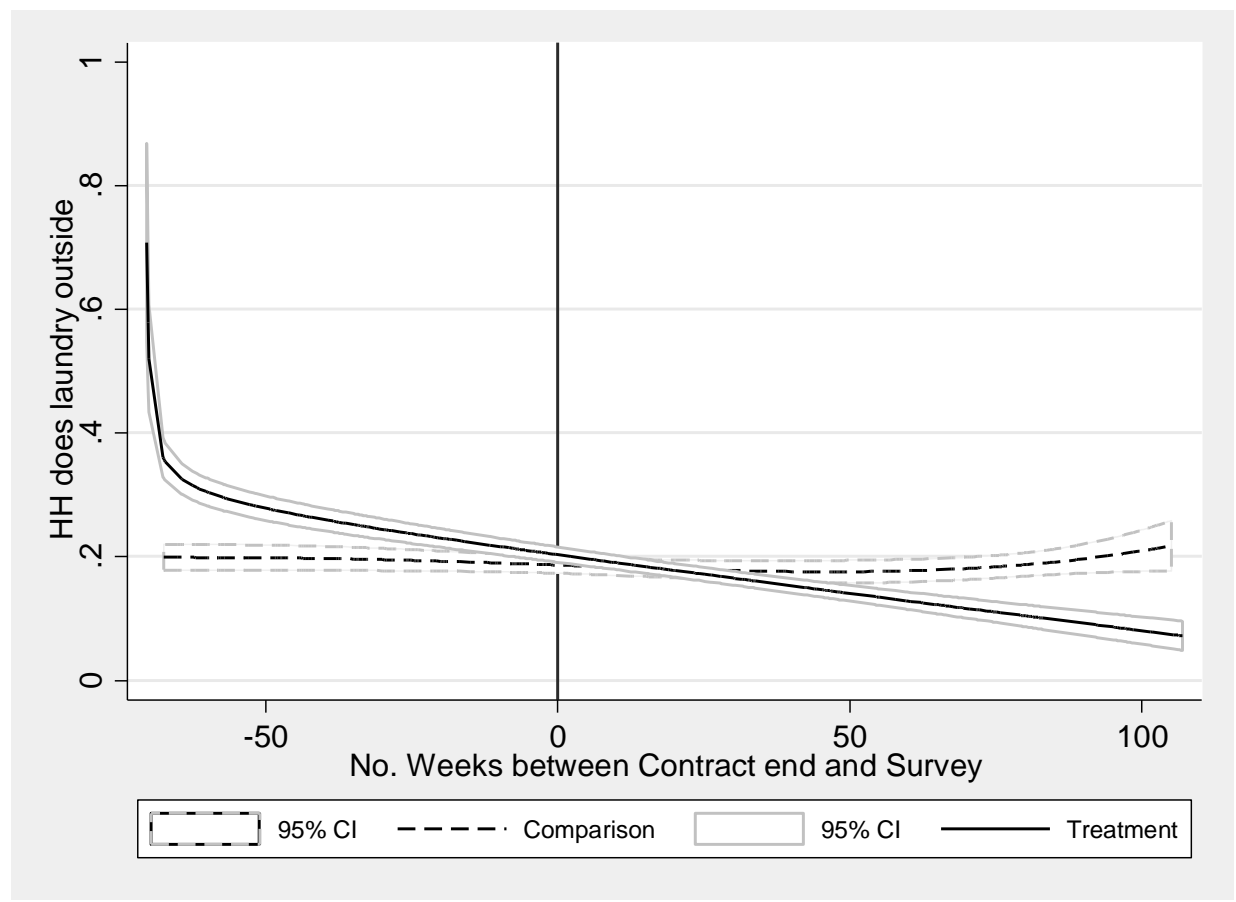

FIGURE 58 SUSTAINABILITY OF IMPACTS: COPING, TIME SPENT CARRYING WATER

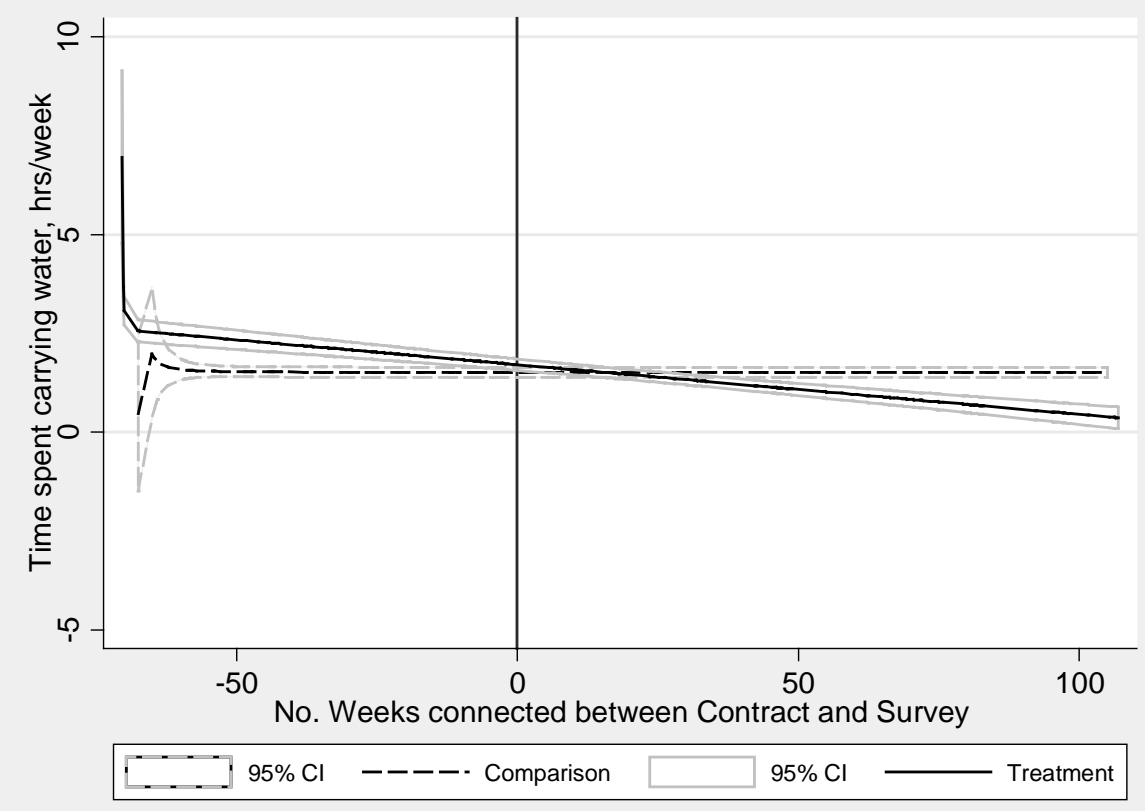


FIGURE 59 SUSTAINABILITY OF IMPACTS: COPING, TIME SPENT DOING LAUNDRY OUTSIDE THE HOME

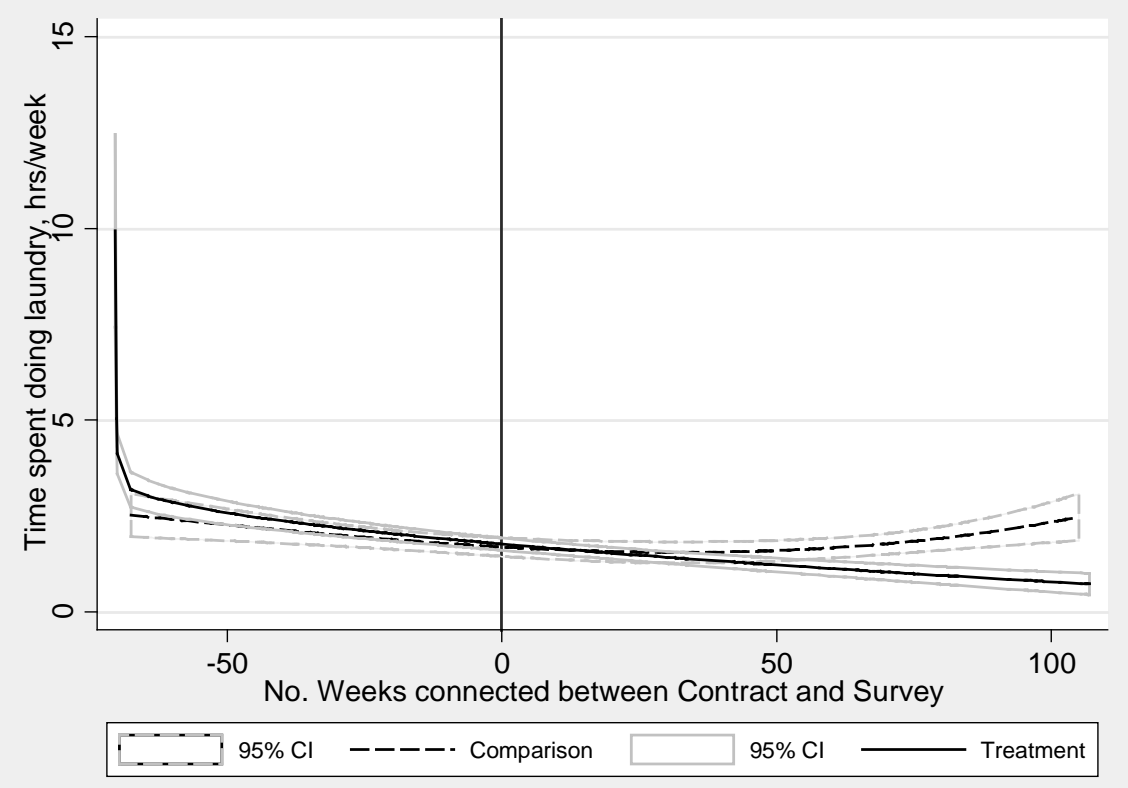




\section{CONCLUSIONS}

Access to water for the rural poor is essential both for basic needs and for productive purposes. In El Salvador, while the level of access to water and sanitation is not as dire as in other places, present us an opportunity to explore the effects of WASH interventions and the infrastructure component, in particular, and see how the effects might differ from other more depressed areas.

This impact evaluation presented and in-depth analysis of indicators that reflect how WASH interventions can affect the lives of the rural poor in Northern El Salvador, such as access to improve water and sanitation, satisfaction coping costs and time use. We saw this research as an opportunity to demonstrate how a rigorous research design that combines matching and panel data could be used to estimate the impacts of infrastructure projects and provide credible and robust evidence of the impacts of this type of projects.

We found robust and significant benefits across the measures of access to water and sanitation: time to improved water sources, ownership and use of improved water and sanitation services, reliability of service, satisfaction with the water system, and reductions in the perceived risk. Exploring how these effects differed by the amount of time beneficiary households were connected to the new or improved system, we found that these effects manifest within the first months of being connected. Once the households were connected for a longer period, these effects persisted and evolved as beneficiaries and their communities adjusted and learned as the systems continued function over 2 years after the completion of the WASH interventions.

The reliability of the water system is very important given the potential of contamination from storage. Using additional data on a subsample and laboratory results on the chlorination levels and contamination with fecal coliform, including E.coli, we found that new systems have better chlorination rates but that the contamination of drinking water at the point of consumption remained. We found significant decreases in contamination of the water source used to drinking but no effects on the water stored for drinking from these same sources.

We also found increases in water expenses as all beneficiaries were billed for their water consumption to ensure the sustainability and maintenance of the new and improved systems. The effects on the quantity of water consumed was not very precisely estimated because of the difficulty in measuring water consumption from multiple unmetered sources.

We found limited impacts on the indicator most related to the soft intervention or the information campaigns. We found marginal effects on the knowledge of ways to prevent diarrhea, the frequency with which children use the improved sanitation facilities and the washing vegetables with chlorines before cooking.

The impacts of the WASH intervention on coping costs were significant and robust. Beneficiaries experience significant decreases in time spent carrying water and doing laundry outside because of lack of access to water in the area. We explored heterogeneity in the impacts on time coping cost by age, gender and socio-economic groups. We found that women benefit most and particularly adult women in the middle of the age distribution. Particularly in the probability of having to engage in these activities. The reduction in the time spent in these activities was similar across the age distribution.

Finally, since the time savings due to the WASH interventions could potentially be used in productive activities. We explored the impacts on the time use of children and women in the households for activities such as, agricultural labor, non-farm labor, leisure and other non-labor social activities. We found that in this case the reallocation of these time savings was directed towards education towards for male and female children. This effect was coupled with a decrease in the time spent on agricultural work for female and a decrease in leisure time for males. For adult women, the evidence suggests that time savings are reflected as a reduction in time spent in childcare, perhaps through women having to spend less time bathing children and/or taking care of sick children, and allocating more time to leisure. 


\section{LESSONS AND RECOMMENDATIONS FOR FUTURE WASH INTERVENTIONS}

The results in this impact places us in a better position to understand the mechanisms through which these WASH interventions affect beneficiaries across different aspects of their lives and on the need of adjusting our expectation on the size of the impacts depending on the context.

In promoting the millennium development goals that called for the world to halve the proportion of people without access to safe drinking water as well as the proportion of people who do not have access to basic sanitation we can go beyond 2015 and these interventions helps the world to approach that goal and gain on the gap in this goal.

As for lessons for future interventions:

- Future impact evaluations should attempt to use administrative data on water consumption. Measuring water consumption using a survey instrument is very difficult and using the billing data from the utility company, for example, would provide better estimates on the impact on water consumption behavior and how this might change when potable water is generally available.

- The impacts of sanitation are difficult to separately identify in any water and sanitation activity. The importance of separating these effects depends much on the context being studied. In our case, the levels of improved sanitation in El Salvador are large enough that it would be difficult to estimate these effects separately. In developing areas where open defecation is more common, separating the effects of water versus sanitation interventions would be more important.

- The impact of water and sanitation projects should measure through coping costs, both in time and in expenses. In the design stage, we used expenditure as our main indicator to power the sample for the study. However, this was due to a lack of data on coping cost before doing the baseline. In future water and sanitation impact evaluations, if the data is available, it would be preferable to use measures of coping costs and/or water borne diseases to design the sample.

- Finally, having observed differential effects depending on the time the households were connected, we think it is important for future interventions to explicitly include this in the design stage. A carefully and rigorously designed evaluation of the effects of different levels of improved water and sanitations access and the dynamics from the duration with increased access would be a welcome addition to the WASH infrastructure literature. 


\section{Chapter 5 - Discussion ANd POLICY IMPLICATIONS}

The role of government investment for the development of a country cannot be understated. Government expenditures can directly stimulate the economy and promote growth that incentivizes the private sector to invest and the household sector to stimulate demand. However, this understanding of the dynamics of the economy can easily become too simplistic in developing economies where government and foreign aid spending are critical to provide public services and infrastructure that can spur private investments and improve access to good and services in the household sector. In addition, in many developing countries issues of inequality exacerbate obstacles in the provision of public services and infrastructure which can prevent the poorest groups in society from benefiting from aggregate economic growth or investment in infrastructure.

\section{KEY CONTRIBUTIONS}

In this dissertation, we look at these problems from an aggregate perspective in two countries in Africa, Rwanda and Tanzania, exploring how issues of inequality affect who benefits from the growth in these and government expenditures. This is followed by a detailed exploration of the impacts that improvements in infrastructure can have in the lives of the rural poor. Specifically, through the evaluation of the impacts of the Northern Transnational Highway in El Salvador and a set of community-demand driven water and Sanitation interventions in the Northern Zone of El Salvador. Across the three essays in this dissertation the unifying thread is the use of micro-data or household level data to evaluate the effects of policies or investments. The findings are based on a common theoretical framework that allows for better understanding of the mechanisms through which these policies and investments affect the lives of the poor.

This dissertation contributes to the literature by analyzing the links between growth, government expenditures in the delivery of public services and infrastructure investments. First, the essay in chapter 2 contributes to the literature a common theoretical framework to examine how the benefits of economic growth spill into the household sector and how such benefits affect the distribution of income within the household sector. It also examines the extent to which fiscal policy contributes to increase social equity and to decrease poverty, using empirical illustrations in Rwanda and Tanzania. It uses a model of the economy within a comprehensive distributional framework that does not rely on single measures of inequality, to better understand what groups benefit from growth and government expenditure.

The dissertation separates government expenditures into public/social goods expenditures, like health, education, and infrastructure; and other expenditures, like administrative expenses and expenditures in sectors where positive social externalities are limited or nonexistent. We found that the better-off sectors of the population in these two countries benefit more from average growth in the economy, highlighting how the benefits of economic grown can vary in different countries. In the case of Rwanda and Tanzania we did not find growth to be pro-poor and inclusive, although those are findings generally encountered in the existing literature.

In chapters 3 and 4 , we provided two illustration of the effects of improvement in rural road infrastructure and water, sanitation and hygiene interventions in the Northern Zone of El Salvador. Both studies contribute methodologically to the literature on the impact evaluation of infrastructure projects by providing an econometric framework to evaluate these types of projects. In the case of road infrastructure, we contribute one of the few rigorous evaluations and provide an impact evaluation strategy based on a sound theoretical framework that can be used by future evaluation of rural roads projects. The empirical strategy provides two parallel approaches that use a panel household survey to exploit variation in the improvement of the road across time and space: A reduced form difference-in-difference estimator base on a pipeline design, and a continuous treatment structural estimator that exploits the variation induce to market access by analyzing the 
timing of the improvements and the spatial distribution of households. The impact of the road improvement in this case proved to be modest in the short run. The econometric framework provided firm ground for the interpretation of the effects and our understanding of how the relation between market access and income can change due to road improvements. For example, placing the impact found across the agriculture and nonagriculture sector within the model allowed us to contrast the cross section (negative) relation between income and market access to the (positive) relation we found when using longitudinal data. The availability of the model relating income to market access allowed us to interpret the negative short run impact on the household income as a change in the labor supply in agricultural sector and market competition in the nonagriculture sector.

In chapter 4, we found the evidence on the effects of access to water and sanitation for the rural poor in El Salvador. The initial level of access to water and sanitation in the beneficiary communities in northern El Salvador provided us with a fertile ground to explore how WASH interventions affect communities that have some access to water and sanitation but perhaps not of the adequate quality and safety. This impact evaluation explored the effects of WASH interventions on indicators of reliability, satisfaction, contamination, coping costs and time use. We found robust and significant benefits across the measures of access to water and sanitation, time to improved water sources, ownership and use of improved water and sanitation services, reliability of service, satisfaction with the water system, and reductions in the perceived risk. In addition, the results in this evaluation shows that in contexts where the initial level of water access is high, effects on the quantity of water are difficult to measure. The impact evaluation was also an opportunity to illustrate how a rigorous research design that combines matching and panel data could be used to estimate the impacts of infrastructure projects and provide credible and robust evidence of the impacts of this type of projects. This is a welcome contribution to the WASH literature and provides an empirical framework that future impact evaluations of community demand driven WASH interventions could adopt.

Both impact evaluations highlight the importance of combining design and longitudinal data to provide rigorous evidence of the impact (or lack of impacts) that can help us understand the different pathways through which these kinds of investments can improve the lives on the poor in rural areas.

\section{GROWTH AND GOVERNMENT EXPENDITURE DISTRIBUTIONAL EFFECTS}

Our results have several implications as to what type of budgetary allocation can compensate for the unequal effects growth has across different income groups. Social expenditures, such as health and education, should be better targeted toward the poor to achieve a higher pass-through from the fiscal to the household sector among the poorer sectors of the population. Finally, it shows that the possible distortionary effects that fiscal outlays can have among the better-off group can be buffered by the higher incidence of the benefits of growth on this group.

\section{RURAL ROADS IMPROVEMENT}

The impact evaluation of the Northern Transnational Highway (NTH) provides us with many important policy implications and lessons for the future; for El Salvador and for rural accessibility/road development projects in general. In this dissertation, we discuss the main policy implications of this impact evaluation and highlight what steps could improve similar impact evaluations in the future.

First, it is essential when thinking of roads - and especially of the NTH-to consider the need for a program that includes the improvement of the network of connecting roads (NCR). A major role of the NTH itself is to connect all the major roadways across the north of El Salvador; but households and small businesses (agricultural and non-agricultural), which are located at least thirty minutes from the NTH, will also need connecting roads that will allow them to maximize the benefits of the NTH. Although the project as originally conceived included both the NTH and NCR, the NCR were ultimately not built and this enormously affected the 
potential benefits of the NTH. What a household gains in travel times by moving across the NTH, it loses when traveling to locations off that major artery.

One major issue of the NTH is that, despite being designed to interconnect the northern part of El Salvador with Honduras and Guatemala, this never came to fruition because the agreements with the border countries were not implemented. This is a major lesson learned: These types of agreements should have been in place even before starting construction. The NTH could have been a trade corridor between the three countries. Instead, all the bilateral trade continues to go through the Pan-American Highway.

A project like the NTH could benefit many other interventions in the northern area. The existence of the NTH could have attracted many investment projects by the government or multilateral organizations like the InterAmerican Development Bank and World Bank, but this did not happen. One major policy recommendation for the present and into the future is to increase communication among stakeholders and the development community to raise awareness of the existence of the NTH across the multilateral agencies and other potential investors. In several meetings with project managers for the region at the IADB and World Bank, it was clear that they were not aware of this investment and of the potential that exists when developing new projects around the NTH area. These projects could substantially benefit from the NTH. In addition, many projects that would not have otherwise been feasible, including new private investments, could increase their economic rate of return.

The creation of the NTH for its own sake is not justified. It will not be sufficient on its own to create the desired changes and dynamics in the economy of the northern part of El Salvador. For this reason, it will be important for future projects like this to pay close attention to all the necessary investments and institutional reforms that are vital to create and promote the economic dynamism that is required to promote development in depressed regions. The Northern Zone of El Salvador is a region with an extremely complicated history, and it currently depends significantly on remittances for its subsistence. Many development projects are implemented in this region and, frequently, the explanation for their lack of success is that lack of accessibility results in lower-than-expected economic returns. In this case, however, the big investment has already been made and there needs to be a push to develop the region through other necessary investments. These investments could increase agricultural productivity or promote the development of a non-farm labor market in the region. These investments, in turn, will maximize future benefits from the significant investment that is the NTH. One important consideration is the set of complementarities in the provision of different types of infrastructure. Large projects can provide an opportunity to explore complementarities with other infrastructure programs, such as mobile telephony, road access, and improved water and sanitation access. They can shed light on what the most welfare-enhancing policy options are when deciding what types of infrastructure to provide in rural areas, and especially to poor rural households. This is an additional factor that foreign aid agencies, like the Millennium Challenge Corporation, should look at in different projects. For example, the overlap with the rural electrification project and the water and sanitation interventions was not optimized. In future research, we look to explore the effects of these complementarities in the impacts of the infrastructure projects that were implemented in the area.

\section{WATER, SANITATION AND HYGIENE}

When drawing policy implications, we are forced to consider the generalizability of our results. How similar interventions would work in a different context will depend on many variables: The targeted beneficiaries, the initial conditions of water and sanitation access in the zone, etc.

The main policy implications we draw from our WASH intervention impact results are the following:

- Even in areas where people do not spend very much time carrying or fetching water, the introduction of reliable potable water systems can provide time savings. 
- These time savings could potentially be used in productive activities. However, this reallocation of labor would not be considerable in a setting comparable to this. In fact, we found that the time saved is largely allocated to leisure, with some gains spent in education for children. The reallocation of these savings would largely depend in complementary activities that promote participation in nonfarm productive labor and that perhaps couples the increased availability of water to productive activities, such as small rural businesses and productive time at home, especially for women.

- The reliability of the water system is very important given the potential of contamination from storage. We find that new systems have better chlorination rates but the level of contamination of drinking water at the point of consumption was not very different. The increase in the quality of water directly from the tap is easily degraded due to inadequate treatment and storage.

- Frequent water quality tests of the water systems are necessary to monitor water quality and systems that provide automatic chlorination have the potential of improving water quality. While we find that the new water systems had higher chlorination rates in general, the number of treatment communities with appropriate levels of chlorine at the point of consumption was low and the contamination with fecal matter remained.

- Campaigns that promote good practices for drinking water and water storage at the household level could improve water quality at the point of consumption. ${ }^{49}$ In this study, we found that households were receiving more reliable service, but contamination at the point of consumption remained high. The implication from this finding is that even with appropriate levels of service, information campaigns and change in behaviors have an opportunity to decrease waterborne and watershed diseases.

\footnotetext{
${ }^{49}$ This intervention included information campaigns to promote appropriate hygiene practices. However, we did not find significant effects in the hygiene practices measures we explored. The implication here is that content of the campaign, and perhaps the way it is delivered, could be of importance.
} 


\section{BIBLIOGRAPHY}

\section{References on Distributional Effects of Growth and Public Expenditures}

Afonso, A., L. Schuknecht, and V. Tanzi. 2010. "Income distribution determinants and public spending efficiency." The Journal of Economic Inequality 8 (3): 367-389

Agénor, P. R., and K. C. Neanidis. 2011. "The Allocation of Public Expenditure and Economic Growth." The Manchester School 79 (4): 899-931.

Alesina, A., and E. La Ferrara. 2005. "Preferences for Redistribution in the Land of Opportunities." Journal of Public Economics 89 (5-6): 897-931.

Alesina, A., and D. Rodrik. 1994. "Distributive Policies and Economic Growth." Quarterly Journal of Economics 109: 465-490.

Arjona, R., M. Ladaique, and M. Pearson. 2003. "Growth, Inequality and Social Protection." Canadian Public Policy/Analyse de Politiques 29: S119-S139.

Aschauer, D. 1989. "Is Public Expenditure Productive?" Journal of Monetary Economics 23 (2): 177-200.

Ashley, R. A. 2006. Growth May Be Good for the Poor, But Decline is Disastrous: On the Non-Robustness of the Dollar-Kraay 'Growth is Good for the Poor' Result. Department of Economics Working Paper e06-8. Blacksburg, VA, US: Virginia Polytechnic Institute and State University.

Balakrishnan, R., C. Steinberg, and M. Syed. 2013. "The Elusive Quest for Inclusive Growth: Growth, Poverty, and Inequality," IMF Working Paper WP/13/152

Barro, R. J. 1990. "Government Spending in a Simple Model of Endogenous Growth." Journal of Political Economy 98 (S5): 103-125.

- - . 1991. "Economic Growth in a Cross Section of Countries." Quarterly Journal of Economics 106 (2): $407-$ 443.

Bassett, W. F., J. P. Burkett, and L. Putterman. 1999. "Income Distribution, Government Transfers, and the Problem of Unequal Influence." European Journal of Political Economy 15 (2): 207-228.

Benabou, R. 1996. "Inequality and Growth." In NBER Macroeconomics Annual 1996, Vol. 11, edited by B. S. Bernanke and J. J. Rotemberg, 11-92. Cambridge, MA, US: MIT Press.

- - . 2000. "Unequal Societies: Income Distribution and the Social Contract." American Economic Review 90 (1): 96-129.

Bertola, G. 1993. "Factor Shares and Savings in Endogenous Growth." American Economic Review 83 (5): 11841198.

Bose, N., M. Haque, and D. R. Osborn. 2003. "Public Expenditure and Growth in Developing Countries: Education is the Key." Presented at the 35th Annual Money Macro and Finance (MMF) Research Group Conference, Cambridge, UK, September 10-12, 2003.

Bradley, D., E. Huber, S. Moller, F. Nielsen, and J. D. Stephens. 2003. "Distribution and Redistribution in Postindustrial Democracies." World Politics 55 (2): 193-228.

Caselli, F., E. Esquire, and F. Lefort. 1996. "Re-opening the Convergence Debate: A New Look at Cross-Country Growth Empirics." Journal of Economic Growth 1 (3): 363-389.

Castello, A., and R. Domenech. 2002. "Human Capital Inequality and Economic Growth: Some New Evidence." The Economic Journal 112 (478): C187-C200. 
Chen, S., and M. Ravallion. 1997. "What Can New Survey Data Tell Us about Recent Changes in Distribution and Poverty?" The World Bank Economic Review 11 (2): 357-382.

Deaton, A. 2003. "Health, Inequality, and Economic Development." Journal of Economic Literature 41 (1): $113-$ 158.

Deininger, K., and L. Squire. 1996. "A New Data Set Measuring Income Inequality." The World Bank Economic Review 10 (3): 565-591.

- - . 1998. "New Ways of Looking at Old Issues: Inequality and Growth." Journal of Development Economics 57 (2): 259-287.

Devarajan, S., V. Swaroop, and H. Zou. 1996. "The Composition of Public Expenditure and Economic Growth." Journal of Monetary Economics 37 (2): 313-344.

Dollar, D., and A. Kraay. 2002. "Growth is Good for the Poor." Journal of Economic Growth 7 (3): $195-225$.

- - . 2004. "Trade, Growth, and Poverty." The Economic Journal 114 (493): F22-F49.

Dollar, D., Kleineberg, T., and Kraay, Aart, 2016."Growth still is good for the poor," European Economic Review 81(1): 68-85

Easterly, W., and S. Rebelo. 1993. "Fiscal Policy and Economic Growth: An Empirical Investment." Journal of Monetary Economics 32 (3): 417-458.

Folster, S., and M. Henrekson. 2001. "Growth Effects of Government Expenditure and Taxation in Rich Countries." European Economic Review 45 (8): 1501-1520.

Foster, J. E., and M. Székely. 2008. "Is Economic Growth Good For The Poor? Tracking Low Incomes Using General Means." International Economic Review 49 (4): 1143-1172.

Gallup, J., S. Radelet and A. Warner. 1999. Economic Growth and the Income of the Poor. CAER II Discussion Paper No. 36. Cambridge, MA, US: Harvard Institute for International Development.

Gylafson, T., and G. Zoega. 2003. Education, Social Equality and Economic Growth: A View of the Landscape. CESifo Working Paper Series No. 876. Munich, Germany: CESifo Group Munich.

Islam, N. 1995. "Growth Empirics: A Panel Data Approach." The Quarterly Journal of Economics 110 (4): $1127-$ 1170.

Jones, L., R. Manuelli, and P. Rossi. 1993. "Optimal Taxation in Models of Endogenous Growth." Journal of Political Economy 101 (3): 485-517.

Kenworthy, L., and J. Pontusson. 2005. Rising Inequality and the Politics of Redistribution in Affluent Countries. Luxembourg Income Study Working Paper Series No. 400. Syracuse, NY, US: Syracuse University, Maxwell School of Citizenship and Public Affairs.

Kneller, R., M. Bleaney, and N. Gemmell. 1999. "Fiscal Policy and Growth: Evidence of OECD Countries." Journal of Public Economics 74 (2): 171-190.

Kormendi, R., and P. Meguire. 1985. "Macroeconomics Determinants of Growth: Cross-Country Evidence." Journal of Monetary Economics 16 (2): 141-163.

Kristov, L., P. Linder, and R. McClelland. 1992. "Pressure Groups and Redistribution." Journal of Public Economics 48 (2): 135-163.

Landau, D. 1986. "Government and Economic Growth in the Less Developed Countries: An Empirical Study for 1960-80." Economic Development and Cultural Change 35 (1): 36-75. 
Levine, R., and D. Renelt. 1992. "A Sensitivity Analysis of Cross-Country Growth Regressions." The American Economic Review 82 (4): 942-963.

Mankiw, G., D. Romer, and D. Weil. 1992. "A Contribution to the Empirics of Economic Growth." Quarterly Journal of Economics 107 (2): 407-437.

Milanovic, B. 2000. "The Median Voter Hypothesis, Income Inequality, and Income Distribution: An Empirical Test with the Required Data." European Journal of Political Economy 16 (3): 367-410.

Moene, K. O., and M. Wallerstein. 2001. "Inequality, Social Insurance, and Redistribution." The American Political Science Review 95 (4): 859-874.

Osberg, L. S. 1995. “The Equity/Efficiency Tradeoff in Retrospect.” Canadian Business Economics 3 (3): 5-20.

Perroti, R. 1992. “Income Distribution, Policies, and Growth.” The American Economic Review 82 (2): 311-316.

- - 1996. "Growth, Income Distribution, and Democracy: What the Data Say." Journal of Economic Growth 1 (2): 149-187.

Persson, T., and G. Tabellini. 1994. “Is Inequality Harmful for Growth?” The American Economic Review 84 (3): $600-621$.

Ram, R. 1986. "Government Size and Economic Growth: A New Framework and Some Evidence from CrossSection and Time-Series Data." The American Economic Review 76 (1): 191-203.

Ravallion, M. 2004. Pro-Poor Growth: A Primer. World Bank Policy Research Working Paper No. 3242. Washington, DC: World Bank.

Ross, C., and C. Wu. 1995. "The Links between Education and Health." American Sociological Review 60 (5): 719-745.

Sala-i-Martin, X. 1997. “Transfers, Social Safety Nets, and Economic Growth.” IMF Staff Papers 44 (1): 81-102.

Sattar, Z. 1993. "Public Expenditure and Economic Performance: A Comparison of Developed and Low-Income Developing Economies." Journal of International Development 5 (1): 27-49.

Schaltegger, C., and B. Torgler. 2006. "Growth Effects of Public Expenditure on the State and Local Level: Evidence from a Sample of Rich Governments." Applied Economics 38 (10): 1181-1192.

Shirima, L. L. 2004. Intergovernmental Transfers Reform and Equalization Formula Design for the Republic of Rwanda. Kigali, Rwanda: Ministry of Local Government, Information and Social Affairs (MINALOC)/USAID Fiscal Decentralization Project.

Stokey, N., and S. Rebelo. 1993. "Growth Effects of Flat-Rate Taxes." Journal of Political Economy 101 (3): $519-$ 550.

Turnbull, G. K., and S. S. Djoundourian. 2005. "The Median Voter Hypothesis: Evidence from General Purpose Local Governments." Public Choice 81 (3-4): 223-240.

Van der Ploeg, F. 2003. Do Social Policies Harm Employment and Economic Growth? CESifo Working Paper No. 886. Munich, Germany: CESifo Group Munich.

Wikstrom, M. 1999. Income Distribution Effects from Local Public Expenditures in the Swedish Municipalities. Umeå Economic Studies No. 515. Umeå, Sweden: University of Umeå, Department of Economics.

World Bank. 2006. World Development Report 2006: Equity and Development. Washington, DC: World Bank.

- - . 2016. World Development Indicators: GDP per capita growth (annual \%), General government final consumption expenditure (annual \% growth). Retrieved from http://databank.worldbank.org/ 


\section{REFERENCES ON ROAD IMPROVEMENTS AND DEVELOPMENT}

Aigner, D. J., Lovell, C. A., \& Schmidt, P. (1977). Formulation and Estimation of Stochastic Frontier Production Function Models. Journal of Econometrics, 6, 21-37.

Antle, J. (1983). Infrastructure and Aggregate Agricultural Productivity: International Evidence. Economic Development and Cultural Change, 31, 600-619.

---. (1984). Human Capital, Infrastructure, and the Productivity of Indian Rice Farmers. Journal of Development Economics, 14, 163-181.

Armington, P. S. (1969). A theory of demand for products distinguished by place of production. IMF Staff papers, 16, pp.159-76.

Binswanger, H., Khandker, S., \& Rosenzweig, M. (1993). How Infrastructure and Financial Institutions Affect Agricultural Output and Investment. World Bank Working Paper.

Casaburi, L., Glennester, R., \& Suri, T. (2013). Rural Roads and Intermediated Trade: Regression Discontinuity Evidence from Sierra Leone.

Datta, S. (2012). The Impact of Improved Highways on Indian Firms. Journal of Development Economics, 99.

Dercon, S., Gilligan, D., Hoddinott, J., \& Woldehanna, T. (2008). The Impact of Agricultural Extension and Roads on Poverty and consumption Growth in Fifteen Ethiopian Villages.

Fan, S., Hazell, P., \& Thorat, S., (2000), Government Spending, Growth and Poverty in Rural India, American Journal of Agricultural Economics, 82, issue 4, p. 1038-1051

Jacoby, H. G. (2000). Access to Markets and the Benefits of Rural Roads. The Economic Journal, 110, 713-737.

Jacoby, H. G., \& Minten, B. (2009). On Measuring the Benefits of Lower Transport Costs. Journal of Development Economics, 89(2009), 28-38.

Khandker, B., \& Koolwal, G. (2011). Estimating the Long-term Impact of Rural Roads. Policy Research Working Papers, The World Bank.

Khandker, S., Bakht, Z., \& Koolwal, G. (2009). The Poverty Impact of Rural Roads in Bangladesh. Economic Development and Cultural Change, 57(4), 685-722.

Lofgren, H., Lee Harris, R., \& Robinson, S. (2001) "A Standard Computable General Equilibrium (CGE) Model in GAMS."

Lokshin, M., \& Yemtsov, R. (2005). Has Rural Infrastructure Rehabilitation in Georgia Helped the Poor. World Bank Economic Review, 19(2), 311-333.

Meeusen, W., \& van den Broeck, J. (1977). Efficiency Estimation from Cobb-Douglas Production Functions with Composed Error. International Economic Review, 18, 435-444.

Morley, S., Piñeiro, V., \& Robinson, S. (2011). External shocks and policy alternatives in small open economies: the case of El Salvador, Trade and Markets Division Discussion Paper 1134. International Food Policy Research Institute, Washington, D.C.

Mortensen, D. (2003). Wage Dispersion: Why are similar workers Paid Differently. Cambridge: MIT Press. 192 
Mu, R., \& Van de Walle, D. (2011). Rural Roads and Local Market Development in Vietnam. Journal of Development Studies, 47(5), 709-734.

Peters, D. (2001). Gender and Transport in Less developed Countries." UNED Forum. London.

Qin, Y., \& Zhang, X. (2012). Road to Specialization in Agricultural Production: Evidence from Rural China. IFPRI Discussion Paper.

Raballand, G., Macchi, P., \& Petracco, C. (2010). Rural Road Investment Efficiency. World Bank.

Rand, J. (2011). Evaluating the Employment-generating Impact of rural Roads in Nicaragua. Journal of Development Effectiveness, 3(1), 28-43.

Roy, A. (1951). Some Thoughts on the Distribution of Earnings. Oxford Economic Papers 3:135-145.

Rubin, D. (1974). Estimating Causal Effects to Treatments in Randomized and Nonrandomized Studies. Journal of Educational Psychology 66: 688-701.

- - - (1977). Assignment to Treatment Group on the Basis of a Covariate. Journal of Educational Studies. 2:1-26.

- - - (1979). Using Multivariate Matched Sampling and Regression Adjustment to Control Bias in Observational Studies. Journal of the American Statistical Association 74:318-328.

Stifel, D., Minten, B., \& Koro, B. (2012). Economic Benefits and Returns to Rural Feeder Roads: Evidence from a Quasi-Experimental Setting in Ethiopia. IFPRI ESSP II Working Paper.

Stock, J.H. and Yogo, M. 2005. Testing for Weak Instruments in Linear IV Regression. In D.W.K. Andrews and J.H. Stock, eds. Identification and Inference for Econometric Models: Essays in Honor of Thomas Rothenberg. Cambridge: Cambridge U, Press, 2005, pp. 80-108. Working paper version: NBER Technical Working Paper 284. http://www.nber.org/papers/T0284.

Torero, M. (2014). Targeting investments to link farmers to markets: a framework for capturing the heterogeneity of smallholder farmers. 2014. In: New Directions for Smallholder Agriculture. Hazell et al. Oxford University Press.

Valdivia, M. (2009). Contracting the Road to Development: Early Impacts of a Rural Roads Program. GRADE Working Paper.

Van de Walle, D. (2002). Choosing Rural Road Investments to Help Reduce Poverty. World Development, 30(4), 575-589.

- - . (2009). Impact Evaluation of Rural Road Projects. Journal of Development Effectiveness, 1(1), 15-36.

Van de Walle, D., \& Cratty, D. (2002). Impact Evaluation of a Rural Road Rehabilitation Project. World Bank.

Wondemu, K., \& Weiss, J. (2012). Rural Roads and Development: Evidence from Ethiopia. European Journal of Transport and Infrastructure Research, 12(4), 417-439.

World Bank. (2011). Making Transport Work for Women and Men: Challenges and Opportunities in the Middle East and North Africa.

Yamauchi, F., Muto, M., Chowdhury, S., \& Dewina, R. (2011). Are Schooling and Roads Complementary? Evidence from Income Dynamics in Rural Indonesia. World Development, 39(12), 2232-2244. 
Zhang, X., \& Fan, S. (2004). How Productive is Infrastructure? A New Approach and Evidence from Rural India. American Journal of Agricultural Economics, 86(2), 492-501.

\section{REFERENCES ON WASH INTERVENTIONS AND DEVELOPMENT}

Abadie, A. \& Imbens, G. W., 2006. Large Sample Properties of Matching Estimators for Average Treatment Effects. Econometrica, 74(1), pp. 235-267.

Abadie, A. \& Imbens, G. W., 2008. On the Failure of the Bootstrap for Matching Estimators. Econometrica, November, Volume 76(6), pp. 1537-1557.

Angrist, J. D. \& Hahn, J., 2004. When to Control for Covariates? Panel-Asymptotic Results for Estimates of Treatment Effects. The Review of Economics and Statistics, 86(1):(February ), p. 58-72.

Austin, P. C., 2011. Optimal caliper widths for propensity-score matching when estimating differences in means and differences in proportions in observational studies. Pharmaceutical Statistics, March/April, 10(2), p. 150-161.

Bosch, C. et al., 2000. Water and Sanitation. In: A Sourcebook for Poverty Reduction Strategies. Washington(D.C): World Bank, pp. 371-404.

Cameron, A. C., Gelbach, J. B. \& Miller, D. L., 2011. Robust Inference With Multiway Clustering. Journal of Business \& Economic Statistics, 29(2), pp. 238-249.

Chase, R. S., 2002. Supporting Communities in Transition: The Impact of the Armenian Social Investment Fund. World Bank Economic Review, 16(2), pp. 219-240.

Clasen, T. \& Bastable, A., 2003. Faecal contamination of drinking water during collection and household storage: the need to extend protection to the point of use. Journal of Water and Health, 109(15).

Deaton, A. \& Zaidi, S., 1999. Guidelines for Constructing Consumption Aggregates For Welfare Analysis, s.l.: Princeton University.

Dehejia, R. H. \& Wahba, S., 1994. Causal Effects in Nonexperimental Studies: Reevaluating the Evaluation of Trainning Programs. Journal of the American Statistical Society, pp. 1053-1062.

Devoto, F. et al., 2012. Happiness on Tap: Piped Water Adoption in Urban Morocco. American Economic Journal: Economic Policy, 4(4), pp. 68-99.

DIGESTYC, 2007. Encuesta de Hogares de Própositos Múltiples - Zona Norte.

DIGESTYC, 2012. Encuesta de Hogares de Propósitos Múltiples 2011, Ciudad Delgado,: s.n.

Diggle, P., Liang, K.-Y. \& Zeger, S. L., 1994. Analysis of Longitudinal Data. New York, NY: Oxford University Press.

Donner, A., 1998. Some Aspects of the Design and Analysis of Cluster Randomization Trials. Journal of the Royal Statistical Society, 47(1). 
Donner, A., Birkett, N. \& Buck, C., 1981. Randomization by cluster: sample size requirements and analysis. American Journal of Epidemiology, Issue 114, pp. 906-914.

Esrey, S. A., 1996. Water, waste, and well-being: a multicountry study. American journal of epidemiology, 143(6), pp. 608-623.

Esrey, S. A., Potash, J. B., Roberts, L. \& Shiff, C., 1991. Effects of improved water supply and sanitation on ascariasis, diarrhoea, dracunculiasis, hookworm infection, schistosomiasis, and trachoma.. Bulletin of the World Health organization, 69(5).

Fan, V. Y.-M. \& Mahal, A., 2011. What prevents child diarrhoea? The impacts of water supply, toilets, and hand-washing in rural India. Journal of Development Effectiveness, 3(3), pp. 340-370.

Fewtrell, L. et al., 2005. Water, Sanitation, and Hygiene Interventions to Reduce Diarrhoea in Less Developed Countries: A Systematic Review and Meta-Analysis. The Lancet Infectious Diseases, 5(1), pp. 42-52.

Firth, J. et al., 2010. Point-of-Use Interventions to Decrease Contamination of Drinking Water: A Randomized, Controlled Pilot Study on Efficacy, Effectiveness, and Acceptability of Closed Containers, Moringa oleifera, and In-home Chlorination in Rural South India. The American Journal of Tropical Medicine and Hygiene, 82(5), pp. 759-765.

FISDL, 2005. Fondo de Inversión Social para el Desarrollo. [Online] Available at: $\quad$ http://www.fisdl.gob.sv/documentos/libromapapobreza/ [Accessed 2012].

Galiani, S., Gertler, P. \& Schargrodsky, E., 2005. Water for Life: The Impact of the Privatization of Water Services on Child Mortality. Journal of Political Economy, 113(1), pp. 83-120.

Galiani, S., Gonzalez-Rozada, M. \& Schargrodsky, E., 2009. Water Expansions in Shantytowns: Health and Savings. Economica, 76(304), pp. 607-622.

Gamper-Rabindran, S., Khan, S. \& Timmins, C., 2010. The impact of piped water provision on infant mortality in Brazil: A quantile panel data approach. Journal of Development Economics, 92(2), pp. 188-200.

Ham, J. C., Li, X. \& Reagan, P. B., 2011. Matching and semi-parametric IV estimation, a distancebased measure of migration, and the wages of young men. Journal of Econometrics, April, Volume 161(2), pp. 208-227.

Heckman, J., Ichimura, H., Smith, J. \& Todd, P., 1998. Characterizing Selection Bias Using Experimental Data. Econometrica, pp. 1017-1098.

Heckman, J., Ichimura, H. \& Todd, P., 1997. Matching as an Econometric Evaluation Estimator: Evidence from Evaluating a Job Training Program. Review of Economic Studies, pp. 605-654.

Heckman, J., Ichimura, H. \& Todd, P., 1998. Matching as an Econometric Evaluation Estimator. Review of Economic Studies, pp. 261-294. 
Imbens, G. W., 2004. Nonparametric Estimation of Average Treatment Effects: A Review. The Review of Economics and Statistics, 86(1):(February), p. 4-29.

Jalan, J. \& Ravallion, M., 2003. Does piped water reduce diarrhea for children in rural India?. Journal of Econometrics, 112(1), pp. 153-173.

Klasen, S., Lechtenfeld, T., Meier, K. \& Rieckmann, J., 2011. Impact Evaluation Report: Water Supply and Sanitation in Provincial Towns in Yemen, Courant Research Centre PEG, Gottingen: Courant Research Centre: Poverty, Equity and Growth - Discussion Papers 102.

Klasen, S., Lechtenfeld, T., Meier, K. \& Rieckmann, J., 2012. Benefits trickling away: the health impact of extending access to piped water and sanitation in urban Yemen. The Journal of Development Effectiveness, 4(4), pp. 537-565.

Koolwal, G. \& van de Walle, D., 2013. Access to Water, Women's Work, and Child Outcomes. Economic Development and Cultural Change, 61(2), pp. 369 - 405.

Kremer, M., Leino, J., Miguel, E. \& Zwane, A. P., 2011. Spring Cleaning: Rural Water Impacts, Valuation, and Property Rights Institutions. The Quarterly Journal of Economics, 126(1), pp. 145-205.

Lamichhane, D. K. \& Mangyo, E., 2011. Water accessibility and child health: Use of the leave-out strategy of instruments. Journal of Health Economics, 30(5), pp. 1000-1010.

Levy, K., Nelson, K. L., Hubbard, A. \& Eisenberg, J. N. S., 2008. Following the Water: A Controlled Study of Drinking Water Storage in Northern Coastal Ecuador. Environmental Health Perspectives, 116(11), pp. 1533-1540.

Lokshin, M. \& Yemtsov, R., 2005. Has rural infrastructure rehabilitation in Georgia helped the poor?. The World Bank Economic Review, 19(2), pp. 311-333.

Mangyo, E., 2008. The effect of water accessibility on child health in China. Journal of Health Economics, 27(5), pp. 1343-1356.

MCC, 2012. Millennium Challenge Account - El Salvador, Monitoring and Evaluation Plan, s.I.: s.n.

Miguel, E. \& Kremer, M., 2004. Worms: Identifying Impacts on Education and Health in the Presence of Treatment Externalities. Econometrica, 72(1), pp. 159-217.

Murray, D., 1998. Sample Size Detectable Difference, and Power. In: Design and Analysis of GroupRandomized Trials. New York and Oxford: Oxford University Press, pp. 349-413.

Nauges, C. \& Strand, J., 2007. Estimation of non-tap water demand in Central American cities. Resource and Energy Economics, 29(3), pp. 165-182.

Newman, J. et al., 2002. An Impact Evaluation of Education, Health, and Water Supply Investments by the Bolivian Social Investment Fund. World Bank Economic Review, 16(2), pp. 241-274 .

Olmstead, S. M., Hanemann, M. W. \& Stavins, R. N., 2007. Water demand under alternative price structures. Journal of Environmental Economics and Management, 54(2), pp. 181-198. 
Oswald, W. et al., 2007. Fecal contamination of drinking water within peri-urban households, Lima, Peru. The American Journal of Tropical Medicine and Hygiene, 77(4), pp. 699-704.

Pattanayak, S. K., Poulos, C., Yang, J.-C. \& Patil, S., 2010. How valuable are environmental health interventions? Evaluation of water and sanitation programmes in India. Bulletin of the World Health Organization, Issue 88, pp. 535-542.

Pattanayak, S. K., Yang, J.-C., Whittington, D. \& Bal Kumar, K. C., 2005. Coping with unreliable public water supplies: Averting expenditures by households in Kathmandu, Nepal. Water Resources Research, 41(2).

Pattanayak, S. et al., 2009. Of taps and toilets: quasi-experimental protocol for evaluating community-demand-driven projects. Journal of Water and Health, 7(3), pp. 434-451.

Pattanayak, S. et al., 2008. Three years later: Environmental health impacts of a communitydemand-driven water and sanitation program in rural Maharashtra, India. RTI International Working Paper 08-01.

Poulos, C., Pattanayak, S. \& Jones, K., 2006. A Guide to Water and Sanitation Sector Impact Evaluations. Doing Impact Evaluation Series, World Bank.

Purdon, S., 2002. Estimating the impact of labour market programmes, Great Britain: Department for Work and Pensions, Social Research Branch.

Rauniyar, G., Orbeta, A. \& Sugiyarto, G., 2011. Impact of water supply and sanitation assistance on human welfare in rural Pakistan. Journal of Development Effectiveness, 3(1), pp. 62-102.

Ravallion, M., 2007. Evaluating anti-poverty programs.. Handbook of development economics, Volume 4, pp. 3787-3846.

Ravallion, M., 2008. Evaluating Anti-Poverty Programs. In: T. P. Schultz \& J. Strauss, eds. Handbook of Development Economics. Amsterdam: s.n.

Rosenbaum, P. \& Rubin, D. B., 1983. The Central Role of Propensity Score in Observational Studies. Biometrika, pp. 41-55.

Roy, A., 1951. Some Thoughts on the Distribution of Earnings". Oxford Economic Papers, Volume 3, pp. $135-145$.

Rubin, D., 1974. Estimating Causal Effects to Treatments in Randomized and Nonrandomized Studies. Journal of Educational Psychology, Volume 66, pp. 688-701.

Rubin, D., 1977. Assignment to Treatment Group on the Basis of a Covariate. Journal of Educational Studies. , Volume 2, pp. 1-26.

Rubin, D., 1979. Using Multivariate Matched Sampling and Regression Adjustment to Control Bias in Observational Studies. Journal of the American Statistical Association, Volume 74, pp. 318-328.

Schmidt, W.-P. \& Cairncross, S., 2009. Household Water Treatment in Poor Populations: Is There Enough Evidence for Scaling up Now?. Environmental Science \& Technology, 43(4), p. 986-992. 
Simonne Rufener, c. a., Mäusezahl, D., Mosler, H.-J. \& Weingartner, R., 2010. Quality of Drinkingwater at Source and Point-of-consumption-Drinking Cup As a High Potential Recontamination Risk: A Field Study in Bolivia. Journal of Health, Population, and Nutrition, 28(1), pp. 34-41.

Strand, J. \& Walker, I., 2005. Water markets and demand in Central American cities. Environment and Development Economics, June, Volume 10(03), pp. 313-335.

Talley, N., Weaver, A., Zinsmeister, A. \& Melton, L. 3., 1994. Self-reported diarrhea: what does it mean?. American Journal of Gastroenterology , 89(8).

Todd, P. E., 2008. Evaluating Social Programs with Endogenous Program Placement and Selection of the Treated. In: T. P. S. \&. J. A. Strauss, ed. Handbook of Development Economics. 1 ed. s.l.:s.n.

van de Walle, D. \& Cratty, D., 2002. Impact Evaluation of a Rural Road Rehabilitation Project, s.I.: s.n.

WHO/UNICEF, 2005. Water for life : making it happen, s.l.: World Health Organization Press.

WHO; UNICEF, 2013. Progress on sanitation and drinking-water. 2013 update: Joint Monitoring Programme for Water Supply and Sanitation, s.I.: s.n.

WHO, 2013. media Center: Fact sheets: Diarrhoeal disease. [Online] Available at: http://www.who.int/mediacentre/factsheets/fs330/en/ [Accessed July 2013].

World Health Organization, 1997. Volume 3 - Surveillance and Control of Community Supplies. In: Guidelines for Drinking-Water Quality. 2nd ed. Geneva: s.n., pp. 114-115.

Wright, J., Gundry, S. \& Conroy, R., 2004. Household drinking water in developing countries: a systematic review of microbiological contamination between source and point-of-use. Tropical Medicine \& International Health, 9(1), pp. 106-117.

Zwane, A. P. \& Kremer, M., 2007. What works in fighting diarrheal diseases in developing countries?. NBER Working Paper Series, March. 


\section{Annex 1 -Calculating the Time And Cost of TRAVel: AcCessibility MODEL}

GIS data made it possible to investigate the market access question in a more sophisticated way. With this data, one can calculate the shortest time or distance from any village to a regional or local market using the distance traveled on different road surfaces combined with an impedance measure (for example rivers, or geographical faults) which reflects the speed one can travel on roads of different qualities and on the slope of the terrain through which the road passes. The resulting market access measure can be expressed as a weighted average of the distance traveled on each type of road, where the weights are proportional to the impedance factor.

There are two problems with these measures of access. The first is that they do not incorporate transportation costs, which may well vary with distance and type of road surface in a different way than does with time. Where that is the case, the time based measure will be misleading because it could imply that for a particular village, one market is closer than another-taking less time to get there even though it may cost more to get there. By the same token, it could imply that one village is "closer" to market than another as measured by time but not when measured by cost. But presumably what the farmer wants to know is not how far it is to his market, but rather how much he can sell his produce for in that market or, equivalently, what his farm gate price is, net of transportation cost. In this study, we use a measure that incorporates both aspects and report our measure of the merge market distance data for each household in the influence area with a matrix of transportation costs by truck on two different classes of roads, and on rivers or by animal on trails where there are no roads This gives us a measure of accessibility in terms of costs.

The second problem with the typical market access indicator is that it considers only the local market. However, the level of prices in local markets may well vary according to how far they are from the country's largest market. It could well be that a farmer would get a higher price for his products by shipping them to a market which, while further from his village, is closer to the largest market or equivalently, in which the price of his product is higher. Therefore, we estimate the costs to simultaneously access the local market and the largest market. The variable reported is the one that minimizes the cost of access to both markets simultaneously.

\section{The Accessibility Model}

To "connect" every household with the closest market, we constructed a series of accessibility indicators. The notion behind them is that accessibility is not a discrete variable (i.e. have or do not have access), but a continuum that reflects the difficulties each household faces when trying to access different types of infrastructure. This accessibility analysis was applied to the entire land surface.

Accessibility is defined as how feasible it is to reach a location from others, considering factors like distance, moving costs, type of transportation, and time. In other words, any indicator of effort to reach or access a particular location. The base of this analysis is assuming that people are likely to move through highways, major roads, or paths in the case those exist, but otherwise would walk their way around to the nearest market. The final objective is calculating the time a person invests on reaching the nearest market through the fastest way.

The moving time on the land surface depends on different factors, the most important one being the distance. However, there are other important factors, such as the existing road network and its specific characteristics, the slope and the presence of obstacles like rivers (except for those cases where rivers are used as a means of transport), etc. 
The accessibility analysis was developed on a raster format, which means that the entire area of analysis was converted into a grid of cells measuring 25 by 25 meters, in the case of El Salvador. Each cell was assigned a "friction" value based on characteristics of slope, roads, and barriers, which allowed each cell to be allotted a value for the time required to reach the nearest facility (Figure 60 and Figure 61). Having created the friction grid, the cost weighted distance algorithm runs over the raster surface, calculating the accumulated time departing from each market available, replacing overlapping values with the least time consuming route.

\section{FIGURE 60 FRICTION SURFACE BETWEEN POINTS A AND B}

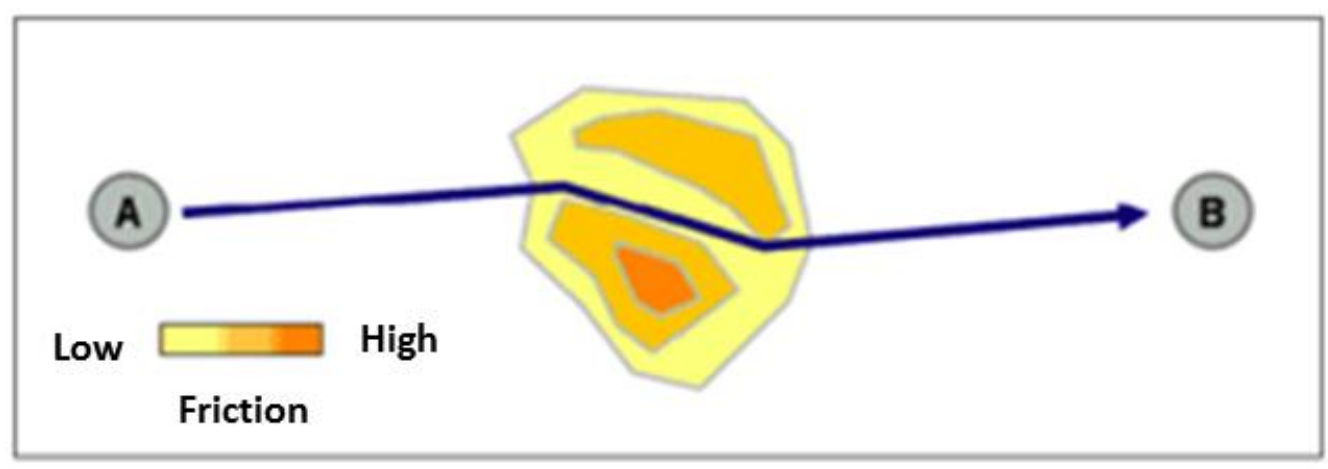

FIGURE 61 VALUES INDICATING THE DIFFICULTY OF CROSSING A “CELL”

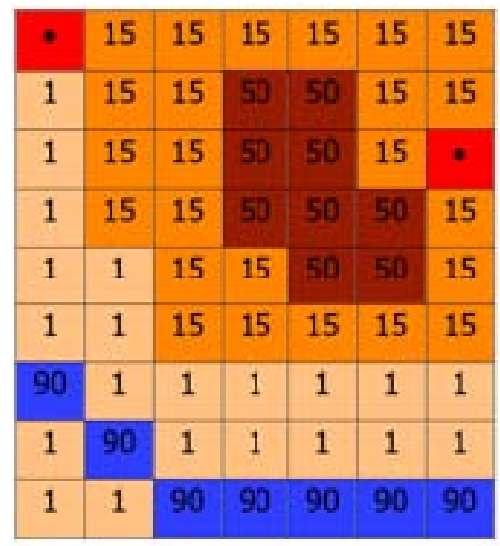

The first variable is the slope, which has been used to calculate a walking travel speed that depends indirectly from it. Tobler's (1993) walking velocity has three variations, one corresponding to a footpath, another to a horseback, and finally one for off path. The horseback walking velocity is assigned to the dirt road tracks, the footpaths velocity is assigned to walking trails, and the off path walking velocity is assigned when there are no paths available. The following calculations resulted, where (see Figure 62):

\section{FIGURE 62 CALCULATION OF SLOPE}

$$
\text { SLOPE }=\frac{\text { height }}{\text { distance }} * 100
$$

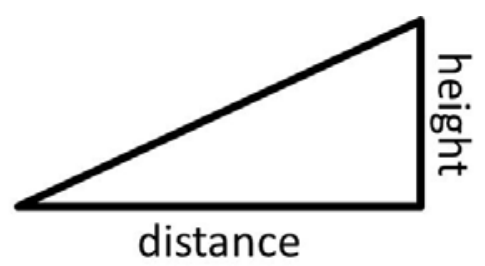

Walking velocity on footpath $=[6 \times \exp (-3.5 \times$ abs $(S+0.05))]$

Walking velocity on horseback $=[6 \times \exp (-3.5 \times$ abs $(S+0.05))] \times 1.25$ 
Walking velocity off-path $=[6 \times \exp (-3.5 \times$ abs $(S+0.05))] \times 0.6$

The following table presents the results for each of the road classifications:

TABLE 88 RESULTS PER ROAD CLASSIFICATION

\begin{tabular}{|l|c|}
\hline & Average speed travel Km/Hour \\
\hline Dirt Road Tracks & (Walking Velocity on footpath)X1.25 \\
\hline Walking Trails & Walking Velocity on footpath \\
\hline No ways & (Walking Velocity on footpath)X0.6 \\
\hline
\end{tabular}

FIGURE 63 TIMES CALCULATED ONLY WITH THE OFF-PATH WALKING VELOCITY

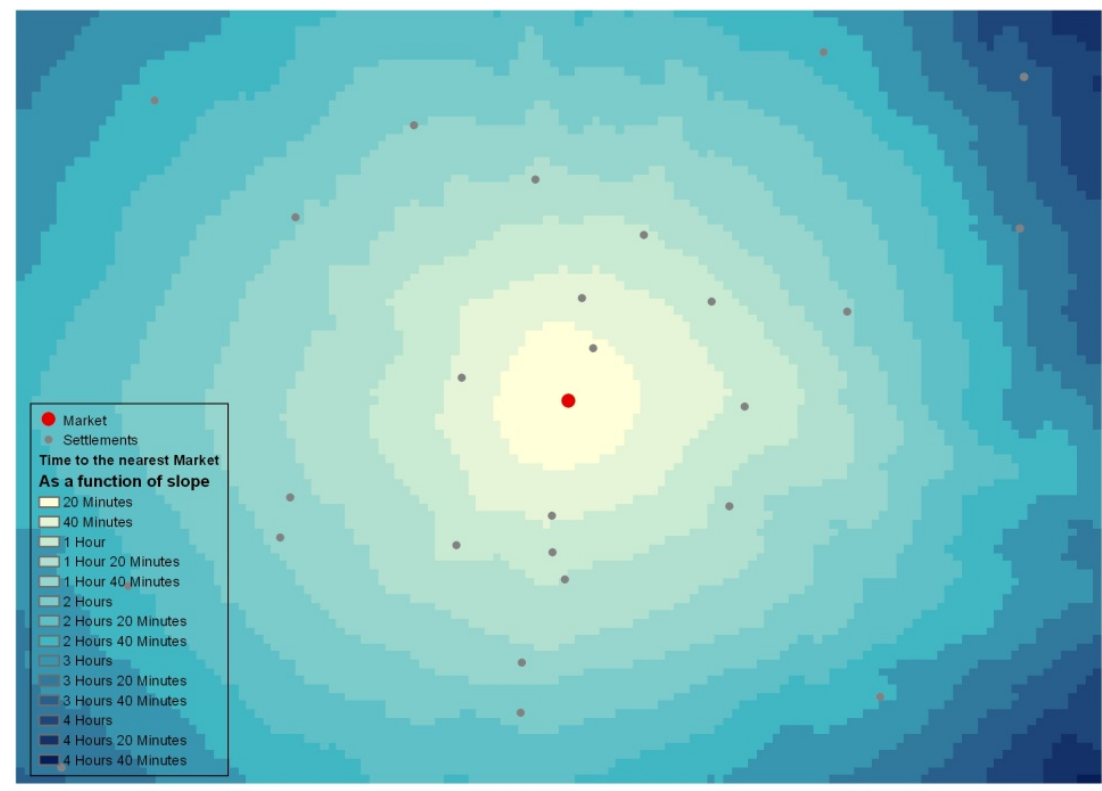

The second variable used in this analysis was transportation infrastructure, of which El Salvador has two major kinds: paved roads and unpaved roads. In addition there are some rivers though which navigation occurs. Each type of road was assigned an average travel speed and the corresponding cell given a crossing time in seconds:

$$
\text { Cell crossing time (seconds) }=25 \times\left(\frac{1}{\text { Speed }(\mathrm{Km} / \mathrm{hr}) \times\left(\frac{1000}{3600}\right)}\right)
$$

MODE OF TRANSPORTATION

AVERAGE TRAVEL SPEED

(KMS PER HOUR)
CELL CROSSING TIME

(IN SECONDS)
FIRST ORDER ROADS

SECOND ORDER ROADS

RIVER NAVIGATION 


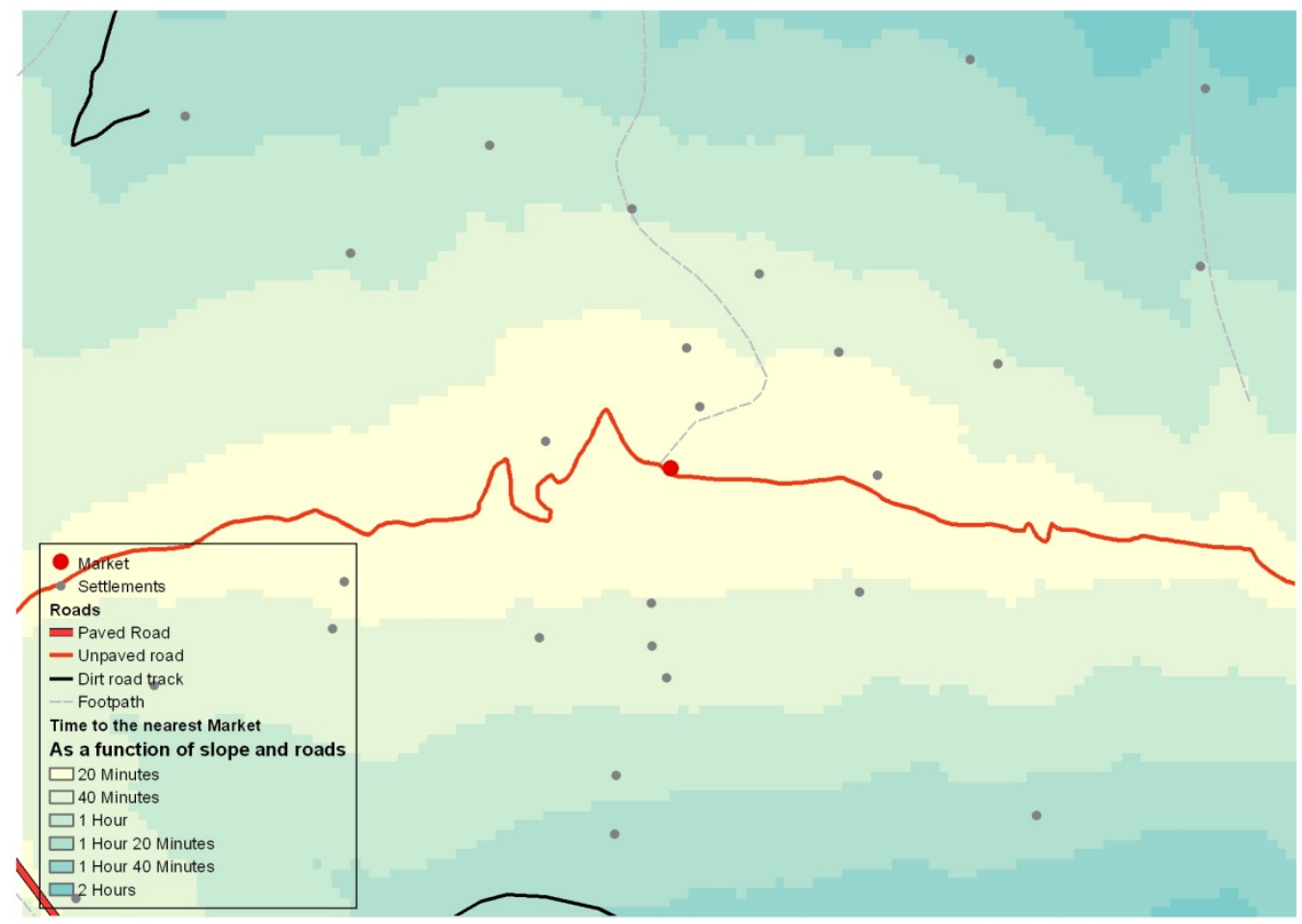

The third and final variable used in this model corresponds to the presence of natural barriers as rivers, which prevent people from traveling a straight line if there is no bridge. Cells corresponding to areas with a river and no bridge are assigned a travel time 10 times their value, so that the crossing would only be considered where a bridge is available.

Once the friction model is built and each cell has been allocated a travel time value, cost-weighted distance algorithms are run over the raster surface, calculating the accumulated time required to travel a particular route (choosing the one that is least time-consuming). This information is then used to simulate the impacts of improvements of road segments. Specifically, if a road is improved from a walking trail to a dirt road track, then the new average speed is assigned with the upgraded category and re-estimates all the accessibility measures.

For El Salvador, we ran the model in two occasions, one before the transnational highway was improved and another one after it (see Figure 65) 
FIGURE 65 TIME TO MARKETS BEFORE AND AFTER THE TRANSNATIONAL HIGHWAY IMPROVEMENT

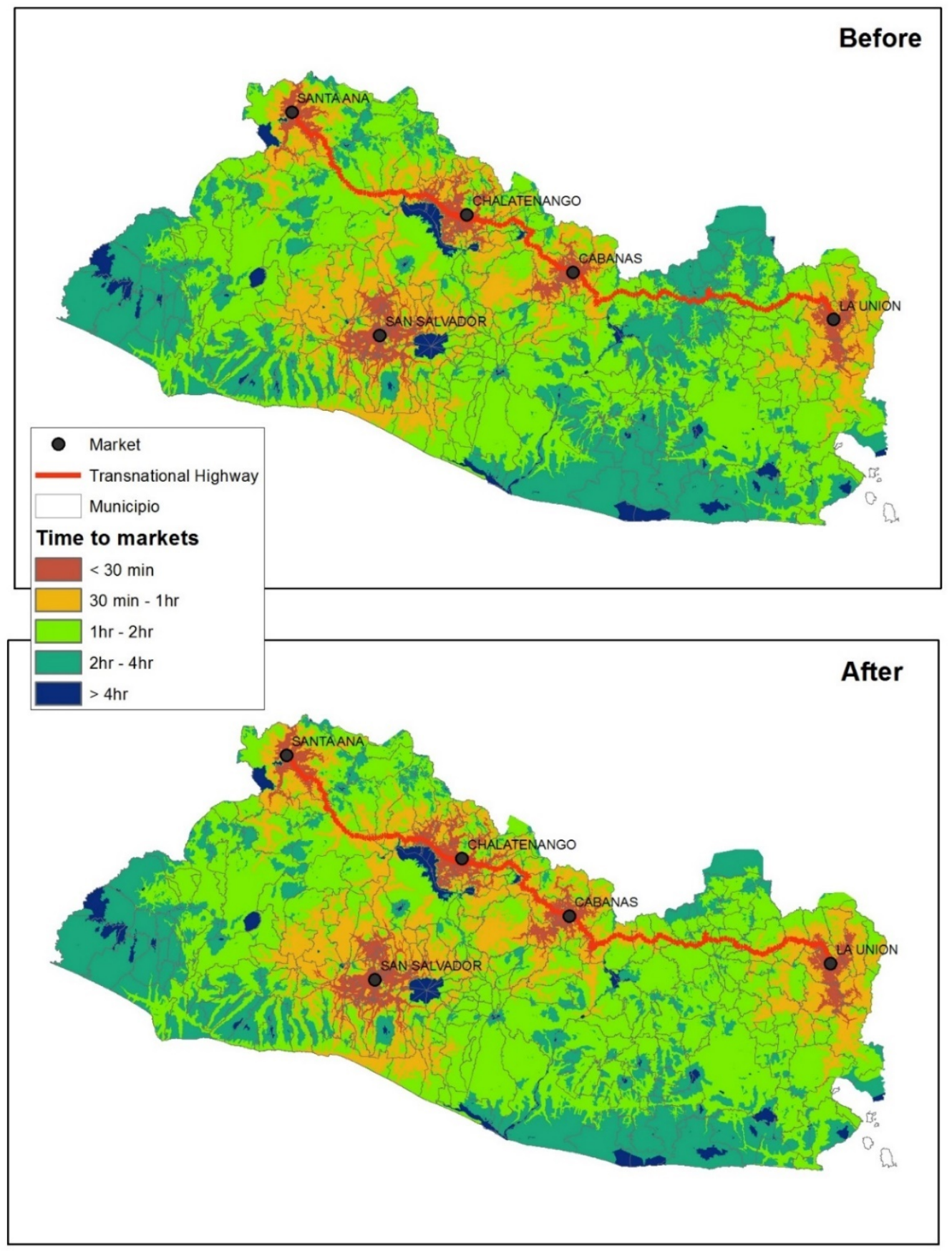




\section{ANNEX 2- AdditionAl RESUltS: RoAd IMPROVEMENT IMPACTS}

Time to border with Guatemala (minutes)

(1)

(2)

(3)

(4)

(5) (6)

(6)

Group 1 Group 2 Group 3 Group 4 Group 5 Sample

First Stage and Segment Difference in Difference

\begin{tabular}{|c|c|c|c|c|c|c|}
\hline \multirow[t]{2}{*}{ Treatment\#Post Road Improvement } & -8.91 & -1.63 & 23.1 & -36 & -85.4 & -38.7 \\
\hline & {$[1.02]^{* * *}$} & [1.38] & {$[3.11]^{* * *}$} & {$[3.75]^{* * *}$} & {$[2.42]^{* * *}$} & {$[1.33]^{* * *}$} \\
\hline \multirow[t]{2}{*}{ Post Road Improvement } & 0.51 & -2.87 & -56.4 & -60.2 & -2.98 & 28.8 \\
\hline & {$[0.11]^{* * *}$} & {$[0.52]^{* * *}$} & {$[3.08]^{* * *}$} & {$[2.99]^{* * *}$} & {$[0.34]^{* * *}$} & {$[1.40]^{* * *}$} \\
\hline \multicolumn{7}{|l|}{ Construction Administrative Data } \\
\hline \multirow[t]{2}{*}{ Improved Sub-Segment } & -6.88 & -13 & -15.7 & -40.1 & -85.4 & -49.1 \\
\hline & {$[0.76]^{* * *}$} & {$[0.99]^{* * *}$} & {$[4.11]^{* * *}$} & {$[5.08]^{* * *}$} & {$[2.42]^{* * *}$} & {$[2.30]^{* * *}$} \\
\hline \multirow[t]{2}{*}{ Post Road Improvement } & -3.32 & -1.77 & -32.7 & -52.2 & -2.98 & \\
\hline & {$[0.37]^{* * *}$} & {$[0.32]^{* * *}$} & {$[4.57]^{* * *}$} & {$[4.67]^{* * *}$} & {$[0.34]^{* * *}$} & \\
\hline \multirow[t]{2}{*}{$\%$ of Sub-segment Improved } & -9.65 & -20.8 & -51.4 & -79.7 & -89.7 & -65.5 \\
\hline & {$[1.03]^{* * *}$} & {$[1.06]^{* * *}$} & {$[2.34]^{* * *}$} & {$[3.19]^{* * *}$} & {$[2.63]^{* * *}$} & {$[2.03]^{* * *}$} \\
\hline \multirow[t]{2}{*}{ Post Road Improvement } & -0.27 & 3.82 & 0.3 & -7.49 & -0.24 & \\
\hline & {$[0.075]^{* * *}$} & {$[0.36]^{* * *}$} & {$[0.83]$} & {$[2.32]^{* * *}$} & {$[0.18]$} & \\
\hline Mean of Comp. at Pre-Period & 199.8 & 234.4 & 331 & 331 & 486.1 & 349 \\
\hline SD of Comp. at Pre-Period & 51.3 & 28.8 & 19.1 & 19.1 & 29.7 & 122.3 \\
\hline Number of Clusters & 113 & 142 & 96 & 138 & 135 & 410 \\
\hline Number of Households & 1,219 & 1,496 & 1,006 & 1,652 & 1,415 & 4,667 \\
\hline Observations & 5,549 & 6,795 & 4,560 & 7,639 & 6,490 & 21,406 \\
\hline
\end{tabular}

Standard errors in brackets

Std. errors are clustered at the census segment level.

All equations include household and year fixed effects. Columns(1)-(5) shows the impact for each treatment Assignment group along the NTH. Column (6) shows impact across the whole NTH.

$* p<0.10, * * p<0.05, * * * p<0.01$ 
Time to border with Honduras (minutes)
(1)
(2)
(3)
(4)
(5)
(6)

Group $1 \quad$ Group $2 \quad$ Group $3 \quad$ Group $4 \quad$ Group $5 \quad$ Sample

\begin{tabular}{|c|c|c|c|c|c|c|}
\hline & & & & & & \\
\hline \multicolumn{7}{|c|}{ First Stage and Segment Difference in Difference } \\
\hline \multirow[t]{2}{*}{ Treatment\#Post Road Improvement } & -36.5 & -26.7 & -17.7 & 7.83 & -6.2 & -15.4 \\
\hline & {$[1.06]^{* * *}$} & {$[1.65]^{* * *}$} & {$[2.55]^{* * *}$} & {$[2.25]^{* * *}$} & {$[0.78]^{* * *}$} & {$[0.75]^{* * *}$} \\
\hline \multirow[t]{2}{*}{ Post Road Improvement } & 3.8 & -1.33 & -25.1 & -24.7 & -0.21 & 7.48 \\
\hline & {$[0.47]^{* * *}$} & {$[0.67]^{* *}$} & {$[1.92]^{* * *}$} & {$[1.86]^{* * *}$} & {$[0.045]^{* * *}$} & {$[0.40]^{* * *}$} \\
\hline \multicolumn{7}{|l|}{ Construction Administrative Data } \\
\hline \multirow{2}{*}{ Improved Sub-Segment } & -26.4 & -28.9 & -11.4 & 0.6 & -6.2 & -15.3 \\
\hline & {$[0.86]^{* * *}$} & {$[1.00]^{* * *}$} & {$[2.59]^{* * *}$} & [2.59] & {$[0.78]^{* * *}$} & {$[0.85]^{* * *}$} \\
\hline \multirow[t]{2}{*}{ Post Road Improvement } & -12.2 & -9.51 & -21.5 & -20.2 & -0.21 & \\
\hline & {$[1.32]^{* * *}$} & {$[1.22]^{* * *}$} & {$[3.15]^{* * *}$} & {$[2.43]^{* * *}$} & {$[0.045]^{* * *}$} & \\
\hline \multirow[t]{2}{*}{$\%$ of Sub-segment Improved } & -38.4 & -40.9 & -33.1 & -23.4 & -6.41 & -23.3 \\
\hline & {$[1.13]^{* * *}$} & {$[1.04]^{* * *}$} & {$[1.50]^{* * *}$} & {$[1.42]^{* * *}$} & {$[0.81]^{* * *}$} & {$[0.91]^{* * *}$} \\
\hline \multirow[t]{2}{*}{ Post Road Improvement } & 0.094 & 1.01 & -1.41 & 2.38 & -0.077 & \\
\hline & {$[0.055]^{*}$} & {$[0.37]^{* * *}$} & {$[0.91]$} & {$[0.85]^{* * *}$} & [0.050] & \\
\hline Mean of Comp. at Pre-Period & 322.9 & 291.6 & 202.4 & 202.4 & 67.1 & 191.6 \\
\hline SD of Comp. at Pre-Period & 36.4 & 26.7 & 19.6 & 19.6 & 28.1 & 105.2 \\
\hline Number of Clusters & 113 & 142 & 96 & 138 & 135 & 410 \\
\hline Number of Households & 1,219 & 1,496 & 1,006 & 1,652 & 1,415 & 4,667 \\
\hline Observations & 5,549 & 6,795 & 4,560 & 7,639 & 6,490 & 21,406 \\
\hline
\end{tabular}

Standard errors in brackets

Std. errors are clustered at the census segment level.

All equations include household and year fixed effects. Columns(1)-(5) shows the impact for each treatment Assignment group along the NTH. Column (6) shows impact across the whole NTH.

${ }^{*} \mathrm{p}<0.10,{ }^{* *} \mathrm{p}<0.05,{ }^{* * *} \mathrm{p}<0.01$ 


\section{Time to Sesuntepeque Market (minutes)}

(1) (2) (3) (4) (5) $\quad$ Full

Group 1 Group 2 Group 3 Group 4 Group 5 Sample

\begin{tabular}{lllllll}
\hline First Stage and Segment Difference in Difference & \multicolumn{7}{l}{} \\
\hline \hline Treatment\#Post Road Improvement & -55.3 & -46.5 & -33.4 & -39.4 & -56.3 & -29.8 \\
& {$[1.04]^{* * *}$} & {$[1.54]^{* * *}$} & {$[1.92]^{* * *}$} & {$[1.28]^{* * *}$} & {$[1.67]^{* * *}$} & {$[0.97]^{* * *}$} \\
Post Road Improvement & 5.7 & 0.63 & -4.66 & -6.56 & -1.93 & 16.3 \\
& {$[0.69]^{* * *}$} & {$[0.67]$} & {$[0.92]^{* * *}$} & {$[0.91]^{* * *}$} & {$[0.22]^{* * *}$} & {$[0.75]^{* * *}$} \\
Construction Administrative Data & & & & & & \\
Improved Sub-Segment & -40.1 & -37.5 & -11.7 & -26 & -56.3 & -38 \\
& {$[1.00]^{* * *}$} & {$[1.02]^{* * *}$} & {$[2.30]^{* * *}$} & {$[1.58]^{* * *}$} & {$[1.67]^{* * *}$} & {$[0.99]^{* * *}$} \\
Post Road Improvement & -18.6 & -15.5 & -7.01 & -11.6 & -1.93 & \\
& {$[1.94]^{* * *}$} & {$[1.68]^{* * *}$} & {$[2.02]^{* * *}$} & {$[1.12]^{* * *}$} & {$[0.22]^{* * *}$} & \\
\% of Sub-segment Improved & -58.3 & -49.3 & -18.4 & -24.7 & -59.4 & -45.1 \\
& {$[1.14]^{* * *}$} & {$[1.10]^{* * *}$} & {$[2.31]^{* * *}$} & {$[3.02]^{* * *}$} & {$[1.81]^{* * *}$} & {$[1.21]^{* * *}$} \\
Post Road Improvement & 0.11 & -3.17 & -0.78 & -8.11 & 0.053 \\
& {$[0.056]^{*}$} & {$[0.37]^{* * *}$} & {$[0.89]$} & {$[2.39]^{* * *}$} & {$[0.14]$} \\
\hline Mean of Comp. at Pre-Period & 176.1 & 134 & 21 & 21 & 202.6 & 142.2 \\
SD of Comp. at Pre-Period & 39.5 & 35.3 & 17 & 17 & 37 & 64.4 \\
Number of Clusters & 113 & 142 & 96 & 138 & 135 & 410 \\
Number of Households & 1,219 & 1,496 & 1,006 & 1,652 & 1,415 & 4,667 \\
Observations & 5,549 & 6,795 & 4,560 & 7,639 & 6,490 & 21,406 \\
\hline \hline
\end{tabular}

Standard errors in brackets

Std. errors are clustered at the census segment level.

All equations include household and year fixed effects. Columns(1)-(5) shows the impact for each treatment Assignment group along the NTH. Column (6) shows impact across the whole NTH.

* $p<0.10,{ }^{* *} p<0.05, * * * p<0.01$ 
Time to Anamoros Market (minutes)
(1)
(2)
(3)
(4)
(5)
(6)

Group 1

Group 2

Group 3

Group 4

Group 5

Sample

\begin{tabular}{|c|c|c|c|c|c|c|}
\hline \multicolumn{7}{|c|}{ First Stage and Segment Difference in Difference } \\
\hline \multirow[t]{2}{*}{ Treatment\#Post Road Improvement } & -58.3 & -43.4 & -20 & 11.2 & -17.1 & -27.4 \\
\hline & {$[1.05]^{* * *}$} & {$[2.15]^{* * *}$} & {$[3.13]^{* * *}$} & {$[3.24]^{* * *}$} & {$[1.67]^{* * *}$} & {$[1.07]^{* * *}$} \\
\hline \multirow[t]{2}{*}{ Post Road Improvement } & 5.98 & -1.9 & -45.5 & -45.2 & -0.64 & 14 \\
\hline & {$[0.72]^{* * *}$} & {$[0.99]^{*}$} & {$[2.64]^{* * *}$} & {$[2.55]^{* * *}$} & {$[0.11]^{* * *}$} & {$[0.65]^{* * *}$} \\
\hline \multicolumn{7}{|l|}{ Construction Administrative Data } \\
\hline \multirow[t]{2}{*}{ Improved Sub-Segment } & -42.3 & -45.6 & -18.8 & -1.59 & -17.1 & -28 \\
\hline & {$[1.05]^{* * *}$} & {$[1.41]^{* * *}$} & {$[3.88]^{* * *}$} & {$[4.20]$} & {$[1.67]^{* * *}$} & {$[1.30]^{* * *}$} \\
\hline \multirow[t]{2}{*}{ Post Road Improvement } & -19.6 & -15.4 & -36 & -36.9 & -0.64 & \\
\hline & {$[2.03]^{* * *}$} & {$[1.85]^{* * *}$} & {$[4.62]^{* * *}$} & {$[3.86]^{* * *}$} & {$[0.11]^{* * *}$} & \\
\hline \multirow[t]{2}{*}{$\%$ of Sub-segment Improved } & -61.5 & -64 & -56.2 & -43.9 & -17.3 & -41.7 \\
\hline & {$[1.13]^{* * *}$} & {$[1.04]^{* * *}$} & {$[1.52]^{* * *}$} & {$[1.84]^{* * *}$} & {$[1.79]^{* * *}$} & {$[1.30]^{* * *}$} \\
\hline \multirow[t]{2}{*}{ Post Road Improvement } & 0.094 & 1.01 & -1.41 & 3.43 & -0.47 & \\
\hline & {$[0.055]^{*}$} & {$[0.37]^{* * *}$} & {$[0.91]$} & {$[1.16]^{* * *}$} & {$[0.13]^{* * *}$} & \\
\hline Mean of Comp. at Pre-Period & 327.2 & 295.8 & 206.1 & 206.1 & 57.3 & 192.8 \\
\hline SD of Comp. at Pre-Period & 36.4 & 26.7 & 20.4 & 20.4 & 35.1 & 109.6 \\
\hline Number of Clusters & 113 & 142 & 96 & 138 & 135 & 410 \\
\hline Number of Households & 1,219 & 1,496 & 1,006 & 1,652 & 1,415 & 4,667 \\
\hline Observations & 5,549 & 6,795 & 4,560 & 7,639 & 6,490 & 21,406 \\
\hline
\end{tabular}

Standard errors in brackets

Std. errors are clustered at the census segment level.

All equations include household and year fixed effects. Columns(1)-(5) shows the impact for each treatment Assignment group along the NTH. Column (6) shows impact across the whole NTH.

$* \mathrm{p}<0.10, * * \mathrm{p}<0.05, * * * \mathrm{p}<0.01$ 


\section{ANNEX 3 AdDITIONAL RESULTS: WASH IMPACTS}

\section{TIME DIARY MINOR SAMPLE}

\section{Heterogeneity by Gender: Non-Labor Activities}

\begin{tabular}{|c|c|c|c|c|c|}
\hline & (1) & (2) & (3) & (4) & (5) \\
\hline & DID & DID-FE & DID-Pairs & RF-Area-ITT & RF-ATE \\
\hline \multirow[t]{2}{*}{ Treatment \# Post Period \# Male } & 4.22 & -1.81 & 5.23 & & \\
\hline & [11.3] & {$[14.6]$} & [11.8] & & \\
\hline \multirow[t]{2}{*}{ Treatment \# Post Period \# Female } & -32.1 & -29.6 & -32.3 & & \\
\hline & {$[14.9]^{* *}$} & [18.0] & {$[15.5]^{* *}$} & & \\
\hline \multirow[t]{2}{*}{ Inside Project Area \# Post Period \# Male } & & & & 11.6 & \\
\hline & & & & [11.5] & \\
\hline \multirow[t]{2}{*}{ Inside Project Area \# Post Period \# Female } & & & & -58 & \\
\hline & & & & {$[17.1]^{* * *}$} & \\
\hline \multirow[t]{2}{*}{ Beneficiary \# Post Period \# Male } & & & & & 5.57 \\
\hline & & & & & [13.0] \\
\hline \multirow[t]{2}{*}{ Beneficiary \# Post Period \# Female } & & & & & -52.3 \\
\hline & & & & & {$[15.8]^{* * *}$} \\
\hline Pairs Indicators & NO & NO & YES & YES & YES \\
\hline Mean of Comp. at Baseline & 78.8 & 78.8 & 79.4 & 76.7 & 76.6 \\
\hline SD of Comp. at Baseline & 113.8 & 113.8 & 115.2 & 108.3 & 109.8 \\
\hline Number of Clusters & 128 & 128 & 122 & 122 & 122 \\
\hline Observations & 4,234 & 4,234 & 4,027 & 3,991 & 3,991 \\
\hline
\end{tabular}

Standard errors in brackets

Std. errors are clustered at the census segment level.

All equations include year fixed effects. Equations are DID, in (1)-(3) the treatment is defined as living in a treatment assigned segment, (4) treatment is defined as living inside the project area within the matched pairs, (5) treatment is defined as having reported being beneficiary of the WASH project within the matched pairs. Equations (4)-(5) control for initial treatment assignment.

Equation (2) includes household fixed effects. Pair dummies indicated in the table are based in on nearest neighbor matching propensity score matching based on 2007 census segment data.

Impact estimates represent the DID estimates for each gender.

$* p<0.10, * * p<0.05, * * * p<0.01$ 
Heterogeneity by Gender: Education

(1)

$(2)$

(3)

(4)

(5)

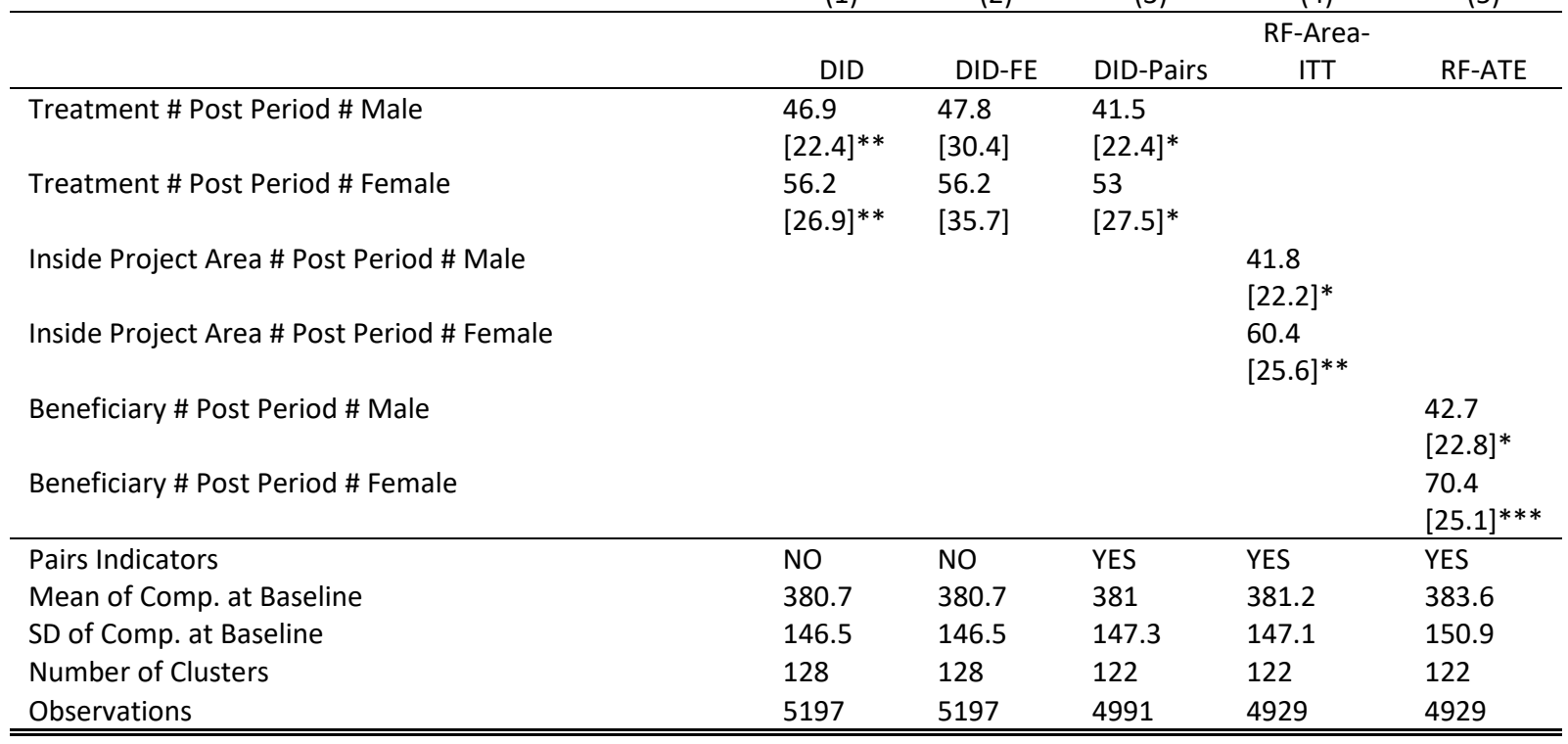

Standard errors in brackets

Std. errors are clustered at the census segment level.

All equations include year fixed effects. Equations are DID, in (1)-(3) the treatment is defined as living in a treatment assigned segment, (4) treatment is defined as living inside the project area within the matched pairs, (5) treatment is defined as having reported being beneficiary of the WASH project within the matched pairs. Equations (4)-(5) control for initial treatment assignment.

Equation (2) includes household fixed effects. Pair dummies indicated in the table are based in on nearest neighbor matching propensity score matching based on 2007 census segment data.

Impact estimates represent the DID estimates for each gender.

${ }^{*} \mathrm{p}<0.10, * * \mathrm{p}<0.05, * * * \mathrm{p}<0.01$ 
Heterogeneity by Gender: Time for Self

(1)

(2)

\begin{tabular}{|c|c|c|c|c|c|}
\hline & \multirow[b]{3}{*}{ DID } & \multirow[b]{3}{*}{ DID-FE } & \multirow{2}{*}{\multicolumn{3}{|c|}{ RF-Area- }} \\
\hline & & & & & \\
\hline & & & DID-Pairs & ITT & RF-ATE \\
\hline \multirow[t]{2}{*}{ Treatment \# Post Period \# Male } & -32 & -33.3 & -37.6 & & \\
\hline & {$[15.1]^{* *}$} & {$[19.2]^{*}$} & {$[14.9]^{* *}$} & & \\
\hline \multirow[t]{2}{*}{ Treatment \# Post Period \# Female } & -5.37 & -13.2 & 0.48 & & \\
\hline & {$[15.5]$} & {$[20.2]$} & {$[15.4]$} & & \\
\hline \multirow[t]{2}{*}{ Inside Project Area \# Post Period \# Male } & & & & -36.4 & \\
\hline & & & & {$[14.9]^{* *}$} & \\
\hline \multirow[t]{2}{*}{ Inside Project Area \# Post Period \# Female } & & & & 1.13 & \\
\hline & & & & {$[14.5]$} & \\
\hline \multirow[t]{2}{*}{ Beneficiary \# Post Period \# Male } & & & & & -33.1 \\
\hline & & & & & {$[15.6]^{* *}$} \\
\hline \multirow[t]{2}{*}{ Beneficiary \# Post Period \# Female } & & & & & -1.51 \\
\hline & & & & & [15.3] \\
\hline Pairs Indicators & NO & NO & YES & YES & YES \\
\hline Mean of Comp. at Baseline & 378.6 & 378.6 & 376.2 & 379.4 & 378.6 \\
\hline SD of Comp. at Baseline & 141.8 & 141.8 & 141.3 & 143.3 & 143.7 \\
\hline Number of Clusters & 128 & 128 & 122 & 122 & 122 \\
\hline Observations & 6,261 & 6,261 & 5,962 & 5,891 & 5,891 \\
\hline
\end{tabular}

(5)

Standard errors in brackets

Std. errors are clustered at the census segment level.

All equations include year fixed effects. Equations are DID, in (1)-(3) the treatment is defined as living in a treatment assigned segment, (4) treatment is defined as living inside the project area within the matched pairs, (5) treatment is defined as having reported being beneficiary of the WASH project within the matched pairs. Equations (4)-(5) control for initial treatment assignment.

Equation (2) includes household fixed effects. Pair dummies indicated in the table are based in on nearest neighbor matching propensity score matching based on 2007 census segment data.

Impact estimates represent the DID estimates for each gender.

${ }^{*} \mathrm{p}<0.10,{ }^{* *} \mathrm{p}<0.05, * * * \mathrm{p}<0.01$ 


\section{Adult Women Time Use}

\section{Children Care}

\begin{tabular}{|c|c|c|c|c|c|c|c|}
\hline & $(1)$ & $(2)$ & (3) & (4) & (5) & $(6)$ & (7) \\
\hline & DID & DID-FE & $\begin{array}{l}\text { DID- } \\
\text { Pairs }\end{array}$ & $\begin{array}{l}\text { RF-Area- } \\
\text { ITT }\end{array}$ & $\begin{array}{l}\text { IV-Area- } \\
\text { ITT }\end{array}$ & RF-ATE & IV-LATE \\
\hline \multirow[t]{2}{*}{ Treatment \# Post Period } & -21.4 & -27.7 & -21 & & & & \\
\hline & {$[11.5]^{*}$} & {$[14.5]^{*}$} & {$[12.0]^{*}$} & & & & \\
\hline \multirow[t]{2}{*}{ Inside Project Area \# Post Period } & & & & -34.4 & & & \\
\hline & & & & {$[12.5]^{* * *}$} & & & \\
\hline \multirow[t]{2}{*}{ Inside Project Area-ITT in Post Period } & & & & & -35.2 & & \\
\hline & & & & & {$[18.4]^{*}$} & & \\
\hline \multirow[t]{2}{*}{ Beneficiary \# Post Period } & & & & & & -28.1 & \\
\hline & & & & & & {$[14.3]^{*}$} & \\
\hline \multirow[t]{2}{*}{ Beneficiary-LATE in Post Period } & & & & & & & -39.7 \\
\hline & & & & & & & {$[21.6]^{*}$} \\
\hline Pairs Indicators & NO & NO & YES & YES & NO & YES & NO \\
\hline Mean of Comp. at Baseline & 60.4 & 60.4 & 59.1 & 57.4 & 57.4 & 59.4 & 59.4 \\
\hline SD of Comp. at Baseline & 95.8 & 95.8 & 94.1 & 89.8 & 89.8 & 91.3 & 91.3 \\
\hline Number of Clusters & 128 & 128 & 122 & 122 & 122 & 122 & 122 \\
\hline Observations & 2,293 & 2,293 & 2,198 & 2,174 & 2,174 & 2,174 & 2,174 \\
\hline K-P rk Wald F & & & & & 123.1 & & 77.2 \\
\hline
\end{tabular}

Standard errors in brackets

Std. errors are clustered at the census segment level.

All equations include year fixed effects. Equations are DID, in (1)-(3) the treatment is defined as living in a treatment assigned segment, (4)(5) treatment is defined as living inside the project area within the matched pairs, (6)-(7) treatment is defined as having reported being beneficiary of the WASH project within the matched pairs. Equations (4)-(7) control for initial treatment assignment.

Equation (2) includes household fixed effects. Pair dummies indicated in the table are based in on nearest neighbor matching propensity score matching based on 2007 census segment data.

IV estimates in columns (5) and (7) use the census segment treatment assignment to instrument for indicators for being in a proyect area in 2012-2013 (5); and the households reporting being a beneficiary of the WASH proyects from MCC in (7)

^IV estimates partial out the indicators for pairs to compute the std. errors of the coefficients of interest. We report the K-P rk Wald $F$ statistic following the results in Stock and Yogo (2005)

$* \mathrm{p}<0.10, * * \mathrm{p}<0.05, * * * \mathrm{p}<0.01$ 
Time for Self

\begin{tabular}{|c|c|c|c|c|c|c|c|}
\hline & (1) & (2) & (3) & (4) & (5) & (6) & (7) \\
\hline & DID & DID-FE & $\begin{array}{l}\text { DID- } \\
\text { Pairs }\end{array}$ & $\begin{array}{l}\text { RF-Area- } \\
\text { ITT }\end{array}$ & $\begin{array}{l}\text { IV-Area- } \\
\text { ITT }\end{array}$ & RF-ATE & IV-LATE \\
\hline \multirow[t]{2}{*}{ Treatment \# Post Period } & 14.5 & 17.7 & 17.9 & & & & \\
\hline & {$[7.83]^{*}$} & {$[9.41]^{*}$} & {$[7.92]^{* *}$} & & & & \\
\hline \multirow{2}{*}{ Inside Project Area \# Post Period } & & & & 11.1 & & & \\
\hline & & & & [7.80] & & & \\
\hline \multirow[t]{2}{*}{ Inside Project Area-ITT in Post Period } & & & & & 24.9 & & \\
\hline & & & & & {$[12.1]^{* *}$} & & \\
\hline \multirow[t]{2}{*}{ Beneficiary \# Post Period } & & & & & & 7.85 & \\
\hline & & & & & & {$[8.42]$} & \\
\hline \multirow[t]{2}{*}{ Beneficiary-LATE in Post Period } & & & & & & & 30.9 \\
\hline & & & & & & & {$[14.3]^{* *}$} \\
\hline Pairs Indicators & NO & NO & YES & YES & NO & YES & NO \\
\hline Mean of Comp. at Baseline & 400.7 & 400.7 & 401.4 & 403.8 & 403.8 & 401.4 & 401.4 \\
\hline SD of Comp. at Baseline & 155.9 & 155.9 & 156.3 & 154.1 & 154.1 & 155.8 & 155.8 \\
\hline Number of Clusters & 128 & 128 & 122 & 122 & 122 & 122 & 122 \\
\hline Observations & 9,104 & 9,104 & 8,653 & 8,557 & 8,557 & 8,557 & 8,557 \\
\hline K-P rk Wald F & & & & & 162.6 & & 116 \\
\hline
\end{tabular}

Standard errors in brackets

Std. errors are clustered at the census segment level.

All equations include year fixed effects. Equations are DID, in (1)-(3) the treatment is defined as living in a treatment assigned segment, (4)-(5) treatment is defined as living inside the project area within the matched pairs, (6)-(7) treatment is defined as having reported being beneficiary of the WASH project within the matched pairs. Equations (4)-(7) control for initial treatment assignment.

Equation (2) includes household fixed effects. Pair dummies indicated in the table are based in on nearest neighbor matching propensity score matching based on 2007 census segment data.

IV estimates in columns (5) and (7) use the census segment treatment assignment to instrument for indicators for being in a proyect area in 2012-2013 (5); and the households reporting being a beneficiary of the WASH proyects from MCC in (7)

^IV estimates partial out the indicators for pairs to compute the std. errors of the coefficients of interest. We report the K-P rk Wald F statistic following the results in Stock and Yogo (2005)

${ }^{*} p<0.10,{ }^{* *} p<0.05,{ }^{* * *} p<0.01$ 


\section{HYGIENE}

Children 3-6 use Sanitation frequently

\begin{tabular}{|c|c|c|c|c|c|c|c|}
\hline & (1) & $(2)$ & (3) & (4) & (5) & (6) & (7) \\
\hline & DID & DID-FE & $\begin{array}{l}\text { DID- } \\
\text { Pairs }\end{array}$ & $\begin{array}{l}\text { RF-Area- } \\
\text { ITT }\end{array}$ & 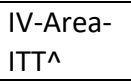 & RF-ATE & $\begin{array}{l}\text { IV- } \\
\text { LATE^ }\end{array}$ \\
\hline Treatment \# Post Period & $\begin{array}{l}0.073 \\
{[0.044]}\end{array}$ & $\begin{array}{l}0.073 \\
{[0.048]}\end{array}$ & $\begin{array}{l}0.074 \\
{[0.044]^{*}}\end{array}$ & & & & \\
\hline Inside Project Area \# Post Period & & & & $\begin{array}{l}0.027 \\
{[0.044]}\end{array}$ & & & \\
\hline Inside Project Area-ITT in Post Period & & & & & $\begin{array}{l}0.11 \\
{[0.065]^{*}}\end{array}$ & & \\
\hline Beneficiary \# Post Period & & & & & & $\begin{array}{l}0.039 \\
{[0.046]}\end{array}$ & \\
\hline Beneficiary-LATE in Post Period & & & & & & & $\begin{array}{l}0.12 \\
{[0.076]}\end{array}$ \\
\hline Pairs Indicators & NO & NO & YES & YES & NO & YES & NO \\
\hline Mean of Comp. at Baseline & 0.73 & 0.73 & 0.73 & 0.72 & 0.72 & 0.72 & 0.72 \\
\hline SD of Comp. at Baseline & 0.44 & 0.44 & 0.44 & 0.45 & 0.45 & 0.45 & 0.45 \\
\hline Number of Clusters & 128 & 128 & 128 & 128 & 128 & 128 & 128 \\
\hline Observations & 1,949 & 1,949 & 1,949 & 1,923 & 1,923 & 1,923 & 1,923 \\
\hline K-P rk Wald F & & & & & 89.2 & & 97.1 \\
\hline \multicolumn{8}{|c|}{ Children almost/always wash hands after defecating } \\
\hline Treatment \# Post Period & $\begin{array}{l}0.0085 \\
{[0.018]}\end{array}$ & $\begin{array}{l}0.0053 \\
{[0.023]}\end{array}$ & $\begin{array}{l}0.0082 \\
{[0.019]}\end{array}$ & & & & \\
\hline Inside Project Area \# Post Period & & & & $\begin{array}{l}0.01 \\
{[0.020]}\end{array}$ & & & \\
\hline Inside Project Area-ITT in Post Period & & & & & $\begin{array}{l}0.011 \\
{[0.030]}\end{array}$ & & \\
\hline Beneficiary \# Post Period & & & & & & $\begin{array}{l}0.019 \\
{[0.022]}\end{array}$ & \\
\hline Beneficiary-LATE in Post Period & & & & & & & $\begin{array}{l}0.015 \\
{[0.036]}\end{array}$ \\
\hline Pairs Indicators & NO & NO & YES & YES & NO & YES & NO \\
\hline Mean of Comp. at Baseline & 0.96 & 0.96 & 0.96 & 0.96 & 0.96 & 0.96 & 0.96 \\
\hline SD of Comp. at Baseline & 0.21 & 0.21 & 0.21 & 0.2 & 0.2 & 0.2 & 0.2 \\
\hline Number of Clusters & 128 & 128 & 128 & 128 & 128 & 128 & 128 \\
\hline Observations & 2,284 & 2,284 & 2,284 & 2,253 & 2,253 & 2,253 & 2,253 \\
\hline K-P rk Wald F & & & & & 88.6 & & 88.2 \\
\hline
\end{tabular}

Standard errors in brackets

Std. errors are clustered at the census segment level.

All equations include year fixed effects. Equations are DID, in (1)-(3) the treatment is defined as living in a treatment assigned segment, (4)-(5) treatment is defined as living inside the project area within the matched pairs, (6)-(7) treatment is defined as having reported being beneficiary of the WASH project within the matched pairs. Equations (4)-(7) control for initial treatment assignment.

Equation (2) includes household fixed effects. Pair dummies indicated in the table are based in on nearest neighbor matching propensity score matching based on 2007 census segment data.

IV estimates in columns (5) and (7) use the census segment treatment assignment to instrument for indicators for being in a proyect area in 2012-2013 (5); and the households reporting being a beneficiary of the WASH proyects from MCC in (7)

^IV estimates partial out the indicators for pairs to compute the std. errors of the coefficients of interest. We report the K-P rk Wald F statistic following the results in Stock and Yogo (2005)

${ }^{*} p<0.10,{ }^{* *} p<0.05, * * * p<0.01$ 
Children almost/always wash hands before eating

\begin{tabular}{|c|c|c|c|c|c|c|c|}
\hline & (1) & $(2)$ & (3) & (4) & (5) & $(6)$ & (7) \\
\hline & DID & DID-FE & $\begin{array}{l}\text { DID- } \\
\text { Pairs }\end{array}$ & $\begin{array}{l}\text { RF-Area- } \\
\text { ITT }\end{array}$ & 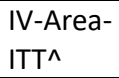 & RF-ATE & $\begin{array}{l}\text { IV- } \\
\text { LATE^ }^{\wedge}\end{array}$ \\
\hline Treatment \# Post Period & $\begin{array}{l}-0.013 \\
{[0.014]}\end{array}$ & $\begin{array}{l}-0.017 \\
{[0.016]}\end{array}$ & $\begin{array}{l}-0.013 \\
{[0.014]}\end{array}$ & & & & \\
\hline Inside Project Area \# Post Period & & & & $\begin{array}{l}-0.013 \\
{[0.013]}\end{array}$ & & & \\
\hline Inside Project Area-ITT in Post Period & & & & & $\begin{array}{l}-0.022 \\
{[0.022]}\end{array}$ & - & \\
\hline Beneficiary \# Post Period & & & & & & $\begin{array}{l}0.0064 \\
{[0.014]}\end{array}$ & \\
\hline Beneficiary-LATE in Post Period & & & & & & & $\begin{array}{l}-0.026 \\
{[0.027]}\end{array}$ \\
\hline Pairs Indicators & NO & NO & YES & YES & NO & YES & NO \\
\hline Mean of Comp. at Baseline & 0.97 & 0.97 & 0.97 & 0.97 & 0.97 & 0.97 & 0.97 \\
\hline SD of Comp. at Baseline & 0.18 & 0.18 & 0.18 & 0.17 & 0.17 & 0.17 & 0.17 \\
\hline Number of Clusters & 128 & 128 & 128 & 128 & 128 & 128 & 128 \\
\hline Observations & 2,284 & 2,284 & 2,284 & 2,253 & 2,253 & 2,253 & 2,253 \\
\hline K-P rk Wald F & & & & & 88.6 & & 88.2 \\
\hline \multicolumn{8}{|c|}{ Vegetables are washed with chemical products } \\
\hline Treatment \# Post Period & $\begin{array}{l}0.076 \\
{[0.044]^{*}}\end{array}$ & $\begin{array}{l}0.075 \\
{[0.044]^{*}}\end{array}$ & $\begin{array}{l}0.077 \\
{[0.044]^{*}}\end{array}$ & & & & \\
\hline Inside Project Area \# Post Period & & & & $\begin{array}{l}0.057 \\
{[0.044]}\end{array}$ & & & \\
\hline Inside Project Area-ITT in Post Period & & & & & $\begin{array}{l}0.11 \\
{[0.067]^{*}}\end{array}$ & & \\
\hline Beneficiary \# Post Period & & & & & & $\begin{array}{l}0.06 \\
{[0.043]}\end{array}$ & \\
\hline Beneficiary-LATE in Post Period & & & & & & & $\begin{array}{l}0.13 \\
{[0.079]^{*}}\end{array}$ \\
\hline Pairs Indicators & NO & NO & YES & YES & NO & YES & NO \\
\hline Mean of Comp. at Baseline & 0.48 & 0.48 & 0.48 & 0.47 & 0.47 & 0.46 & 0.46 \\
\hline SD of Comp. at Baseline & 0.5 & 0.5 & 0.5 & 0.5 & 0.5 & 0.5 & 0.5 \\
\hline Number of Clusters & 128 & 128 & 128 & 128 & 128 & 128 & 128 \\
\hline Observations & 9,325 & 9,325 & 9,325 & 9,208 & 9,208 & 9,208 & 9,208 \\
\hline K-P rk Wald F & & & & & 249.6 & & 129.9 \\
\hline
\end{tabular}

Standard errors in brackets

Std. errors are clustered at the census segment level.

All equations include year fixed effects. Equations are DID, in (1)-(3) the treatment is defined as living in a treatment assigned segment, (4)-(5) treatment is defined as living inside the project area within the matched pairs, (6)-(7) treatment is defined as having reported being beneficiary of the WASH project within the matched pairs. Equations (4)-(7) control for initial treatment assignment.

Equation (2) includes household fixed effects. Pair dummies indicated in the table are based in on nearest neighbor matching propensity score matching based on 2007 census segment data.

IV estimates in columns (5) and (7) use the census segment treatment assignment to instrument for indicators for being in a proyect area in 2012-2013 (5); and the households reporting being a beneficiary of the WASH proyects from MCC in (7)

AIV estimates partial out the indicators for pairs to compute the std. errors of the coefficients of interest. We report the K-P rk Wald F statistic following the results in Stock and Yogo (2005)

${ }^{*} \mathrm{p}<0.10,{ }^{* *} \mathrm{p}<0.05,{ }^{* * *} \mathrm{p}<0.01$ 
Empty latrine frequency (months)

\begin{tabular}{|c|c|c|c|c|c|c|c|}
\hline & $(1)$ & $(2)$ & (3) & (4) & (5) & (6) & (7) \\
\hline & DID & DID-FE & $\begin{array}{l}\text { DID- } \\
\text { Pairs }\end{array}$ & $\begin{array}{l}\text { RF-Area- } \\
\text { ITT }\end{array}$ & $\begin{array}{l}\text { IV-Area- } \\
\text { ITT^ }\end{array}$ & RF-ATE & $\begin{array}{l}\text { IV- } \\
\text { LATE^ }\end{array}$ \\
\hline \multirow[t]{2}{*}{ Treatment \# Post Period } & -0.44 & 0.19 & -0.4 & & & & \\
\hline & [0.89] & [0.93] & {$[0.90]$} & & & & \\
\hline \multirow[t]{2}{*}{ Inside Project Area \# Post Period } & & & & -0.55 & & & \\
\hline & & & & {$[0.91]$} & & & \\
\hline \multirow[t]{2}{*}{ Inside Project Area-ITT in Post Period } & & & & & -0.36 & & \\
\hline & & & & & {$[1.16]$} & & \\
\hline \multirow[t]{2}{*}{ Beneficiary \# Post Period } & & & & & & -1.01 & \\
\hline & & & & & & [0.93] & \\
\hline \multirow[t]{2}{*}{ Beneficiary-LATE in Post Period } & & & & & & & -0.43 \\
\hline & & & & & & & {$[1.32]$} \\
\hline Pairs Indicators & NO & NO & YES & YES & NO & YES & NO \\
\hline Mean of Comp. at Baseline & 12.2 & 12.2 & 12.2 & 12.2 & 12.2 & 12.1 & 12.1 \\
\hline SD of Comp. at Baseline & 8.32 & 8.32 & 8.32 & 8.22 & 8.22 & 7.94 & 7.94 \\
\hline Number of Clusters & 110 & 110 & 110 & 110 & 110 & 110 & 110 \\
\hline Observations & 2,025 & 2,025 & 2,025 & 2,011 & 2,011 & 2,011 & 2,011 \\
\hline K-P rk Wald F & & & & & 85.1 & & 115.2 \\
\hline \multicolumn{8}{|c|}{ Product use frequency is every day or more often } \\
\hline \multirow[t]{2}{*}{ Treatment \# Post Period } & 0.043 & 0.053 & 0.052 & & & & \\
\hline & [0.044] & [0.043] & [0.043] & & & & \\
\hline \multirow[t]{2}{*}{ Inside Project Area \# Post Period } & & & & 0.052 & & & \\
\hline & & & & [0.041] & & & \\
\hline \multirow[t]{2}{*}{ Inside Project Area-ITT in Post Period } & & & & & 0.065 & & \\
\hline & & & & & {$[0.060]$} & & \\
\hline \multirow[t]{2}{*}{ Beneficiary \# Post Period } & & & & & & 0.033 & \\
\hline & & & & & & [0.041] & \\
\hline \multirow[t]{2}{*}{ Beneficiary-LATE in Post Period } & & & & & & & 0.061 \\
\hline & & & & & & & [0.070] \\
\hline Pairs Indicators & NO & NO & YES & YES & NO & YES & NO \\
\hline Mean of Comp. at Baseline & 0.48 & 0.48 & 0.48 & 0.46 & 0.46 & 0.46 & 0.46 \\
\hline SD of Comp. at Baseline & 0.5 & 0.5 & 0.5 & 0.5 & 0.5 & 0.5 & 0.5 \\
\hline Number of Clusters & 128 & 128 & 128 & 128 & 128 & 128 & 128 \\
\hline Observations & 4,705 & 4,705 & 4,705 & 4,642 & 4,642 & 4,642 & 4,642 \\
\hline K-P rk Wald F & & & & & 100 & & 154.8 \\
\hline
\end{tabular}

Standard errors in brackets

Std. errors are clustered at the census segment level.

All equations include year fixed effects. Equations are DID, in (1)-(3) the treatment is defined as living in a treatment assigned segment, (4)-(5) treatment is defined as living inside the project area within the matched pairs, (6)-(7) treatment is defined as having reported being beneficiary of the WASH project within the matched pairs. Equations (4)-(7) control for initial treatment assignment.

Equation (2) includes household fixed effects. Pair dummies indicated in the table are based in on nearest neighbor matching propensity score matching based on 2007 census segment data.

IV estimates in columns (5) and (7) use the census segment treatment assignment to instrument for indicators for being in a proyect area in 20122013 (5); and the households reporting being a beneficiary of the WASH proyects from MCC in (7)

AIV estimates partial out the indicators for pairs to compute the std. errors of the coefficients of interest. We report the K-P rk Wald F statistic following the results in Stock and Yogo (2005)

${ }^{*} \mathrm{p}<0.10,{ }^{* *} \mathrm{p}<0.05, * * * \mathrm{p}<0.01$ 


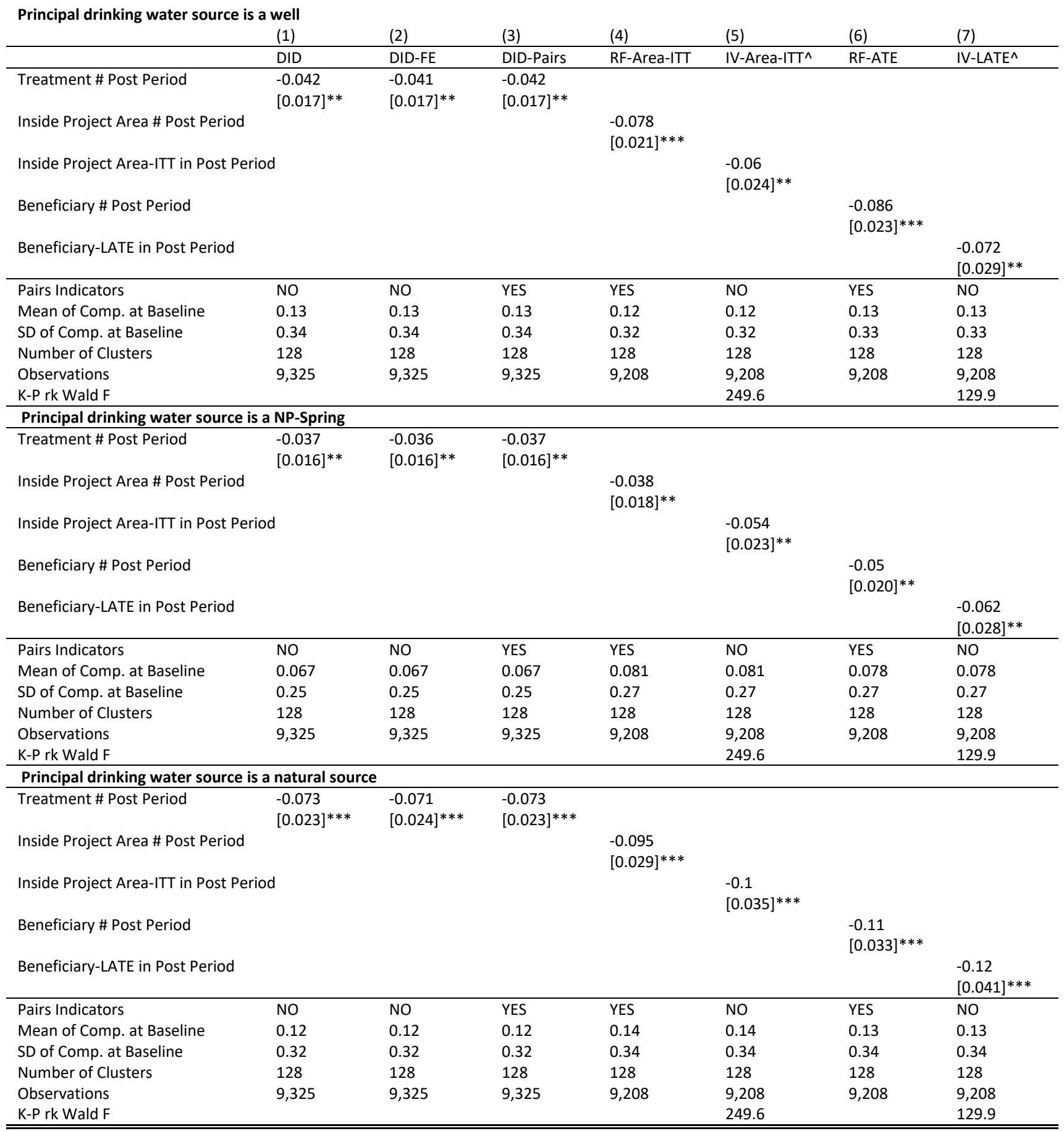

Standard errors in brackets

Std. errors are clustered at the census segment level.

All equations include year fixed effects. Equations are DID, in (1)-(3) the treatment is defined as living in a treatment assigned segment, (4)-(5) treatment is defined as living inside the project area within the matched pairs, (6)-(7) treatment is defined as having reported being beneficiary of the WASH project within the matched pairs. Equations (4)-(7) control for initial treatment assignment.

Equation (2) includes household fixed effects. Pair dummies indicated in the table are based in on nearest neighbor matching propensity score matching based on 2007 census segment data. IV estimates in columns (5) and (7) use the census segment treatment assignment to instrument for indicators for being in a project area in 2012-2013 (5); and the households reporting being a beneficiary of the WASH projects from MCC in (7) ^IV estimates partial out the indicators for pairs to compute the std. errors of the coefficients of interest. We report the K-P rk Wald F statistic following the results in Stock and Yogo (2005)

${ }^{*} p<0.10,{ }^{* *} p<0.05,{ }^{* * *} p<0.01$ 
Principal cooking water source is a well

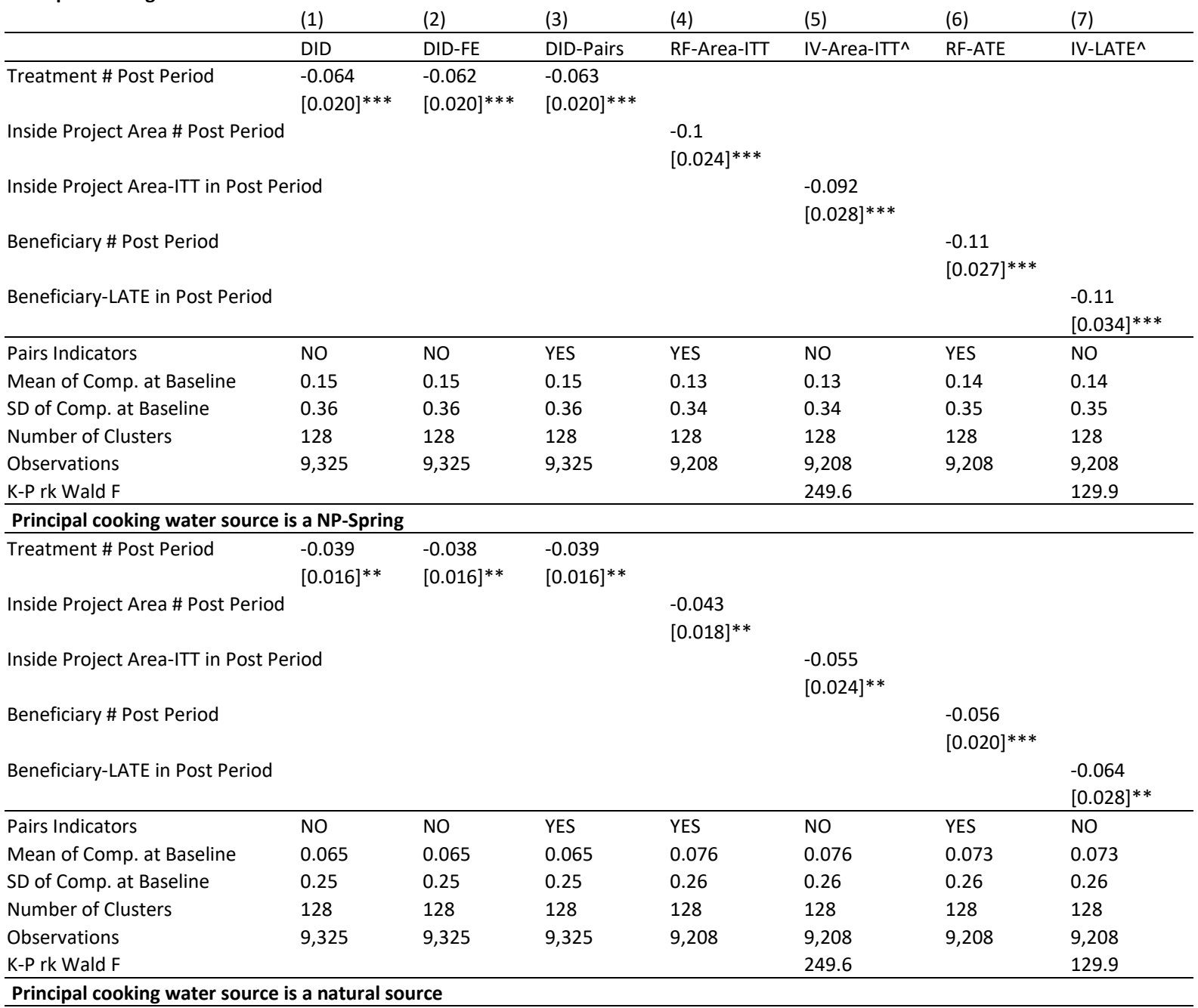

Principal cooking water source is a natural source

\begin{tabular}{llll}
\hline Treatment \# Post Period & -0.079 & -0.077 & -0.079 \\
& {$[0.024]^{* * *}$} & {$[0.024]^{* * *}$} & {$[0.024]^{* * *}$}
\end{tabular}

Inside Project Area \# Post Period

Inside Project Area-ITT in Post Period

$-0.11$

$[0.028]^{* * *}$

$[0.035]^{* * *}$

$\begin{array}{rr}-0.13 & {[0.033]^{* * *}} \\ {[0.0350}\end{array}$

Beneficiary-LATE in Post Period

$-0.13$

$[0.042]^{* * *}$

Pairs Indicators

NO NO

Mean of Comp. at Baseline $\quad 0.11 \quad 0.11$

SD of Comp. at Baseline

$0.32 \quad 0.32$

$128 \quad 128$

Number of Clusters

$9,325 \quad 9,325$

128

Observations

YES
0.11
0.32
128
9,325

YES
0.13
0.34
128
9,208

NO

0.13

0.34

128

9,208

249.6

Standard errors in brackets

Std. errors are clustered at the census segment level.

All equations include year fixed effects. Equations are DID, in (1)-(3) the treatment is defined as living in a treatment assigned segment, (4)-(5) treatment is defined as living inside the project area within the matched pairs, (6)-(7) treatment is defined as having reported being beneficiary of the WASH project within the matched pairs. Equations (4)-(7) control for initial treatment assignment.

Equation (2) includes household fixed effects. Pair dummies indicated in the table are based in on nearest neighbor matching propensity score matching based on 2007 census segment data.

IV estimates in columns (5) and (7) use the census segment treatment assignment to instrument for indicators for being in a project area in 2012-2013 (5); and the households reporting being a beneficiary of the WASH projects from MCC in (7)

^IV estimates partial out the indicators for pairs to compute the std. errors of the coefficients of interest. We report the K-P rk Wald $\mathrm{F}$ statistic following the results in Stock and Yogo (2005)

${ }^{*} \mathrm{p}<0.10,{ }^{* *} \mathrm{p}<0.05,{ }^{* * *} \mathrm{p}<0.01$ 


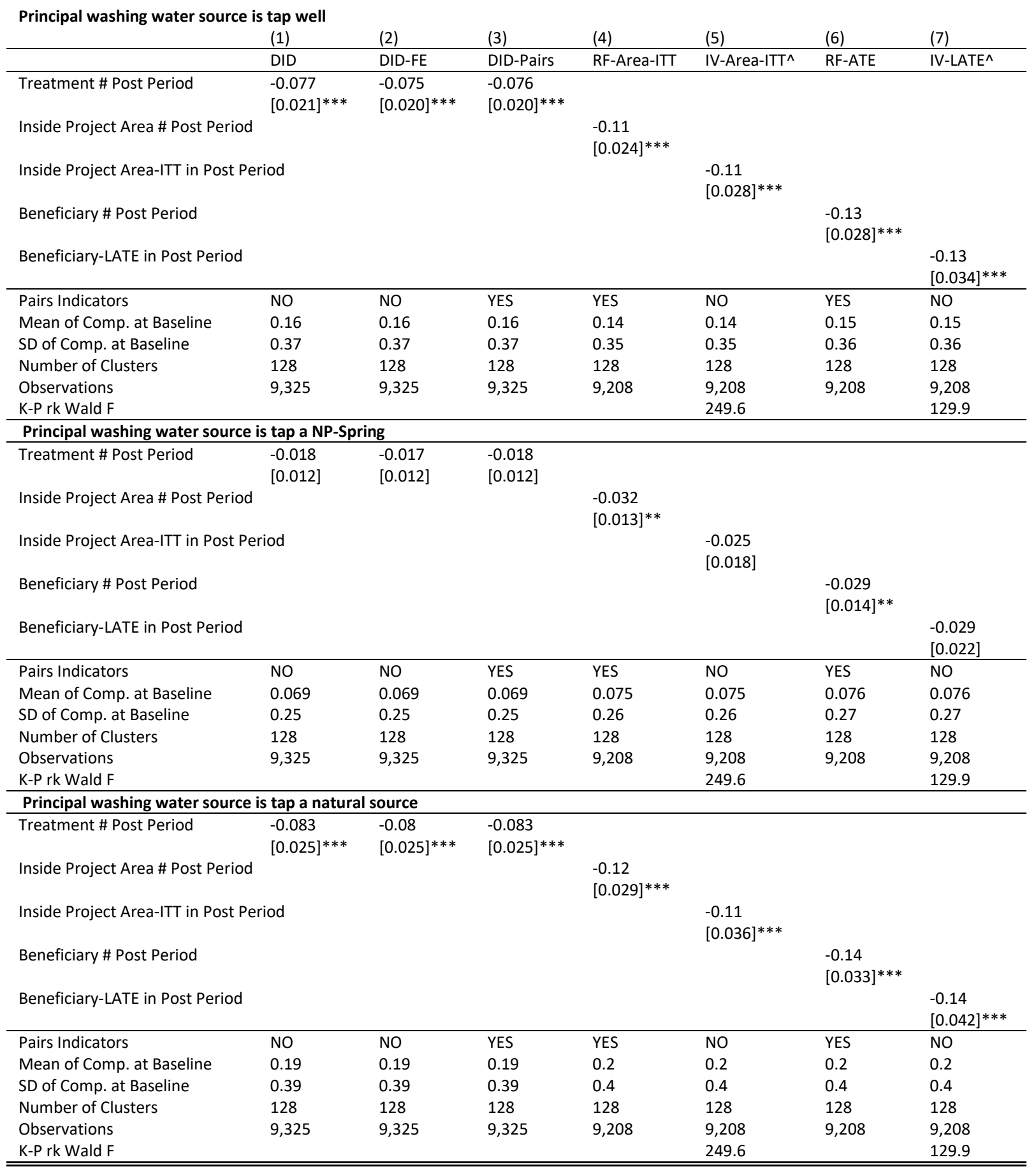

Standard errors in brackets

Std. errors are clustered at the census segment level.

All equations include year fixed effects. Equations are DID, in (1)-(3) the treatment is defined as living in a treatment assigned segment,

(4)-(5) treatment is defined as living inside the project area within the matched pairs, (6)-(7) treatment is defined as having reported being beneficiary of the WASH project within the matched pairs. Equations (4)-(7) control for initial treatment assignment.

Equation (2) includes household fixed effects. Pair dummies indicated in the table are based in on nearest neighbor matching propensity score matching based on 2007 census segment data.

IV estimates in columns (5) and (7) use the census segment treatment assignment to instrument for indicators for being in a project area in 2012-2013 (5); and the households reporting being a beneficiary of the WASH projects from MCC in (7)

AIV estimates partial out the indicators for pairs to compute the std. errors of the coefficients of interest. We report the K-P rk Wald $F$ statistic following the results in Stock and Yogo (2005)

$* \mathrm{p}<0.10, * * \mathrm{p}<0.05, * * * \mathrm{p}<0.01$ 
No. days HH tap available

(1) (2) - (3)

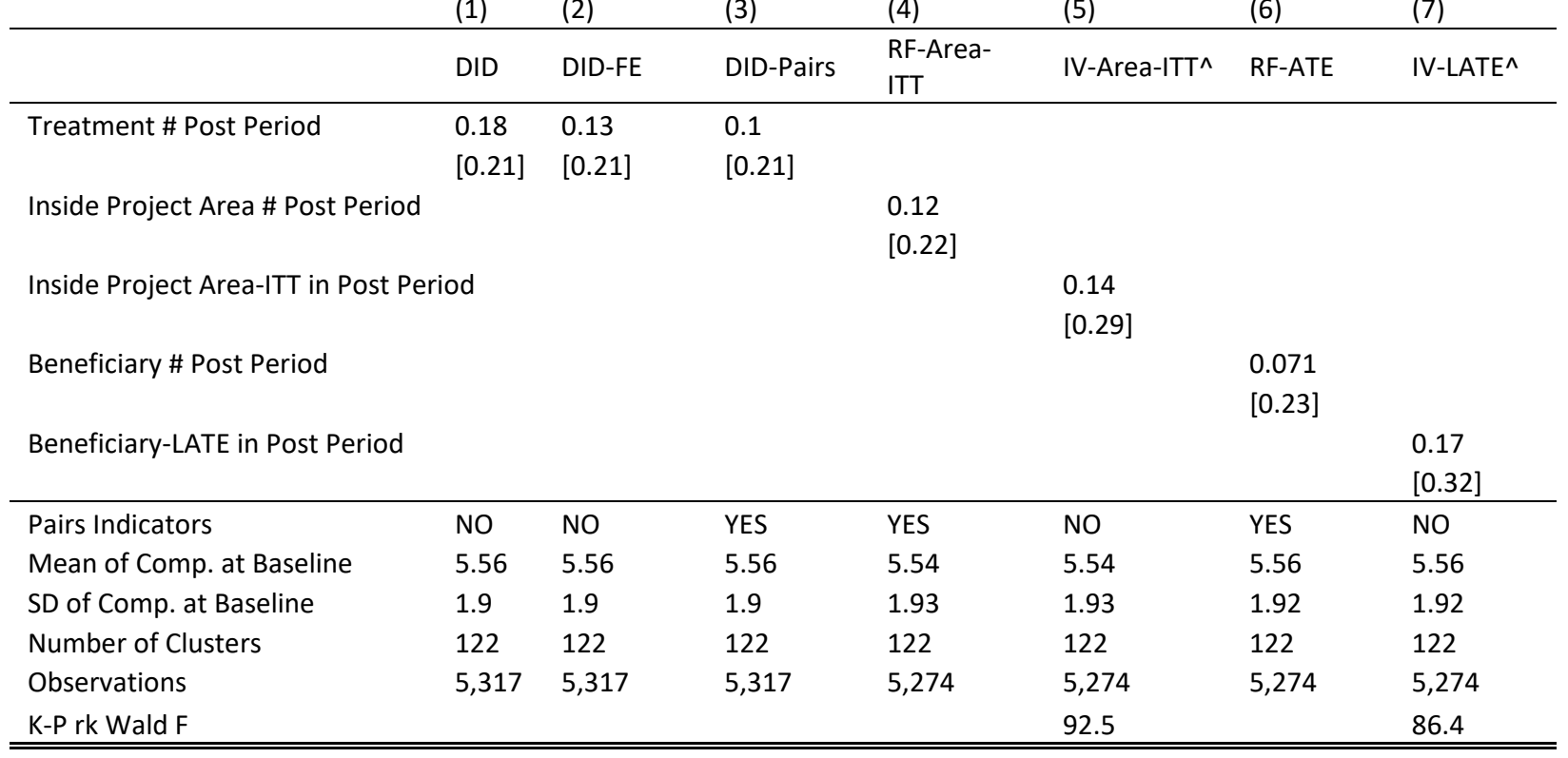

Standard errors in brackets

Std. errors are clustered at the census segment level.

All equations include year fixed effects. Equations are DID, in (1)-(3) the treatment is defined as living in a treatment assigned segment, (4)-(5) treatment is defined as living inside the project area within the matched pairs, (6)-(7) treatment is defined as having reported being beneficiary of the WASH project within the matched pairs. Equations (4)-(7) control for initial treatment assignment.

Equation (2) includes household fixed effects. Pair dummies indicated in the table are based in on nearest neighbor matching propensity score matching based on 2007 census segment data.

IV estimates in columns (5) and (7) use the census segment treatment assignment to instrument for indicators for being in a proyect area in 2012-2013 (5); and the households reporting being a beneficiary of the WASH proyects from MCC in (7)

^IV estimates partial out the indicators for pairs to compute the std. errors of the coefficients of interest. We report the K-P rk Wald F statistic following the results in Stock and Yogo (2005)

${ }^{*} \mathrm{p}<0.10, * * \mathrm{p}<0.05, * * * \mathrm{p}<0.01$ 


\section{AnNex 4 - Water Quality Testing Design}

In all households interviewed for this evaluation, we conducted a field test of residual chlorine levels in the household's drinking water supply. This test alone, however, is not enough to show whether water poses a health risk to the households. Non-chlorinated water may have no bacterial contamination, for example. To have better insight into the health risk posed by the water supply before and after the Compact investments, additional laboratory-based tests of water quality were conducted in a sample of households. Also, the water quality in piped systems and some other non-piped sources were tested in a subsample of communities.

These additional tests were done in two ways. First, the Ministry of Health (through personnel of the health posts) conducted tests for bacteriological contamination in piped water systems. We compiled these results during the endline survey, with the health post survey.

Second, a private firm tested drinking water for bacteriological contamination. The tests of household drinking water were done on stored water, if the household stored drinking water, or were taken directly from the tap or pipe if the household did not store drinking water. For the tests of source water quality, the firm searched for the sources used by the households included in the water quality testing program.

Testing was done in April - May each year of the survey, as close as possible to the timing of the household survey. The lab technicians filled out a small survey at each household visited to assist in the process of linking household survey results and the results of household-level and source-level water quality tests.

The sample size of water quality tests will not necessarily give us sufficient power to draw conclusions about water quality across the whole sample. The idea is to get a sense of how important water quality problems are in the project and comparison areas and whether problems lie in source contamination, in in-house contamination, or both.

\section{Water Testing Procedure}

The following procedure was followed to identify the number of sources to test and which sources to test:

Drinking water quality tests among households were interviewed in 66 census segments, with 12 households in each segment. These tests included a sample from the home and the source of the water supply (see Table 89). The samples were taken from either the home or the source to a laboratory to be analyzed.

\section{TABLE 89 SAMPLE SIZE FOR WATER QUALITY TESTS}

\begin{tabular}{lc} 
Sample Frame & $\mathbf{6 6}$ Census Segments \\
\hline Sample from household drinking water & $66 \times 12=792$ \\
$\begin{array}{l}\text { Sample from source } \\
\text { (between } \mathbf{3} \text { and } 6 \text { per census segment) }\end{array}$ & Between $198-396$ \\
\hline \hline
\end{tabular}

All the tests were a microbiological analysis of the water as well as a residual chlorine analysis using a colorimeter. The scope of the microbiological analysis of the water samples included: total number of coliform bacteria and fecal coliforms and the presence of E.coli.

i) The laboratory personnel took 12 drinking water samples from the list of homes in each census segment, according to the following:

- If the home used some device for storing water (canteen, bucket), take a sample from this storage device. 
- If the home obtained its water directly from its own or a neighbor's tap, a private well, a hose or pipeline from a spring, take the sample directly from the source. In the case of pipelines or hoses, it was not necessary to conduct the test in the initial source, except from a tap or hose. For artificial wells and other water sources (watering hole, spring, stream, and river) go to the source for the sample.

ii) The laboratory personnel took a minimum of three and a maximum of six water samples at the sources these households used, according to the following criteria:

In segments where the principal source of water was a piped water system, take three samples from the household tap. Of the 12 homes, choose three: one that is closest to the storage tank, one that is mid-way, and one that is the furthest.

- Take the three remaining water samples from other water sources that do not have a connection to their home. In the case that there was no other non-piped water source in a segment, only three water samples in this segment were taken.

If there are public taps in the segments, samples were always taken from these sources.

In segments without piped water systems, take up to six water samples from the household's sources. If there are not six different sources, take one sample from each source.

- If the 12 households obtained water from more than six different sources, take a sample from the six most commonly used sources.

- Take one sample per source (even if two or more households use the same source). Take a maximum of six samples in these segments.

iii) Personnel filled out a short survey to identify the home, the corresponding geocode, and the sample associated with the home (for both drinking water and the source).

iv) Personnel used the equipment to transport the water samples for the microbiological analysis and residual chlorine, in the time required by the laboratory so that the analysis would be valid.

\section{Locations of Water Quality Testing}

The 66 census segments (paired). 



\section{DeCLARATION ABOUT CO-AUthORED PAPERS}

I worked jointly with Maximo Torero in the first paper (chapter 2), with Maximo Torero and Eduardo Nakasone in the second paper (chapter 3) and with Maureen Cropper and Raymond Guiteras in the third paper (chapter 4).

The concepts and final methodology were developed jointly, with my participation at different stages of the initial design. I lead the empirical analysis in all three papers and the data collection/field work for the last three survey waves in chapter 3 and the three survey waves in chapter 4. We all contributed to writing and I was responsible for the initial drafts and revisions of the impact evaluation reports on which chapter 3 and 4 are based on.

The results on the impact evaluation reports submitted to the Millennium Challenge Corporation are consistent with those presented here. The results and methodology here are related but distinct from those in the reports; here they are further developed for a specialized audience. 
Name

Date of birth

Place of birth

Nationality

Official address
Miguel ALMANZAR

: $\quad 2$ July 1985

: $\quad$ Santo Domingo, Dominican Republic

: $\quad$ United States of America and Dominican Republic (Dual)

International Food Policy Research institute

$2033 \mathrm{~K}$ street NW, \#8049

20009 Washington, DC, USA

Tel. 202-862-4679

Email: m.almanzar@cgiar.org

Professional Positions AND EXPERIENCE

Since Apr. 2013

Aug. 2011-Apr. 2013

Jan. 2011-July 2015

June-Aug. 2011

\section{Senior Research Analyst}

International Food Policy Research Institute (IFPRI), Washington, DC

- Development and implementation of quantitative surveys in Africa, Asia and Latin America

- Preparation of proposals, data, briefs, policy memos and scientific papers

- Econometric/statistical analysis of survey data

- Management and supervision of a team of research assistants

\section{Research Analyst}

International Food Policy Research Institute (IFPRI), Washington, DC

- Monitoring and evaluation design for development initiatives

- Coordination and supervision of survey implementation

- Design of the survey instruments

- Econometric/statistical analysis of survey data

\section{Research Associate/Consultant} with Professor Maureen Cropper and Professor Raymond Guiteras University of Maryland, College Park, MD

- Enumerator training for household survey

- Coordination and supervision of survey activities of statistical agency

- Econometric/statistical analysis of household surveys and report findings to specialized and general audiences

\section{Consultant}

\section{Private Sector Development Support Project}

The World Bank, Washington, DC

- Developed background paper on social networks and firm performance in developing countries

- Provided guidance and policy recommendations to estimate the potential effects and implement development programs that rely on social interactions 
June- July 2010

Graduate Assistant for Professor Gary Charness

Game theory and Behavioral Economics

University of California, Santa Barbara, CA

American Economic Association Summer Training Program

- Taught discussion sections each week; held review sessions before exams

- Mentored students interested in pursuing graduate studies

EDUCATION

Since October 2013

Georg-August University of Göttingen (Germany)

PhD in Agricultural Economics and Rural Development (IPAG)

Chair International Food Economics and Rural Development

Supervisor : Prof. Matin Qaim

Expected : July 2017

September 2009 - $\quad$ University of Maryland, College Park (USA)

June 2011

Master of Arts in Economics,

Fields: Labor Economics, Public Finance and Econometrics

September 2008 -

June 2009

Université de Lausanne, HEC (Switzerland)

Coursework in Economics

January 2005-

City University of New York, Brooklyn College (USA)

June 2008

Bachelor of Arts in Mathematics and Economics, Summa Cum Laude

June-August 2008

University of California, Santa Barbara (USA)

American Economic Association Summer Training Program, Advanced Level

September 2006- $\quad$ Université de Paris, Saint-Denis \& Dauphine (France)

June 2007

Study Abroad Program, City University of New York

Economics and French Language/Culture

FIELDS OF INTEREST

- Development Economics

- Agricultural Economics

- Micro-econometrics

- Labor Economics

- Public Economics

Extended research stays and/or project experience in

El Salvador, Honduras, Peru, Cambodia, USA 
- Graduate Fellowship, University of Maryland 2009-2011

- National Science Foundation Graduate Fellowship, Honorable Mention 2009-2010

- American Economic Association/NSF Minority Fellowship 2008

- Golden Key International Honour Society, 2008

- Harry D. Gideonse Scholarship, CUNY-Brooklyn College 2006-2007

- Rose Goldstein Memorial Scholarship, CUNY-Brooklyn College 2006-2007

- Jack Devine Scholarship in Caribbean Studies, CUNY-Brooklyn College 2005-2006

SKILLS

- Languages : $\quad$ English-Fluent, Spanish-Fluent, French-Advanced

- Computers : $\quad$ STATA, SPSS, MatLab, C++, Lyx/LaTeX, Office Suite

- "Public Expenditures and the Distribution of Income: Rwanda and Tanzania," with Maximo Torero, World Development, Vol. 95, pp. 177-195, 2017

- "On the Validity of Compulsory Education Laws as Instruments for Educational Attainment: Evidence from 1920-1969," with Cristina Tello-Trillo, Michael Mejia and Moises Yi, BC Undergraduate Research Journal, 2009 